\title{
Strain Rate Effect on Development Length of Steel Reinforcement Using Shock Tube Testing
} by

Lauren Toikka

A thesis submitted to the Faculty of Graduate and Postdoctoral Affairs in partial fulfillment of the requirements for the degree of

\author{
Master of Applied Science \\ in
}

Civil Engineering

Carleton University

Ottawa, Ontario

(C) 2012, Lauren Toikka 
Library and Archives

Canada

Published Heritage

Branch

395 Wellington Street

Ottawa ON K1A ON4

Canada
Bibliothèque et

Archives Canada

Direction du

Patrimoine de l'édition

395 , rue Wellington

Ottawa ON K1A ON4

Canada
Your file Votre référence

ISBN: 978-0-494-94288-8

Our file Notre référence

ISBN: $978-0-494-94288-8$
NOTICE:

The author has granted a nonexclusive license allowing Library and Archives Canada to reproduce, publish, archive, preserve, conserve, communicate to the public by telecommunication or on the Internet, loan, distrbute and sell theses worldwide, for commercial or noncommercial purposes, in microform, paper, electronic and/or any other formats.

The author retains copyright ownership and moral rights in this thesis. Neither the thesis nor substantial extracts from it may be printed or otherwise reproduced without the author's permission.
AVIS:

L'auteur a accordé une licence non exclusive permettant à la Bibliothèque et Archives Canada de reproduire, publier, archiver, sauvegarder, conserver, transmettre au public par télécommunication ou par l'Internet, prêter, distribuer et vendre des thèses partout dans le monde, à des fins commerciales ou autres, sur support microforme, papier, électronique et/ou autres formats.

L'auteur conserve la propriété du droit d'auteur et des droits moraux qui protege cette thèse. $\mathrm{Ni}$ la thèse ni des extraits substantiels de celle-ci ne doivent être imprimés ou autrement reproduits sans son autorisation.
In compliance with the Canadian Privacy Act some supporting forms may have been removed from this thesis.

While these forms may be included in the document page count, their removal does not represent any loss of content from the thesis.
Conformément à la loi canadienne sur la protection de la vie privée, quelques formulaires secondaires ont été enlevés de cette thèse.

Bien que ces formulaires aient inclus dans la pagination, il n'y aura aucun contenu manquant. 


\section{Abstract}

Research is currently underway to study the effects of both accidental and premeditated explosions on concrete infrastructure systems with an ultimate goal of minimizing infrastructure damage and saving lives. In reinforced concrete design, it is desirable to dissipate energy through yielding and essential to preclude non-ductile failure modes such as bond failure. There currently exists a limited amount of data for the strain rate effects caused by blast loads on concrete-reinforcement bond strength. An experimental program was therefore designed to investigate bond characteristics in reinforced concrete beams subject to blast loads using the shock tube at the University of Ottawa. Static and dynamic strain profiles at yield were developed from the experimental data along the bond length to determine the effect of increased strain on the bond characteristics in reinforced concrete beams. The test results showed that the development length required for load transfer at high strain rates was lower than that required under static loading. Thus the development length requirement for reinforced concrete beams under static loading in accordance with the Canadian Standards Association standard for design of concrete structures is sufficient for reinforced concrete beams subject to high strain rate such as under blast loading. 


\section{Acknowledgments}

I cannot thank my supervisor, Dr. Abass Braimah, enough for his support over the last two years. Without his guidance, encouragement, enthusiasm, and passion for teaching and mentoring his students, completing my thesis would have been an incredibly difficult or near-impossible task.

I would like to acknowledge Dr. Murat Saatcioglu of University of Ottawa and Dr. Ghani Razaqpur of McMaster University for their support and also making this research project possible. I would also like to acknowledge Carleton University and OGS for their financial support, which allowed me to concentrate on my studies.

The support of my colleagues was also critical to my success in the laboratory. I would like to thank Alan Lloyd and Eric Jacques for being incredible mentors throughout this process. Not only did they teach me everything I needed to know in the lab, but they also provided me with guidance on understanding my experimental results and writing my thesis. I also want to express my gratitude to Ben Riley for all of his help in the laboratory. Without the long hours he put in and his genuine interest in my research subject, I would not have been able to complete my lab work with as much ease and success.

Finally I would like to thank my parents for their incredible support throughout all my years of study at Carleton University. Both my family and friends provided me with the encouragement and reassurance that I needed to get me through the completion of this degree. 


\section{Table of Contents}

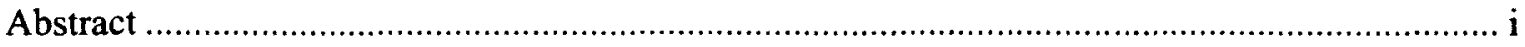

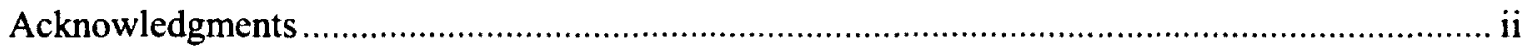

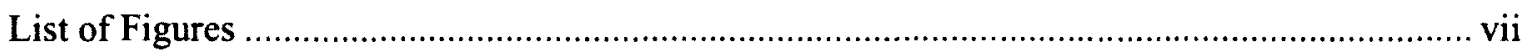

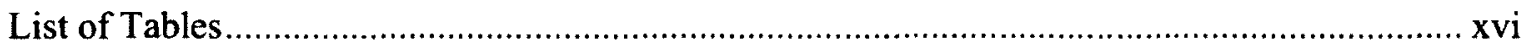

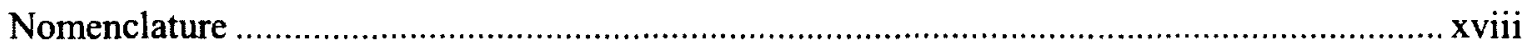

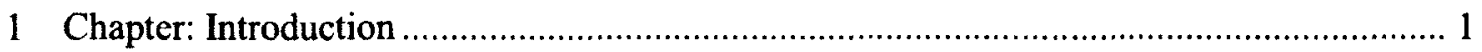

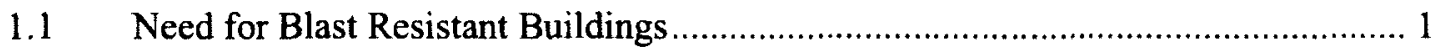

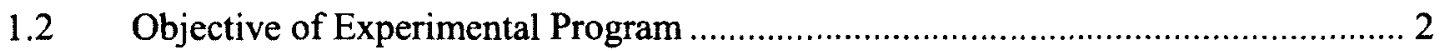

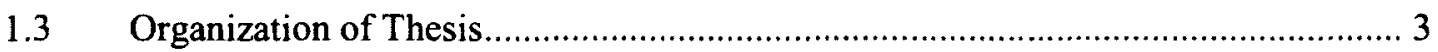

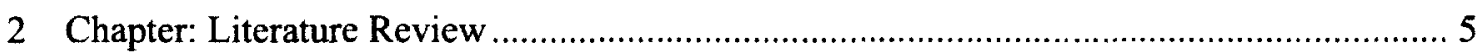

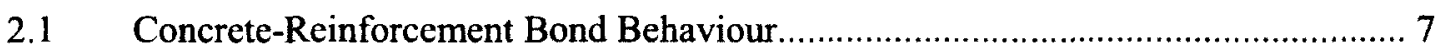

2.1.1 Transfer of Forces from Steel Reinforcement to Surrounding Concrete............... 7

2.1.2 Theoretical and Experimental Determination of Development Length ............... 8

2.1.3 Factors that Affect the Bond of Concrete to Reinforcing Steel ....................... 11

2.1.4 Failure Mechanisms of Reinforced Concrete Beams .................................... 14

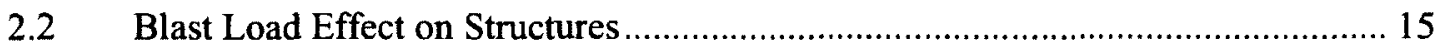

2.3 High strain rate Effect on the Compressive and Tensile Strength of Concrete ....... 18

$2.4 \quad$ Numerical models for Concrete under Dynamic Loading ................................... 21

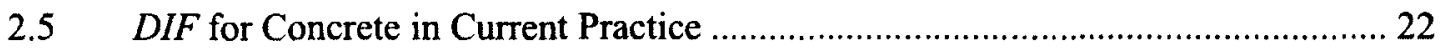

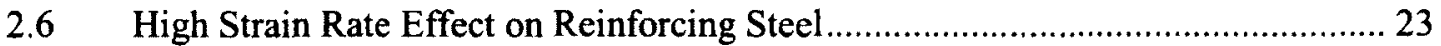

2.7 Derivations of Numerical Models for Steel Reinforcement Under High -Strain Rate

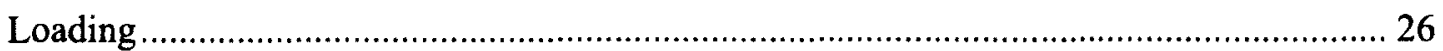

2.7.1 Soroushian and Choi (1987): Steel Mechanical Properties at Different Strain Rates 27 
2.7.2 Malvar and Crawford (1998): Dynamic Increase Factors for Steel Reinforcing

Bars 29

2.7.3 Comité Euro-International du Béton (CEB): Concrete Structures Under Impact

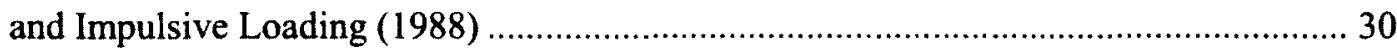

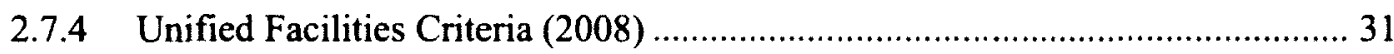

2.8 The Effect of Dynamic Loads on Bond of Reinforcing Steel to Concrete .............. 33

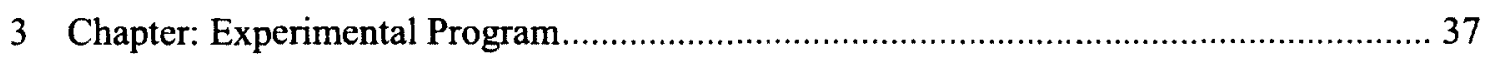

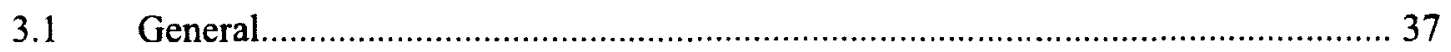

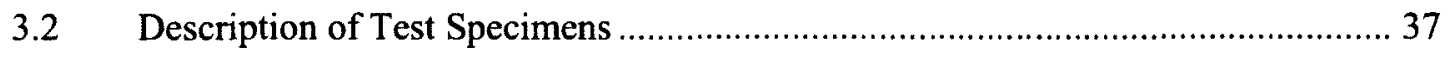

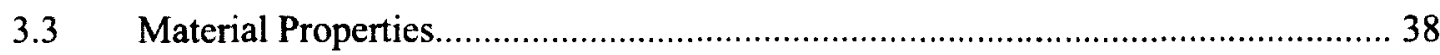

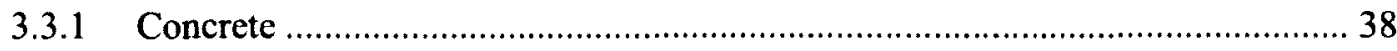

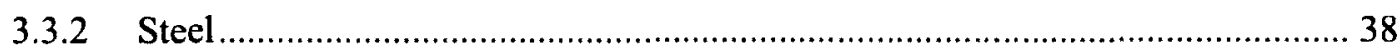

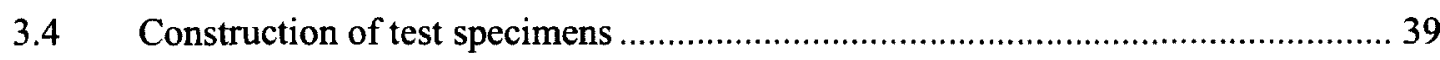

3.4.1 Longitudinal reinforcement and strain gauge application ................................. 39

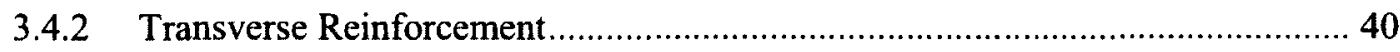

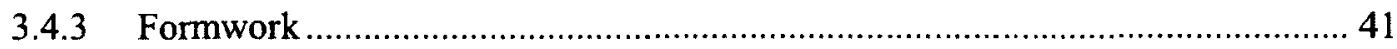

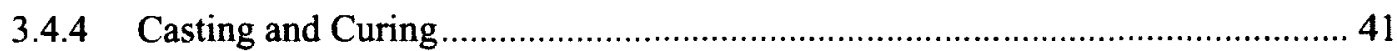

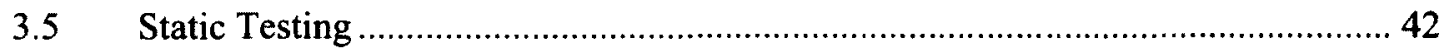

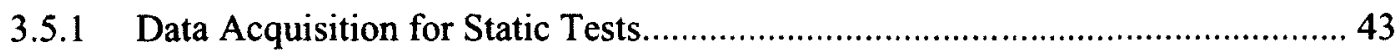

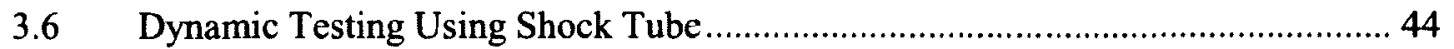

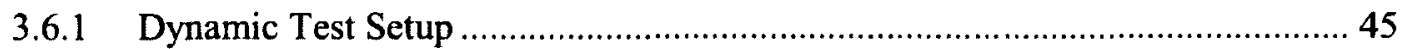

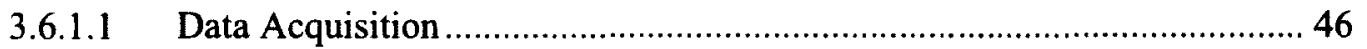

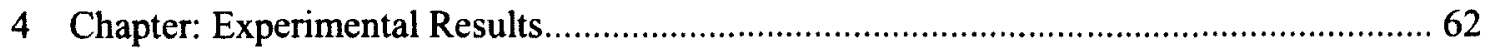

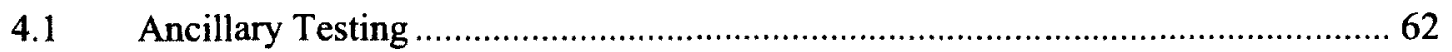

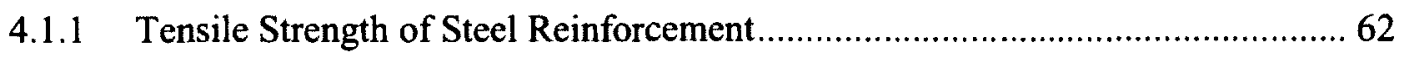

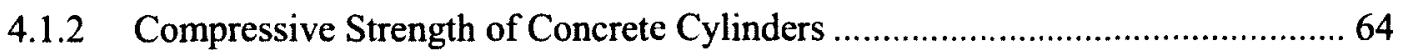




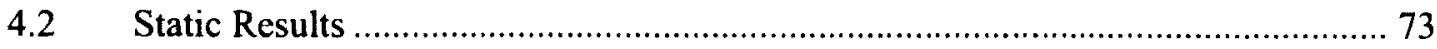

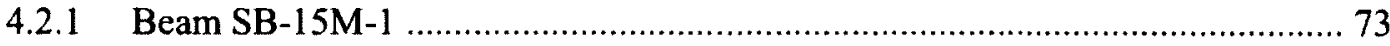

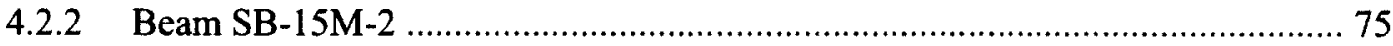

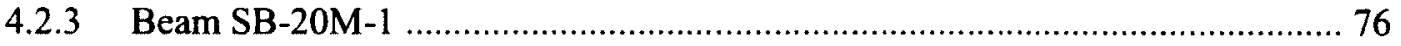

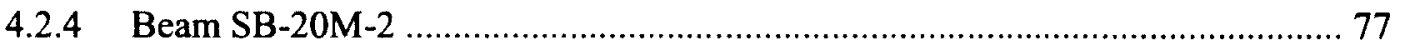

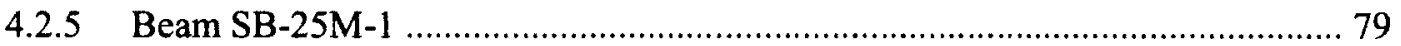

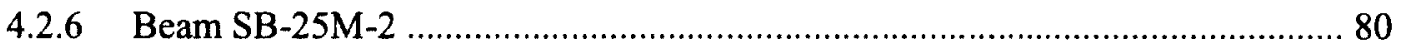

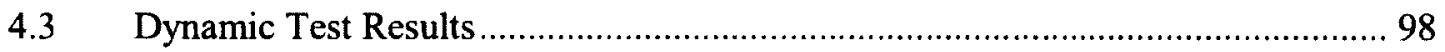

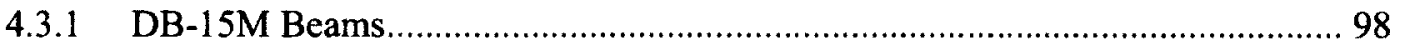

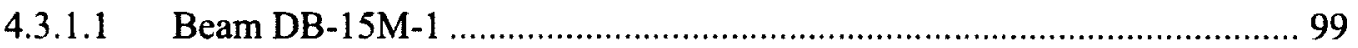

4.3.1.2 Beam DB-15M-2 and DB-15M-3 _............................................... 104

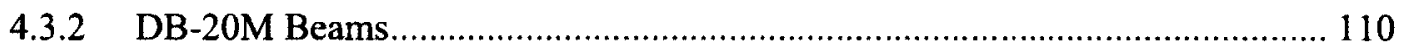

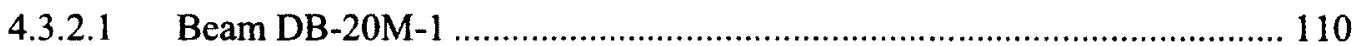

4.3.2.2 Beam DB-20M-2 and DB-20M-3 _............................................... 114

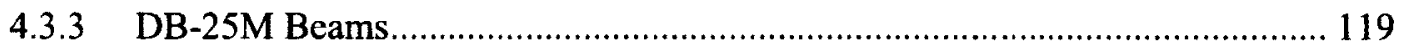

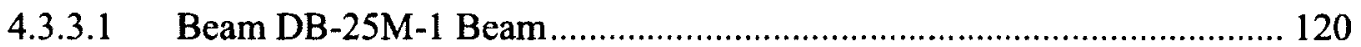

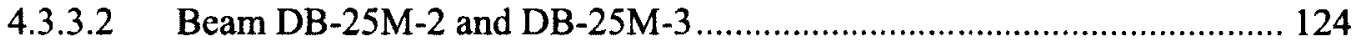

4.4 Comparison of Static and Dynamic Results .................................................. 192

4.4.1 Comparison of SB-15M and DB-15M Beams .......................................... 193

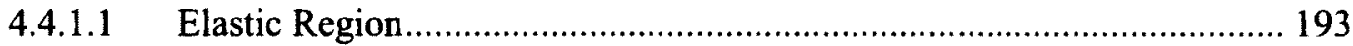

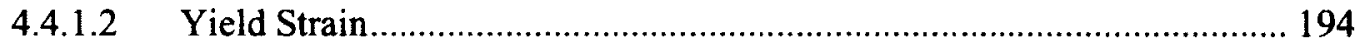

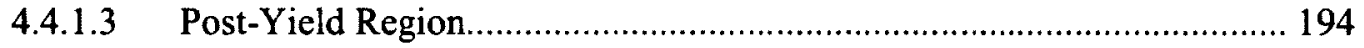

4.4.2 Comparison of SB-20M and DB-20M Beams …....................................... 194

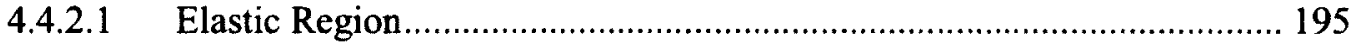

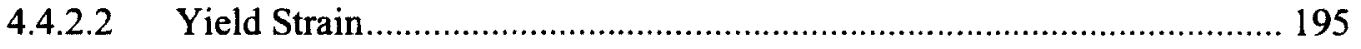

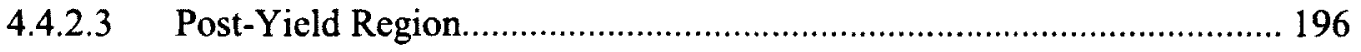


4.4.3 Comparison of SB-25M and DB-25M Beams ......................................... 196

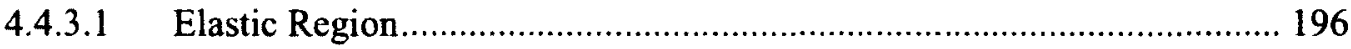

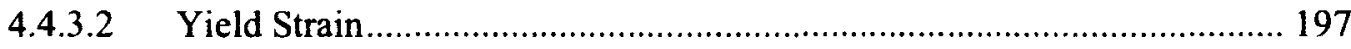

4.4.3.3 Post-Yield Region.................................................................... 197

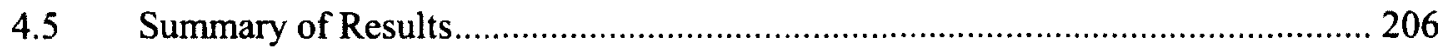

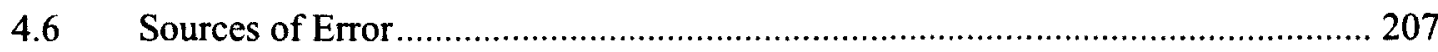

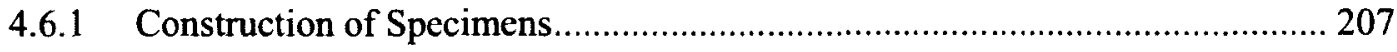

4.6.2 Installation of Specimen on Shock tube or Static Loading Apparatus ............. 209

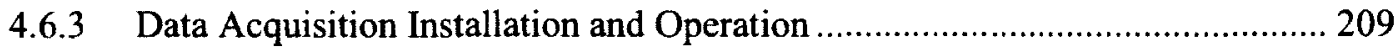

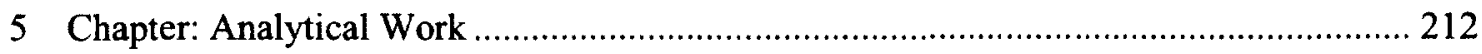

5.1 Determination of Bond Strength from Strain Gauge Readings ......................... 212

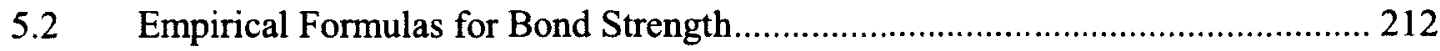

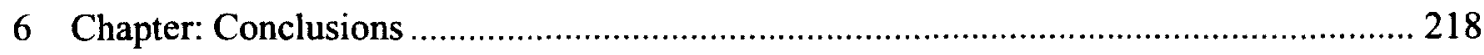

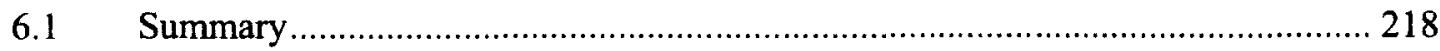

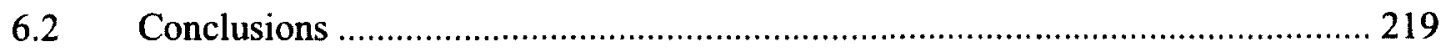

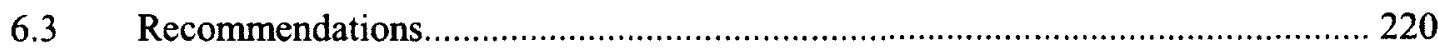




\section{List of Figures}

Figure 2-1: Blast wave parameters (Ngo et al. 2007) ......................................... 16

Figure 2-2: Effect of Strain Rate on Concrete Strength (ASCE 1997) ....................... 19

Figure 2-3: Effect of Strain Rate on Steel Strength (ASCE 1997) ............................... 24

Figure 3-1: Debonded Region in Concrete Beam ............................................... 48

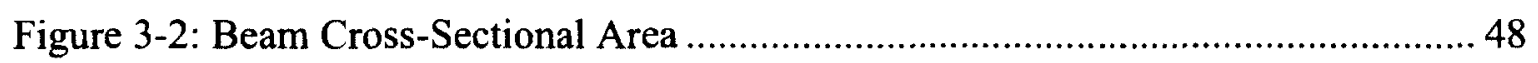

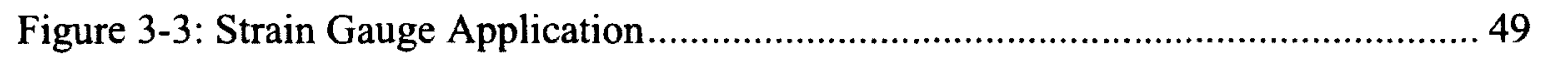

Figure 3-4: Soldering of Strain Gauge Lead Wires ............................................... 49

Figure 3-5: Strain Gauge Locations Along Length of Reinforcement .......................... 50

Figure 3-6: Construction of Cages for Transverse Reinforcement ............................. 50

Figure 3-7: Steel Reinforcement Protruding Through Formwork .............................. 51

Figure 3-8: Concrete Gauge Installation and Preformed Crack ................................. 51

Figure 3-9: Caulking of Vinyl Pipe for Debonded Region .................................. 52

Figure 3-10: Concrete Gauge Locations .......................................................... 52

Figure 3-11: Concrete Gauges in Formwork .................................................. 53

Figure 3-12: Placement of Steel Cages, Longitudinal Reinforcement, and Concrete

Gauges Prior to Casting of Concrete .................................................................... 54

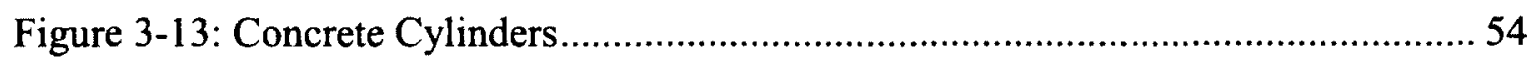

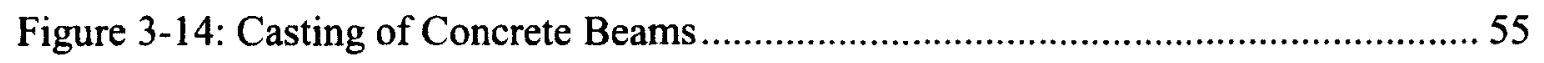

Figure 3-15: Location of Load Points in Static Tests ............................................. 55

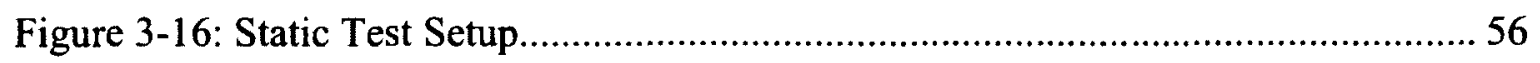

Figure 3-17: Midspan and Load-Point Gauges ................................................. 56

vii 


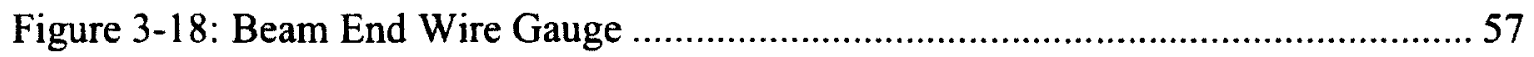

Figure 3-19: Load Transfer Device at Shock Tube Opening …………………............... 57

Figure 3-20: Angle View of Load Transfer Device ......................................................... 58

Figure 3-21: Placement of Concrete Beam of Shock Tube Using Forklift....................... 58

Figure 3-22: Welded Rod to Achieve Simply Supported Conditions................................ 59

Figure 3-23: Concrete Beam Setup on Shock Tube ...................................................... 59

Figure 3-24: Anchor Bolt Installation for Connection to LVDT ....................................... 60

Figure 3-25: Installation of Welded Member Used for Bottom LVDT ........................... 60

Figure 3-26: Placement of Bottom LVDT in Welded Member....................................... 61

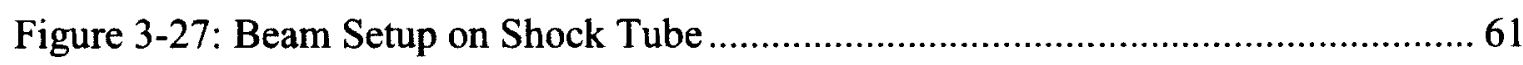

Figure 4-1: Stress-strain curve for $15 \mathrm{M}$ reinforcement .................................................. 71

Figure 4-2: Stress-strain curve for 20M reinforcement ................................................. 71

Figure 4-3: Stress-strain curve for 25M reinforcement ................................................. 72

Figure 4-4: Load vs. Deflection of Beam SB-15M-1 …............................................. 83

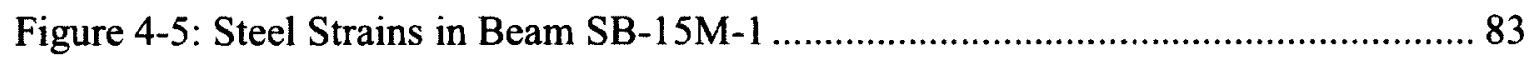

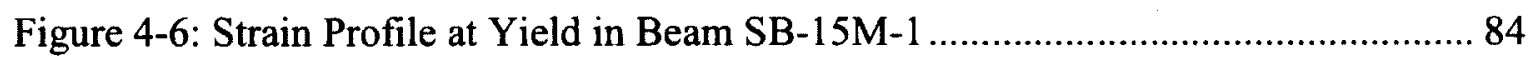

Figure 4-7: Concrete Strains in Beam SB-15M-1 ........................................................ 84

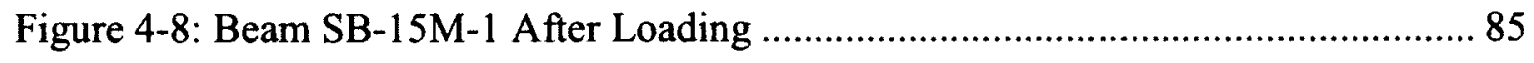

Figure 4-9: Load vs. Deflection of Beam SB-15M-2 ……............................................ 85

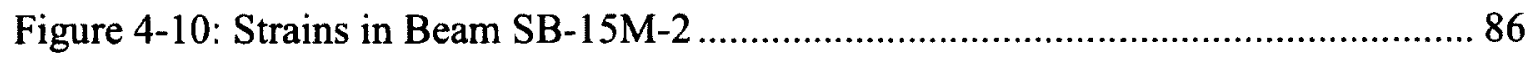

Figure 4-11: Strain Profile at Yield in Beam SB-15M-2 ……...................................... 86

Figure 4-12: Concrete Strains in Beam SB-15M-2 ………....................................... 87

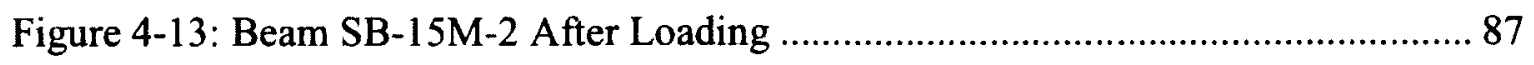


Figure 4-14: Load vs. Deflection of Beam SB-20M-1 ……....................................... 88

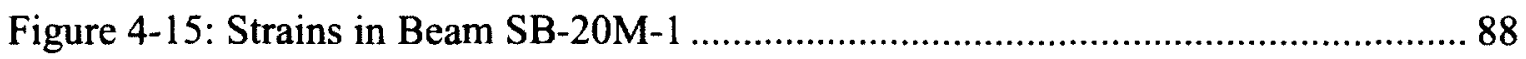

Figure 4-16: Strain Profile at Yield in Beam SB-20M-1 ............................................. 89

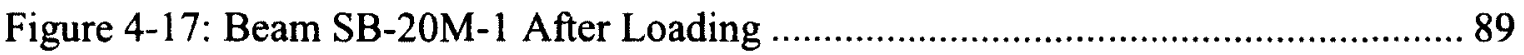

Figure 4-18: Load vs. Deflection of Beam SB-20M-2 …………................................ 90

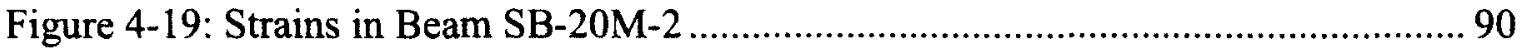

Figure 4-20: Strain Profile at Yield in Beam SB-20M-2 ............................................... 91

Figure 4-21: Concrete Strains in Beam SB-20M-2

Figure 4-22: Beam SB-20M-2 After Loading …………....................................... 92

Figure 4-23: Load vs. Deflection of Beam SB-20M-2 …………………................... 92

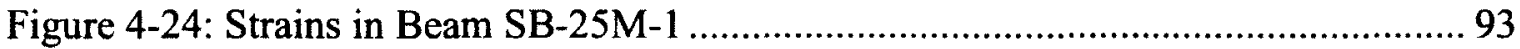

Figure 4-25: Strain Profile at Yield in Beam SB-25M-1 .............................................. 93

Figure 4-26: Concrete Strains in Beam SB-25M-1 .................................................... 94

Figure 4-27: Beam SB-25M-1 After Loading ………………..................................... 94

Figure 4-28: Load vs. Deflection of Beam SB-25M-2 ………………………………... 95

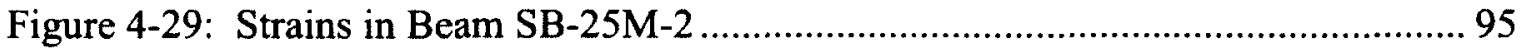

Figure 4-30: Strain Profile at Yield in Beam SB-25M-2 ……...................................... 96

Figure 4-31: Concrete Strains in Beam SB-25M-2 ………...................................... 96

Figure 4-32: Beam SB-25M-2 After Loading ........................................................... 97

Figure 4-33: Pressure and Impulse Time History for Test DB-15M-1-1 ...................... 134

Figure 4-34: Pressure and Displacement Time History for Test DB-15M-1-1 ............. 134

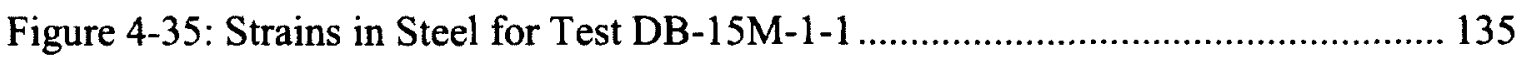

Figure 4-36: Strains in Concrete for Test DB-15M-1-1 …....................................... 135 


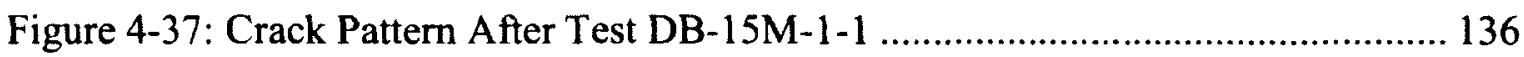

Figure 4-38: Pressure and Impulse Time History for Test DB-15M-1-2 ..................... 136

Figure 4-39: Pressure and Displacement Time History for Test DB-15M-1-2 …......... 137

Figure 4-40: Crack Pattern After Test DB-15M-1-2 ……....................................... 137

Figure 4-41: Pressure and Impulse Time History for Test DB-15M-1-3 ..................... 138

Figure 4-42: Pressure and Displacement Time History for Test DB-15M-1-3 …......... 138

Figure 4-43: Strain in Steel for Test DB-15M-1-3 ………...................................... 139

Figure 4-44: Strain in Concrete for Test DB-15M-1-3 …………............................. 139

Figure 4-45: Crack Pattern After Test DB-15M-1-3 …………………………....... 140

Figure 4-46: Pressure and Impulse Time History for Test DB-15M-1-4 _.................... 140

Figure 4-47: Pressure and Displacement Time History for Test DB-15M-1-4 ............. 141

Figure 4-48: Strains in Steel for Test DB-15M-1-4 .................................................. 141

Figure 4-49: Crack Pattern After Test DB-15M-1-4 ….......................................... 142

Figure 4-50: Pressure and Impulse Time History for Test DB-15M-2-1 ..................... 142

Figure 4-51: Pressure and Displacement History for Test DB-15M-2-1 ....................... 143

Figure 4-52: Strains in Steel for Test DB-15M-2-1 ................................................ 143

Figure 4-53: Strain Profile at Yield for Test DB-15M-2-1 ........................................ 144

Figure 4-54: Strains in Concrete for Test DB-15M-2-1 ............................................. 144

Figure 4-55: Crack Pattern After Test DB-15M-2-1 ............................................. 145

Figure 4-56: Pressure and Impulse Time History for Test DB-15M-2-2 …................... 145

Figure 4-57: Pressure and Displacement Time History for Test DB-15M-2-2 …......... 146

Figure 4-58: Strains in Steel for Test DB-15M-2-2 ……….................................. 146

Figure 4-59: Strain Profile at Yield for Test DB-15M-2-2 ………............................ 147 
Figure 4-60: Strains in Concrete for Test DB-15M-2-2 …..................................... 147

Figure 4-61: Crack Pattern After Test DB-15M-2-2 …………………………….... 148

Figure 4-62: Pressure and Impulse Time History for Test DB-15M-3-1 ....................... 148

Figure 4-63: Pressure and Displacement Time History for Test DB-15M-3-1 ............. 149

Figure 4-64: Strains in Steel for Test DB-15M-3-1 ................................................ 149

Figure 4-65: Strain Profile at Yield for Test DB-15M-3-1 ....................................... 150

Figure 4-66: Strains in Concrete for Test DB-15M-3-1 ......................................... 150

Figure 4-67: Crack Pattern After Test DB-15M-3-1 .............................................. 151

Figure 4-68: Pressure and Impulse Time History for Test DB-15M-3-2 ….................. 151

Figure 4-69: Pressure and Displacement Time History for Test DB-15M-3-2 …......... 152

Figure 4-70: Strains in Steel for Test DB-15M-3-2 …………………..................... 152

Figure 4-71: Strain Profile at Yield for Test DB-15M-3-2 …….................................. 153

Figure 4-72: Crack Pattern After Test DB-15M-3-2 ……………............................ 153

Figure 4-73: Pressure and Impulse Time History for Test DB-20M-1-1 ...................... 154

Figure 4-74: Pressure and Displacement Time History for Test DB-20M-1-1 ............. 154

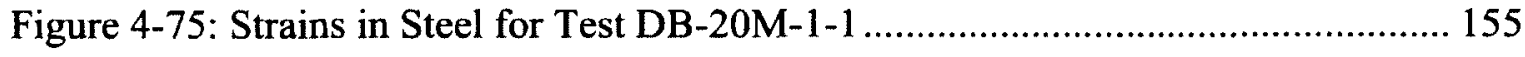

Figure 4-76: Strains in Concrete for Test DB-20M-1-1 …….................................. 155

Figure 4-77: Crack Pattern After Test DB-20M-1-1 ............................................... 156

Figure 4-78: Pressure and Impulse Time History for Test DB-20M-1-2 ...................... 156

Figure 4-79: Pressure and Displacement Time History for Test DB-20M-1-2 ............. 157

Figure 4-80: Strains in Steel for Test DB-20M-1-2 ….......................................... 157

Figure 4-81: Crack Pattern After Test DB-20M-1-2 ……….................................... 158

Figure 4-82: Pressure and Impulse Time History for Test DB-20M-1-3 .................... 158 
Figure 4-83: Pressure and Displacement Time History for Test DB-20M-1-3 159

Figure 4-84: Strains in Steel for Test DB-20M-1-3 ……......................................... 159

Figure 4-85: Crack Pattern After Test DB-20M-1-3 ................................................. 160

Figure 4-86: Pressure and Impulse Time History for Test DB-20M-2-1 ...................... 160

Figure 4-87: Pressure and Displacement Time History for Test DB-20M-2-1 ............. 161

Figure 4-88: Strains in Steel for Test DB-20M-2-1 ............................................... 161

Figure 4-89: Strain Profile at Yield for Test DB-20M-2-1 ......................................... 162

Figure 4-90: Strains in Concrete for Test DB-20M-2-1 ........................................... 162

Figure 4-91: Crack Pattern After Test DB-20M-2-1 .................................................. 163

Figure 4-92: Pressure and Impulse Time History for Test DB-20M-2-2 ..................... 163

Figure 4-93: Pressure and Displacement Time History for Test DB-20M-2-2 ….......... 164

Figure 4-94: Strains in Steel for Test DB-20M-2-2 ............................................... 164

Figure 4-95: Strain Profile at Yield for Test DB-20M-2-2 ......................................... 165

Figure 4-96: Strains in Concrete for Test DB-20M-2-2 ……..................................... 165

Figure 4-97: Crack Pattern After Test DB-20M-2-2 …........................................... 166

Figure 4-98: Pressure and Impulse Time History for Test DB-20M-3-1 ..................... 166

Figure 4-99: Pressure and Displacement Time History for Test DB-20M-3-1 ............. 167

Figure 4-100: Strains in Steel for Test DB-20M-3-1 .................................................. 167

Figure 4-101: Strain Profile at Yield for Test DB-20M-3-1 ...................................... 168

Figure 4-102: Strains in Concrete for Test DB-20M-3-1 ........................................ 168

Figure 4-103: Crack Pattern After Test DB-20M-3-1 ................................................. 169

Figure 4-104: Pressure and Impulse Time History for Test DB-20M-3-2 .................... 169

Figure 4-105: Pressure and Displacement Time History for Test DB-20M-3-2 …....... 170 
Figure 4-106: Strains in Steel for Test DB-20M-3-2 ………................................ 170

Figure 4-107: Strain Profile at Yield for Test DB-20M-3-2 ……………................... 171

Figure 4-108: Crack Pattern After Test DB-20M-3-2 ……......................................... 171

Figure 4-109: Pressure and Impulse Time History for Test DB-25M-1-1 ................... 172

Figure 4-110: Pressure and Displacement Time History for Test DB-25M-1-1 ........... 172

Figure 4-111: Strain in Steel for Test DB-25M-1-1 …............................................ 173

Figure 4-112: Strains in Concrete for Test DB-25M-1-1 ........................................... 173

Figure 4-113: Crack Pattern After Test DB-25M-1-1 …….................................. 174

Figure 4-114: Pressure and Impulse Time History for Test DB-25M-1-2 …............... 174

Figure 4-115: Pressure and Displacement Time History for Test DB-25M-1-2 …....... 175

Figure 4-116: Strains in Steel for Test DB-25M-1-2 ............................................... 175

Figure 4-117: Strains in Concrete for Test DB-25M-1-2 …..................................... 176

Figure 4-1 18: Crack Pattern After Test DB-25M-1-2 ……...................................... 176

Figure 4-119: Pressure and Impulse Time History for Test DB-25M-1-3 ………........ 177

Figure 4-120: Pressure and Displacement Time History for Test DB-25M-1-3 …....... 177

Figure 4-121: Strains in Steel for Test DB-25M-1-3 ................................................ 178

Figure 4-122: Strains in Concrete for Test DB-25M-1-3 ........................................ 178

Figure 4-123: Crack Pattern After Test DB-25M-1-3 ……........................................ 179

Figure 4-124: Pressure and Impulse Time History for Test DB-25M-2-1 .................... 179

Figure 4-125: Pressure and Displacement Time History for Test DB-25M-2-1 ........... 180

Figure 4-126: Strains in Steel for Test DB-25M-2-1 .............................................. 180

Figure 4-127: Strain Profile at Maximum Strain for Test DB-25M-2-1 ...................... 181

Figure 4-128: Strains in Concrete for Test DB-25M-2-1 .......................................... 181 
Figure 4-129: Crack Pattern After Test DB-25M-2-1

Figure 4-130: Pressure and Impulse Time History for Test DB-25M-2-2 …................ 182

Figure 4-131: Pressure and Displacement Time History for Test DB-25M-2-2 …....... 183

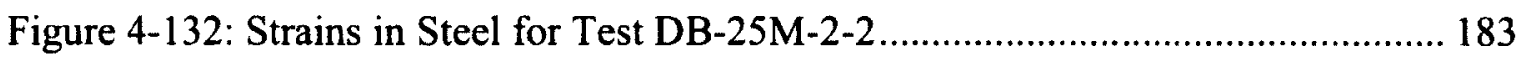

Figure 4-133: Strain Profile at Yield for Test DB-25M-2-2 ........................................ 184

Figure 4-134: Strains in Concrete for Test DB-25M-2-2 .......................................... 184

Figure 4-135: Crack Pattern After Test DB-25M-2-1 ……....................................... 185

Figure 4-136: Pressure and Impulse Time History for Test DB-25M-3-1 …................ 185

Figure 4-137: Pressure and Displacement Time History for Test DB-25M-3-1 …....... 186

Figure 4-138: Strains in Steel for Test DB-25M-3-1 ............................................... 186

Figure 4-139: Strain Profile at Maximum Strain for Test DB-25M-3-1 ….................. 187

Figure 4-140: Strains in Concrete for Test DB-25M-3-1 ........................................... 187

Figure 4-141: Crack Pattern After Test DB-25M-3-1 ……………….......................... 188

Figure 4-142: Pressure and Impulse Time History for Test DB-25M-3-2 …................. 188

Figure 4-143: Pressure and Displacement Time History for Test DB-25M-3-2 …....... 189

Figure 4-144: Strains in Steel for Test DB-25M-3-2 ……...................................... 189

Figure 4-145: Strain Profile at Yield for Test DB-25M-3-2 ....................................... 190

Figure 4-146: Strains in Concrete for Test DB-25M-3-2 …….................................. 190

Figure 4-147: Crack Pattern After Test DB-25M-3-2 …………………………....... 191

Figure 4-148: Strain Profile at 1500 microstrain in Debonded Region for 15M

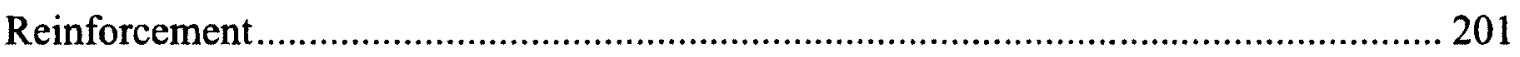

Figure 4-149: Strain Profile at Yield Strain in Debonded Region for 15M Reinforcement 
Figure 4-150: Strain Profile Post-Yield Strain in Debonded Region for 15M

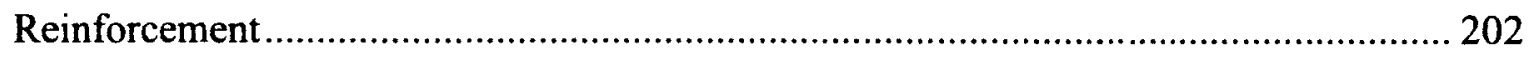

Figure 4-151: Strain Profile at 1500 microstrain in Debonded Region for 20M

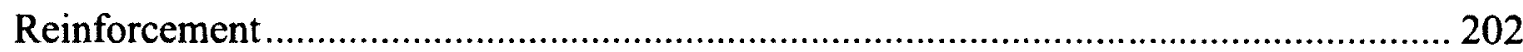

Figure 4-152: Strain Profile at Yield Strain in Debonded Region for 20M Reinforcement 203

Figure 4-153: Strain Profile at Post-Yield Strain in Debonded Region for 20M

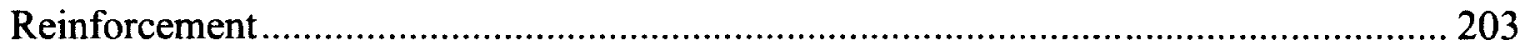

Figure 4-154: Strain Profile at 1500 microstrain in Debonded Region for 25M

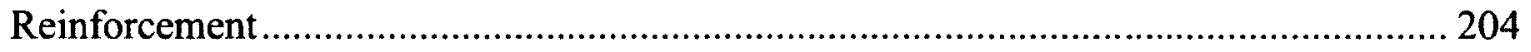

Figure 4-155: Strain Profile at Yield Strain in Debonded Region for 25M Reinforcement 204

Figure 4-156: Strain Profile Post-Yield Strain in Debonded Region for 25M

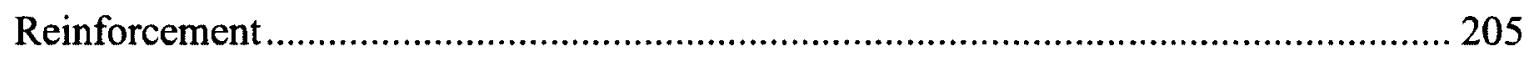




\section{List of Tables}

Table 2-1: Dynamic Increase Factors for Concrete (UFC 2008) ................................... 23

Table 2-2: Yield Strength increase of Steel Subject to Rapid Loading Rates (Keenan and

Feldman 1960, Flathau. 1971, ACI Committee 439 1969) _........................................ 25

Table 2-3: Dynamic Increase Factors for Steel Reinforcement (UFC 2008) …............... 32

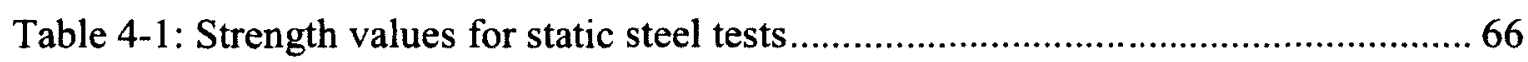

Table 4-2: Strength values for steel tests conducted at a rate of $0.1 \mathrm{strain} / \mathrm{s} . \ldots \ldots \ldots \ldots \ldots \ldots \ldots . . .66$

Table 4-3: Strength values for steel tests conducted at a rate of 0.2 strain/s .................. 67

Table 4-4: Dynamic Increase Factor for Steel Reinforcement ………………………....67

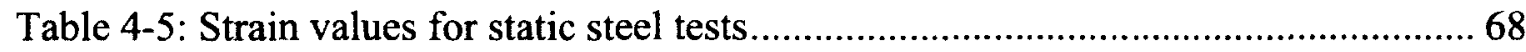

Table 4-6: Strain values for steel tests conducted at a rate of $0.1 \mathrm{strain} / \mathrm{s} \ldots \ldots \ldots \ldots \ldots \ldots \ldots \ldots \ldots . .68$

Table 4-7: Strain values for steel tests conducted at a rate of $0.2 \mathrm{strain} / \mathrm{s} . \ldots \ldots \ldots \ldots \ldots \ldots \ldots \ldots . . .69$

Table 4-8: Increase in Strain Values for Steel Reinforcement at High Strain Rates ........ 69

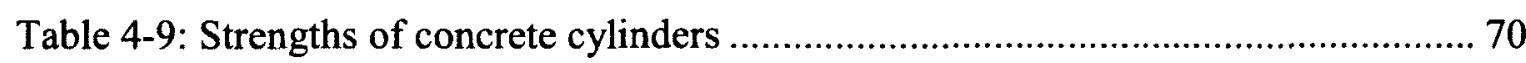

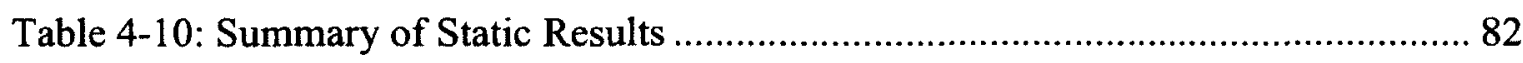

Table 4-11: Pressure, impulse, displacement, support rotation and crack width data for

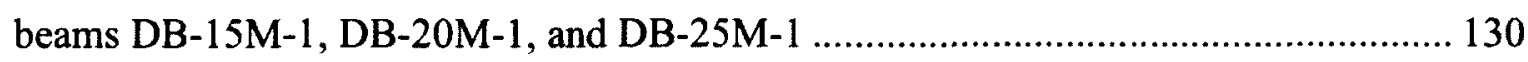

Table 4-12: Strain and displacement data for beams DB-15M-1, DB-20M-1, and DB$25 \mathrm{M}-1$

Table 4-13: Pressure, impulse, displacement, support rotation and crack width data for beams DB-15M-2, DB-15M-3, DB-20M-2, DB-20M-3, DB-25M-2, and DB-25M-3.. 132 
Table 4-14: Strain and displacement data for beams DB-15M-2, DB-15M-3, DB-20M-2, DB-20M-3, DB-25M-2, and DB-25M-3 ……………......................................... 133

Table 4-15: Average Strain Gauge Values for SB-15M Beams ..................................... 198

Table 4-16: Average Strain Gauge Values for DB-15M Beams ................................... 198

Table 4-17: Average Strain Gauge Values for SB-20M Beams ..................................... 199

Table 4-18: Average Strain Gauge Values for DB-20M Beams .................................... 199

Table 4-19: Average Strain Gauge Values for SB-25M Beams ................................... 200

Table 4-20: Average Strain Gauge Values for DB-25M Beams …………………….... 200

Table 5-1: Bond Stress in 15M Reinforcing Steel .................................................... 213

Table 5-2: Bond Stress in 20M Reinforcing Steel .................................................. 213

Table 5-3: Bond Stress in 25M Reinforcing Steel ..................................................... 213

Table 5-4: Variables used to calculate bond strength ................................................. 217

Table 5-5: Bond strengths calculated from various empirical formulas........................ 218 


\section{Nomenclature}

$A_{b}$ - area of reinforcing bar

$A_{t r}-$ area of transverse reinforcement

$c$ - smallest of either the reinforcement spacing or concrete cover dimension

$c_{\max }$ - greater of the clear bottom cover to the longitudinal reinforcement or the side cover

to the longitudinal reinforcement

$c_{\min }-$ smaller of the clear bottom cover to the longitudinal reinforcement or the side

cover to the longitudinal reinforcement

$d_{b}$ - diameter of the reinforcing bar

$D I F$ - dynamic increase factor

$d_{l}-$ load point displacement

$d_{m}-$ midspan displacement

$E_{b}$ - mean slope of the strain-hardening region in the static stress-strain diagram

$E_{s}$ - modulus of elasticity of steel

$f_{c}^{\prime}-$ concrete compressive strength

$f_{d c}{ }^{\prime}$ - dynamic compressive strength of concrete

$f_{d u}$ - dynamic ultimate strength of steel

$f_{d y}$ - dynamic yield strength of steel

$f_{s}$ - stress in reinforcing bar

$f_{u}$-ultimate strength of steel

$f_{y}-$ yield strength of steel

$f_{y t}-$ yield stress of transverse reinforcement

$I_{r}-$ reflected impulse 
$k_{I}-$ bar location factor

$k_{2}$ - coating factor

$k_{3}$ - concrete density factor

$k_{4}$-bar size factor

$K_{t r}$ - transverse reinforcement index

$l_{d}-$ development length

$n$-number of longitudinal bars being developed

$N$-number of stirrups within the development length

$P_{d}$ - driver pressure

$P_{r}-$ reflected pressure

$R_{r}$ - relative rib area of the reinforcement

$s$ - spacing of transverse reinforcement

$S I F$ - strength increase factor

$T$ - bond force

$t_{d}$-positive phase duration

$t_{\max }$ - time to maximum displacement

$t_{r}$ - factor representing the effect of the relative rib area on the steel contribution to the bond force

$t_{d}-$ factor representing the effect of the bar size on the steel contribution to the bond force

$U$ - bond force per unit length

$w_{c f}$ - final width of preformed crack

$w_{c i}-$ initial width of preformed crack 
$\alpha$ - exponent for DIF of steel (section 2.7.2)

$\alpha_{f u}$ - exponent for $D I F$ of yield strength of steel (section 2.7.2)

$\alpha_{f y}$ - exponent for $D I F$ of yield strength of steel (section 2.7.2)

$\alpha_{s}$ - exponent in equation for $D I F$ of concrete in compression (see section 2.4)

$\beta$ - factor in equation for $D I F$ of concrete in compression (see section 2.4)

$\gamma_{s}$ - factor in equation for DIF of concrete in compression (see section 2.4)

$\delta$ - exponent in equation for $D I F$ of concrete in compression (see section 2.4)

$\Delta l$ - change in length

$\Delta \mathrm{T}$ - change in tensile force in the reinforcing steel

$\dot{\varepsilon}$ - dynamic strain rate

$\varepsilon_{d u}-$ dynamic ultimate strain in steel

$\dot{\varepsilon_{0}}$ - quasi static strain rate

$\dot{\varepsilon_{s}}-$ static strain rate

$\varepsilon_{s}-$ strain in steel

$\theta_{\max }$ - maximum support rotation

$\mu$-bond stress 


\section{Chapter: Introduction}

\subsection{Need for Blast Resistant Buildings}

In recent years, the occurrence of both accidental and premeditated explosions has raised concern about the integrity of critical infrastructures and their ability to protect people from the effects of explosions. The Oklahoma City bombing in 1995 and the September 11, 2001 attacks on the twin towers in New York City have raised concerns about the ability of buildings designed for aesthetic and economy to resist extreme loading from terrorist attacks. Damage from explosive effects is not limited to terrorist action alone. Accidental explosions may have similar detrimental effects. For example, The Halifax explosion that occurred in 1917 , from the accidental collision involving a cargo ship carrying explosives resulted in many fatalities, collapsed or severely damaged buildings within a $25-\mathrm{km}$ radius from the centre of explosion (MacDonald 2005). There are however, methods available for mitigating some of the damaging effects of explosions and improving the integrity of building infrastructure. These include mitigating window glass hazard and strengthening the exterior façade of buildings to increase their blast resistance.

Reinforced concrete is the most common building material used in blast resistant infrastructure due to its ability to absorb energy produced by explosions. The detailing of reinforcing steel within concrete elements is the key to achieving increased structural integrity and ductility. Thus, it is important to attain high-quality bond of reinforcing steel to concrete in structural elements through the development of reinforcing steel. 
While the current level of knowledge on the bond of reinforcing steel to concrete in beams is quite advanced, most of this knowledge is on the effect of static or low-cycle dynamic loading on bond. The effect of dynamic loads, such as impact and blast, on bond of reinforcement to concrete is a subject that has not been thoroughly explored. It is a well-known fact that dynamic loads affect both steel and concrete properties, but it is the interaction between these two materials that is of particular importance for bond characteristics.

\subsection{Objective of Experimental Program}

In order to advance the current level of knowledge in blast design and mitigation, the current experimental research program was designed to determine the bond strength of rebar in reinforced concrete beams under short duration dynamic loads such as those produced by a blast; using the shock tube at the University of Ottawa. The bond strength was investigated using concrete beams with three different sizes of reinforcement and at different strain rates. The results of the experimental program make it possible to determine how the loading rate affects the bond between the steel reinforcement and concrete. The goal is to develop code specifications for anchorage of steel reinforcement in concrete beams for the recently published "Design and Assessment of Buildings Subjected to Blast Loads" (CSA S850-12 2012). Studying the behavior of steel reinforcement bond with concrete will lead to safer infrastructure design against blast loading through the use of proven design methodologies, economic building practices, and reinforcement detailing for the protection of Canada's infrastructure. 


\subsection{Organization of Thesis}

Chapter 2 of this thesis presents a comprehensive literature review on the current level of knowledge on the factors that affect bond of reinforcing steel to concrete in beams, and derivations of bond and development length equations through experimental and theoretical work. The effect of blast loads on structures, the effects of dynamic loading on properties of reinforcing steel and concrete and the effects of dynamic loading on bond between concrete and steel reinforcement are also discussed.

Chapter 3 describes the experimental program. The construction of 15 reinforced concrete beams with 3 different sizes of reinforcement $(15 \mathrm{M}, 20 \mathrm{M}$, and $25 \mathrm{M})$ is presented. The procedure for completing ancillary testing to determine the properties of concrete and steel reinforcement are described. Furthermore, a description of the static and dynamic test procedure of reinforced concrete beams to determine static and dynamic characteristics and behaviour of steel reinforcement- concrete bond is provided.

Chapter 4 presents a discussion of the results obtained from the experimental work. This includes the concrete and steel strengths from ancillary testing, the behaviour of reinforced concrete beams, including reinforcement and concrete strains in bonded region, under static loading, and the behaviour of reinforced concrete beams under shock tube testing. Strain profiles obtained in steel reinforcement under both static and dynamic loading are also presented and discussed.

Chapter 5 analyzes the differences in bond behaviour from static and dynamic tests in the elastic range, at the yield strain, and the post-yield range. The bond force calculated from experimental results and compared to the empirical data is also presented in Chapter 5. 
Chapter 6 presents conclusions drawn from the experimental program and recommendations for future work. 


\section{Chapter: Literature Review}

In recent years, the occurrence of both accidental and premeditated explosions close to building structures and other infrastructure systems has raised concern about the integrity of buildings and infrastructure systems and their ability to protect the occupants, processes, and critical systems. The London underground bombing of 2005, the September $11^{\text {th }}$ attacks of 2001 in the USA, the, and the Oklahoma City Bombing of 1995 , to name only a few, have forever changed the way buildings are designed (Bangash 2006), especially those deemed critical or of national significance.

Even though the driving force behind the new interest in blast resistant design is the numerous premeditated attacks on buildings, explosion damage is not limited to only events of a terrorist attack. Accidental explosions could have similar detrimental effects on buildings and infrastructure systems close to the center of explosion. The Halifax explosion of 1917 from the accidental collision involving a cargo ship carrying about 2400 metric tonnes of explosives resulted in the loss of many lives and collapse of buildings within a $25-\mathrm{km}$ radius of Halifax Harbour (MacDonald 2005). In 1944, another accidental explosion occurred in Port Chicago while munitions that were being loaded onto a vessel detonated. This resulted in many deaths as well as damage to businesses and about 90 percent of the homes in the town (Allen 2006). Only a few years later, in 1947, a fire was discovered aboard the Grandchamp in Texas City (Stephens 1997). After failed attempts to put out the fire, the ammonium nitrate fertilizer aboard the ship exploded, which later caused a second explosion on the High Flyer, another ship in the port carrying ammonium nitrate. These two explosions destroyed over 500 homes and resulted in total property losses of $\$ 600$ million including $\$ 500$ million in petroleum products from the 
Monsanto Chemical Company plant (Stephens 1997). In 1974, another chemical plant was destroyed in Flixborough, England as a result of a rupture in the bypass system, which caused cyclohexane to leak from the reactor. Once the cyclohexane was ignited, a large explosion took place, resulting in the death of many workers and damage to the surrounding properties (HSE 2012). More recently, in Cyprus at the Evangelos Florakis Naval Base near the village of Zygi, 98 containers of explosives which were exposed to high outdoor temperatures for over two years detonated (Psyllides 2011). A power station in the vicinity was severely damaged leaving almost half of Cyprus without electricity. Almost every home in a small town in Cyprus sustained damaged. The above examples highlight only a few accidental explosions and their attendant damage to infrastructures and human fatalities. Regardless of the source of blast loading, whether accidental or premeditated, human casualties and the damage to buildings and infrastructure systems can be substantial. Thus, buildings with a high probability of exposure to blast loading must be designed to mitigate or limit the explosion hazard to occupants and critical systems.

Today, reinforced concrete is the most common building material used in blast resistant infrastructure design. Its ability to absorb energy produced by explosions is a quality that makes reinforced concrete suitable for blast resistant design. The detailing of reinforcing steel within concrete elements is the key to achieving structural integrity and ductility. 


\subsection{Concrete-Reinforcement Bond Behaviour}

The design of structures subjected to extreme loading such as blast, impact, and earthquake loads depends on ductility to dissipate energy. The ductility also ensures that even though the structure could sustain extensive damage its stability is not compromised. Ductility is the capacity of a reinforced concrete member to achieve deformations without considerably reducing its flexural capacity (Park and Ruitong 1988). When a reinforced concrete member is undergoing deformation, the steel reinforcement stress is transferred into the concrete through the reinforcement-concrete bond. The minimum bond length required to transfer the yield stress of steel is termed the development length (Park and Paulay 1975). Upon loading of a simply-supported beam, the yielding of reinforcement will be initiated towards the midspan where cracks in concrete are present. A strong bond between the tension reinforcing steel and the surrounding concrete is essential to achieve a ductile failure mode.

The development length requirements of reinforcement in concrete beams are derived through sectional analysis. There are many research works in the literature devoted to studying the development length of reinforced and prestressed concrete under static loading conditions. The following section briefly presents the theoretical and experimental derivation of the development length equation for reinforced concrete beams under static loads.

\subsubsection{Transfer of Forces from Steel Reinforcement to Surrounding Concrete}

In order to understand the bond length required to develop the yield strength in steel reinforcement, it is imperative to understand how forces are transferred from one 
material to the other. The resistance of reinforced concrete structures to loads depends greatly on the transfer of forces between concrete and steel reinforcement. ACI Committee 408 (2003) recognized that transfer of forces between reinforcement and concrete in a reinforced concrete beam may take the form of:

- adhesion of concrete to steel reinforcement,

- friction between steel reinforcement and concrete,

- $\quad$ aggregate interlock between concrete aggregate and steel reinforcement ribs.

Alsiwat and Saatcioglu (1992) explain that when a reinforcing bar is stressed up to its cutoff point (the point at which the reinforcing steel is terminated), the embedded rebar will slip with respect to the surrounding concrete. When this happens, adhesion of the materials to one another is lost. Beyond this point, the friction at the interface of the steel and concrete, and the interlocking of the rebar's ribs with the concrete aggregate are responsible for the transfer of forces. As these forces become large, bond strength is reduced. The concrete may begin to crack or crush in areas adjacent to the rebar and can lead to the eventual failure of the concrete element. It is also important to note that because the transfer of forces occurs on the contact area between the rebar and concrete, an increase in length of the bar increases the strength of the bond (ACI Committee 408 2003).

\subsubsection{Theoretical and Experimental Determination of Development Length}

The development length of reinforcement is based on the ability of the bond between reinforcing steel and concrete to transfer forces present in the steel to the 
concrete (Park and Paulay 1975). MacGregor (1997) defined the development length as "the shortest length of bar in which bar stress can increase from zero to yield strength before bond failure". By understanding the equation for yield stress, it is possible to derive an equation for the development length. If $U$ is the bond force per unit length, $d_{b}$ is the diameter of the reinforcing bar, and $\pi d_{b}$ is the perimeter of the bars developed at the section, then the bond stress per unit length, $\mu$, is defined by Equation (2-1) (ACI Committee 408 2003).

$\mu=\frac{U}{\pi d_{b}}$

The bond force per unit length is equal to the change in tensile force in the reinforcing steel, $\Delta \mathrm{T}$, divided by the length over which this change occurs, $\Delta l$. The change in tensile force is equal to the product of the bar stress, $f_{s}$ and the bar area $A_{b}$. By MacGregor's (1997) definition for development length, the reinforcement undergoes a change in stress from zero to the yield strength, $f_{y}$. Therefore,

$\Delta T=\Delta f_{s} A_{b}=\left(f_{y}-0\right) A_{b}=f_{y} A_{b}$

The bond stress equation then becomes

$\mu=\frac{\Delta T}{\Delta l \pi d_{b}}=\frac{f_{y} A_{b}}{\Delta l \pi d_{b}}=\frac{f_{y}\left(\pi d_{b}{ }^{2} / 4\right)}{\Delta l \pi d_{b}}=\frac{f_{y} d_{b}}{4 \Delta l}$

Equation (2-3) can then be rearranged to determine the change in length over which the bar stress changes from zero to the yield stress as presented in Equation (2-4).

$\Delta l=\frac{f_{y} d_{b}}{4 \mu}=l_{d}$

Where the length, $l_{d}$, is the length needed to develop the bond stress $\mu$. 
Through experimental testing it was determined that the bond stress is a function of the concrete strength and size of the reinforcement. Orangun et al. (1977) developed an equation relating the force in steel reinforcement and concrete compressive strength, $f_{c}$, to the development length and amount of transverse reinforcement. The equation was then modified and simplified by ACI Committee 318 (2008) to yield the following equation:

$\frac{l_{d}}{d_{b}}=\frac{3}{40} \frac{f_{y}}{\sqrt{f_{c}^{\prime}}\left(\frac{c+K_{t r}}{d_{b}}\right)}$

Where $c$ is the radius of a cylindrical prism of concrete surrounding the tensile reinforcement. Converting Equation 2-5a into SI units gives:

$\frac{l_{d}}{d_{b}}=0.9 \frac{f_{y}}{\sqrt{f_{c}^{\prime}}\left(\frac{c+K_{t r}}{d_{b}}\right)}$

Where $K_{t r}$ is the transverse reinforcement index given as;

$K_{t r}=\frac{A_{t r} f_{y t}}{1500 s n}$

$A_{t r}$ is the area of transverse reinforcement $\left(\mathrm{mm}^{2}\right), f_{y t}$ is the yield stress of transverse reinforcement (MPa), $s$ is the spacing $(\mathrm{mm}), n$ is the number of bars being developed, and $c$ is the smallest of either the reinforcement spacing or concrete cover dimension (mm). According to MacGregor (1997), the effect of concrete cover can be taken into account by assuming a minimum clear cover of $d_{b}$ and $c$ equal to $1.5 d_{b}$ for cases where no transverse reinforcement is provided. In cases where minimum transverse reinforcement is provided the value of $c+K_{t r}$ is set to $2 d_{b}$.

The development length equation is modified by applying factors to reflect the in situ condition of reinforcement. These factors include the bar location factor, $k_{l}$, the 
coating factor, $k_{2}$, the concrete density factor, $k_{3}$, and the bar size factor, $k_{4}$ (CSA A23.304 2004) as per Equation 2-7 and 2-8.

The simplified equation in CSA A23.3-04 (2004) then becomes

$l_{d}=0.6 k_{1} k_{2} k_{3} k_{4} \frac{f_{y}}{\sqrt{f_{c}^{\prime}}} d_{b}$

where no transverse reinforcement is provided, and

$l_{d}=0.45 k_{1} k_{2} k_{3} k_{4} \frac{f_{y}}{\sqrt{f_{c}^{\prime}}} d_{b}$

where at least minimum transverse reinforcement is provided. Through the derivation of this equation it is possible to understand the effect that concrete cover, transverse reinforcement, material properties, rebar sizes, and coatings have on the development of rebar in reinforced concrete beams.

\subsubsection{Factors that Affect the Bond of Concrete to Reinforcing Steel}

The steel reinforcement-concrete bond characteristics and development length have been investigated by many researchers (Orangun et al. 1977, Moehle et al. 1991, ACI Committee 408 2003, Darwin 2005). The researchers reported that reinforcementconcrete bond is affected by the material properties of concrete and steel; including: reinforcement spacing and concrete cover of the rebar, the presence of transverse reinforcement or ties, the position of the bottom longitudinal reinforcement, bar size, and coatings on the rebar. As described in the previous section, all of these factors have been taken into consideration in the derivation of the development length equation. This section describes how these parameters affect bond strength. 
It has been found that material properties of concrete and steel determines the magnitude of tensile and compressive forces that a beam can withstand, and thus have a significant effect on bond strength. The concrete cover and clear spacing of adjacent longitudinal bars also affects the bond strength. Orangun et al. (1977) modified the ACI 318 Equation 2-5a for reinforcement anchorage to include the effect of clear spacing of steel rebar and concrete cover to rebar. Moehle et al. (1991) proposed a new approach to development length calculations which took into account the influence of concrete cover on anchorage strength based on ACI Committee 408 recommendations. ACI Committee 408 (2003) further explained that concrete subjected to tensile forces will split in a manner depending on the clear concrete cover to rebar, clear rebar spacing, and concrete strength. As a result, the larger the clear rebar spacing and clear concrete cover to rebar, the greater the bond resistance, and the required development and splice lengths will be minimized.

In addition to the provisions for concrete cover and spacing made by Orangun et al. (1977) and Moehle et al. (1991), the presence of transverse reinforcement has also been taken into consideration. Transverse reinforcement has proved to have a substantial effect on required embedment lengths. Esfahani and Kianoush (2005) explain that when transverse reinforcement is added to beams, it acts in a manner that prevents further splitting crack growth in the concrete beam. Confinement prevents radial expansion of the concrete, thus preventing cracking and increasing the mechanical interlock of steel lugs with the surrounding concrete (Solomos and Berra 2010). As more transverse reinforcement is added to a beam, the failure mode is more likely to be pullout rather than 
concrete splitting failure, which leads to greater bond resistance (Esfahani and Kianoush 2005).

It has also been confirmed that the position of reinforcement in a concrete specimen will affect the bond strength (ACI Committee 408 2003, Darwin 2005). Rebar cast near the top of a beam has a lower bond strength than rebar near the bottom of a beam. ACI Committee 408 (2003) and Darwin (2005) give reasons for this behaviour and explain that it is the result of bleed water collected at the surface of the top reinforcement during concrete setting (hydration). The water at the interface of the rebar and concrete creates a condition where the concrete and rebar will not adhere to one another, thus reducing bond resistance (Darwin 2005).

Although reinforcing steel configuration in the concrete plays a significant role in bond strength development, reinforcing steel properties have been observed to affect the bond capacity as well. ACI Committee 408 (2003) explained that larger diameter rebar in beams increase the bond resistance since there is a larger surface area of rebar bonded to the concrete. Tests dating as far back as 1945 (Kluge et al. 1945) confirm that rebar with larger diameters are capable of providing greater bond strengths. However, when a certain cross sectional area of reinforcement is required, a larger number of small bars has demonstrated more favourable results since it provides a greater surface area between the reinforcement and the concrete (ACI Committee 408 2003). Darwin (2005) explain that properties such as coatings on reinforcing steel reduce the bond capacity since it causes the rebar's surface to be smoother, thus reducing the friction at the interface of the concrete and steel (Darwin 2005). 


\subsubsection{Failure Mechanisms of Reinforced Concrete Beams}

The resistance of concrete beams to applied loads can be better understood by appreciating the failure modes that may exist. The anchorage of the reinforcement, in particular the development or splice length, plays a significant role in a beam's performance. Every reinforced concrete beam will fail at a certain load, but the components or sections of the beam that fail will depend on both the configuration and strength of the concrete and reinforcement (ACI Committee 408 2003). Orangun et al. (1977) recognized that splitting of the concrete can occur due to the force exerted by reinforcement's ribs on the adjacent concrete. The authors described three failure mechanisms and the beam configuration under each failure mode. The failure modes of beams (not confined by transverse reinforcement) are a function of the clear cover of the rebar to the bottom of the beam and the clear spacing between bars. If half the clear spacing between bars is less than the bottom cover, then the concrete would crack in the plane of the longitudinal reinforcement (horizontal cracking). However, when the bottom cover is less than one-half the clear spacing between rebar, the failure crack would propagate from the rebar to the bottom of the beam (Orangun et al. 1977). ACI Committee 408 (2003) also recognized the failure modes presented by Orangun et al. (1977), but in addition outlined that the CSA A23.3-04 (2004) standard uses a greater value for half the clear spacing between bars to account for the fact that cracks propagating from adjacent bars will not meet in the middle and additional concrete cracking is required for these cracks to meet, thus resulting in a greater calculated bond strength and a less conservative calculation for development length. 


\subsection{Blast Load Effect on Structures}

In order to understand the effect of blast loads on structures, it is necessary to understand what happens during an explosion. Baker et al. (1983) defined an explosion as a "sudden release of energy", which is caused by physical, nuclear, or chemical reactions. Although physical and nuclear explosions can be very destructive to their surroundings, their occurrence is less frequent than chemical explosions. Therefore, for the purpose of mitigating against terrorist activities, or the effects of accidental explosions, the outcome of chemical explosions acting on structures is sought.

In a chemical explosion, elements such as carbon, hydrogen, nitrogen, and oxygen undergo an oxidation reaction. This reaction is responsible the bulk of the energy that is released in an explosion (detonation). When an explosive detonates, hot gases are produced creating a high pressure zone and pushing the surrounding air outwards (blast wave) at a very high velocity. The leading edge of the expanding gases (blast wave) forms a thin compressed gas layer known as the shock front. When the blast wave encounters or interacts with the environment or structures it imparts its energy to it in the form of pressure loading. The compressed air in the shock front will cause very high pressures to act on the structure. However, behind the shock front, the pressure will drop very rapidly. As a result, the high pressures will only be exerted on the surface for a very short duration, and the structure will be subject to dynamic pressures. (Ngo et al. 2007)

It is also important to note that as the pressure decreases behind the shock front, it reaches a magnitude below atmospheric pressure for a period of time, as shown in Figure 2-1. When the pressure is below the atmospheric pressure (a period known as the negative phase), suction forces are produced (Ngo et al. 2007). The magnitude of 
pressure produced in the negative phase is much less than the pressure produced in the positive phase, and therefore may often be ignored in design (Krauthammer et al. 1994). It is however important to note that the suction forces caused by the negative phase may cause movement of fragments and other large debris. If these fragments come in contact with the structures façade, large forces may appear in elements and there is potential for damage to structural components. Depending on the location of the detonation, high pressure will also be exerted on the ground. Consequently, detonations may cause ground shock, which will further induce vibrations into structures within a close proximity (Ngo et al. 2007). The impact of the blast wave on the structure above ground is however of particular concern to the above ground infrastructure.

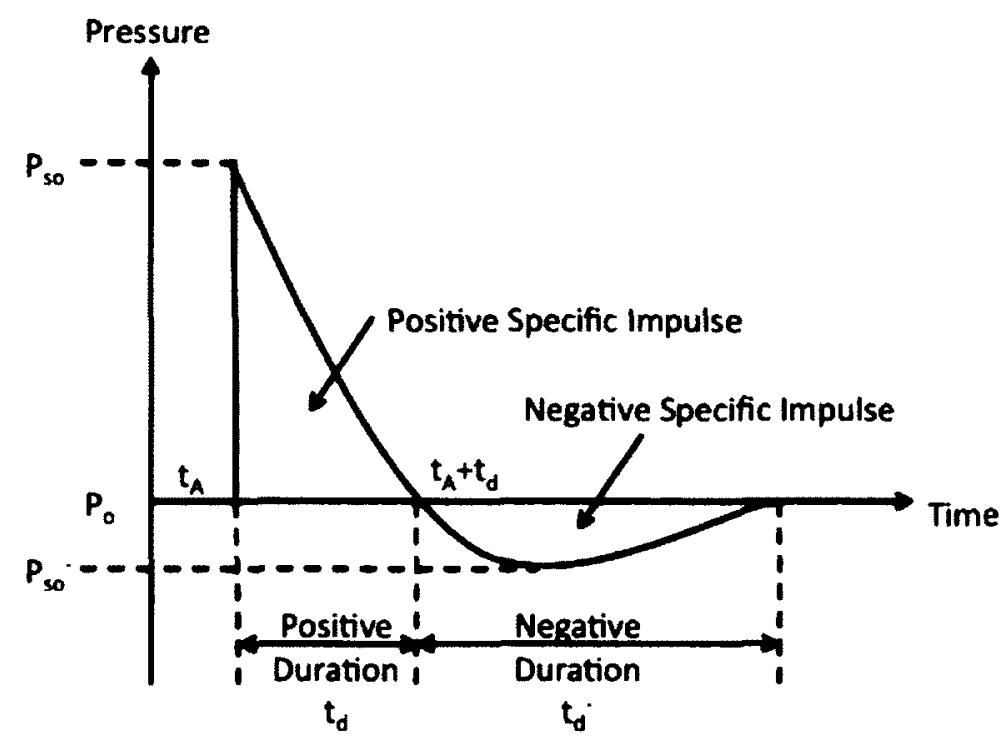

Figure 2-1: Blast wave parameters (Ngo et al. 2007)

The former described the general means by which blast loads affect structures. However, for the design of structures and materials used in construction, specific loads 
acting on the structure must be determined. In order to gain an estimate of the pressure that may be exerted on a structure due to an explosion, the risk that the structure is facing must be determined. The blast loading is dependent on the size of explosive charge and its location relative to the structure (Krauthammer et al. 1994). The peak pressure acting on the structure from an explosion decreases as the distance from the center of detonation increases. For the same standoff distance, the size of the explosive is directly proportional to the peak reflected pressure experienced by the structure.

The shape and orientation of the structure is also an important consideration. When the shock front acts on a building, the face of the structure normal to the explosive charge (center of detonation) will experience reflected pressures due to blast wave reflection from the surface. Although the blast wave may not be acting normal to the other surfaces, it could engulf the structure and cause a side-on pressure on the roof and sides of the structure where there is no direct reflection of the blast wave (Ngo et al. 2007). The blast load parameters, including magnitude of the reflected and side-on (incident) pressure, the impulse, and the duration of the positive phase, are most commonly determined with the Kingery-Bulmash polynomials (Kingery and Bulmash 1984). The Kingery-Bulmash polynomials are based on experimental data collected from five large-scale explosions in Canada (Kingery and Bulmash 1984 ) and have proved to give very good results given a scaled distance of an explosion. The Kingery-Bulmash polynomials are presented as charts in UFC (2008) and the Conventional Weapons Effects Calculator (CONWEP) for determining blast load parameters (Hyde 1992). Dynamic effects may be responsible for inelastic behavior of material due to the high strain rates induced in the structural components. Krauthammer et al. (1994) state that 
strain rates ranging from $1 \mathrm{~s}^{-1}$ to $10^{3} \mathrm{~s}^{-1}$ may be produced as the result of blast loads (which is in the order of $10^{3}$ times greater than those produced by earthquakes). Ngo et al. (2007) claim that even greater strain rates ranging from $10^{2} \mathrm{~s}^{-1}$ to $10^{4} \mathrm{~s}^{-1}$ may be produced as the result of blast loads, in comparison to static strain rates ranging from $10^{-6} \mathrm{~s}^{-1}$ to $10^{-5}$ $\mathrm{s}^{-1}$. Regardless of the exact magnitude of these strain rates, it has been determined that properties of construction materials, such as strength, ultimate strain, and modulus of elasticity are affected by strain rate.

The effect of dynamic loads on reinforced concrete may be quite complex. Short duration dynamic loads may affect the properties of concrete and steel in different manners, thus altering the failure modes in reinforced concrete elements from ductile to brittle behavior (Yang and Lok 2007). Furthermore, the bond characteristics of concrete to steel reinforcement are not very well researched and may affect the behaviour of reinforced concrete elements.

The blast resistance of a reinforced concrete structure depends on the performance of concrete and steel reinforcement under high strain rates. The load transfer from the steel reinforcement to the adjacent concrete becomes essential for achieving ductile response. Thus understanding the behaviour of concrete and rebar in reinforced concrete elements under blast load actions are of particular interest.

\subsection{High strain rate Effect on the Compressive and Tensile Strength of Concrete}

Numerous tests have been conducted to determine the effect that strain rates have on the compressive strength of concrete (Fu et al. 1991, Le Nard and Bailly 2000, Lu and Xu 2004, Yan and Lin 2006). Fu et al. (1991) present a review of research on the strain 
rate effect on compressive strength of concrete and reported increased strength with increase in loading rate. Figure 2-2 shows the effect that a rapid strain rate has on the concrete strength. Le Nard and Bailly (2000), Lu and Xu. (2004), and Yan and Lin (2006) also report increase in strength due to dynamic load effects, where high strain rate levels are present. An increase in the modulus of elasticity and strain at ultimate stress was also found to be a consistent trend by Fu et al. (1991).

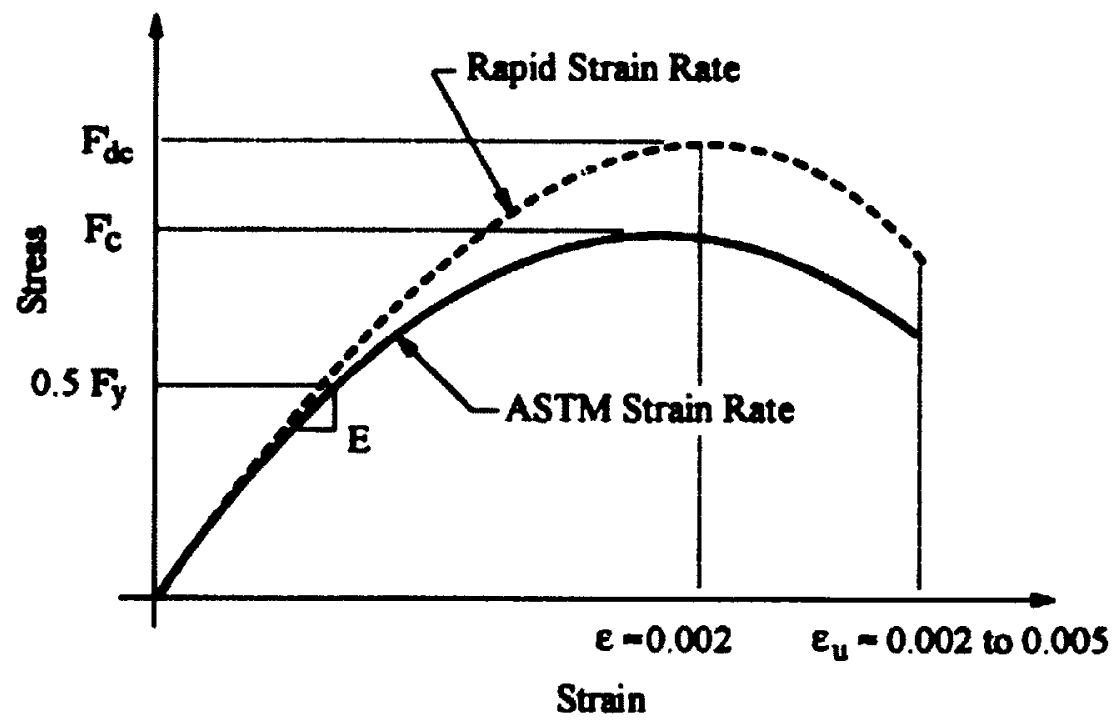

Figure 2-2: Effect of Strain Rate on Concrete Strength (ASCE 1997)

Dynamic loading also has an effect on the tensile strength of concrete. Malvar and Ross (1998), report that the increase in tensile strength of concrete is even greater than the increase in compressive strength for the same loading rate. In fact Malvar and Ross (1998) state that the compressive strength can increase by about $100 \%$ of the static strength at high strain rate, whereas the tensile strength can increase by up to $600 \%$ of the static strength under high strain rate. $\mathrm{Lu}$ and $\mathrm{Xu}$ (2004) reported compressive strength increases up to 1.5 times and tensile strength increases up to 7 times. Both Malvar and 
Ross (1998), and Yan and Lin (2006) suggested that a dynamic increase factor (DIF) may be applied to the static strengths to account for material strength increases due to high strain rates. The $D I F$ is defined as the ratio of dynamic-to-static strength of the material. Formulas derived to determine the $D I F$ of concrete are discussed later in this chapter.

Although increase in the compressive and tensile strength of concrete is established by various researchers, there is some discrepancy in the actual magnitude of this increase between the researchers. Concrete properties and failure modes considered can have a major impact on the increase in strength. The moisture content of concrete specimens is one of the reasons there exists variation in reported DIF values (Fu et al. 1991). The moisture content can have a substantial effect on the increase in concrete strength under dynamic loading as the concrete will not have enough time for the pore water pressure to dissipate under high strain rate as is the case under static loading. Thus Fu et al. (1991) concluded that saturated concrete is much more sensitive to strain rate effects than is dry concrete. The strength of concrete also affects the magnitude of the increase in strength under high strain rates. Yan and Lin (2006) explained that lower strength concrete contains more voids which allow the concrete to resist more deformation, thus giving low strength concrete a greater DIF. Fu et al. (1991) also discuss that flexure tests by Zech and Wittman (1979) confirmed that higher strength concretes are less susceptible to strength increases under dynamic loading. Other properties that can have an effect on the strength increase in concrete under high strain rates is the "aggregate type, curing conditions, age at testing, geometry, rate and type of loading" (Fu et al. 1991). 


\subsection{Numerical models for Concrete under Dynamic Loading}

For concrete in compression, the CEB (1988) formulation is used in predicting the $D I F$ for design. The formulas are presented in $\mathrm{Li}$ and Meng (2003) and CEB (1988) as follows:

$\frac{f_{d c}^{\prime}}{f_{c}^{\prime}}=\left(\frac{\dot{\varepsilon}}{\dot{\varepsilon}_{s}}\right)^{1.026 \alpha_{s}}$ for $\dot{\varepsilon} \leq 30 \mathrm{~s}^{-1}$

$\frac{f_{d c}^{\prime}}{f_{c}^{\prime}}=\gamma_{s}\left(\frac{\dot{\varepsilon}}{\dot{\varepsilon}_{s}}\right)^{1 / 3} \quad$ for $\dot{\varepsilon}>30 \mathrm{~s}^{-1}$

Where,

$\dot{\varepsilon}=$ dynamic strain rate, $\dot{\varepsilon}_{\mathrm{s}}=$ static strain rate, $f^{\prime}{ }_{d c}=$ dynamic compressive strength, $f_{c}^{\prime}=$ static compressive strength

$\gamma_{s}=10^{6.156 \alpha_{s}}$

$\alpha_{s}=\frac{1}{\left(5+9 \frac{f_{c}^{\prime}}{f_{c o}^{\prime}}\right)}$

$f_{c o}^{\prime}=10 \mathrm{MPa}$

For concrete in tension, a similar formulation was derived by CEB. However, according to several researchers, the formulae are not very accurate because the concrete strength increase was over-predicted for high strain rates ( $\mathrm{Li}$ and Meng 2003). Malvar and Ross (1998) conducted a literature review on the effect of high strain rate on the tensile strength of concrete and modified the CEB formulae to correlate with experimental results. Equation 2-11 and 2-12 are therefore used for the DIF of concrete in tension. 
$\frac{f_{d t}^{\prime}}{f_{t}^{\prime}}=\left(\frac{\dot{\varepsilon}}{\dot{\varepsilon_{s}}}\right)^{\delta} \quad$ for $\dot{\varepsilon} \leq 1 \mathrm{~s}^{-1}$

$\frac{f_{d t}^{\prime}}{f_{t}^{\prime}}=\beta\left(\frac{\dot{\varepsilon}}{\dot{\varepsilon}_{s}}\right)^{1 / 3} \quad$ for $\dot{\varepsilon}>1 \mathrm{~s}^{-1}$

Where,

$\log \beta=6 \delta-2$

$\delta=\frac{1}{\left(1+8 \frac{f_{c}^{\prime}}{f_{c o}^{\prime}}\right)}$

$f^{\prime}{ }_{d l}=$ dynamic tensile strength, $f_{r}^{\prime}=$ static tensile strength

\subsection{DIF for Concrete in Current Practice}

Although there are some disagreements in data regarding the exact magnitude of strength increase under increased strain rate between researchers, certain values for the dynamic increase factor have been published and may be used in design. In Table 2-1 provides design $D I F$ values for concrete loaded from close-in and far-range blasts (UFC 2008). The far design range produces pressures that are relatively uniform along the surface of a building, where as the close-in design range produces relatively short duration non-uniform pressures, leading to localized stresses (UFC 2008).

The dynamic strength $\left(f^{\prime} d c\right)$ used for design is the product of the dynamic increase factor $(D I F)$ and the static strength $\left(f_{c}^{\prime}\right)$ expressed by Equation 2-13 below.

$f_{d c}^{\prime}=D I F \times f_{c}^{\prime}$ 
Table 2-1: Dynamic Increase Factors for Concrete (UFC 2008)

\begin{tabular}{|l|l|l|}
\hline & \multicolumn{2}{|l|}{ Dynamic Increase Factor $(D I F)$} \\
\hline Type of Stress & Far Design Range & Close-in Design Range \\
\hline & $f^{\prime}{ }_{d c} / f_{c}^{\prime}$ & $f^{\prime}{ }_{d} / f_{c}$ \\
\hline Bending & 1.19 & 1.25 \\
\hline Diagonal Tension & 1.00 & 1.00 \\
\hline Direct Shear & 1.10 & 1.10 \\
\hline Bond & 1.00 & 1.00 \\
\hline Compression & 1.12 & 1.16 \\
\hline
\end{tabular}

\subsection{High Strain Rate Effect on Reinforcing Steel}

Similarly with concrete, strength characteristics of steel are dependent on the loading rate (Figure 2-3). Several studies have proven that steel reinforcement undergoing rapid loading experiences an increase in both yield and ultimate strength (Keenan and Feldman 1960), Flathau 1971, Mirza and Macgregor 1979). In tests by Flauthau (1971), it was determined that at rapid strain rates, the increase in the yield strength of regular grade reinforcement is approximately $75 \%$ greater than the static yield strength. Higher grade steel reinforcements were however less sensitive to the rate of loading, showing an increase in yield strength of only $17 \%$. Keenan and Feldman (1960) reported yield strength increases of approximately $50 \%$ in their studies. Flathau (1971) reported that increases between $18 \%$ and $53 \%$ were observed by Cowell, and increases of up to $33 \%$ were observed by Siess. These differences could be attributed to the difference 
in the strain rates between the tests, the differences in the grade of steel, the differences in bar sizes being tested, difference in the loading apparatus used and material testing standards. These differences are summarized in Table 2-2.

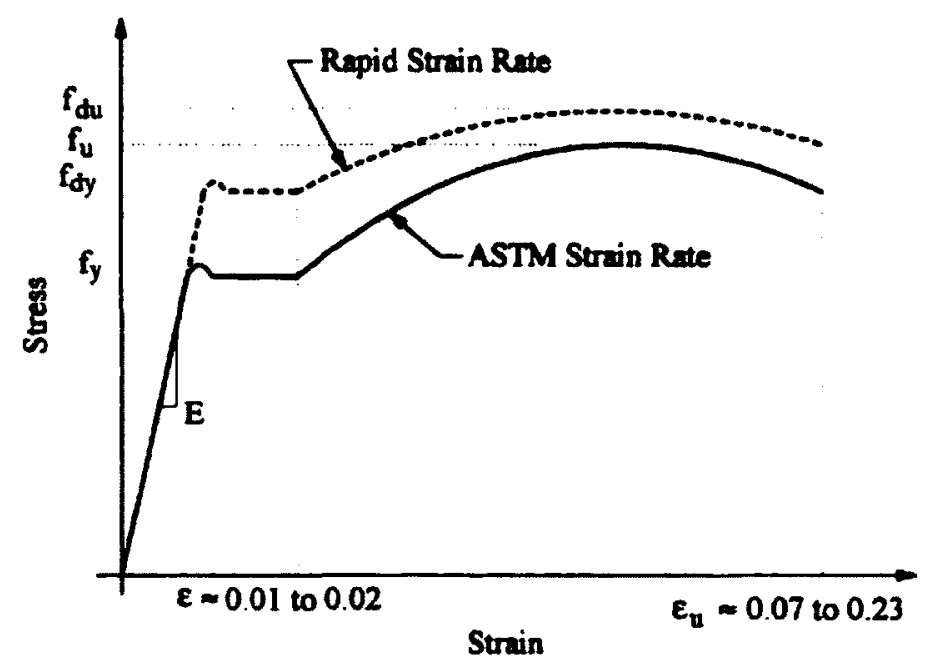

Figure 2-3: Effect of Strain Rate on Steel Strength (ASCE 1997)

Referring to the data of previous tests, it is clear that the mechanical properties of steel, and the change in mechanical properties of steel under dynamic loads is a complex matter. To better understand steel properties, Mirza and Macgregor (1979) have identified and described sources of variation in the yield strength of steel. The main sources that have been recognized are: differences in strength of steel, variability in the cross sectional area of the bar, the rate at which steel is loaded, and the value of strain at which yield is defined. 
Table 2-2: Yield Strength increase of Steel Subject to Rapid Loading Rates (Keenan and Feldman 1960, Flathau. 1971, ACI Committee 439 1969)

\begin{tabular}{|l|l|l|l|l|}
\hline Investigator & $\begin{array}{l}\text { Increase in } \\
\text { yield strength } \\
\text { under rapid } \\
\text { loading rate } \\
{[\%]}\end{array}$ & $\begin{array}{l}\text { Strain rate used } \\
\text { for rapid tests } \\
{[1 / \mathrm{s}]}\end{array}$ & $\begin{array}{l}\text { Rebar sizes } \\
\text { tested }\end{array}$ & $\begin{array}{l}\text { Static yield } \\
\text { strength of steel } \\
\text { [psi] }\end{array}$ \\
\hline $\begin{array}{l}\text { Keenan and } \\
\text { Feldman }\end{array}$ & 50 & 1 & $\begin{array}{l}\text { No. 6, No. 7, } \\
\text { No. } 9\end{array}$ & $40500-48900$ \\
\hline Flathau & 17 & $4-5$ & No. 11 & 75000 \\
\hline Flathau & 75 & $4-5$ & No. 11 & 60000 \\
\hline Cowell & 42 & 0.1 & No. 8 & 56000 \\
\hline Cowell & 27 & 0.1 & No. 8 & 59000 \\
\hline Cowell & 11 & 0.1 & No. 8 & 87000 \\
\hline Cowell & 51 & 1 & No. 8 & 56000 \\
\hline Cowell & 40 & 1 & No. 8 & 59000 \\
\hline Cowell & 18 & 1 & No. 8 & 87000 \\
\hline Siess & 33 & $0.10-1.0$ & No. 6 & 47000 \\
\hline
\end{tabular}

By reviewing previous test data, Mirza and Macgregor (1979) reported variability in the yield strength of reinforcing bars and coefficients of variation of up to $12 \%$ between data from various researchers. It was also noticed that the reported nominal and actual area of rebar are often quite different. This difference can lead to errors in the stress calculations. The rate of loading was also identified as a potential source of error in determining loading rate effects since even a small change in the static rate of loading could lead to differences in yield stress of steel reinforcement. Additionally, the strain at which yield is defined was found to vary between $0.35-0.5 \%$ strain. 
Although the factors affecting the steel reinforcement yield strength have been identified and listed above, many of them can be controlled to some extent to obtain more consistent results. The effect of loading rate (strain rate) on yield strength was established and showed a consistent increase with significant variation between researchers. The factors affecting strength increase will be discussed in the following sections.

\subsection{Derivations of Numerical Models for Steel Reinforcement Under High -Strain}

\section{Rate Loading}

The results of dynamic testing on steel reinforcement has shown that steel reinforcement subjected to high strain rates exhibit greater yield and ultimate strengths in comparison with steel reinforcement under static strain rates. Furthermore, steels with lower strengths are more sensitive to increases at high strain rates than high strength steels. While many properties of steel change under high strain rates, the modulus of elasticity of steel remains relatively constant.

Understanding the trends that steel undergoes due to dynamic effects is crucial in predicting the strain-rate effects on reinforcing steel. In order to predict the changes in mechanical properties, Soroushian and Choi (1987), Malvar and Crawford (1998), and the Comité Euro-International du Béton (1988) derived equations to predict the strain rate effects on certain strengths of steel. These derivations make it possible to quantify the changes in properties of steel due to dynamic effects and are discussed in subsequent sections. 


\subsubsection{Soroushian and Choi (1987): Steel Mechanical Properties at Different Strain}

Rates

Soroushian and Choi (1987) compared dynamic test results conducted by a variety of investigators and plotted the effect of strain rate on the yield strength and ultimate strength of steel reinforcement. The test results showed some large deviations when compared to one another, however the trends observed were all similar; the yield strength increased with strain rate and the upper yield strength was observed to be more strain rate sensitive than the lower yield strength. In addition, the ultimate strength increased with strain rates in all test results, but appears to be less sensitive to increases in strain rate than the yield strength. In view of the fact that the results from the various tests were based on strain rate effects on rebars of different shapes and yield strengths, it made sense that there was some variability in the results. Soroushian and Choi (1987) determined that this variability was primarily due to the assortment of steel yield strengths used in the investigations. Consequently, examining the effect that the static yield strength has on the sensitivity of steel properties to increased strain rates is practical.

Soroushian and Choi (1987) proposed several equations for determining the $D I F$ of steel. Equation 2-14 provides the DIF of yield strength of steel as a function of strain rate $(\dot{\varepsilon})$ :

$\frac{f_{d y}}{f_{y}}=\left(-0.451 \times 10^{-6} f_{y}+1.46\right)+\left(-9.20 \times 10^{-7} f_{y}+0.0927\right) \log _{10} \dot{\varepsilon}$

Where $f_{d y}$ is the dynamic yield strength, and $f_{y}$ is the static yield strength. Similarly, the ratio of dynamic ultimate strength $\left(f_{d u}\right)$ to static ultimate strength $\left(f_{u}\right)$ was given by Equation 2-15. 


$$
\frac{f_{d u}}{f_{y}}=\left(-7.71 \times 10^{-7} f_{y}+1.15\right)+\left(-2.44 \times 10^{-7} f_{y}+0.04969\right) \log _{10} \dot{\varepsilon}
$$

In the Equations 2-14 and 2-15, it can be observed that the coefficients in front of $f_{y}$ in Equation 2-14 are higher than in Equation 2-15, and the expression in the brackets in front of $\log _{10} \varepsilon^{-}$will yield larger values in Equation 2-14 than in Equation 2-15. This is because the yield strength is more strain rate sensitive than the ultimate strength, as previously discussed. Furthermore, a constitutive model was proposed for dynamic stress-strain of steel. The steel stress $\left(f_{s}\right)$ is a function of the modulus of elasticity of steel $\left(E_{s}\right)$ and the strain in the steel $\left(\varepsilon_{s}\right)$ for stresses below the dynamic yield stress. At stress levels above the dynamic yield stress, the steel stress is a function of the dynamic yield stress, the steel strain, the modulus of elasticity, and the mean slope of the strain-hardening region in the static stress-strain diagram $\left(E_{b}\right)$. The simplified versions of these equations are the given by Equations 2-16 and 2-17.

$$
f_{s}=\left\{\begin{array}{cc}
E_{s} \varepsilon_{s} & \text { for } \varepsilon_{s}<\frac{f_{d y}}{E_{s}} \\
f_{y}^{\prime}+E_{h}^{\prime}\left(\varepsilon_{s}-\frac{f_{y}}{E_{s}}\right) & \text { for } \frac{f_{d y}}{E_{s}}<\varepsilon_{s}<\varepsilon_{d u}
\end{array}\right.
$$

Where $\varepsilon_{d u}$ is the dynamic ultimate strain of steel and $E_{h}^{\prime}$ is given by Equation 2-17.

$$
E_{h}^{\prime}=E_{h}\left[2 \times 10^{-5} f_{y}+0.0770+\left(4 \times 10^{-6} f_{y}-0.185\right) \log _{10} \dot{\varepsilon}\right]<E_{h}
$$

From Equation 2-16, for the stresses below the dynamic yield stress, the stress is simply equal to the product of the strain and Young's Modulus. This is because the modulus of elasticity is not strain rate sensitive.

The use of these equations make it possible to predict the behavior of steel reinforcement of a known grade under a given strain rate. The development of such 
models is important in understanding the behaviour of steel reinforcement in concrete beams for design purposes.

\subsubsection{Malvar and Crawford (1998): Dynamic Increase Factors for Steel}

\section{Reinforcing Bars}

Malvar and Crawford (1998) conducted a literature review on the strain rate effects on reinforcing bars of ASTM A615 grade 40,60 and 75 reinforcement, in order to develop equations for the $D I F$ of reinforcing bars. The $D I F$ was determined to be important in the design of structures to resist blast effects.

Malvar and Crawford (1998) also investigated both static and dynamic properties of steel reinforcement so as to understand the relationship between steel strength and increase in strain rate. The report by Mirza and Macgregor (1979), and studies by Cowell (Flathau 1971), and other investigators were used to determine the best estimate of yield strength, ultimate strength and ultimate strain of the three grades of reinforcement considered. Subsequently, data obtained on the dynamic properties of reinforcing bars through a variety of sources, including investigations by Keenan and Feldman (1960), and Cowell (Flathau 1971were analyzed. Least squares regression analysis was used to obtain the exponent, $\alpha$, in Equation 2-18 for DIF for the yield stress and ultimate stress.

$D I F=\left(\frac{\dot{\varepsilon}}{10^{-4}}\right)^{\alpha}$

where $\varepsilon$ is the strain rate $(1 / \mathrm{sec})$.

When calculating the DIF for the yields stress, the exponent $\alpha$ may be taken as $\alpha_{f y}$ and is determined by the following Equation 2-19. 
$\alpha_{f y}=0.074-0.040 \frac{f_{y}}{60}$

While for $D I F$ for the ultimate stress, the exponent $\alpha$ may be taken as $\alpha_{f u}$ and is determined by the Equation 2-20.

$\alpha_{f u}=0.019-0.009 \frac{f_{y}}{60}$

Where $f_{y}$ is the static yield stress in ksi. If $f_{y}$ is given in MPa, the denominator of $60 \mathrm{ksi}$ should be replaced with $414 \mathrm{MPa}$.

From the proposed formulations, the exponent for yield stress (Equation 2-19) will provide a greater value than the exponent for ultimate stress (Equation 2-20) thus giving higher $D I F$ for yield than ultimate stress of steel reinforcement. This is similar to the equations developed by Soroushain and Choi (1987) which showed that yield stress is more sensitive to the strain rate than the ultimate stress.

\subsubsection{Comité Euro-International du Béton (CEB): Concrete Structures Under Impact and Impulsive Loading (1988)}

The CEB (1988) presented a formulation for DIF for both the dynamic yield strength and ultimate strength of steel reinforcement. The proposed formulation for the increase in yield strength $\left(f_{y}\right)$ is as follows:

$\frac{f_{d y}}{f_{y}}=1+\frac{6.0}{f_{y}} \ln \frac{\dot{\varepsilon}}{\dot{\varepsilon}_{o}}$

where $\dot{\varepsilon}$ is the strain rate $(1 / \mathrm{sec})$ and $\dot{\varepsilon_{0}}$ is the quasi static strain rate $\left(5 \times 10^{-5} \mathrm{~s}^{-1}\right)$. The proposed formulation for the increase in ultimate strength $\left(f_{u}\right)$ is 
$\frac{f_{d u}}{f_{u}}=1+\frac{7.0}{f_{u}} \ln \frac{\dot{\varepsilon}}{\dot{\varepsilon}_{o}}$

From Equations $2-21$ and $2-22$, it is noticed that the coefficient in front of $\ln \frac{\dot{\varepsilon}}{\dot{\varepsilon}_{o}}$ is based on the yield strength for Equation 2-21, and the ultimate strength for the Equation 2-22, whereas Equation 2-20 only requires the input of yield strength into the formula for increase in ultimate strength.

Asprone, Cadoni, and Prota (2009) compared the equations proposed by Malvar (1998) and CEB formula (CEB 1988). Using steel from an existing bridge (Tenza bridge), dynamic tests were conducted on the specimens and compared to predetermined strength values using the two formulas. Through the investigation Asprone, Cadoni, and Prota (2009) found that using CEB formula yielded a maximum underestimation of the yield stress by $24 \%$ while the Malvar (1998) formula overestimated the yield stress by a maximum of $34 \%$. Both the CEB and Malvar formulations, however, provided accurate estimations of the ultimate stress in the specimens.

\subsubsection{Unified Facilities Criteria (2008)}

Up to this point, the behavior of steel rebar under high strain rates has been examined for specimens in tension. However, reinforcing steel may also be used as stirrups in concrete beams and slabs, as hooks for adequate connection of beams to columns, or in the top of beams in case of load reversal. As a result, reinforcing steel may experience compressive stresses, shear stresses and other forms of stress. Table 2-3 presents DIF values published in the Unified Facilities Criteria (2008) for yield and ultimate strength of rebar under different element stresses at both close-in and far design ranges. 
Table 2-3: Dynamic Increase Factors for Steel Reinforcement (UFC 2008)

\begin{tabular}{|c|c|c|c|c|}
\hline \multirow{3}{*}{ Type of Stress } & \multicolumn{4}{|c|}{ Dynamic Increase Factor } \\
\hline & \multicolumn{2}{|c|}{ Far Design Range } & \multicolumn{2}{|c|}{ Close-in Design Range } \\
\hline & $\overline{f_{d y}} f_{y}$ & $f_{d u} / f_{u}$ & $\overline{f_{d y} / f_{y}}$ & $\overline{f_{d u} / f_{u}}$ \\
\hline Bending & 1.17 & 1.05 & 1.23 & 1.05 \\
\hline $\begin{array}{l}\text { Diagonal } \\
\text { Tension }\end{array}$ & 1.00 & 1.00 & 1.10 & 1.00 \\
\hline Direct Shear & 1.10 & 1.00 & 1.10 & 1.00 \\
\hline Bond & 1.17 & 1.05 & 1.23 & 1.05 \\
\hline Compression & 1.10 & 1.00 & 1.13 & 1.00 \\
\hline
\end{tabular}

In addition to dynamic increase factors, a strength increase factor $(S I F)$ is also used in Unified Facilities Criteria (2008) to account for in situ increase in material strengths over design strengths. For ASTM steels, a 10\% strength increase is specified by the Unified Facilities Criteria (2008).

The use of $D I F$ and $S I F$ is relatively simple in design. The Unified Facilities Criteria (2008) expresses the dynamic design stress as the product of the static stress, dynamic increase factor $(D I F)$ and strength increase factor $(S I F)$ as per Equations 2- 23 and 2-24.

$f_{d y}=f_{y} \times D I F \times S I F$

$f_{d u}=f_{u} \times D I F \times S I F$

Although trends in the changes in properties of steel were previously identified and presented in Table 2-3, it is important to use numerical models such as those 
presented in this section. Use of these equations will provide more accuracy in design of reinforced concrete elements under the impact of blast loads. Strain rates are normally not constant, so using equations provides a more accurate method than using tabulated values.

\subsection{The Effect of Dynamic Loads on Bond of Reinforcing Steel to Concrete}

While the effects of dynamic loads on concrete and steel properties have been thoroughly researched, the interaction between the two materials under dynamic loads is much more convoluted. Although both materials demonstrate an increase in strength under high loading rates such as produced by blast and impact loads, the rate of increase is different for both materials. As a result, predicting the interaction at the steel-concrete interface becomes a very intricate problem involving many factors.

Some research has been conducted where pullout tests under high strain rates have demonstrated that bond strength under dynamic loads is higher than under static loads (Hansen and Liepens 1962, Shah 1963, Vos and Reinhardt 1982, Yan and Mindess 1991, Weathersby 2003, Solomos and Berra 2010). Although all tests show that bond stress increases with loading rate, a number of factors were identified to affect the rate of bond stress increase.

The only case where the bond strength will not experience an increase under increase loading rate is when smooth bars are used in lieu of deformed bars (Reinhardt 1982, Vos and Reinhardt 1982). This is because there are no lugs from the steel bearing against the surrounding concrete and the bond strength is solely based on frictional and adhesive forces. Vos and Reinhardt (1982) reported that adhesion and friction are 
insensitive to loading rate. Since smooth bars are bonded to concrete by means of these two mechanisms (adhesion and friction), the loading rate will not affect the bond strength.

The effect of concrete strength on the rate of increase of bond stress at high strain may also be taken into consideration. Hansen and Liepens (1982) determined that the ultimate bond strength under dynamic loading from pullout tests was equal to the compressive strength $\left(f_{c}\right)$. This is higher than the ultimate bond stress under static pullout testing $\left(0.75 f_{c}\right)$. Shah (1963) also found a similar trend; under static loading the ultimate bond strength ranged from $0.5 f_{c}$ to $0.6 f_{c}^{\prime}$, while under dynamic loading the ultimate bond strength ranged from $0.6 \mathrm{f}^{\prime}{ }_{c}$ to $0.9 \mathrm{f}^{\prime} \mathrm{c}$. The reason for the difference in the data obtained from different experiments is that the rate of increase in bond strength under dynamic loading depends on the concrete strength. Lower strength concretes experience a greater increase in bond strength under dynamic loads than high strength concretes (Shah 1963, Reinhardt 1982, Vos and Reinhardt 1982, Vos 1963, Solomos and Berra 2009). Some authors report that the increase in bond strength is dependent on the tensile strength of concrete, however Vos and Reinhardt (1982) argue that it is more reasonable for the bond stress to depend on concrete compressive strength since the ribs of the deformed bars exert a compressive force on the surrounding concrete.

Some investigators (Hansen and Liepens 1962, Shah 1963) report steel strength and size as factors affecting the bond stress between steel reinforcement and concrete. According to Hansen and Liepens (1962) the increase of steel strength under high loading rates is responsible for the higher bond stress at failure under dynamic loading. It was also reported that the bond strength increase under dynamic loading is more pronounced 
for smaller bars (Shah 1963). Although steel properties are reported to also have an influence on bond strength increase under rapid loading, only the aforementioned investigators have reported bond stress increase to be a function of the steel strength or reinforcement size to date.

Most research work investigating the strain rate effect on bond strength has used pullout testing (Weathersby 2003, Shah 1963). Pullout tests cause a compressive force on the concrete surrounding the reinforcement, thus leading to greater confinement and an increase in the bond strength (Weathersby 2003). When dealing with beams in flexure, the concrete surrounding the reinforcement is in tension and could also be in a cracked state. Thus pullout test might not be representative of bond behaviour in flexural elements such as beams. According to Shah (1963), greater accuracy in bond strength tests could be achieved by beam tests rather than using pullout tests.

In concrete beam design, it is essential to achieve ductile failure modes in order to give warning of an imminent collapse. To achieve this condition, non-ductile failure modes such as shear and bond failures must be avoided. For blast design, where high strain rates are introduced, the same conditions are desired. It is therefore important to investigate bond under high strain rates to rule out the possibility of a bond failure in blast design.

Existing literature on the effect of strain rate on bond strength in beams is limited. While some investigators have shown little or no increase in bond strength at higher loading rates from pullout tests, the conservatism of these test may be limited because of the influence of the high confining forces. A more accurate approach may be achieved by conducting flexural tests, which provide more realistic measures of bond strength in 
reinforced beams. An experimental program was designed to determine the effect of high strain rates on bond in concrete beams and is described in the following chapter. 


\section{Chapter: Experimental Program}

\subsection{General}

The experimental program was designed to study the effect of strain rate on the bond between concrete and steel reinforcement. A total of 15 concrete beams were constructed and tested under third-point bending. Each beam was designed with one reinforcing bar bonded to the concrete for the bar development length calculated in accordance with CSA A23.3-04 (2004). The primary objective of the experimental test program was to determine whether the development length provided for static loading is sufficient for beams under high strain rates. The following sections describe the construction of the reinforced concrete beams, material properties, instrumentation, testing, and data acquisition used in the experimental test program.

\subsection{Description of Test Specimens}

The concrete beams used in this experimental program were designed to contain one longitudinal reinforcement with the development length, specified by CSA A23.3-04 (2004), provided at each end. In order to achieve the required development length, the reinforcement in the beams was debonded from the surrounding concrete at midspan. Three different sizes of longitudinal reinforcement were used in the experiment; $15 \mathrm{M}$ bars, 20M bars, and 25M bars. Figure 3-1 and Figure 3-2 shows the debonded regions for each size of reinforcement size, and a cross-sectional view of the concrete beams used in the experimental program. Five beams were constructed with each reinforcement size to 
obtain a total of 15 beams. constructed with each different size of reinforcement to obtain a total of 15 beams.

\subsection{Material Properties}

\subsubsection{Concrete}

All 15 beams were cast from the same concrete mix. A 28-day strength of concrete compressive strength of $30 \mathrm{MPa}$, and aggregate size of $10 \mathrm{~mm}$ were specified. A local concrete supplier designed the concrete mix and supplied the concrete to cast the beams. The concrete used limestone aggregate and had an average slump of $125 \mathrm{~mm}$, fifteen (15) $152 \mathrm{~mm} \times 305 \mathrm{~mm}$ concrete cylinders were cast with the beams and tested in accordance with ASTM C873(2010) to obtain compressive strength of concrete. The concrete compression tests were performed at the time of testing and resulted in an average compressive strength of $37.0 \mathrm{MPa}$.

\subsubsection{Steel}

The steel reinforcements: $15 \mathrm{M}, 20 \mathrm{M}$, and $25 \mathrm{M}$ were cut to a length of $2440 \mathrm{~mm}$ using a hand saw and used as longitudinal reinforcement in the concrete beams. Steel samples from each reinforcement size were cut and tested in tension in accordance with ASTM A370-11a (2011) to obtain the yield stress, ultimate stress and stress-strain behaviour of the reinforcement. From the tests results, the average yield strength of $15 \mathrm{M}$, $20 \mathrm{M}$, and $25 \mathrm{M}$ bars was $465 \mathrm{MPa}, 437 \mathrm{MPa}$, and $449 \mathrm{MPa}$ respectively. The yield strain of $15 \mathrm{M}, 20 \mathrm{M}$, and $25 \mathrm{M}$ bars was $2584 \times 10^{-6}, 2408 \times 10^{-6}, 2448 \times 10^{-6}$ respectively. 


\subsection{Construction of test specimens}

\subsubsection{Longitudinal reinforcement and strain gauge application}

The longitudinal reinforcement was strain gauged to monitor changes in strain during testing. Predetermined locations along the length of the reinforcement were treated to create smooth surfaces for strain gauge installation The reinforcement ribs at the predetermined locations were first ground with an electric grinder with $4.5^{\prime \prime}$ diameter discs. Then a pneumatic grinder with 2 " diameter discs was used to create a smooth surface. Once all strain gauge locations were ground smooth, they were cleaned with a water based acidic surface cleaner (M-Prep Conditioner A) to remove any dirt from the surface. Then a water based alkaline surface cleaner (M-Prep Neutralizer A) was used to further clean and neutralize the surface.

Once the surface was prepared for the application of strain gauges, all-purpose cyanoacrylate adhesive was applied to the back of the strain gauge and then placed on the smooth clean surface of the steel reinforcement. Pressure was then applied until the strain gauge was bonded to the surface. Once the strain gauge was in place, the gauge leads were slowly lifted from the surface to ensure they were not bonded to the reinforcement as shown in Figure 3-3. Electrical tape was used to cover the gauge and wrapped around the bar under the leads to isolate the leads from the rebar surface. The strain gauges used in this experiment program were type FLA-6-350-11 manufactured by Tokyo Sokki Kenkyujo Co. Ltd. The gauges were $6 \mathrm{~mm}$ in length and had a $350 \Omega$ gauge resistance.

In order to obtain data from the strain gauges, long cables were soldered to the gauge leads and run along the rebar and out one end of the beam. The cables were 600 volt type CMG Deca cables. Before soldering the cables to gauge leads they were cut to 
length and wire strippers were used to remove the outer casing. The tip of two inner cables was then stripped so that their ends could be soldered to the gauge leads. Soldering was done using a soldering iron (Figure 3-4), MG chemicals solder, and LA-CO regular soldering flux paste. Electrical tape was used between wires to ensure that wires did not touch. Once all gauges and cables were installed, a multimeter was used to ensure that a $350 \Omega$ gauge resistance reading was achieved across the ends of the cables. The strain gauge locations along the length of the rebar were different for each size of reinforcement (Figure 3-5). In the debonded region two strain gauges were installed while four gauges were installed on either side within the bonded region (Figure 3-5).

\subsubsection{Transverse Reinforcement}

The transverse reinforcement used in the concrete beams was $6.3-\mathrm{mm}$ wire. First, the wire was measured and cut to size using wire cutters. The wires were bent using a hand bending jig; forming 90 degree angles at three corners and two 45 degree angles at the wire ends to obtain rectangular stirrups as shown in the cross-sectional view in Figure 3-2. Once all stirrups were formed, they were placed around 6.3-mm diameter longitudinal wires. The ties were spaced at $100 \mathrm{~mm}$ at either end of the beam and at 150 $\mathrm{mm}$ around midspan. The stirrups were fastened to the longitudinal reinforcement using loop tie wires and a hand tying tool with a hook to form transverse reinforcement cages as shown in Figure 3-6. 


\subsubsection{Formwork}

The formwork for the beams was constructed with 19-mm thick plywood. The plywood was cut to size using a circular saw and assembled using screws. Holes were drilled into the ends of the plywood formwork to allow longitudinal reinforcement to protrude out from the end of the beams (Figure 3-7). The formwork was oiled with motor oil on the inside before concrete was poured to ensure the formwork could easily be removed.

\subsubsection{Casting and Curing}

Before concrete was poured, additional measures were needed for the construction of the beams used in this experimental program. A debonded region along the longitudinal reinforcement was formed, as well as a preformed crack at midspan and installation of concrete strain gauges (Figure 3-8). The preformed crack was created by placing sheet metal in the midspan of the beam before casting. In order to achieve a debonded region at the midspan of each beam, the longitudinal reinforcement was covered with $25-\mathrm{mm}$ diameter vinyl tubing and each caulked to prevent ingress of concrete (Figure 3-9).

The transverse reinforcement cages and longitudinal reinforcement were placed in the forms simultaneously. The longitudinal reinforcement was held at the proper height by placing either end through the pre-drilled holes in the formwork. Once the steel was in place, the concrete gauges were installed.

Concrete strain gauges were placed at midspan of the beam at three different depths so that the strain profile of concrete could be determined. Holes were formed in 
the side of the formwork and nylon cabled twine was threaded through. This allowed the concrete strain gauges to be suspended at different heights along the midspan of the beam as shown in Figure 3-10 and Figure 3-11.

Once all formwork and additional construction materials were in place as shown in Figure 3-12, concrete was ready to be poured. Concrete was poured into the forms using extensions on the chute at the back of the concrete mixing truck. During this time a concrete vibrator was used to consolidate the freshly poured concrete and ensure concrete was distributed to all edges and corners of the formwork.

$152 \times 305 \mathrm{~mm}$ cylinders were also cast (Figure $3-13$ ) from the concrete used for the beams in order to obtain actual strength characteristics of the concrete. The concrete was poured in the cylinders in 3 layers and each layer was tamped to remove voids. Once the forms and cylinders were filled, the surfaces were smoothed using a trowel. Hooks were placed in either end of each concrete beam (Figure 3-14) to facilitate transporting of the beams using the crane. The beams and cylinders were covered with wet burlap to control drying and ensure proper curing. Forms were removed after 24 hours, but the burlap was kept in place and wet once daily for 7 days after the concrete was poured.

\subsection{Static Testing}

Static testing was performed on a total of 6 beams. These tests consisted of two beams containing $15 \mathrm{M}$ rebar, two beams containing $20 \mathrm{M}$ rebar, and two beams containing $25 \mathrm{M}$ rebar. A hydraulic jack equipped with a hand pump was used to load the beams as shown in Figure 3-15 and Figure 3-16. The jack was placed above a spreader beam which was used to apply two point loads to the beam at third-points. Large 
diameter threaded rods were bolted into the concrete slab on either side of the beam at mid-span. A hollow steel section with pre-drilled holes on either end was placed on the threaded rod and bolted into place. The hydraulic jack was clamped to the hollow steel section so that it was placed above the spreader beam at mid-span.

The beams were simply supported at either end. This was achieved by placing two bearing plates together with a pivot inserted in between. Bearing plates with pivot points were also used at the location where point loads were applied.

The beams were loaded at an approximate rate of $20 \mathrm{kN} / \mathrm{min}$. Each beam was loaded past the yield point of the reinforcement and up to failure in order to determine strains along the bonded steel region at yield and the capacity of the concrete beam.

\subsubsection{Data Acquisition for Static Tests}

In order to obtain values for strain and displacements during testing, strain gauges and string potentiometer gauges were used. The strain gauges were installed before casting of the concrete as previously described. The string potentiometer gauges were placed at the mid-span and load point of the beam to record displacements. The wire gauges were held in place by fastening them to a $2^{\prime \prime} \times 4 "(38 \times 89 \mathrm{~mm})$ wood joist which was placed on the floor and weighed down (Figure 3-17). In order to fasten the string potentiometer gauges to the concrete beam, Tapcon concrete screws were installed and a small length of fishing line tied the string to the Tapcon screws. Small steel plates were welded and drilled to construct a device that could hold the wire gauges in place on top of the beam at either end. These devices were fastened to the surface with the use of Tapcon screws as well. The end of the wire gauge was fastened to a small steel piece that was 
welded perpendicular to the end of the rebar protruding from both ends of the beam (Figure 3-18). Once all gauges were in place and all wires from strain gauges and wire gauges were connected to the data acquisition unit, the beam was ready for testing.

\subsection{Dynamic Testing Using Shock Tube}

The shock tube located in the University of Ottawa's Structural Engineering Laboratory was used to test the development length of reinforcement in concrete beams subject to the effect of blast loads. Unlike other loading devices, the shock tube can induce high amplitude and short duration dynamic loads into structural elements. In fact, the shock tube is capable of simulating the effect of real explosion from a given explosive charge mass and standoff on structural elements. In order to understand how the shock tube simulates blast loads, a brief description of its assembly and mechanisms is outlined below.

The purpose of the shock tube is to generate a high pressure wave, otherwise known as a shock wave, that will act on the face of a structural element. The shock tube consists of a driver, spool, and expansion sections. The driver is at the back of the shock tube and has a variable length depending on the desired pressure and impulse. A longer driver section will lead to a longer positive phase duration of the blast wave. Therefore the driver length in this experimental program was selected to achieve the desired blast wave parameters. Next to the driver section is a spool section, separated from the driver section by double diaphragm firing mechanism which controls the pressure wave release of the shock tube. The double diaphragm firing mechanism allows the driver and spool sections to be pressurized to different values and balanced to ensure the diaphragm 
capacity is not exceeded. Once pressurized, the pressure in the spool is release by means of a valve. This creates a large pressure differential between the driver and the spool and causes rupture of the adjacent diaphragm and simultaneous release of the pressure from the driver.

In front of the spool section is the expansion section, which connects to the end frame used for loading the specimen. Once the pressure is released from the driver, it expands and forms a shock wave as it travels through the expansion section. Once this wave reaches the end of the expansion area, it acts on the end frame and transfers the load to the structural member, thus introducing dynamic loads into the concrete beams that were tested.

The shock tube is a very complex testing apparatus. A more detailed description of the shock tube's construction, initiation of the firing mechanism, and calibration is presented elsewhere (Lloyd 2010, Lloyd et al. 2010).

\subsubsection{Dynamic Test Setup}

In order to employ the shock tube to test the concrete beams, the shock tube and beams were setup to undergo third-point loading. In order to achieve this behaviour, a load transfer device was installed at the end frame of the shock tube (Figure 3-19 and Figure 3-20). The load transfer device is comprised of two rigid steel panels measuring $2032 \mathrm{~mm}$ tall by $1000 \mathrm{~mm}$ wide and placed side-by-side. These rigid steel panels were fastened to sliding hinges, allowing the load transfer device to deflect when subject to a blast load. Once both rigid steel panels were secured onto the hinges, adjacent to one another, the shock tube opening was completely covered. Attached to the front of the 
rigid steel panels, were two steel I-beams, that when fastened to both the left and right panels, ensured the panels would deflect in unison and be dependant of one another. Aircraft cables were attached to the sliding hinges and steel panels by the use of cable clamps to ensure the load transfer device remained intact and did not undergo excessive deflections. The entire system was capable of moving laterally to a maximum of $200 \mathrm{~mm}$. The total mass of the system was $283.6 \mathrm{~kg}$.

After installing the load transfer device, the beam was placed vertically on its edge so that the hollow steel sections of the load transfer device lay perpendicular to the beams length. This was accomplished by clamping the beam between two small hollow steel sections placed perpendicular to the length of the beam (Figure 3-21). The beam was then lifted by one end with a crane and the steel clamps placed so that they were bearing on the two forks of the forklift (Figure 3-21). Once in place, the top and bottom of the beam were fastened to the load transfer device by means of clamping the beam between two steel sections held up by threaded rod. These steel sections had a steel rod welded to its surface to ensure simply supported conditions (Figure 3-22 and Figure 3-23).

\subsubsection{Data Acquisition}

During testing, all important data was recorded to a computer based data acquisition system. The strains in the reinforcement and concrete and displacements during testing were measured with strain gauges and linear variable displacement transducers (LVDT's). The strain gauges were installed before casting of the concrete as previously described. The LVDT's on the other hand were placed at the midspan and load point of the beam just before testing to record the beam displacements. In order to 
fasten the LVDT's to the concrete beam, anchor bolts were installed and a small length of 6-mm wire was welded to them so that one end could be threaded into the end of the LVDT, and the other end fastened to the anchor bolt (Figure 3-24). Once the welded piece was fastened to the beam, the other end of the LVDT was fastened to a shoring post placed parallel to the beam to ensure the LVDT was perpendicular to the length of the beam. LVDT's were also attached to the ends of the longitudinal reinforcement in the beam, at the top and bottom, to record slippage between the reinforcement and concrete. Small steel plates were welded together to construct a device to hold the LVDT's in place on the side of the beam at both the top and bottom to measure the slippage of the reinforcement (Figure 3-25). These devices were fastened to the surface with the use of anchor bolts and the LVDT placed and clamped in predrilled holes. The end of the LVDT was fastened to a small steel piece that was welded perpendicular to the end of the rebar protruding from both the top and bottom of the beams (Figure 3-26). Prior to testing, all wires from strain gauges and LVDT's were connected to the data acquisition unit, the beam was ready for testing (Figure 3-27). The data from the strain gauges and LVDT's were recorded using a Yokogawa SL1000 High-Speed Data Acquisition Unit.

A high-speed camera was also used to observe the behaviour of the beams when subject to the blast loads induced by the shock tube. The high speed camera was placed perpendicular to the face of the frame so as to observe lateral deflections of the beam during testing. 


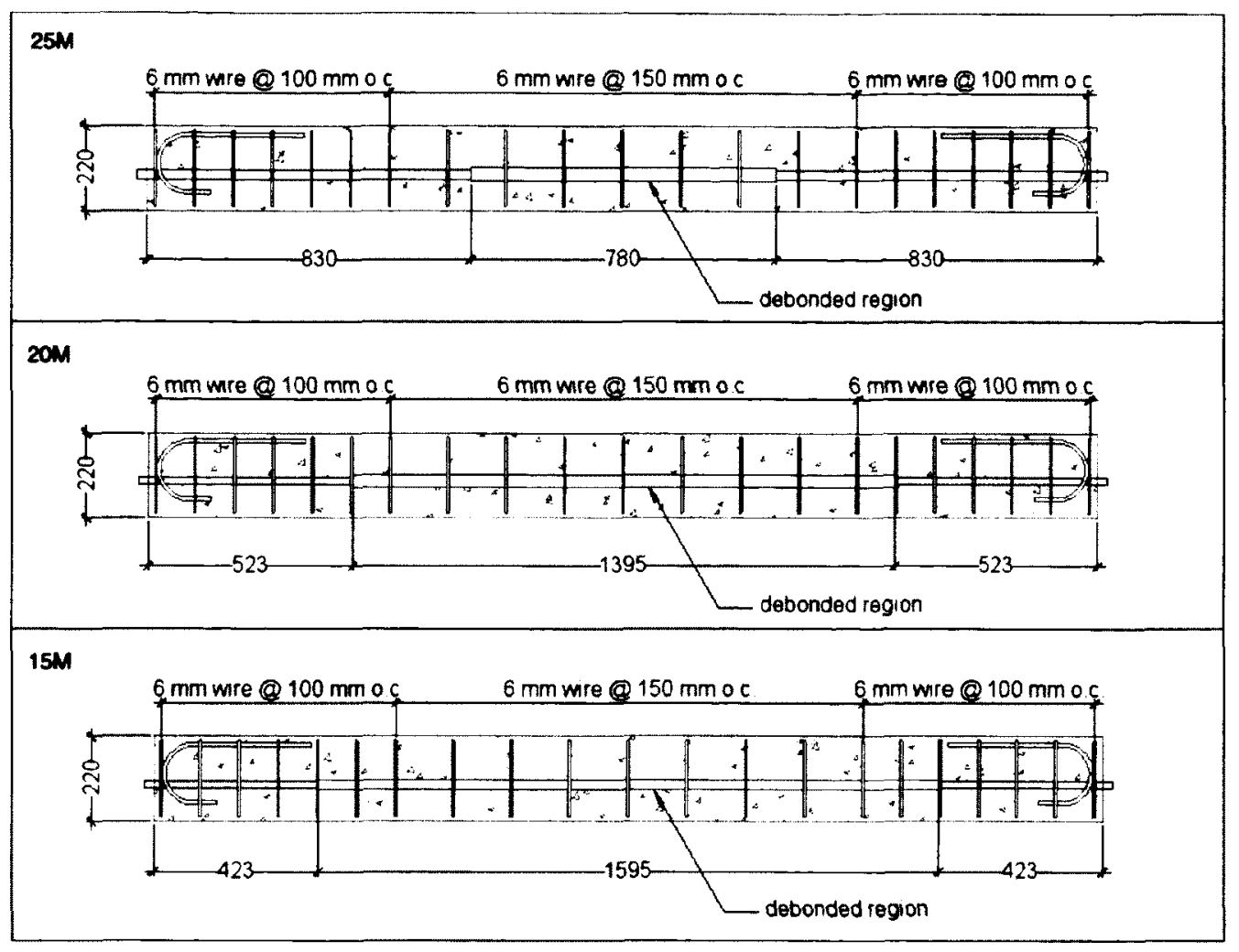

Figure 3-1: Debonded Region in Concrete Beam

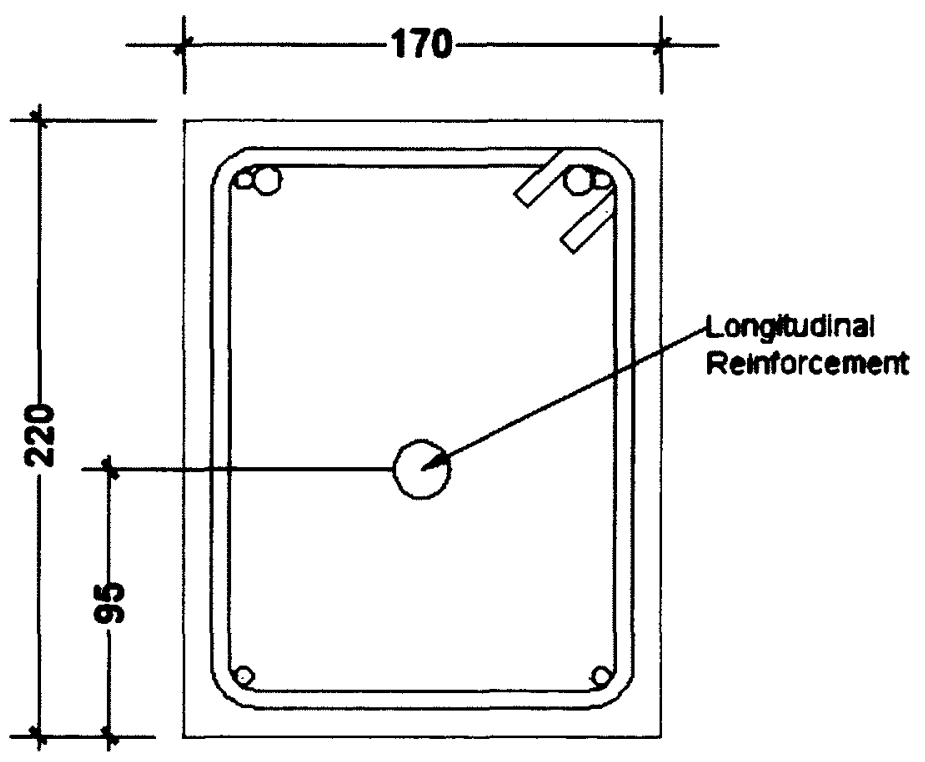

Figure 3-2: Beam Cross-Sectional Area 


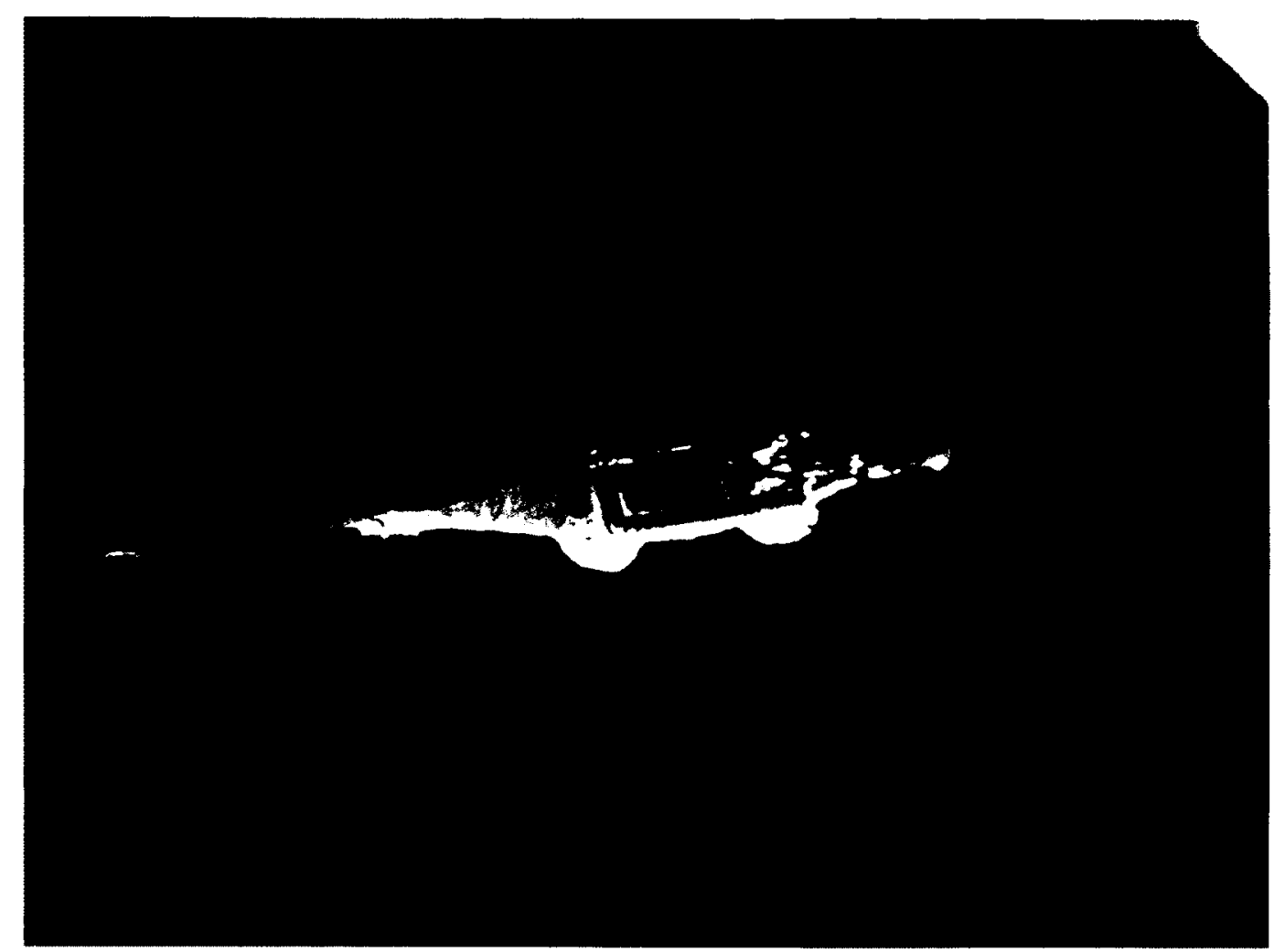

Figure 3-3: Strain Gauge Application

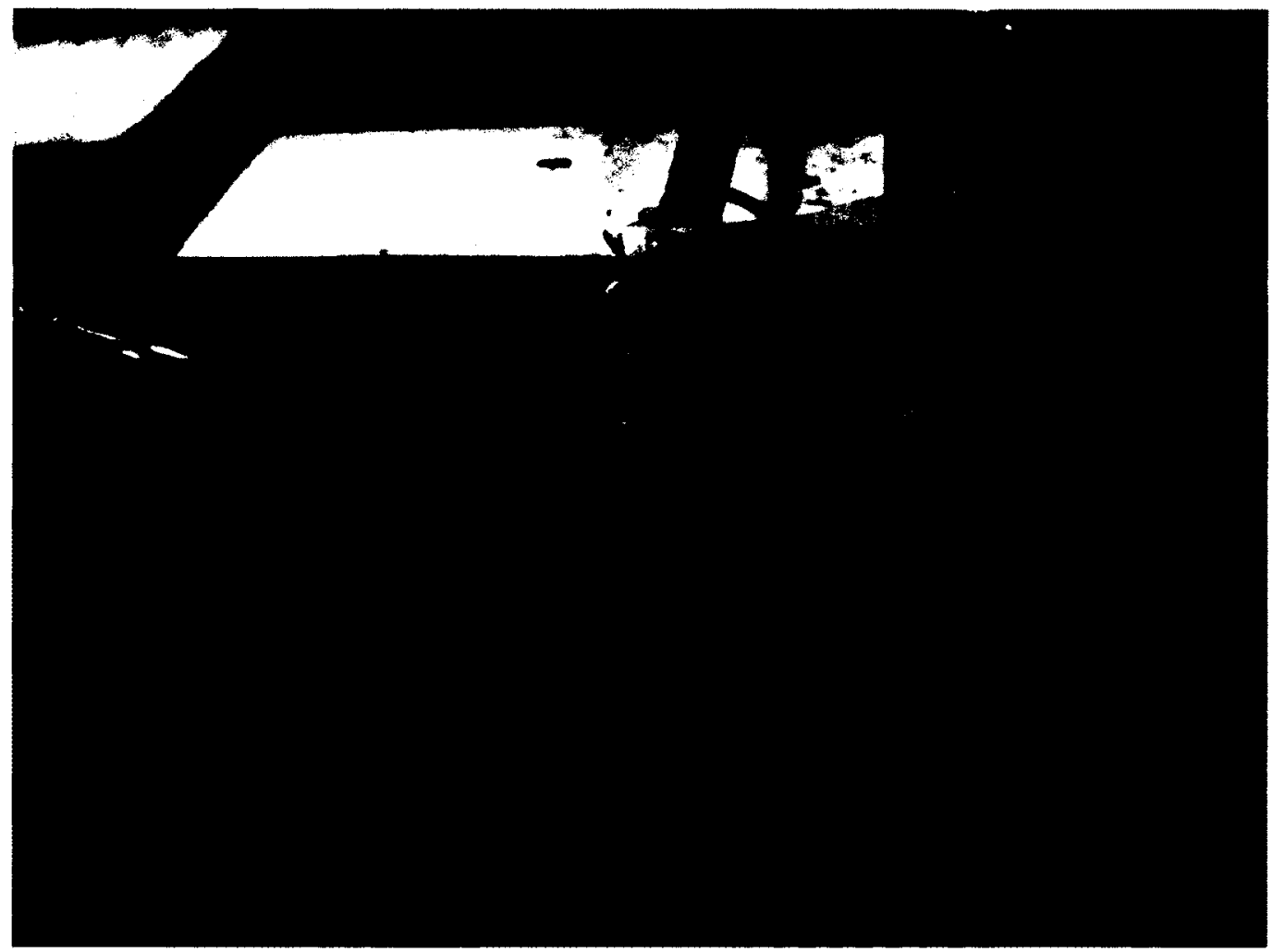

Figure 3-4: Soldering of Strain Gauge Lead Wires 


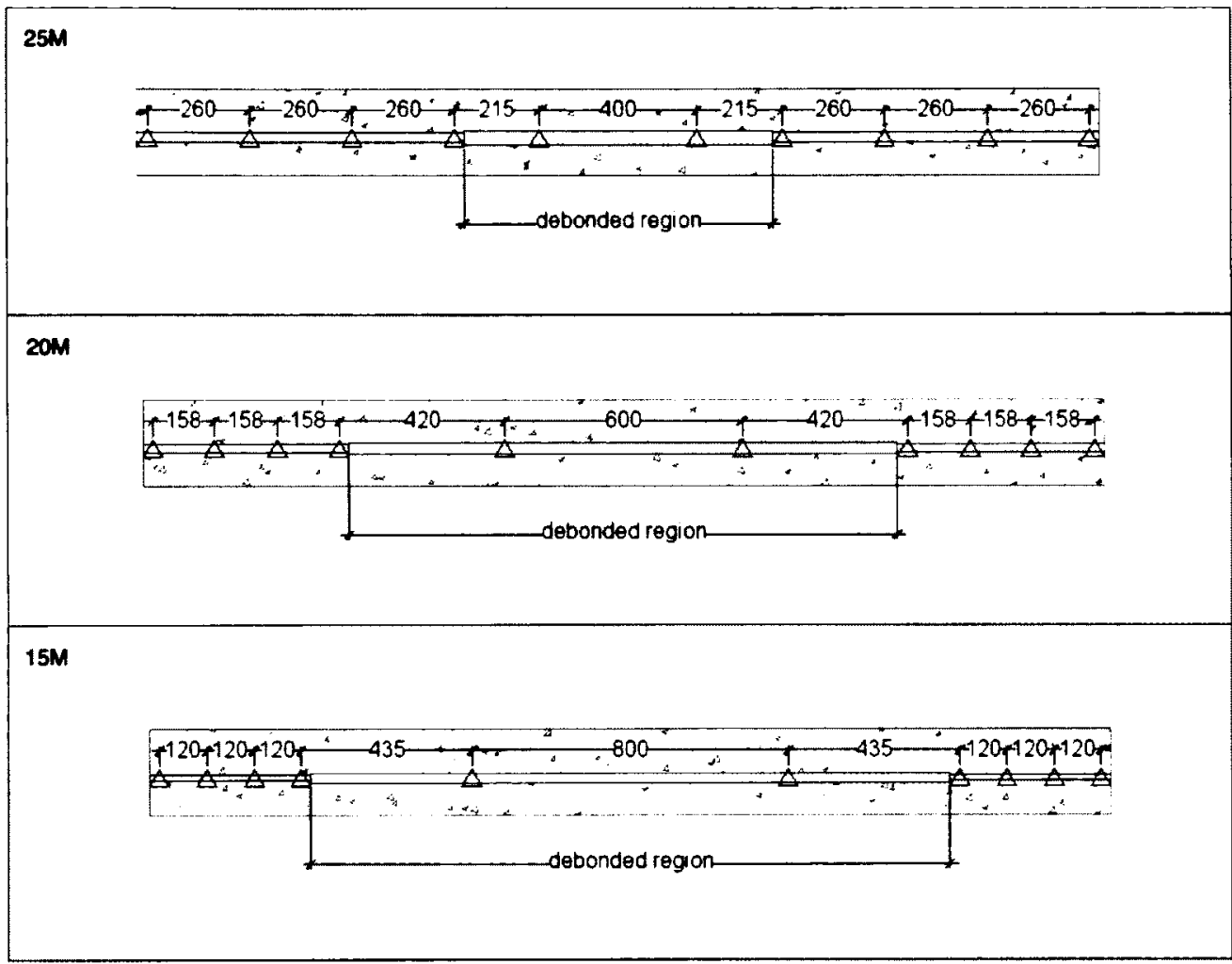

Figure 3-5: Strain Gauge Locations Along Length of Reinforcement

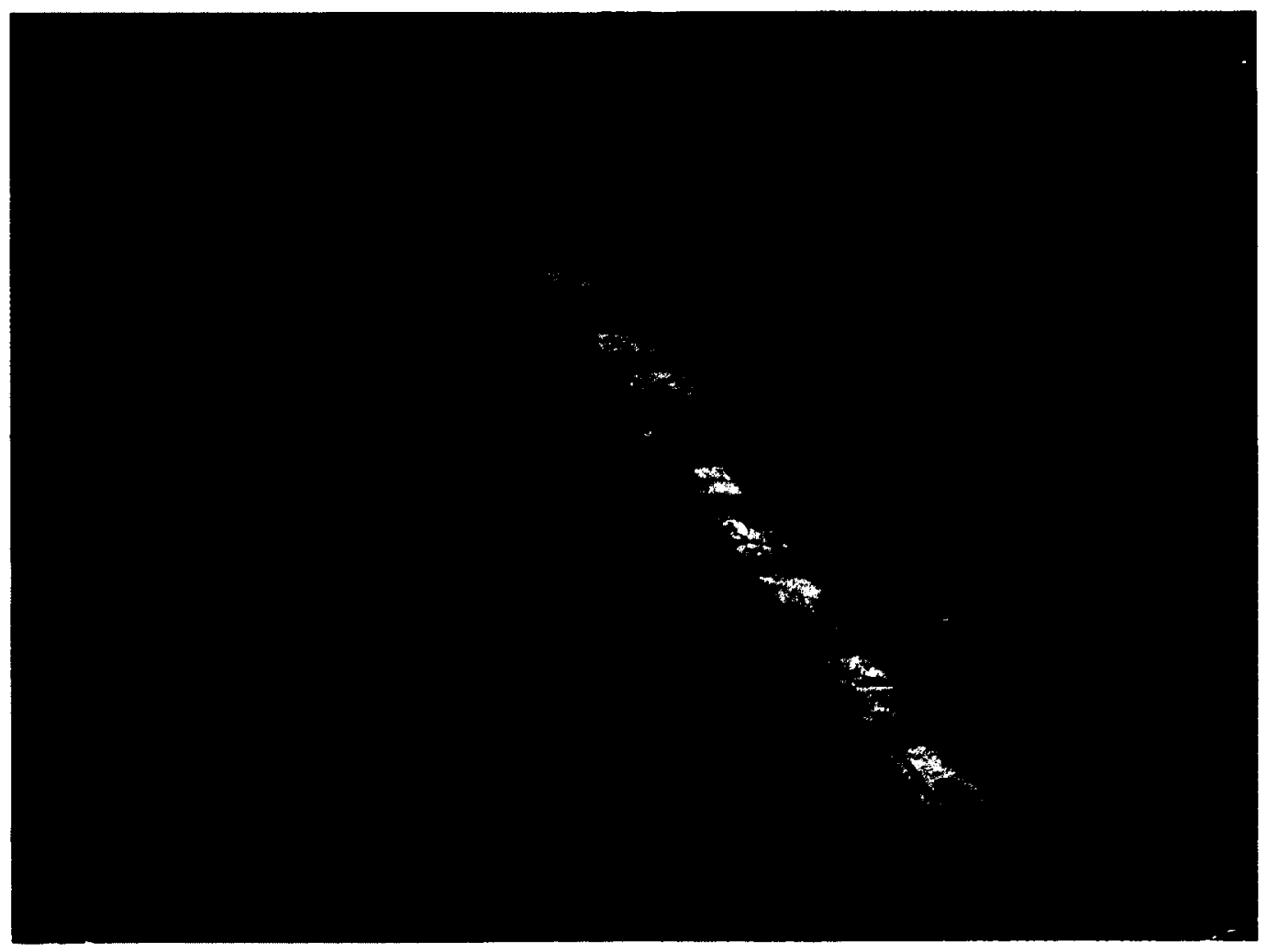

Figure 3-6: Construction of Cages for Transverse Reinforcement 
Figure 3-7: Steel Reinforcement Protruding Through Formwork

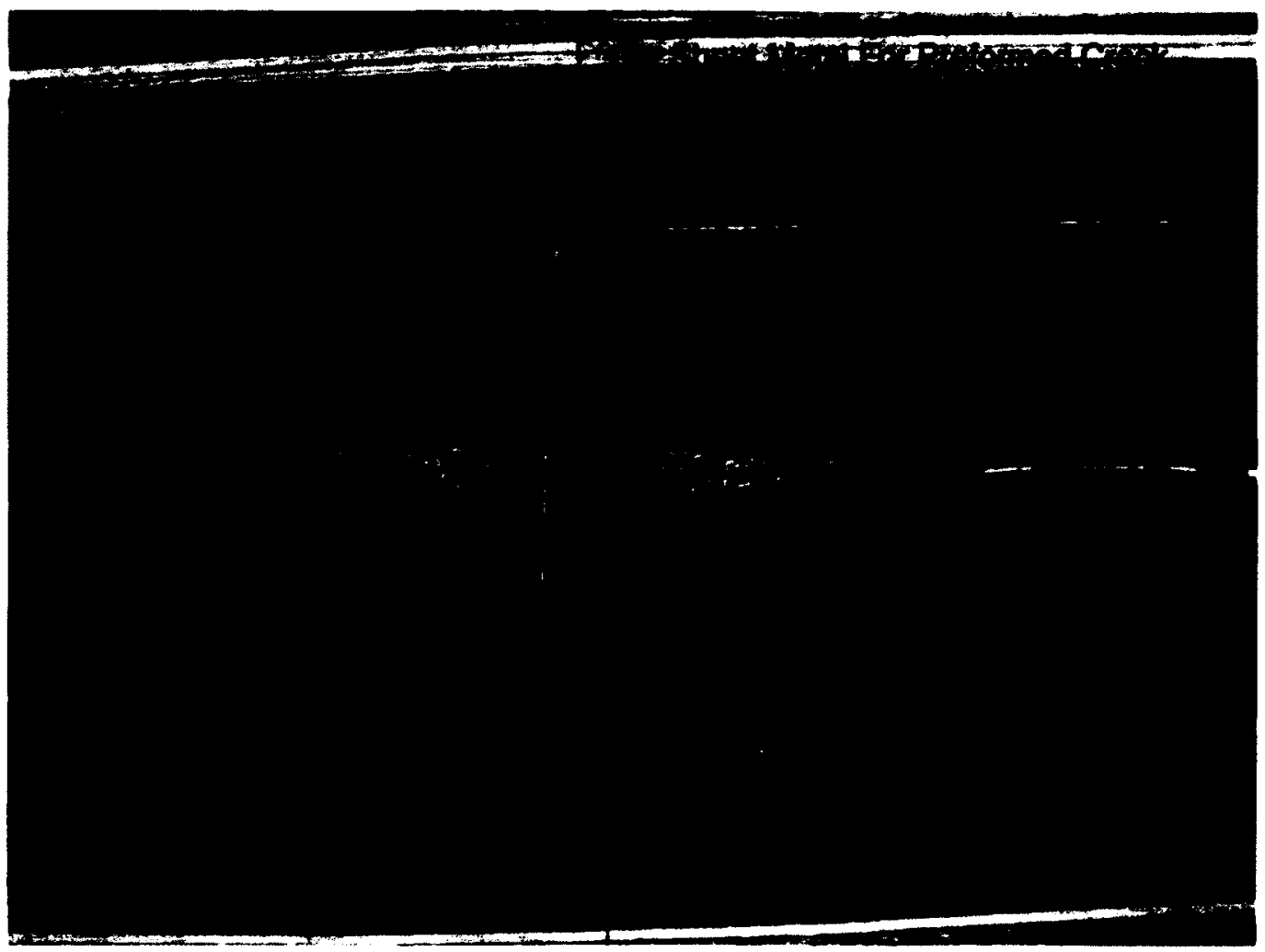

Figure 3-8: Concrete Gauge Installation and Preformed Crack 


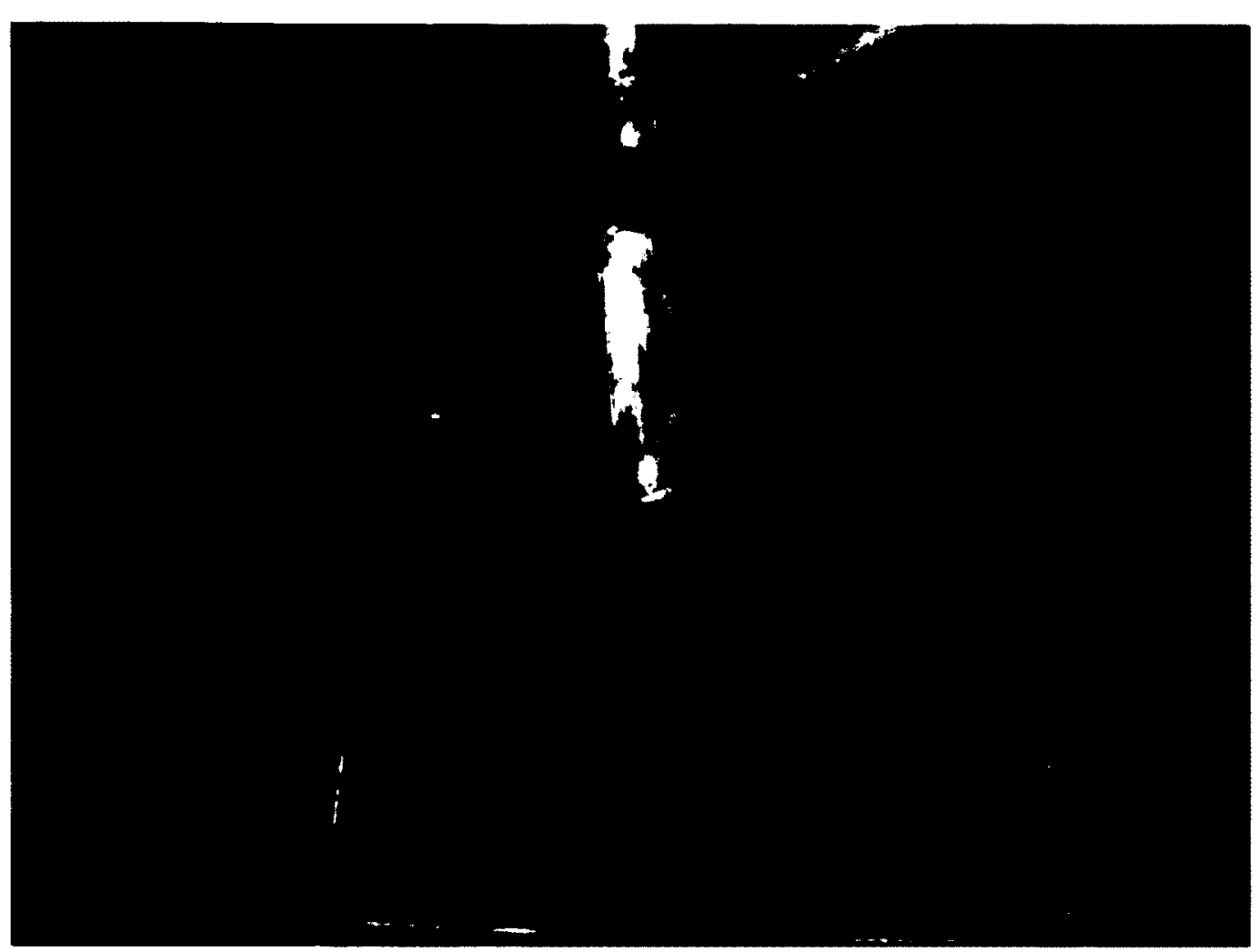

Figure 3-9: Caulking of Vinyl Pipe for Debonded Region

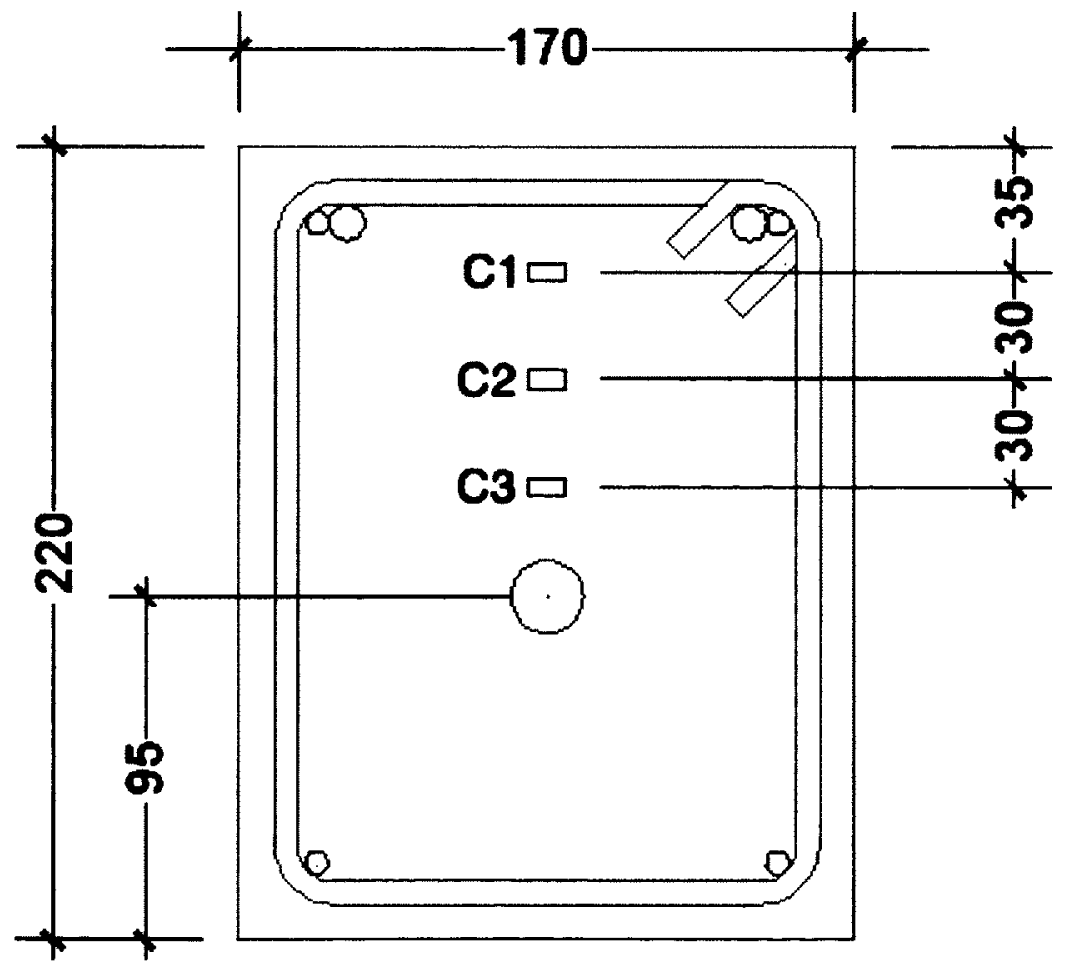

Figure 3-10: Concrete Gauge Locations 


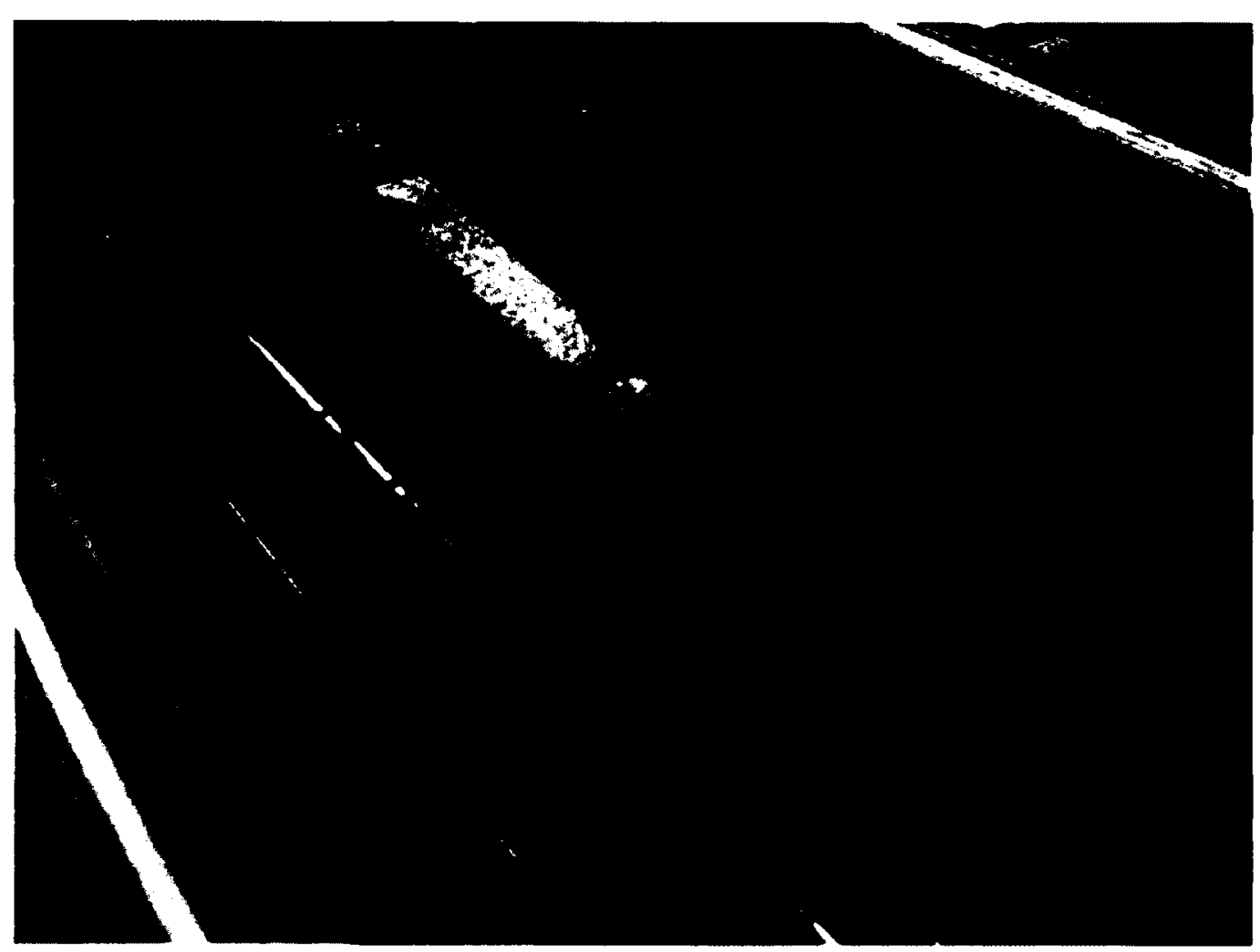

Figure 3-11: Concrete Gauges in Formwork

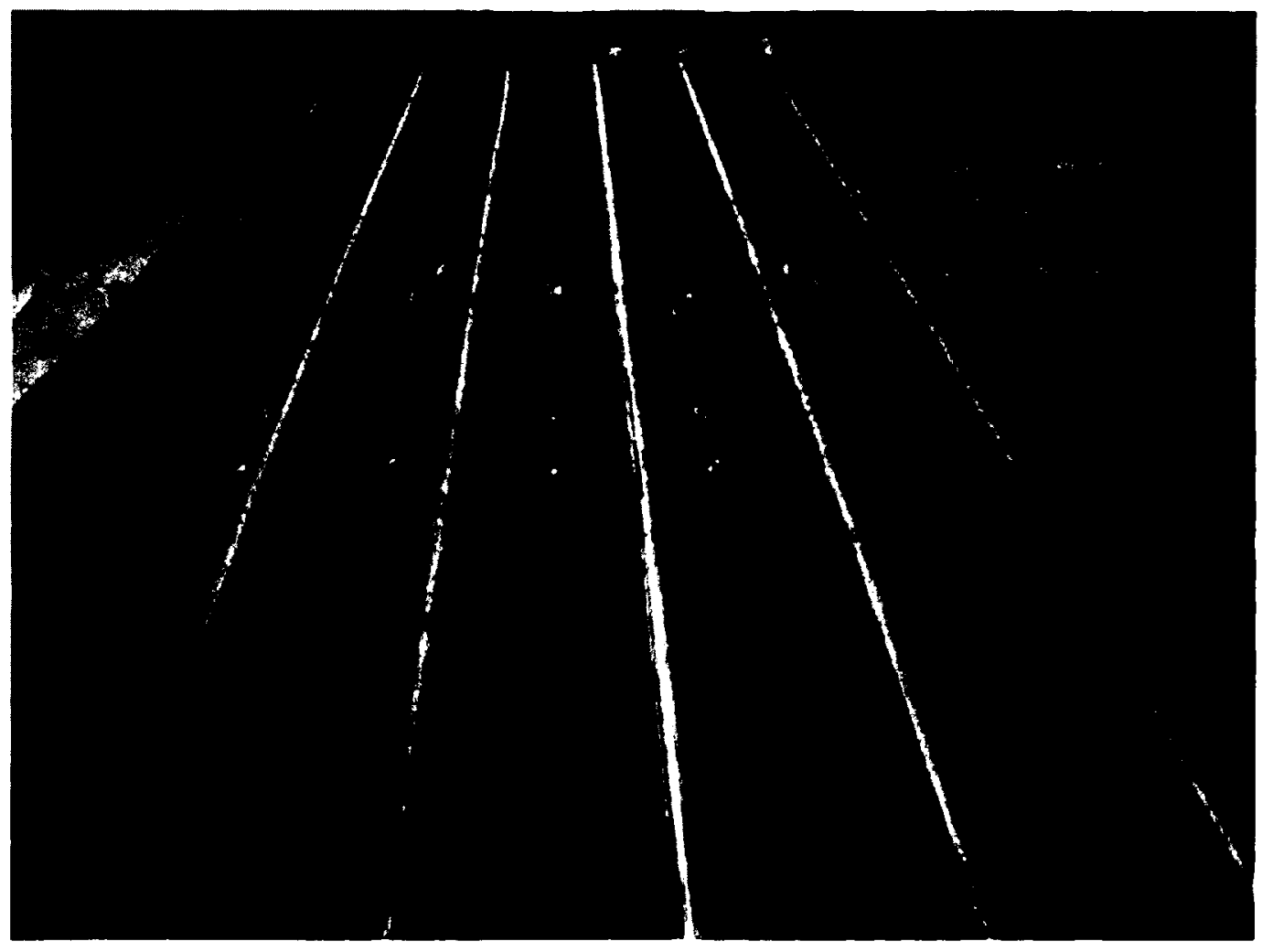


Figure 3-12: Placement of Steel Cages, Longitudinal Reinforcement, and Concrete Gauges Prior to Casting of Concrete

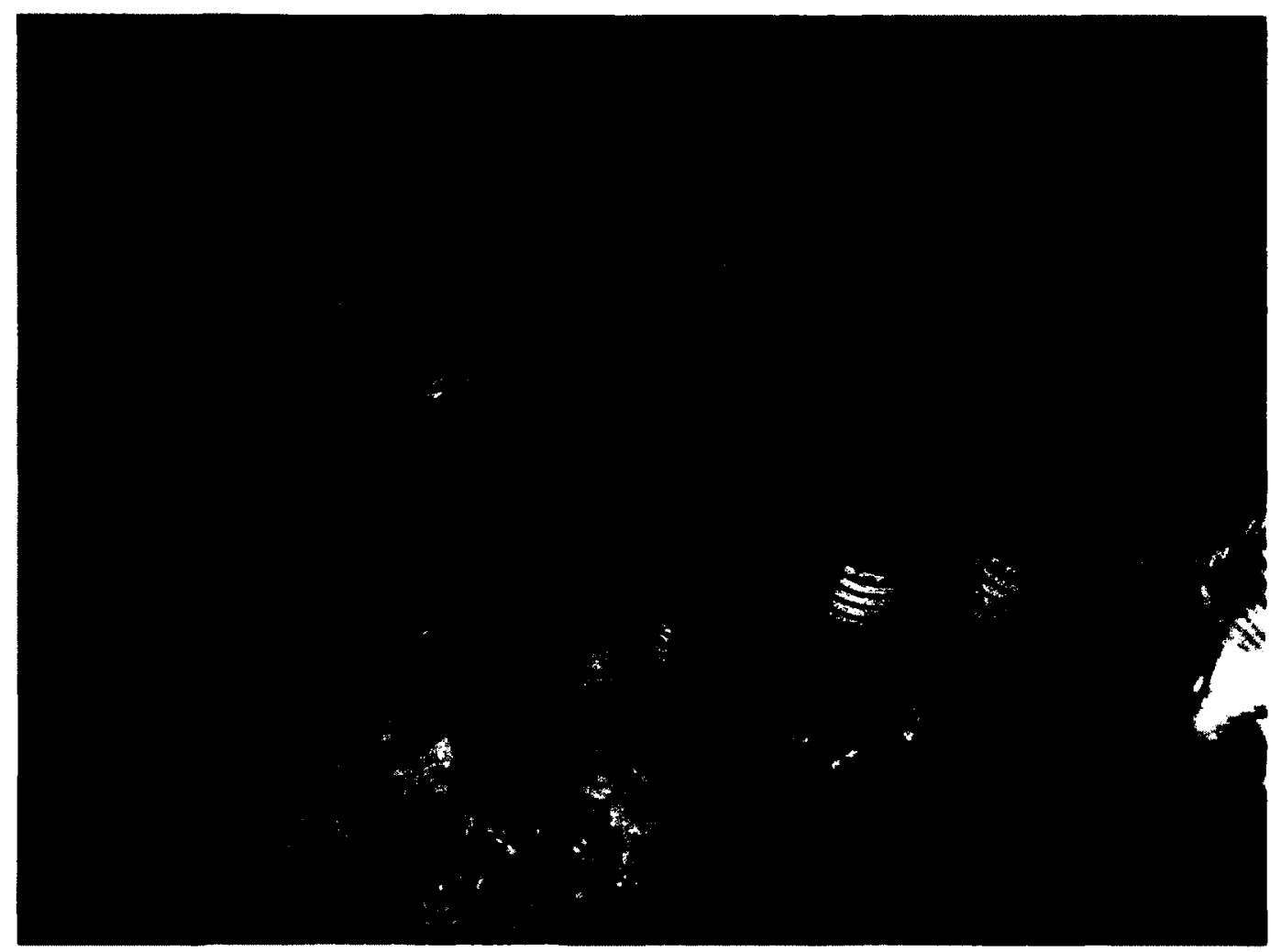

Figure 3-13: Concrete Cylinders 


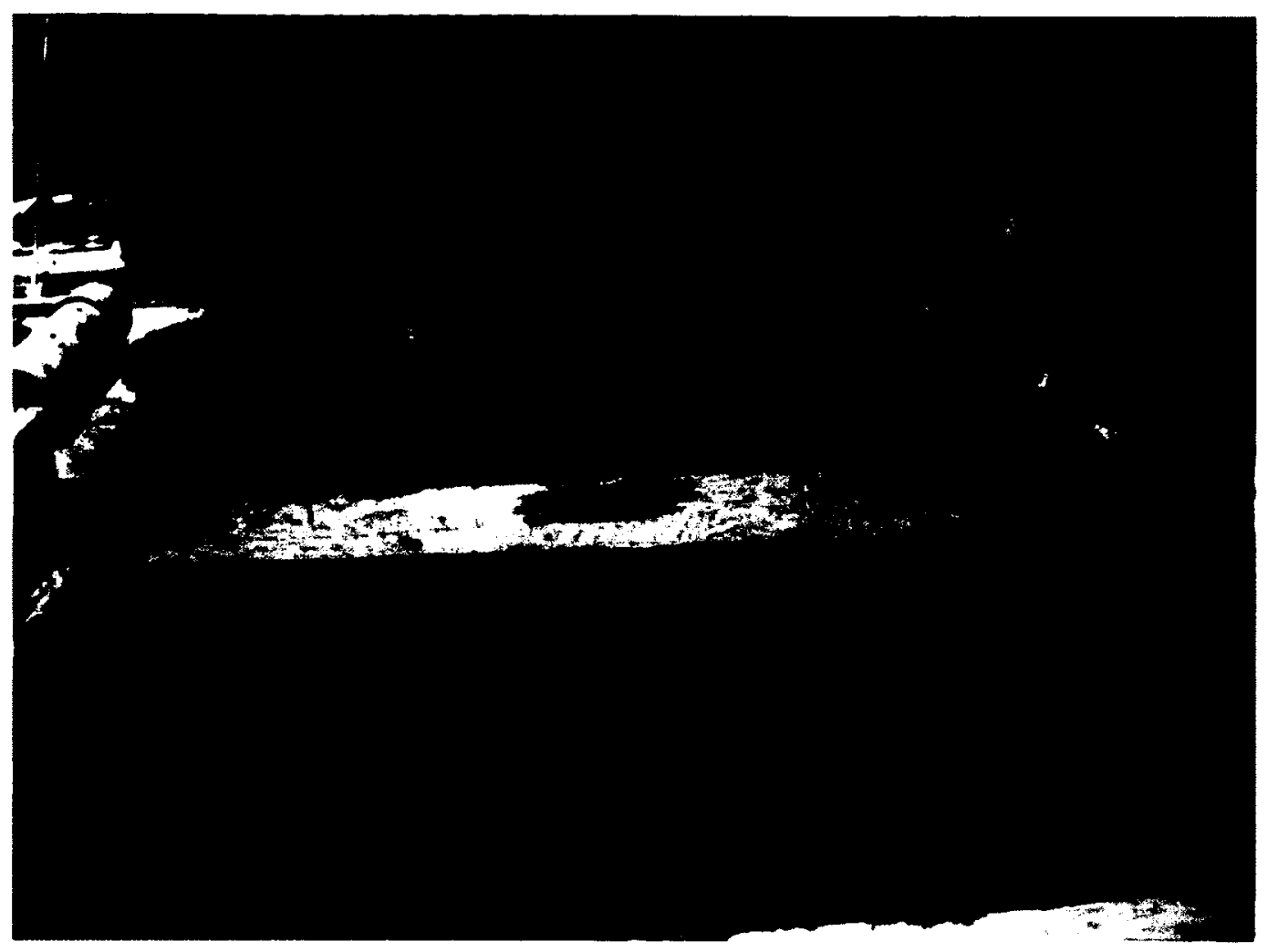

Figure 3-14: Casting of Concrete Beams

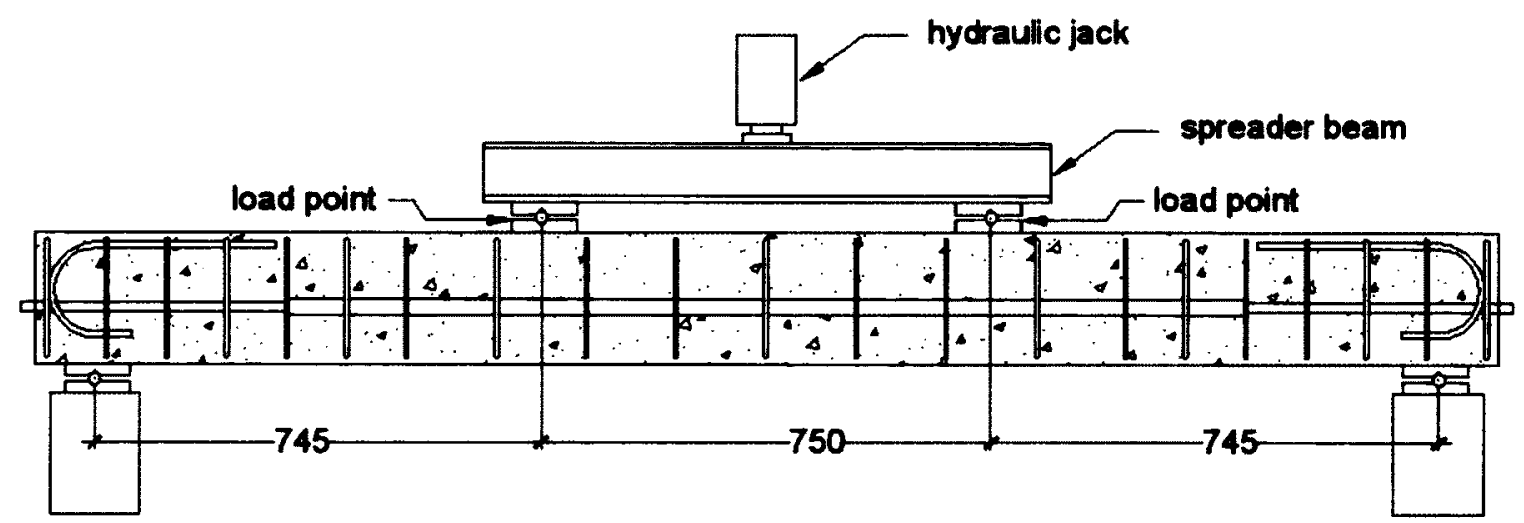

Figure 3-15: Location of Load Points in Static Tests 


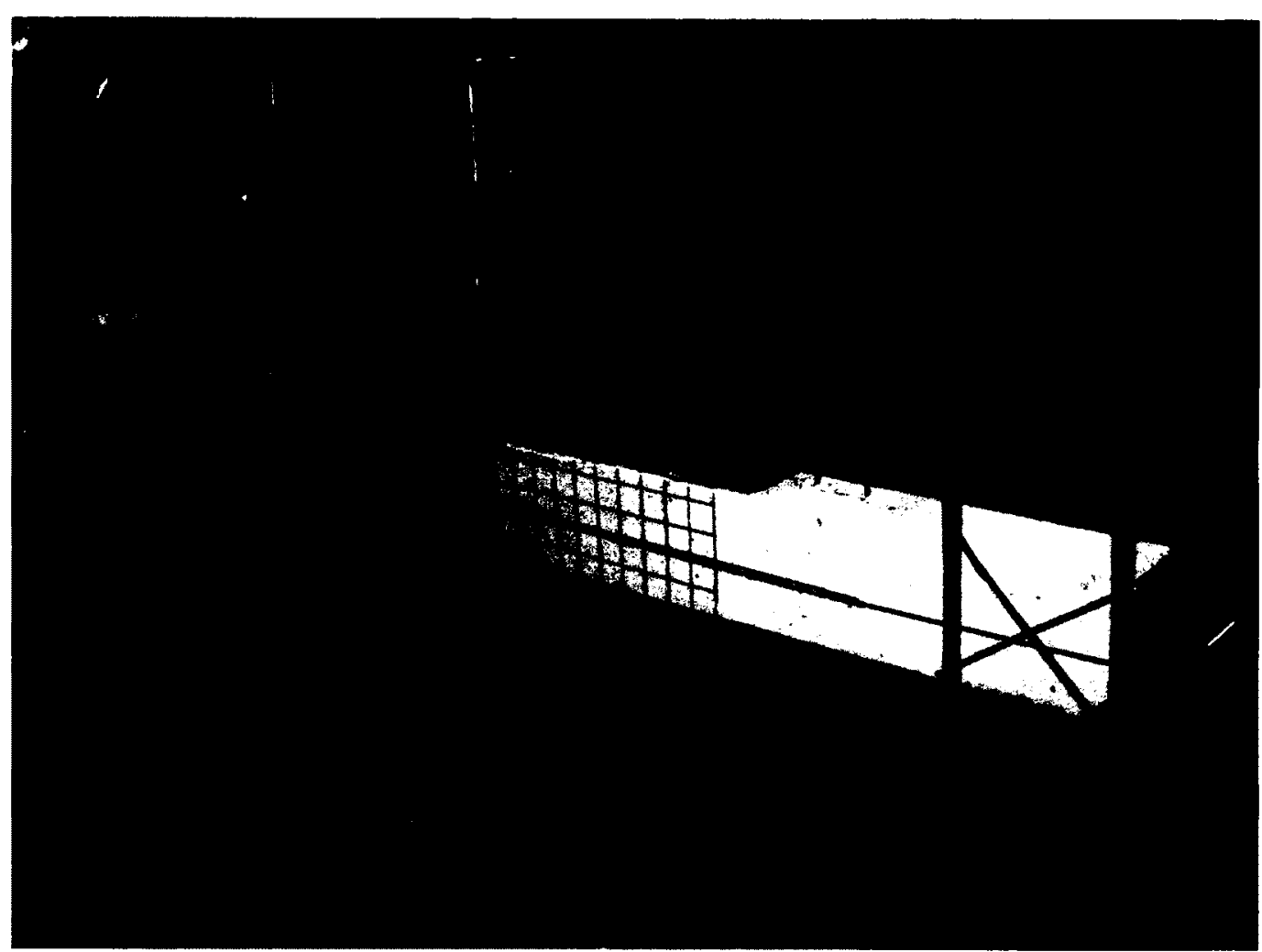

Figure 3-16: Static Test Setup

Figure 3-17: Midspan and Load-Point Gauges 


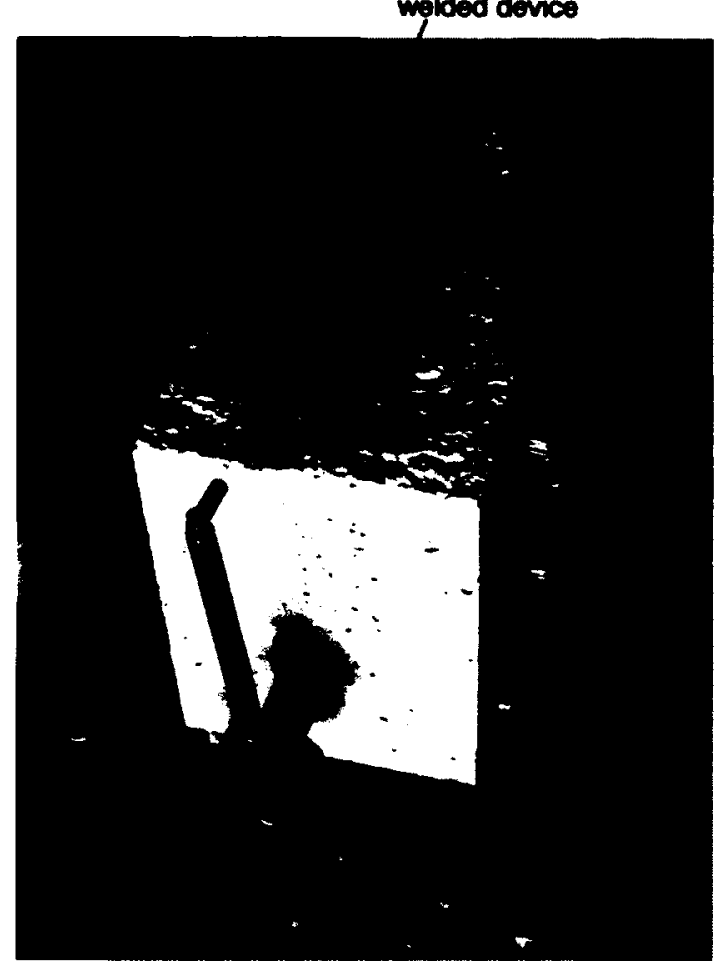

Figure 3-18: Beam End Wire Gauge

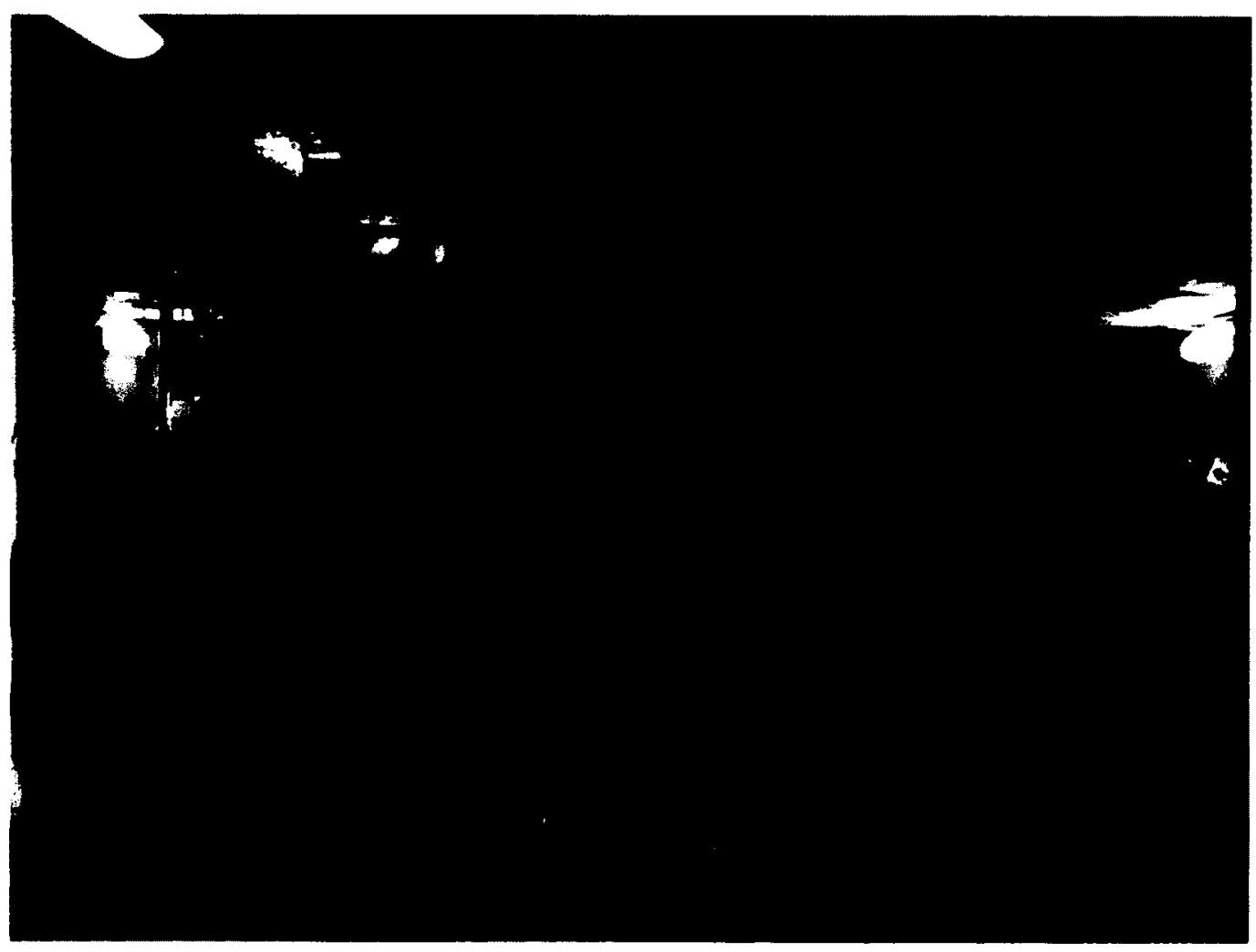

Figure 3-19: Load Transfer Device at Shock Tube Opening 


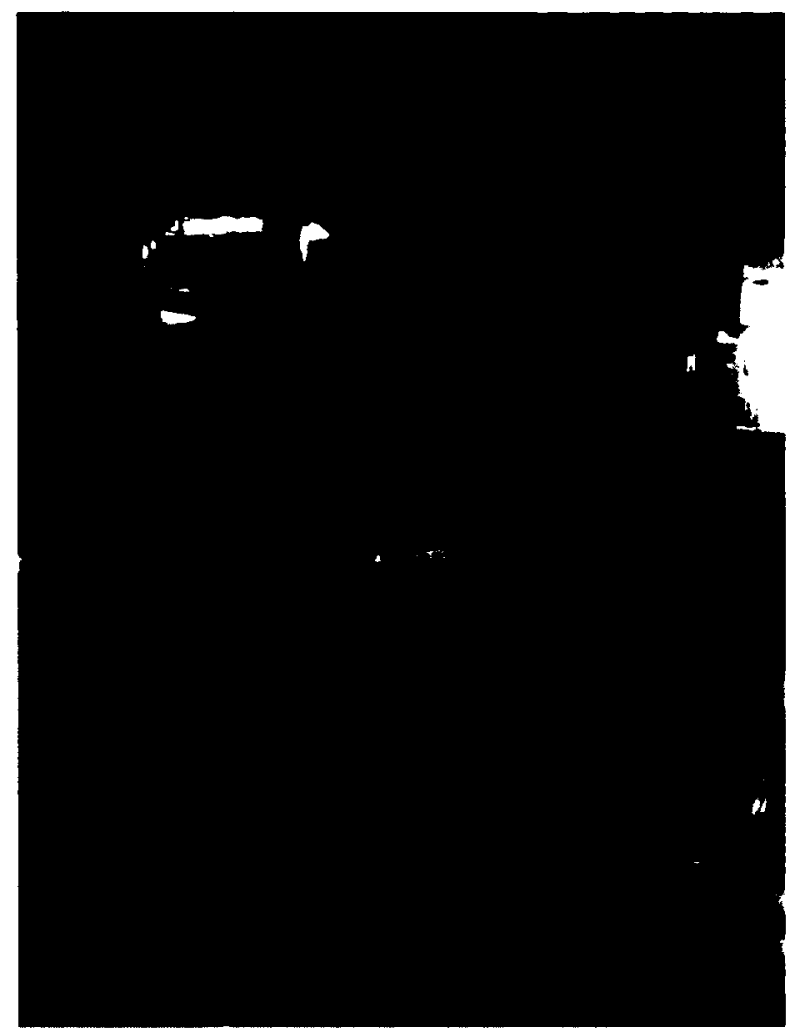

Figure 3-20: Angle View of Load Transfer Device

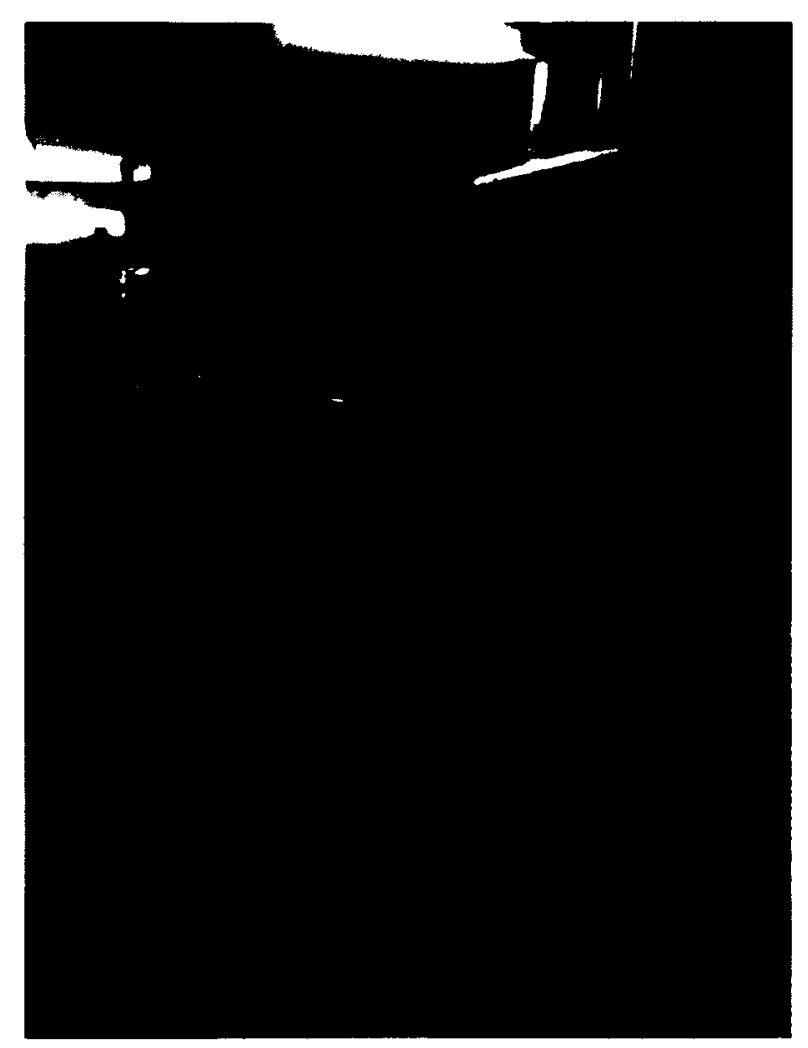

Figure 3-21: Placement of Concrete Beam of Shock Tube Using Forklift 


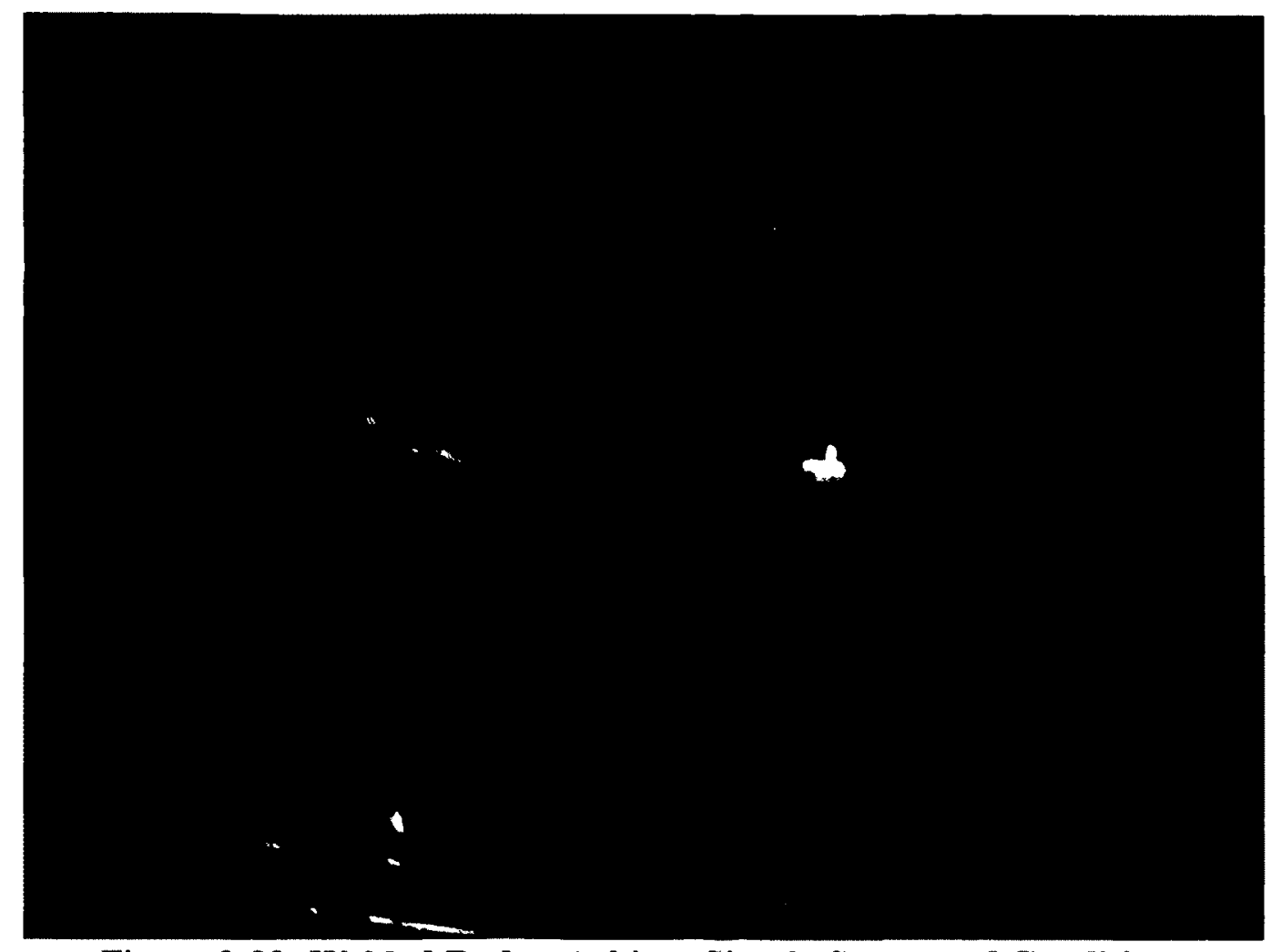

Figure 3-22: Welded Rod to Achieve Simply Supported Conditions

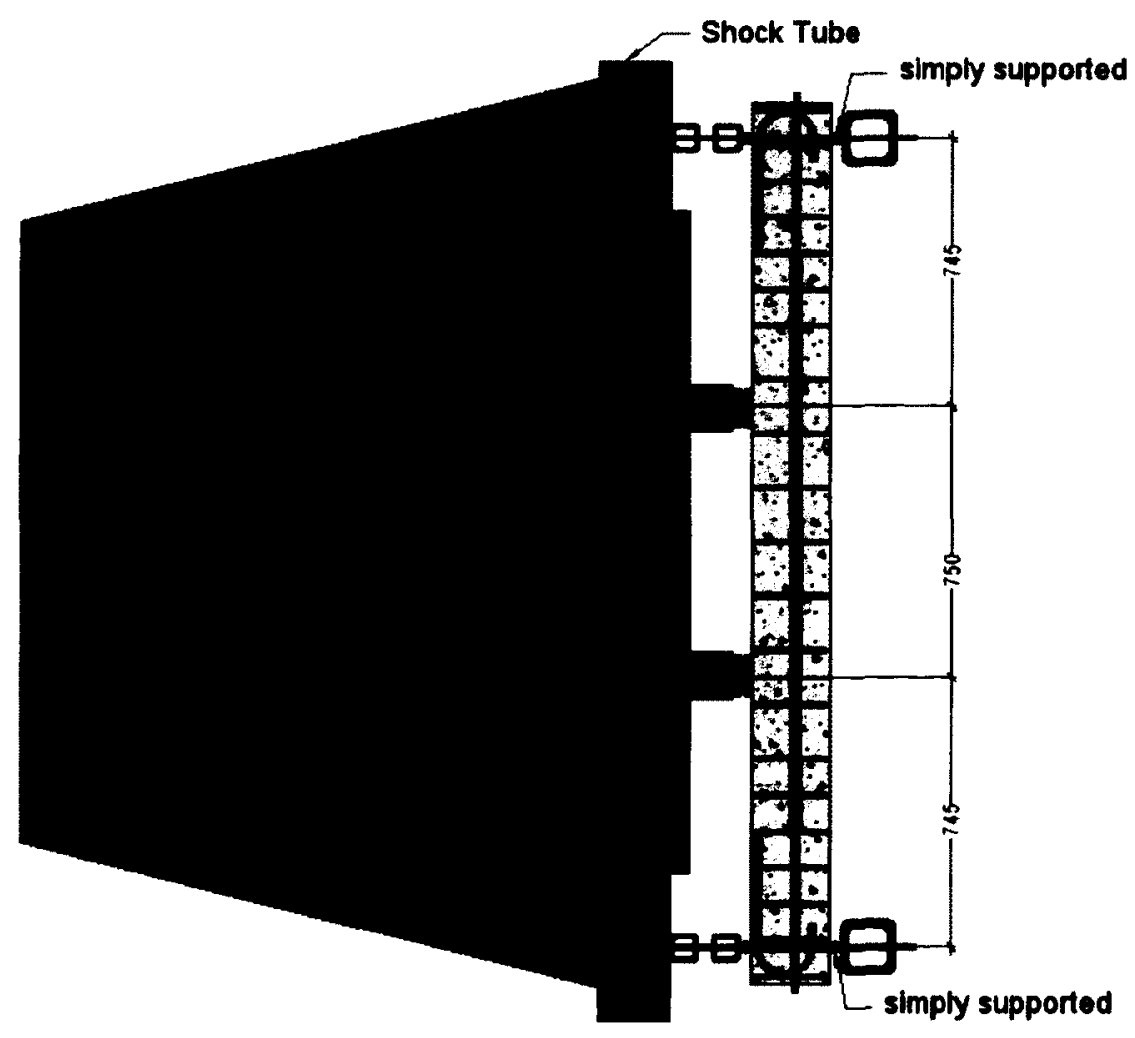

Figure 3-23: Concrete Beam Setup on Shock Tube 


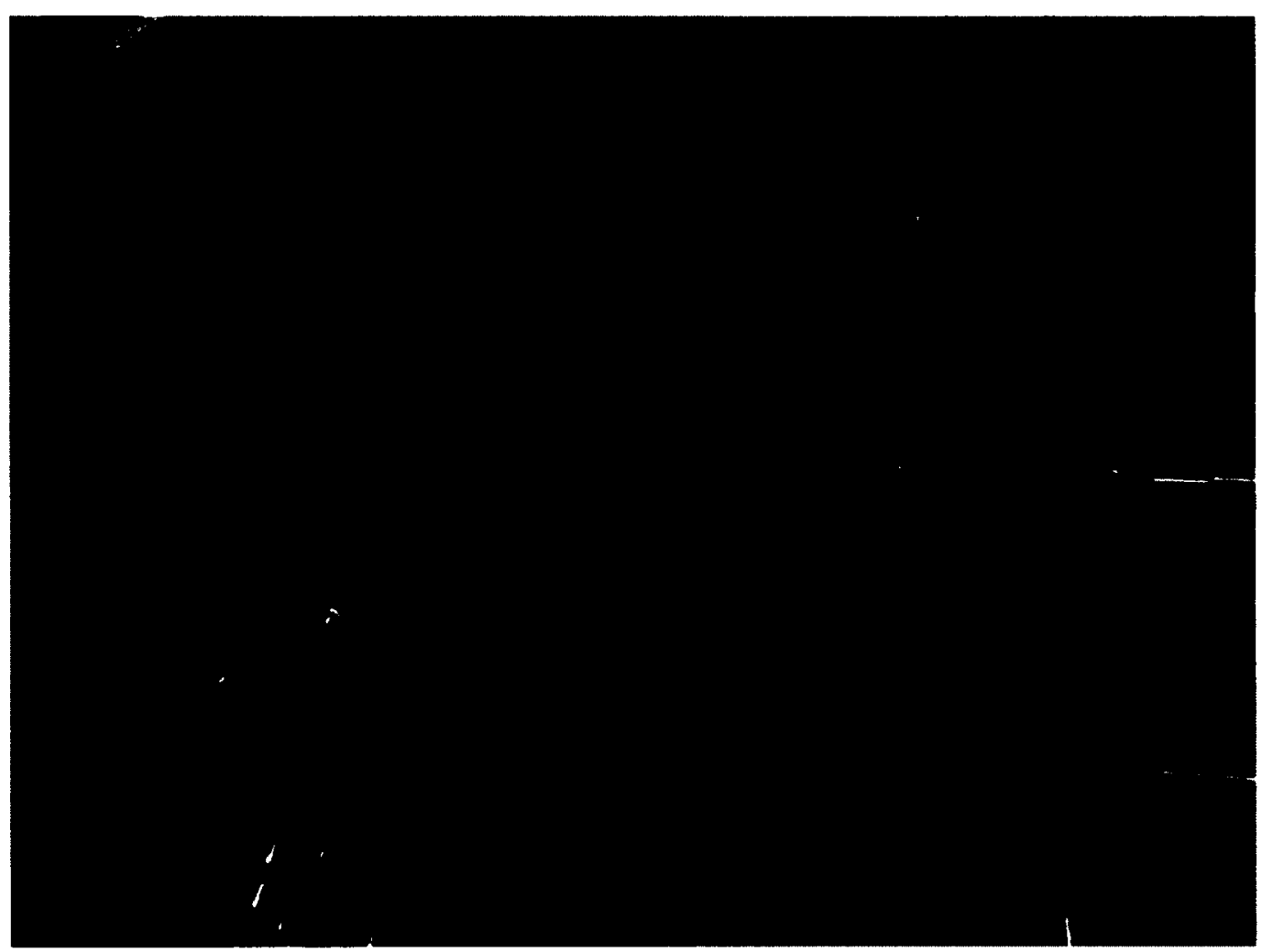

Figure 3-24: Anchor Bolt Installation for Connection to LVDT

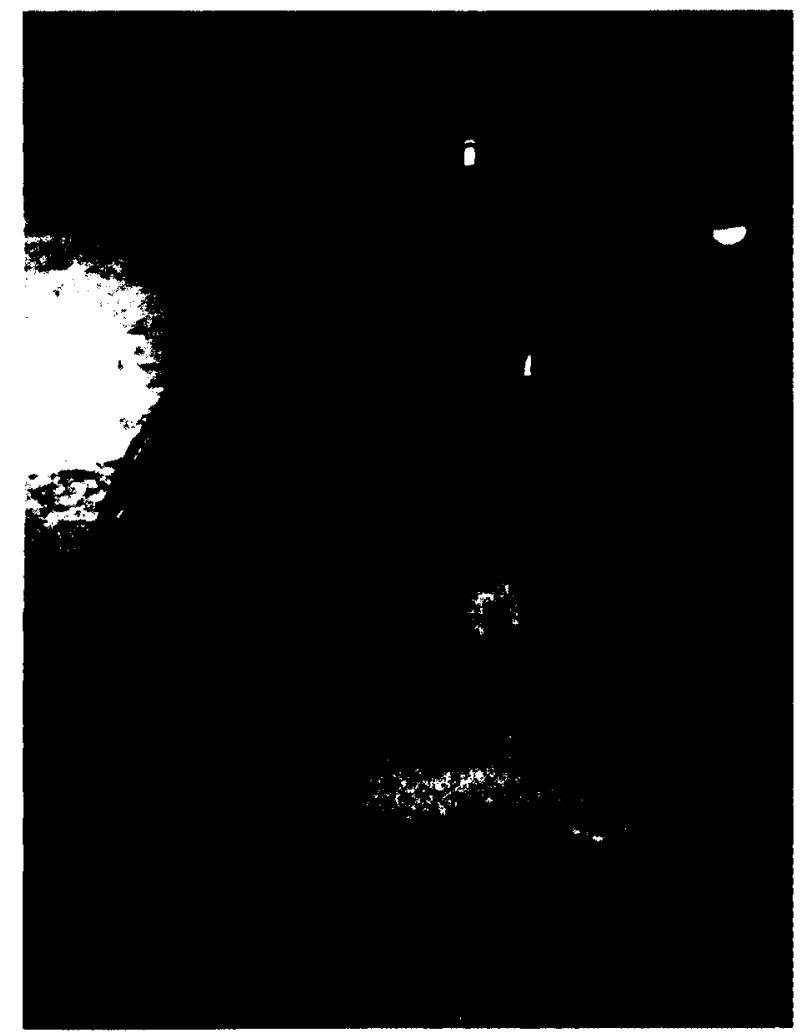

Figure 3-25: Installation of Welded Member Used for Bottom LVDT 


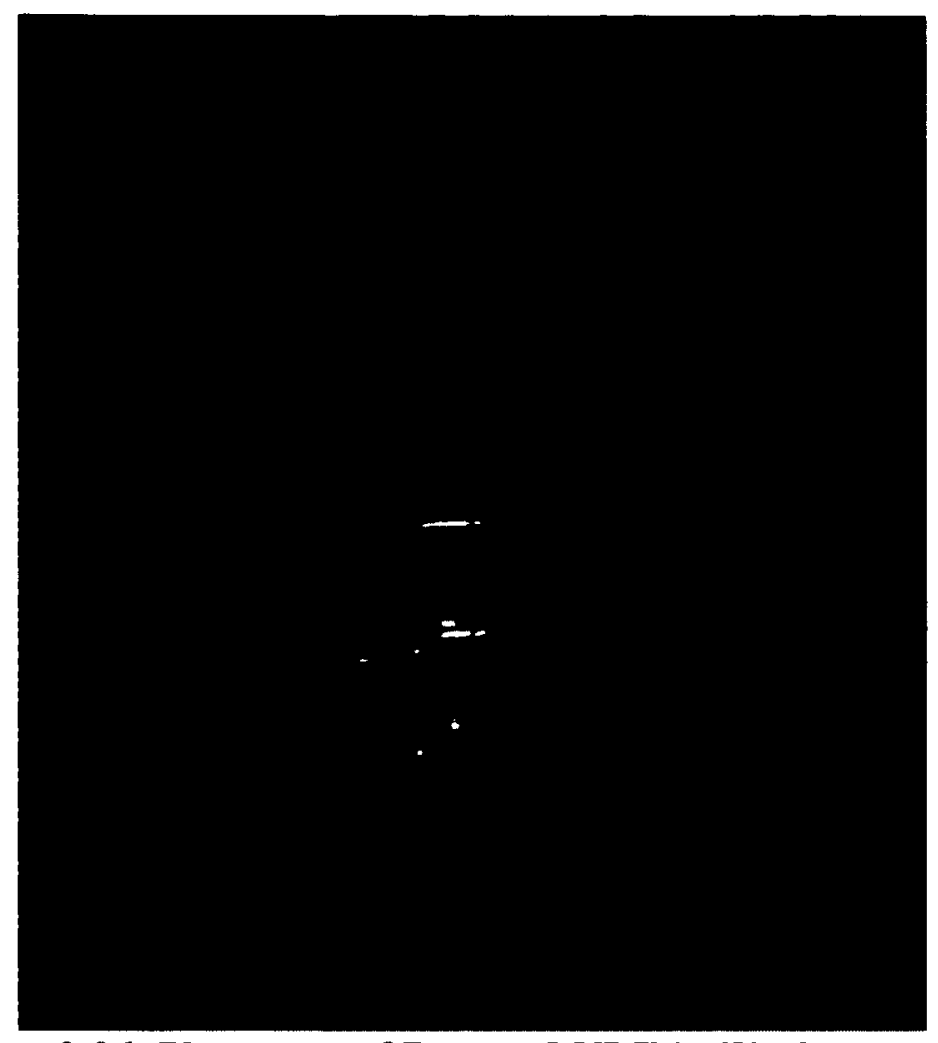

Figure 3-26: Placement of Bottom LVDT in Welded Member

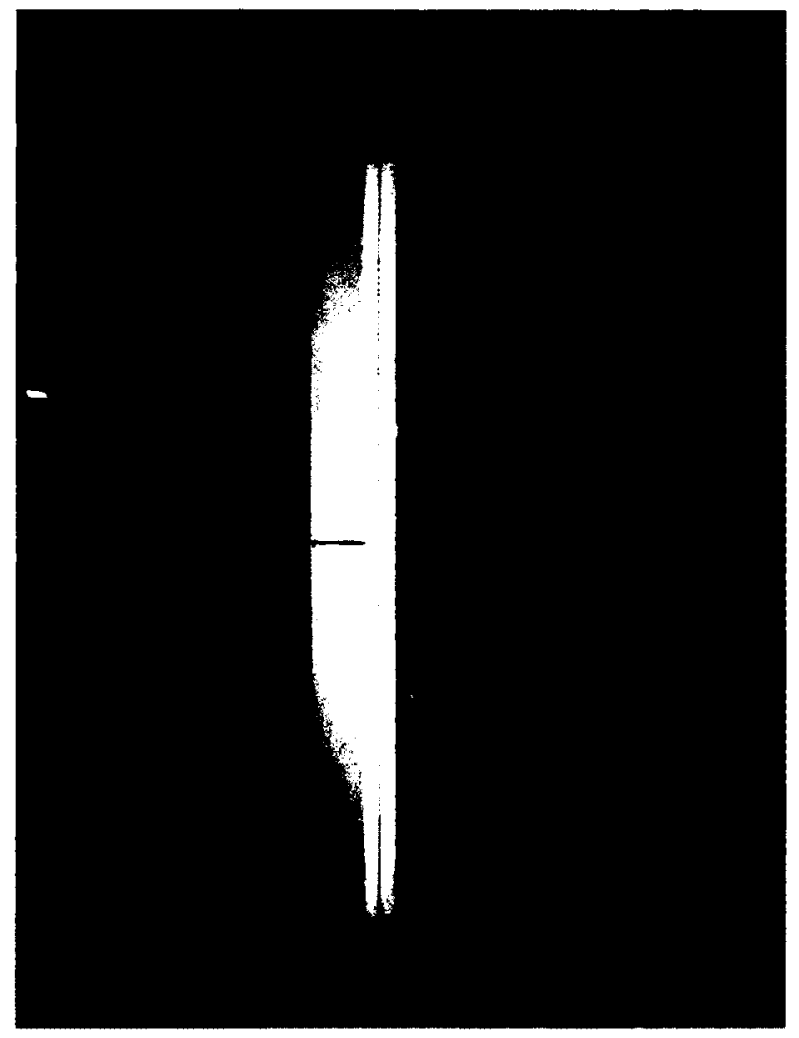

Figure 3-27: Beam Setup on Shock Tube 


\section{Chapter: Experimental Results}

\subsection{Ancillary Testing}

\subsubsection{Tensile Strength of Steel Reinforcement}

All sizes of reinforcement used in the construction of the concrete beams were tested in tension to obtain their strength and strain characteristics. The apparatus used to test the steel specimens was a MTS 810 Material Testing System, equipped with MTS FlexTests SE data acquisition software. A clip gauge placed on the steel specimen was used to record strain values.

A minimum of three static tests each were completed for $15 \mathrm{M}, 20 \mathrm{M}$ and $25 \mathrm{M}$ reinforcement. The tests were performed in accordance with ASTM A370-11a (2011). The static tests began at a strain rate of $30 \mu$ strain/s in load control mode until a strain of 0.005 was reached in the steel specimen. After this, the strain rate was increased to 950 $\mu$ strain/s. The test mode was changed from load control to displacement control when the maximum displacement of the clip gauge was reached.

Once all tests were completed, the data was analyzed and stress-strain curves were produced and used to obtain strength characteristics for each size of reinforcement. The upper yield strength, lower yield strength, strength in the yield plateau (before strainhardening occurs) and the ultimate strength were determined. Strain characteristics such as strain at yield strength, strain at ultimate strength and strain of fracture were also determined. The test data is presented in Table 4-1 and Table 4-5 including average values for each size of reinforcing steel. The size of the reinforcing steel was determined 
by taking 3 measurements with calipers along the length of each steel reinforcement specimen and determining the average diameter of each bar. The average diameter of all bars was then determined.

Dynamic tests were also performed in order to gain an understanding reinforcement behaviour under high strain rate (dynamic testing). The strain rate was increased to approximately 6667 times the static strain rates for these tests which was the maximum rate of loading for the testing machine. For both $15 \mathrm{M}$ and $20 \mathrm{M}$ rebar a strain rate of $0.2 \mathrm{strain} / \mathrm{s}$ was used to determine the dynamic strength characteristics. For $25 \mathrm{M}$ rebar, a strain rate of $0.2 \mathrm{strain} / \mathrm{s}$ was attempted, but the specimen slipped from and failed at the grips. Values of strength and strain obtained in tests at $0.2 \mathrm{strain} / \mathrm{s}$ are reported in Table 4-3 and Table 4-7.

Following the dynamic tests conducted at a rate of $0.2 \mathrm{strain} / \mathrm{s}$, a second set of dynamic test were conducted using a strain of $0.1 \mathrm{strain} / \mathrm{s}$ or approximately 3333 times that of the static tests. These tests were done for $15 \mathrm{M}, 20 \mathrm{M}$ and $25 \mathrm{M}$ size rebar. The strength and strain characteristics obtained from all tests conducted at 0.1 strain/s are reported in Table 4-2 and Table 4-6.

A comparison of the stress-strain curves for different strain rates were also produced and are shown in Figure 4-1, Figure 4-2, and Figure 4-3 for the 15M, 20M and $25 \mathrm{M}$ reinforcements respectively. The stress-strain curves show a significant increase in strength at higher strains rates $\left(0.2 \mathrm{~s}^{-1}\right.$ and $\left.0.1 \mathrm{~s}^{-1}\right)$. The yield strength and ultimate strength increases are presented in Table 4-4. For $15 \mathrm{M}$ rebar the yield strength increase factor was 1.11 while the ultimate strength increase factor was 1.05 at 0.1 strain rate, and the yield strength increase was 1.12 while the ultimate strength increase factor was 1.05 
at 0.2 strain rate. For $20 \mathrm{M}$ rebar the yield strength increase factor and the ultimate strength increase was 1.10 at 0.1 strain rate, and the yield strength increase was 1.09 while the ultimate strength increase was 1.11 at 0.2 strain rate. For $25 \mathrm{M}$ rebar the yield strength increase was 1.10 while the ultimate strength increase was 1.05 at 0.1 strain rate. No significant difference was observed between the response of reinforcement tested at $0.1 \mathrm{~s}^{-1}$ and $0.2 \mathrm{~s}^{-1}$ for the $15 \mathrm{M}$ and $20 \mathrm{M}$ reinforcements.

Table 4-8 shows the strain values at yield for increased strain rates. For $15 \mathrm{M}$ rebar the yield strain increase factor was 1.05 at 0.1 strain rate, and 1.07 at 0.2 strain rate. For $20 \mathrm{M}$ rebar the yield strain increase factor was 1.02 at 0.1 strain rate, and 1.18 at 0.2 strain rate. For $25 \mathrm{M}$ rebar the yield strain increase factor was 1.29 at 0.1 strain rate. Figure $4-1$, Figure 4-2, and Figure 4-3 for the $15 \mathrm{M}, 20 \mathrm{M}$ and $25 \mathrm{M}$ reinforcements respectively show the stress-strain curves at different strain rates. From the curves, it is apparent the strain rate increase had very diminutive effects on the strain at ultimate strength and ultimate strain for $15 \mathrm{M}$ rebar. However, when $20 \mathrm{M}$ and $25 \mathrm{M}$ rebar was loaded more rapidly, the strain at ultimate strength was significantly lower than that in the static tests. No change in the modulus of elasticity of the reinforcement was observed with increase in strain rate.

\subsubsection{Compressive Strength of Concrete Cylinders}

During casting of concrete beams, concrete cylinders were also cast to determine compressive strength of concrete. The cylinders use had a diameter of $152 \mathrm{~mm}$ and a height of $305 \mathrm{~mm}$. The concrete was cast on January 23, 2012 and cured for over three months. The period over which Shock Tube testing took place was approximately 2 
weeks In order to determine the concrete strength during shock tube testing, 5 concrete cylinders were tested at the onset of Shock Tube testing and another 5 concrete cylinders tested at the end of Shock Tube testing. The average strength for the concrete tests on these days were $36.54 \mathrm{MPa}$ and $37.90 \mathrm{MPa}$ respectively as shown in Table 4-9.

Once all shock tube testing was completed, the remaining beams were tested in static conditions. At the end this testing another 5 concrete cylinders were tested. The average strength of concrete that was determined to be $37.50 \mathrm{MPa}$ as shown in Table 4-9. 
Table 4-1: Strength values for static steel tests

\begin{tabular}{|c|c|c|c|c|}
\hline $\begin{array}{c}\text { Rebar Size } \\
\text { and } \\
\begin{array}{c}\text { Specimen } \\
\text { Number }\end{array}\end{array}$ & $\begin{array}{c}\text { Upper Yield } \\
\text { Strength } \\
(\mathrm{MPa})\end{array}$ & $\begin{array}{c}\text { Lower Yield } \\
\text { Strength } \\
(\mathrm{MPa})\end{array}$ & $\begin{array}{c}\text { Strength in } \\
\text { Yield } \\
\text { Plateau } \\
(\mathrm{MPa})\end{array}$ & $\begin{array}{c}\text { Ultimate } \\
\text { Strength } \\
(\mathrm{MPa})\end{array}$ \\
\hline $15 \mathrm{M}-2$ & 463.4 & 408.2 & 448.8 & 655.3 \\
\hline $15 \mathrm{M}-3$ & 469.5 & 419.2 & 449.2 & 654.6 \\
\hline 15M-4 & 462.6 & 422.2 & 448.7 & 654.4 \\
\hline Average & 465.2 & 416.6 & 448.9 & 654.8 \\
\hline \multicolumn{5}{|l|}{} \\
\hline $20 \mathrm{M}-1$ & 429.4 & 412.3 & 415.6 & 689.1 \\
\hline $20 \mathrm{M}-2$ & 445.3 & 394.3 & 427.1 & 622.6 \\
\hline $20 \mathrm{M}-3$ & 432.6 & 394.2 & 417.7 & 691.1 \\
\hline $20 \mathrm{M}-4$ & 441.8 & 402.2 & 427.9 & 621.1 \\
\hline Average & 437.3 & 400.8 & 422.1 & 656.0 \\
\hline \multicolumn{5}{|l|}{} \\
\hline $25 \mathrm{M}-1$ & 447.6 & 433.2 & 433.6 & 622.6 \\
\hline $25 \mathrm{M}-2$ & 450.4 & 431.3 & 434.5 & 624.3 \\
\hline $25 \mathrm{M}-3$ & 449.4 & 432.1 & 433.6 & 623.7 \\
\hline Average & 449.1 & 432.2 & 433.9 & 623.5 \\
\hline
\end{tabular}

Table 4-2: Strength values for steel tests conducted at a rate of $0.1 \mathrm{strain} / \mathrm{s}$

\begin{tabular}{|c|c|c|c|c|}
\hline $\begin{array}{c}\text { Rebar Size } \\
\text { and } \\
\begin{array}{c}\text { Specimen } \\
\text { Number }\end{array}\end{array}$ & $\begin{array}{c}\text { Upper Yield } \\
\text { Strength } \\
(\mathrm{MPa})\end{array}$ & $\begin{array}{c}\text { Lower Yield } \\
\text { Strength } \\
(\mathrm{MPa})\end{array}$ & $\begin{array}{c}\text { Strength in } \\
\text { Yield } \\
\text { Plateau } \\
(\mathrm{MPa})\end{array}$ & $\begin{array}{c}\text { Ultimate } \\
\text { Strength } \\
(\mathrm{MPa})\end{array}$ \\
\hline $15 \mathrm{M}-1$ & 515.4 & 464.4 & 474.5 & 687.9 \\
\hline $15 \mathrm{M}-2$ & 514.1 & 445.81 & 489.1 & 683.6 \\
\hline Average & 514.8 & 455.1 & 481.8 & 685.7 \\
\hline \multicolumn{5}{|l}{} \\
\hline $20 \mathrm{M}-1$ & 481.5 & 466.4 & 471.6 & 719.8 \\
\hline $20 \mathrm{M}-2$ & 479.2 & 454.5 & 464.8 & 719.5 \\
\hline Average & 480.3 & 460.5 & 468.2 & 719.6 \\
\hline \multicolumn{5}{|l|}{} \\
\hline $25 \mathrm{M}-1$ & 479.1 & 476.3 & 477.5 & 650.3 \\
\hline $25 \mathrm{M}-2$ & 508.0 & 490.4 & 491.3 & 663.8 \\
\hline Average & 493.5 & 483.4 & 484.4 & 657.1 \\
\hline
\end{tabular}


Table 4-3: Strength values for steel tests conducted at a rate of 0.2 strain/s

\begin{tabular}{|c|c|c|c|c|}
\hline $\begin{array}{l}\text { Rebar Size } \\
\text { and } \\
\text { Specimen } \\
\text { Number }\end{array}$ & $\begin{array}{l}\text { Upper Yield } \\
\text { Strength } \\
(\mathrm{MPa})\end{array}$ & $\begin{array}{l}\text { Lower Yield } \\
\text { Strength } \\
(\mathrm{MPa})\end{array}$ & $\begin{array}{l}\text { Strength in } \\
\text { Yield } \\
\text { Plateau } \\
\text { (MPa) }\end{array}$ & $\begin{array}{c}\text { Ultimate } \\
\text { Strength } \\
(\mathrm{MPa})\end{array}$ \\
\hline $15 \mathrm{M}-1$ & 519.8 & 475.3 & 479.7 & 682.7 \\
\hline $15 \mathrm{M}-2$ & 516.1 & 478.3 & 483.5 & 688.4 \\
\hline $15 \mathrm{M}-3$ & 520.8 & 479.3 & 484.8 & 688.5 \\
\hline Average & 518.9 & 477.6 & 482.7 & 688.2 \\
\hline $20 \mathrm{M}-1$ & 472.6 & 452.3 & 456.4 & 726.5 \\
\hline $20 \mathrm{M}-2$ & 482.6 & 456.4 & 459.5 & 725.6 \\
\hline $20 \mathrm{M}-3$ & 478.7 & 459.8 & 460.1 & 728.7 \\
\hline Average & 478.0 & 456.1 & 458.7 & 726.9 \\
\hline
\end{tabular}

Table 4-4: Dynamic Increase Factor for Steel Reinforcement

\begin{tabular}{|c|c|c|c|}
\hline & Rebar Size & $\begin{array}{c}\text { Yield } \\
\text { Strength } \\
\text { (MPa) }\end{array}$ & $\begin{array}{c}\text { Ultimate } \\
\text { Strength } \\
\text { (MPa) }\end{array}$ \\
\hline Static & \multirow{5}{*}{$15 \mathrm{M}$} & 465.2 & 654.8 \\
\hline 0.1 strain $/ \mathrm{s}$ & & 514.8 & 685.7 \\
\hline DIF & & 1.11 & 1.05 \\
\hline 0.2 strain $/ \mathrm{s}$ & & 518.9 & 688.2 \\
\hline DIF & & 1.12 & 1.05 \\
\hline Static & \multirow{5}{*}{$20 \mathrm{M}$} & 437.3 & 656 \\
\hline 0.1 strain $/ \mathrm{s}$ & & 480.3 & 719.6 \\
\hline DIF & & 1.10 & 1.10 \\
\hline 0.2 strain $/ \mathrm{s}$ & & 478.0 & 726.9 \\
\hline DIF & & 1.09 & 1.11 \\
\hline Static & \multirow{3}{*}{$25 M$} & 449.1 & 623.5 \\
\hline 0.1 strain $/ \mathrm{s}$ & & 493.5 & 657.1 \\
\hline DIF & & 1.10 & 1.05 \\
\hline
\end{tabular}


Table 4-5: Strain values for static steel tests

\begin{tabular}{|c|c|c|c|}
\hline $\begin{array}{c}\text { Rebar Size and } \\
\text { Specimen } \\
\text { Number }\end{array}$ & $\begin{array}{c}\text { Strain at Yield } \\
\text { Strength } \\
(\mathrm{mm} / \mathrm{mm})\end{array}$ & $\begin{array}{c}\text { Strain at } \\
\text { Ultimate } \\
\text { Strength } \\
(\mathrm{mm} / \mathrm{mm})\end{array}$ & $\begin{array}{c}\text { Ultimate Strain } \\
(\mathrm{mm} / \mathrm{mm})\end{array}$ \\
\hline $15 \mathrm{M}-2$ & 0.002990 & 0.1216 & 0.1606 \\
\hline $15 \mathrm{M}-3$ & 0.002379 & 0.1171 & 0.2621 \\
\hline $15 \mathrm{M}-4$ & 0.002383 & 0.1164 & 0.1419 \\
\hline Average & $\mathbf{0 . 0 0 2 5 8 4}$ & $\mathbf{0 . 1 1 8 4}$ & $\mathbf{0 . 1 8 8 2}$ \\
\hline \multicolumn{4}{|l}{} \\
\hline $20 \mathrm{M}-1$ & 0.002342 & 0.1080 & 0.1265 \\
\hline $20 \mathrm{M}-2$ & 0.002490 & 0.1369 & 0.2952 \\
\hline $20 \mathrm{M}-3$ & 0.002413 & 0.1044 & 0.1288 \\
\hline $20 \mathrm{M}-4$ & 0.002389 & 0.1320 & 0.3386 \\
\hline Average & 0.002408 & 0.1203 & 0.2223 \\
\hline \multicolumn{4}{|l|}{} \\
\hline $25 \mathrm{M}-1$ & 0.002342 & 0.1307 & 0.1650 \\
\hline $25 \mathrm{M}-2$ & 0.002537 & 0.1285 & 0.1760 \\
\hline $25 \mathrm{M}-3$ & 0.002467 & 0.1237 & 0.1525 \\
\hline Average & 0.002448 & 0.1276 & 0.1645 \\
\hline
\end{tabular}

Table 4-6: Strain values for steel tests conducted at a rate of 0.1 strain/s

\begin{tabular}{|c|c|c|c|}
\hline $\begin{array}{c}\text { Rebar Size and } \\
\text { Specimen } \\
\text { Number }\end{array}$ & $\begin{array}{c}\text { Strain at Yield } \\
\text { Strength } \\
(\mathrm{mm} / \mathrm{mm})\end{array}$ & $\begin{array}{c}\text { Strain at } \\
\text { Ultimate } \\
\text { Strength } \\
(\mathrm{mm} / \mathrm{mm})\end{array}$ & $\begin{array}{c}\text { Ultimate Strain } \\
(\mathrm{mm} / \mathrm{mm})\end{array}$ \\
\hline $15 \mathrm{M}-1$ & 0.002807 & 0.1163 & 0.2451 \\
\hline $15 \mathrm{M}-2$ & 0.002606 & 0.1203 & 0.1615 \\
\hline Average & 0.002707 & 0.1183 & 0.2033 \\
\hline \multicolumn{4}{|l}{} \\
\hline $20 \mathrm{M}-1$ & 0.002256 & 0.1085 & 0.1434 \\
\hline $20 \mathrm{M}-2$ & 0.002668 & 0.1120 & 0.1549 \\
\hline Average & 0.002462 & 0.1102 & 0.1492 \\
\hline \multicolumn{4}{|l|}{} \\
\hline $25 \mathrm{M}-1$ & 0.002694 & 0.1193 & 0.1306 \\
\hline $25 \mathrm{M}-2$ & 0.003632 & 0.0991 & 0.1117 \\
\hline Average & 0.003163 & 0.1092 & 0.1212 \\
\hline
\end{tabular}


Table 4-7: Strain values for steel tests conducted at a rate of 0.2 strain/s

\begin{tabular}{|c|c|c|c|}
\hline $\begin{array}{c}\text { Rebar Size and } \\
\text { Specimen } \\
\text { Number }\end{array}$ & $\begin{array}{c}\text { Strain at Yield } \\
\text { Strength } \\
(\mathrm{mm} / \mathrm{mm})\end{array}$ & $\begin{array}{c}\text { Strain at } \\
\text { Ultimate } \\
\text { Strength } \\
(\mathrm{mm} / \mathrm{mm})\end{array}$ & $\begin{array}{c}\text { Ultimate Strain } \\
(\mathrm{mm} / \mathrm{mm})\end{array}$ \\
\hline $15 \mathrm{M}-1$ & 0.002632 & 0.1161 & 0.1654 \\
\hline $15 \mathrm{M}-2$ & 0.003001 & 0.1162 & 0.1616 \\
\hline $15 \mathrm{M}-3$ & 0.002682 & 0.1167 & 0.1719 \\
\hline Average & $\mathbf{0 . 0 0 2 7 7 2}$ & $\mathbf{0 . 1 1 6 3}$ & 0.1663 \\
\hline & & & 0.2827 \\
\hline $20 \mathrm{M}-1$ & 0.002384 & 0.1111 & 0.1592 \\
\hline $20 \mathrm{M}-2$ & 0.003060 & 0.1072 & 0.1658 \\
\hline $20 \mathrm{M}-3$ & 0.003067 & 0.1058 & 0.2026 \\
\hline Average & $\mathbf{0 . 0 0 2 8 3 7}$ & $\mathbf{0 . 1 0 8 0}$ & \\
\hline
\end{tabular}

Table 4-8: Increase in Strain Values for Steel Reinforcement at High Strain Rates

\begin{tabular}{|c|c|c|}
\hline & Rebar Size & $\begin{array}{c}\text { Strain at Yield } \\
\text { Strength }(\mathrm{mm} / \mathrm{mm})\end{array}$ \\
\hline Static & \multirow{6}{*}{$15 M$} & 0.002584 \\
\hline 0.1 strain $/ \mathrm{s}$ & & 0.002707 \\
\hline DIF for Yield Strain & & 1.05 \\
\hline $0.2 \mathrm{strain} / \mathrm{s}$ & & 0.002772 \\
\hline DIF for Yield Strain & & 1.07 \\
\hline $\begin{array}{c}\text { Average Yield Strain at Increased } \\
\text { Strain Rate } \\
\end{array}$ & & 0.002740 \\
\hline Static & \multirow{6}{*}{$20 M$} & 0.002408 \\
\hline 0.1 strain $/ \mathrm{s}$ & & 0.002462 \\
\hline DIF for Yield Strain & & 1.02 \\
\hline $0.2 \mathrm{strain} / \mathrm{s}$ & & 0.002837 \\
\hline DIF for Yield Strain & & 1.18 \\
\hline $\begin{array}{c}\text { Average Yield Strain at Increased } \\
\text { Strain Rate }\end{array}$ & & 0.002650 \\
\hline Static & \multirow{3}{*}{$25 M$} & 0.002448 \\
\hline 0.1 strain $/ \mathrm{s}$ & & 0.003163 \\
\hline DIF for Yield Strain & & 1.29 \\
\hline
\end{tabular}


Table 4-9: Strengths of concrete cylinders

\begin{tabular}{|c|c|c|c|}
\hline $\begin{array}{l}\text { Cylinder } \\
\text { Number }\end{array}$ & $\begin{array}{c}\text { Strength on } \\
\text { May } 8^{\text {th }} \text { (MPa) }\end{array}$ & 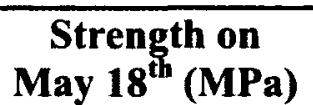 & $\begin{array}{c}\text { Strength on } \\
\text { May } 25^{\text {st }}(\mathrm{MPa})\end{array}$ \\
\hline$\# 1$ & 37.67 & 37.70 & 37.56 \\
\hline$\# 2$ & 35.32 & 37.02 & 38.19 \\
\hline$\# 3$ & 38.45 & 37.84 & 37.64 \\
\hline$\# 4$ & 34.01 & 38.70 & 37.98 \\
\hline$\# 5$ & 37.24 & 38.23 & 36.15 \\
\hline Average & 36.54 & 37.90 & 37.50 \\
\hline $\begin{array}{l}\text { Average of } \\
\text { all } 3 \text { days }\end{array}$ & \multicolumn{3}{|c|}{37.31} \\
\hline
\end{tabular}




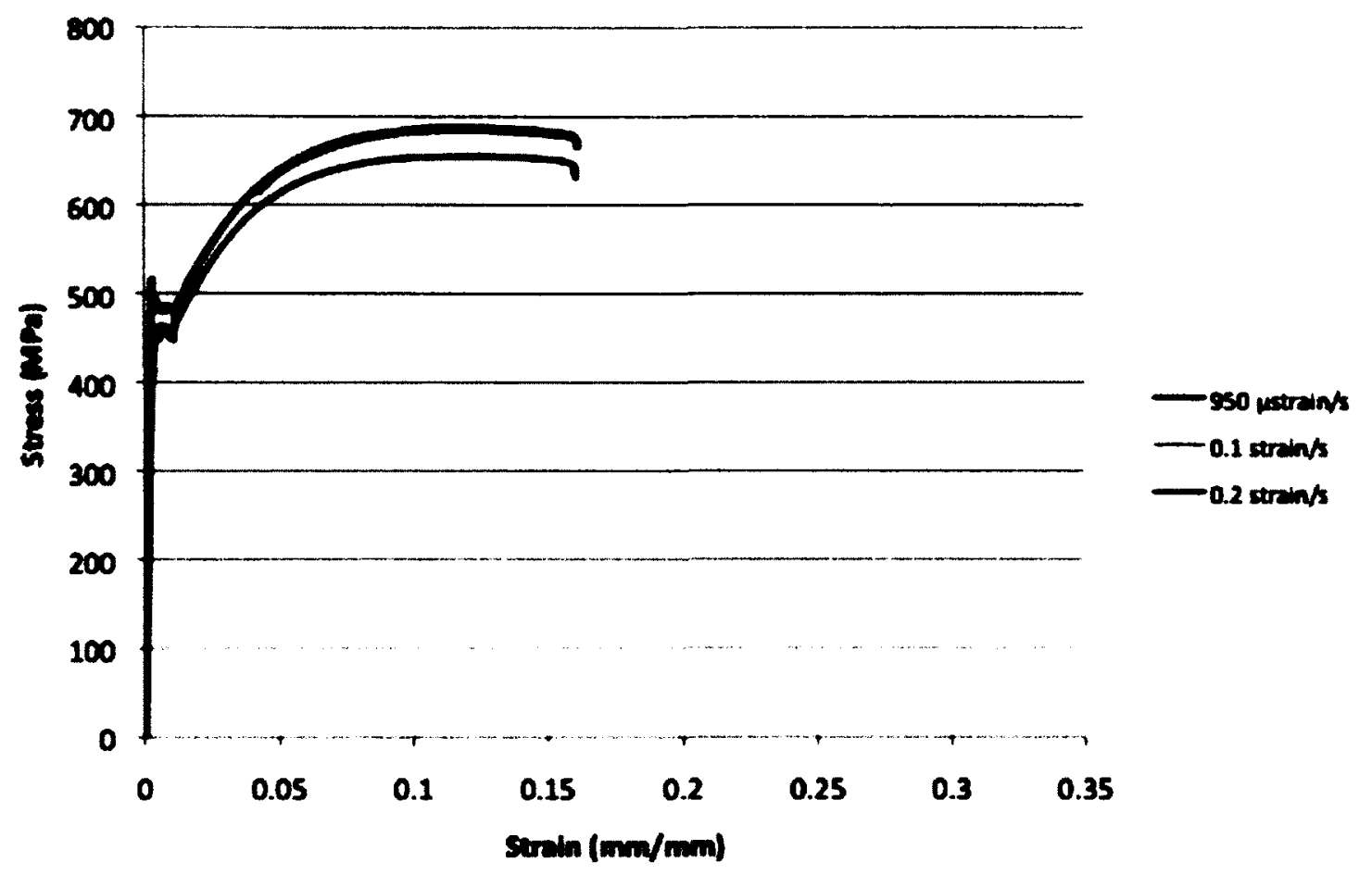

Figure 4-1: Stress-strain curve for $15 M$ reinforcement

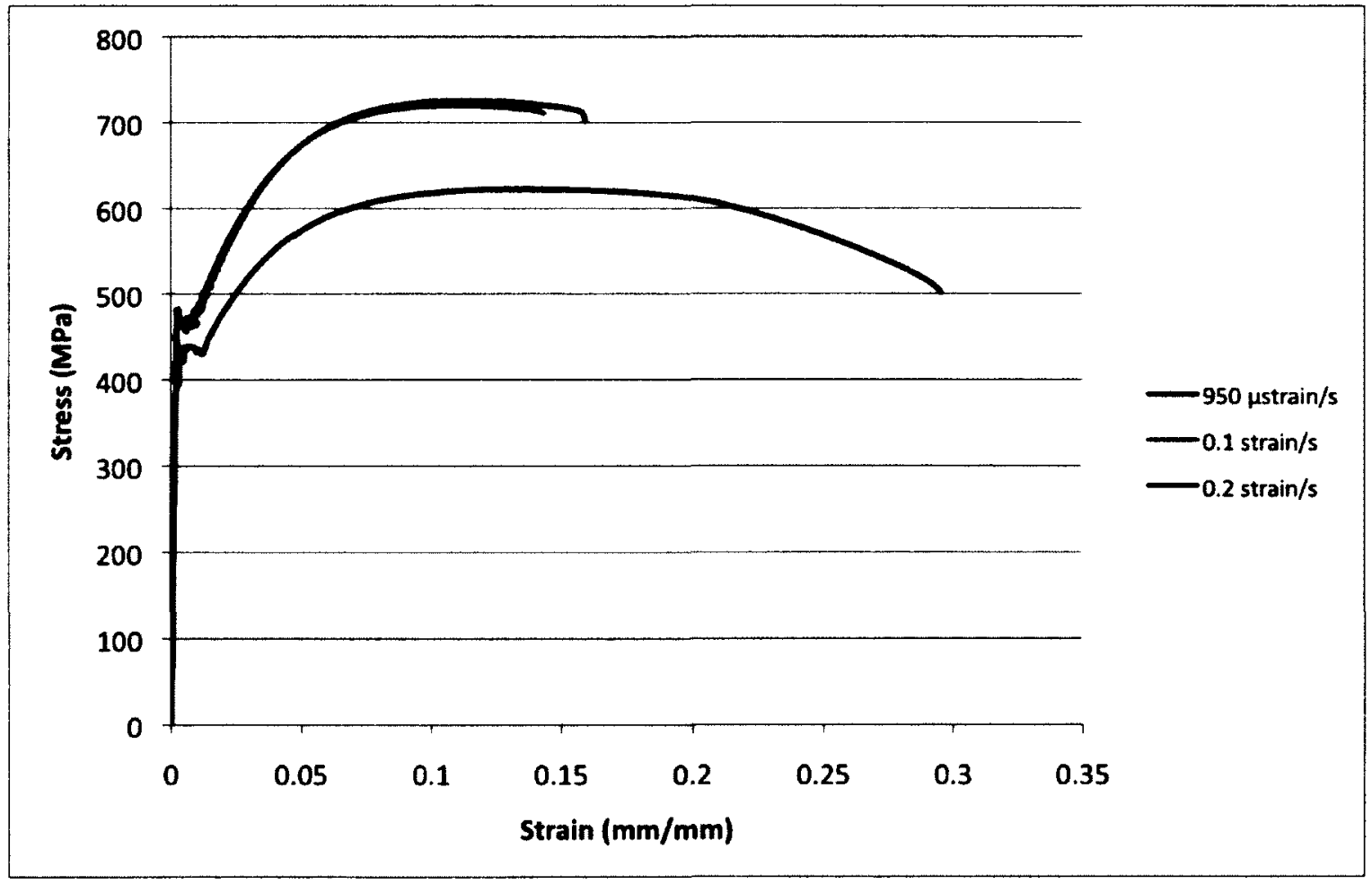

Figure 4-2: Stress-strain curve for $20 \mathrm{M}$ reinforcement 


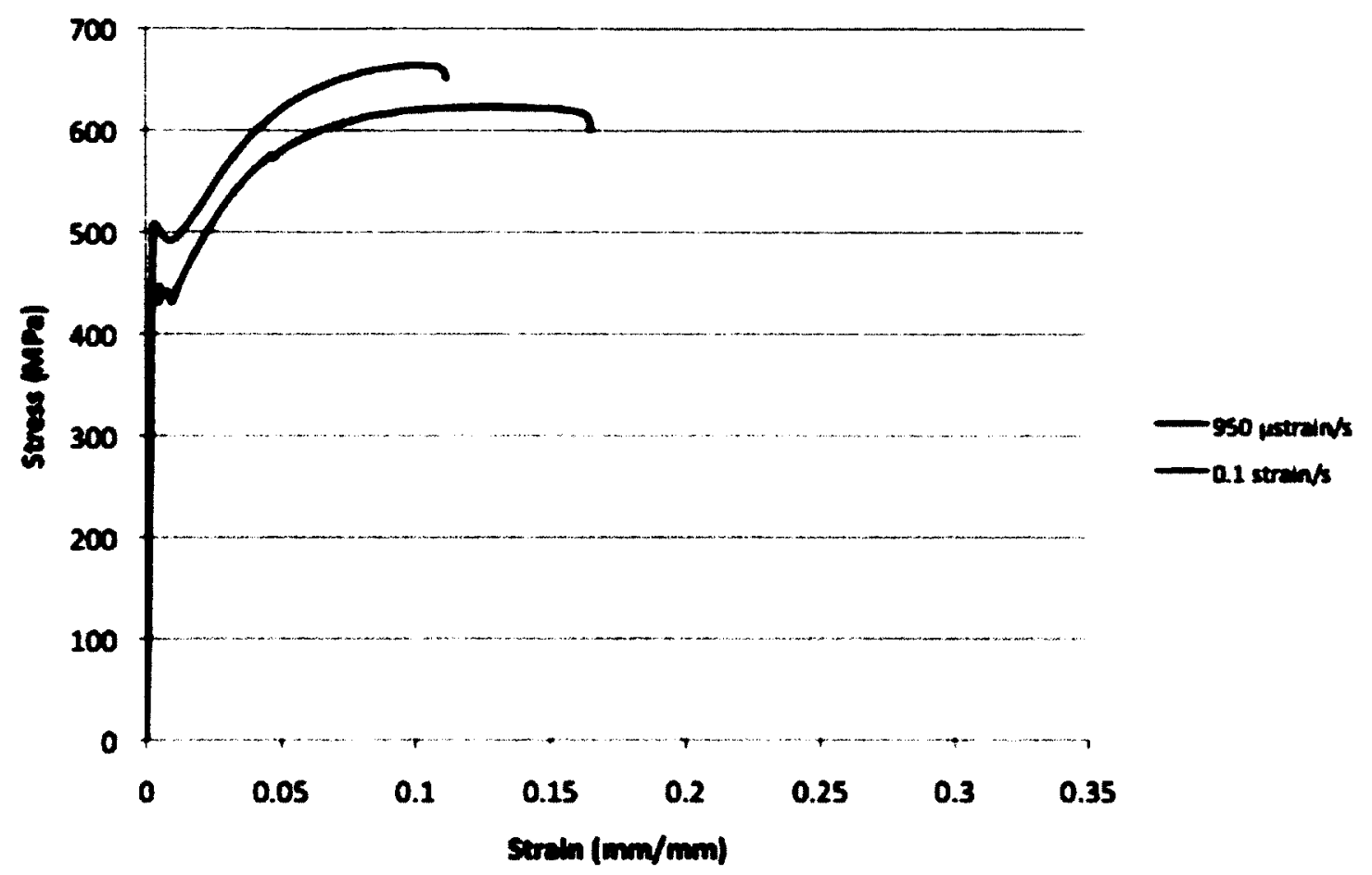

Figure 4-3: Stress-strain curve for $25 \mathrm{M}$ reinforcement 


\subsection{Static Results}

This section presents results from the 6 static tests performed on reinforced concrete beams. During the static tests the rate of loading, beams capacity, time to ultimate capacity, midspan and load point deflections, and steel reinforcement strains were monitored and recorded. The results were used to study the behaviour of the beams in general and the bond behaviour in particular. All support rotations were calculated from the displacement at the load point of the beam. Table 4-10 presents a summary of the test results.

The nomenclature used for the beams is as follows: SB or DB denotes static test beams or shocktube (dynamic) test beams, $15 \mathrm{M}, 20 \mathrm{M}$, and $25 \mathrm{M}$ denotes reinforcement type, the first number denotes the beam number, and for dynamic tests where more than one test is conducted on each beam, the second number denotes the number of tests applied to that beam. For example beam SB-15M-1 is a static test beam with $15 \mathrm{M}$ reinforcement and is the first beam tested in the series, and beam DB-15M-1-2 is a dynamic beam with $15 \mathrm{M}$ reinforcement, is the first beam tested in the series, and the second time it has been tested.

\subsubsection{Beam SB-15M-1}

Beam SB-15M-1 was loaded at a rate of $19.4 \mathrm{kN}$ per minute $(9.70 \mathrm{kN} / \mathrm{min}$ at each load point). The maximum capacity of the beam was $22.8 \mathrm{kN}$. Figure $4-4$ presents the load-deflection response of the beam. The midspan deflection at peak load was $27.1 \mathrm{~mm}$ while the load point deflection was lower at $18.4 \mathrm{~mm}$ corresponding to a support rotation of $1.41^{\circ}$. 
Once maximum capacity was reached, and the reinforcing steel began to yield, there was an increase in deformation without an appreciable increase in load. The residual displacements after the load was removed were $148.0 \mathrm{~mm}$ at midspan and 99.1 $\mathrm{mm}$ at the load point corresponding to a support rotation of $7.58^{\circ}$.

Strains along the steel recorded during static testing are presented in Figure 4-5. The strain profile along the bonded steel region was plotted at the point when gauges 5 and 6 reached $2584 \times 10^{-6}$ (the static yield strain) and is shown in Figure 4-6. The reinforcement strain decreased in the bonded region and zero strains were recorded at S1 and S2 (S9 and S10). This indicates the development length, the length over which the yield stress is transferred in to the bonded concrete, is less than the bonded length of 423 $\mathrm{mm}$. This was confirmed by the fact that the steel reinforcement protruding from the ends of the beam did not experience any slip. The accuracy of the development length measurement (estimate) is dependent on the spacing of the strain gauges in the bonded region. It can be definitively stated that the development length is between $385 \mathrm{~mm}$ and $265 \mathrm{~mm}$, location of gauges S1 and S2 (S10 and S9), respectively, but no better.

All concrete gauges initially experienced tensile strains as the preformed crack opened up (Figure 4-7). At this point, the neutral axis was above all gauges. Concrete gauges $\mathrm{C} 2$ and $\mathrm{C} 3$ failed after undergoing high tensile strains (tensile rupture). Once the concrete on the compression face began to crush (Figure 4-8), the neutral axis moved down and the concrete at the location of gauge $\mathrm{Cl}$ moved into compression. Once the maximum load was reached and the beam continued to deflect, gauge $\mathrm{Cl}$ reached high values of compressive strain. 
The only visual cracking in the beam was at the location of the preformed crack at midspan of the beam (Figure 4-8). Therefore the beam acted as two rigid bodies rotating about a pivot in the compression zone of the beam. The width of the crack before testing was $6.2 \mathrm{~mm}$ and was measured to be $37.2 \mathrm{~mm}$ after testing.

\subsubsection{Beam SB-15M-2}

Beam SB-15M-2 was loaded at a rate of $18.7 \mathrm{kN}$ per minute. This load was distributed along the spreader beam to create a loading rate of $9.36 \mathrm{kN} / \mathrm{min}$ at the two point loads. The maximum capacity of the beam was $20.2 \mathrm{kN}$ (Figure 4-9). The maximum capacity was reached at deflection at midspan deflection of $32.7 \mathrm{~mm}$ and load point deflection of $22.1 \mathrm{~mm}$ corresponding to a support rotation of $1.70^{\circ}$.

Once maximum capacity was reached, the beam continued to deflect without any significant increase in load (the steel reinforcement began yielding). The residual displacements were $143.0 \mathrm{~mm}$ at midspan and $96.6 \mathrm{~mm}$ at the load point corresponding to a support rotation of $7.39^{\circ}$.

Strains along the steel were recorded during static testing. Yielding of the steel occurred in the debonded region when the average strain of gauge 5 and 6 reached. The strain profile along the bonded steel region was plotted at the static yield strain of $2584 \times 10^{-6}$ and is shown in Figure 4-11. Similar to beam SB-15M-1 the development length is less than the bonded length of $423 \mathrm{~mm}$ and no slip was recorded. Again, it can be stated that the development length is between $385 \mathrm{~mm}$ and $265 \mathrm{~mm}$ as the strains in the rebar reached zero-strain before S1 (S10). 
The concrete gauges in this test produced similar trends to the data obtained from beam SB-1. All gauges initially went into tension and gauges C2 and C3 broke (Figure 4-12). Concrete gauge $\mathrm{Cl}$ began to experience compressive strains once the concrete on the compression face began to crush and the neutral axis moved away from the top face of the beam.

The only visual cracking in the beam was at the location of the preformed crack at midspan of the beam. Figure 4-13 shows the cracking that occurred at midspan, which was similar to the cracking of Beam 15M-1. The width of the crack before testing was 5.2 $\mathrm{mm}$ and the width measured after testing was $37.6 \mathrm{~mm}$.

\subsubsection{Beam SB-20M-1}

Beam SB-20M-l was loaded at a rate of $13.2 \mathrm{kN}$ per minute. The loading rate for this beam was relatively slower than that of the others. This is due to the fact that it was the first of the 6 static beams tested and used as an exploratory test to check the hydraulic jack at a rate close to $20 \mathrm{kN}$ per minute. This load was distributed along the spreader beam to create a loading rate of $6.61 \mathrm{kN} / \mathrm{min}$ at the two point loads. The maximum capacity of the beam was $26.9 \mathrm{kN}$ (Figure 4-14). The deflection at the midspan at this point was $34.8 \mathrm{~mm}$ and the deflection at the load point was $23.6 \mathrm{~mm}$ corresponding to a support rotation of $1.81^{\circ}$.

Once maximum capacity was reached, the reinforcing steel began to yield and the beam experienced deflections while the load was reduced. The residual displacements were $159.9 \mathrm{~mm}$ at midspan and $115.7 \mathrm{~mm}$ at the load point corresponding to a support rotation of $8.83^{\circ}$. 
Strains along the 20M reinforcement were recorded and shown in Figure 4-15. Strain gauge 6 malfunctioned and is therefore not shown in Figure 4-15. The strain profile along the bonded steel region was plotted at the point where the strain in debonded region reached $2408 \times 10^{-6}$ (the yield strain) and is shown in Figure 4-16. The reinforcement strain decreased in the bonded region and zero strains were recorded at gauges furthest from the debonded region. This indicates the development length is less than the bonded length of $523 \mathrm{~mm}$. No slip was recorded. Due to the strain gauge spacing, it can be concluded that the development length is between $500 \mathrm{~mm}$ and 340 $\mathrm{mm}$.

Before the beam was dropped in the laboratory. While not much damage was observed, all concrete gauges were damaged. As a result, no concrete strains were recorded.

Similar to the beams containing $15 \mathrm{M}$ rebar, the only visual cracking was at midspan of the beam. Figure 4-17 shows the cracking that occurred at midspan and how the beam behaved as two rigid bodies. The width of the crack before testing was $3.9 \mathrm{~mm}$ and the width measured after testing was $47.2 \mathrm{~mm}$.

\subsubsection{Beam SB-20M-2}

Beam SB-20M-2 was loaded at a rate of $18.7 \mathrm{kN}$ per minute. This load was distributed along the spreader beam to create a loading rate of $9.35 \mathrm{kN} / \mathrm{min}$ at the two point loads. The maximum capacity of the beam was $28.0 \mathrm{kN}$ (Figure 4-18). The deflection at the midspan at this point was $38.0 \mathrm{~mm}$ and the deflection at the load point was $28.3 \mathrm{~mm}$ corresponding to a support rotation of $2.18^{\circ}$. 
Once the beam reached its maximum capacity, the reinforcing steel began to yield and the beam continued to deflect while the load reduced. The residual displacements when the load was removed were $114.9 \mathrm{~mm}$ at midspan and $85.4 \mathrm{~mm}$ at the load point corresponding to a support rotation of $6.54^{\circ}$.

Strains along the $20 \mathrm{M}$ reinforcement were also recorded and shown in Figure 4-19. No signal was received from strain gauges 6 and 10 during testing and they are therefore not shown in Figure 4-19. Yielding as with the other beams was initiated in the debonded region at strain gauge 5. Consequently, the highest strain readings were recorded in the debonded region where gauge 5 is located. However, during testing of beam SB-4, the gauges in the bonded region adjacent to the debonded region (gauges 4 and 7) had the highest readings. This could be due to the fact that gauge 5 was not properly bonded to the steel or zeroed before testing. The time of yield in this beam was therefore assumed to take place when strain gauge 4 and 7 reached an average strain equal to that of the yield strain of $20 \mathrm{M}$ reinforcement. Yielding of the steel occurred when the average strain in gauge 4 and 7 was $2010 \times 10^{-6}$. The strain profile along the bonded steel region was plotted at this point and is shown in Figure 4-20. Similar to beam SB-20M-1 the development length is less than the bonded length of $523 \mathrm{~mm}$ and no slip was recorded. Again, the development length is between $500 \mathrm{~mm}$ and $340 \mathrm{~mm}$.

Concrete strains behaved similarly to tests on beam SB-15M-1 and SB-15M-2. All gauges initially go into tension. The tensile strain in gauge $\mathrm{Cl}$ begins to reduce and become compressive strain as the concrete on the compression face begins to crush (Figure 4-21). 
The beam behaved as two rigid bodies and the only visual cracking in the beam occurred at midspan as depicted in Figure 4-22. The width of the crack before testing was $20.32 \mathrm{~mm}$ and the width of the crack after testing was $35.05 \mathrm{~mm}$.

\subsubsection{Beam SB-25M-1}

Beam SB-25M-1 was loaded at a rate of $20.2 \mathrm{kN}$ per minute. This load was distributed along the spreader beam to create a loading rate of $10.1 \mathrm{kN} / \mathrm{min}$ at the two point loads. The maximum capacity of the beam was $47.0 \mathrm{kN}$ (Figure 4-23). The deflection at the midspan at this point was $46.5 \mathrm{~mm}$ and the deflection at the load point was $35.6 \mathrm{~mm}$ corresponding to a support rotation of $2.74^{\circ}$.

Once maximum capacity was reached, the reinforcing steel began to yield and the beam experienced deflections while the load decreased. The residual displacements were $81.5 \mathrm{~mm}$ at midspan and $62.9 \mathrm{~mm}$ at the load point corresponding to a support rotation of $4.83^{\circ}$.

Strains along the $25 \mathrm{M}$ reinforcement were also recorded and shown in Figure 4-24. Strain gauge 7 was the only gauge not working in this test and is therefore not shown in Figure 4-24. The strain profile along the bonded steel region was plotted at the point where the debonded steel reached its yield strain $\left(2448 \times 10^{-6}\right)$ in gauges 5 and 6 and is shown in Figure 4-25. The reinforcement strain decreased in the bonded region and zero strains were recorded at gauges furthest from the debonded region. This indicates the development length is less than the bonded length of $830 \mathrm{~mm}$. No slip was recorded. Due to the strain gauge spacing, it can be concluded that the development length is between $805 \mathrm{~mm}$ and $545 \mathrm{~mm}$. 
Concrete gauges $\mathrm{C} 2$ and $\mathrm{C} 3$ initially experienced tensile strains, while gauge $\mathrm{C} 1$ initially experienced compressive strains. This indicates that the neutral axis is above gauges $\mathrm{C} 2$ and $\mathrm{C} 3$ but below gauge $\mathrm{C} 1$. Once the preformed crack continued to open and crushing of concrete on the compression face took place, the neutral axis moved down and gauge $\mathrm{C} 2$ began to experience compressive strains while gauge C3 broke (Figure 4-26).

Unlike the others beams that were tested under static loading, the beam containing $25 \mathrm{M}$ rebar had flexural cracking along its span. Figure 4-27 shows the cracking that occurred along the beam's length. Although cracking did occur in areas other than midspan, the majority of cracking still occurred at midspan. The width of the crack before testing was $5.13 \mathrm{~mm}$ and the width measured after testing was $23.8 \mathrm{~mm}$.

\subsubsection{Beam SB-25M-2}

Beam SB-25M-2 had 25M longitudinal reinforcement and was loaded at a rate of $18.7 \mathrm{kN}$ per minute. This load was distributed along the spreader beam to create a loading rate of $9.34 \mathrm{kN} / \mathrm{min}$ at the two point loads. The maximum capacity of the beam was 49.4 $\mathrm{kN}$ (Figure 4-28). The deflection at the midspan at this point was $29.1 \mathrm{~mm}$ and the deflection at the load point was $23.7 \mathrm{~mm}$ corresponding to a support rotation of $1.82^{\circ}$.

Once the beam reached its maximum capacity, the reinforcing steel began to yield and the beam continues to deflect without any increase in load. The residual displacements were $51.41 \mathrm{~mm}$ at midspan and $41.39 \mathrm{~mm}$ at the load point corresponding to a support rotation of $3.18^{\circ}$. 
Strains along the $25 \mathrm{M}$ reinforcement were also recorded and shown in Figure 4-29. Strain gauges 2,7 and 8 were detached during testing and are therefore not presented on Figure 4-29. Yielding of the steel occurred in the debonded region when the average strain readings in gauges 5 and 6 was $2450 \times 10^{-6}$.The strain profile along the bonded steel region was plotted at the point where the debonded steel reached yield and is shown in Figure 4-30. Although not all gauges were working in the bonded region on either side for this test, the strain profile in the steel should be fairly symmetrical on both sides of the debonded region. Therefore, where strain values were missing, the corresponding strain value from the opposite end of the beam was used to plot the strain profile. Similar to beam SB-25M-1 the development length is less than the bonded length of $830 \mathrm{~mm}$ and no slip was recorded. Again, the development length is between $805 \mathrm{~mm}$ and $545 \mathrm{~mm}$.

Concrete gauges behaved similarly to the static test on SB-25M-1. C2 and C3 initially experienced tensile strains, while gauge $\mathrm{C} 1$ initially experienced compressive strain. Gauge C3 broke after undergoing high tensile strain values and gauge C2 moved into compression (Figure 4-31). The compressive strains in gauges $\mathrm{C} 1$ and $\mathrm{C} 2$ are then reduced as the beam rebounds after reaching its maximum displacement.

Similar to the other $25 \mathrm{M}$ beam tested statically, the beam had cracking along its span. Figure 4-32 shows the cracking that occurred along the beam's length and spalling of the concrete cover at midspan on the loaded side of the beam. The width of the midspan crack before testing was $1.52 \mathrm{~mm}$ and the width measured after testing was 20.9 $\mathrm{mm}$. 
Table 4-10: Summary of Static Results

\begin{tabular}{|c|c|c|c|c|c|c|c|c|c|c|}
\hline & $\begin{array}{c}\text { Loading } \\
\text { rate } \\
(\mathrm{kN} / \mathrm{min})\end{array}$ & $\begin{array}{c}\text { Beam } \\
\text { Capacity } \\
(\mathbf{k N})\end{array}$ & $\begin{array}{c}\text { Midspan } \\
\text { Deflec- } \\
\text { tion at } \\
\text { Capacity } \\
\text { (mm) }\end{array}$ & $\begin{array}{c}\text { Load } \\
\text { Point } \\
\text { Deflect- } \\
\text { ion at } \\
\text { Capacity } \\
\text { (mm) }\end{array}$ & $\begin{array}{c}\text { Support } \\
\text { Rotation } \\
\text { at } \\
\text { Capacity } \\
\left({ }^{\circ}\right)\end{array}$ & $\begin{array}{c}\text { Residual } \\
\text { Midspan } \\
\text { Deflec- } \\
\text { tion } \\
(\mathbf{m m})\end{array}$ & $\begin{array}{c}\text { Residual } \\
\text { Load } \\
\text { Point } \\
\text { Deflec- } \\
\text { tion } \\
(\mathrm{mm})\end{array}$ & $\begin{array}{c}\text { Residual } \\
\text { Support } \\
\text { Rotation } \\
\left(^{\circ}\right)\end{array}$ & $\begin{array}{c}\text { Width of } \\
\text { Preformed } \\
\text { Crack } \\
\text { Before } \\
\text { Testing } \\
\text { (mm) }\end{array}$ & $\begin{array}{c}\text { Width of } \\
\text { Preformed } \\
\text { Crack } \\
\text { After } \\
\text { Testing } \\
\text { (mm) }\end{array}$ \\
\hline SB-15M-1 & 19.4 & 22.8 & 27.1 & 18.4 & 1.41 & 148.0 & 99.1 & 7.58 & 6.2 & 37.2 \\
\hline SB-15M-2 & 18.7 & 20.2 & 32.7 & 22.1 & 1.70 & 143.0 & 96.6 & 7.39 & 5.2 & 37.6 \\
\hline Avg. & 19.1 & 21.5 & 29.9 & 20.3 & 1.56 & 145.5 & 97.9 & 7.49 & 5.7 & 37.4 \\
\hline SB-20M-1 & 13.2 & 26.9 & 34.8 & 23.6 & 1.81 & 159.9 & 115.7 & 8.83 & 3.9 & 47.2 \\
\hline SB-20M-2 & 18.7 & 28.0 & 38.0 & 28.3 & 2.18 & 114.9 & 85.4 & 6.54 & 20.3 & 35.0 \\
\hline Avg. & 16.0 & 27.4 & 36.4 & 26.0 & 2.00 & 137.4 & 100.5 & 7.68 & 12.1 & 41.2 \\
\hline SB-25M-1 & 20.2 & 47.0 & 46.5 & 35.6 & 2.74 & 81.5 & 62.9 & 4.83 & 5.1 & 23.8 \\
\hline SB-25M-2 & 18.7 & 49.4 & 29.1 & 23.7 & 1.82 & 51.4 & 41.4 & 3.18 & 1.5 & 20.9 \\
\hline Avg. & 19.5 & 48.2 & 37.8 & 29.6 & 2.28 & 66.5 & 52.2 & 4.01 & 3.3 & 22.3 \\
\hline
\end{tabular}




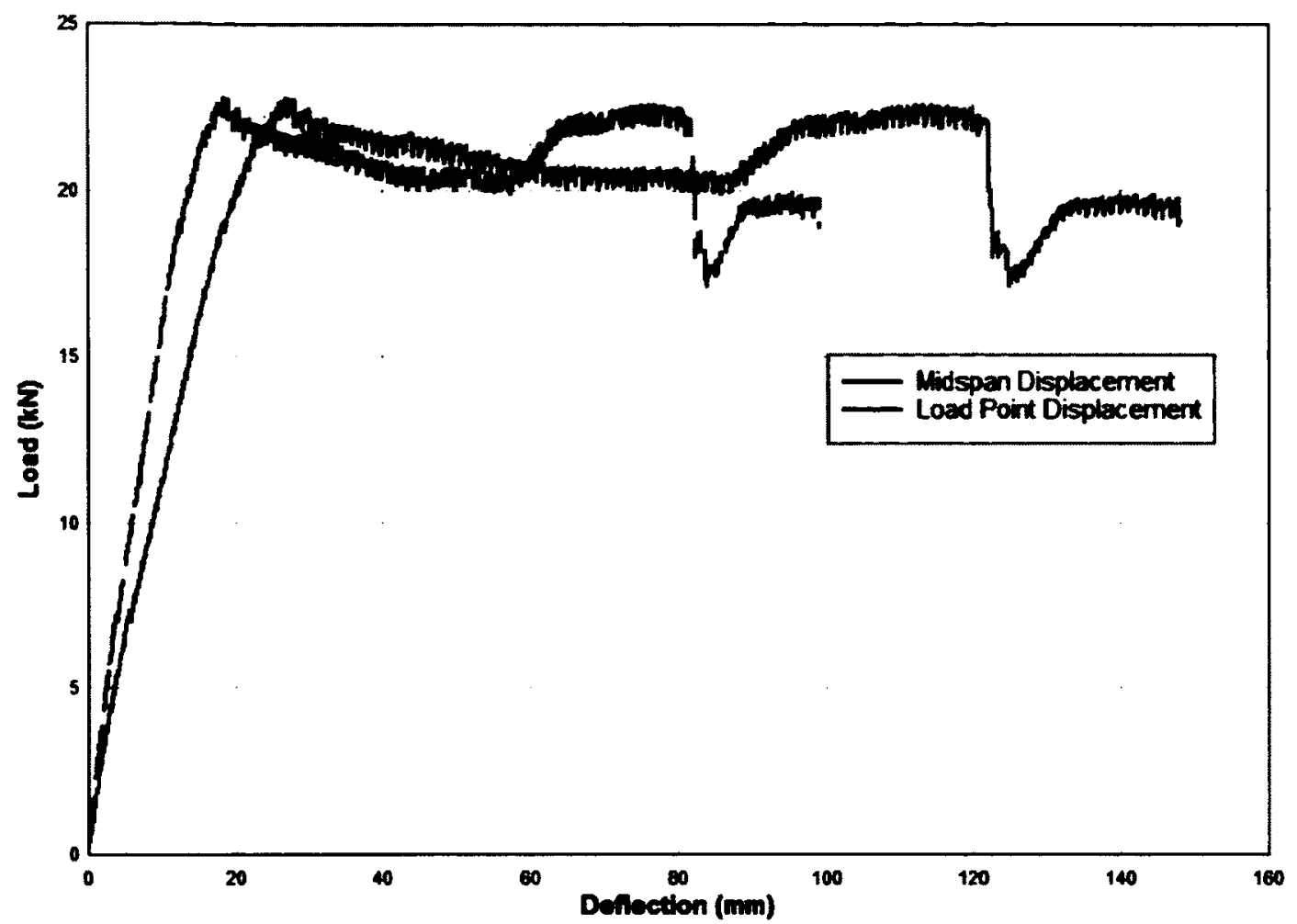

Figure 4-4: Load vs. Deflection of Beam SB-15M-1

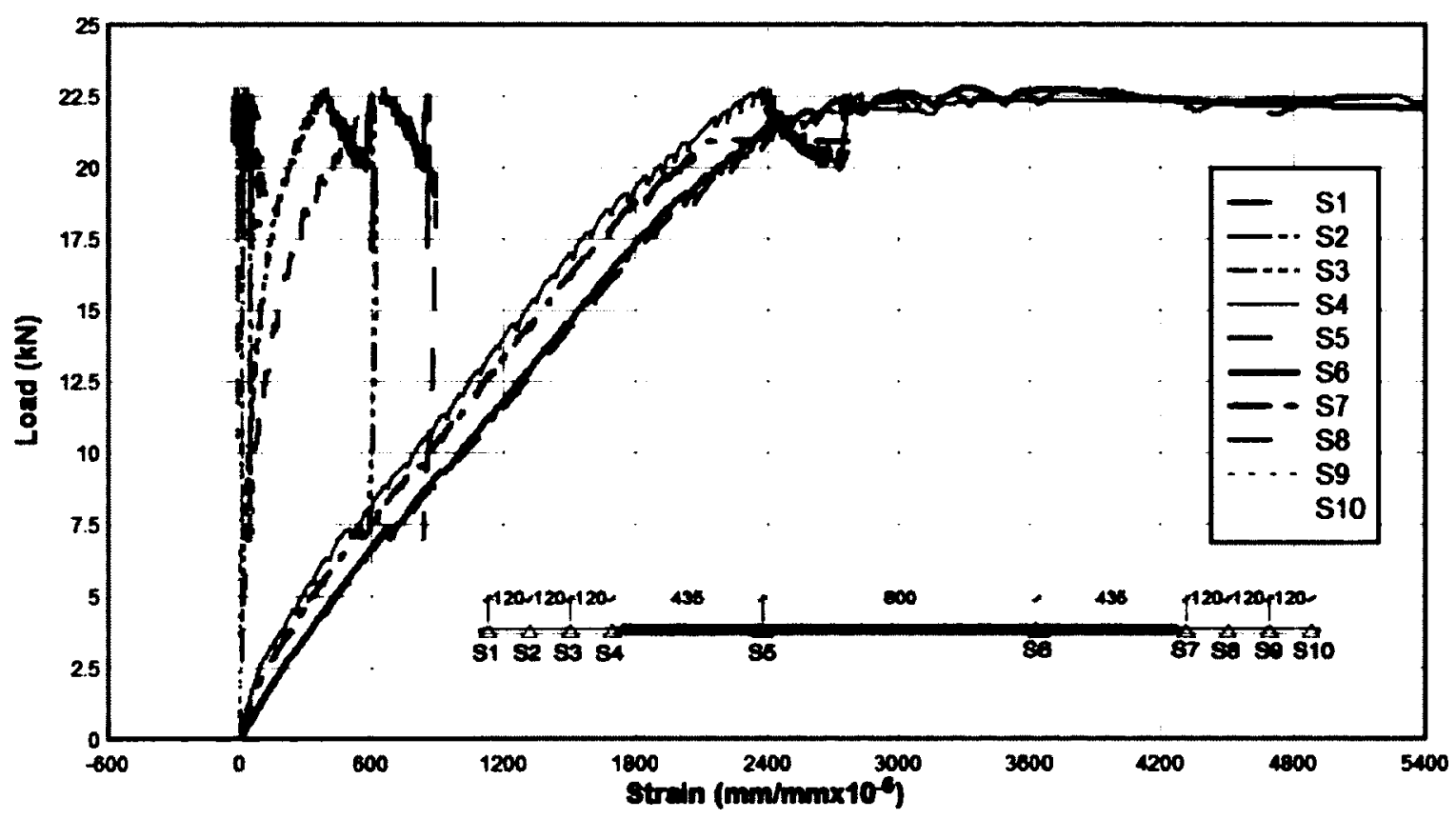

Figure 4-5: Steel Strains in Beam SB-15M-1 


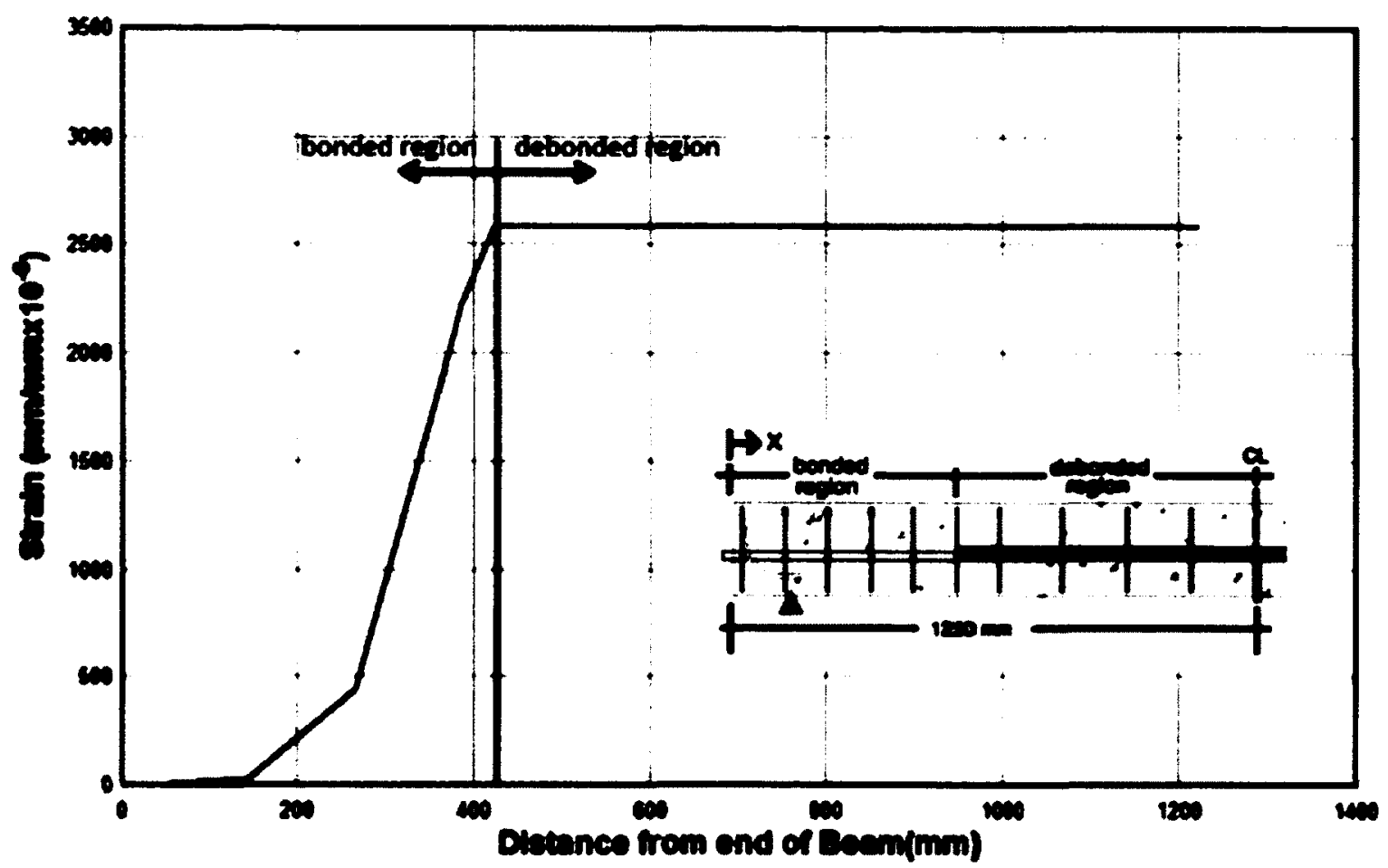

Figure 4-6: Strain Profile at Yield in Beam SB-15M-1

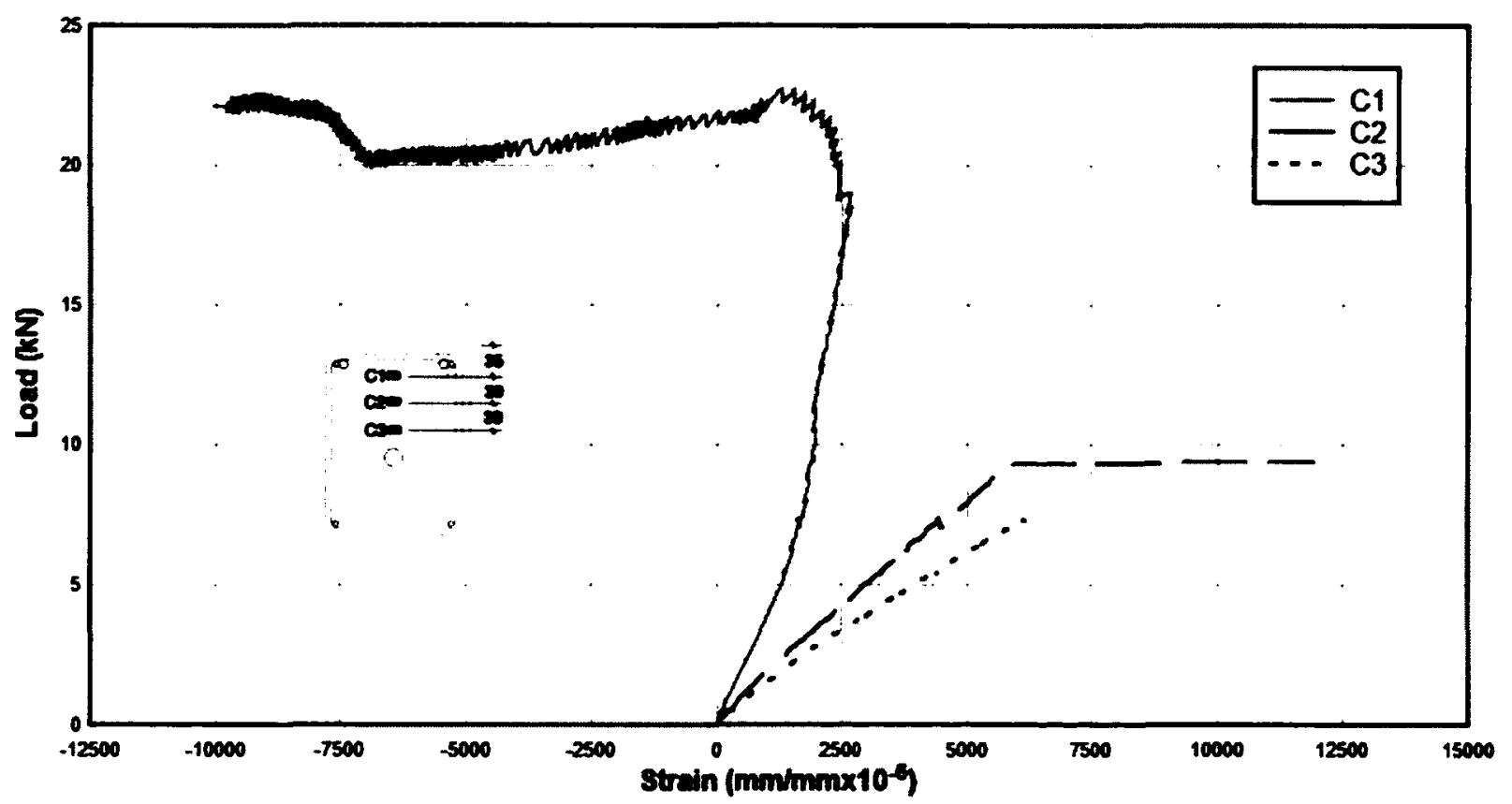

Figure 4-7: Concrete Strains in Beam SB-15M-1 


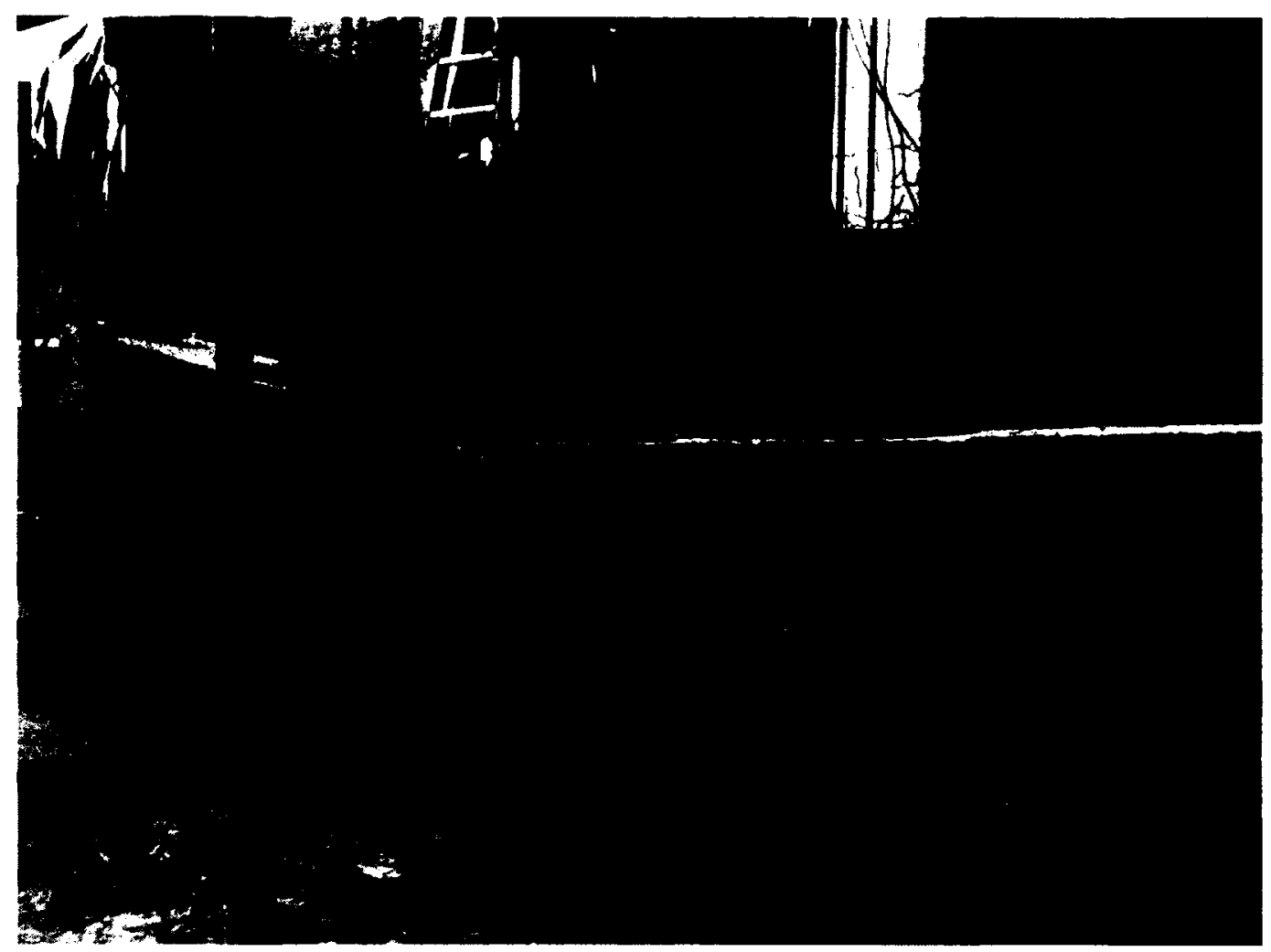

Figure 4-8: Beam SB-15M-1 After Loading

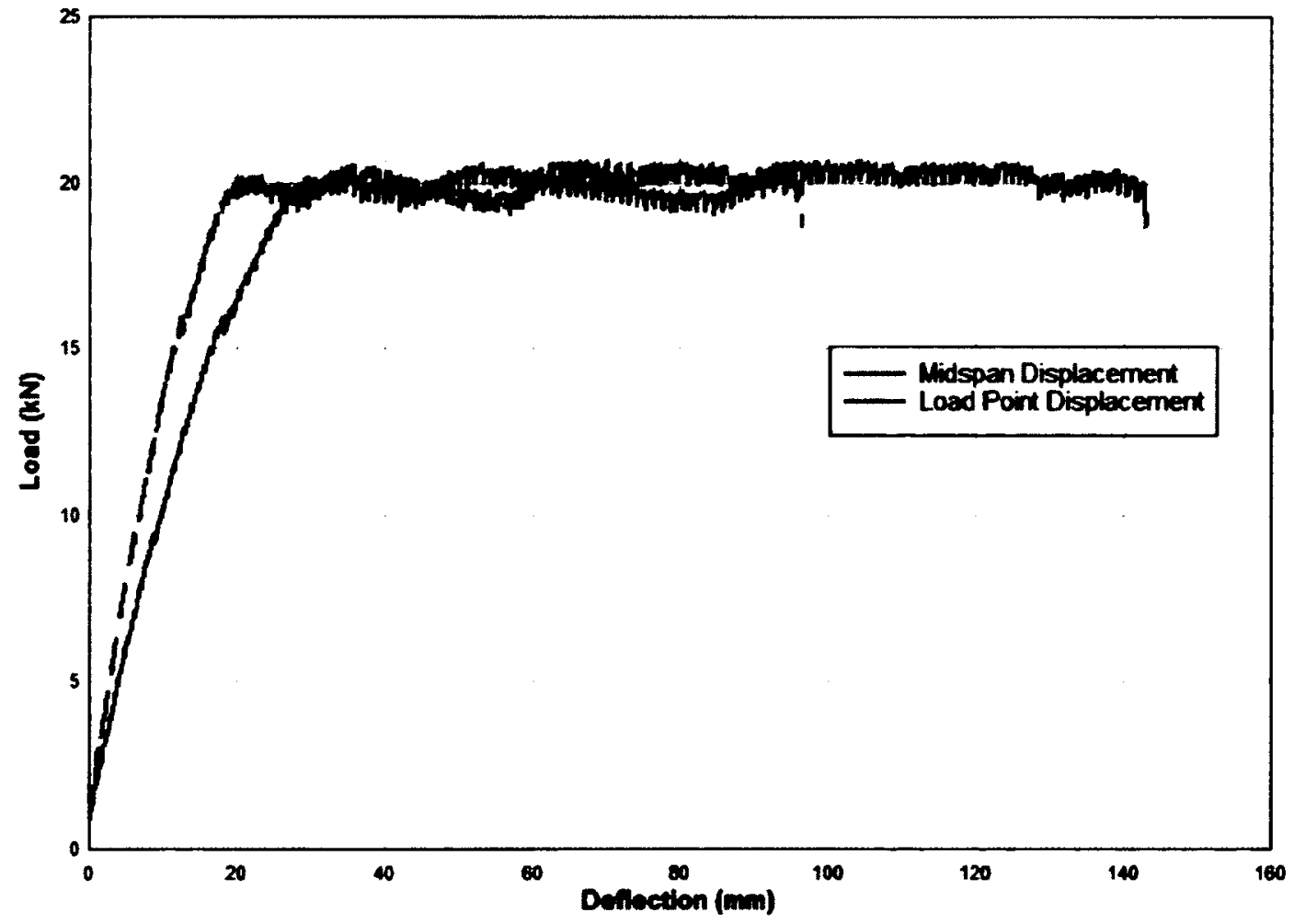

Figure 4-9: Load vs. Deflection of Beam SB-15M-2 


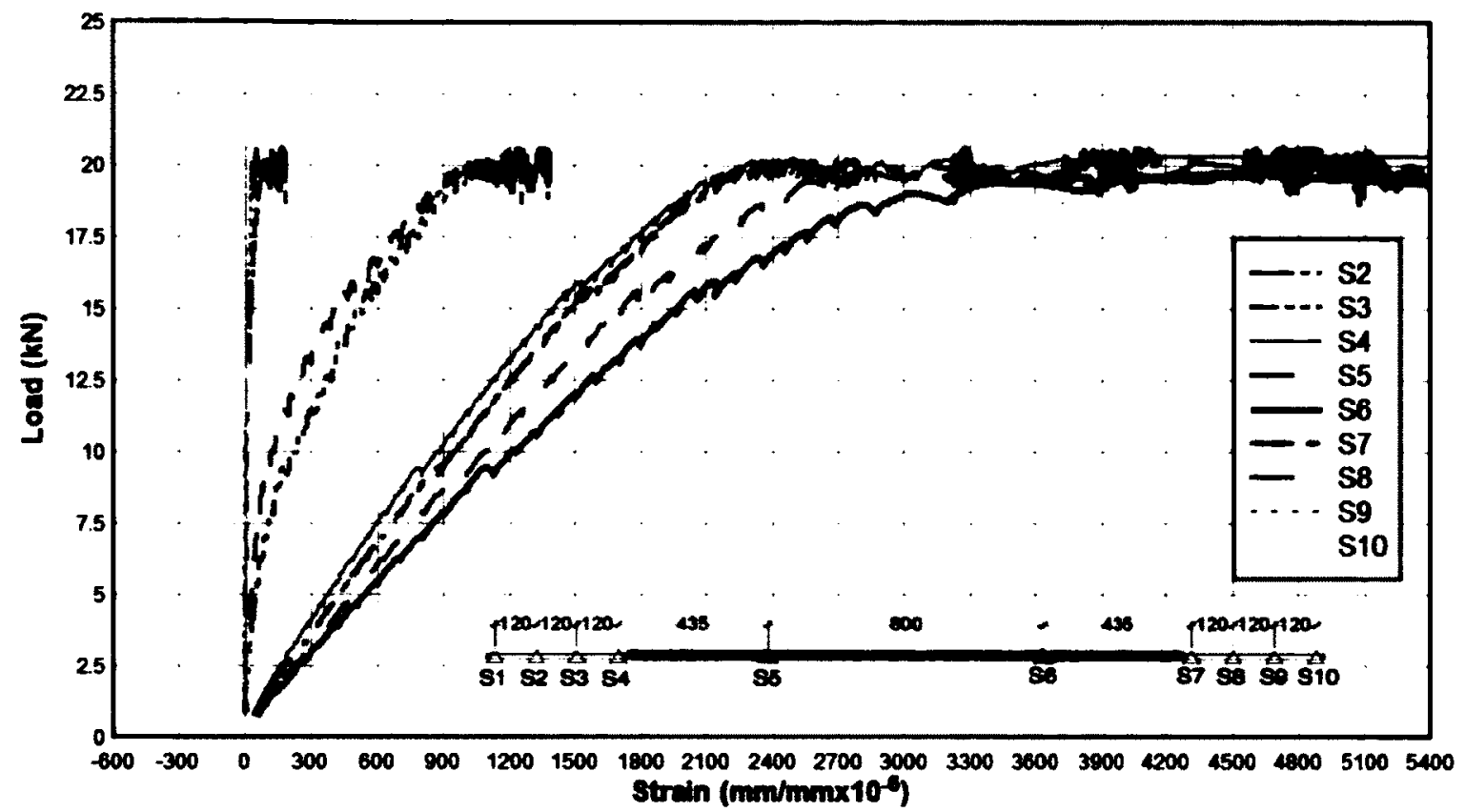

Figure 4-10: Strains in Beam SB-15M-2

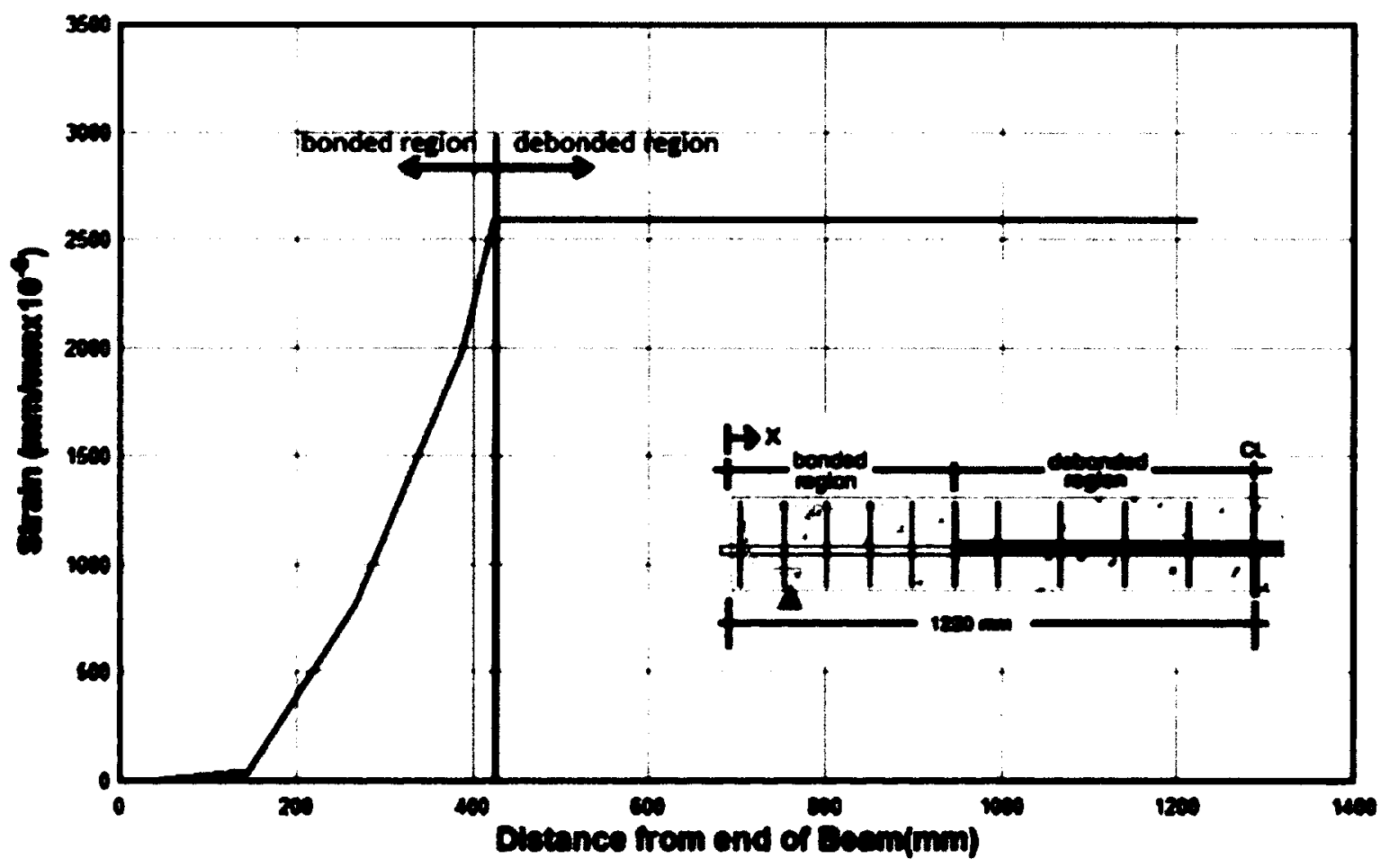

Figure 4-11: Strain Profile at Yield in Beam SB-15M-2 


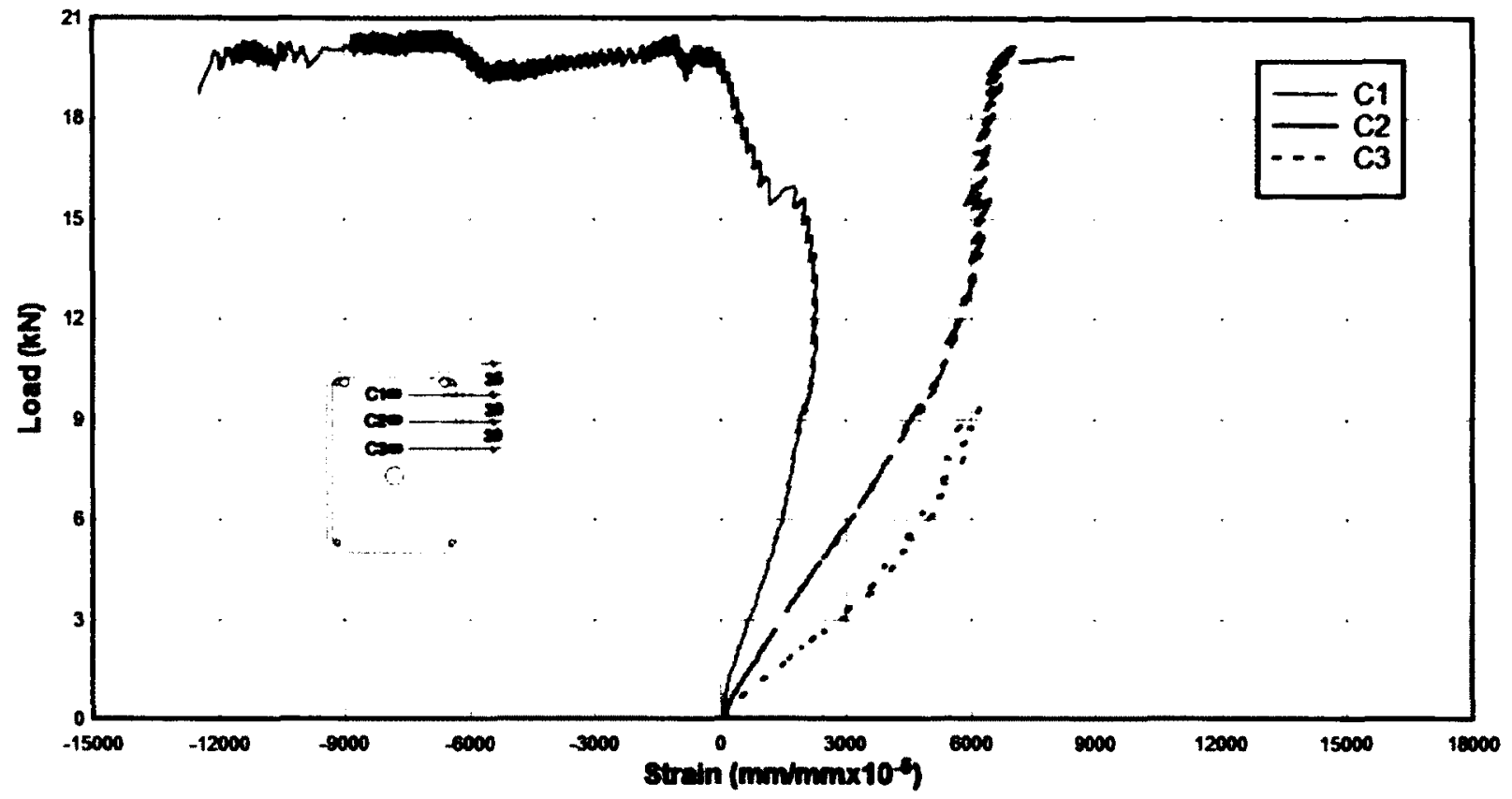

Figure 4-12: Concrete Strains in Beam SB-15M-2

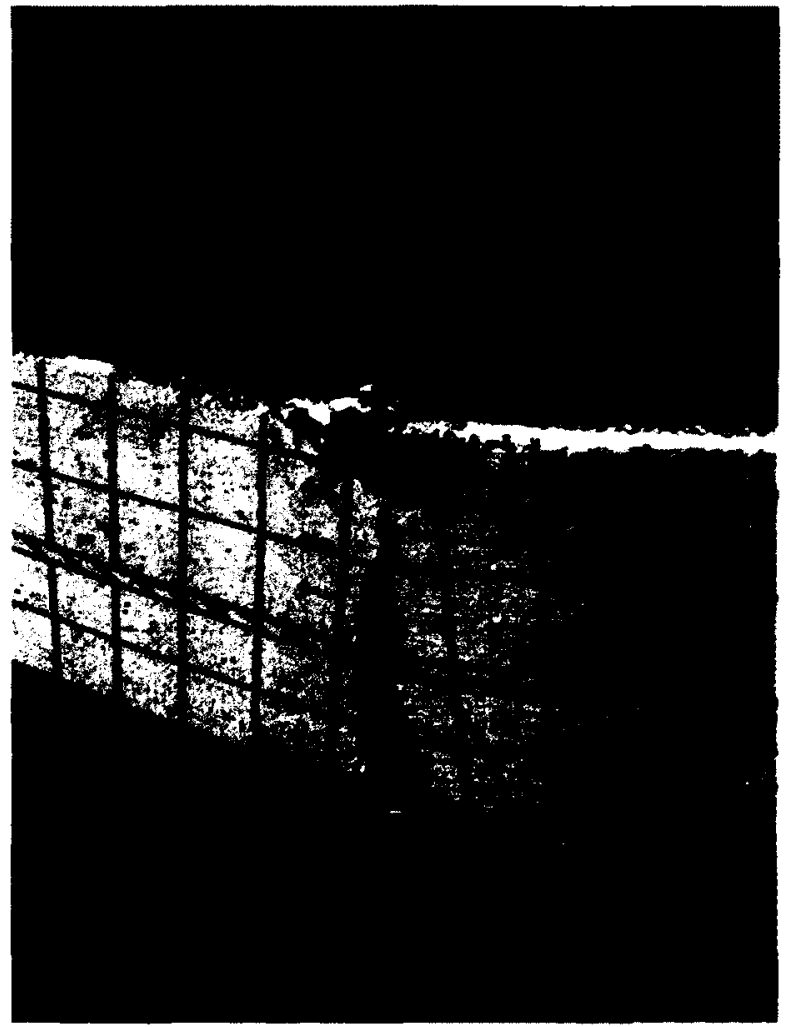

Figure 4-13: Beam SB-15M-2 After Loading 


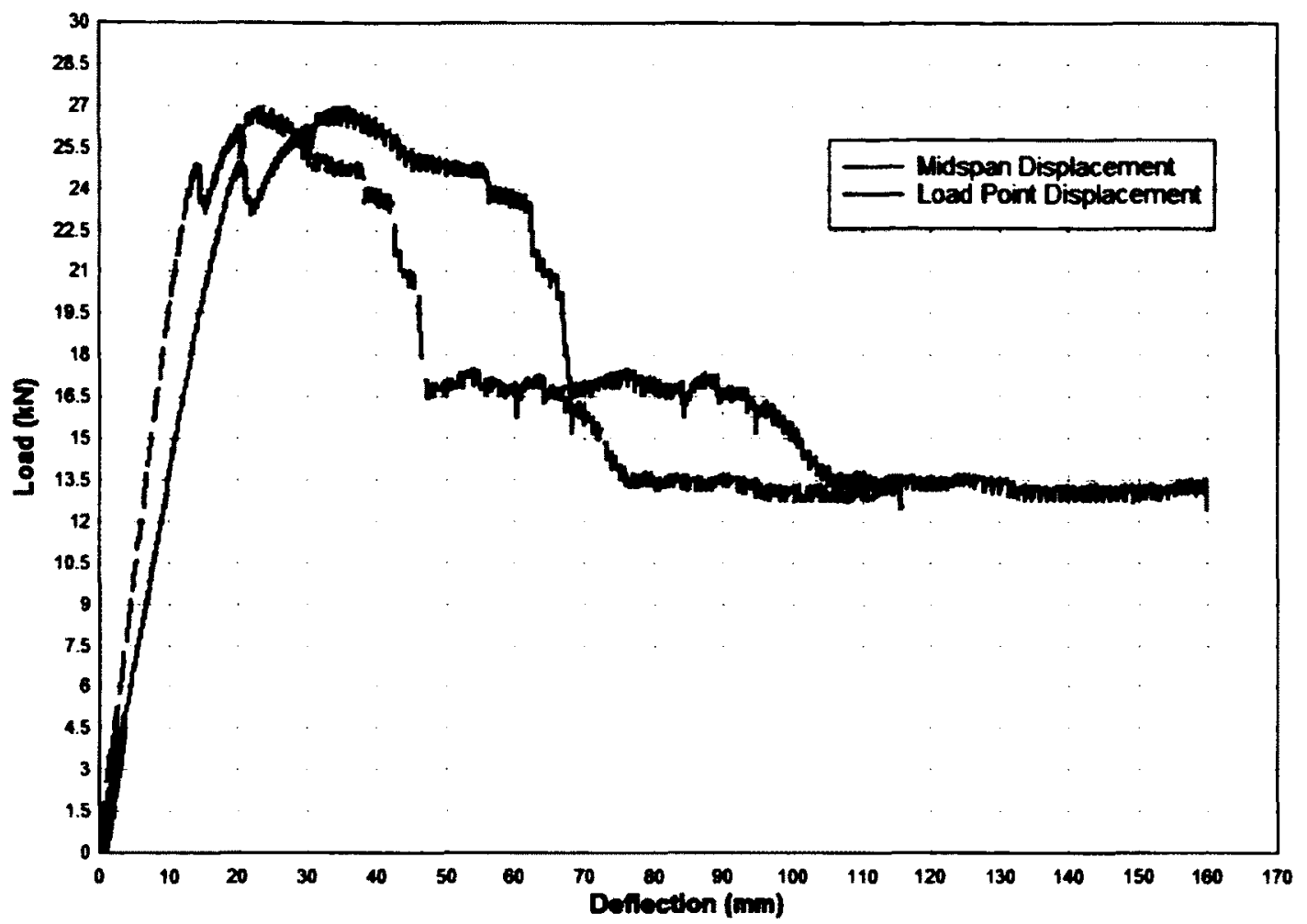

Figure 4-14: Load vs. Deflection of Beam SB-20M-1

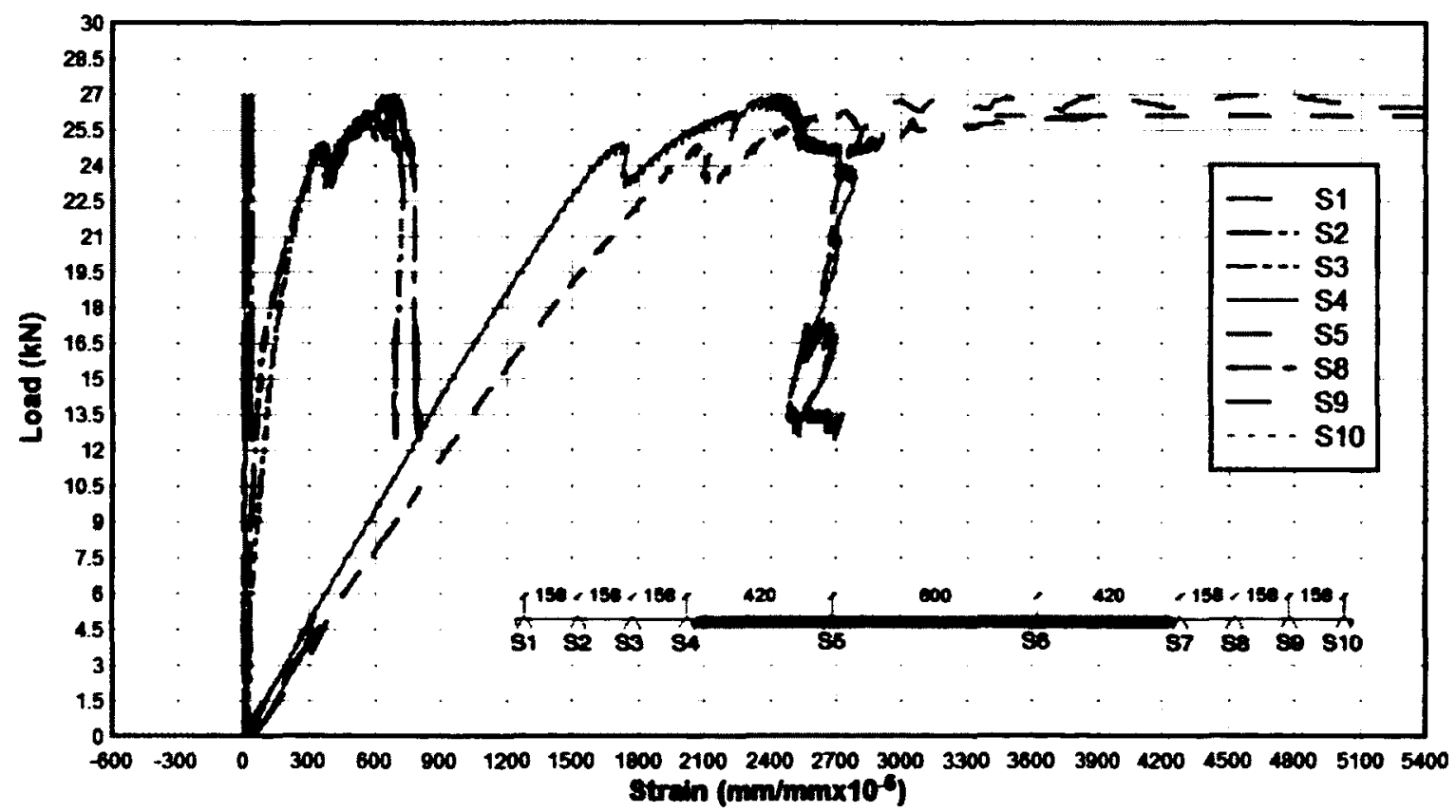

Figure 4-15: Strains in Beam SB-20M-1 


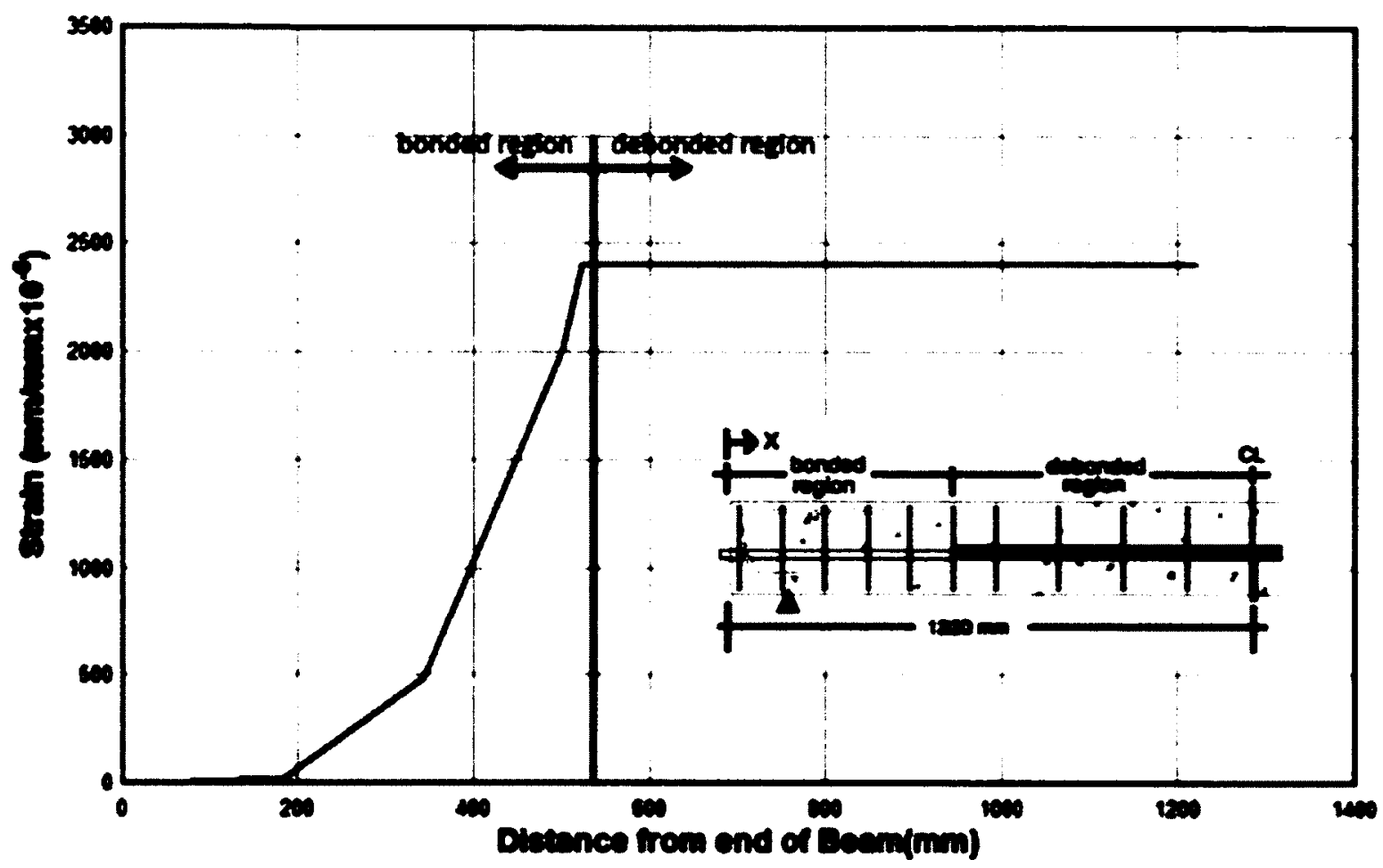

Figure 4-16: Strain Profile at Yield in Beam SB-20M-1

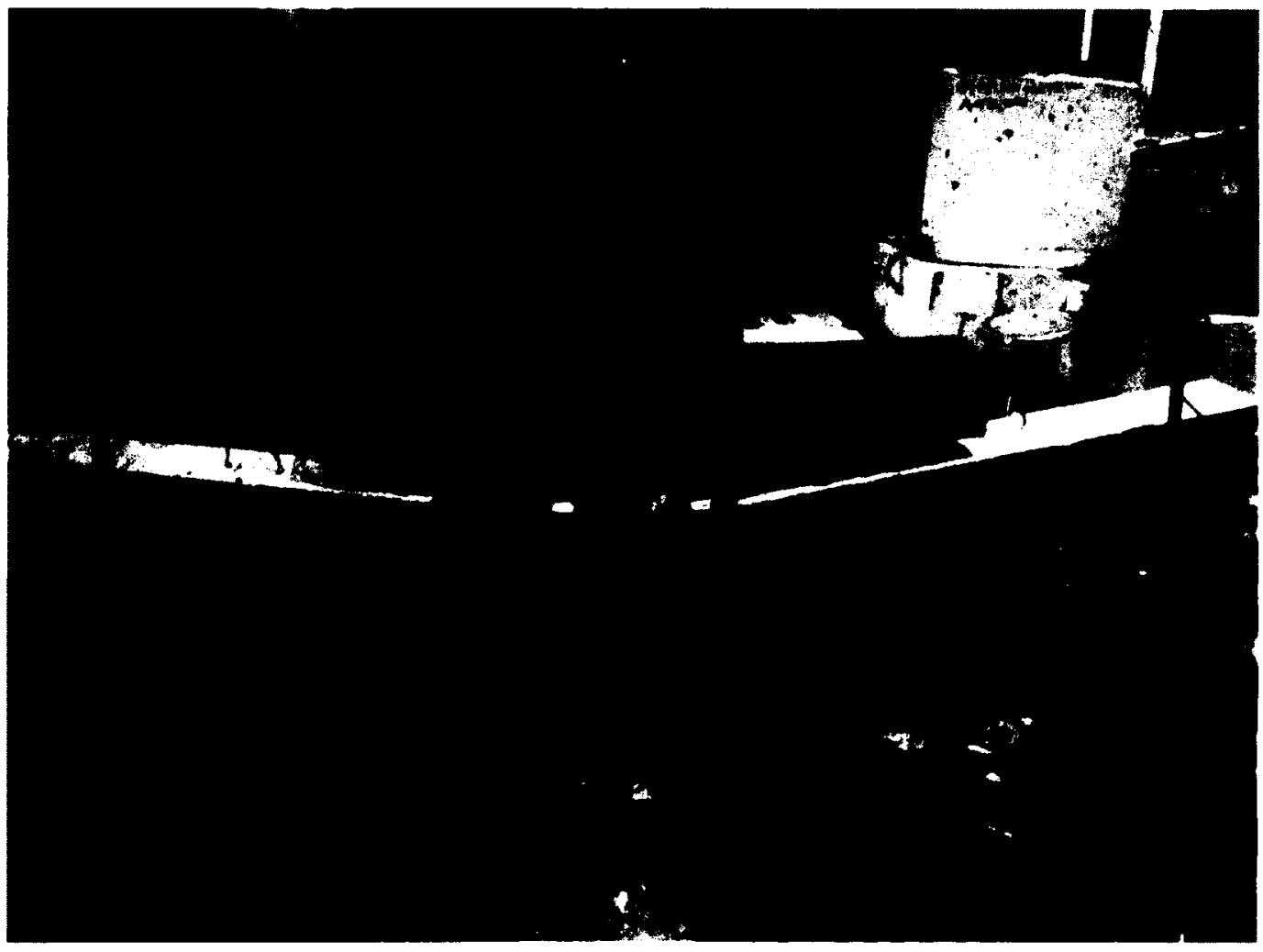

Figure 4-17: Beam SB-20M-1 After Loading 


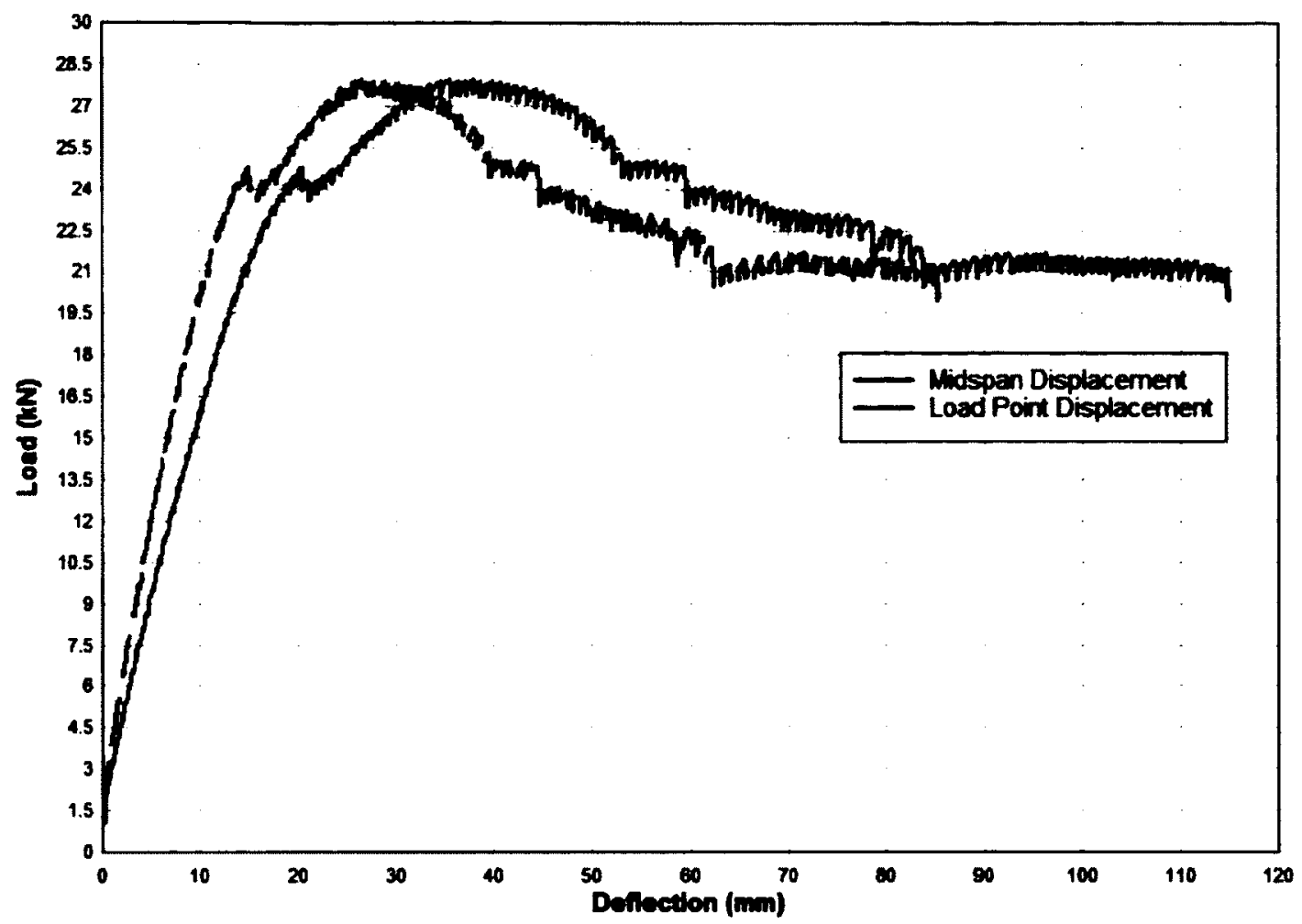

Figure 4-18: Load vs. Deflection of Beam SB-20M-2

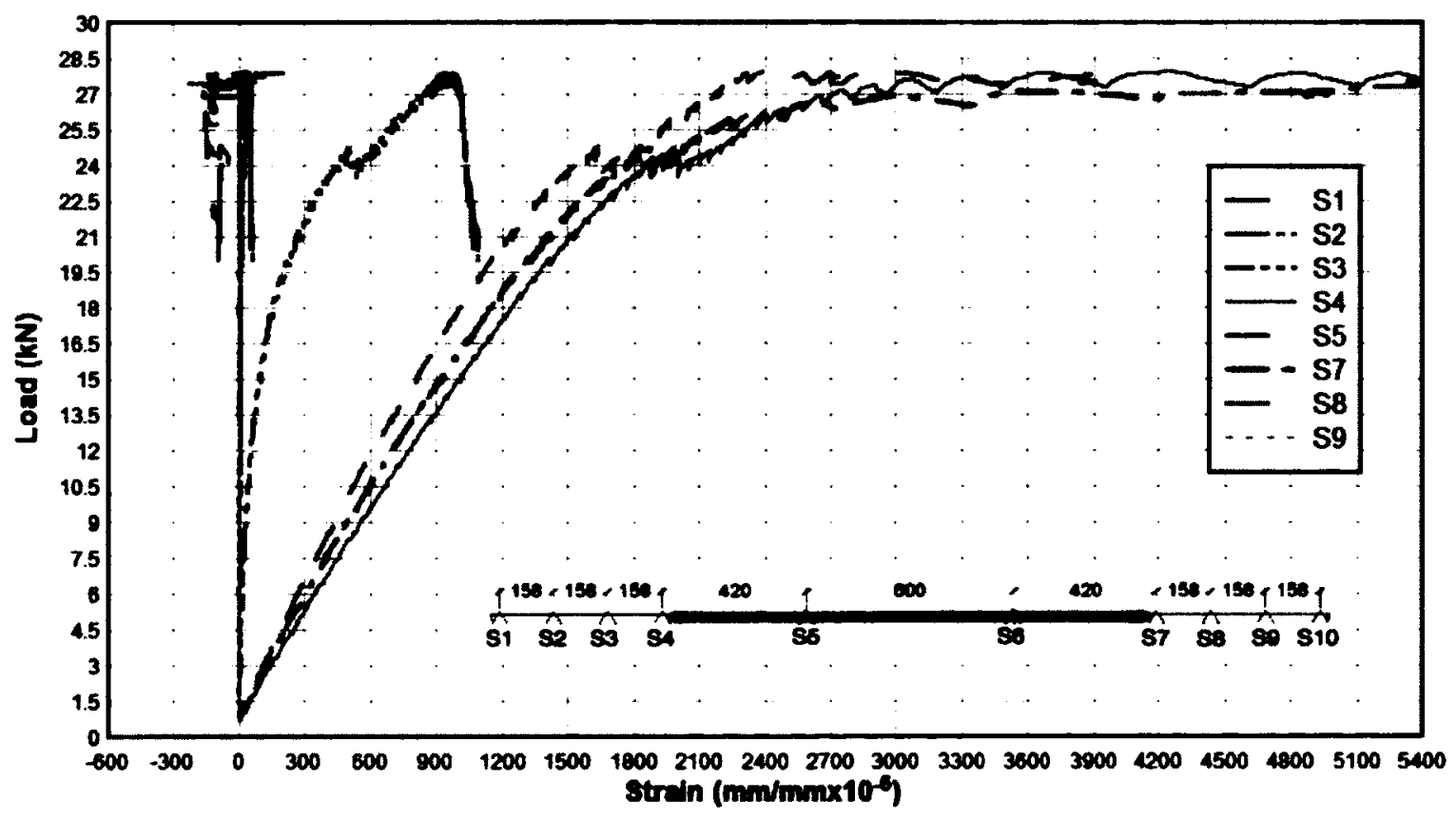

Figure 4-19: Strains in Beam SB-20M-2 


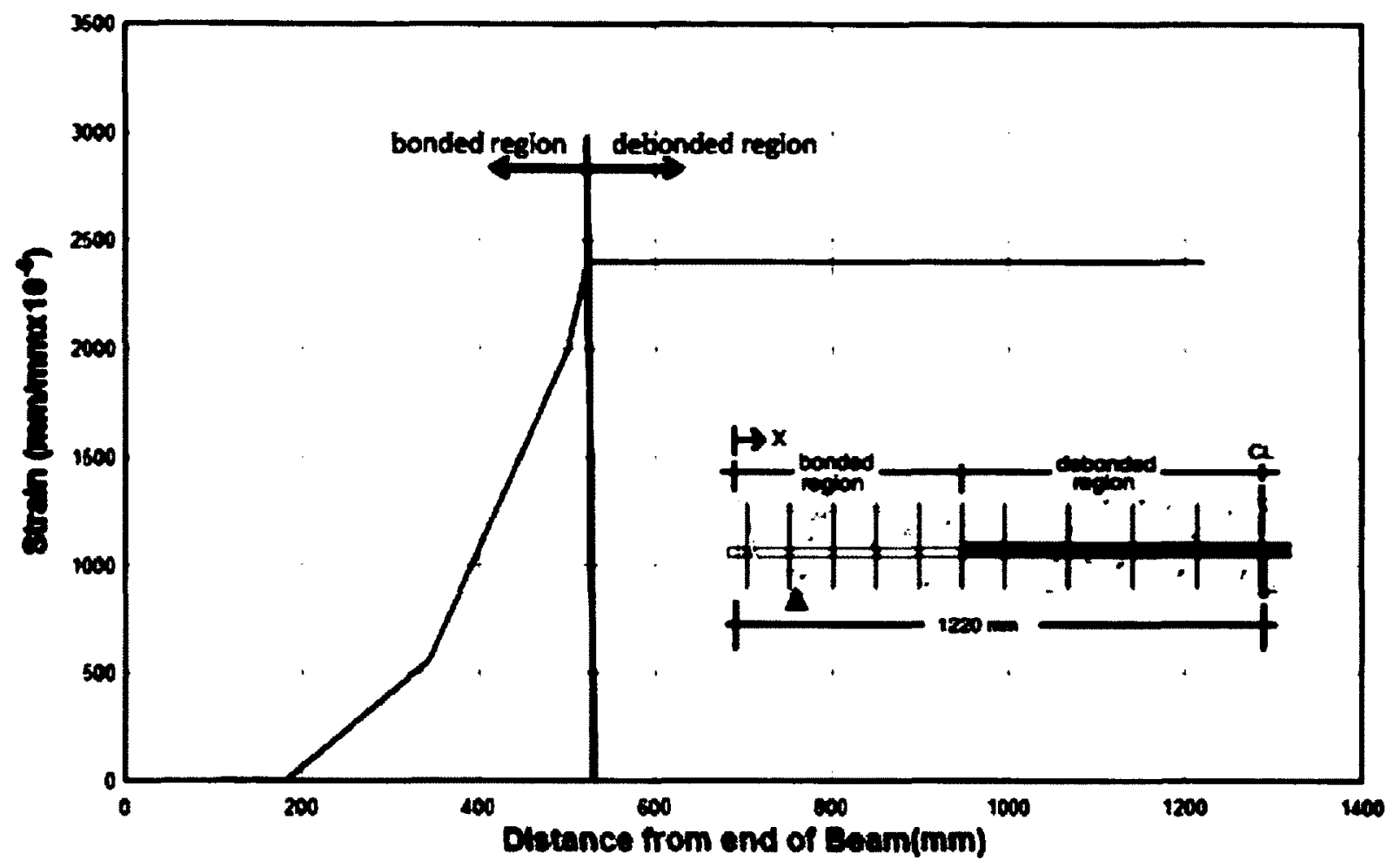

Figure 4-20: Strain Profile at Yield in Beam SB-20M-2

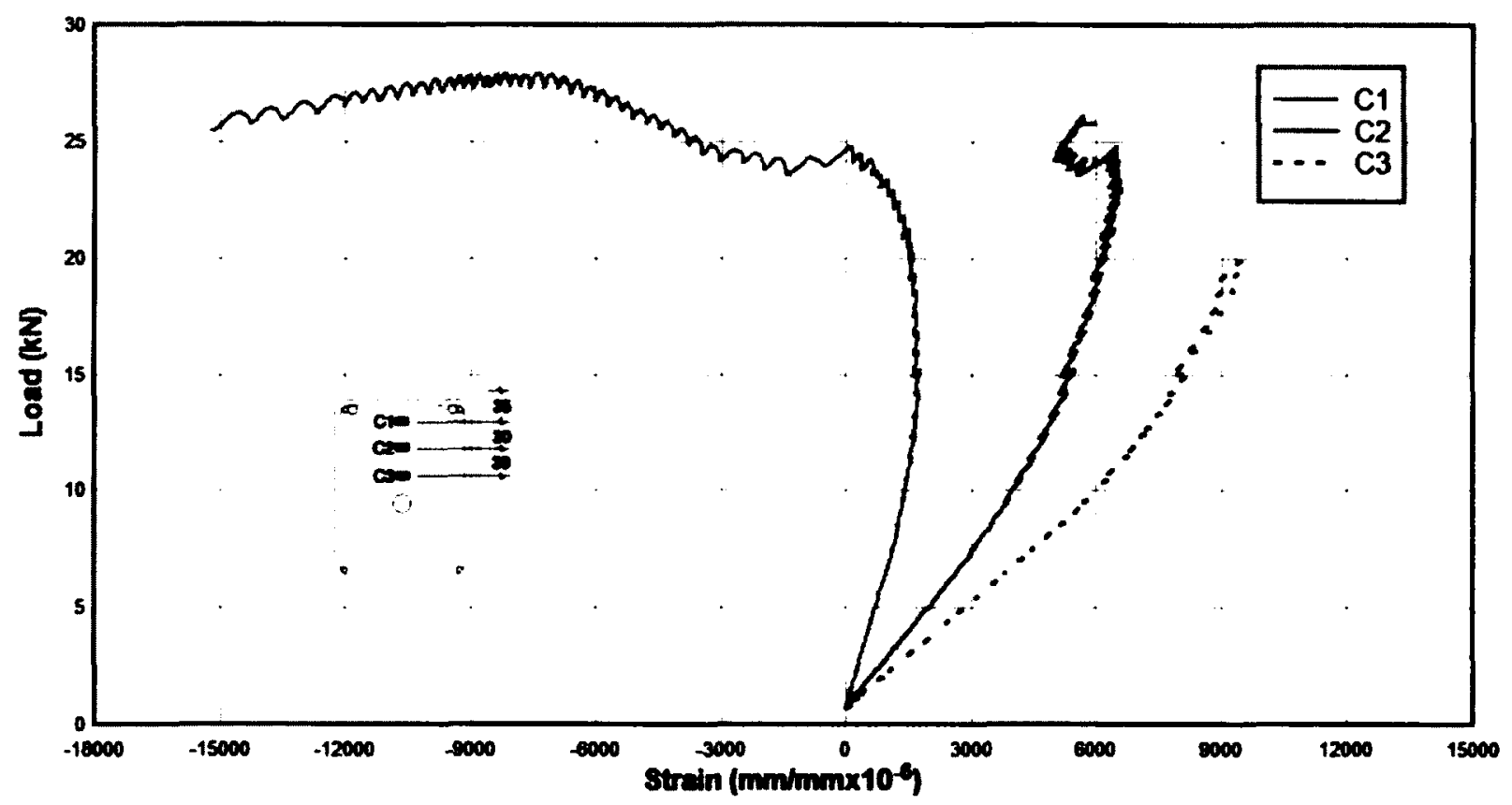

Figure 4-21: Concrete Strains in Beam SB-20M-2 


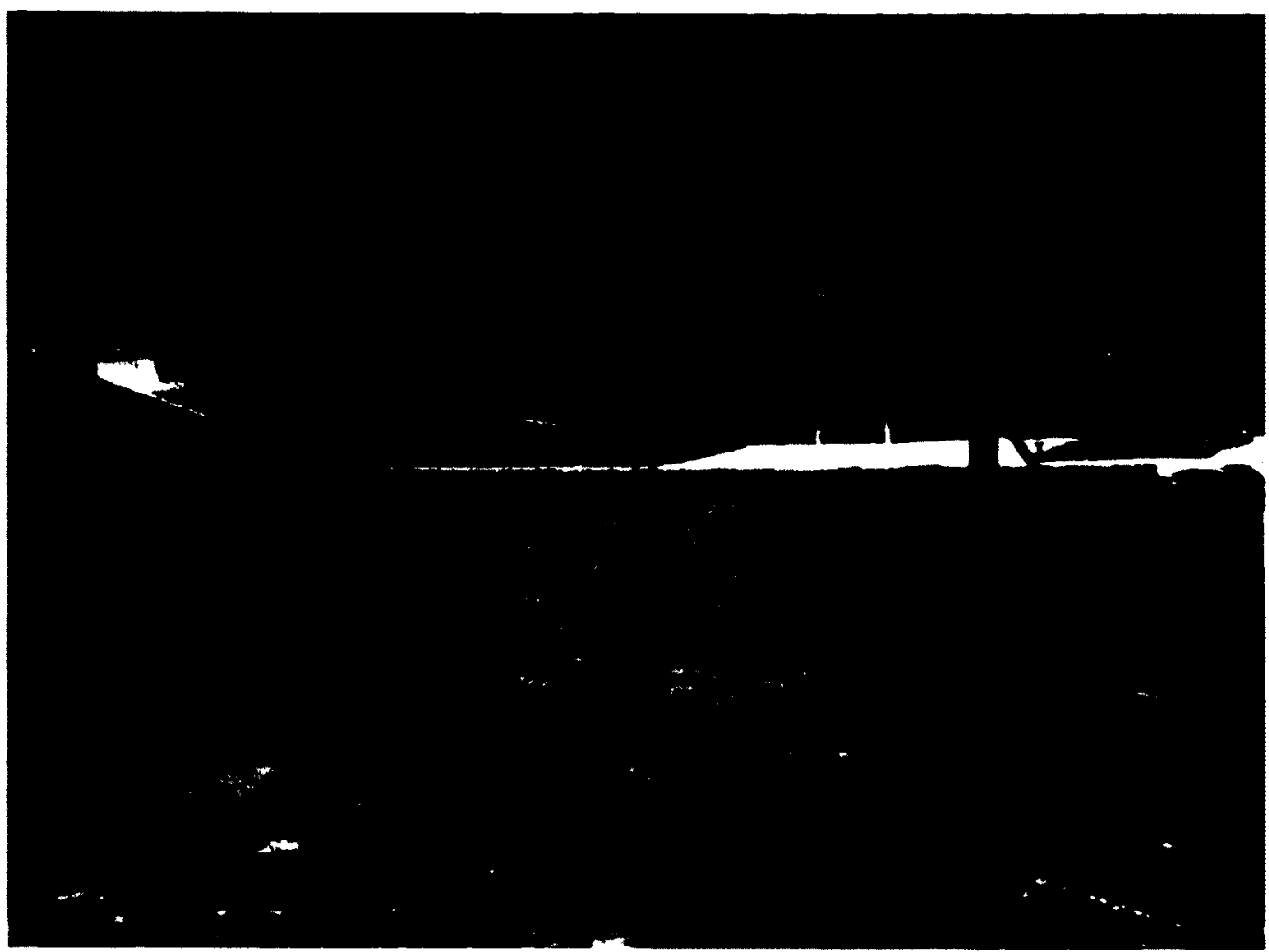

Figure 4-22: Beam SB-20M-2 After Loading

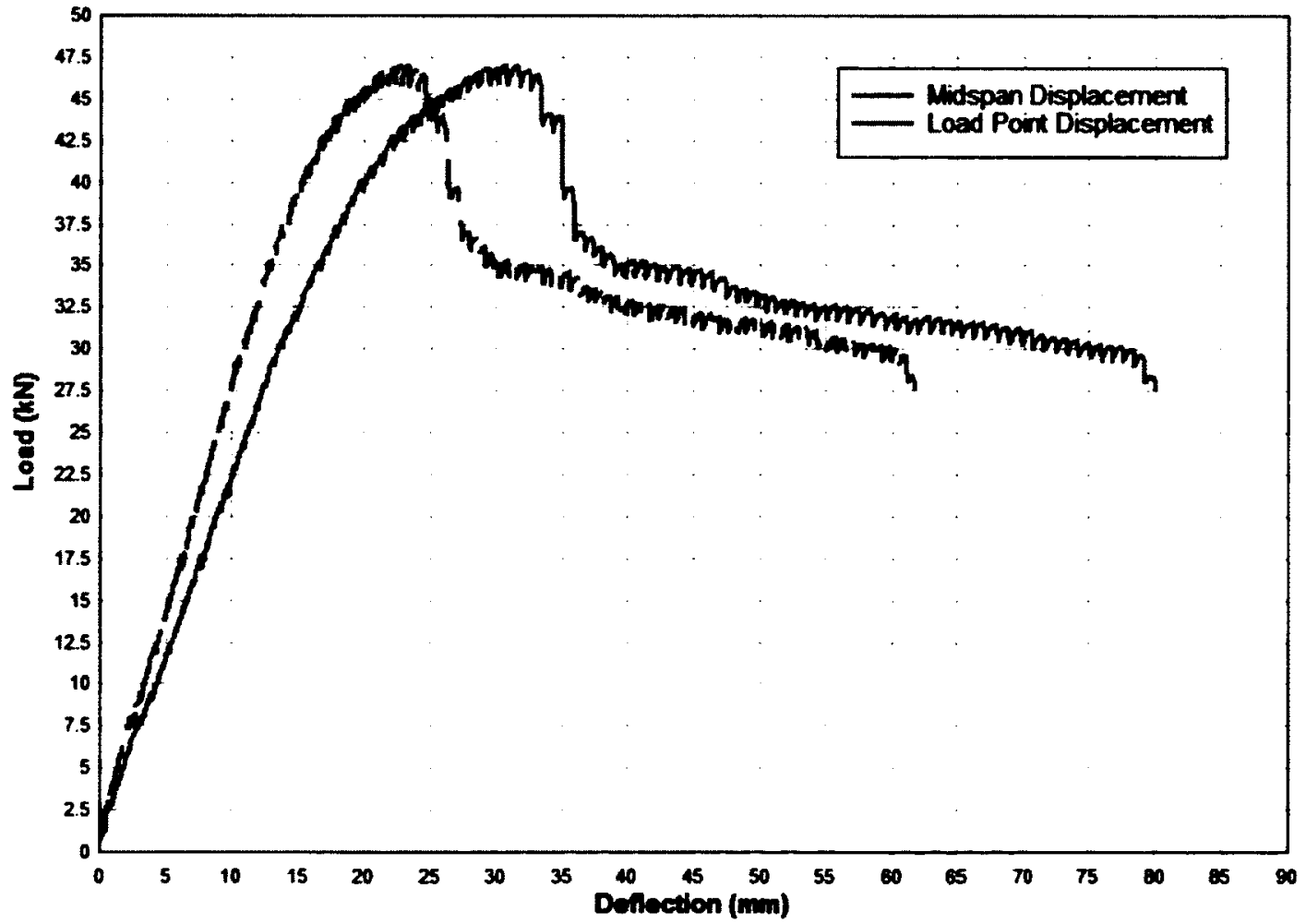

Figure 4-23: Load vs. Deflection of Beam SB-20M-2 


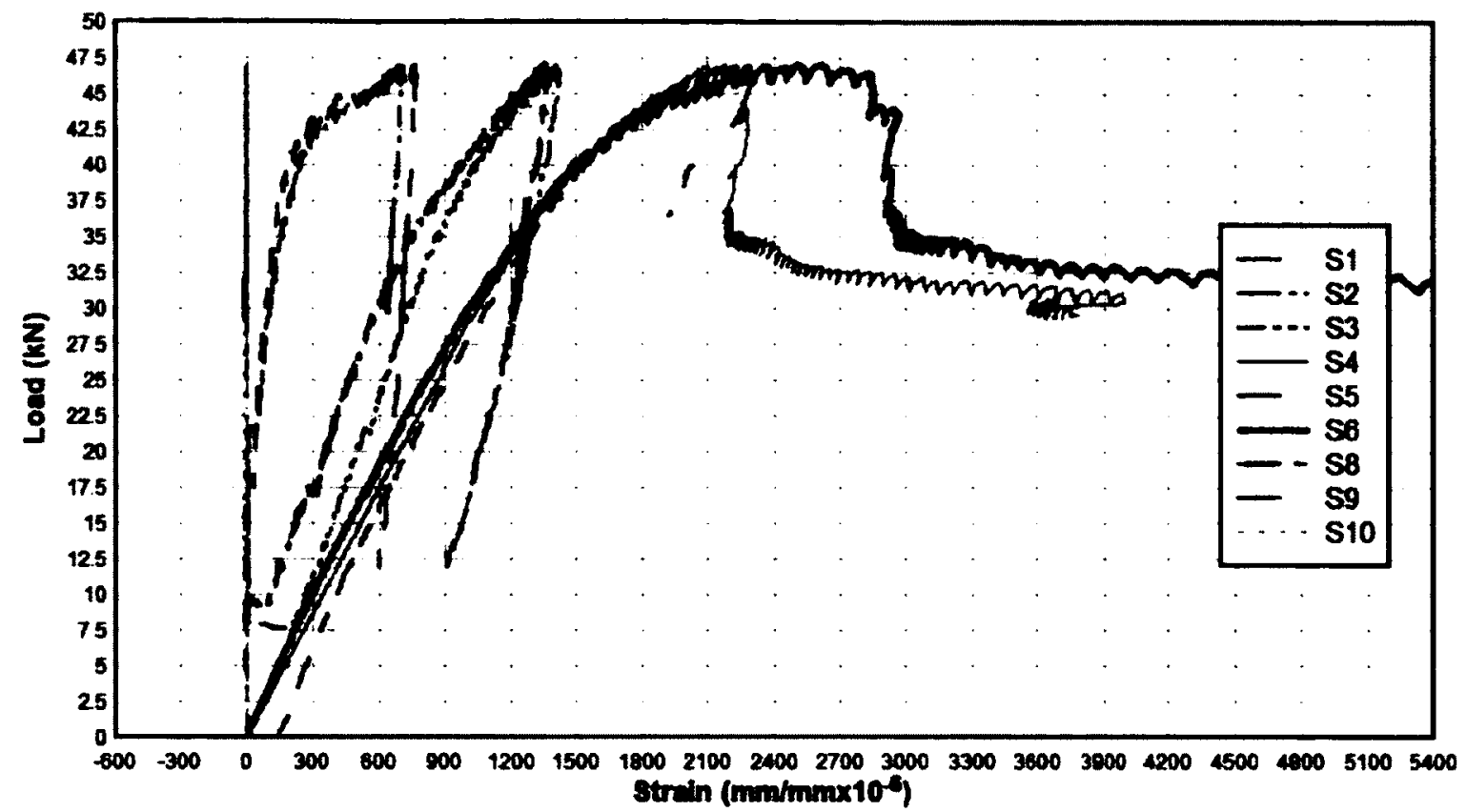

Figure 4-24: Strains in Beam SB-25M-1

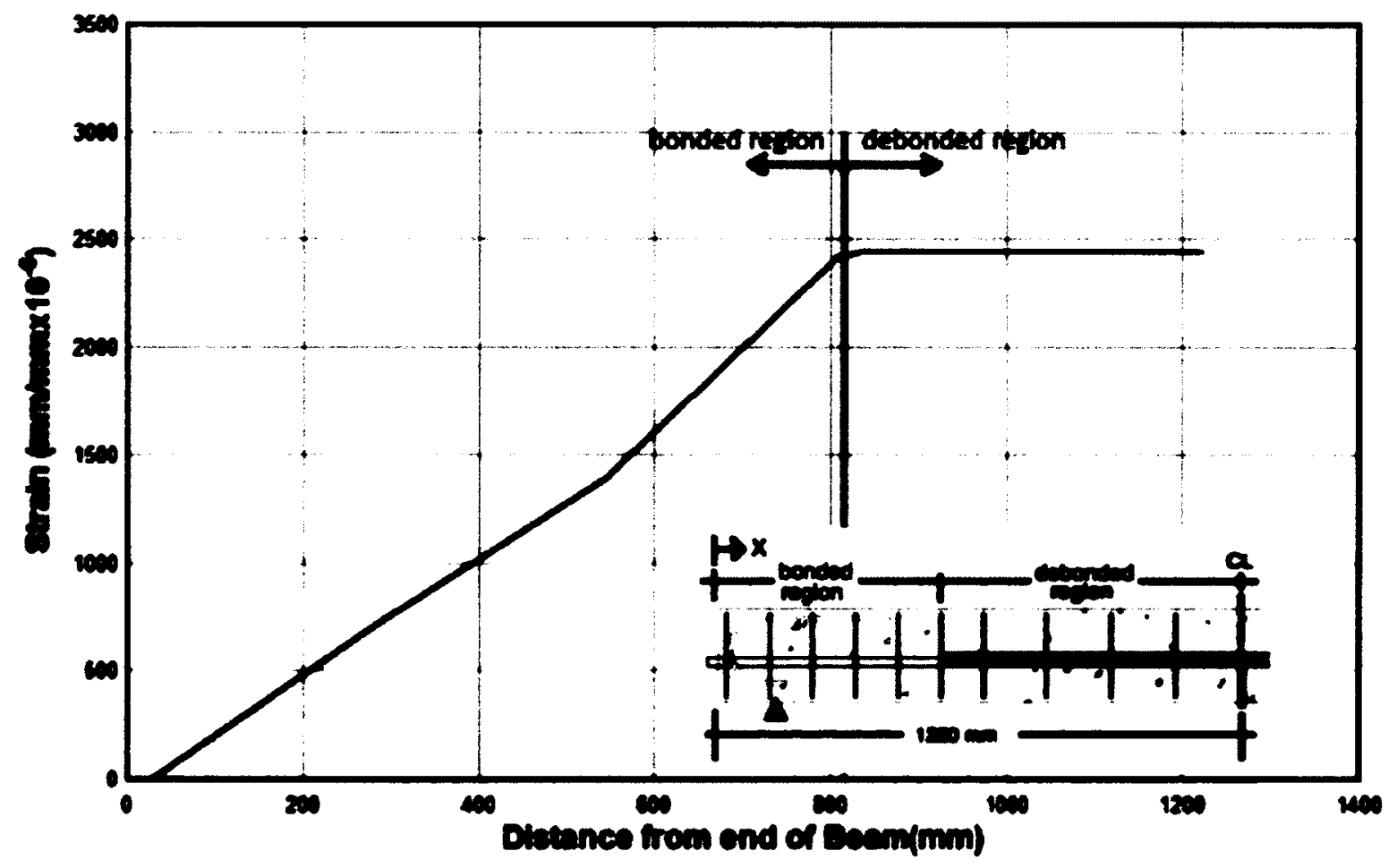

Figure 4-25: Strain Profile at Yield in Beam SB-25M-1 


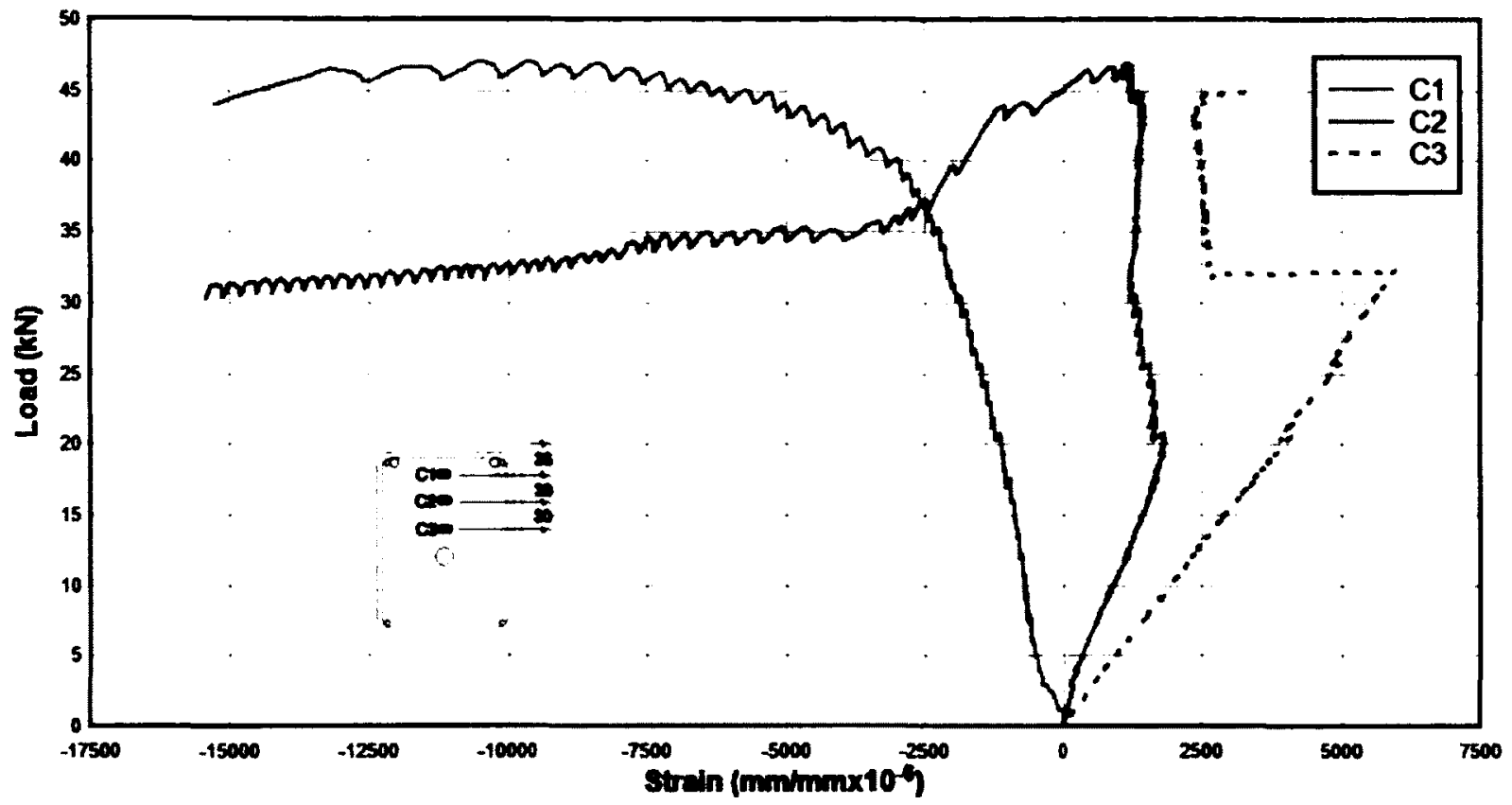

Figure 4-26: Concrete Strains in Beam SB-25M-1

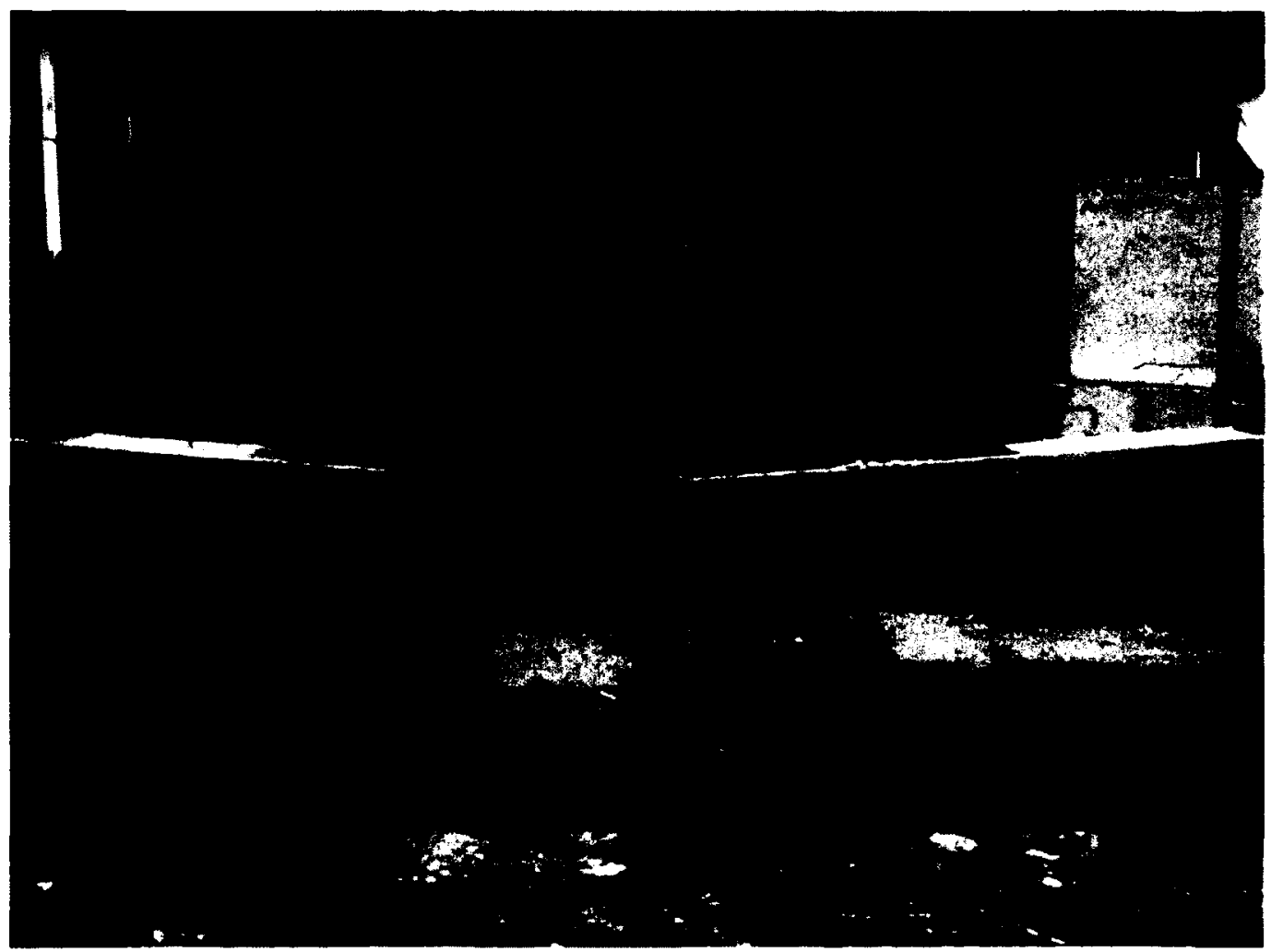

Figure 4-27: Beam SB-25M-1 After Loading 


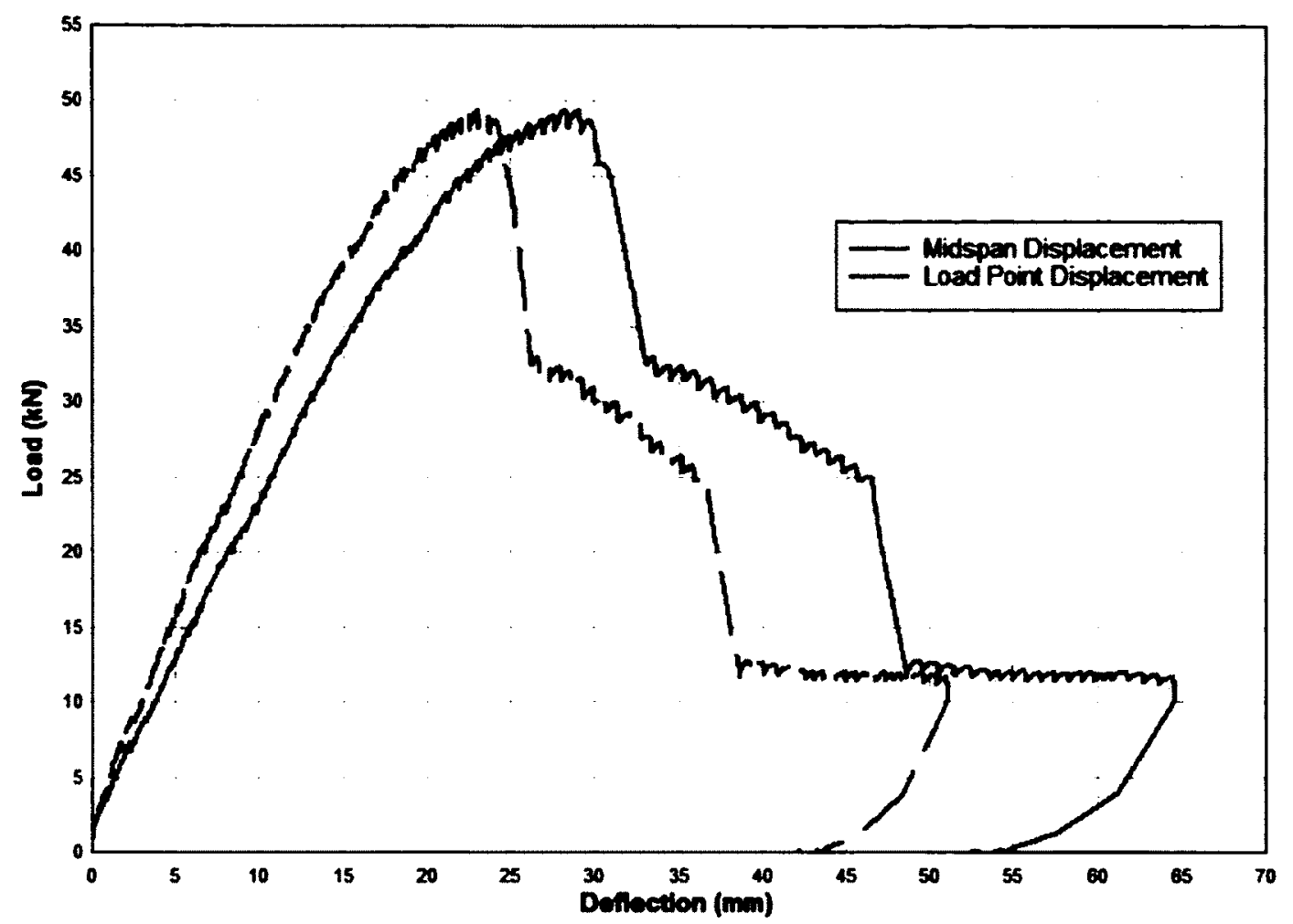

Figure 4-28: Load vs. Deflection of Beam SB-25M-2

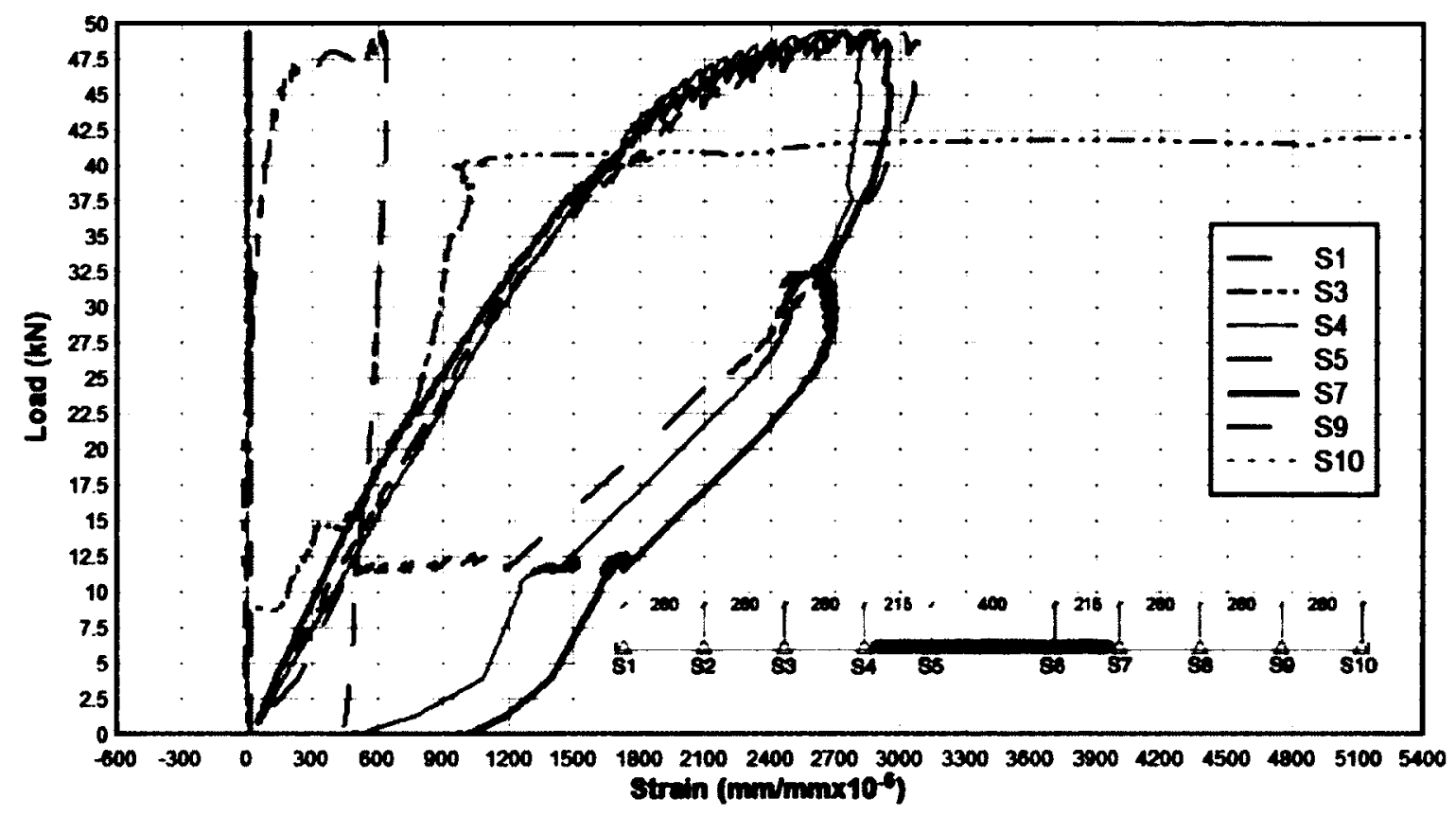

Figure 4-29: Strains in Beam SB-25M-2 


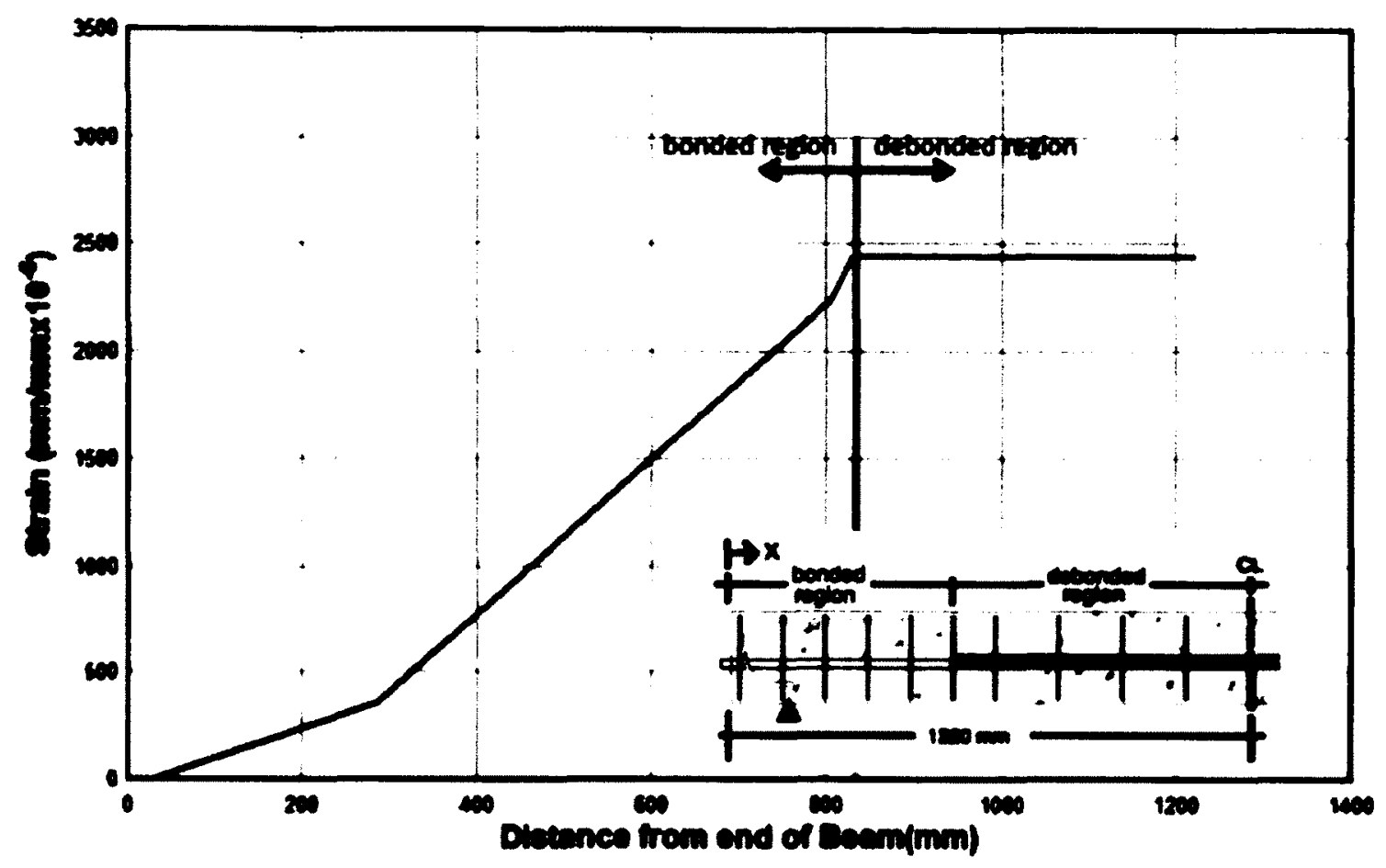

Figure 4-30: Strain Profile at Yield in Beam SB-25M-2

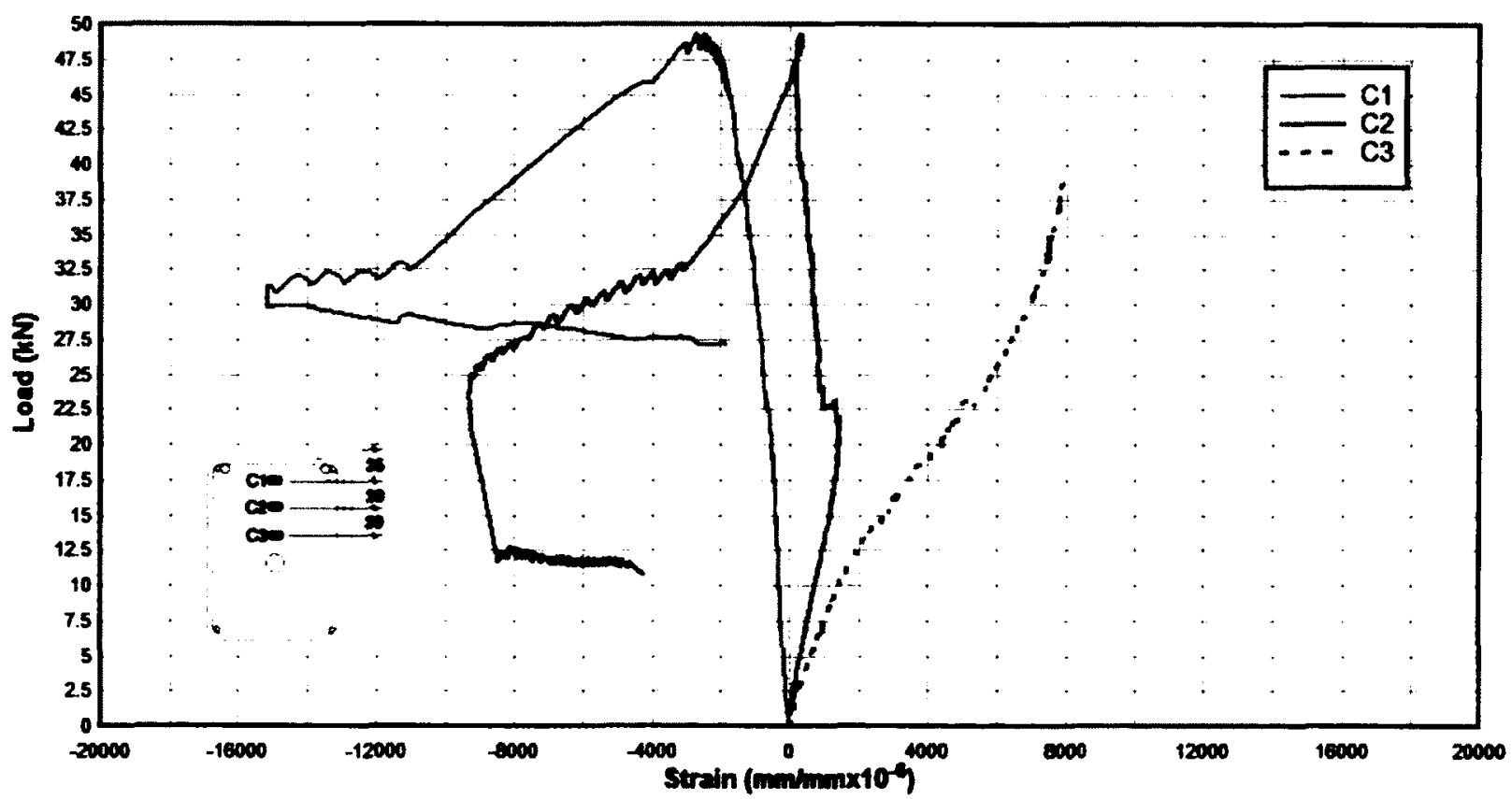

Figure 4-31: Concrete Strains in Beam SB-25M-2 


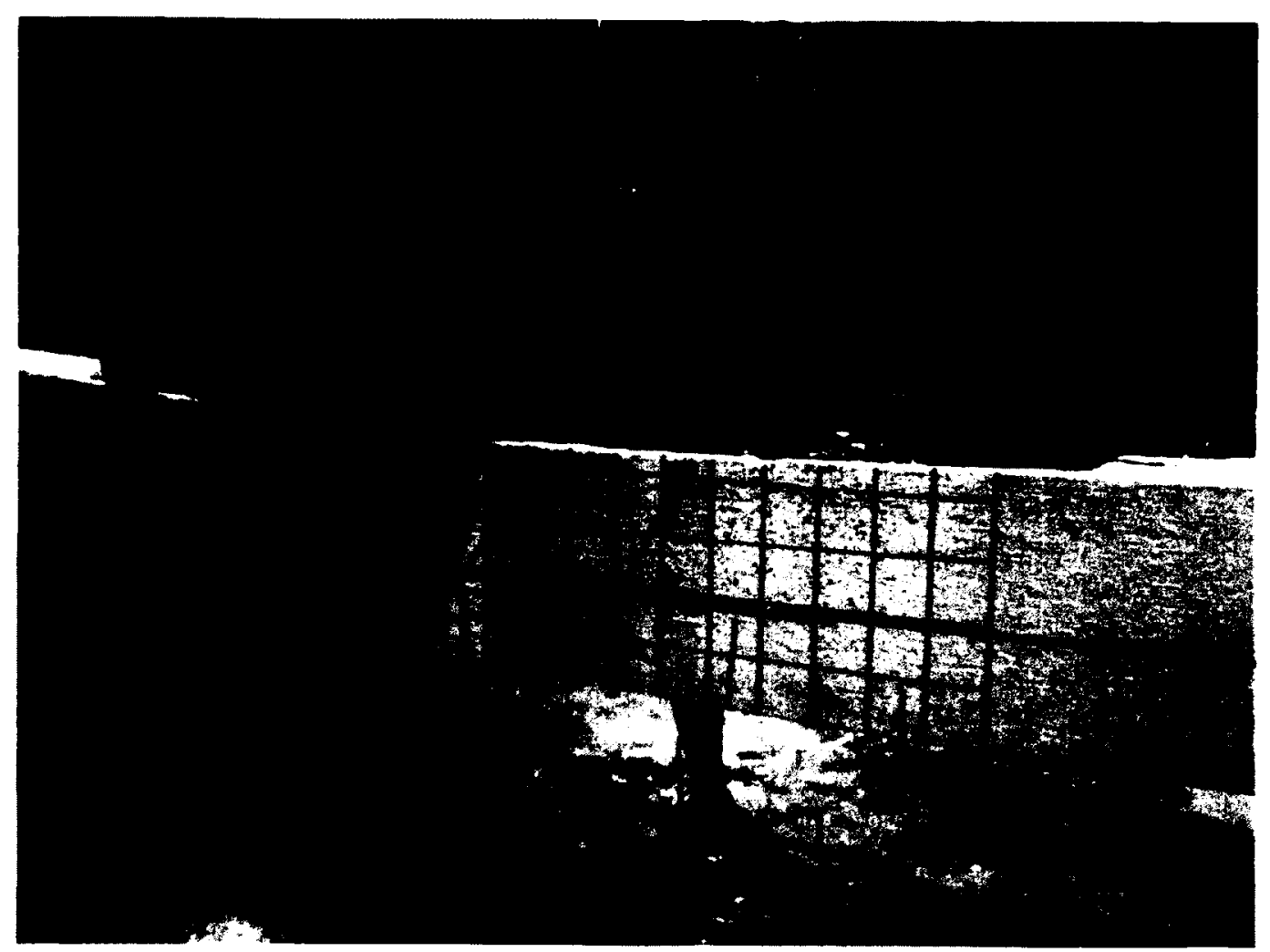

Figure 4-32: Beam SB-25M-2 After Loading 


\subsection{Dynamic Test Results}

All dynamic tests were conducted using the Shock tube at the University of Ottawa. A driver length of $1219 \mathrm{~mm}$ was used for all tests, while the driver pressure was varied between tests. The results of multiple shots on all 9 beams are discussed in this chapter. The reflected pressure, reflected impulse, and positive phase duration resulting from the driver length and driver pressure combination are presented. The maximum displacements at the load point and midspan of the beam during testing, the support rotation at the maximum displacement and initial and final width of the preformed crack are all discussed. Furthermore, the strains in the reinforcing steel and strains in the concrete are reported along with explanations for unusual strain readings. All important data from shock tube tests are reported in Table 4-11, Table 4-12, Table 4-13, and Table 4-14. Finally any visual damage caused to the beam during each test is discussed.

\subsubsection{DB-15M Beams}

Beam DB-15-1, DB-15M-2 and DB-15M-3 contained $15 \mathrm{M}$ rebar, with a bonded length to concrete of $423 \mathrm{~mm}$ on either side of the central debonded region. The beam dimensions and strain gauge spacings are presented in Figure 3-1, Figure 3-2, and Figure 3-5. The yielding of $15 \mathrm{M}$ rebar under dynamic loads was experimentally determined (from ancillary testing) and it was found that yielding occurred at a strain of $2740 \times 10^{-6}$. This strain is the average of the yield strain at 0.1 strain/s and 0.2 strain/s (Table 4-8). The average value was used since the increase in strength for both of the tests were very close to one another. It is important to note that dynamic ancillary testing produced strain 
rates very close to the strain rates produced by the shock tube. For all tests on these beams, concrete gauges $\mathrm{C} 2$ and $\mathrm{C} 3$, at a depth of $65 \mathrm{~mm}$ and $95 \mathrm{~mm}$ from the compression face, break during the first test on each beam. This is due to the fact that the preformed crack on the tension side opens up very quickly causing the neutral axis to shift towards the compression face. As a result, these gauges initially go into tension and quickly rupture.

\subsubsection{Beam DB-15M-1}

Beam DB-15M-1 was the first of all beams containing $15 \mathrm{M}$ rebar to be tested using the shock tube. In order to determine a driver length and driver pressure combination that would cause yielding of the steel reinforcement, the beam was exposed to a total of four shots. Although the first couple of shots did cause some damage to the beam, this method of testing proved useful in finding a suitable driver pressure that caused yielding of the steel reinforcing bar in subsequent tests.

\subsection{Test DB-15M-1-1}

Test DB-15M-1-1 was conducted with a driver pressure of $55 \mathrm{kPa}$. This driver pressure yielded a reflected pressure and reflected impulse of $8.72 \mathrm{kPa}$ and $55.8 \mathrm{kPa}-\mathrm{ms}$ respectively and a positive phase duration of $9.0 \mathrm{~ms}$ at the shock tube opening (Figure 4-33). The beam experienced a maximum midspan displacement of $5.46 \mathrm{~mm}$ and a load point displacement of $3.8 \mathrm{~mm}$ at $18.3 \mathrm{~ms}$ as shown in Figure 4-34. The maximum support rotation was $0.28^{\circ}$. No slip was recorded at either end of the beam. 
The strain rate in the reinforcing steel during this test was $0.0499 \mathrm{~s}^{-1}$. A maximum strain of $576 \times 10^{-6}$ occurred in the debonded region after at $17.4 \mathrm{~ms}$ in this test. This strain is less than the dynamic yield strain of $2740 \times 10^{-6}$. Thus, no yielding occurred in the longitudinal reinforcement under the blast loading from this test. The steel gauges produced lots of noise during this test. For example S1 oscillates between $80 \times 10^{-6}$ and $-60 \times 10^{-6}$ strain. This made it difficult to determine the magnitude of strain in any of the gauges within the bonded region since these strains were quite small. It was however quite clear that the strain in the steel did not reach yielding. Cables leading from the shock tube to the data acquisition system were replaced and repaired to reduce the error in future tests. All steel strains are shown in Figure 4-35.

Concrete strains were also recorded at three different depths as described in the experimental program (Figure 4-36). Although gauges C2 and C3 provide very little useful data since they fail very quickly, gauge $\mathrm{Cl}$ provides information on the strain in the concrete at a depth of $35 \mathrm{~mm}$ from the compression face. At this location the concrete experiences a maximum compressive strain of $333 \times 10^{-6}$. As the beam rebounds, the compressive force on gauge $\mathrm{C} 1$ is reduced. Gauge $\mathrm{C} 1$ moves from compression to tension after $46.96 \mathrm{~ms}$ and a maximum tensile strain of $91 \times 10^{-6}$ is recorded.

Visual inspection of the beam surface after the test revealed no damage. The preformed crack opened up slightly, but no significant residual displacement was observed. A small longitudinal crack was formed at a depth of approximately $60 \mathrm{~mm}$ from the compression face of the beam at midspan as shown in Figure 4-37. No other cracking was observed during this first test. 


\subsection{Test DB-15M-1-2}

The second shot on Beam DB-15M-1 used a driver pressure of $110 \mathrm{kPa}$. This yielded a reflected pressure of $25.8 \mathrm{kPa}$ and a reflected impulse of $117.0 \mathrm{kPa}-\mathrm{ms}$ at the shock tube opening (Figure 4-38). The duration of the positive phase was $10.0 \mathrm{~ms}$. The beam experienced a maximum midspan displacement of $15.7 \mathrm{~mm}$ and a maximum load point displacement of $10.5 \mathrm{~mm}$ at $21.2 \mathrm{~ms}$ as shown in Figure 4-39. The maximum support rotation calculated for this test was $0.80^{\circ}$. The crack at the midspan of the beam opened up to $8.38 \mathrm{~mm}$. No slip was recorded at either end of the beam.

Due to the large amount of noise in the gauges during the first test, an attempt was made to filter out the noise to obtain more accurate data. Unfortunately, the method used to do so did not work and no strain data was recorded for this test. As previously mentioned, future tests were performed with repaired cables, which provided more accurate results.

No additional cracks were formed along the tension face over the span of the concrete beam during test DB-15M-1-2. The only visual damage observed was propagation of the longitudinal crack at midspan formed during the first test as shown in Figure 4-40.

\subsection{Test DB-15M-1-3}

The third shot on beam DB-15M-1 used a driver pressure of $166 \mathrm{kPa}$. This caused a reflected pressure of $33.8 \mathrm{kPa}$ and reflected impulse of $168.3 \mathrm{kPa}-\mathrm{ms}$ at the shock tube opening (Figure 4-41). The positive phase duration was $11.0 \mathrm{~ms}$. This shock caused a maximum midspan displacement of $24.8 \mathrm{~mm}$ and a maximum load point displacement of 
$16.5 \mathrm{~mm}$ at $22.8 \mathrm{~ms}$ as shown in Figure 4-42. The maximum support rotation during the test was $1.27^{\circ}$. The residual width of the preformed crack measured $8.95 \mathrm{~mm}$. No slip was recorded at either end of the beam.

The strain rate in the reinforcing steel during this test was $0.143 \mathrm{~s}^{-1}$. The maximum strain readings in the debonded region were $2539 \times 10^{-6}$ at $22.9 \mathrm{~ms}$ and $3299 \times 10^{-6}$ at $23.8 \mathrm{~ms}$ in gauges $\mathrm{S} 5$ and $\mathrm{S} 6$ respectively. The strains in S5 and S6 should theoretically be equal, but it is difficult to determine which gauge is giving more accurate readings. It was found that yielding of the reinforcing steel in the debonded region occurred at a time of $20.7 \mathrm{~ms}$, where the average strain calculated from S5 and S6 was $2740 \times 10^{-6}$ (the average yield strain found during rapid tests on $15 \mathrm{M}$ rebar). Gauges S1 and S10, which are at the end of the bonded region (toward beam ends), experienced almost no strain increase during testing. The oscillations observed in Figure 4-43 for these gauges was likely due to the sensitivity of the gauges from small vibrations during testing. As a result, it was found that the bar developed over a length less than the 423 $\mathrm{mm}$ provided in this test. The residual strain in S5 and S6 were $28 \times 10^{-6}$ and $523 \times 10^{-6}$ respectively. The residual strain in S5 seems very small and may be caused by the gauge debonding from the steel surface. There was also a residual strain of $253 \times 10^{-6}$ in gauge S8, which was in the bonded region. Gauge S2 was not working and is therefore not shown in the strain-time graph. All strains are shown in Figure 4-44.

During casting of concrete, the sheet metal, which formed the preformed crack in this beam, was bent. This caused the crack to propagate at an angle to the axis of the rather than perpendicular through the midspan. Other visual damage observed during this 
test was longitudinal cracks growth and spalling of concrete on the compression face at midspan (Figure 4-45).

\subsection{Test DB-15M-1-4}

The fourth test on Beam DB-15M-1 was performed with a driver pressure of 303 $\mathrm{kPa}$. This caused a reflected pressure of $51.6 \mathrm{kPa}$ and a reflected impulse of $273.4 \mathrm{kPa}-\mathrm{ms}$ of the positive phase at the shock tube opening (Figure 4-46). The positive phase had a duration of $12.0 \mathrm{~ms}$. The maximum displacement at midspan was $56.2 \mathrm{~mm}$ and the maximum displacement at the load point was $37.2 \mathrm{~mm}$ at $49.6 \mathrm{~ms}$. as shown in

Figure 4-47. The maximum support rotation during this test was $2.85^{\circ}$. The preformed crack had a residual width after testing of $15.50 \mathrm{~mm}$. No slip was recorded at either end of the beam.

The strain rate in the reinforcing steel during this test was $0.323 \mathrm{~s}^{-1}$. During this test, strain gauges S4 and S6 malfunctioned. The maximum strain in the debonded region, determined from gauge S5 only was $4162 \times 10^{-6}$ at $72.5 \mathrm{~ms}$. The maximum strains in gauges S4 and S8 were $1971 \times 10^{-6}$ and $782 \times 10^{-6}$ respectively. It is important to note that the steel had residuals strains before testing since it underwent plastic deformation in the previous test. The residual strain in S5 after test DB-15M-1-4 was $3425 \times 10^{-6}$, while the residual strain on S8 was $39 \times 10^{-6}$ after this test. Due to the fact that this was the fourth shot on the same beam, many of the other gauges were damaged at this and no valuable data was obtained. It is also important to note that while the yield strain of steel in the debonded region was surpassed, gauges $\mathrm{S} 1, \mathrm{~S} 2, \mathrm{~S} 9$, and $\mathrm{S} 10$ were not strained. Thus, the 
steel was developed over a shorter length than $423 \mathrm{~mm}$ provided in the beam. All steel strain responses are presented in Figure 4-48.

The concrete gauges were damaged during the first 3 tests on beam DB-15M-1. Consequently, no concrete strains were successfully recorded during this test.

During this test, new cracks appeared on the tension face of the beam fairly close to the load points. Other cracks propagated and further opening of the preformed crack at midspan occurred as shown in Figure 4-49.

\subsubsection{Beam DB-15M-2 and DB-15M-3}

Only two shots were applied to Beam DB-15M-2 and DB-15M--3. For the first test on each beam, a driver pressure that would result in yielding of the reinforcement was used. By analyzing the results of tests on beam DB-15M--1, it was determined that a driver pressure of $166 \mathrm{kPa}$ caused yielding of reinforcement. As a result, this pressure was used for test DB-15M-2-1 and DB-15M-3-1. The second shots on Beam DB-15M-2 and DB-15M-3 were chosen to have a driver pressure of much greater magnitude than the first shot.

\subsection{Test DB-15M-2-1}

The driver pressure, $165 \mathrm{kPa}$, for this test resulted in a reflected pressure of 35.2 $\mathrm{kPa}$ and a reflected impulse of $168.8 \mathrm{kPa}-\mathrm{ms}$ (Figure 4-50) and positive phase duration of $11.0 \mathrm{~ms}$. During the test, the beam experienced a maximum midspan displacement of $23.2 \mathrm{~mm}$ and a maximum load point displacement of $15.9 \mathrm{~mm}$ at $23.2 \mathrm{~ms}$ as shown in 
Figure 4-51. The corresponding maximum support rotation was $1.22^{\circ}$. The preformed crack width increased from $9.63 \mathrm{~mm}$ to $12.10 \mathrm{~mm}$ during this test. No slip of the reinforcement was recorded at either end of the beam.

The strain rate in the reinforcing steel during this test was $0.167 \mathrm{~s}^{-1}$. The maximum strain readings in the debonded region were $3339 \times 10^{-6}$ and $3091 \times 10^{-6}$ at 24.6 $\mathrm{ms}$ in gauges $\mathrm{S} 5$ and $\mathrm{S} 6$ respectively. The strain values at these gauges (S5 and S6) were higher than yield stress of steel $\left(2740 \times 10^{-6}\right)$. Yielding of the steel reinforcement occurred at a time of $19.9 \mathrm{~ms}$. The residual strain readings in the debonded region were $574 \times 10^{-6}$ from gauge S5 and $427 \times 10^{-6}$ from gauge S6. Marginal strain increases were recorded at S3 while S1, S9 showed no strain increase. Gauge S2 and S8 were observed to be malfunctioning during the test and are therefore not shown in the strain-time history in Figure 4-52. Figure 4-53 shows the strain profile when the steel in the debonded region reaches its dynamic yield strain. The figure can be used to estimate the dynamic development length of the steel reinforcement. Whereas the spacing of strain gauges in the bonded region does not allow for accurate measurement of the development length, an estimate can be made. The dynamic development length was between $256 \mathrm{~mm}$ and $385 \mathrm{~mm}$, less than the static development length calculated in accordance with CSA A23.3-04 (2004).

During testing, concrete gauge $\mathrm{C} 2$ and $\mathrm{C} 3$ immediately experienced high tensile strains exceeding their capacity and ruptured. The behaviour of gauge $\mathrm{Cl}$ was observed up to the time of maximum displacement as shown in Figure 4-54. Cl initially experienced a compressive strain of $92 \times 10^{-6}$ at $4.57 \mathrm{~ms}$. The neutral axis then moved 
below gauge $\mathrm{Cl}$ upon rebound and began to undergo tension. A maximum tensile strain of $1143 \times 10^{-6}$ was then reached at $13.63 \mathrm{~ms}$. The residual strain in gauge $\mathrm{Cl}$ was $69 \times 10^{-6}$.

During this test, a longitudinal crack was formed at midspan near the compression face (Figure 4-55). A transverse crack was also formed near the top load point along the tension face of the beam.

\subsection{Test DB-15M-2-2}

The second shot on beam DB-15M-2 used a driver pressure of $379 \mathrm{kPa}$, which resulted in a reflected pressure of $61.1 \mathrm{kPa}$ and a reflected impulse of $316.8 \mathrm{kPa}-\mathrm{ms}$ (Figure 4-56). The duration of the positive phase was $12.1 \mathrm{~ms}$. The resulting maximum midspan displacement was $81.6 \mathrm{~mm}$ and the maximum load point displacement was 55.5 $\mathrm{mm}$ at $54.9 \mathrm{~ms}$ as shown in Figure 4-57. No displacement of the reinforcement relative to the beam was recorded. The maximum support rotation was $4.26^{\circ}$. The residual width of the preformed crack was $20.20 \mathrm{~mm}$. No slip of the reinforcement was recorded at either end of the beam.

The strain rate in the reinforcing steel during this test was $0.361 \mathrm{~s}^{-1}$. During the test, gauges $\mathbf{S} 5$ and $\mathbf{S 6}$ reach their maximum capacity. As a result the maximum strain in the debonded region could not be determined. However, after maximum strain was reached, gauge S5 appears to record strain readings that appear to be within a reasonable range. The residual strain in gauge S5 is $3509 \times 10^{-6}$. Strain gauges S4 and S7 recorded maximum strains of $2453 \times 10^{-6}$ and $3850 \times 10^{-6}$ respectively. Gauge S7 had a residual strain of $228 \times 10^{-6}$, while the residual strain in S4 was compressive. Gauges S1 and S9 did not undergo any significant strain during testing, only small vibrations. All steel strains are show in Figure 4-58. Figure 4-59 shows the strain profile at the time when the steel 
in the debonded region reaches its dynamic yield strain. The dynamic development length was between $256 \mathrm{~mm}$ and $385 \mathrm{~mm}$, which is less than the static development length of $423 \mathrm{~mm}$.

Concrete gauges $\mathrm{C} 2$ and $\mathrm{C} 3$ were not working for this test. Gauge $\mathrm{C} 1$ initially experiences a compressive strain of $927 \times 10^{-6}$ at $6.6 \mathrm{~ms}$. The strain at $\mathrm{Cl}$ then moved into tension at $10.0 \mathrm{~ms}$. As the crack continued to open up, $\mathrm{Cl}$ reached a maximum tensile force of $1808 \times 10^{-6}$ at $17.2 \mathrm{~ms}$. At this point, the concrete spalled off on the compression face and the strain in $\mathrm{Cl}$ moved back into the compressive zone until maximum displacement was reached (Figure 4-60). The residual tensile strain on gauge $\mathrm{Cl}$ was $100 \times 10^{-6}$.

Transverse cracks appeared near both load points and propagated through the depth of the beam (Figure 4-61). Concrete spalled off the compressive face, exposing the shear stirrup near the midspan of the beam, while additional longitudinal cracks were formed at the midspan of the beam.

\subsection{Test DB-15M-3-1}

The first test on beam DB-15M-3-1 was similar to the first test performed on DB-15M-2. The driver pressure was also $165 \mathrm{kPa}$ resulting in a reflected pressure of $30.4 \mathrm{kPa}$ and a reflected impulse of $160.1 \mathrm{kPa}-\mathrm{ms}$ (Figure 4-62). The duration of the positive phase was $11.3 \mathrm{~ms}$. During this test, midspan displacements were not recorded due to faulty cables to the data acquisition system. The midspan displacement was therefore estimated by assuming rigid body rotation about a pivot in the concrete compression zone. The midspan displacement was calculated by using the principle of 
similar triangles. The calculated maximum midspan displacement was $26.7 \mathrm{~mm}$ and the measured maximum load point displacement was $17.8 \mathrm{~mm}$ at $24.9 \mathrm{~ms}$ as shown in Figure 4-63. The maximum support rotation was $1.37^{\circ}$. The initial width of the preformed crack was $5.92 \mathrm{~mm}$ and the final width after testing was $6.25 \mathrm{~mm}$. No slip was recorded at either end of the beam.

The strain rate in the reinforcing steel during this test was $0.159 \mathrm{~s}^{-1}$. The maximum strain in the debonded region was $2839 \times 10^{-6}$ at $24.5 \mathrm{~ms}$, as recorded by gauge S5. The steel reached the yield strain at $22.4 \mathrm{~ms}$. While gauges S3, S4 and S8 experienced maximum strains of $343 \times 10^{-6}, 2123 \times 10^{-6}$ and $347 \times 10^{-6}$ respectively, no strains were recorded in S9 or S10 except for small oscillations about zero strain. Residual strains of $211 \times 10^{-6}, 214 \times 10^{-6}, 328 \times 10^{-6}$, and $347 \times 10^{-6}$ were recorded at gauges S3, S4, S5 and S8 respectively. All steel strains are shown in Figure 4-64. Figure 4-65 shows the strain profile at the time when the steel in the debonded region reached its dynamic yield strain. From this figure, it can be concluded that he dynamic development length was between $256 \mathrm{~mm}$ and $385 \mathrm{~mm}$, less than the $423 \mathrm{~mm}$ provided.

Concrete gauge $\mathrm{C} 2$ and $\mathrm{C} 3$ broke almost immediately. Gauge $\mathrm{C} 1$ reached a compressive strain of $283 \times 10^{-6}$ at $7.5 \mathrm{~ms}$. As the neutral axis moved towards the compression fibre of the section, $\mathrm{C} 1$ transitioned into tension at $10.7 \mathrm{~ms}$ and reached a tensile strain of $347 \times 10^{-6}$ before the beam reached maximum displacement (Figure 4-66).

Two transverse cracks formed along the compression face near midspan (Figure 4-67), showing a potential area for concrete spalling in subsequent tests. The preformed crack opened up, but no other visual damage occurred. 


\subsection{Test DB-15M-3-2}

The driver pressure used in this test was $483 \mathrm{kPa}$, which caused a reflected pressure of $64.1 \mathrm{kPa}$ and a reflected impulse of $362.8 \mathrm{kPa}-\mathrm{ms}$ at the shock tube opening (Figure 4-68). The positive phase duration was $12.6 \mathrm{~ms}$ The midspan LVDT detached from the beam during this test, so the midpsan displacement was, as with the first test on this beam, calculated from the load point displacement. The maximum midspan displacement was $127.4 \mathrm{~mm}$ and the maximum load point displacement was $84.9 \mathrm{~mm}$ which occurred at $57.4 \mathrm{~ms}$ as shown in Figure 4-69. The maximum support rotation was $6.49^{\circ}$. No slip was recorded at either end of the beam.

The strain rate in the reinforcing steel during this test was $0.357 \mathrm{~s}^{-1}$. During this test, steel strains at S6 were not recorded while gauge S5 exceeded the maximum strain limitation during testing. Therefore the maximum strain in the debonded region could not be determined, but readings from gauge S5 indicated that yielding of the steel occurred after $10.9 \mathrm{~ms}$. Maximum strains recorded in gauges S3, S4 and S8 were $601 \times 10^{-6}$, $2773 \times 10^{-6}$, and $1006 \times 10^{-6}$ respectively. The residual strains in gauges S3 and S8 were $234 \times 10^{-6}$ and $233 \times 10^{-6}$ respectively. The residual strain in S4 was $-472 \times 10^{-6}$. At the location of gauge S4, the steel underwent tensile strain and reached plastic deformation. Since the tensile strain at S4 cannot be fully recovered, a compressive strain would not occur in the steel and it is reasonable to assume that the gauge was damaged during testing. All steel strains are show in Figure 4-70. Figure 4-71 shows the strain profile at the time when the dynamic yield strain was reached. The dynamic development length was between $256 \mathrm{~mm}$ and $385 \mathrm{~mm}$. 
Thus, the dynamic development length for all tests on $15 \mathrm{M}$ beams is less than the development length provided in accordance with CSA A23.3-04 (2004).

Due to previous damage caused to the concrete gauges, no concrete strains were recorded.

Transverse cracks appeared on the tensile surface of the beam near both load points. These cracks were approximately $150 \mathrm{~mm}$ deep. Spalling of concrete on the compressive face also occurred during testing (Figure 4-72).

\subsubsection{DB-20M Beams}

The DB-20M beams contained 20M rebar developed for a length of $523 \mathrm{~mm}$ on either side of the $1395 \mathrm{~mm}$ debonded region. The beam dimensions and strain gauge spacings are described in the experimental program (Figure 3-1, Figure 3-2, and Figure $3-5$ ). The yielding of $20 \mathrm{M}$ size rebar under dynamic loads was experimentally determined to occur at a strain of $2650 \times 10^{-6}$ as shown in Table 4-8. For all tests on these beams, concrete gauges $\mathrm{C} 2$ and $\mathrm{C} 3$, at depths of $65 \mathrm{~mm}$ and $95 \mathrm{~mm}$ from the compression face, ruptured during the first test on each beam.

\subsubsection{Beam DB-20M-1}

This beam was the first of all DB-20M beams to be tested using the shock tube. Similar to Beam DB-15M-1, several shots were made on beam DB-20M-1 to determine the appropriate driver pressure for testing beams containing $20 \mathrm{M}$ rebar. A total of 3 tests were performed on this beam and a driver pressure that could cause yielding of the steel 
reinforcing bar in subsequent tests was determined. The results of these tests are described in the following sections.

\subsection{Test DB-20M-1-1}

For the first shock on beam DB-20M-1, a driver pressure of $138 \mathrm{kPa}$ was used. The resulting reflected pressure was $29.3 \mathrm{kPa}$ and the reflected impulse of the positive phase was $134.8 \mathrm{kPa}$-ms (Figure 4-73). The positive phase duration was $10.4 \mathrm{~ms}$. The LVDT at midspan for this test malfunctioned and thus no midspan displacement data was available for this test. From calculations, it was determined that the measured maximum displacement at midspan was $19.3 \mathrm{~mm}$ and the maximum displacement at the load point was $12.7 \mathrm{~mm}$ which occurred at $21.2 \mathrm{~ms}$ as shown in Figure 4-74. The maximum support rotation was $0.98^{\circ}$. The preformed crack before testing measured $5.99 \mathrm{~mm}$ and has a residual width of $7.57 \mathrm{~mm}$ after testing. No slip of the reinforcement was recorded at either end of the beam.

The strain rate in the reinforcing steel during this test was $0.122 \mathrm{~s}^{-1}$. The maximum strain in the debonded region was $1703 \times 10^{-6}$ at $20.6 \mathrm{~ms}$, as recorded by gauge S6. S4 reached a maximum strain of $1524 \times 10^{-6}$, while S3 and S8 reached small strains of $155 \times 10^{-6}$ and $188 \times 10^{-6}$ respectively. The yield strain was not reached in this test and the beam had very little residual displacement. The strain profile of the reinforcement is shown in Figure 4-75.

Concrete gauge $\mathrm{C} 1$ reaches a maximum compressive strain of $182 \times 10^{-6}$ at $11.1 \mathrm{~ms}$ before crossing over into tension at $13.5 \mathrm{~ms}$. The tensile strains then become very high and the gauge is ruptured as shown in Figure 4-76. No residual strain was recorded in the concrete. 
During this test, the preformed crack opened up slightly and a small longitudinal crack formed near midspan (Figure 4-77). There was no other visible damage caused to the beam.

\subsection{Test DB-20M-1-2}

This test used a driver pressure of $227 \mathrm{kPa}$, which resulted in a reflected pressure of $45.0 \mathrm{kPa}$ and a reflected impulse of the positive phase of $219.7 \mathrm{kPa}-\mathrm{ms}$ (Figure 4-78). The positive phase duration was $11.3 \mathrm{~ms}$. A maximum midspan displacement of $34.8 \mathrm{~mm}$ and a maximum load point displacement of $22.7 \mathrm{~mm}$ occurred at $24.4 \mathrm{~ms}$ as shown in Figure 4-79. The maximum support rotation was $1.75^{\circ}$. The residual crack width was $5.59 \mathrm{~mm}$. No reinforcement slip was recorded at either end of the beam.

The strain rate in the reinforcing steel during this test was $0.212 \mathrm{~s}^{-1}$. The maximum strain in gauges $\mathrm{S} 3$ and $\mathrm{S} 8$ were $618 \times 10^{-6}$ and $592 \times 10^{-6}$ respectively. The maximum strain in the debonded region recorded from gauge S6, which occurred at 23.5 ms was $2990 \times 10^{-6}$. The yield strain was achieved at a time of $16.6 \mathrm{~ms}$. Although the maximum strain reading is expected be in the debonded region, gauge S4 had a higher maximum recorded strain of $3122 \times 10^{-6}$. Gauge $\mathrm{S} 4$ is very close to the debonded region, so it is possible that if there were voids in the concrete near the end of the debonded region, gauge S4 would act very similarly to gauge S6. It is also possible that gauge S6 was not bonded properly to the steel surface and is not very accurate. The strain readings show that the dynamic development length was between $340 \mathrm{~mm}$ and $500 \mathrm{~mm}$, which is less than $523 \mathrm{~mm}$ (the development length provided). The residual strains in gauges $\mathrm{S} 3$, S4 and S8 were $395 \times 10^{-6}, 450 \times 10^{-6}$ and $347 \times 10^{-6}$ respectively, while the residual strain in 
S6 was only $131 \times 10^{-6}$. All steel strains are shown in Figure 4-80. No concrete strain was recorded in this test since the gauges all ruptured during Test DB-20M-1-1.

A transverse crack appeared near the top load point during this test on the tensile side of the beam (Figure 4-81). Longitudinal cracks also propagated at the midspan. Although the preformed crack opened up during the test, the beam moved back to its original position on rebound and the crack width was measured to be smaller than before testing.

\subsection{Test DB-20M-1-3}

The driver pressure for the third test on beam DB-20M-1 was $586 \mathrm{kPa}$. This resulted in a reflected pressure of $90.8 \mathrm{kPa}$ and a reflected impulse of the positive phase of $451.5 \mathrm{kPa}-\mathrm{ms}$ (Figure 4-82). The positive phase duration was $13.6 \mathrm{~ms}$. The maximum midspan displacement was $201.8 \mathrm{~mm}$ and the maximum load point displacement was 142.7 mm which occurred at $71.6 \mathrm{~ms}$ as shown in Figure 4-83. The maximum support rotation was $10.80^{\circ}$. The residual crack width was $34.80 \mathrm{~mm}$. No reinforcement slip was recorded at either end of the beam.

The strain rate in the reinforcing steel during this test was $0.412 \mathrm{~s}^{-1}$. The maximum strain in the debonded region could not be determined in this test since gauge S6 appears to reach its maximum capacity. Gauge S4 also reaches its maximum value. A maximum strain of $823 \times 10^{-6}$ was reach in gauge $S 3$ before it failed, and a maximum strain of $749 \times 10^{-6}$ was recorded in gauge S8. Although residual strains are recorded, it is difficult to tell whether the strain readings are accurate after the gauges reach their maximum capacity. It is however important to note that while gauges S4 and S6 
experienced very high strains. Gauge S9 and S10 experienced no strain, thus confirming that the dynamic development length was between $340 \mathrm{~mm}$ and $500 \mathrm{~mm}$, which is less than the $523 \mathrm{~mm}$ of bonded reinforcement provided. Gauges S1 and S2 were not working during this test. All steel strains are presented in Figure 4-84. All concrete gauges were damaged at this point so no concrete strains were recorded.

Transverse cracking occurred at both load points on the tension face of the beam. The depth of these cracks was greater than $150 \mathrm{~mm}$. On the compression face, a large mass of concrete, with a depth of approximately $50 \mathrm{~mm}$, was spalled off near midspan (Figure 4-85).

\subsubsection{Beam DB-20M-2 and DB-20M-3}

Only two shots were applied to Beam DB-20M-2 and DB-20M-3. For the first test on each beam, a driver pressure that estimated to yield the reinforcement was used. By observing the results of tests on beam DB-20M-1, it was determined that a driver pressure of $227 \mathrm{kPa}$ caused yielding of the $20 \mathrm{M}$ reinforcement. As a result, this pressure was used for test DB-20M-2-1 and DB-20M-3-1. The second shot on Beam DB-20M-2 and DB-20M-3 was chosen to have a driver pressure of much greater magnitude than for the first shot.

\subsection{Test DB-20M-2-1}

The first shot on beam DB-20M-2 resulted in a reflected pressure of $42.6 \mathrm{kPa}$ and a reflected impulse of the positive phase of $216.2 \mathrm{kPa}-\mathrm{ms}$ (Figure 4-86). The positive 
phase duration from this shock was $11.5 \mathrm{~ms}$. The maximum midspan displacement was $44.9 \mathrm{~mm}$ and the maximum load point displacement was $30.3 \mathrm{~mm}$ at $24.7 \mathrm{~ms}$ as shown in Figure 4-87. The maximum was support rotation was $2.33^{\circ}$. Before testing the preformed crack had a width of $4.32 \mathrm{~mm}$ and after testing, the residual width was $4.60 \mathrm{~mm}$. No reinforcement slip was recorded at either end of the beam.

The strain rate in the reinforcing steel during this test was $0.202 \mathrm{~s}^{-1}$. The maximum strain in the debonded region was $2933 \times 10^{-6}$ in gauge $\mathrm{S} 5$ at $23.6 \mathrm{~ms}$. The yield strain was reached at $18.8 \mathrm{~ms}$. Gauge S3 and S8 each had a maximum strain of $474 \times 10^{-6}$. The residual strains in S3 and S8 were $274 \times 10^{-6}$ and $267 \times 10^{-6}$ respectively. The residual strain in S5 was $115 \times 10^{-6}$. Gauges S1, S9, and S10 did not experience significant strains, only small oscillations. Gauge S2 malfunctioned during the testing and hence not shown with the strain profiles in Figure 4-88. Figure 4-89 shows the strain profile at the time when the steel in the debonded region reaches the dynamic yield strain. The dynamic development length was between $340 \mathrm{~mm}$ and $500 \mathrm{~mm}$, which is less than $523 \mathrm{~mm}$ provided.

Gauge $C 1$ initially went into compression, reaching a strain of $417 \times 10^{-6}$ at 6.20 ms. The neutral axis then crossed gauge $\mathrm{Cl}$ at $9.5 \mathrm{~ms}$ and $\mathrm{C} 2$ went into tension, experiencing a maximum tensile strain of $81 \times 10^{-6}$ before the maximum displacement was reached. Gauge $\mathrm{C} 1$ does not appear to have any significant residual strains (Figure 4-90).

A longitudinal crack appeared at midspan at a depth of approximately $40 \mathrm{~mm}$ from the compression fibre of the section, and propagated towards the top support of the beam. A small part of concrete spalled off the edges of the beam near the compression face at midpsan (Figure 4-91). 


\subsection{Test DB-20M-2-2}

The second shot on beam DB-20M-2 used a driver pressure of $586 \mathrm{kPa}$, which resulted in a reflected pressure of $90.4 \mathrm{kPa}$ and a reflected positive phase impulse of $450.9 \mathrm{kPa}-\mathrm{ms}$ (Figure 4-92). The positive phase duration was $13.1 \mathrm{~ms}$. The maximum midspan displacement of the beam was $186.6 \mathrm{~mm}$ and the maximum load point displacement was $124.1 \mathrm{~mm}$ at $69.1 \mathrm{~ms}$ as shown in Figure 4-93. The maximum support rotation was $9.46^{\circ}$. The final width of the preformed crack measured $29.0 \mathrm{~mm}$. No slip was recorded at either end of the beam.

The strain rate in the reinforcing steel during this test was $0.401 \mathrm{~s}^{-1}$. The maximum strain in the debonded region could not be determined for this test since gauge S5 and S6 exceeded their maximum capacity. The yield strain of the steel in the debonded region was reached at $10.05 \mathrm{~ms}$. The maximum strain in gages $\mathrm{S} 3$, and $\mathrm{S} 8$ were $447 \times 10^{-6}$, and $433.17 \times 10^{-6}$ respectively. Gauges S9 and S10 do not exhibit any strains, only small oscillations about zero strain. Thus, the steel was developed over the provided bond length. The strain readings show that the dynamic development length was between $340 \mathrm{~mm}$ and $500 \mathrm{~mm}$, which is less than the bonded length of $523 \mathrm{~mm}$ provided in the beam. Gauges S3 and S6 ruptured during the test, but gauges S4, S5 and S8 show residual strains of $990 \times 10^{-6}, 3991 \times 10^{-6}$ and $214 \times 10^{-6}$ respectively. All steel strains are shown in Figure 4-94. Figure 4-95 shows the strain profile at the time when the steel in the debonded region reaches its dynamic yield strain.

The recorded concrete strains at gauge $\mathrm{C} 1$ shows compressive strain with a peak value of $4360 \times 10^{-6}$ (Figure 4-96). The residual strain was $2340 \times 10^{-6}$. 
After this test, there was cracking at the location of both load points. Concrete was spalled off the compression face to a depth of approximately $75 \mathrm{~mm}$, and the longitudinal wire used for the shear cage was buckled at midspan (Figure 4-97).

\subsection{Test DB-20M-3-1}

The first shot on beam DB-20M-3 resulted in a reflected pressure of $38.6 \mathrm{kPa}$ and a positive phase reflected impulse of $214.8 \mathrm{kPa}-\mathrm{ms}$ (Figure 4-98). The positive phase duration was $11.6 \mathrm{~ms}$. The maximum midspan displacement was $33.4 \mathrm{~mm}$ and the maximum load point displacement was $22.1 \mathrm{~mm}$ at $24.9 \mathrm{~ms}$ as shown in Figure 4-99. The maximum support rotation was $1.70^{\circ}$. The preformed crack initially measured $7.39 \mathrm{~mm}$. Once the beam was loaded, the crack opened up and the sheet metal fell out of the preformed crack. Upon rebound, the crack closed up and had a residual displacement of $5.18 \mathrm{~mm}$. No reinforcement slip was recorded at either end of the beam.

The strain rate in the reinforcing steel during this test was $0.193 \mathrm{~s}^{-1}$. The maximum strain in the steel in the debonded region occurred in gauge S5 at $25.2 \mathrm{~ms}$ and measured $2867 \times 10^{-6}$. Gauge S7 and S8 had maximum strains of $1633 \times 10^{-6}$ and $546 \times 10^{-6}$ respectively. Gauges S2, S9 and S10 only experienced very small increases in strain. Gauges S5 and S8 had residual strains of $305 \times 10^{-6}$ and $376 \times 10^{-6}$ respectively. Gauge S7 has a residual compressive strain. While gauge S8 seems to have a very smooth straintime curve, gauges S5 and S7 have randomly scattered peaks followed by continuous waves. The random behaviour in this strain data is evidence of malfunctioning gauges. Thus, the values reported for gauges S5 and S7 have high uncertainty. All strain profiles are shown in Figure 4-100. Figure 4-101 shows the strain profile at the time when the 
steel in the debonded region reaches its dynamic yield strain and shows that the dynamic development length was between $340 \mathrm{~mm}$ and $500 \mathrm{~mm}$, which is less than the bonded length of $523 \mathrm{~mm}$ provided in the beam.

Gauge $\mathrm{Cl}$ reached a maximum compressive strain of $1972 \times 10^{-6}$ at $47.3 \mathrm{~ms}$. As the beam rebounds, the location of the neural axis begins to move away from the compression face and gauge $\mathrm{Cl}$ goes into tension before rupturing (Figure 4-102).

While this test was performed, some longitudinal cracks were formed at midspan (Figure 4-103). There was also some cracking and spalling of concrete off the compression face at the location of the preformed crack.

\subsection{Test DB-20M-3-2}

The second shot on beam DB-20M-3 had a driver pressure of $586 \mathrm{kPa}$ and resulted in a positive phase reflected pressure and reflected impulse of $68.2 \mathrm{kPa}$ and $427.8 \mathrm{kPa}-\mathrm{ms}$ respectively (Figure 4-104). The duration of the positive phase was 12.8 ms. The maximum midspan displacement measured $134.4 \mathrm{~mm}$ and the maximum load point displacement measured $92.1 \mathrm{~mm}$ at $56.4 \mathrm{~ms}$ as shown in Figure 4-105. The maximum support rotation was $7.05^{\circ}$. After the test was performed, the preformed crack had a residual width of $22.0 \mathrm{~mm}$. No reinforcement slip was recorded at either end of the beam.

The strain rate in the reinforcing steel during this test was $0.287 \mathrm{~s}^{-1}$. From the data, it is difficult to determine the magnitude of the maximum strain in the gauges due to random peaks that appeared. These peaks seem as though they are noise in the gauges rather than strain readings. However, since the gauges exhibit smooth curves before these 
peaks occur, it is possible to determine the time to yield at $11.6 \mathrm{~ms}$. Gages S5, S6, S7 and S8 showed residual strains of $3301 \times 10^{-6}, 5100 \times 10^{-6}, 3703 \times 10^{-6}$, and $350 \times 10^{-6}$ respectively. Gauges S2, S9 and S10 did not show any strain changes. Gauge S4 was hidden because it was not working properly. All strain profiles are presented in Figure 4-106. Figure 4-107 presents the strain profile at the time when the steel in the debonded region reaches its dynamic yield strain. The dynamic development length was between $340 \mathrm{~mm}$ and $500 \mathrm{~mm}$, which is less than the bonded length of $523 \mathrm{~mm}$ provided in the beam. No concrete strains were recorded during this test.

The damage caused to this beam was similar to test DB-20M-2-2. Cracks appear at the location of both load points. Spalling of the concrete at the midspan near the compression face also took place (Figure 4-108).

\subsubsection{DB-25M Beams}

These three beams contained $25 \mathrm{M}$ rebar, which was developed for a length of 830 $\mathrm{mm}$ on either side of the $780 \mathrm{~mm}$ debonded region. The beam dimensions and strain gauge spacings are described in the experimental program (Figure 3-1, Figure 3-2, and Figure 3-5). The yielding of $25 \mathrm{M}$ size rebar under dynamic loads was experimentally determined by increasing strain rate to $0.1 \mathrm{strain} / \mathrm{s}$ and $0.2 \mathrm{strain} / \mathrm{s}$, and it was found that yielding would occur at a strain of $3163 \times 10^{-6}$ (Table $4-8$ ). To determine this yield strain, only two tests were performed since the machine for tensile steel testing was unable to load $25 \mathrm{M}$ rebar at high strain rates. The failure load of each test was very different from one another and the average value obtained is likely an overestimation of the yield strength. This is due to the fact that the yield strain of one of the tests was very large in 
comparison to all other steel testing. However, by observing the strain profile at an overestimated steel strain, the results reported are conservative.

\subsubsection{Beam DB-25M-1 Beam}

Beam DB-25M-1 was the first of all beams containing $25 \mathrm{M}$ rebar to be tested using the shock tube. Similar to Beam DB-15M-1 and DB-20M-1, this beam was exposed to several shock tube shots to determine the appropriate driver pressure for testing DB-25M beams. A total of 3 shots were made to this beam. The results of these tests are described in the following section.

\subsection{Test DB-25M-1-1}

The first shot on beam DB-25M-1 used a driver pressure of $207 \mathrm{kPa}$. This caused a positive phase reflected pressure of $37.4 \mathrm{kPa}$ and a reflected impulse of $200.6 \mathrm{kPa}-\mathrm{ms}$ at the shock tube opening (Figure 4-109). The positive phase duration was $11.5 \mathrm{~ms}$. The maximum midspan displacement was $22.1 \mathrm{~mm}$ and the maximum load point displacement was $15.9 \mathrm{~mm}$ at $20.6 \mathrm{~ms}$ as shown in Figure 4-110. The maximum support rotation was $1.22^{\circ}$. The width of the preformed crack before testing was $7.37 \mathrm{~mm}$. During the test the crack opened up and returned to a width of $7.37 \mathrm{~mm}$. No reinforcement slip was recorded at either end of the beam.

The strain rate in the reinforcing steel during this test was $0.143 \mathrm{~s}^{-1}$. The maximum strain in the debonded region from gauge S5 was $2025 \times 10^{-6}$ at $18.67 \mathrm{~ms}$. The maximum strains in gauges S3, S4, and S8 were $1044 \times 10^{-6}, 1451 \times 10^{-6}$, and $1001 \times 10^{-6}$ respectively. Yielding in the debonded region was not achieved in this test. The residual 
strains in gauges S3, S5 and S8 were $293 \times 10^{-6}, 227 \times 10^{-6}$, and $592 \times 10^{-6}$ respectively. Gauge S4 showed no residual strain. Gauge S9 only experienced small vibrations. All strain profiles are shown in Figure 4-111.

Concrete gauge $\mathrm{Cl}$ reached a maximum compressive strain of $600 \times 10^{-6}$ at 23.5 $\mathrm{ms}$ and gauge $\mathrm{C} 2$ reached a maximum tensile strain of $1428 \times 10^{-6}$ at $16.33 \mathrm{~ms}$ during the first cycle of the beams displacement (Figure 4-112). Gauges C1 and C3 fractured during this test, while gauge $\mathrm{C} 2$ exhibited a residual strain of $266 \times 10^{-6}$.

During this test a longitudinal crack at a depth of approximately $75 \mathrm{~mm}$ from the compression face was formed. There were 3 transverse cracks that formed near the location of the top load point on the tension face and 2 transverse cracks that appear near the bottom load point (Figure 4-113).

\subsection{Test DB-25M-1-2}

This test used a driver pressure of $262 \mathrm{kPa}$ and resulted in a positive phase reflected pressure of $43.2 \mathrm{kPa}$ and a reflected impulse of $238.8 \mathrm{kPa}-\mathrm{ms}$ at the shock tube opening (Figure 4-114). The positive phase duration of the blast load was $12.0 \mathrm{~ms}$. The maximum midspan displacement was $30.3 \mathrm{~mm}$ and the maximum load point displacement was $20.8 \mathrm{~mm}$ at $21.5 \mathrm{~ms}$ as shown in Figure 4-115. The maximum support rotation during the test was $1.60^{\circ}$. The residual displacement of the preformed crack measured $8.13 \mathrm{~mm}$. No reinforcement slip was recorded at either end of the beam.

The strain rate in the reinforcing steel during this test was $0.227 \mathrm{~s}^{-1}$. The maximum strain in the debonded region recorded from gauges S5 and S6 was $3475 \times 10^{-6}$ 
and $3397 \times 10^{-6}$ respectively at $22.1 \mathrm{~ms}$. The steel in this region reached the yield strain at $18.29 \mathrm{~ms}$. Maximum strains recorded in gauges S3, S4 and S8 were $149 \times 10^{-6}$, $2868 \times 10^{-6}$, and $1226 \times 10^{-6}$ respectively. The residual strains in the debonded region were $1339 \times 10^{-6}$ at $\mathrm{S} 5$ and $1228 \times 10^{-6}$ at $\mathrm{S} 6$. The residual strain in S3 and S8 were $278 \times 10^{-6}$ and $382 \times 10^{-6}$. Similar to the previous test, gauge S4 appears to go into compression, thus making the strains recorded for this gauge of questionable accuracy. Gauge S8 also exhibits odd behaviour after the maximum strain is reached in this gauge. Gauge S9 only experienced small vibrations. The strain readings show that the dynamic development length was between $545 \mathrm{~mm}$ and $805 \mathrm{~mm}$, which is less than the bonded length of $830 \mathrm{~mm}$ provided in the beam. All strain profiles are shown in Figure 4-116.

Concrete gauges $\mathrm{C} 1$ and $\mathrm{C} 3$ were not working during this test. Gauge $\mathrm{C} 2$ was initially in tension due to the residual deflection of the beam from Test DB-25M-1-1. Gauge C2 first moved into compression reaching a maximum compressive strain of $332 \times 10^{-6}$ at $6.08 \mathrm{~ms}$ (Figure 4-117). The gauge then began moving back into tension and the neutral axis crossed gauge $\mathrm{C} 2$ at $7.03 \mathrm{~ms}$. After this point, gauge $\mathrm{C} 2$ reached a maximum tensile strain of $1666 \times 10^{-6}$ at $18.45 \mathrm{~ms}$. The residual tensile strain in gauge $\mathrm{C} 2$ was $182 \times 10^{-6}$.

After this test, a diagonal crack appeared at the depth of the longitudinal reinforcement between the top support and top load point. An additional crack appeared on the compression face approximately $200 \mathrm{~mm}$ above midspan. There were a total of 4 transverse cracks below midspan and a total of 3 transverse cracks above midspan (Figure 4-118). 


\subsection{Test DB-25M-1-3}

This test used a driver pressure of $655 \mathrm{kPa}$. The resulting positive phase reflected pressure and reflected impulse at the shock tube opening were $91.1 \mathrm{kPa}$ and $508.0 \mathrm{kPa}$ ms respectively (Figure 4-119). The positive phase duration of the blast load was 14.1 ms. During testing the beam experienced a maximum midspan displacement of $167.6 \mathrm{~mm}$ and a maximum load point displacement of $112.2 \mathrm{~mm}$ at $66.0 \mathrm{~ms}$ as shown in

Figure 4-120. The maximum support rotation was $8.57^{\circ}$. The preformed crack measured $20.30 \mathrm{~mm}$ after testing. No reinforcement slip was recorded at either end of the beam.

The strain rate in the reinforcing steel during this test was $0.307 \mathrm{~s}^{-1}$. The maximum strain in the debonded region recorded in gauges S5 and S6 were $6878 \times 10^{-6}$ at $12.94 \mathrm{~ms}$ and $8331 \times 10^{-6}$ at $13.86 \mathrm{~ms}$ respectively. Gauges $\mathrm{S} 3, \mathrm{~S} 4$ and S8 reached strains of $1000 \times 10^{-6}, 3107 \times 10^{-6}$, and $1997 \times 10^{-6}$ respectively. Although strains on gauges S1, S2, S9, and S10 were not recorded in this test, the fact that no slipping of the rebar occurred on either end is proof that the strain in the steel reached a value of zero before the reaching the end of the beam. All strain profiles are shown in Figure 4-121.

Concrete gauge $\mathrm{C} 2$, the only gauge not damages in previous tests, suffered damage during this test, suffered damage during test DB-25M-1-3 (Figure 4-122).

During this third shot on Beam DB-7, major concrete spalling on the compression face at midspan occurred (Figure 4-123). The cracks that were previously formed continued to open up. The beam had a very large residual deflection. 


\subsubsection{Beam DB-25M-2 and DB-25M-3}

Only two shots were applied to Beam DB-25M-2 and DB-25M-3. For the first test on each beam, a driver pressure of $262.0 \mathrm{kPa}$ was used since this caused yielding of the reinforcement in test DB-25M-1-2. Unfortunately for test DB-25M-2-1 and DB-25M-3-1, this driver pressure did not result in yielding of the reinforcement. This is due to the fact that the resistance of Beam DB-25M-1 was reduced from the previous Test DB-25M-1-1, whereas the tests on Beam DB-25M-2 and DB-25M-3 using driver pressure of $262.0 \mathrm{kPa}$ was on virgin samples. The second shot on Beam DB-25M-2 and DB-25M-3 was chosen to have driver pressure of greater magnitude than what was used for the first shot.

\subsection{Test DB-25M-2-1}

The first shot on Beam DB-25M-2 caused a positive phase reflected pressure of $45.5 \mathrm{kPa}$ and a reflected impulse of $241.1 \mathrm{kPa}-\mathrm{ms}$ at the shock tube opening (Figure 4-124). The duration of the positive phase was $11.9 \mathrm{~ms}$. The maximum midspan displacement was $25.8 \mathrm{~mm}$ and the maximum load point displacement was $19.9 \mathrm{~mm}$ at $21.8 \mathrm{~ms}$ as shown in Figure 4-125. The maximum support rotation was $1.53^{\circ}$. The preformed crack at midspan opened up had an initial width of $5.46 \mathrm{~mm}$ and a residual width of $5.74 \mathrm{~mm}$. No reinforcement slip was recorded at either end of the beam.

The strain rate in the reinforcing steel during this test was $0.157 \mathrm{~s}^{-1}$. The maximum strain in the debonded region recorded on gauges S5 and S6 were $2241 \times 10^{-6}$ at $20.5 \mathrm{~ms}$ and $2486 \times 10^{-6}$ at $20.5 \mathrm{~ms}$ respectively. Gauges S7 and S8 experienced a maximum strain of $789 \times 10^{-6}$ and $581 \times 10^{-6}$ respectively. However, the data from gauge S8 is not very reliable since the gauge produces random peaks. It is possible that this gauge debonded from the surface of the steel but continued to provide strain readings. Gauges 
S1 and S10 did not record any strains, only some noise in the gauges, likely due to oscillations. The residual strains in gauges S5, S6 and S7 were $505 \times 10^{-6}, 578 \times 10^{-6}$, and $482 \times 10^{-6}$ respectively. Gauge S4 malfunctioned during this test and is not shown with other strain gauges in Figure 4-126. Figure 4-127 shows the strain profile along the beam at the time when the steel in the debonded region reaches its maximum strain and shows that the length over which the strain reduces from the maximum strain to zero strain is between $545 \mathrm{~mm}$ and $805 \mathrm{~mm}$ which is less than the bonded length of $830 \mathrm{~mm}$. The dynamic yield strain of $3163 \times 10^{-6}$ was not reached in this test.

The only concrete strains recorded in this test were from gauge $\mathrm{C} 2$. Gauge $\mathrm{Cl}$ and C3 were not properly wired to the data acquisition system. Gauge C1 initially experienced compression and reached a maximum compressive strain of $232 \times 10^{-6}$ at 5.54 $\mathrm{ms}$ (Figure 4-128). The gauges then goes into tension after $6.87 \mathrm{~ms}$, reaching a maximum tensile strain of $573 \times 10^{-6}$ at $9.88 \mathrm{~ms}$.

During testing, about 4 transverse cracks appeared in the constant moment region. Of these cracks, only one crack appeared in the debonded region on both sides of the midspan (Figure 4-129). A diagonal crack also appeared from the depth of the longitudinal reinforcement at midspan and propagated up toward the top load point.

\subsection{Test DB-25M-2-2}

The second shot on beam DB-25M-2 used a driver pressure of $655 \mathrm{kPa}$. This resulted in a positive phase reflected pressure of $86.7 \mathrm{kPa}$ and a reflected impulse of $446.1 \mathrm{kPa}$ at the shock tube opening (Figure 4-130). The positive phase duration was 13.5 ms. The maximum displacement at midspan was $110.2 \mathrm{~mm}$ and the maximum 
displacement at the load point was $75.5 \mathrm{~mm}$ at $49.6 \mathrm{~ms}$ as shown in Figure 4-131. During the test, the beam experienced a maximum support rotation of $5.78^{\circ}$. The measured residual width of the preformed crack was $57.6 \mathrm{~mm}$. No reinforcement slip was recorded at either end of the beam.

The strain rate in the reinforcing steel during this test was $0.251 \mathrm{~s}^{-1}$. The maximum strain in the debonded region was $10945 \times 10^{-6}$ at $17.2 \mathrm{~ms}$ on gauge S5. Gauge S6 exceeded its scaled limit and therefore did not yield valid strain reading during this test. The maximum strain at the location of gauge S7 was $1952 \times 10^{-6}$. By generating the average curve for gauges S5 and S6 before S6 breaks, it can be determined that the reinforcement yielded at $10.7 \mathrm{~ms}$. Data obtained from gauge S8 is not valid since it enters into compression. The residual strain in gauges S5 and S7 are $3030 \times 10^{-6}$ and $1615 \times 10^{-6}$ respectively. All strain profiles are shown in Figure 4-132. Figure 4-133 shows the strain profile at the time when the steel in the debonded region reaches its dynamic yield strain. The dynamic development length is between $545 \mathrm{~mm}$ and $805 \mathrm{~mm}$ which is less than the bonded length of $830 \mathrm{~mm}$.

All concrete gauges initially go into compression. Gauge $\mathrm{Cl}$ experiences compression and breaks very quickly. Gauge $\mathrm{C} 2$ reaches a maximum compressive strain of $1142 \times 10^{-6}$ at $6.5 \mathrm{~ms}$ and gauge $\mathrm{C} 3$ reaches a maximum compressive strain of $1004 \times 10^{-}$ ${ }^{6}$ at 4.43 ms (Figure 4-134). After gauge C2 and C3 reach the maximum compressive strain, $\mathrm{C} 2$ begins to experience tension at $9.03 \mathrm{~ms}$ and $\mathrm{C} 3$ goes into tension at $7.28 \mathrm{~ms}$. Both gauges then experience rupture

During the test, concrete spalls off the compression face at midspan to the depth of the concrete gauge $\mathrm{Cl}$. A second longitudinal crack forms parallel to the fault line of 
the spalled concrete. All four cracks above and below midspan propagated further and a small diagonal crack was formed between the bottom load point and bottom support beginning at the depth of the longitudinal reinforcement (Figure 4-135).

\subsection{Test DB-25M-3-1}

The first shot on Beam DB-25M-3 resulted in a positive phase reflected pressure of $40.4 \mathrm{kPa}$ and a reflected impulse is $231.9 \mathrm{kPa}-\mathrm{ms}$ (Figure 4-136). The positive phase duration was $11.8 \mathrm{~ms}$. During the test, the maximum midspan displacement was $27.6 \mathrm{~mm}$ and the maximum load point displacement was $21.3 \mathrm{~mm}$ at $21.7 \mathrm{~ms}$ as shown in Figure 4-137. The maximum support rotation was $1.64^{\circ}$. The initial crack width for this test was not measured, but the residual crack width was $5.56 \mathrm{~mm}$. No slip reinforcement was recorded at either end of the beam.

The strain rate in the reinforcing steel during this test was $0.226 \mathrm{~s}^{-1}$. The maximum strain in the debonded region was $2798 \times 10^{-6}$ at $22.5 \mathrm{~ms}$ which was recorded by gauge S5. Therefore the dynamic yield strain of $3163 \times 10^{-6}$ (Table 4-8) was not reached in this test. The maximum strains in gauges S3, S4, S8 and S9 were $1204 \times 10^{-6}$, $2261 \times 10^{-6}, 1397 \times 10^{-6}$, and $219 \times 10^{-6}$ respectively. The strain in S9 seems fairly high since no other large strains were found in this gauge in previous tests, including those tests with higher magnitude blast waves (Figure 4-116). No strain occurred in gauge S1. The residual strains in gauges S3, S4, S5, S8 and S9 were $274 \times 10^{-6}, 286 \times 10^{-6}, 861 \times 10^{-6}$, and $109 \times 10^{-6}$ respectively. All strain profiles are shown in Figure 4-138. Figure 4-139 shows the strain profile in the bonded region at the time when the steel in the debonded region reached its maximum strain. The length over which the strain reduces from the 
maximum strain to zero strain is between $545 \mathrm{~mm}$ and $805 \mathrm{~mm}$ which is less than the bonded length of $830 \mathrm{~mm}$.

While concrete gauge $\mathrm{C} 3$ experiences high tensile strains and ruptures almost instantly, gauges $\mathrm{Cl}$ and $\mathrm{C} 2$ provide some data from the test. Both $\mathrm{Cl}$ and $\mathrm{C} 2$ experience compressive strains during early stages of testing, but strains in gauge $\mathrm{C} 2$ changes to tensile at $9.02 \mathrm{~ms}$ as the preformed crack grew and the neutral axis moved towards the compression fibre of the section. After about $31.7 \mathrm{~ms}$ gauge C2 goes back into compression as the beam rebounds and both strain gauges oscillate between tensile and compressive strain states as the beam vibrates. Gauge $\mathrm{Cl}$ experiences a maximum compressive strain of $1654 \times 10^{-6}$ at $25.3 \mathrm{~ms}$, while gauge $\mathrm{C} 2$ experiences a maximum tensile strain of $702 \times 10^{-6}$ at $18.8 \mathrm{~ms}$ during the first cycle (Figure 4-140), both occurring at about maximum displacement of the beam (Figure 4-140). The residual tensile strain in gauge $\mathrm{C} 1$ is $162 \times 10^{-6}$ and the residual tensile strain in gauge $\mathrm{C} 2$ is $389 \times 10^{-6}$.

Similar to the first test on Beam DB-25M-2, four transverse cracks appeared both above and below the midspan on the tension face after the first test on Beam DB-25M-3 (Figure 4-141). No longitudinal cracks were observed during this test.

\subsection{Test DB-25M-3-2}

For the second shot on beam DB-25M-3, a driver pressure of $655 \mathrm{kPa}$ was used. This resulted in a positive phase reflected pressure of $83.0 \mathrm{kPa}$ and a reflected impulse of 490.6 $\mathrm{kPa}-\mathrm{ms}$ at the shock tube opening (Figure 4-142). The positive phase duration was $14.0 \mathrm{~ms}$. At $49.7 \mathrm{~ms}$, the midspan reached a maximum displacement of $112.9 \mathrm{~mm}$ and the load point reached a maximum displacement of $78.5 \mathrm{~mm}$ as shown in Figure 4-143. The 
maximum support rotation was $6.02^{\circ}$. The final width of the preformed crack measured $18.2 \mathrm{~mm}$. No reinforcement slip was recorded at either end of the beam.

The strain rate in the reinforcing steel during this test was $0.293 \mathrm{~s}^{-1}$. The maximum strain in the debonded region cannot be determined for this test since gauge S5 failed during the test. The maximum strains in gauges S3, S4, and S9 were $1632 \times 10^{-6}$, $4541 \times 10^{-6}$, and $296 \times 10^{-6}$ respectively, while the residual strains in gauges $\mathrm{S} 3, \mathrm{~S} 4$, and S9 were $405 \times 10^{-6}, 1985 \times 10^{-6}$, and $159 \times 10^{-6}$ respectively. During this test, gauge S3 experienced random peaks. Thus, it is possible that the data recorded from this gauge is not very accurate. All strain profiles are shown in Figure 4-144. Figure 4-145 shows the strain profile at the time when the steel in the debonded region reaches its dynamic yield strain. The dynamic development length is between $545 \mathrm{~mm}$ and $805 \mathrm{~mm}$ which is less than the bonded length of $830 \mathrm{~mm}$.

Concrete gauge $\mathrm{Cl}$ initially went into compression and then failed. Gauge $\mathrm{C} 2$ initially goes into compression experiencing a compressive strain of $832 \times 10^{-6}$ at $6.96 \mathrm{~ms}$ before moving back into tension at $8.9 \mathrm{~ms}$. The maximum tensile strain on the gauge is then $606 \times 10^{-6}$ at $13.42 \mathrm{~ms}$ before the gauge once again went back into compression at $14.82 \mathrm{~ms}$, reaching a maximum compressive strain of $4967 \times 10^{-6}$ before the gauge breaks (Figure 4-146). No residual strains were recorded since all gauges were damaged by the end of the test.

During this test, the cracks formed in the previous test propagated. Similar to test DB-25M-2-2 a small diagonal crack was formed between the bottom load point and bottom support beginning at the depth of the longitudinal reinforcement. Other damage to the beam included concrete spall on the compression face at midspan (Figure 4-147). 
Table 4-11: Pressure, impulse, displacement, support rotation and crack width data for beams DB-15M-1, DB-20M-1, and DB25M-1

\begin{tabular}{|c|c|c|c|c|c|c|c|c|c|c|}
\cline { 2 - 12 } & $P_{d}(\mathbf{k P a})$ & $P_{r}(\mathbf{k P a})$ & $I_{r}(\mathbf{k P a}-\mathbf{m s})$ & $t_{d}(\mathbf{m s})$ & $d_{m}(\mathbf{m m})$ & $d_{l}(\mathbf{m m})$ & $t_{\max }(\mathbf{m m})$ & $\theta_{\max }\left({ }^{\circ}\right)$ & $w_{c i}(\mathbf{m m})$ & $w_{c f}(\mathbf{m m})$ \\
\hline DB-15M-1-1 & 55 & 8.72 & 55.8 & 9.0 & 5.5 & 3.8 & 18.3 & 0.28 & - \\
\hline DB-15M-1-2 & 110 & 25.8 & 117.0 & 10.0 & 15.7 & 10.5 & 21.2 & 0.80 & - & 8.38 \\
\hline DB-15M-1-3 & 166 & 33.8 & 168.3 & 11.0 & 24.8 & 16.5 & 22.8 & 1.27 & 8.38 & 8.95 \\
\hline DB-15M-1-4 & 303 & 51.6 & 273.4 & 12.0 & 56.2 & 37.2 & 49.6 & 2.85 & 8.95 & 15.50 \\
\hline DB-20M-1-1 & 138 & 29.3 & 134.8 & 10.4 & 19.3 & 12.7 & 21.2 & 0.98 & 5.99 & 7.57 \\
\hline DB-20M-1-2 & 227 & 45.0 & 219.7 & 11.3 & 34.8 & 22.7 & 24.4 & 1.75 & 7.57 & 5.59 \\
\hline DB-20M-1-3 & 586 & 90.8 & 451.5 & 13.6 & 201.8 & 142.7 & 71.6 & 10.80 & 5.59 & 34.80 \\
\hline DB-25M-1-1 & 207 & 37.4 & 200.6 & 11.5 & 22.1 & 15.9 & 20.6 & 1.22 & 7.37 & 7.37 \\
\hline DB-25M-1-2 & 262 & 43.2 & 238.8 & 12.0 & 30.3 & 20.8 & 21.5 & 1.60 & 7.37 & 8.13 \\
\hline DB-25M-1-3 & 655 & 91.1 & 508.0 & 14.1 & 167.6 & 112.2 & 66.0 & 8.57 & 8.13 & 20.30 \\
\hline
\end{tabular}

Notes:

$P_{d}$ - Driver Pressure

$d_{l}$ - Load Point Displacement

$P_{r}$ - Reflected Pressure

$t_{\text {max }}$ - Time to Maximum Displacement

$I_{r}$ - Reflected Impulse

$\theta_{\max }$ - Maximum Support Rotation

$t_{d}$ - Positive Phase Duration

$w_{c i}$ - Initial Width of Preformed Crack

$d_{m}$ - Midspan Displacement

$w_{c f}$ - Final Width of Preformed Crack 
Table 4-12: Strain and displacement data for beams DB-15M-1, DB-20M-1, and DB-25M-1

\begin{tabular}{|c|c|c|c|c|c|c|c|c|}
\hline & $\begin{array}{l}\text { Strain } \\
\text { rate }\left(s^{-1}\right)\end{array}$ & $\begin{array}{c}\text { Maximum } \\
\text { Strain in S5 } \\
(\mathbf{m m} / \mathbf{m m} \times \\
\left.1^{-6}\right)\end{array}$ & $\begin{array}{c}\text { Maximum } \\
\text { Strain in S6 } \\
(\mathbf{m m} / \mathbf{m m} \times \\
\left.10^{-6}\right)\end{array}$ & $\begin{array}{c}\text { Average } \\
\text { Maximum } \\
\text { Strain in } \\
\text { Debonded } \\
\text { Region } \\
\left(\mathrm{mm} / \mathrm{mm}^{-6} \mathrm{x}\right. \\
\left.10^{-6}\right)\end{array}$ & $\begin{array}{c}\text { Time to } \\
\text { Maximum } \\
\text { Strain } \\
(\mathbf{m m})\end{array}$ & $\begin{array}{c}\text { Time to } \\
\text { Yield (ms) }\end{array}$ & $\begin{array}{l}\text { Displace- } \\
\text { ment at DT } \\
(\mathrm{mm})\end{array}$ & $\begin{array}{l}\text { Displace- } \\
\text { ment at DB } \\
\text { (mm) }\end{array}$ \\
\hline DB-15M-1-1 & 0.0499 & 576.2 & - & 576 & 17.4 & - & $\overline{0}$ & 0 \\
\hline DB-15M-1-2 & $\mathrm{n} / \mathrm{a}$ & - & - & - & - & - & 0 & 0 \\
\hline DB-15M-1-3 & 0.143 & 2539.7 & 3299 & 2919 & 23.4 & 20.7 & 0 & 0 \\
\hline DB-15M-1-4 & 0.323 & 4162.5 & - & 4162 & 72.5 & 13.3 & 0 & 0 \\
\hline DB-20M-1-1 & 0.122 & - & 1703 & 1703 & 20.6 & - & 0 & 0 \\
\hline DB-20M-1-2 & 0.212 & - & 2990 & 2990 & 23.5 & 16.6 & 0 & 0 \\
\hline DB-20M-1-3 & 0.412 & - & - & - & - & 9.4 & 0 & 0 \\
\hline DB-25M-1-1 & 0.143 & 2025.0 & - & 2025 & 18.7 & - & 0 & 0 \\
\hline DB-25M-1-2 & 0.227 & 3475.0 & 3397 & 3436 & 22.1 & 18.3 & 0 & 0 \\
\hline DB-25M-1-3 & 0.307 & 6878.2 & 8331 & 7605 & 13.4 & 8.30 & 0 & 0 \\
\hline
\end{tabular}


Table 4-13: Pressure, impulse, displacement, support rotation and crack width data for beams DB-15M-2, DB-15M-3, DB-

20M-2, DB-20M-3, DB-25M-2, and DB-25M-3

\begin{tabular}{|c|c|c|c|c|c|c|c|c|c|c|}
\hline & $P_{d}(\mathbf{k P a})$ & $P_{r}(\mathbf{k P a})$ & $I_{r}(\mathrm{kPa}-\mathrm{ms})$ & $t_{d}(\mathrm{~ms})$ & $d_{m}(\mathrm{~mm})$ & $d_{l}(\mathrm{~mm})$ & $t_{\max }(\mathrm{mm})$ & $\theta_{\max }\left(^{\circ}\right)$ & $w_{c i}(\mathbf{m m})$ & $w_{c f}(\mathrm{~mm})$ \\
\hline DB-15M-2-1 & 165 & 35.2 & 168.8 & 11 & 23.2 & 15.9 & 23.2 & 1.22 & 9.63 & 12.10 \\
\hline DB-15M-3-1 & 165 & 30.4 & 160.1 & 11.3 & 26.7 & 17.8 & 24.9 & 1.37 & 5.92 & 6.25 \\
\hline Average & 165 & 32.8 & 164.5 & 11.1 & 24.9 & 16.9 & 24.2 & 1.30 & 7.77 & 9.19 \\
\hline DB-15M-2-2 & 379 & 61.1 & 316.8 & 12.1 & 81.6 & 55.5 & 54.9 & 4.26 & 12.10 & 20.20 \\
\hline DB-15M-3-2 & 483 & 64.1 & 362.8 & 12.6 & 127.4 & 84.9 & 57.4 & 6.49 & 6.25 & $\mathrm{n} / \mathrm{a}$ \\
\hline Average & 431 & 62.6 & 339.8 & 12.3 & 104.5 & 70.2 & 56.2 & 5.38 & 9.19 & 20.20 \\
\hline DB-20M-2-1 & 227 & 42.6 & 216.2 & 11.5 & 44.9 & 30.3 & 24.7 & 2.33 & 4.32 & 4.60 \\
\hline DB-20M-3-1 & 227 & 38.6 & 214.8 & 11.6 & 33.4 & 22.1 & 24.9 & 1.70 & 7.39 & 5.18 \\
\hline Average & 227 & 40.6 & 215.5 & 11.6 & 39.2 & 26.2 & 24.8 & 2.01 & 5.85 & 4.89 \\
\hline DB-20M-2-2 & 586 & 90.4 & 450.9 & 13.1 & 186.6 & 124.1 & 69.1 & 9.46 & 4.6 & 29.0 \\
\hline DB-20M-3-2 & 586 & 68.2 & 427.8 & 12.8 & 134.4 & 92.1 & 56.4 & 7.05 & 5.18 & 22.0 \\
\hline Average & 586 & 79.3 & 439.3 & 12.9 & 160.5 & 108.1 & 62.7 & 8.25 & 4.89 & 25.5 \\
\hline DB-25M-2-1 & 262 & 45.5 & 241.1 & 11.9 & 25.8 & 19.9 & 21.8 & 1.53 & 5.46 & 5.74 \\
\hline DB-25M-3-1 & 262 & 40.4 & 231.9 & 11.8 & 27.6 & 21.3 & 21.7 & 1.64 & - & 5.56 \\
\hline Average & 262 & 42.9 & 236.5 & 11.8 & 26.7 & 20.6 & 21.8 & 1.59 & 5.46 & 5.65 \\
\hline DB-25M-2-2 & 655 & 86.7 & 446.1 & 13.5 & 110.2 & 75.5 & 49.6 & 5.78 & 5.74 & 57.60 \\
\hline DB-25M-3-2 & 655 & 83.0 & 490.6 & 14.0 & 112.9 & 78.5 & 49.7 & 6.02 & 5.56 & 18.20 \\
\hline Average & 655 & 84.9 & 468.3 & 13.8 & 111.6 & 77.0 & 49.7 & 5.9 & 5.65 & 37.90 \\
\hline
\end{tabular}

Note: see note on Table 4-11 
Table 4-14: Strain and displacement data for beams DB-15M-2, DB-15M-3, DB-20M-2, DB-20M-3, DB-25M-2, and DB-25M-3

\begin{tabular}{|c|c|c|c|c|c|c|c|c|}
\hline & $\begin{array}{c}\text { Strain } \\
\text { rate }\left(s^{-1}\right)\end{array}$ & $\begin{array}{c}\text { Maximum } \\
\text { Strain in } \\
\text { S5 } \\
(\mathrm{mm} / \mathrm{mm} \mathrm{x} \\
\left.10^{-6}\right) \\
\end{array}$ & $\begin{array}{c}\text { Maximum } \\
\text { Strain in } \\
\text { S6 } \\
(\mathrm{mm} / \mathrm{mm} \mathrm{x} \\
\left.10^{-6}\right) \\
\end{array}$ & $\begin{array}{c}\text { Average } \\
\text { Maximum Strain } \\
\text { in Debonded } \\
\text { Region }(\mathbf{m m} / \mathrm{mm} \\
\left.\times 10^{-6}\right) \\
\end{array}$ & $\begin{array}{c}\text { Time to } \\
\text { Maximu } \\
\text { m Strain } \\
\text { (mm) }\end{array}$ & $\begin{array}{l}\text { Time to } \\
\text { Yield } \\
\text { (ms) }\end{array}$ & $\begin{array}{c}\text { Displace- } \\
\text { ment at } \\
\text { DT (mm) }\end{array}$ & $\begin{array}{c}\text { Displace- } \\
\text { ment at } \\
\text { DB (mm) }\end{array}$ \\
\hline DB-15M-2-1 & 0.167 & 3339 & 3092 & 3215 & 25 & 19.9 & 0 & 0 \\
\hline DB-15M-3-1 & 0.159 & 2839 & - & 2839 & 24 & 22.4 & 0 & 0 \\
\hline Average & 0.163 & 3089 & 3092 & 3027 & 24 & 21.1 & 0 & 0 \\
\hline DB-15M-2-2 & 0.361 & - & - & - & - & 10.8 & 0 & 0 \\
\hline DB-15M-3-2 & 0.357 & - & - & - & - & 10.9 & 0 & 0 \\
\hline Average & 0.359 & - & - & - & - & 10.8 & 0 & 0 \\
\hline DB-20M-2-1 & 0.202 & 2923 & - & 2923 & 24 & 19.1 & 0 & 0 \\
\hline DB-20M-3-1 & 0.193 & 2867 & - & 2867 & 25 & 18.9 & 0 & 0 \\
\hline Average & 0.198 & 2895 & - & 2895 & 24 & 19.0 & 0 & 0 \\
\hline DB-20M-2-2 & 0.401 & - & - & - & - & 10.1 & 0 & 0 \\
\hline DB-20M-3-2 & 0.287 & - & - & - & - & 11.6 & 0 & 0 \\
\hline Average & 0.344 & - & - & - & - & 10.8 & 0 & 0 \\
\hline DB-25M-2-1 & 0.157 & 2241 & 2485 & 2363 & 21 & - & 0 & 0 \\
\hline DB-25M-3-1 & 0.226 & 2798 & - & 2798 & 22 & - & 0 & 0 \\
\hline Average & 0.192 & 2520 & 2485 & 2581 & 21 & - & 0 & 0 \\
\hline DB-25M-2-2 & 0.251 & - & - & - & - & 10.7 & 0 & 0 \\
\hline DB-25M-3-2 & 0.293 & - & - & - & - & 9.7 & 0 & 0 \\
\hline Average & 0.272 & - & - & - & - & 10.2 & 0 & 0 \\
\hline
\end{tabular}




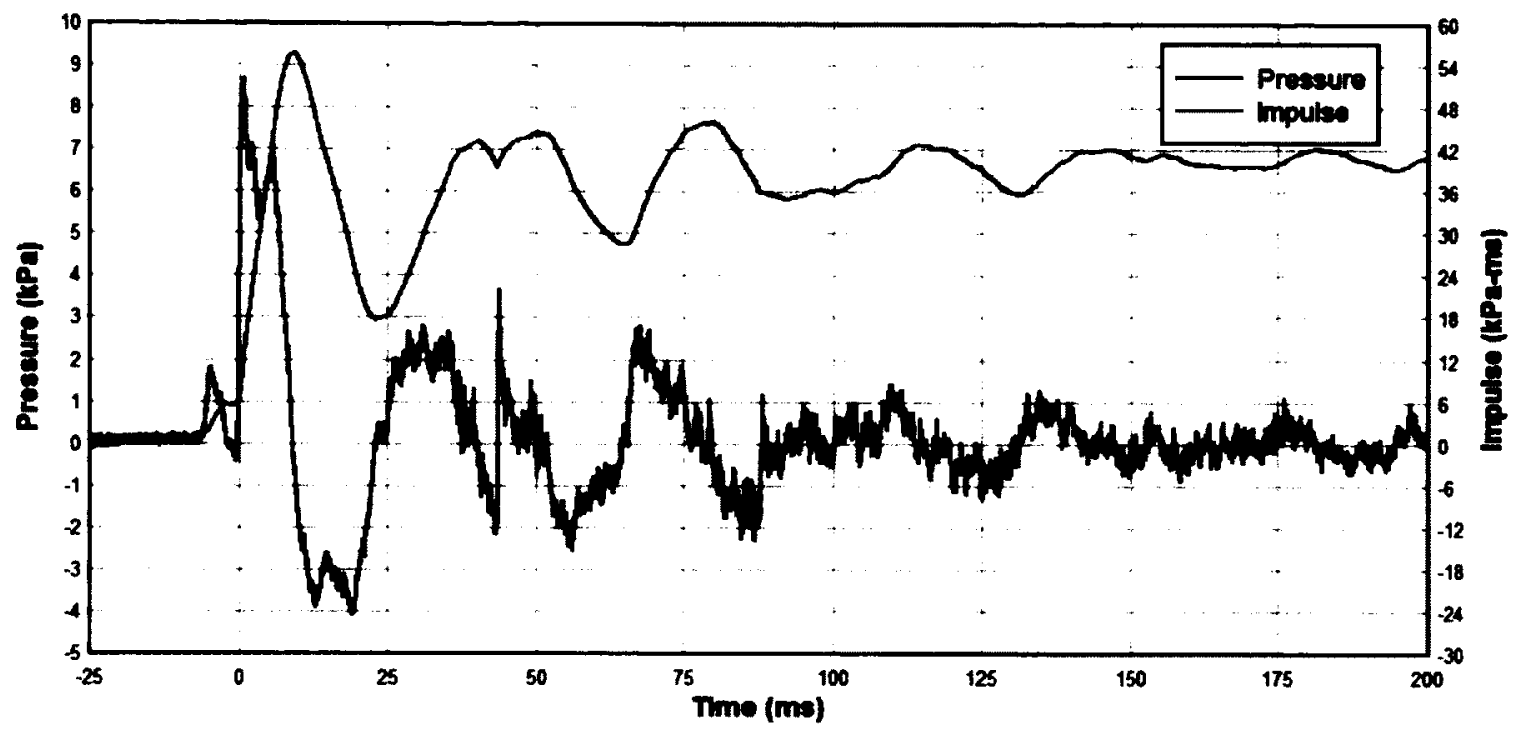

Figure 4-33: Pressure and Impulse Time History for Test DB-15M-1-1

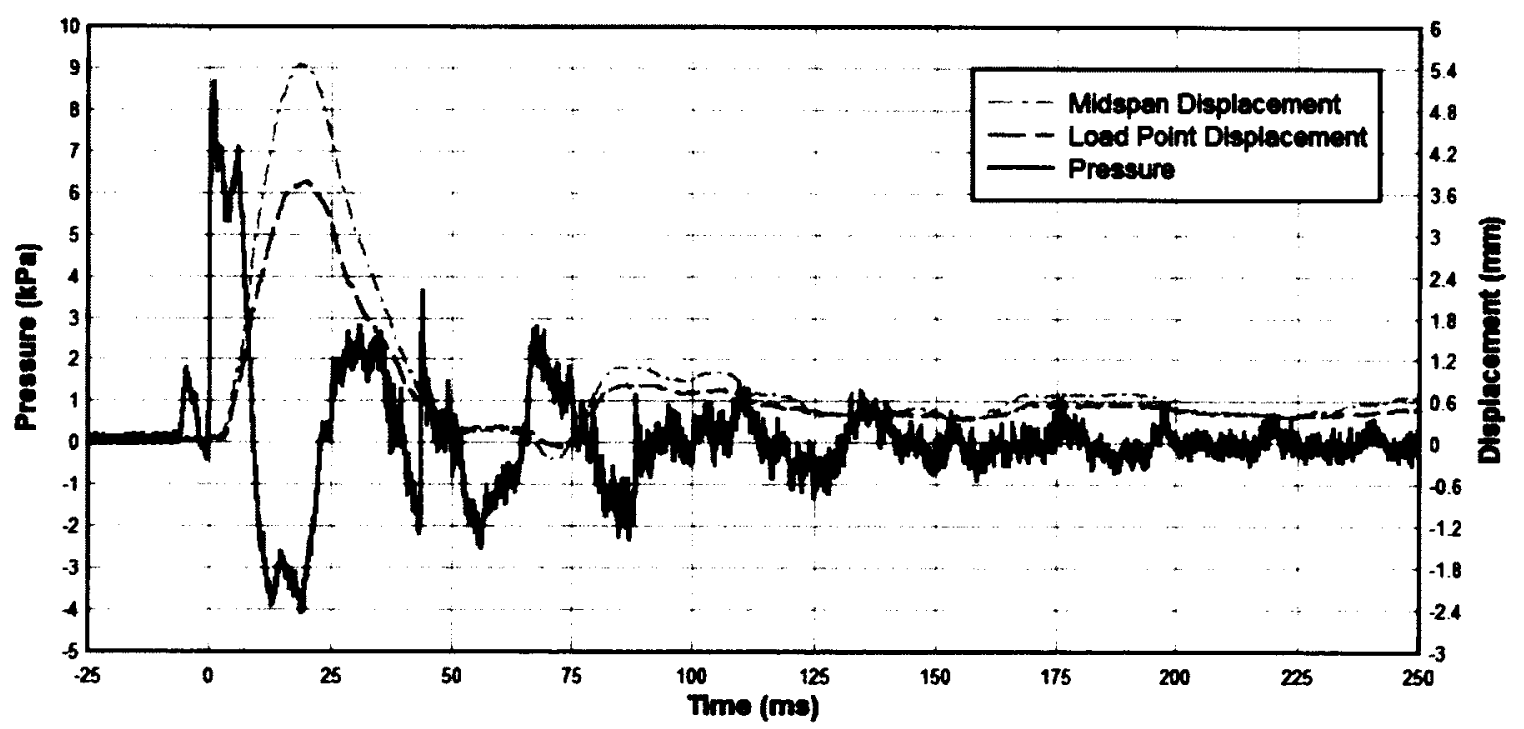

Figure 4-34: Pressure and Displacement Time History for Test DB-15M-1-1 


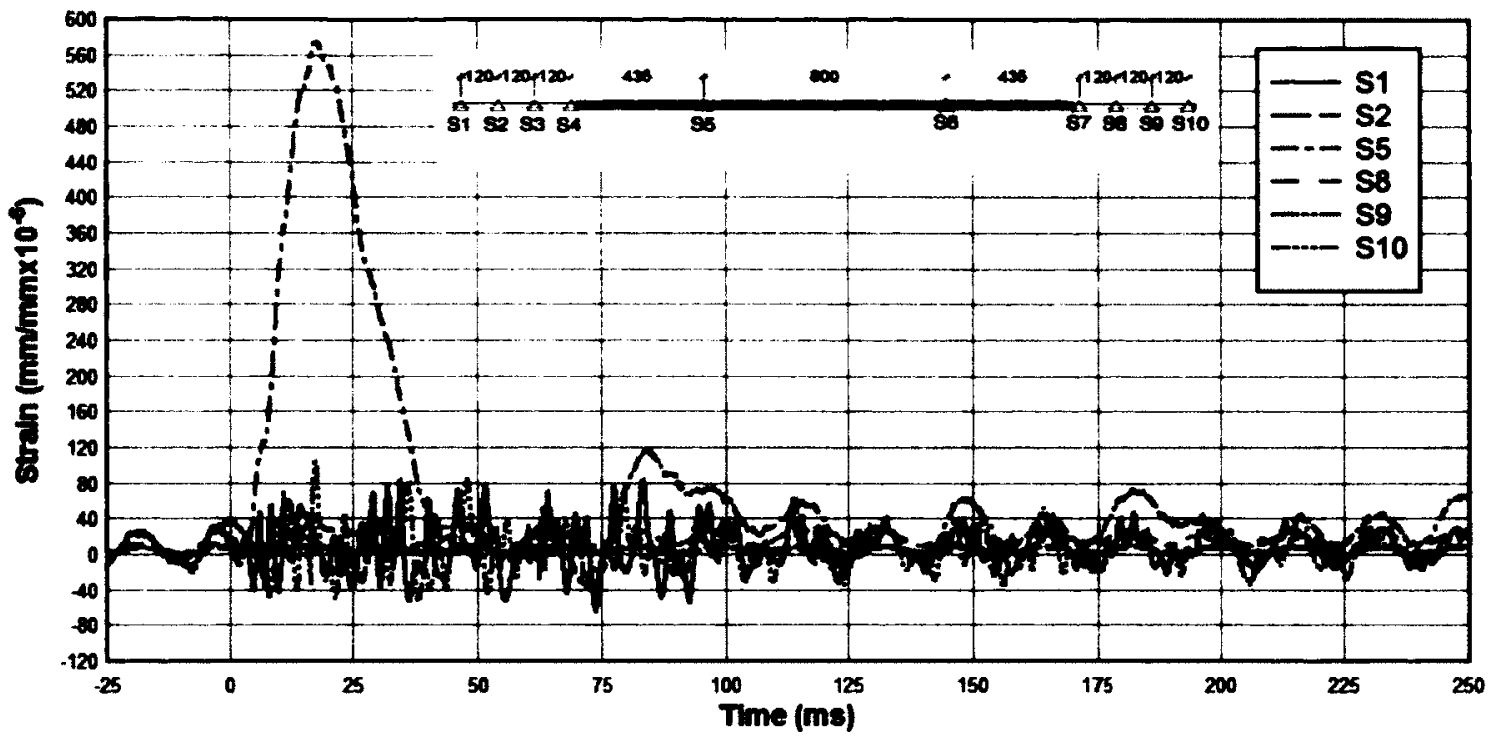

Figure 4-35: Strains in Steel for Test DB-15M-1-1

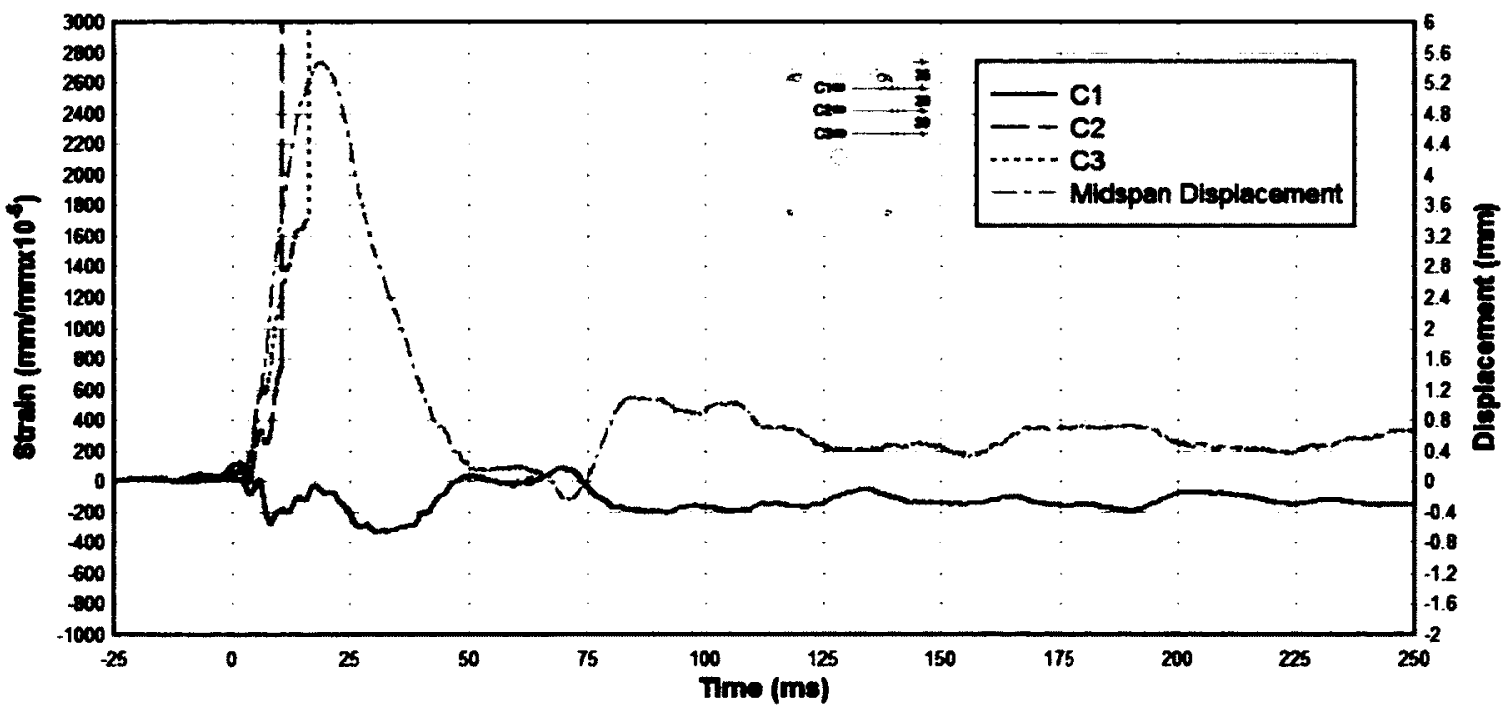

Figure 4-36: Strains in Concrete for Test DB-15M-1-1 


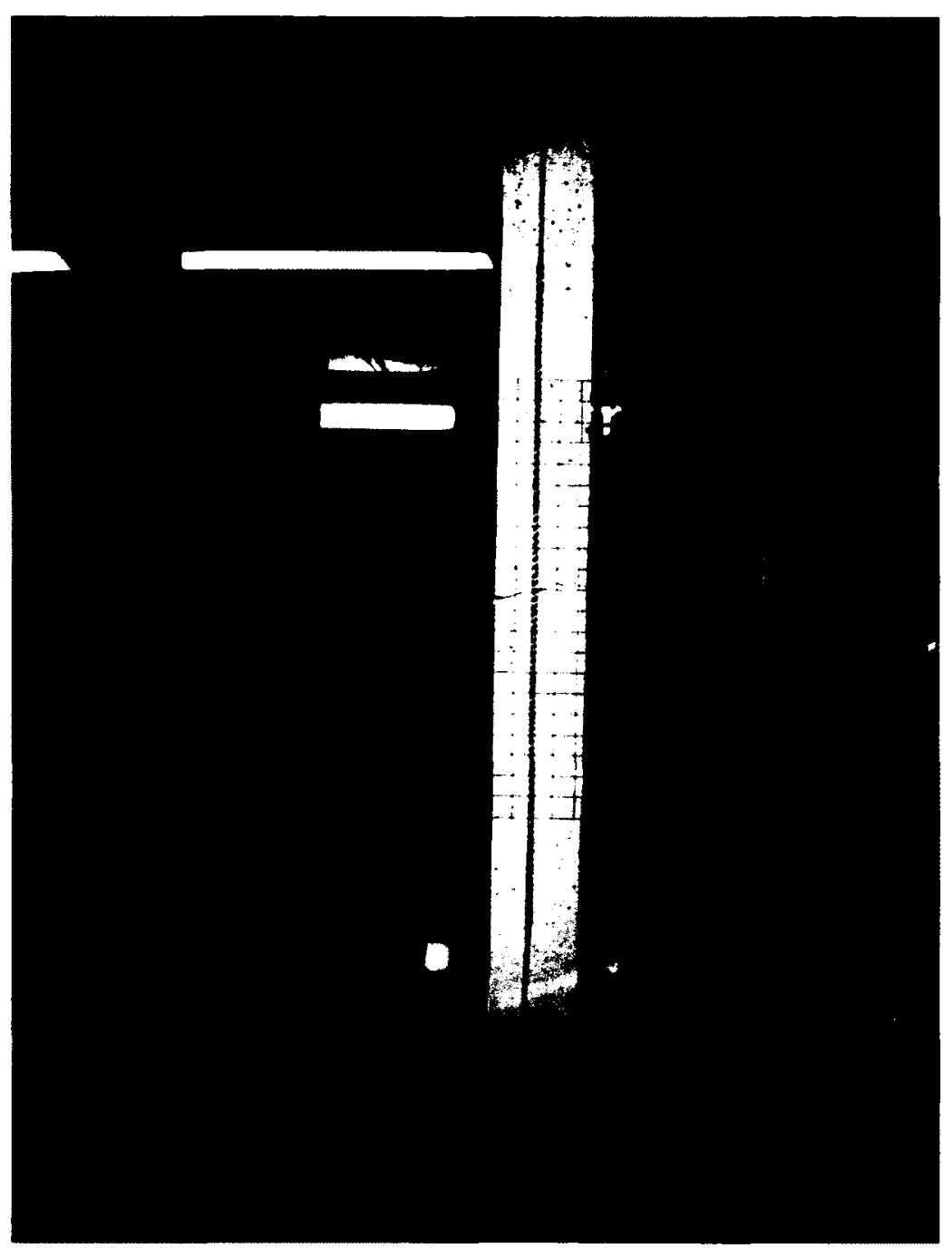

Figure 4-37: Crack Pattern After Test DB-15M-1-1

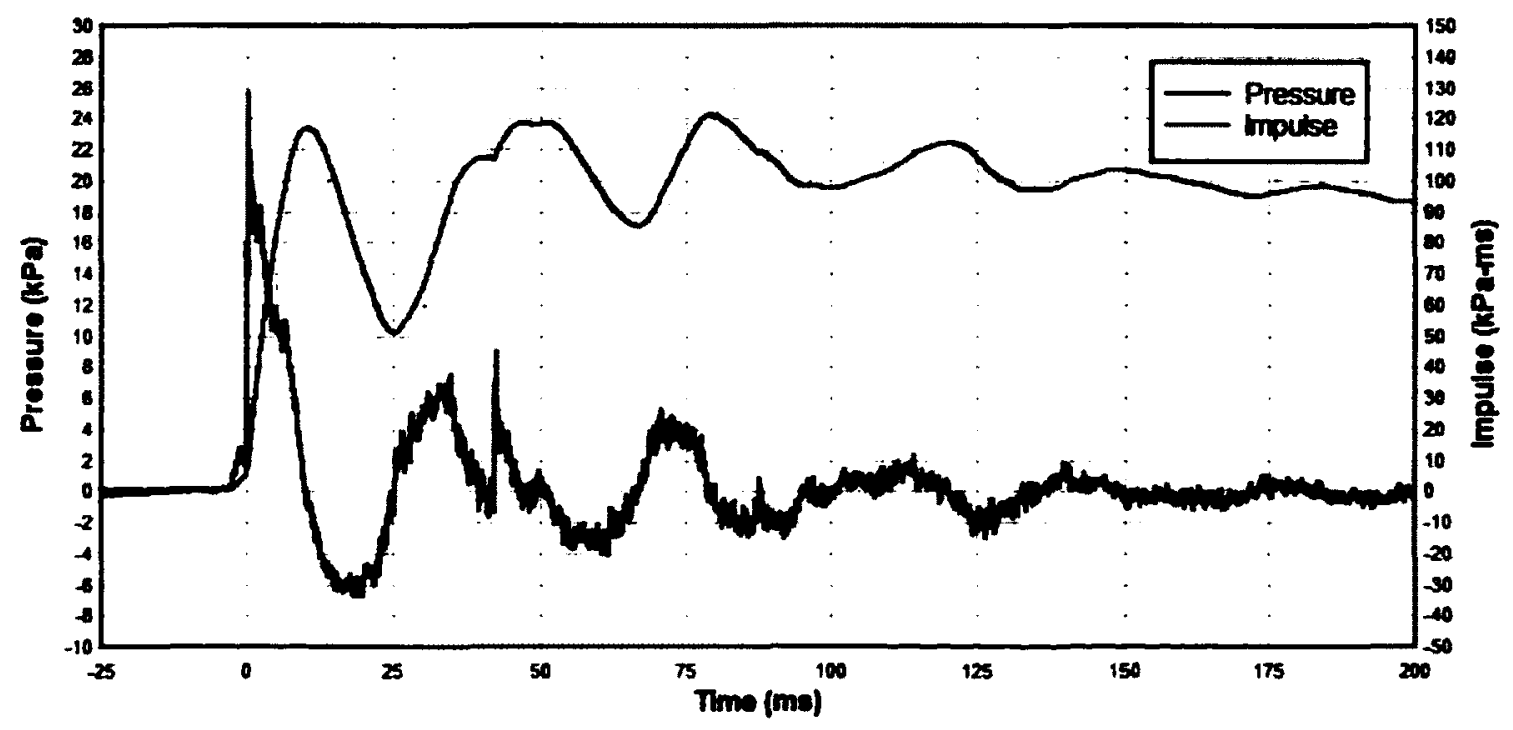

Figure 4-38: Pressure and Impulse Time History for Test DB-15M-1-2 


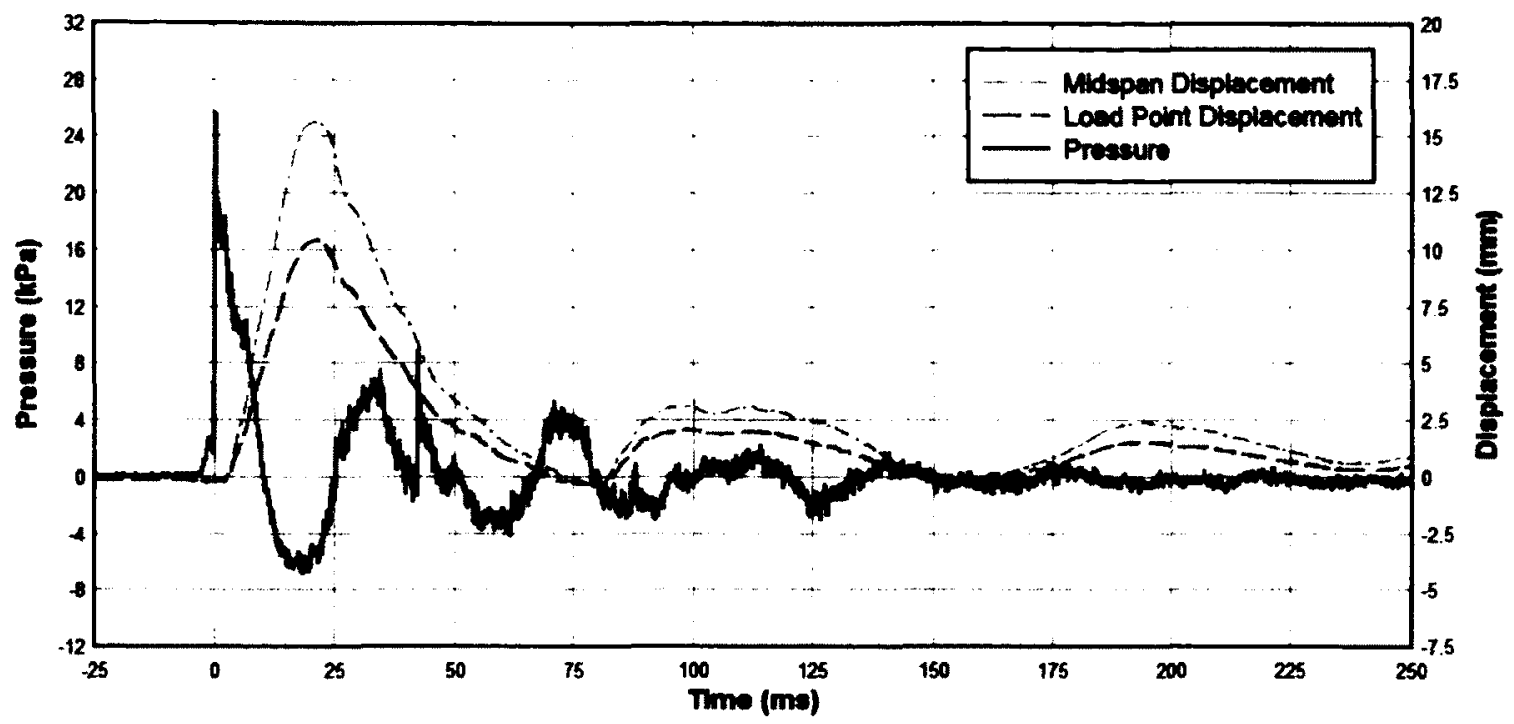

Figure 4-39: Pressure and Displacement Time History for Test DB-15M-1-2

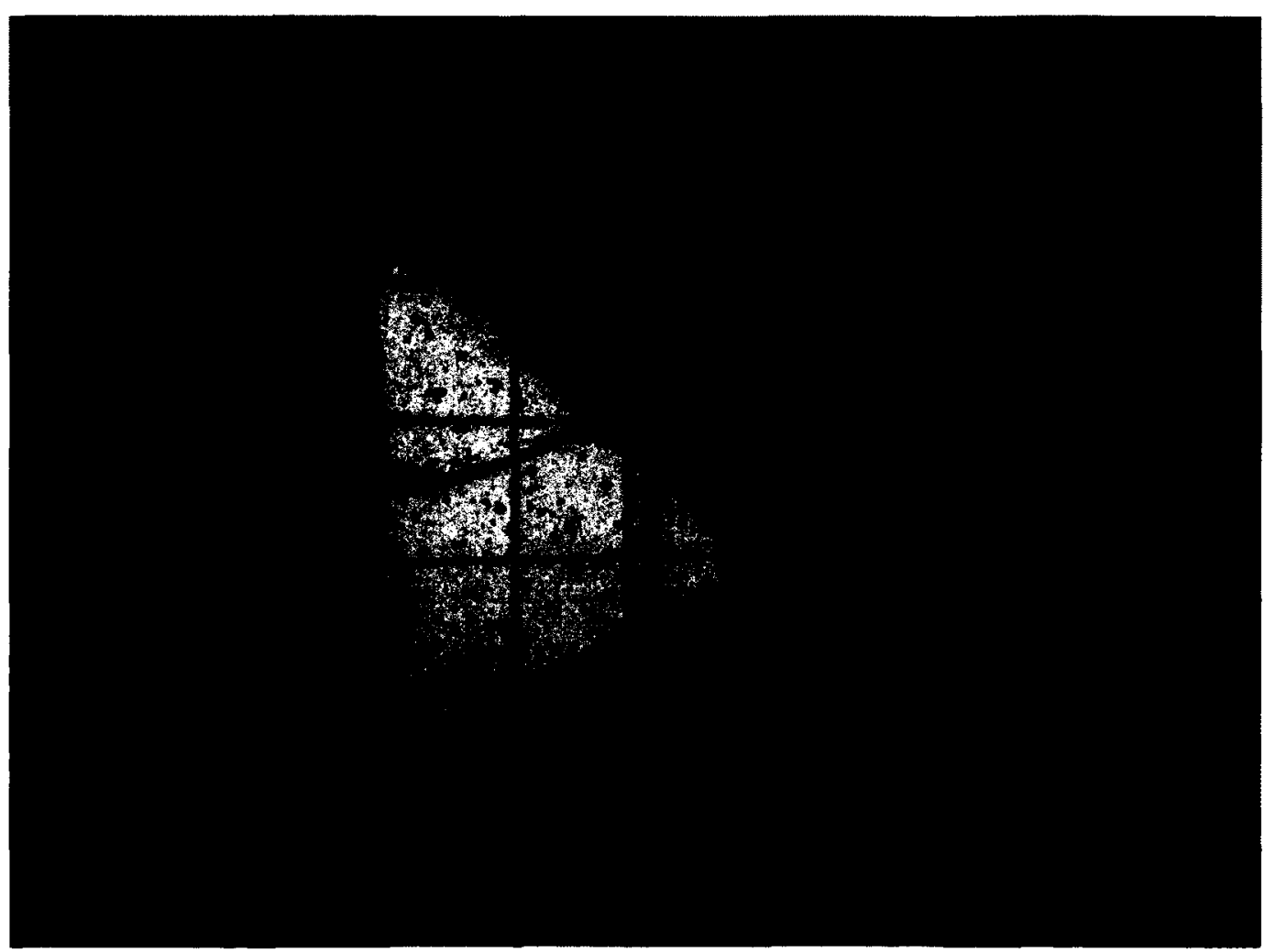

Figure 4-40: Crack Pattern After Test DB-15M-1-2 


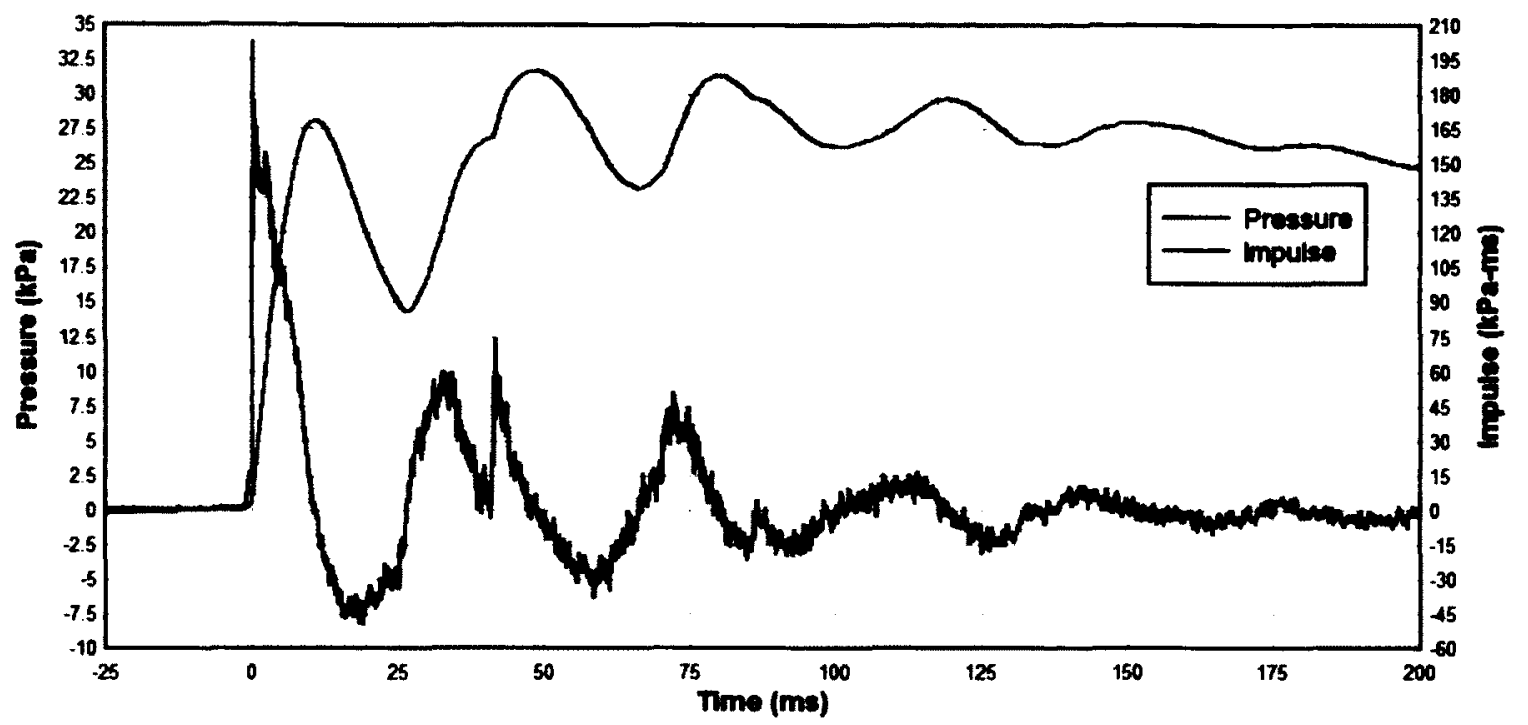

Figure 4-41: Pressure and Impulse Time History for Test DB-15M-1-3

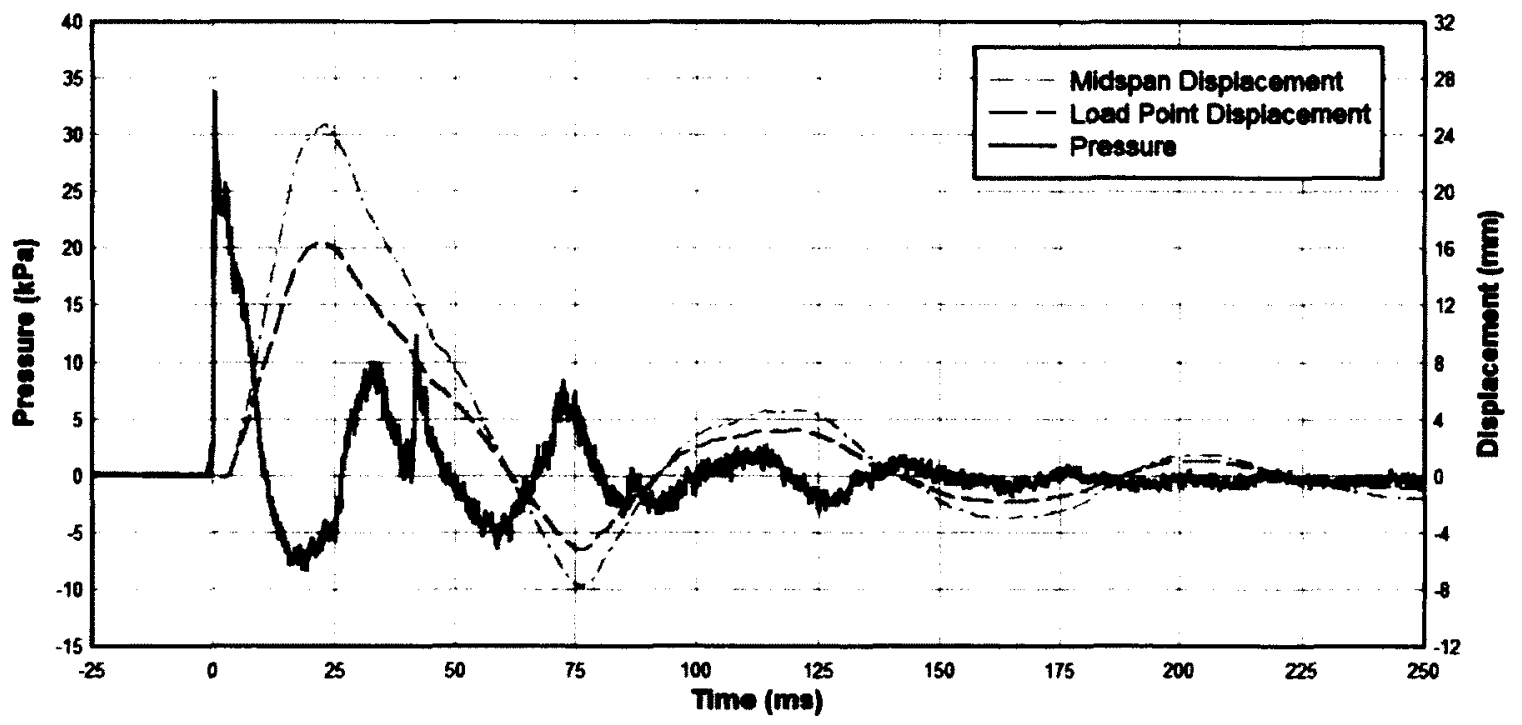

Figure 4-42: Pressure and Displacement Time History for Test DB-15M-1-3 


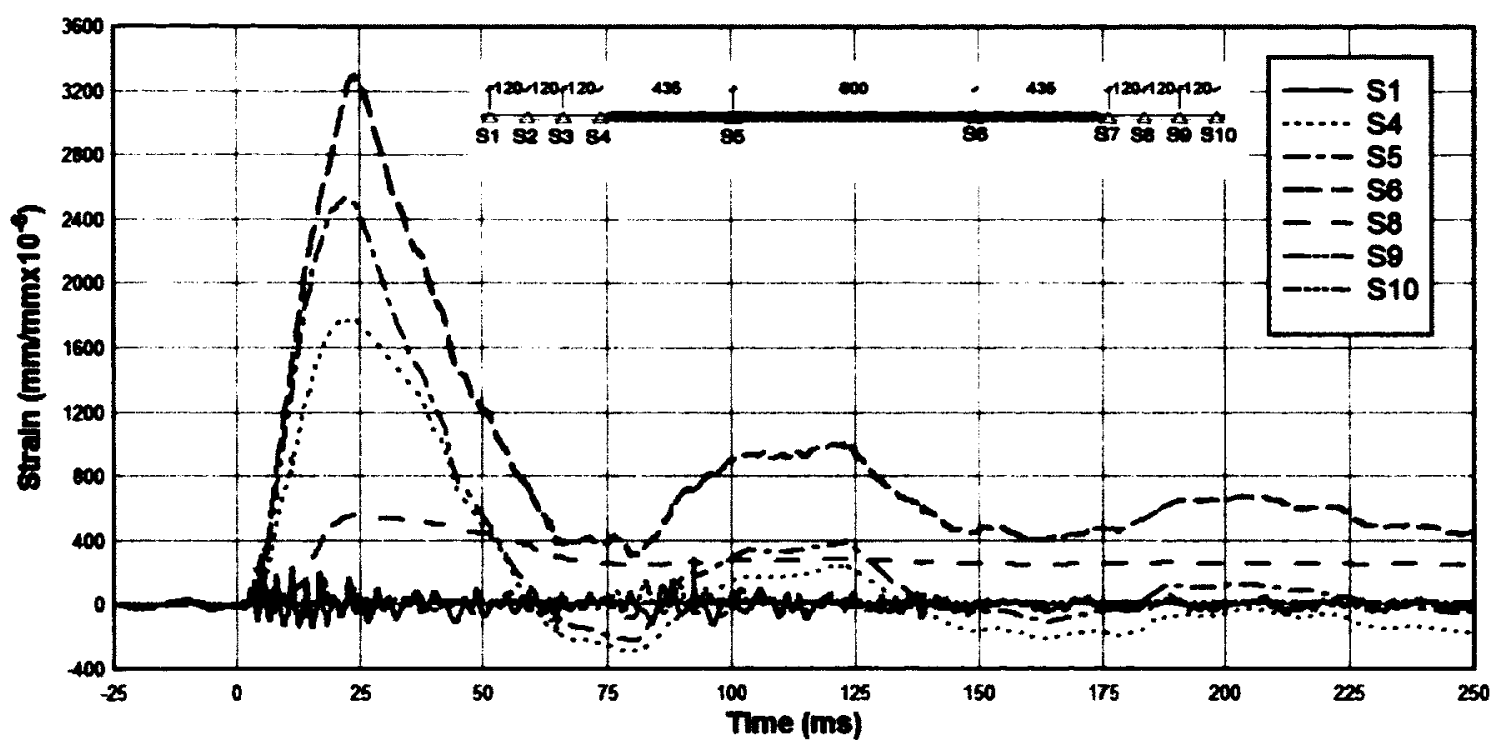

Figure 4-43: Strain in Steel for Test DB-15M-1-3

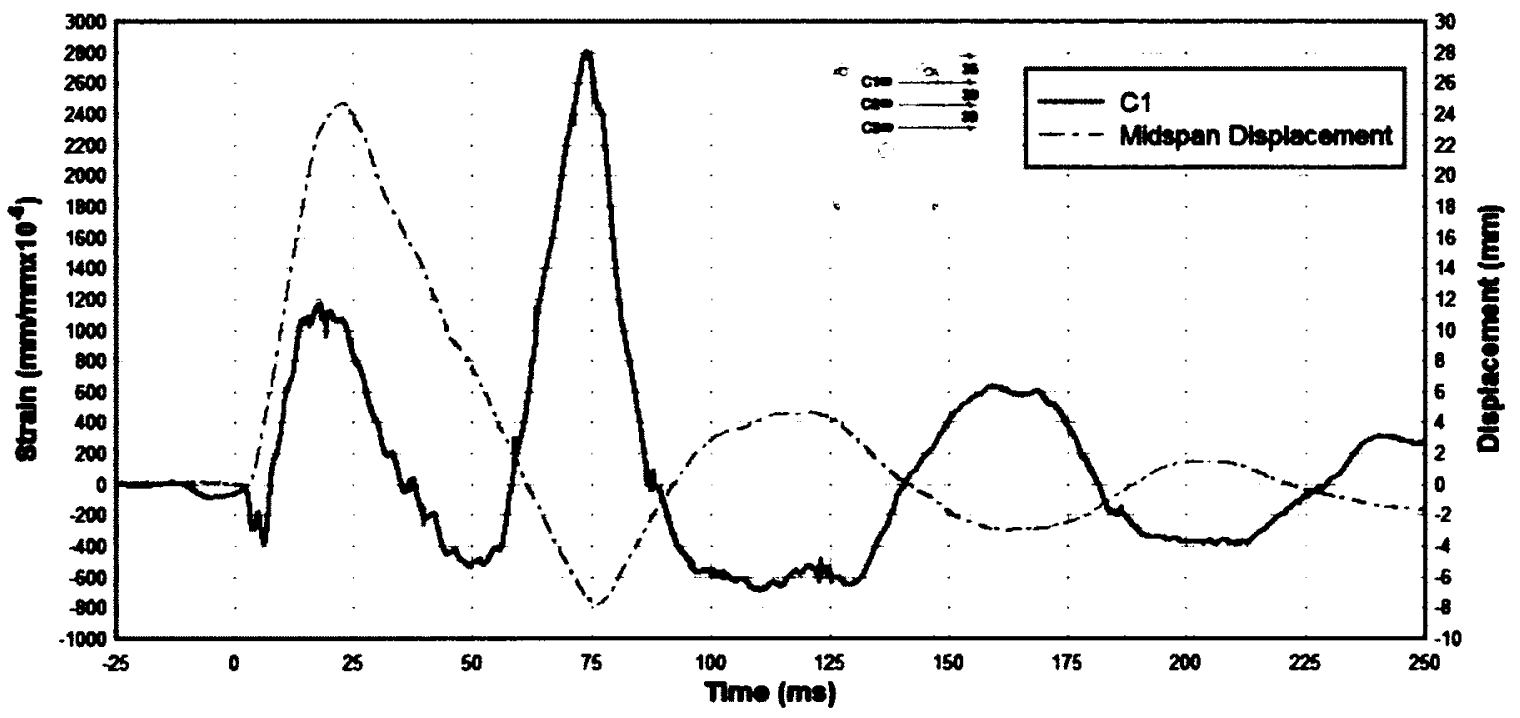

Figure 4-44: Strain in Concrete for Test DB-15M-1-3 
Figure 4-45: Crack Pattern After Test DB-15M-1-3

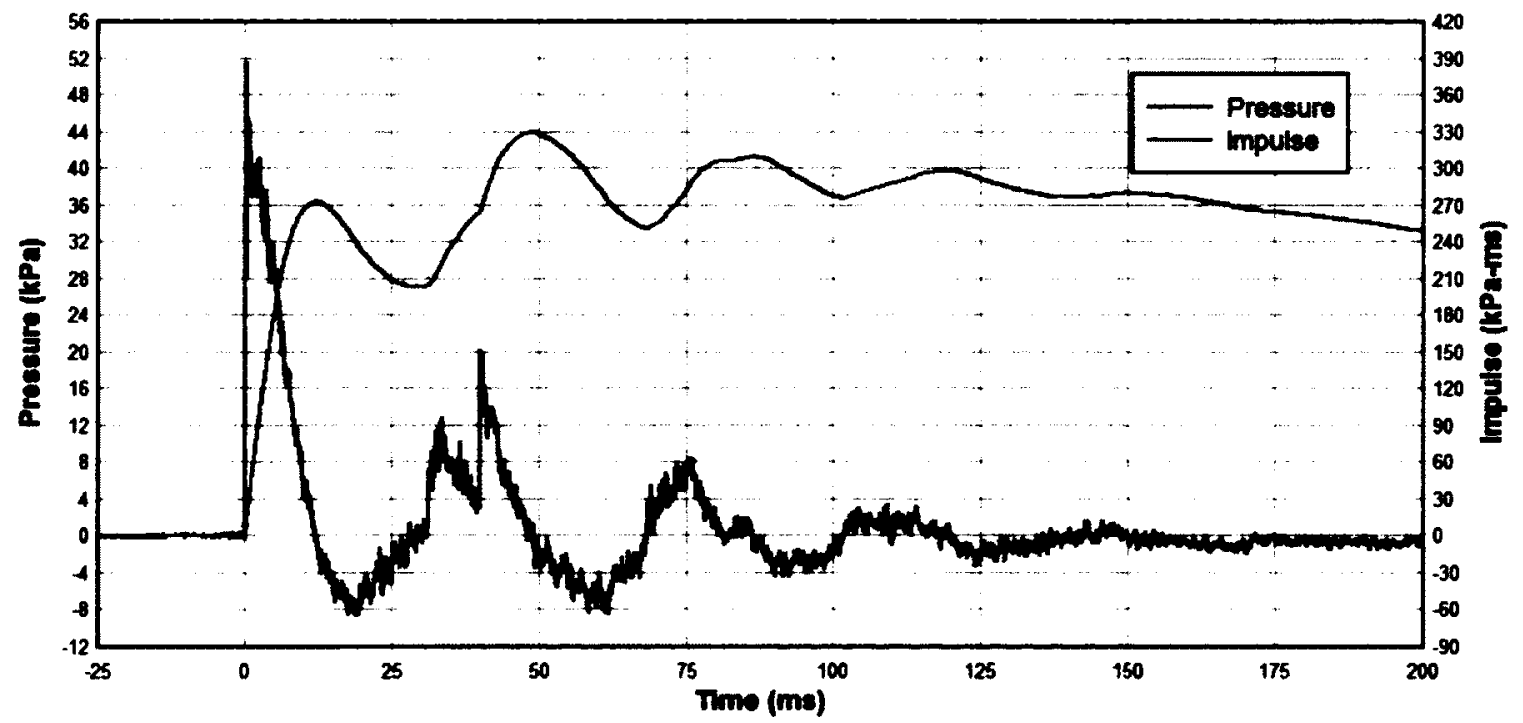

Figure 4-46: Pressure and Impulse Time History for Test DB-15M-1-4 


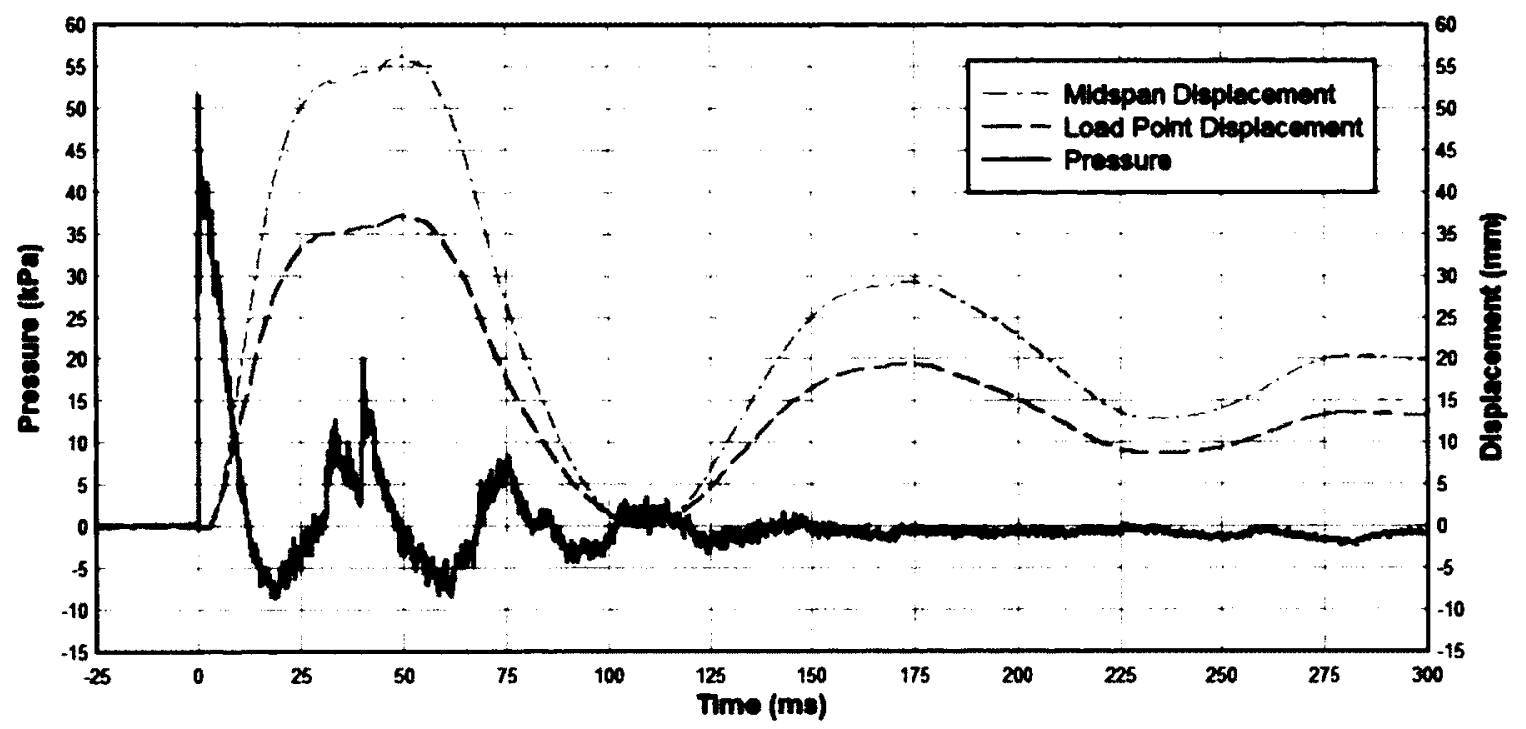

Figure 4-47: Pressure and Displacement Time History for Test DB-15M-1-4

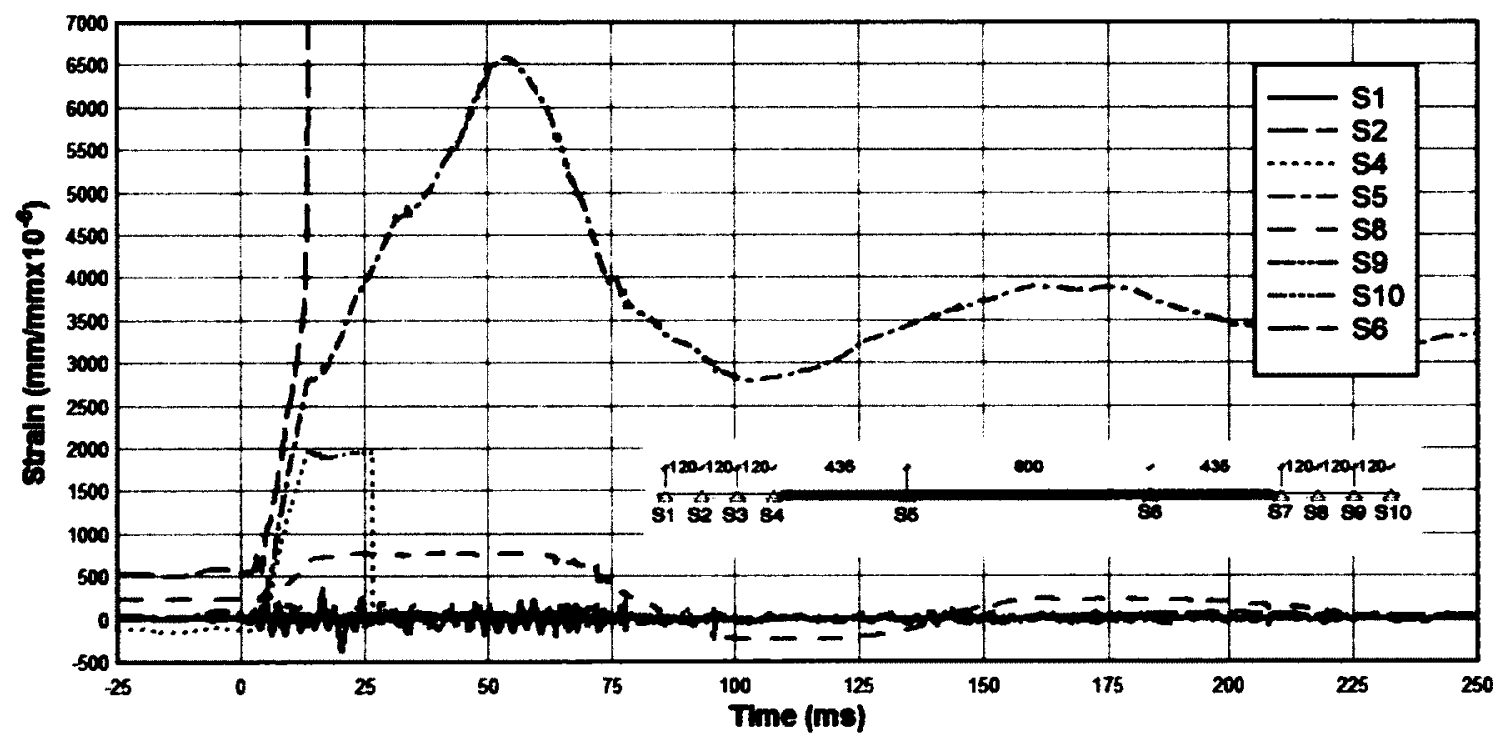

Figure 4-48: Strains in Steel for Test DB-15M-1-4 


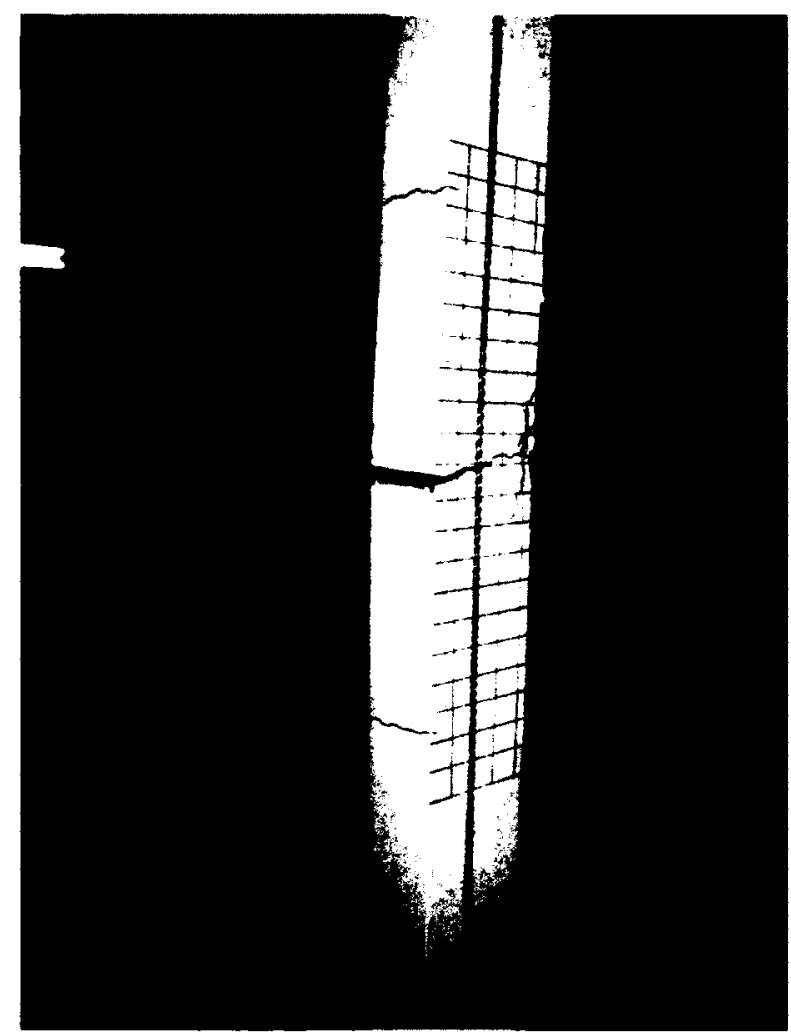

Figure 4-49: Crack Pattern After Test DB-15M-1-4

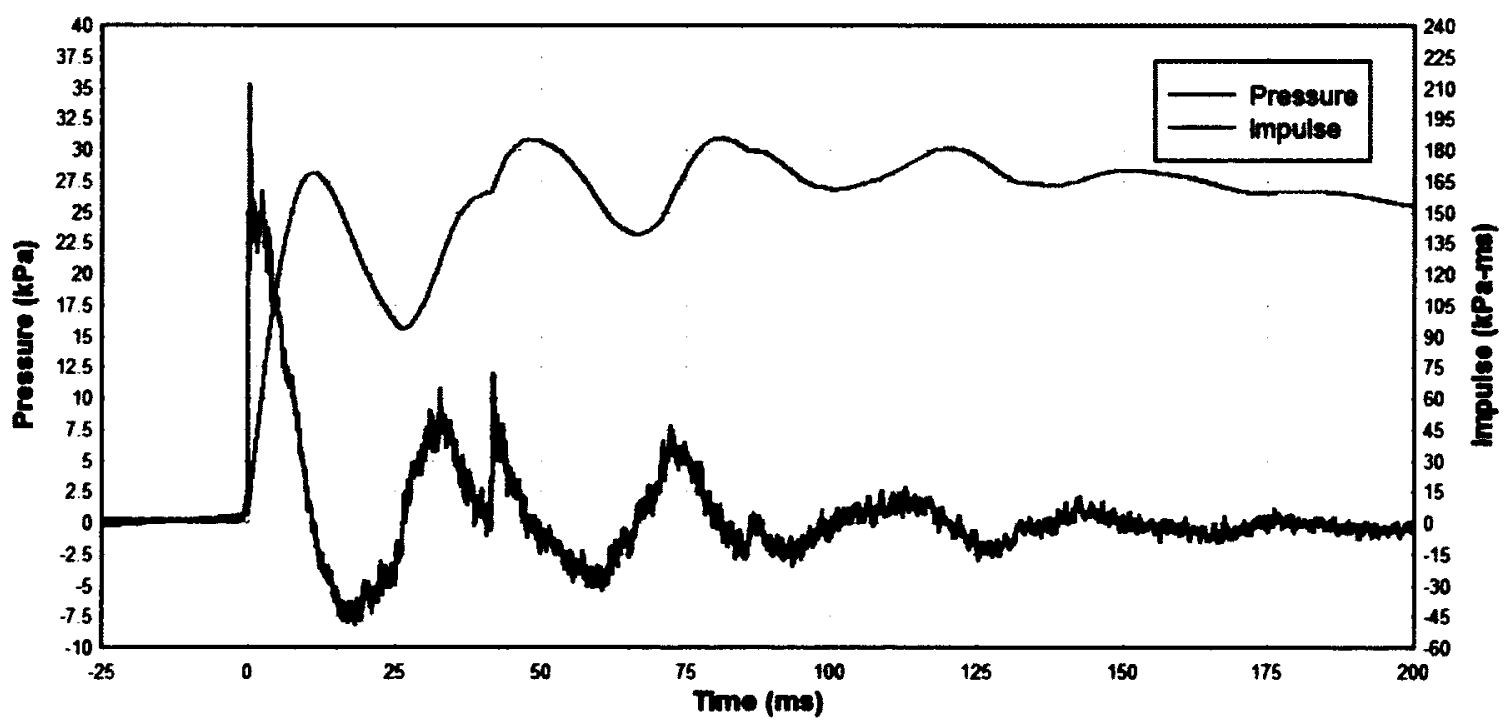

Figure 4-50: Pressure and Impulse Time History for Test DB-15M-2-1 


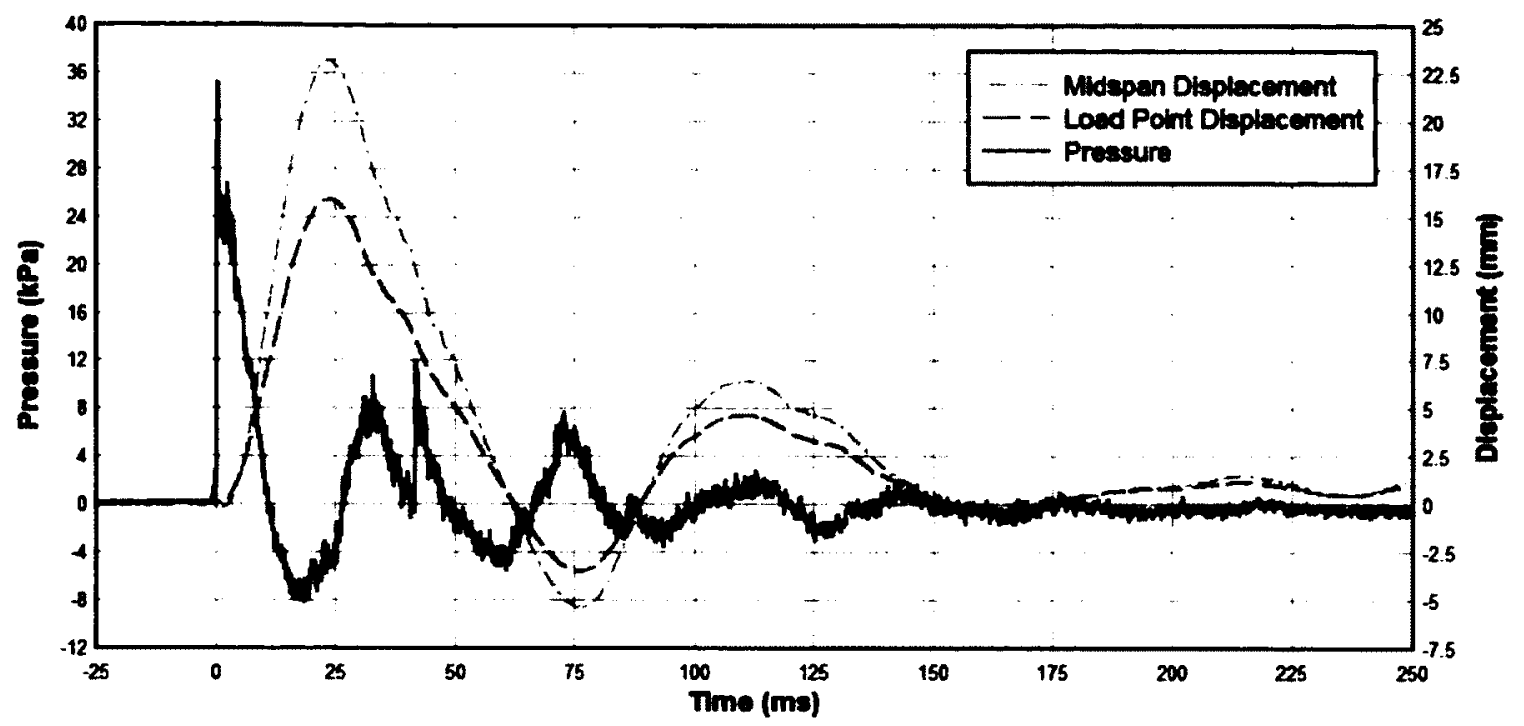

Figure 4-51: Pressure and Displacement History for Test DB-15M-2-1

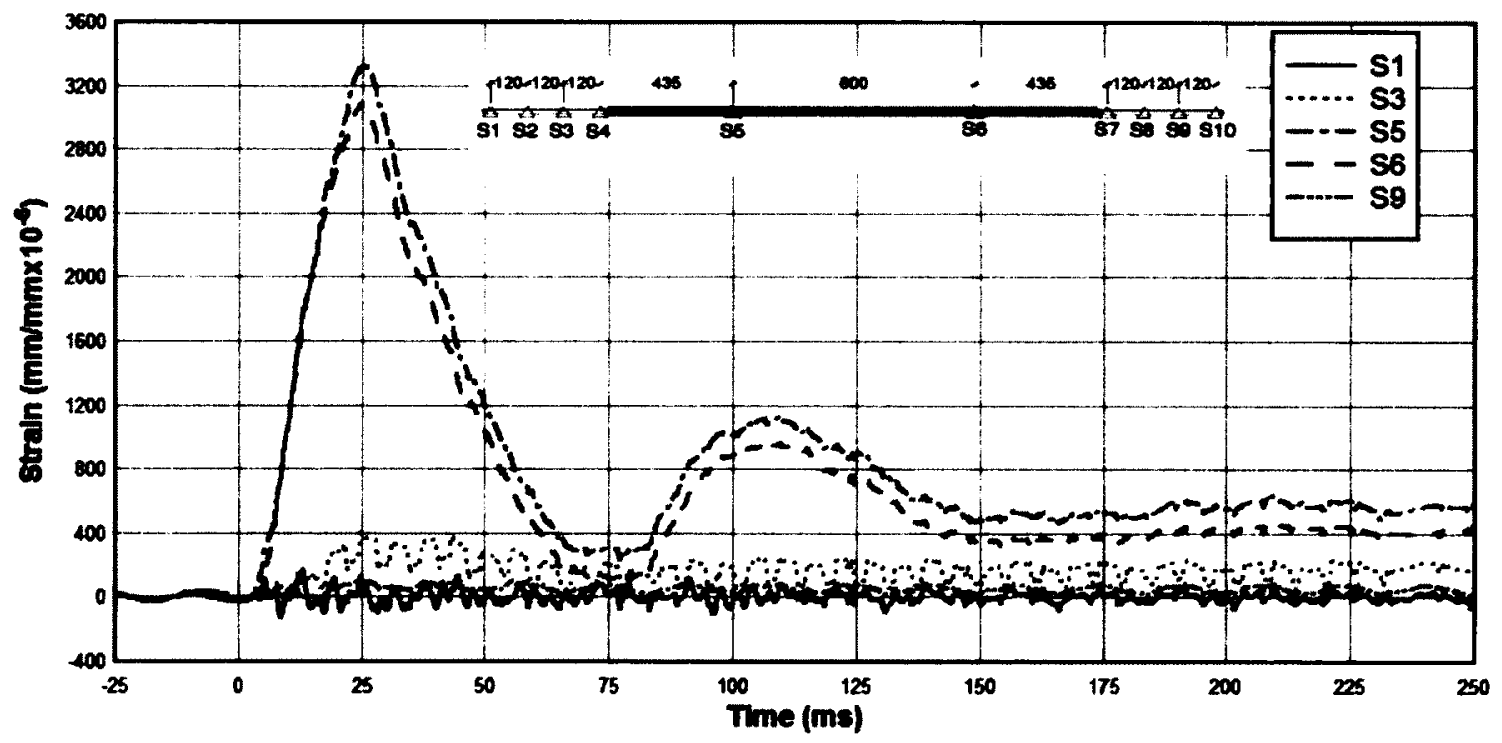

Figure 4-52: Strains in Steel for Test DB-15M-2-1 


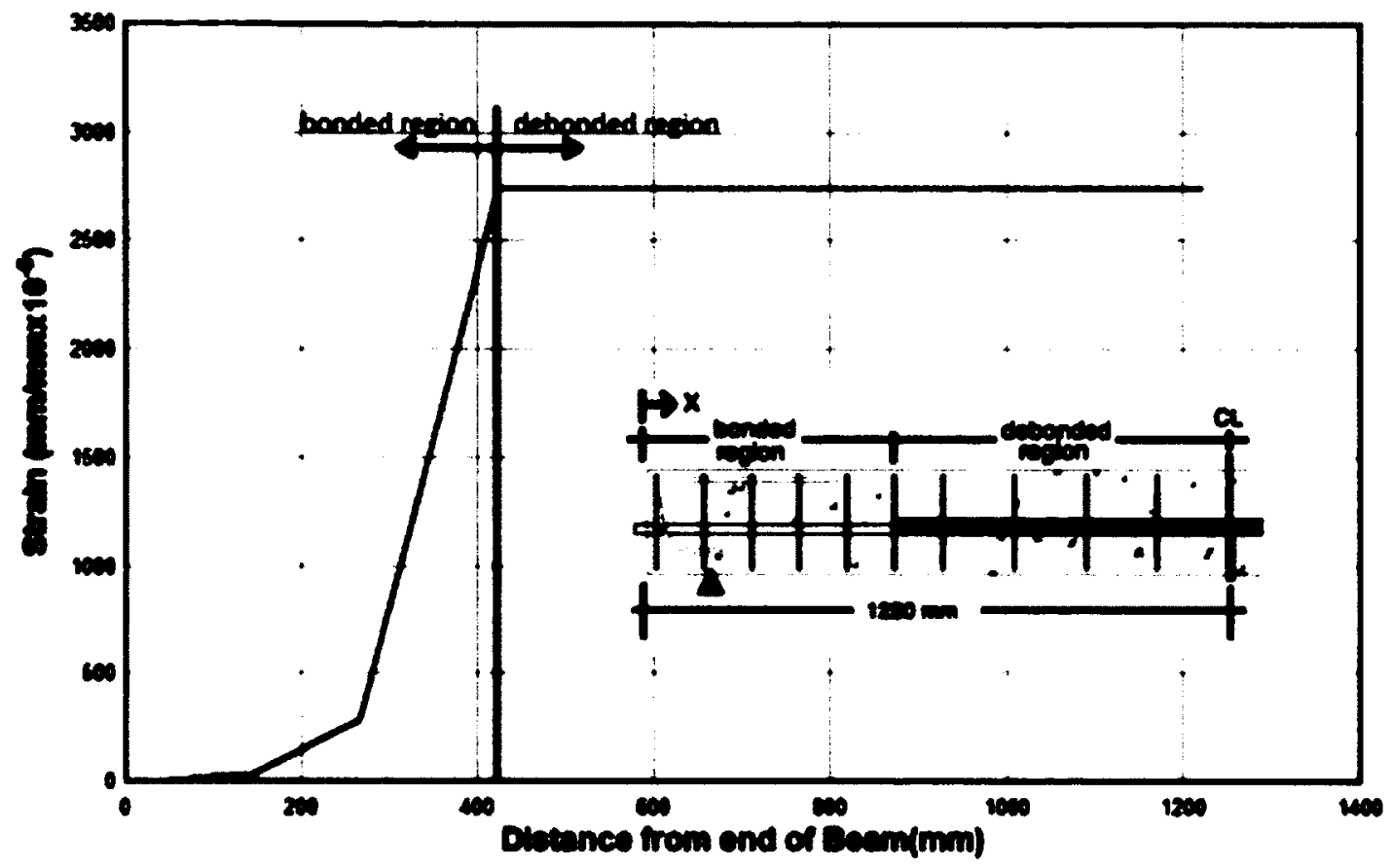

Figure 4-53: Strain Profile at Yield for Test DB-15M-2-1

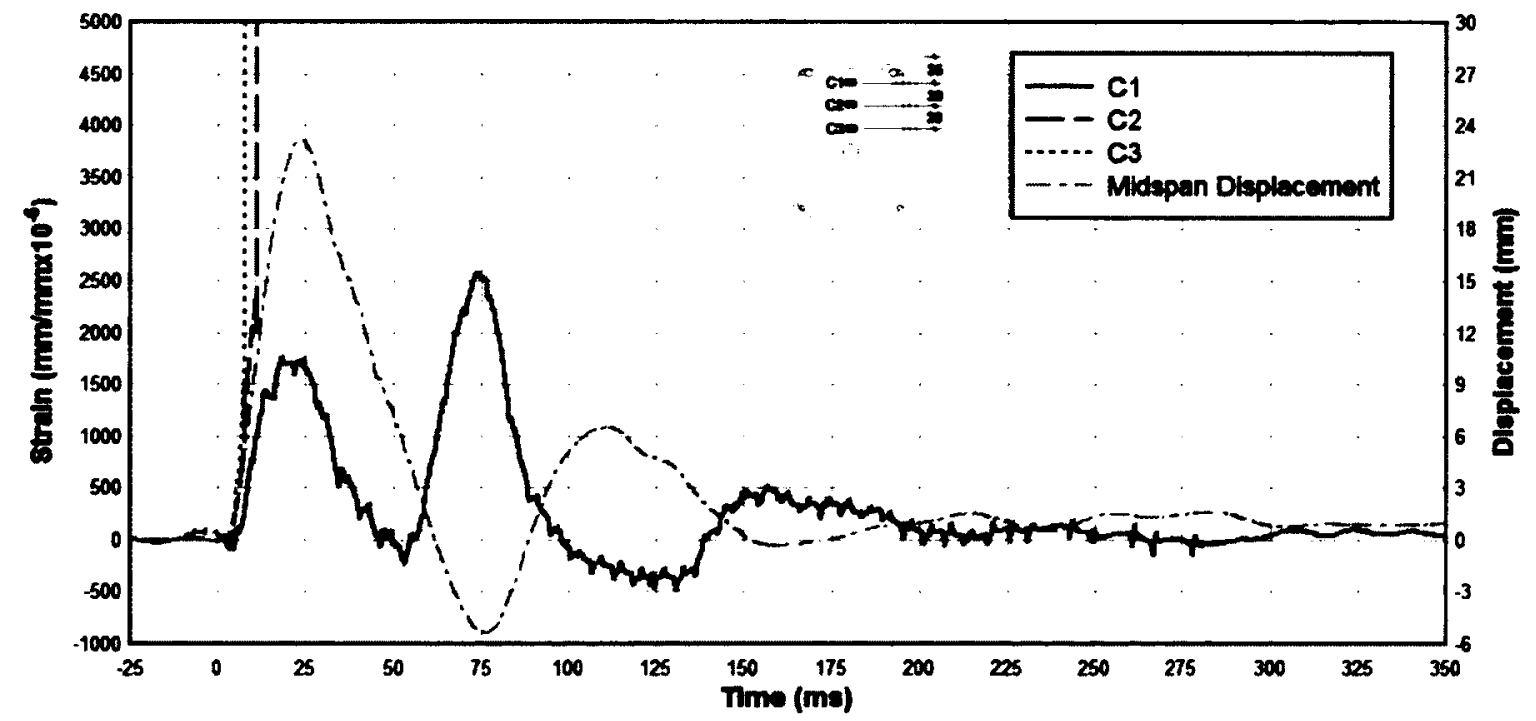

Figure 4-54: Strains in Concrete for Test DB-15M-2-1 


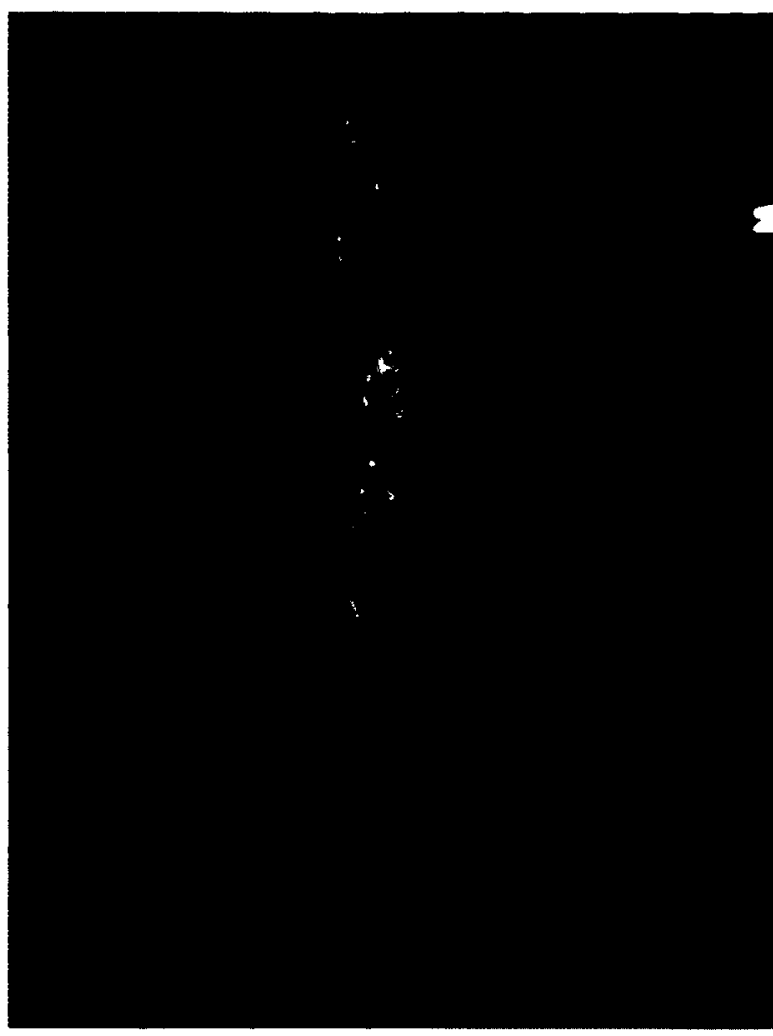

Figure 4-55: Crack Pattern After Test DB-15M-2-1

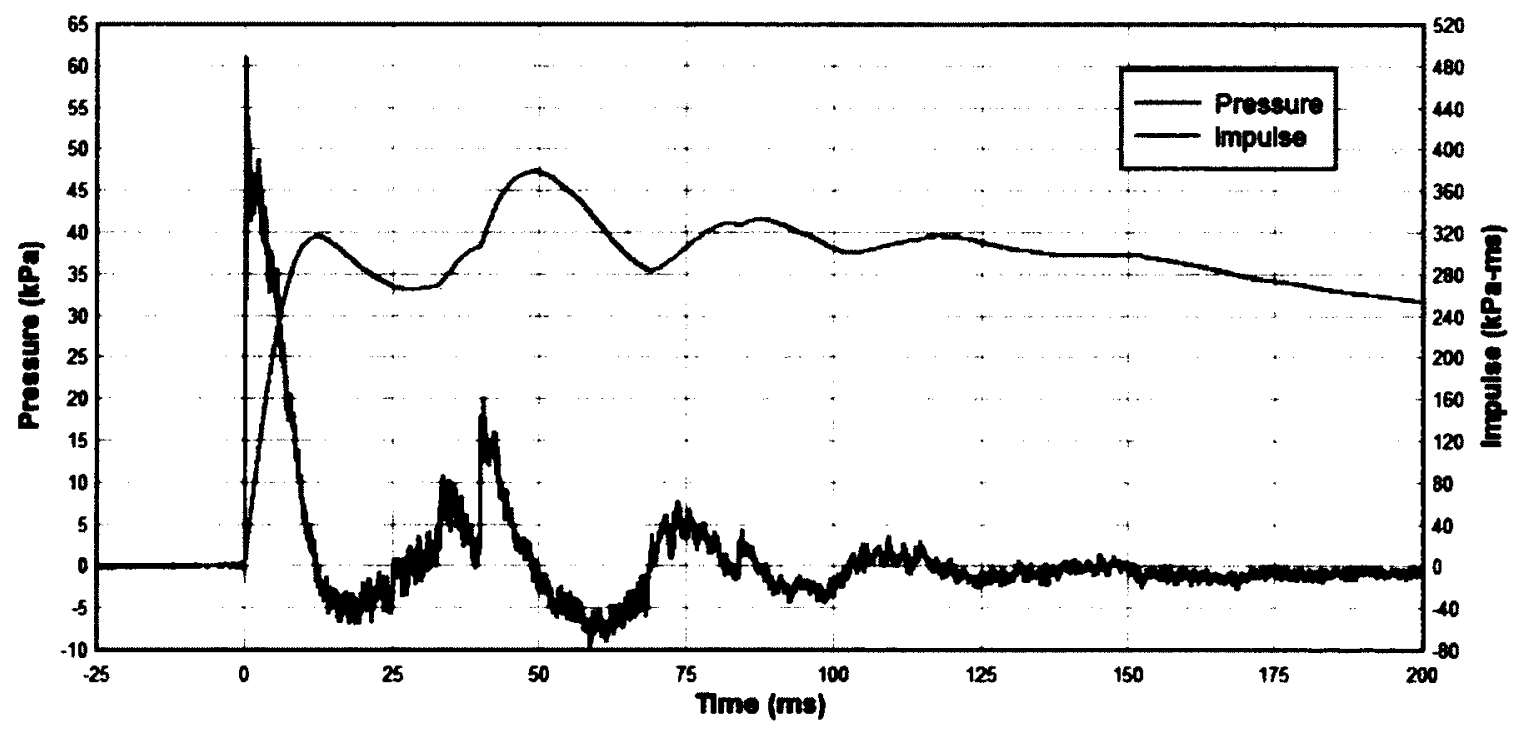

Figure 4-56: Pressure and Impulse Time History for Test DB-15M-2-2 


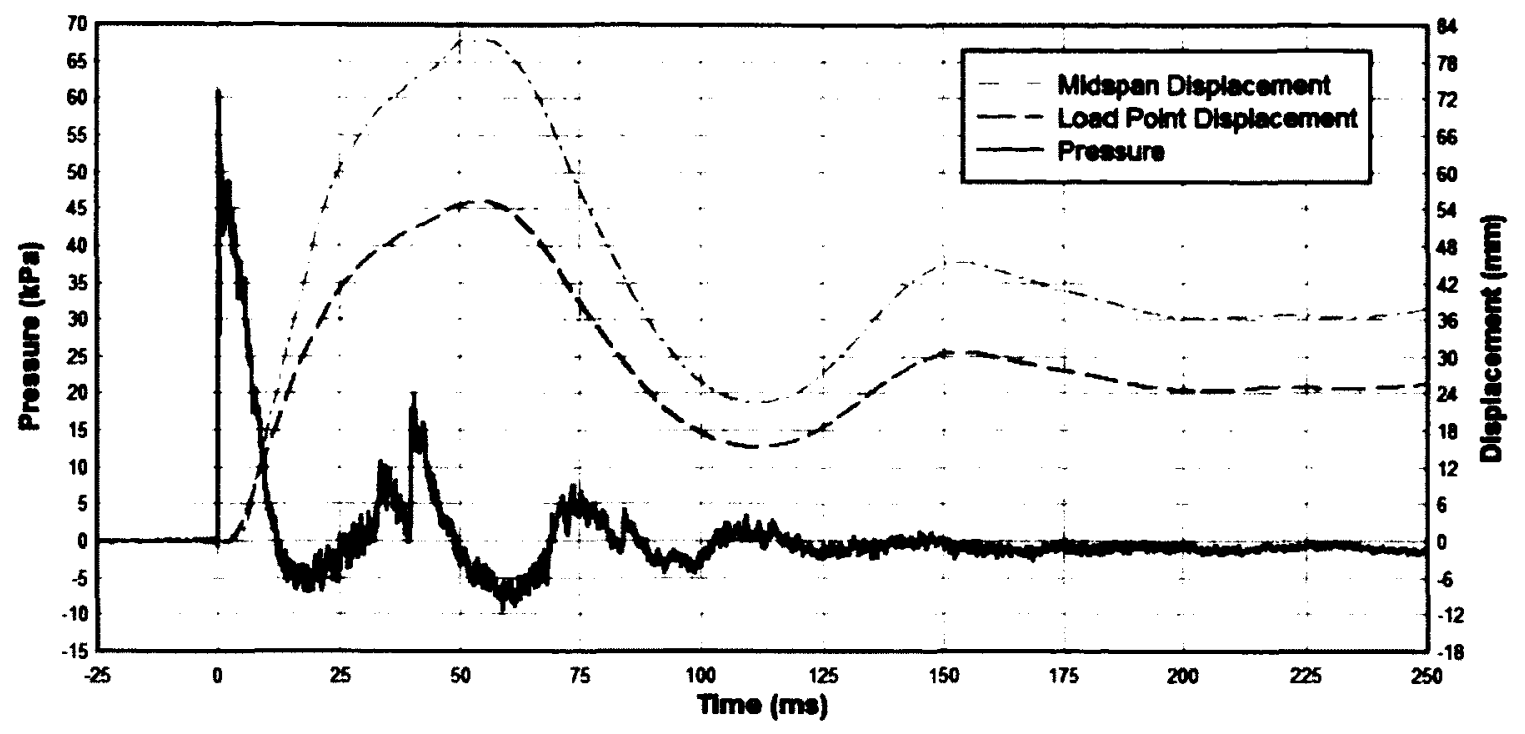

Figure 4-57: Pressure and Displacement Time History for Test DB-15M-2-2

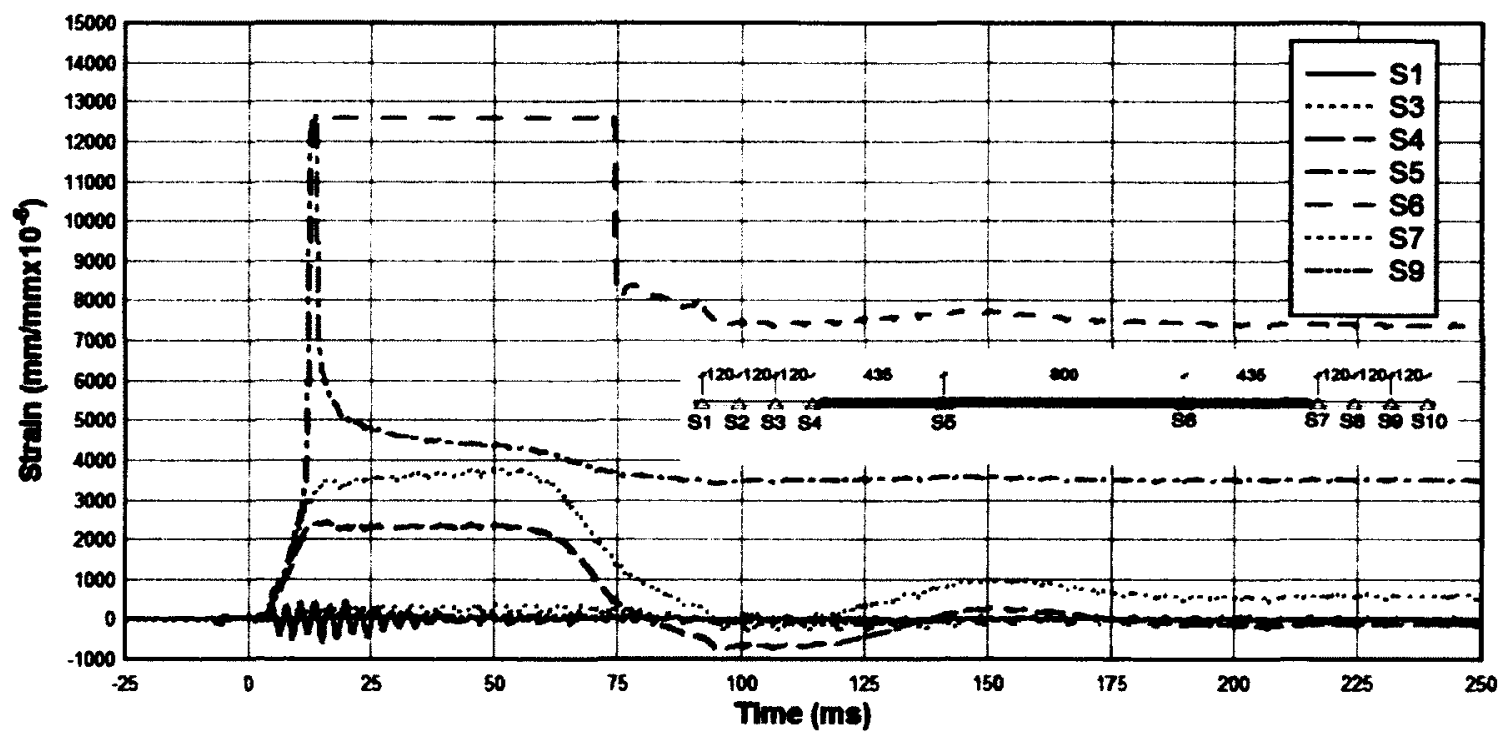

Figure 4-58: Strains in Steel for Test DB-15M-2-2 


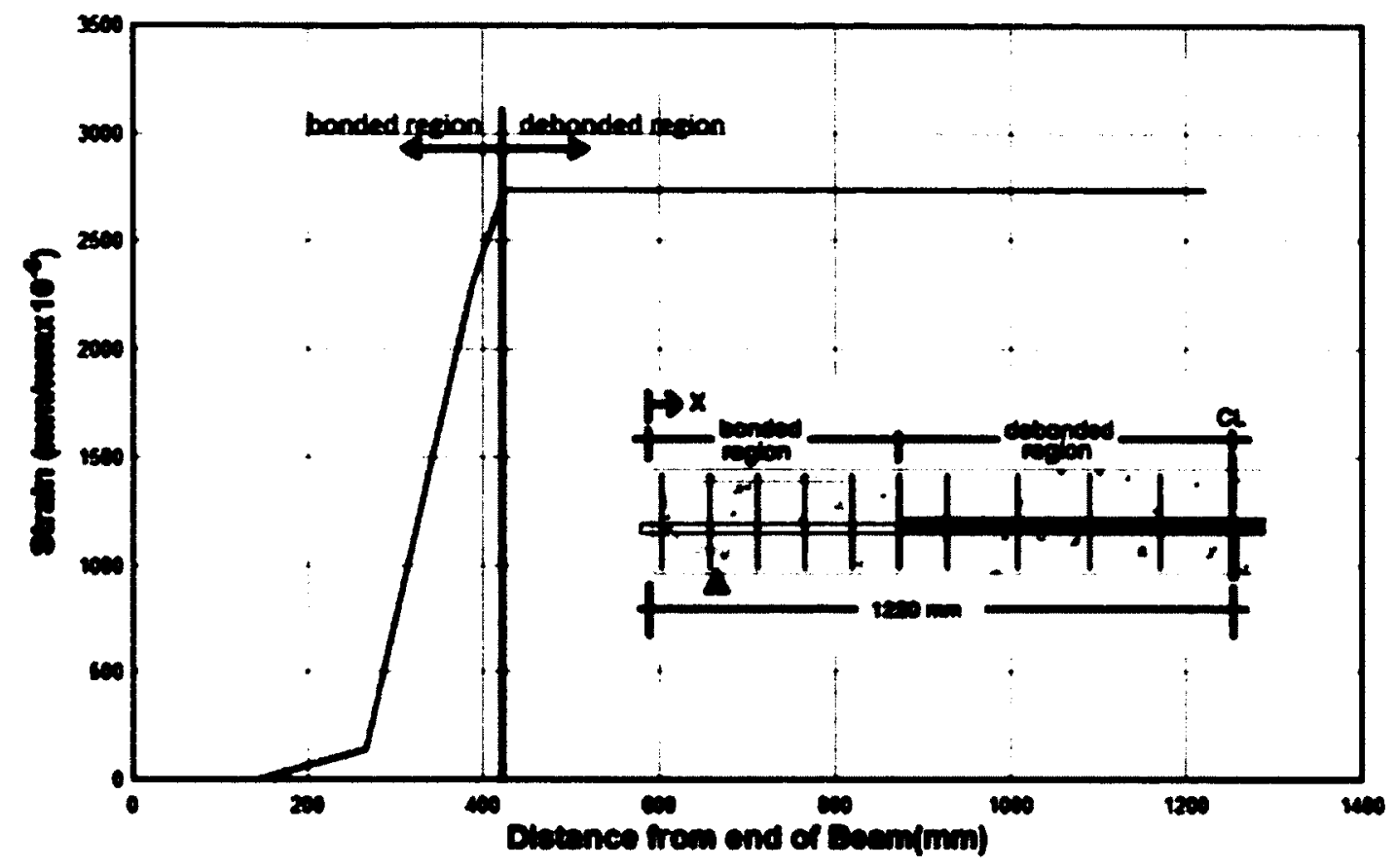

Figure 4-59: Strain Profile at Yield for Test DB-15M-2-2

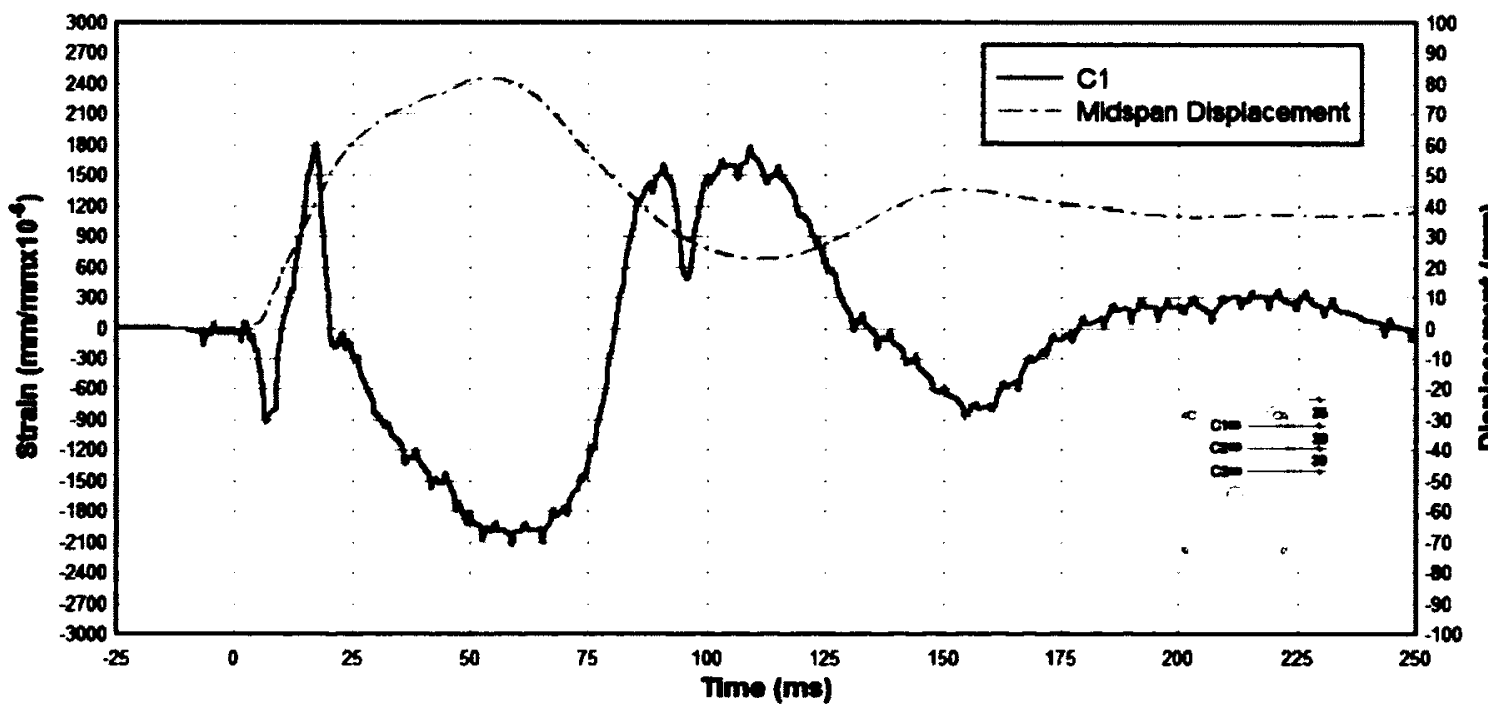

Figure 4-60: Strains in Concrete for Test DB-15M-2-2 


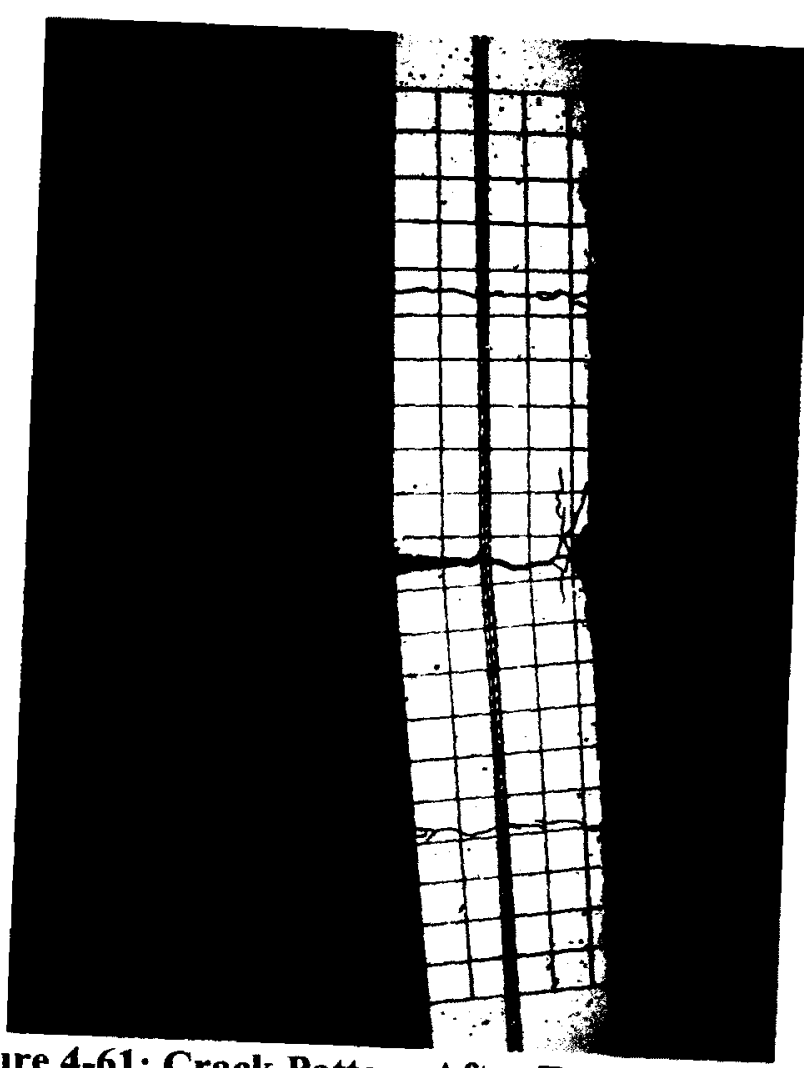

Figure 4-61: Crack Pattern After Test DB-15M-2-2

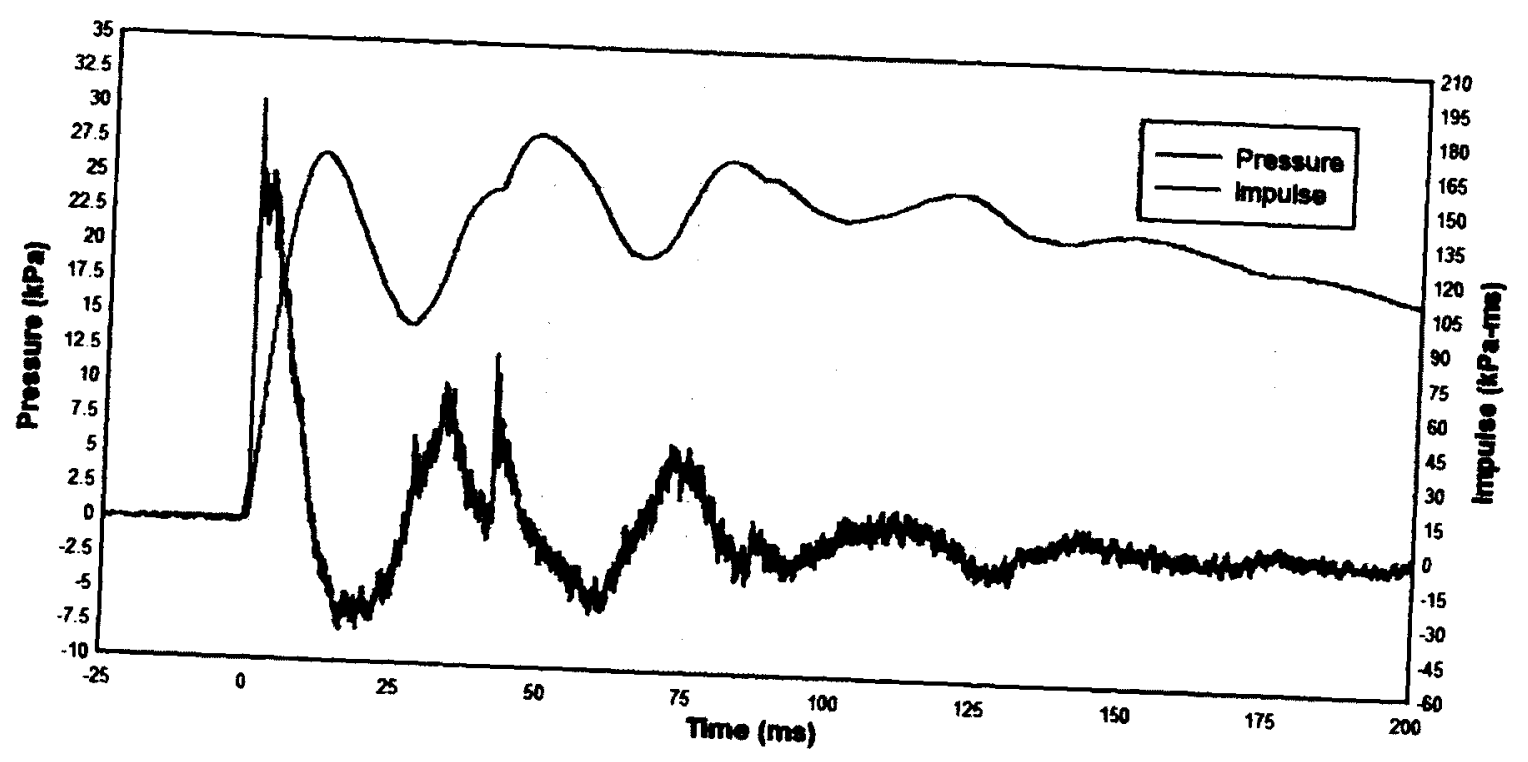

Figure 4-62: Pressure and Impulse Time History for Test DB-15M-3-1 


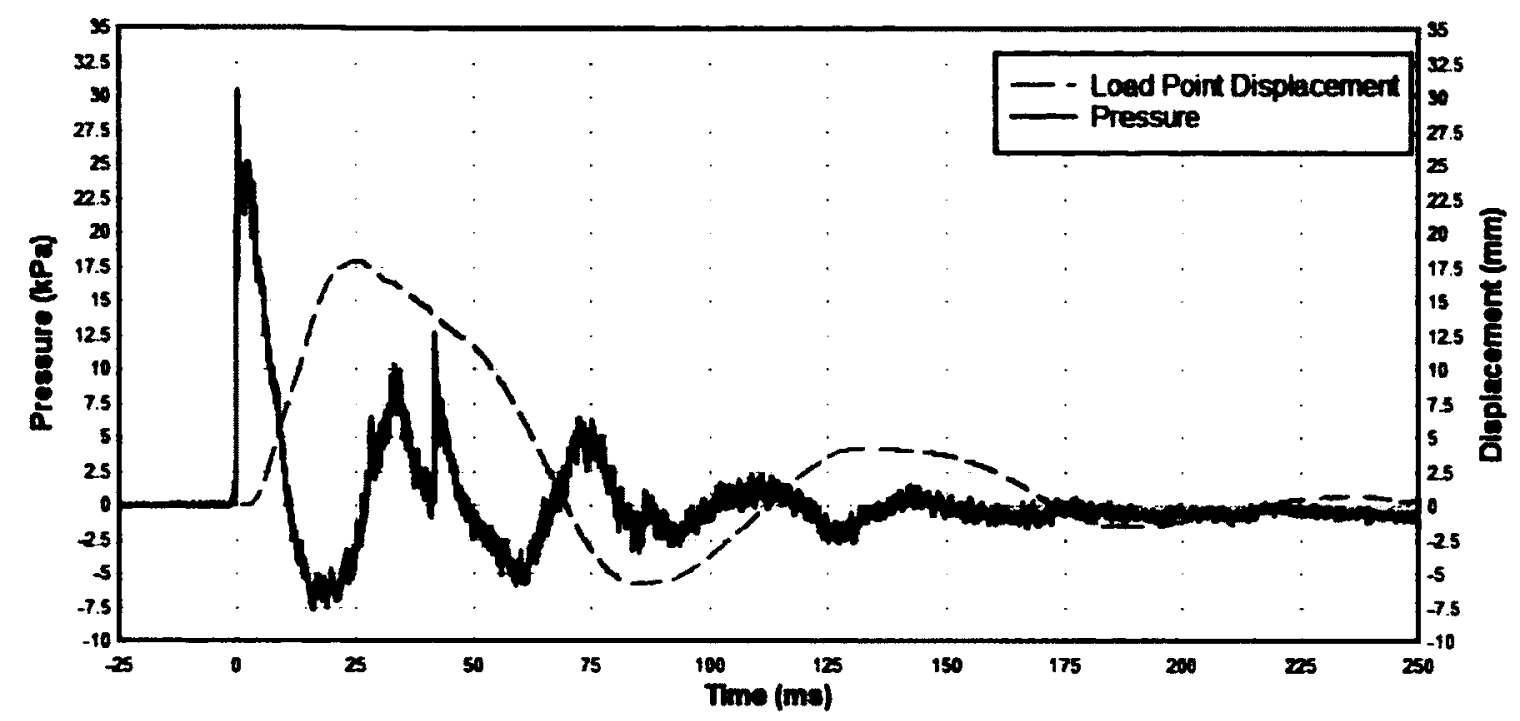

Figure 4-63: Pressure and Displacement Time History for Test DB-15M-3-1

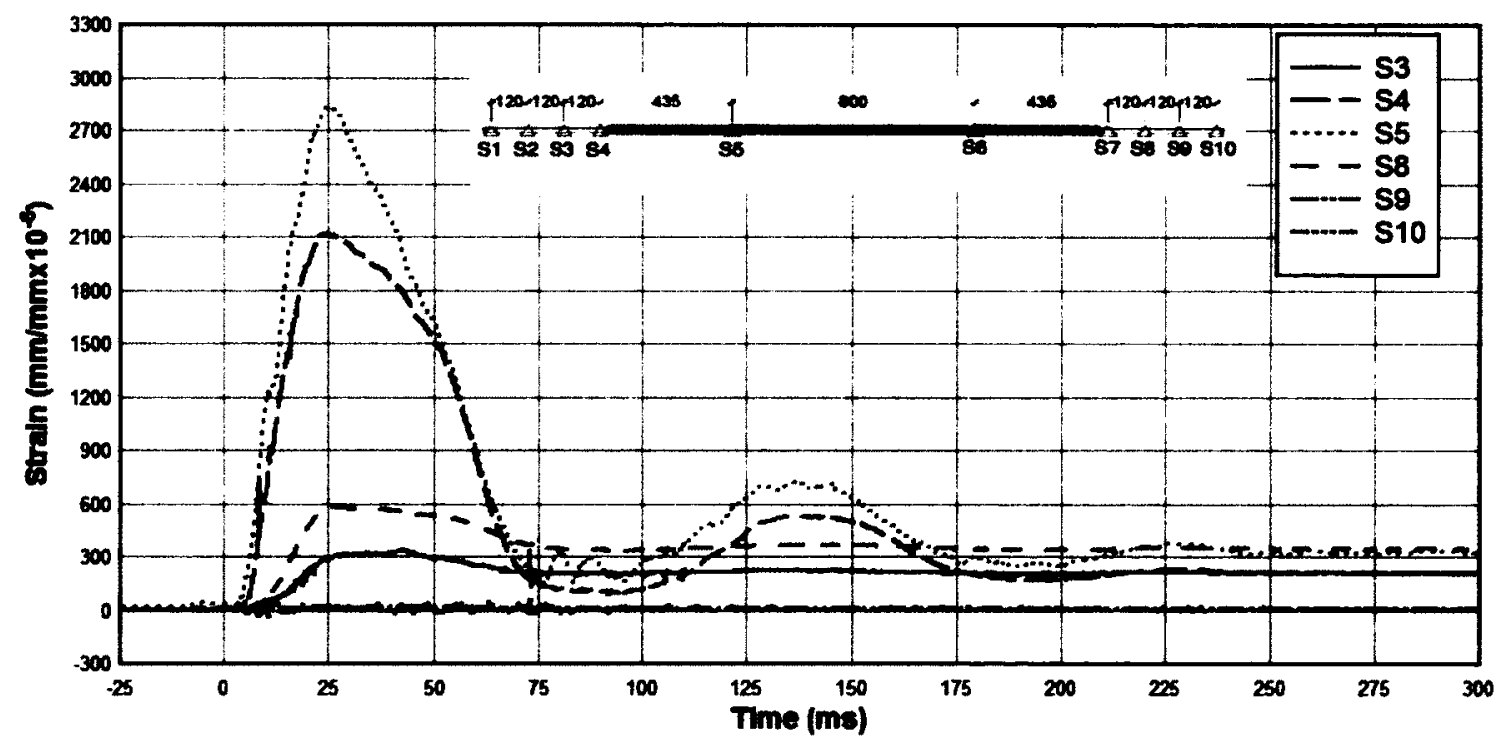

Figure 4-64: Strains in Steel for Test DB-15M-3-1 


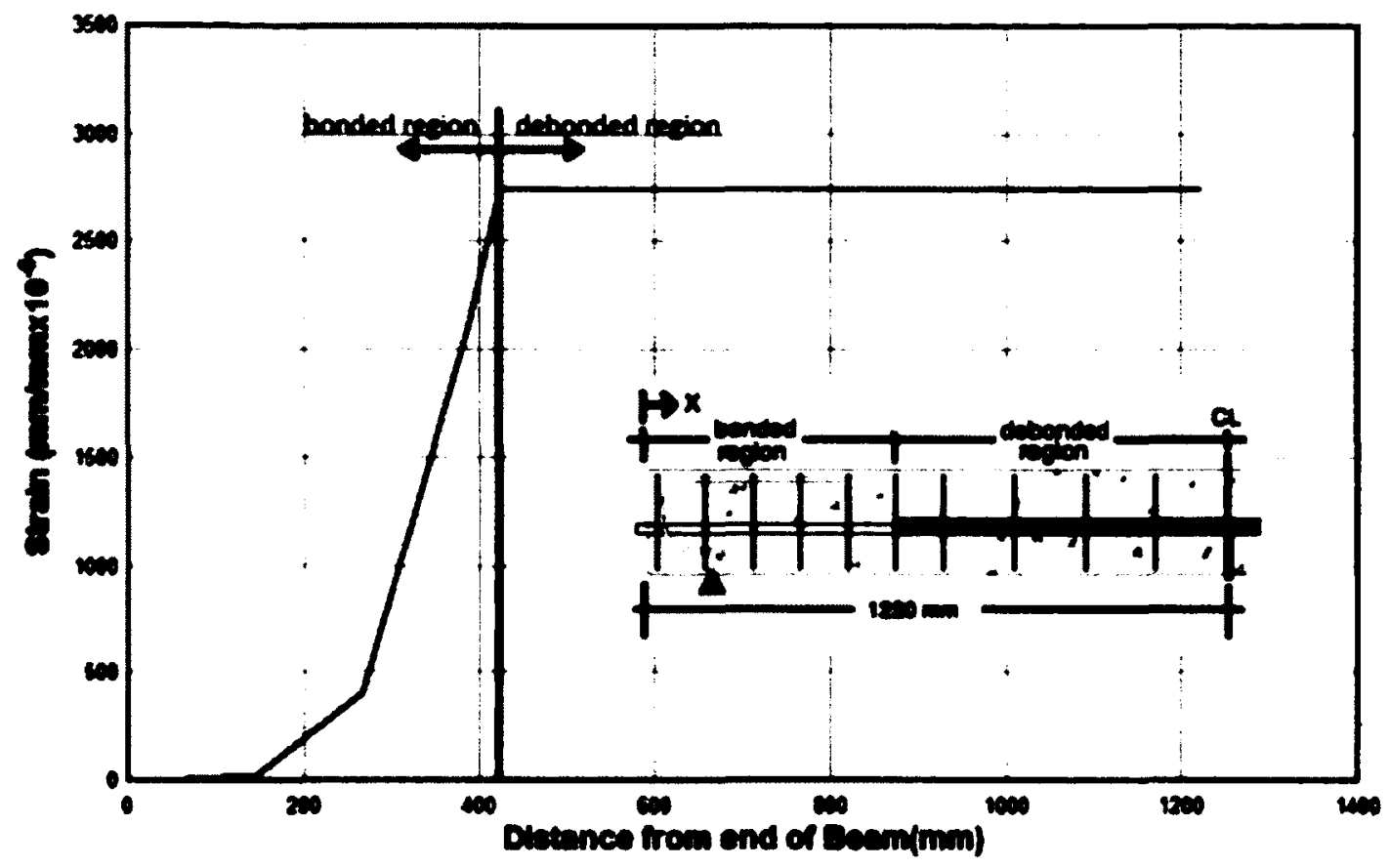

Figure 4-65: Strain Profile at Yield for Test DB-15M-3-1

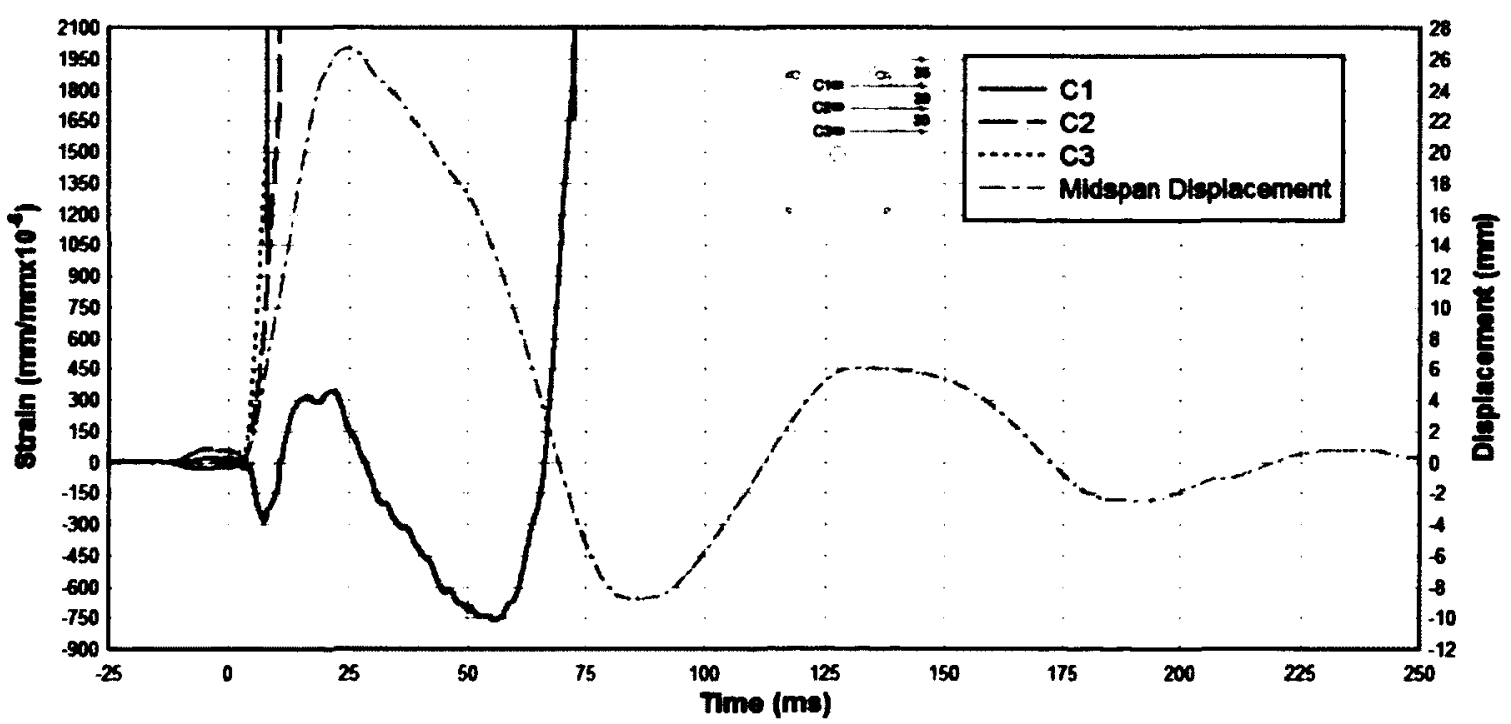

Figure 4-66: Strains in Concrete for Test DB-15M-3-1 


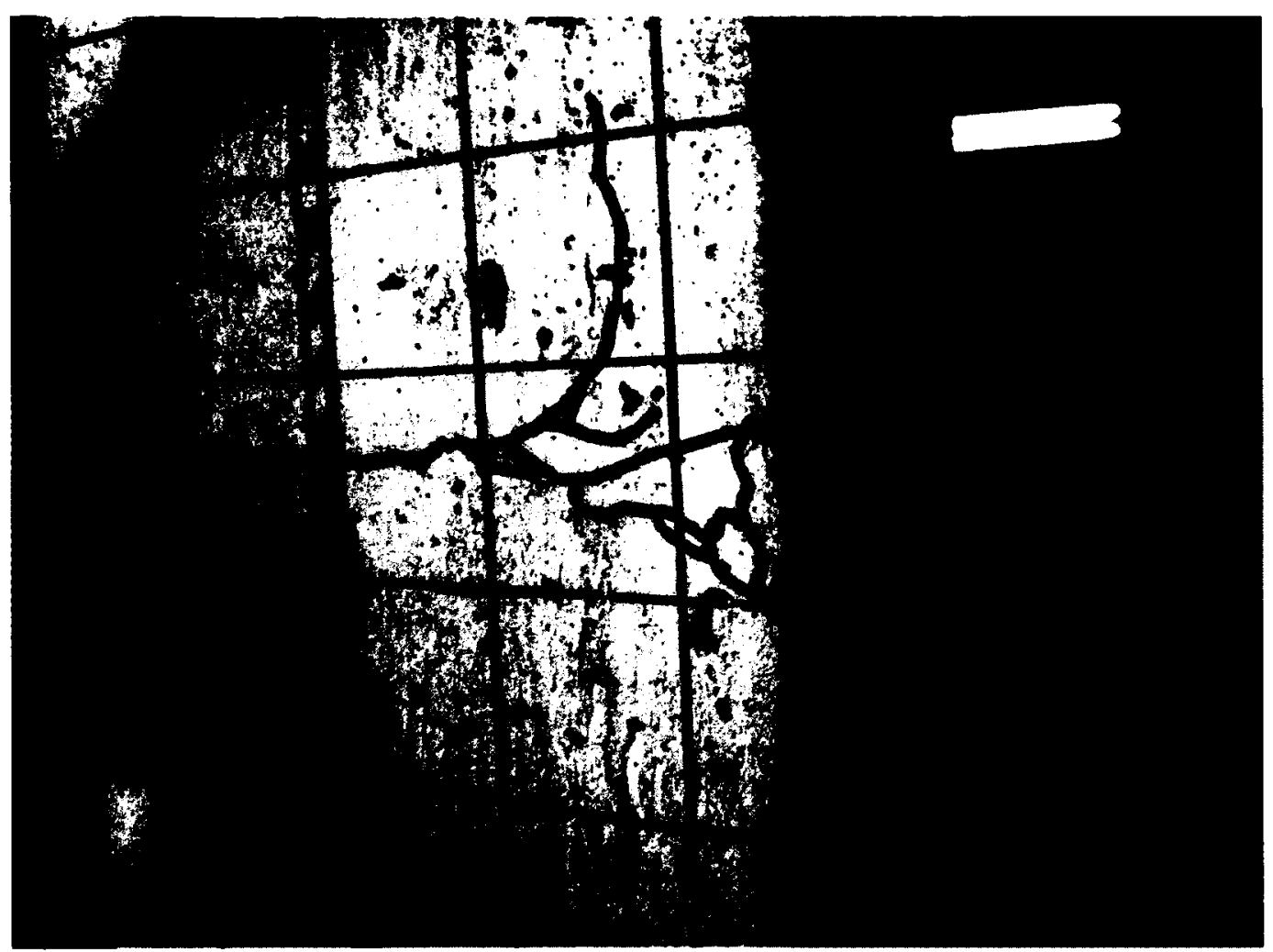

Figure 4-67: Crack Pattern After Test DB-15M-3-1

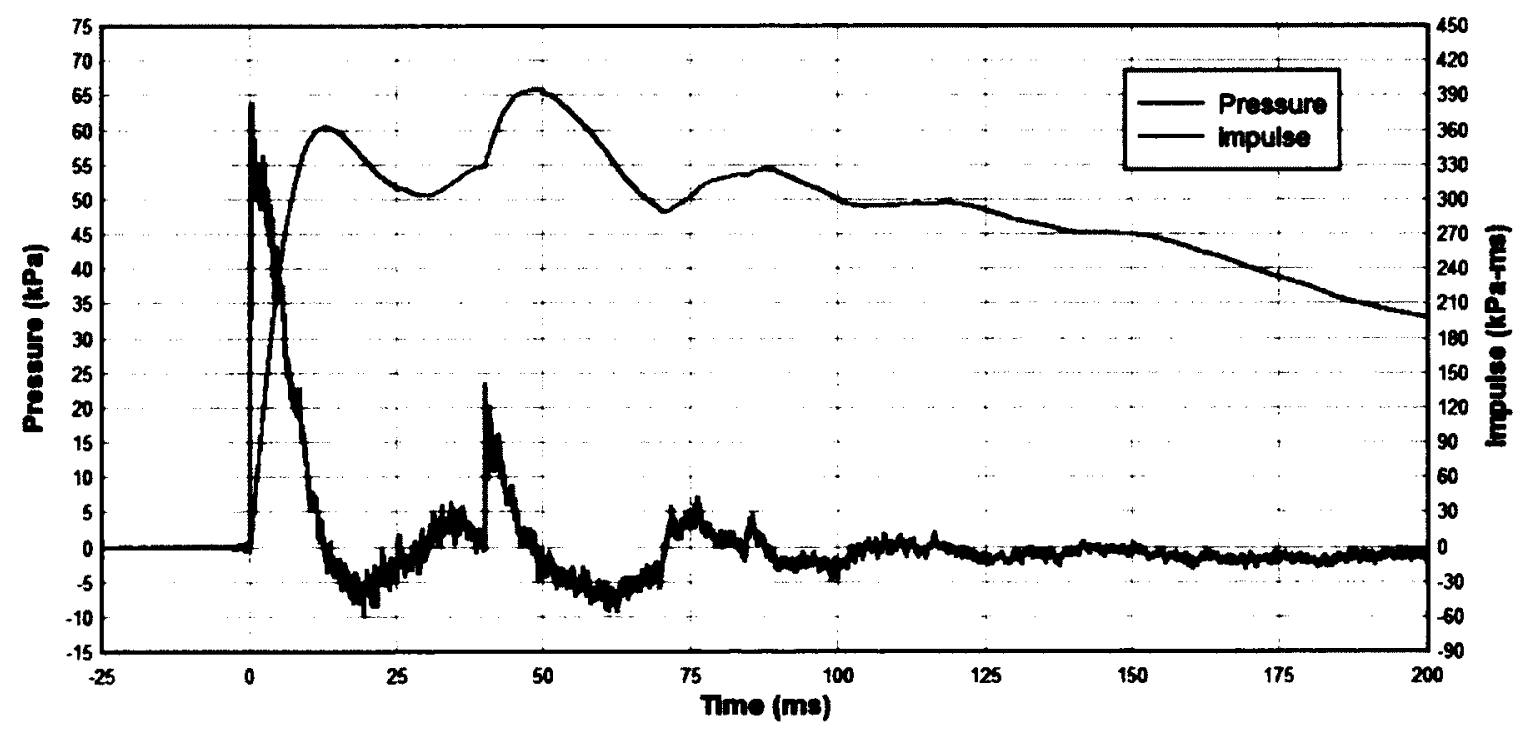

Figure 4-68: Pressure and Impulse Time History for Test DB-15M-3-2 


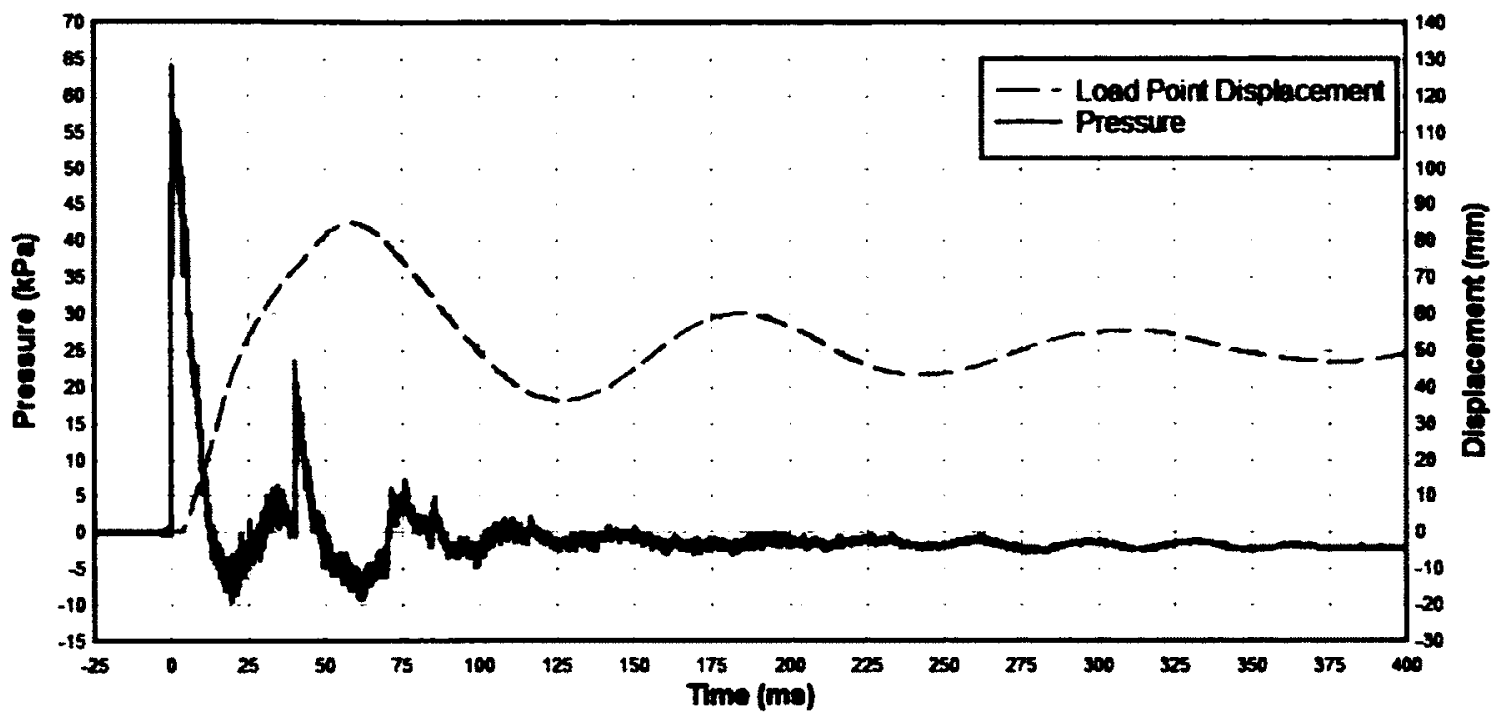

Figure 4-69: Pressure and Displacement Time History for Test DB-15M-3-2

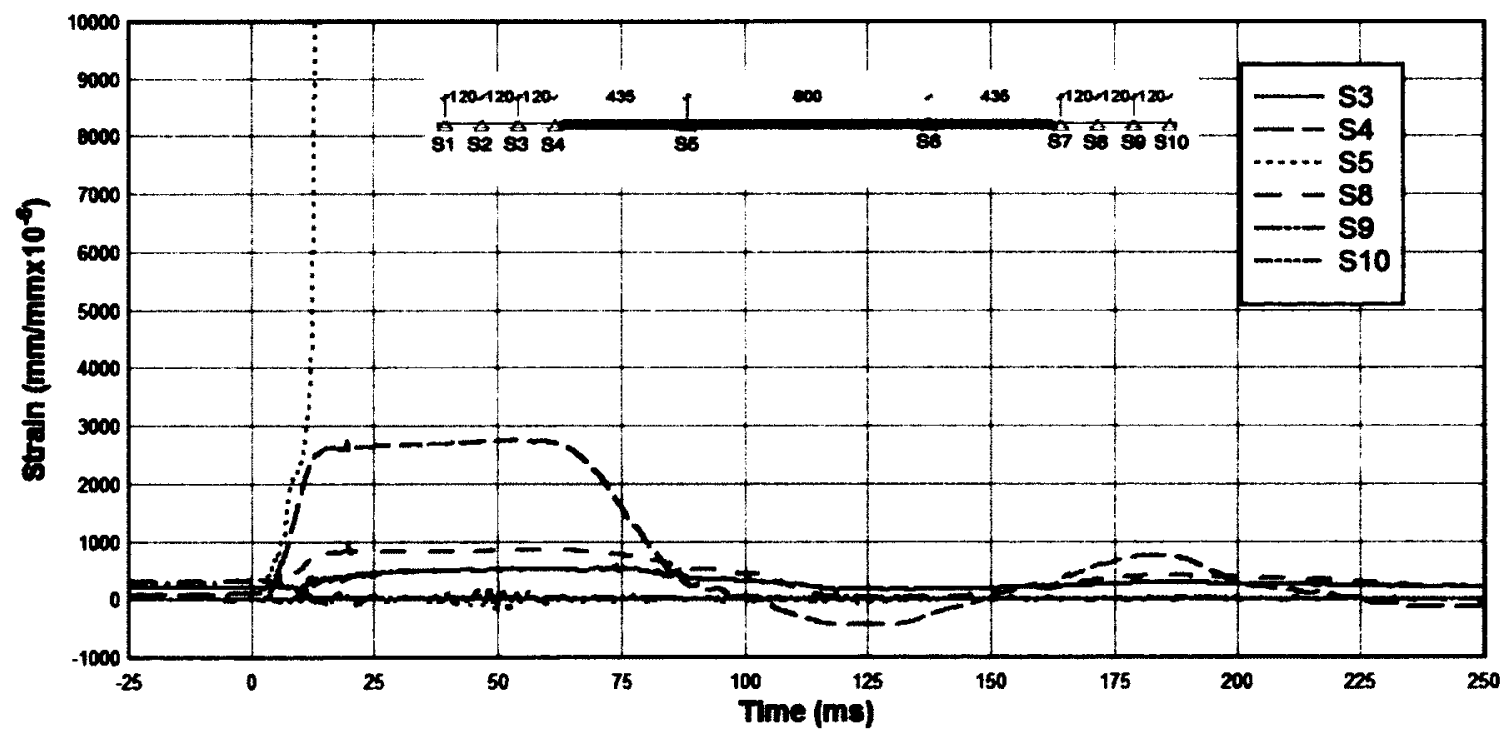

Figure 4-70: Strains in Steel for Test DB-15M-3-2 


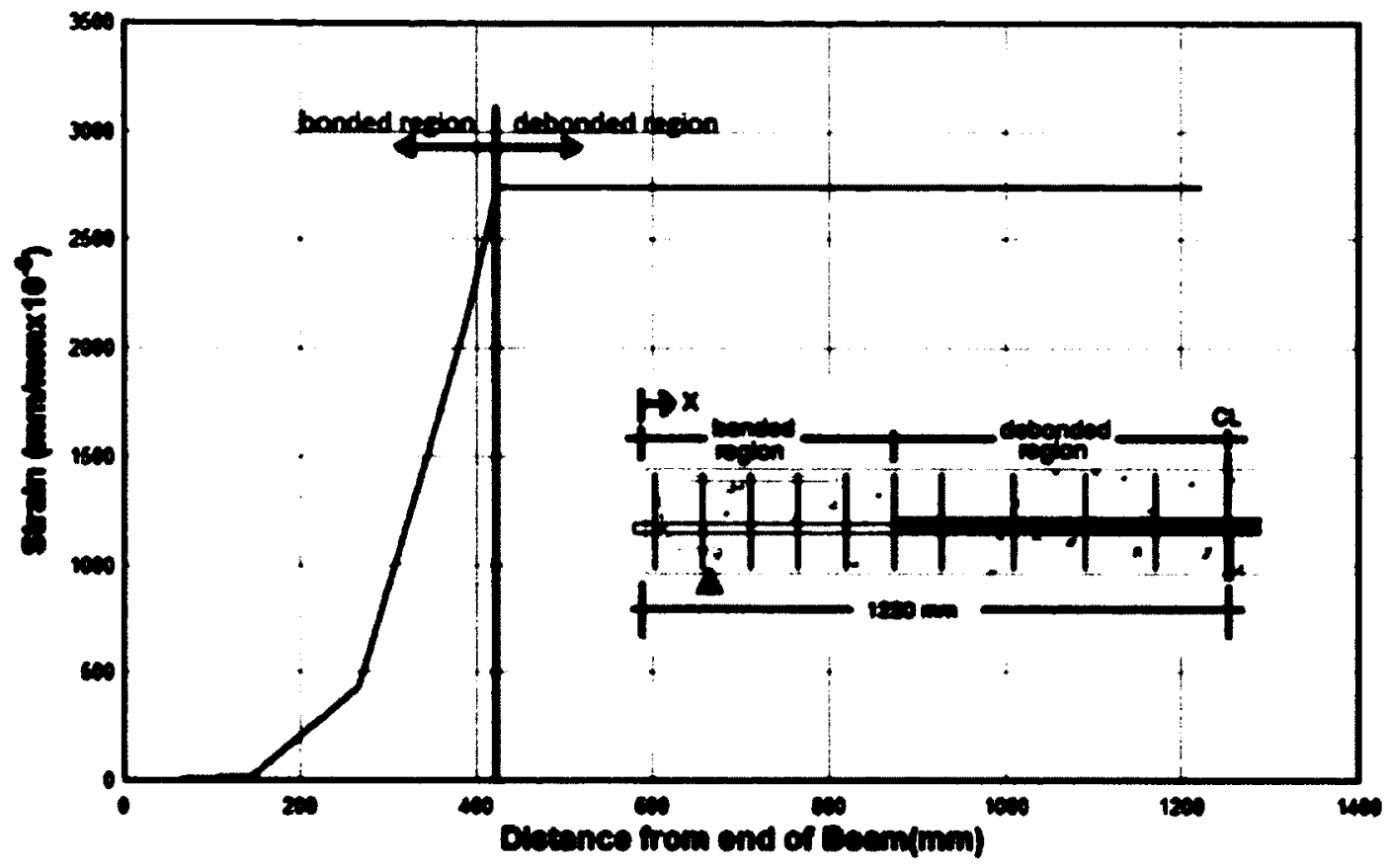

Figure 4-71: Strain Profile at Yield for Test DB-15M-3-2

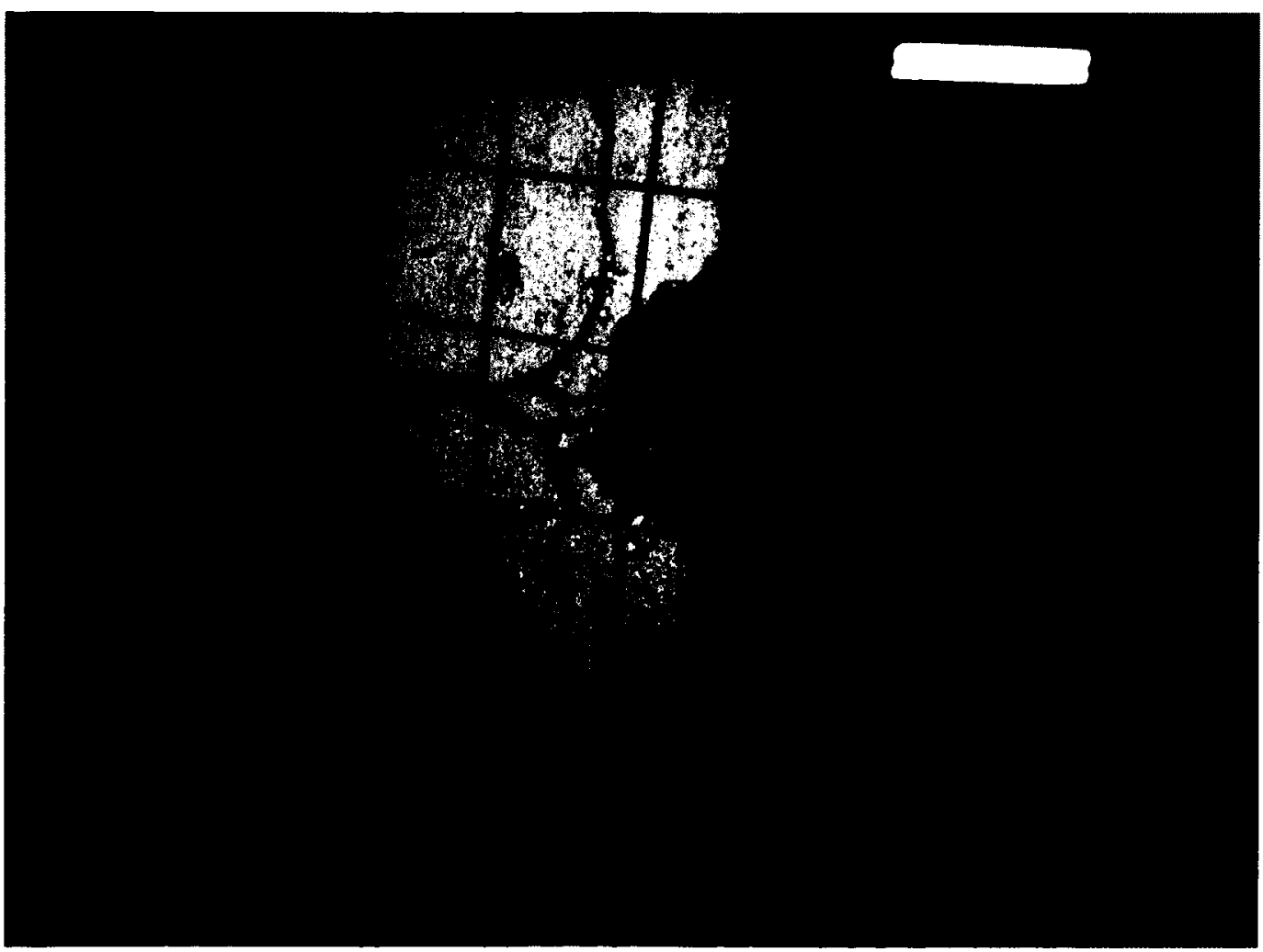

Figure 4-72: Crack Pattern After Test DB-15M-3-2 


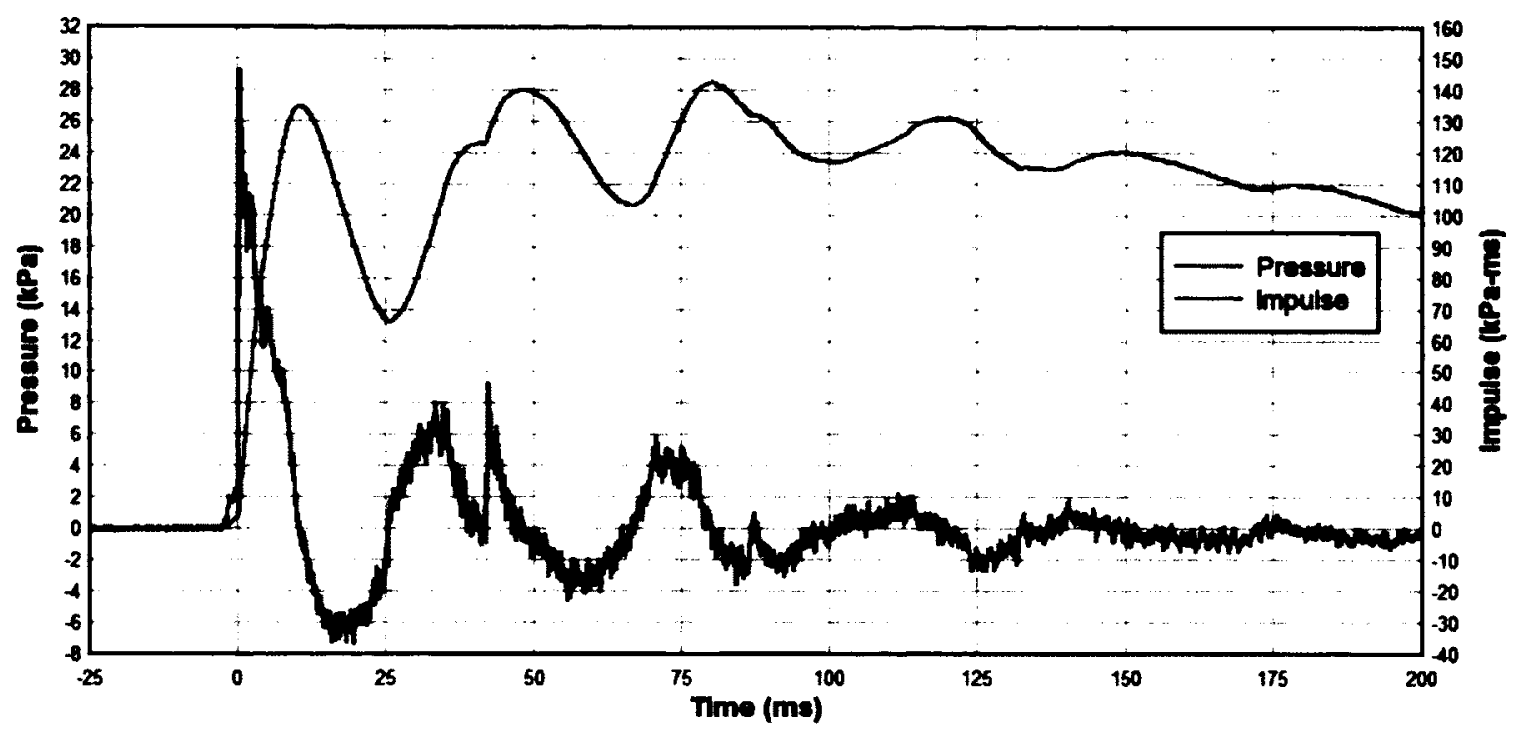

Figure 4-73: Pressure and Impulse Time History for Test DB-20M-1-1

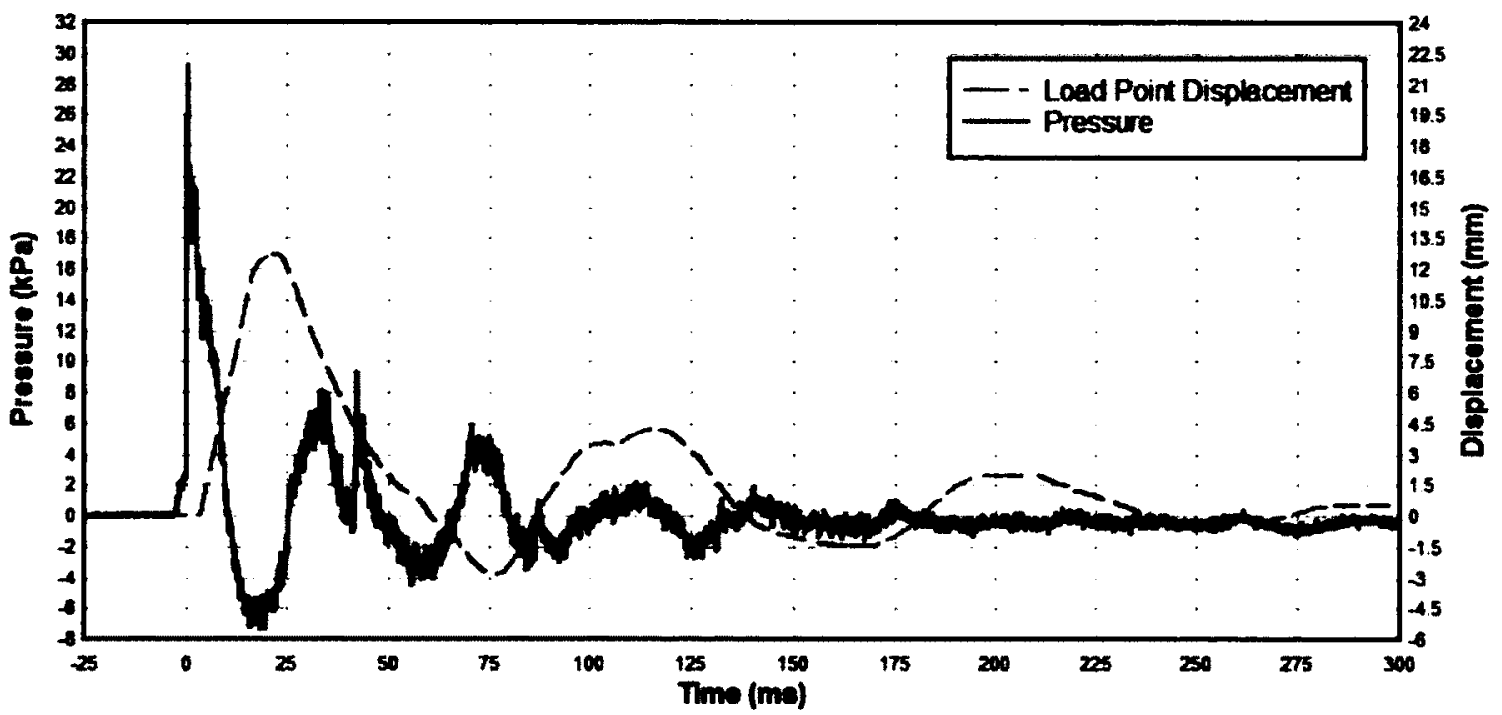

Figure 4-74: Pressure and Displacement Time History for Test DB-20M-1-1 


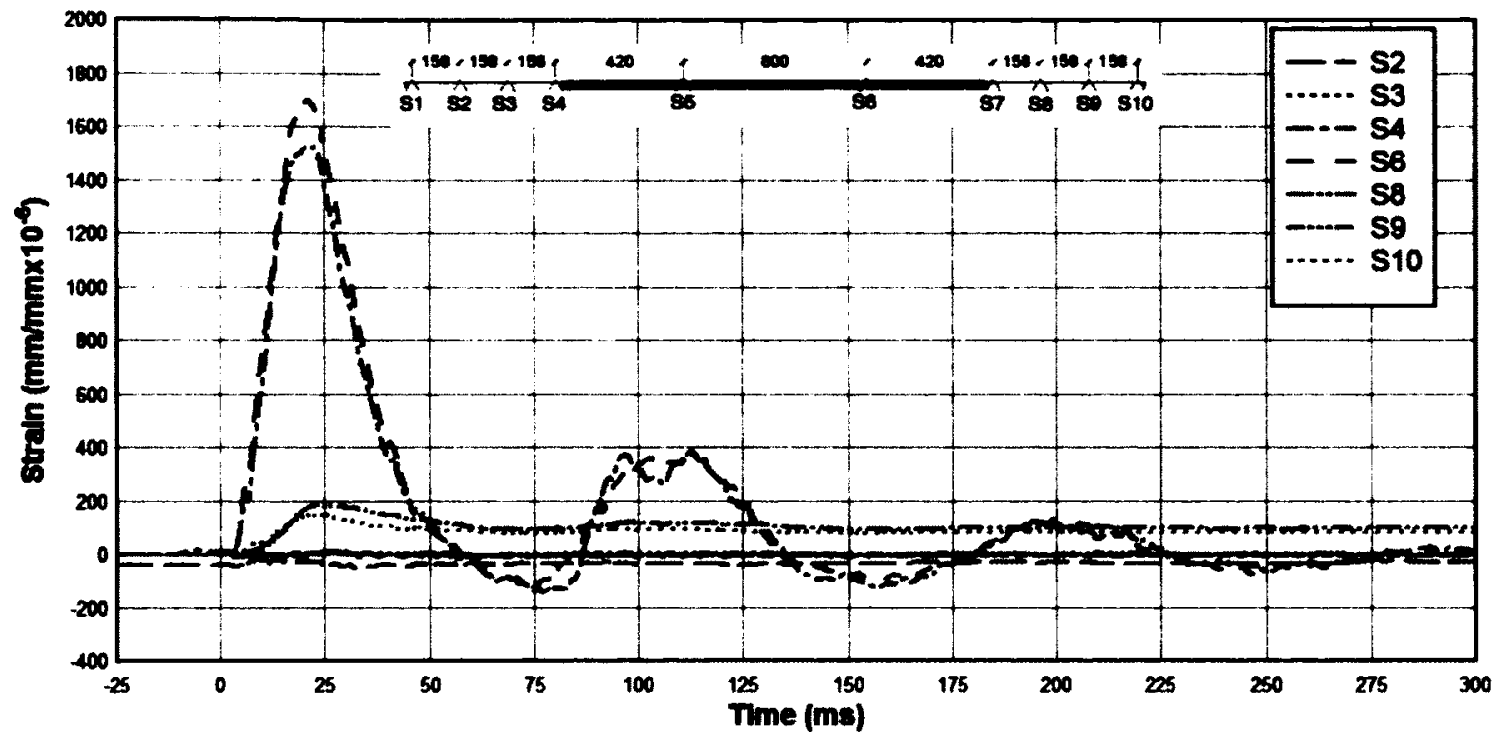

Figure 4-75: Strains in Steel for Test DB-20M-1-1

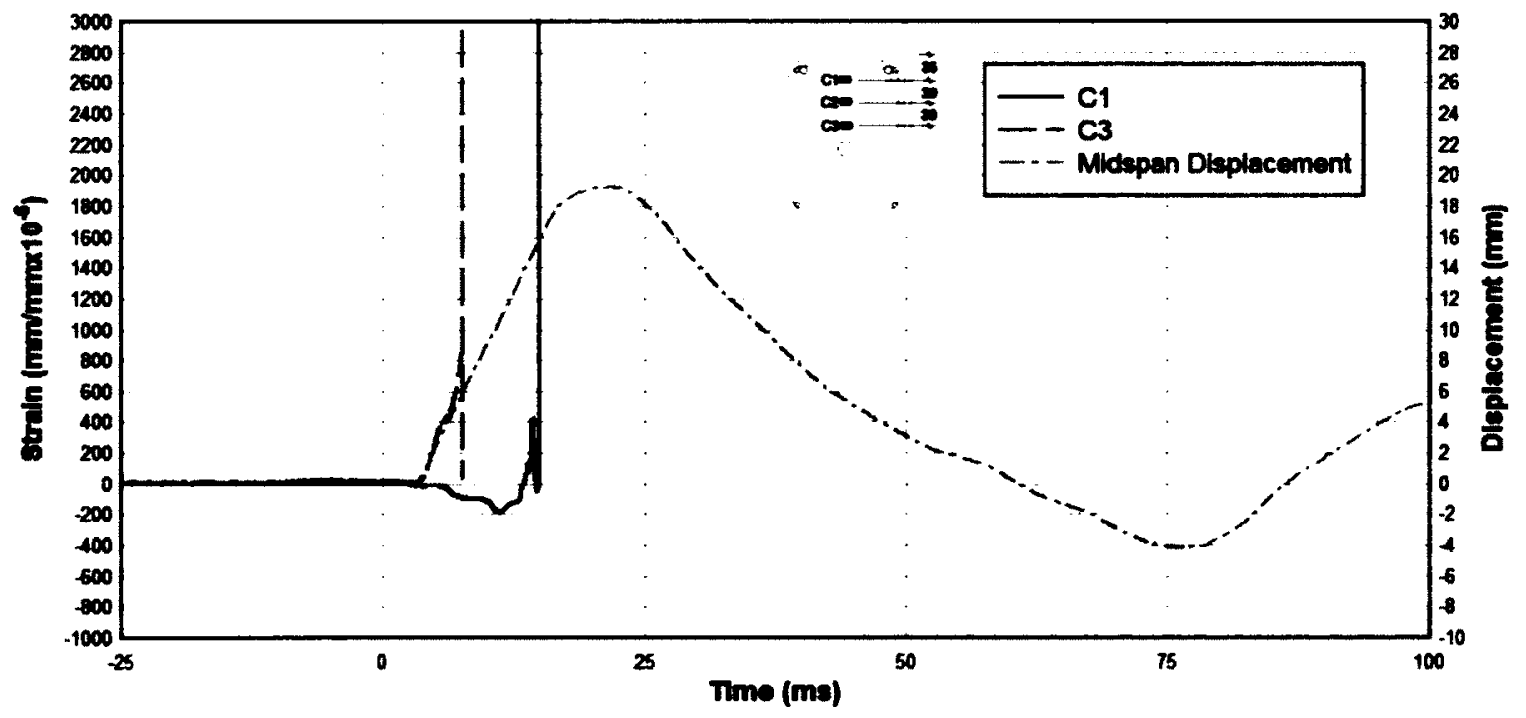

Figure 4-76: Strains in Concrete for Test DB-20M-1-1 


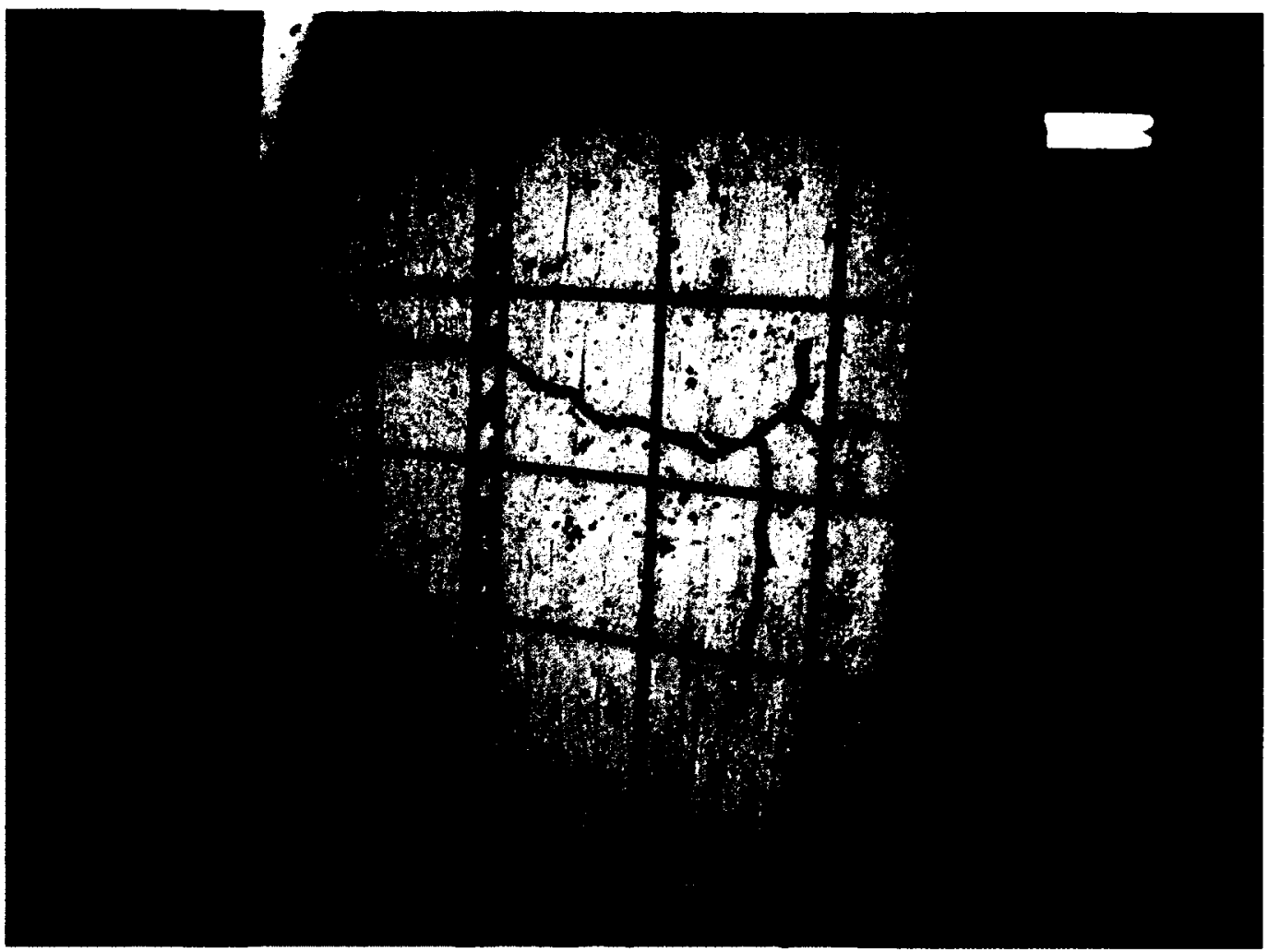

Figure 4-77: Crack Pattern After Test DB-20M-1-1

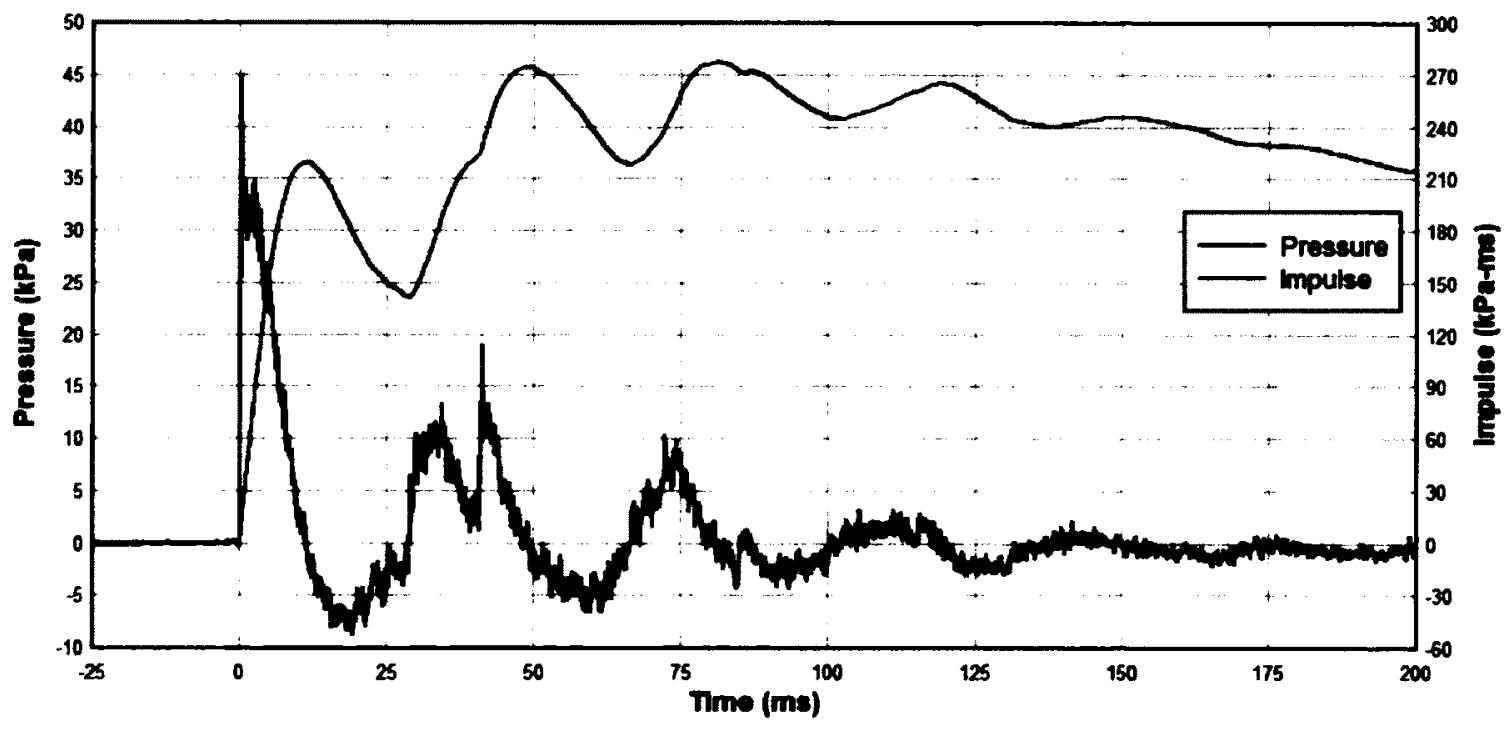

Figure 4-78: Pressure and Impulse Time History for Test DB-20M-1-2 


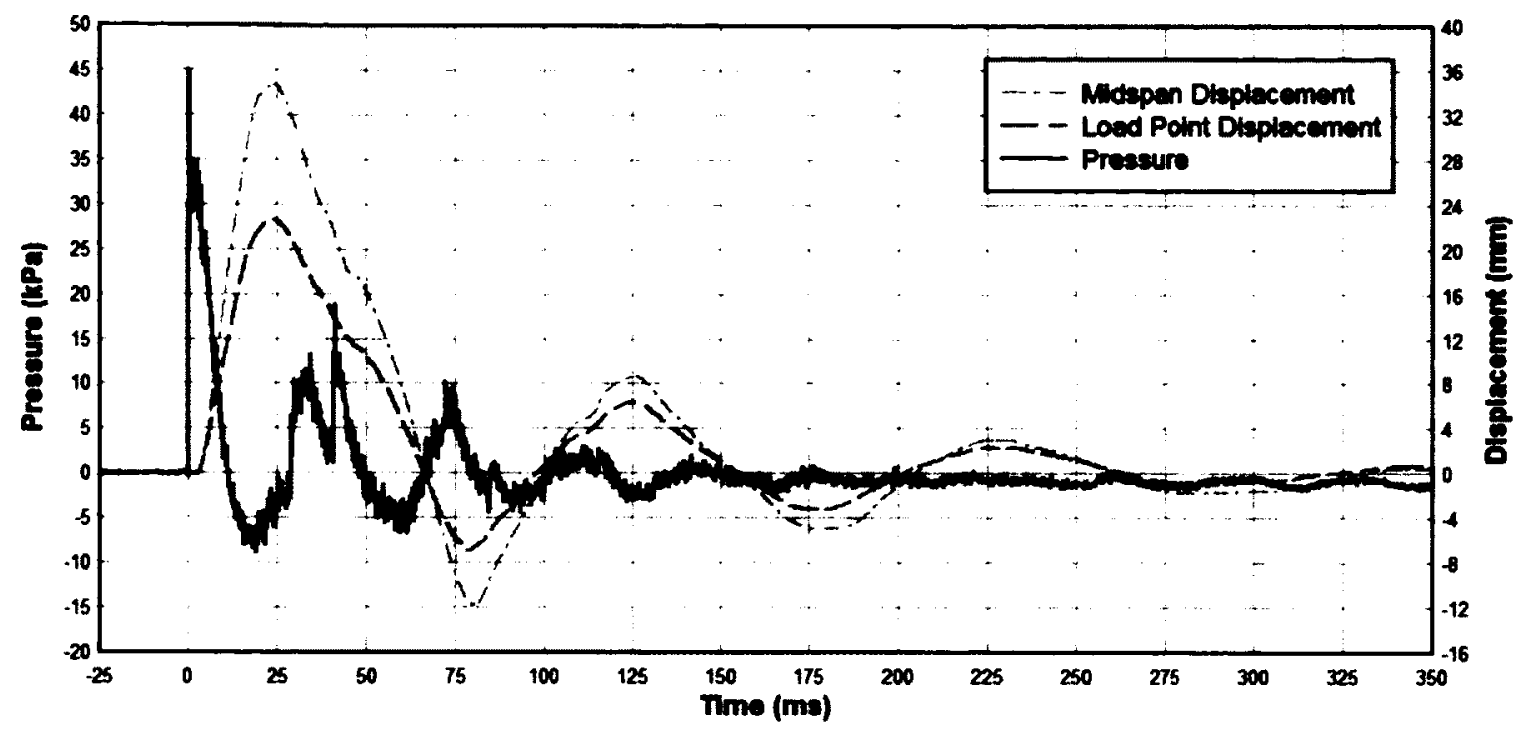

Figure 4-79: Pressure and Displacement Time History for Test DB-20M-1-2

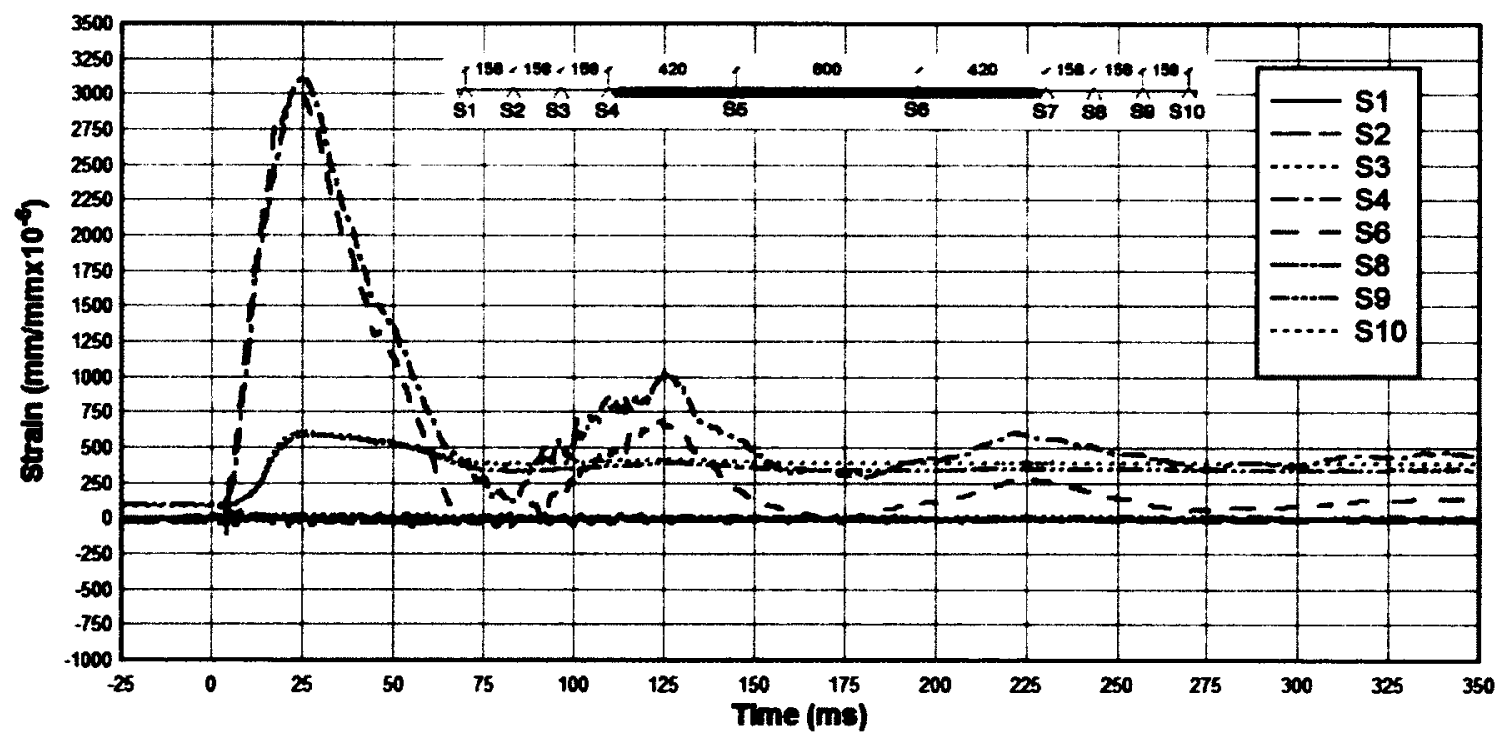

Figure 4-80: Strains in Steel for Test DB-20M-1-2 


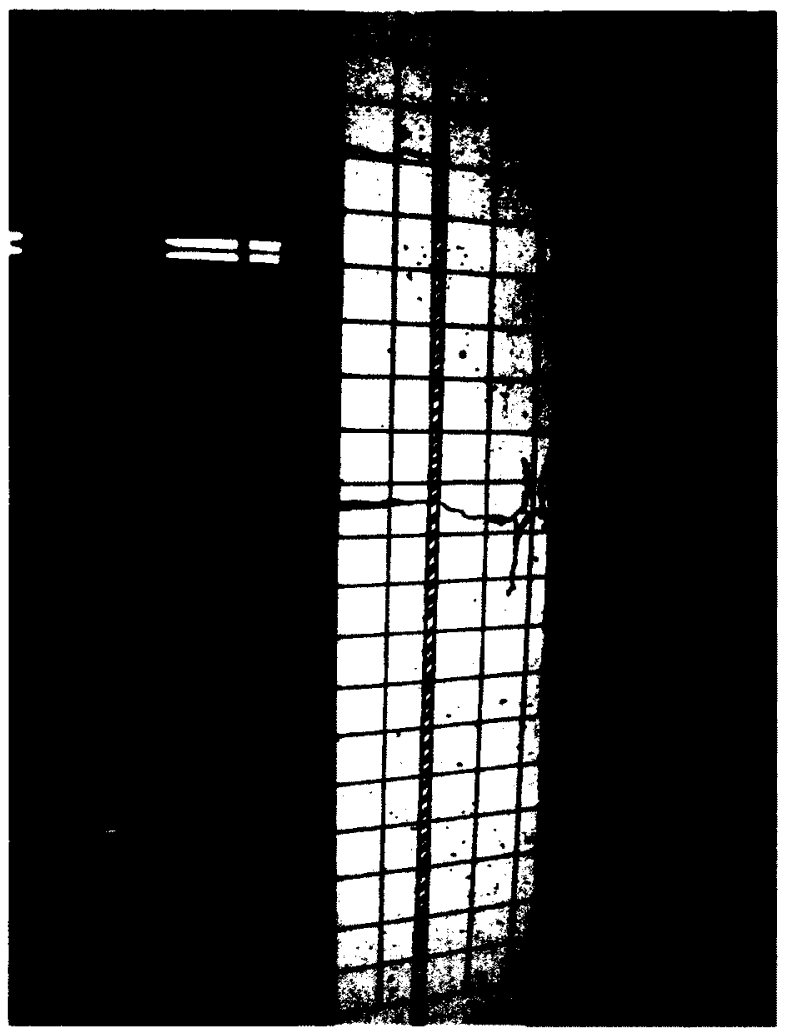

Figure 4-81: Crack Pattern After Test DB-20M-1-2

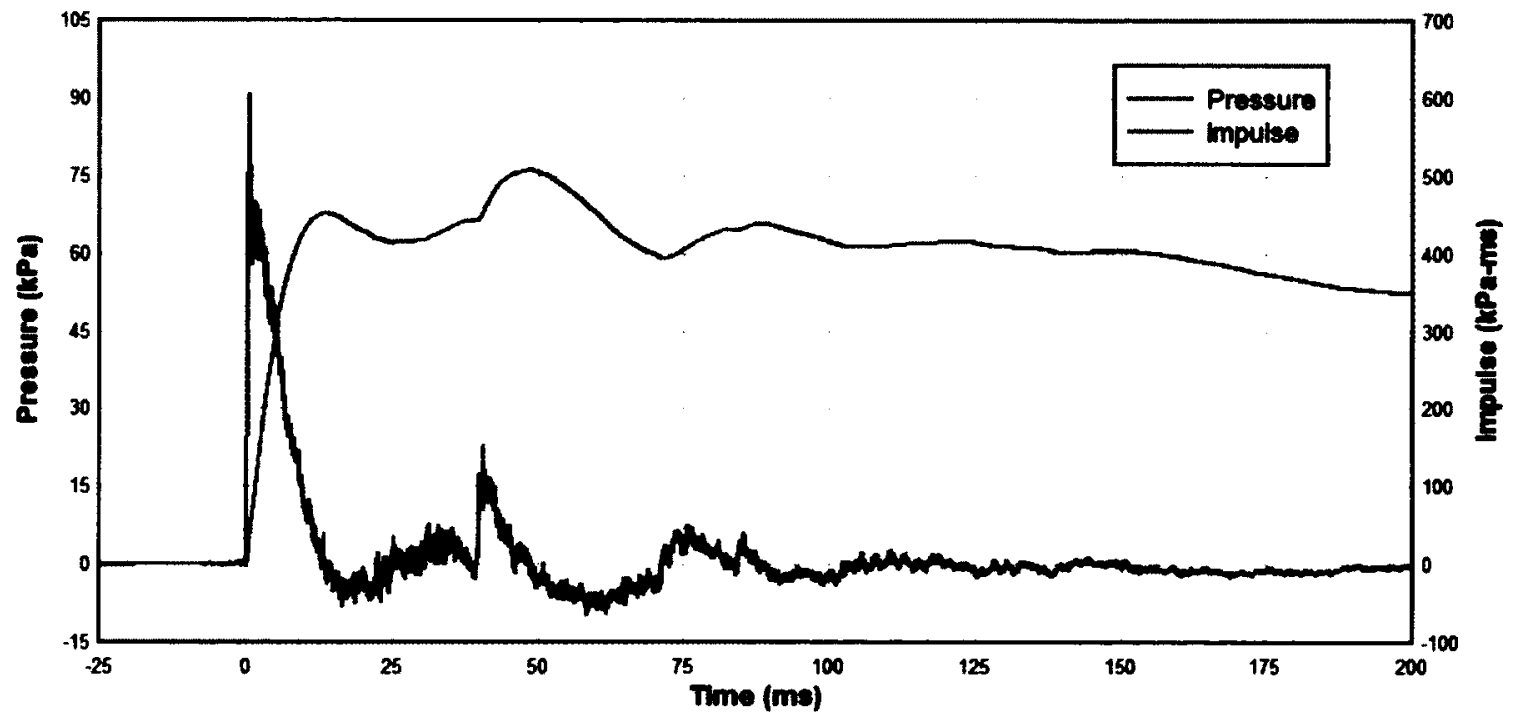

Figure 4-82: Pressure and Impulse Time History for Test DB-20M-1-3 


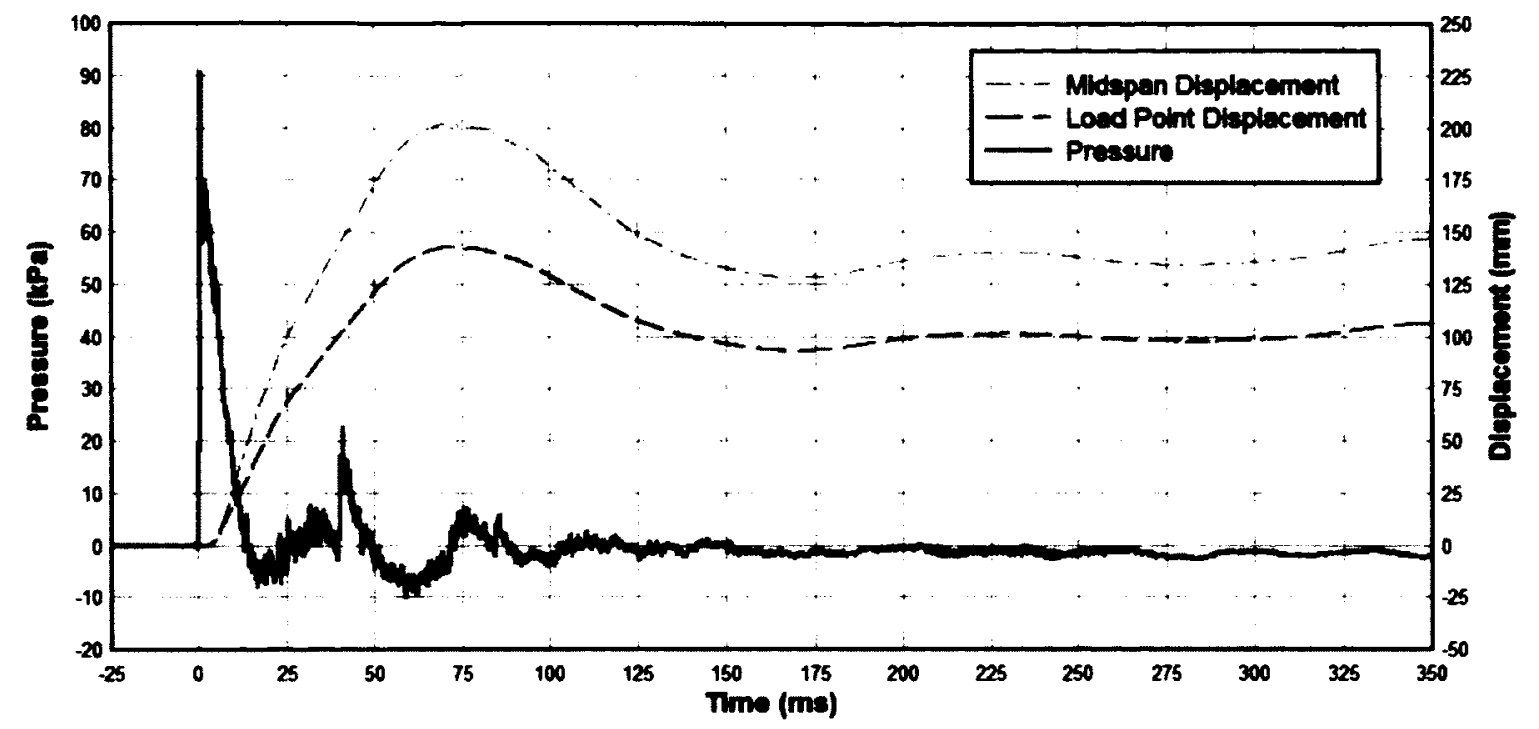

Figure 4-83: Pressure and Displacement Time History for Test DB-20M-1-3

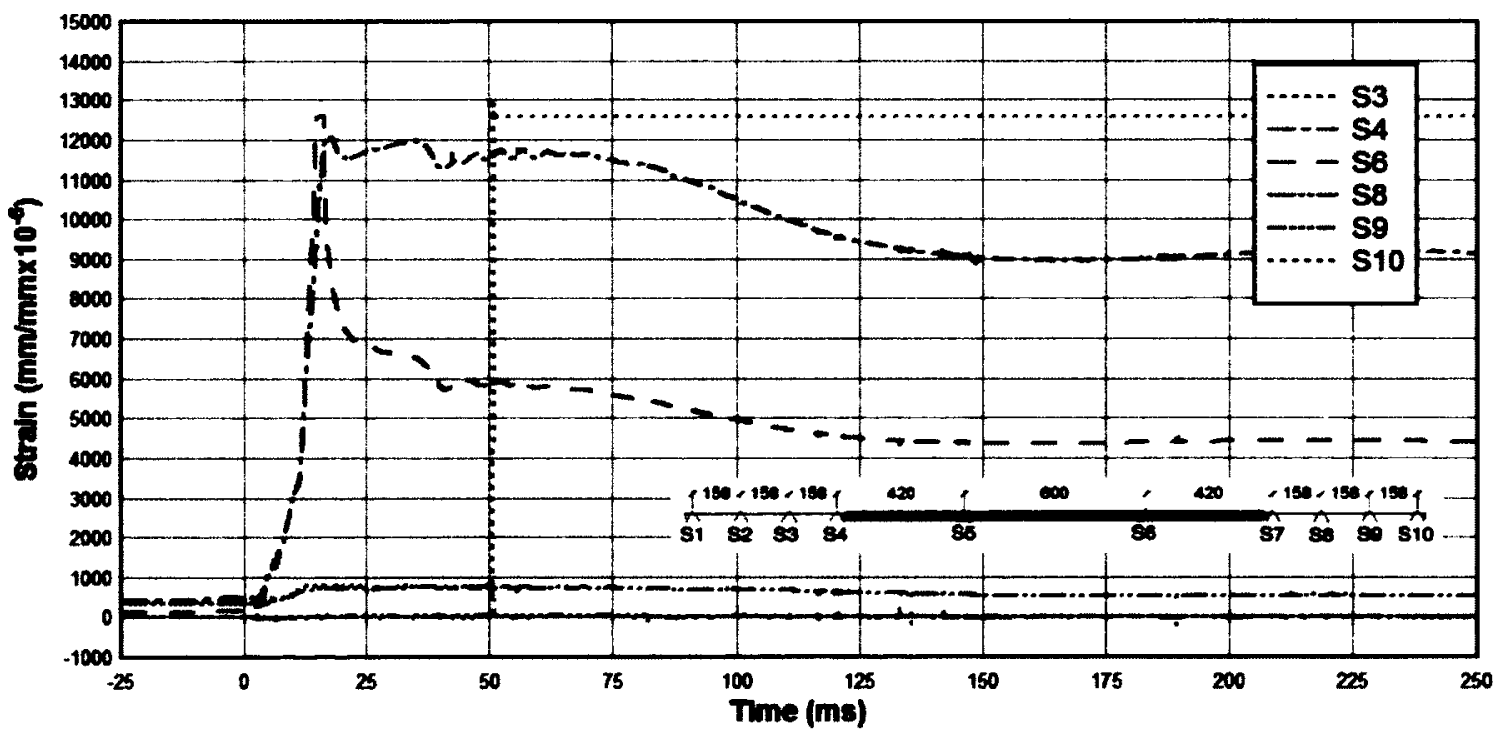

Figure 4-84: Strains in Steel for Test DB-20M-1-3 


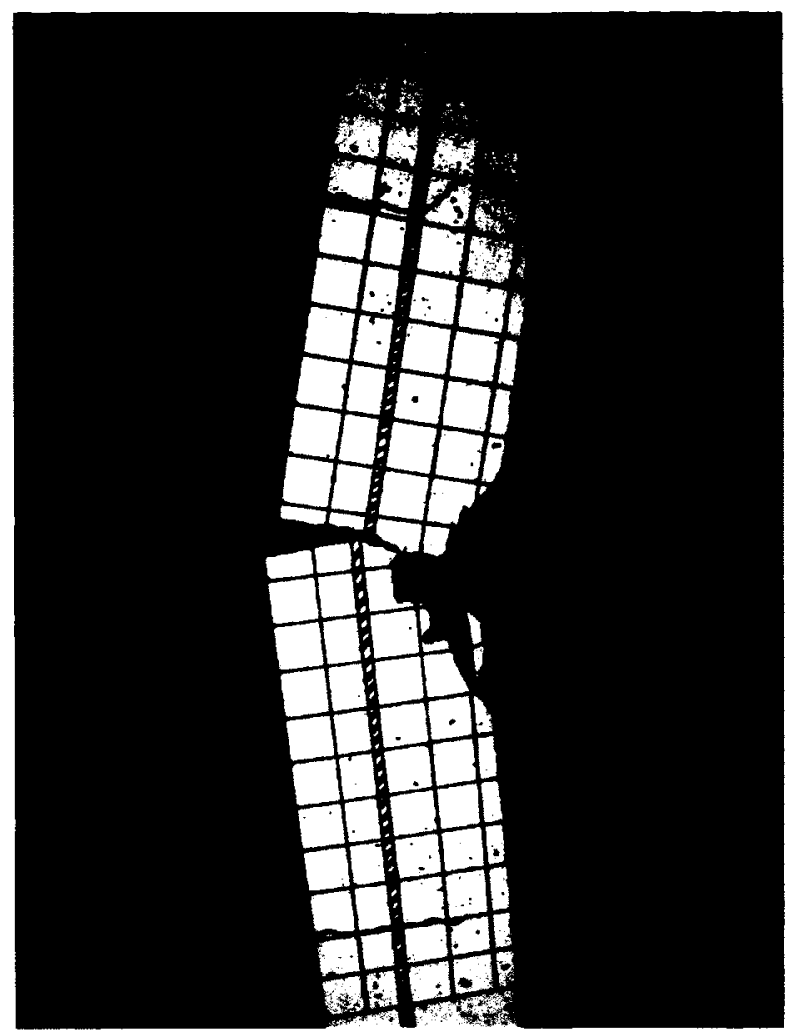

Figure 4-85: Crack Pattern After Test DB-20M-1-3

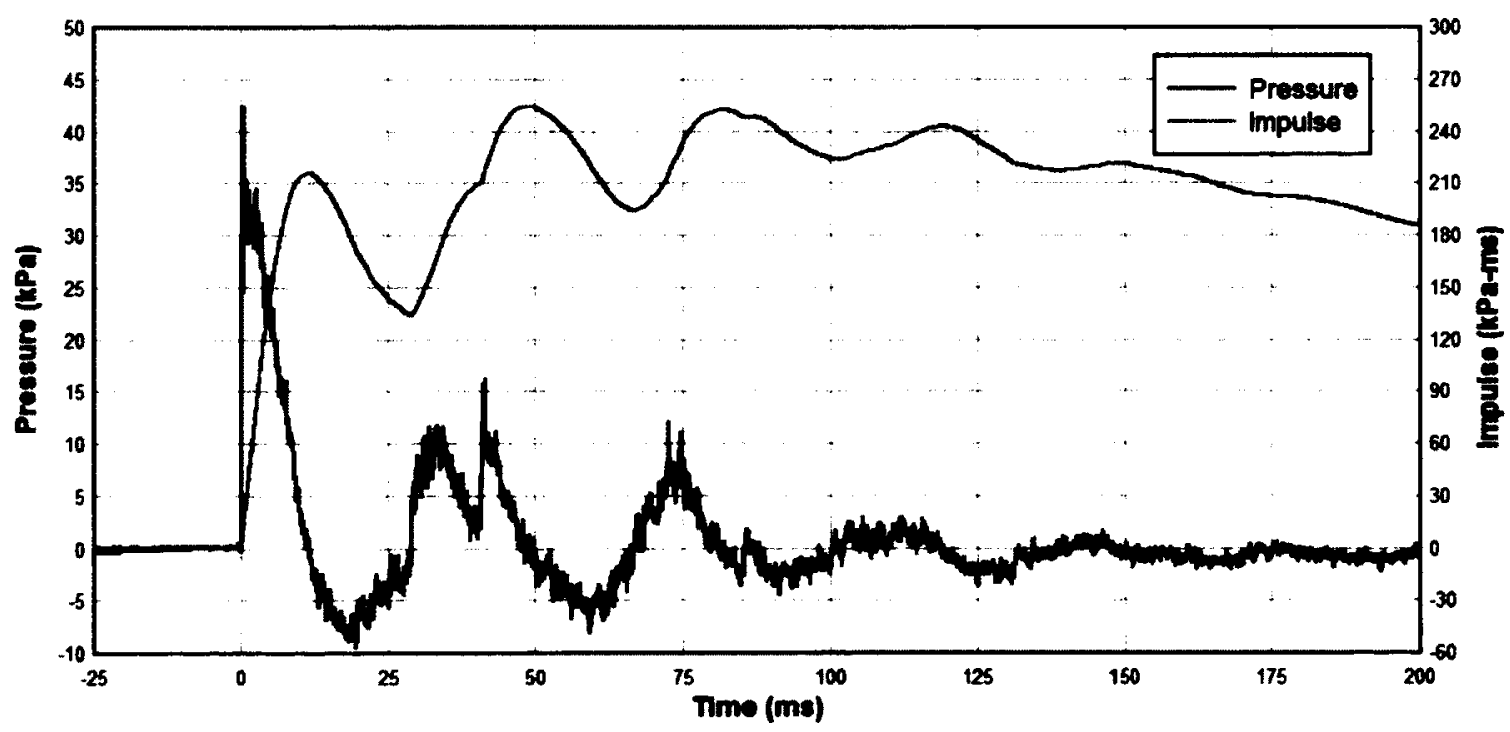

Figure 4-86: Pressure and Impulse Time History for Test DB-20M-2-1 


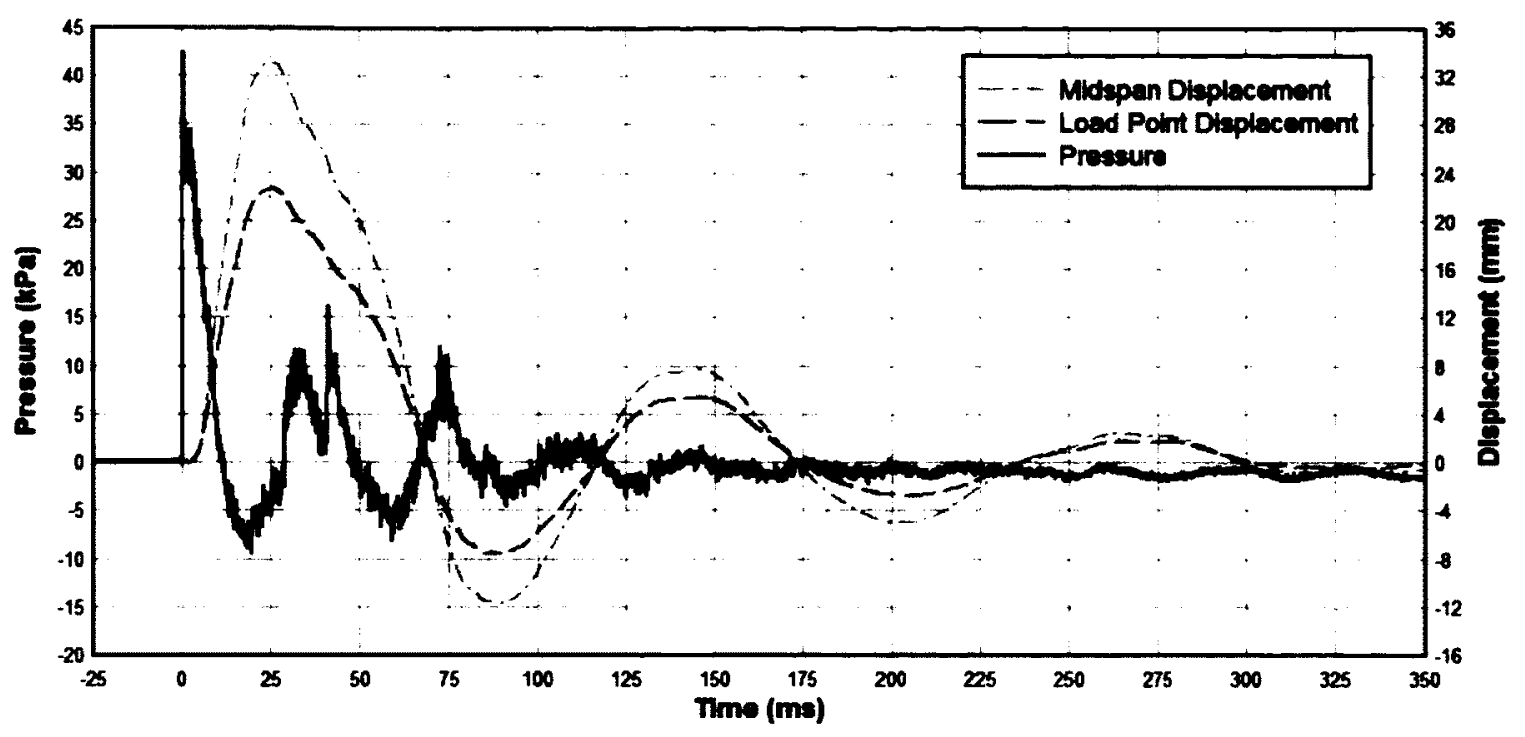

Figure 4-87: Pressure and Displacement Time History for Test DB-20M-2-1

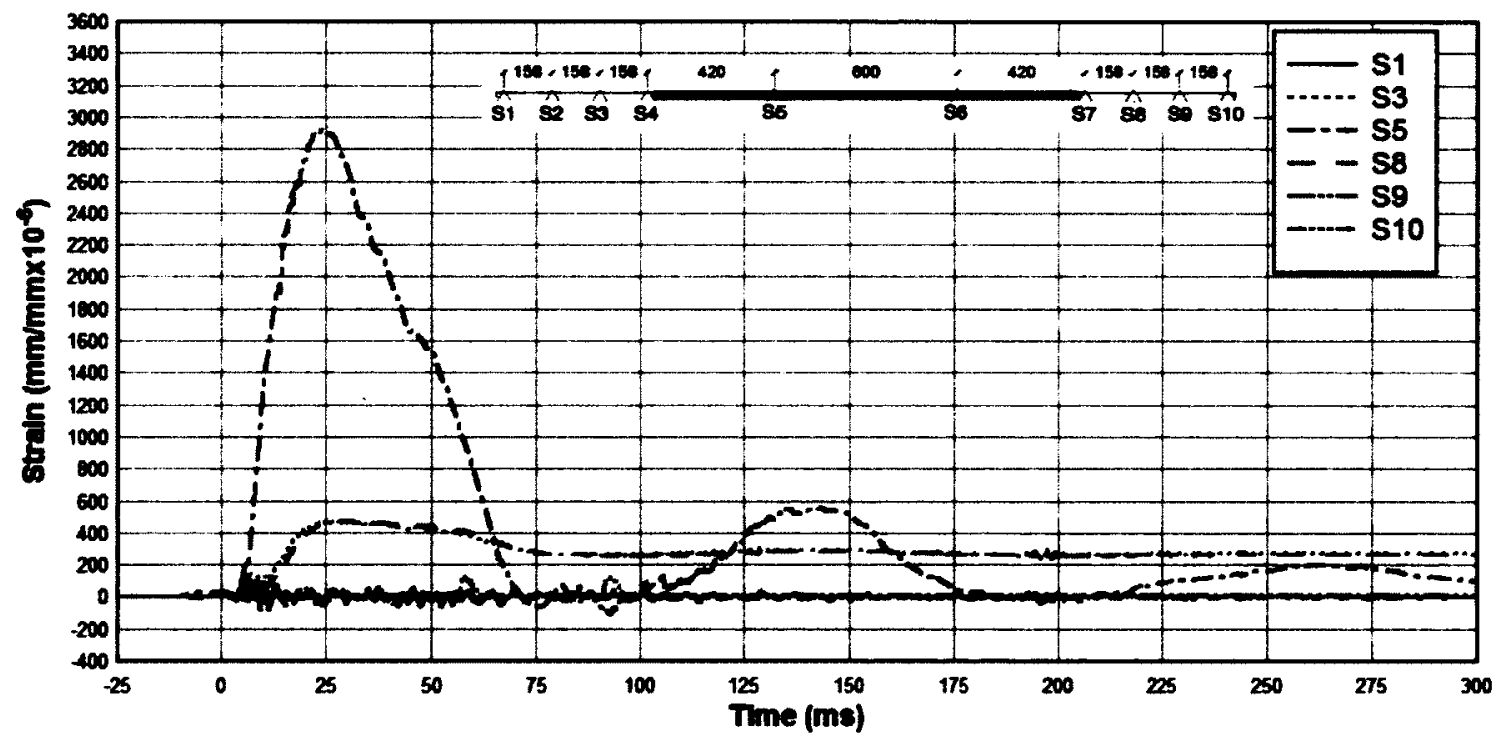

Figure 4-88: Strains in Steel for Test DB-20M-2-1 


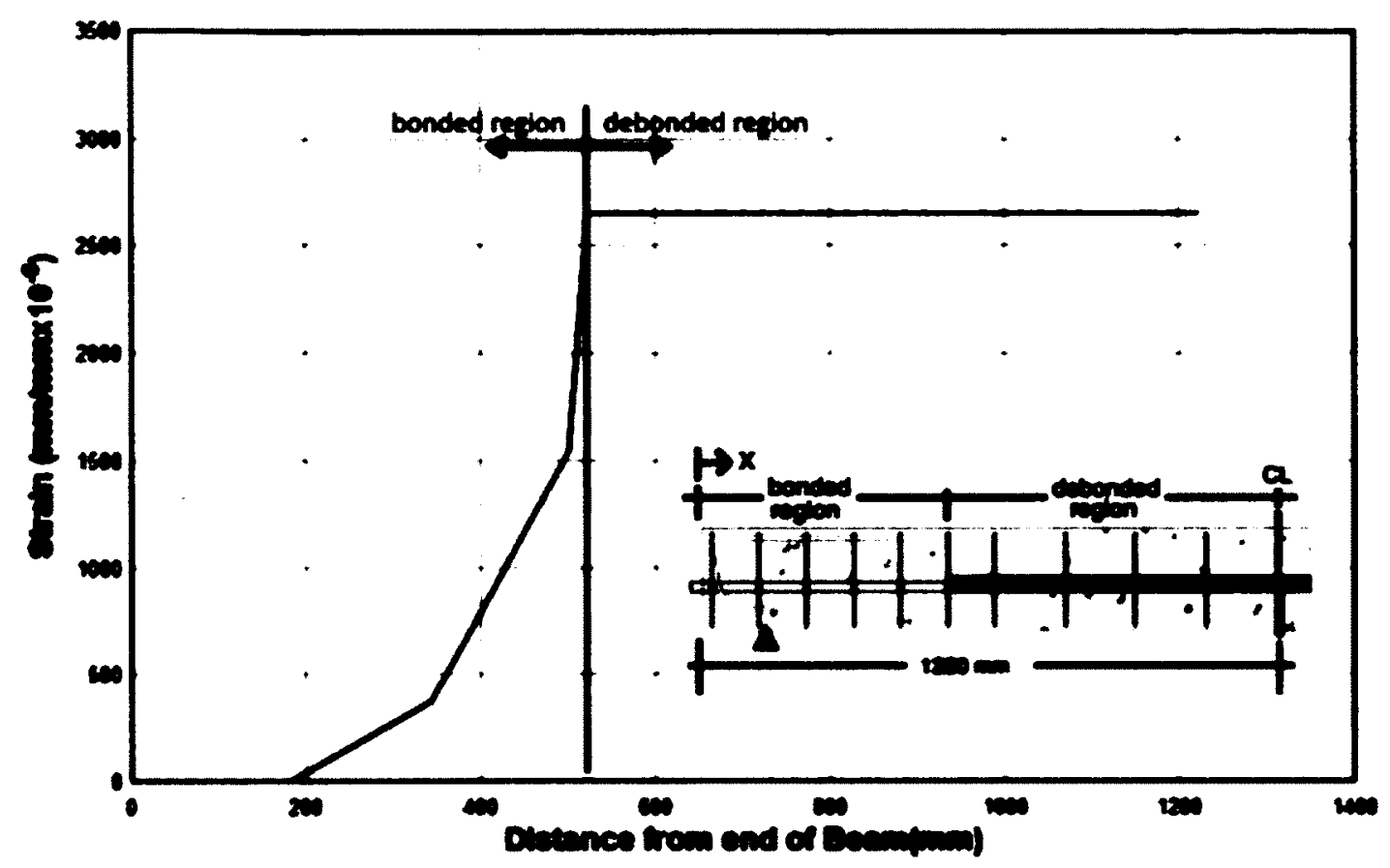

Figure 4-89: Strain Profile at Yield for Test DB-20M-2-1

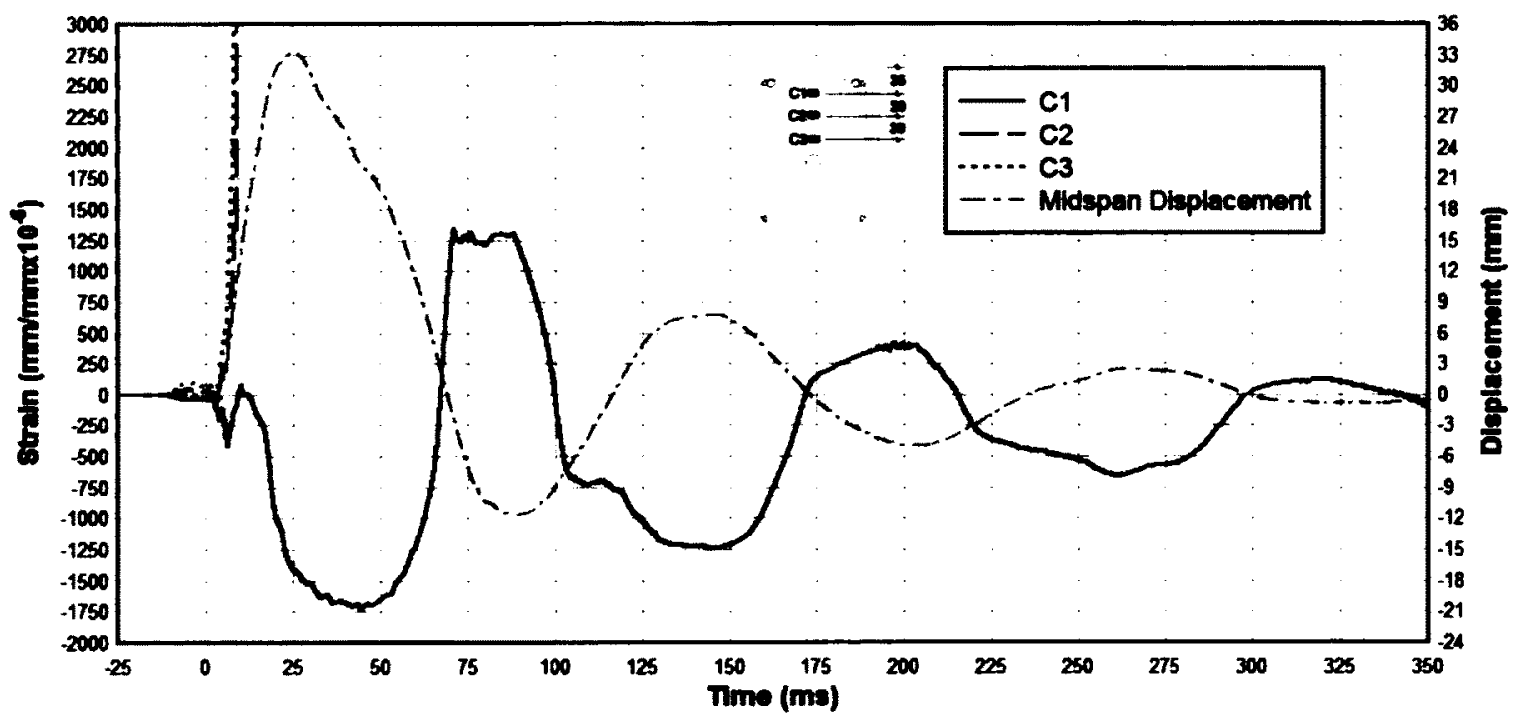

Figure 4-90: Strains in Concrete for Test DB-20M-2-1 


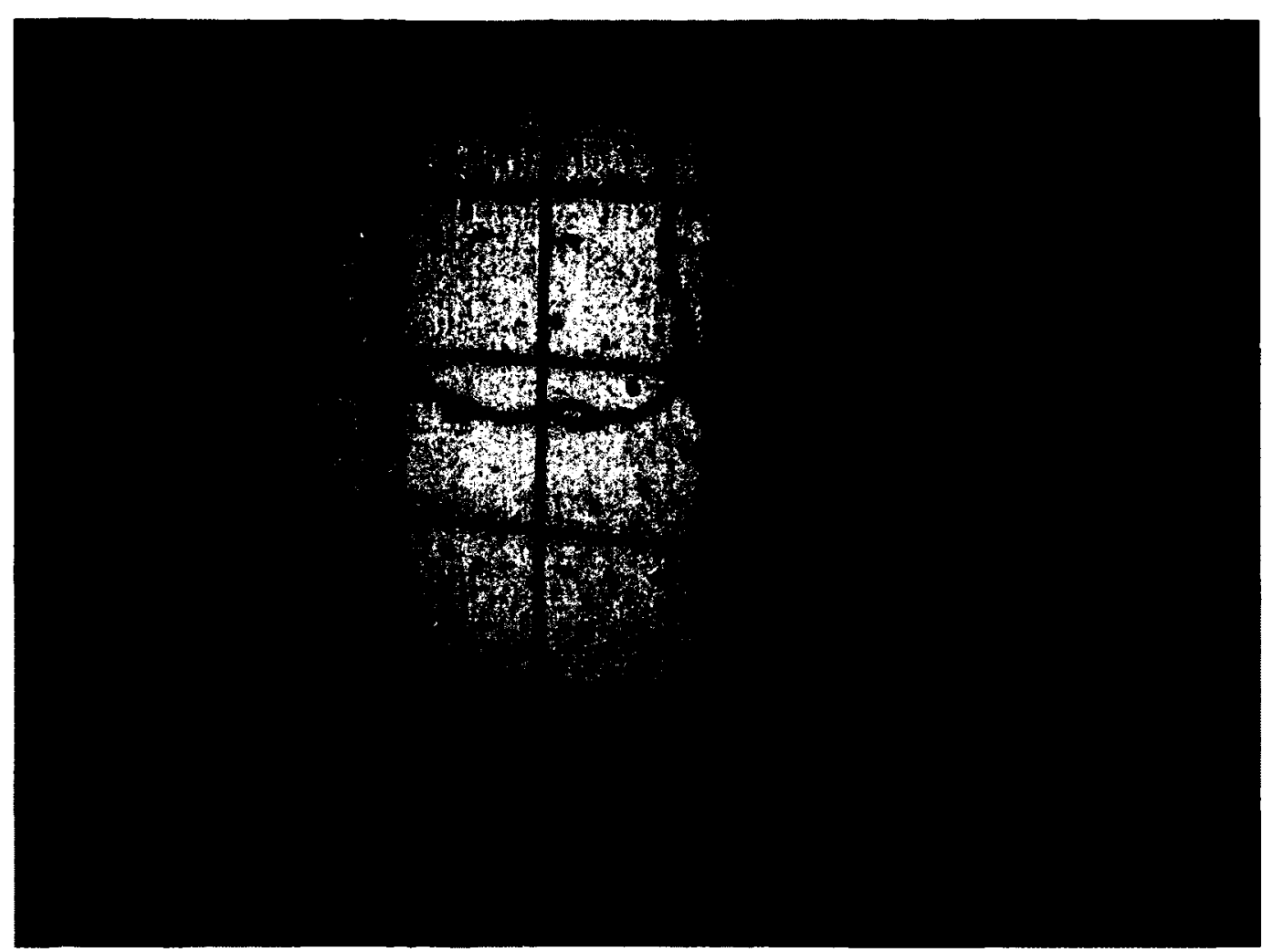

Figure 4-91: Crack Pattern After Test DB-20M-2-1

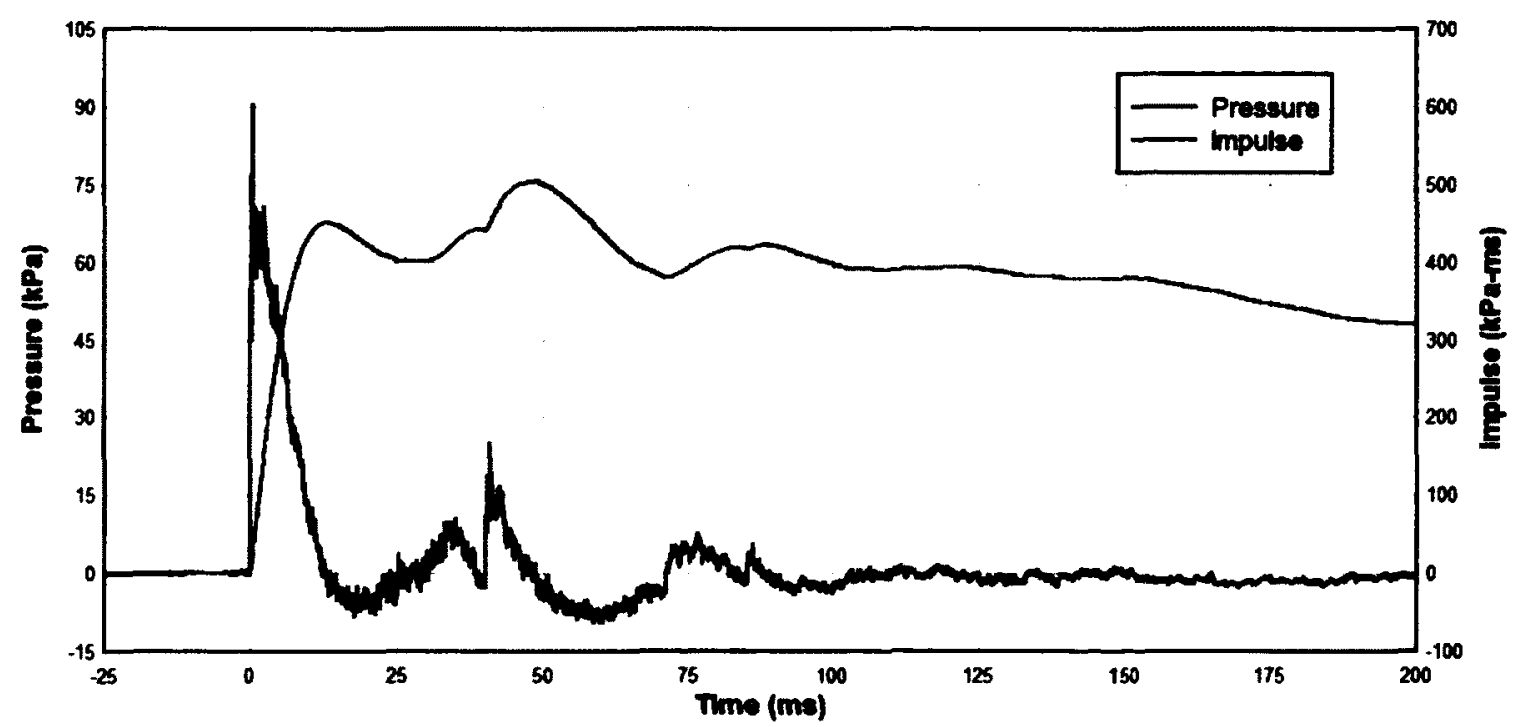

Figure 4-92: Pressure and Impulse Time History for Test DB-20M-2-2 


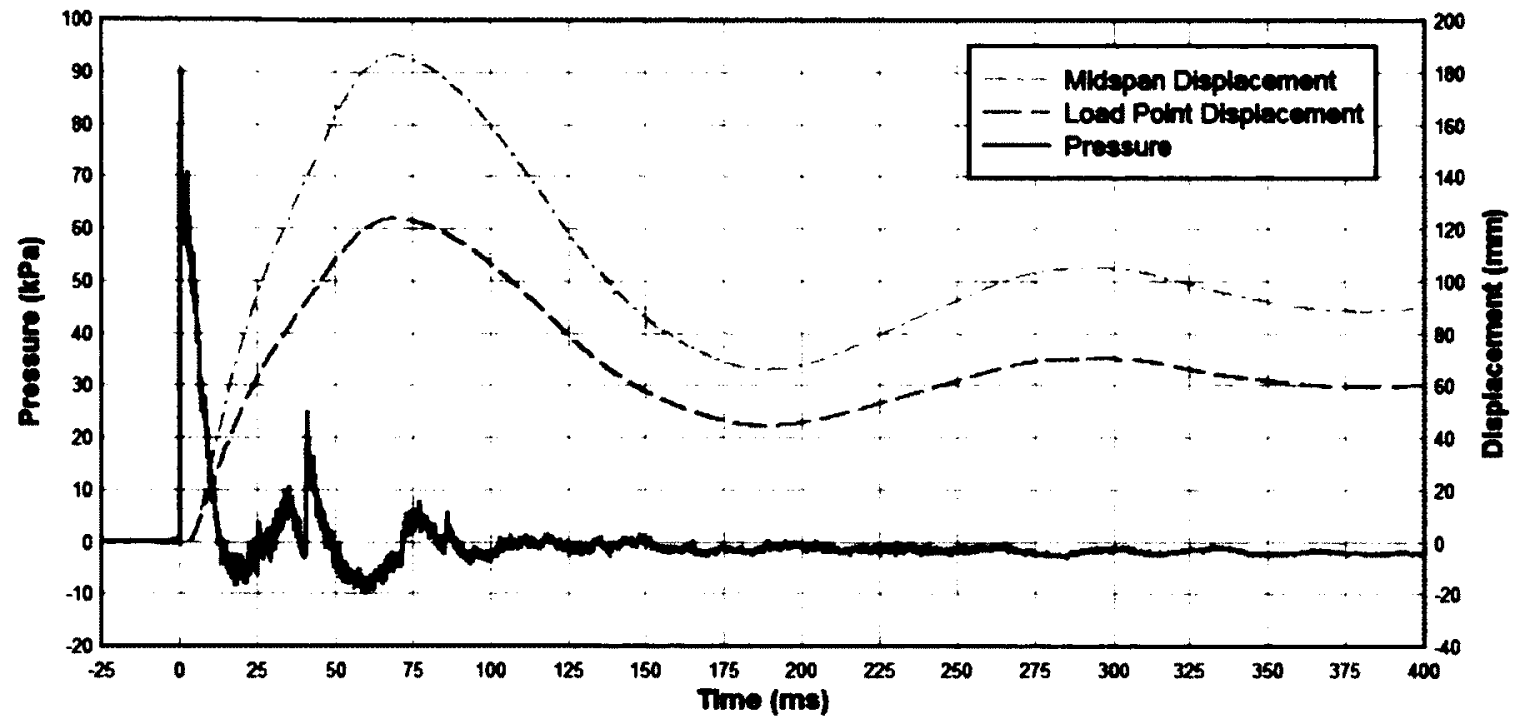

Figure 4-93: Pressure and Displacement Time History for Test DB-20M-2-2

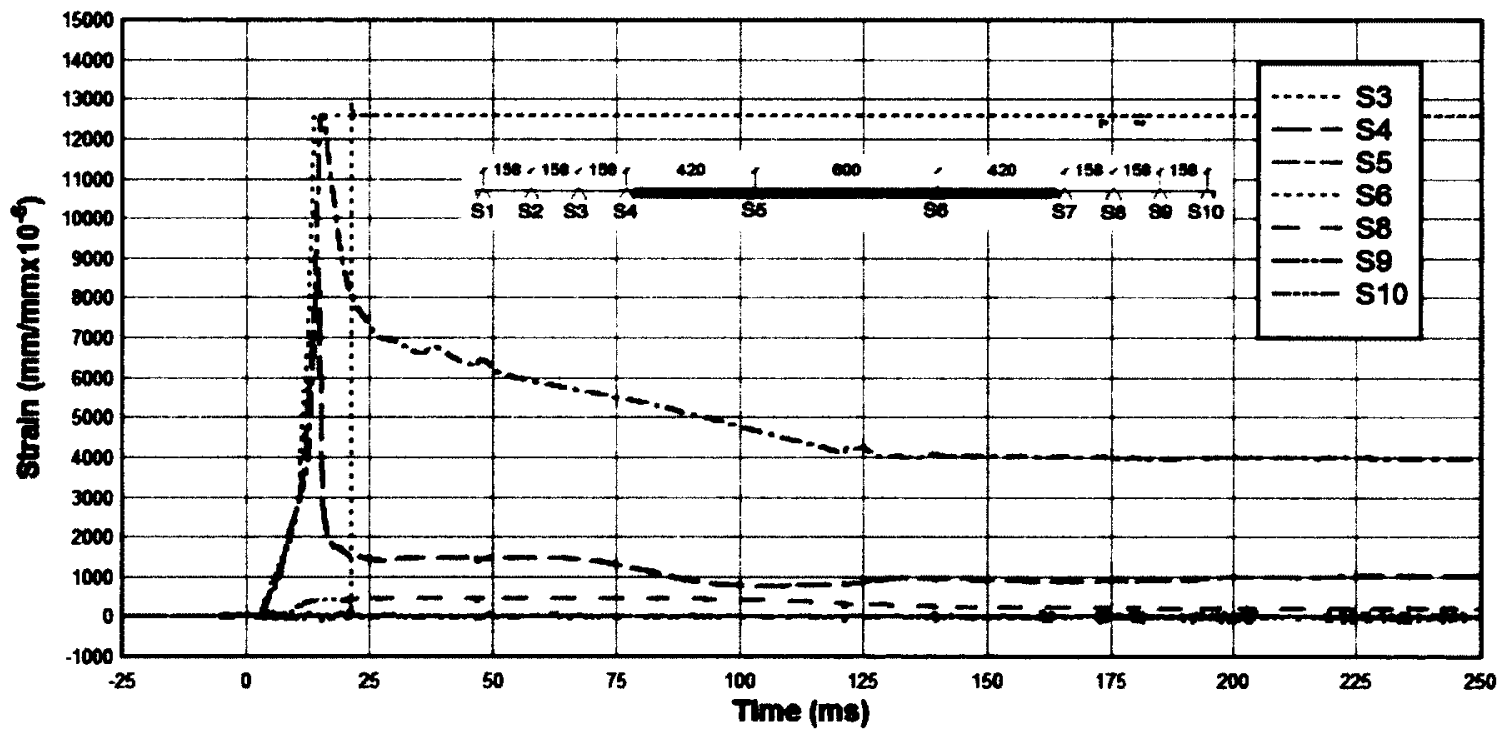

Figure 4-94: Strains in Steel for Test DB-20M-2-2 


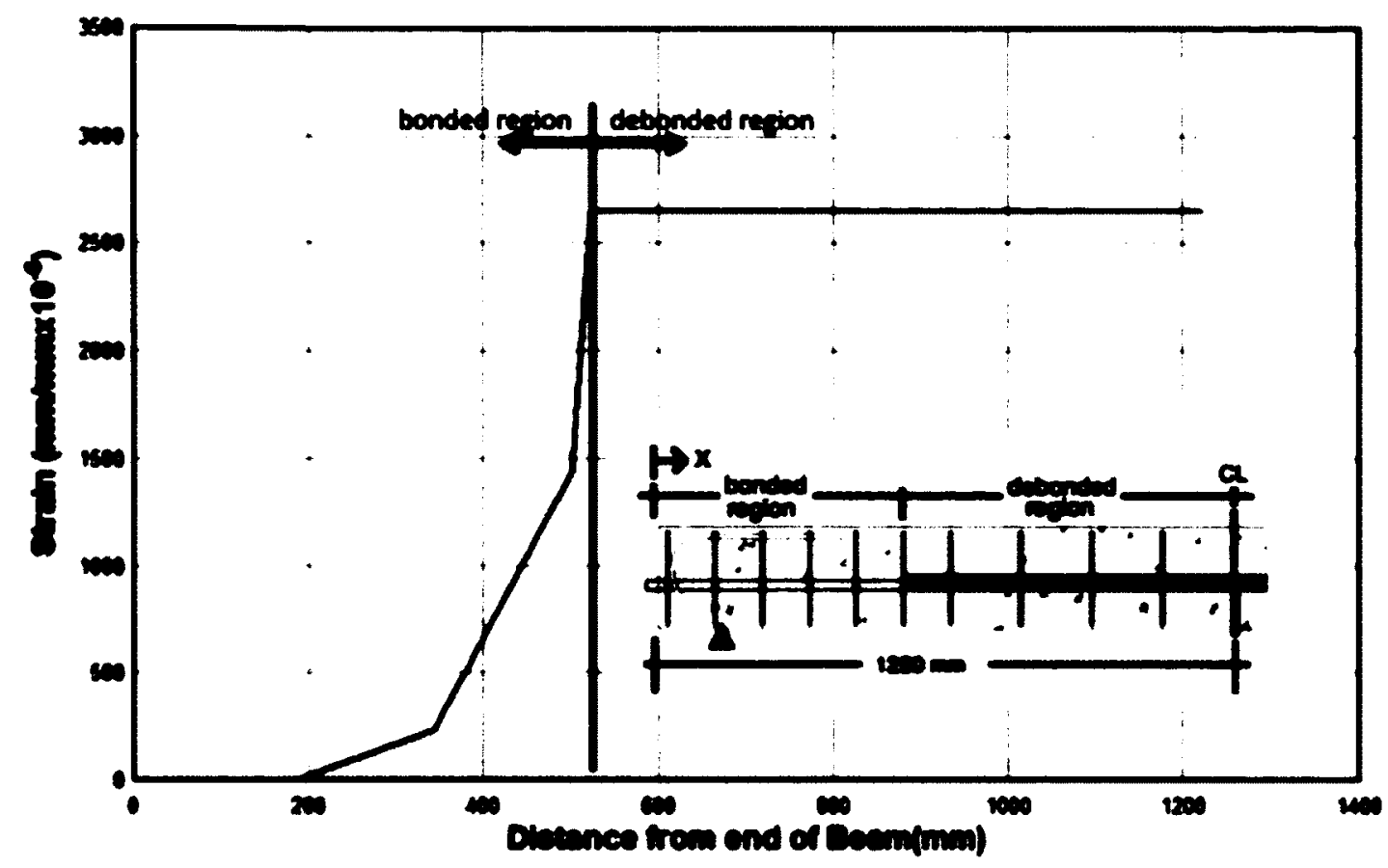

Figure 4-95: Strain Profile at Yield for Test DB-20M-2-2

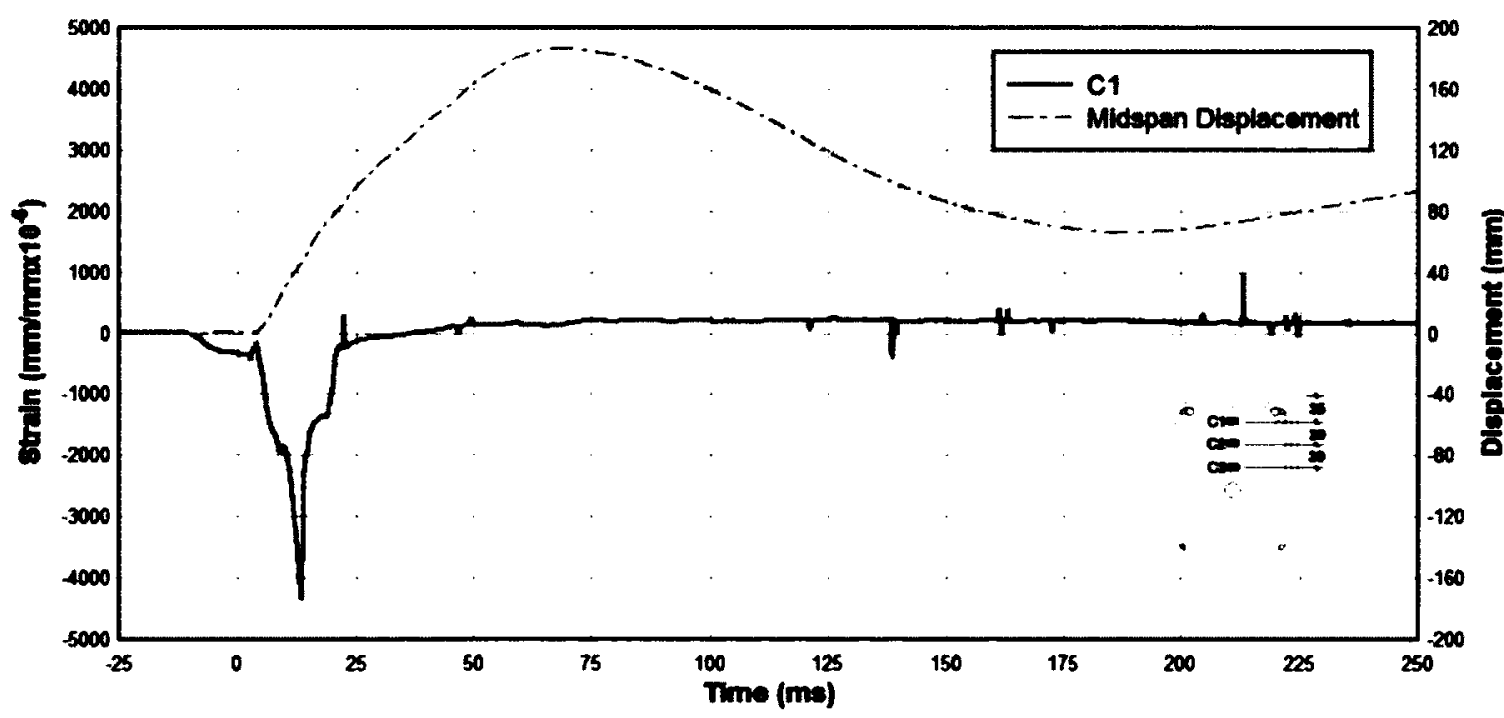

Figure 4-96: Strains in Concrete for Test DB-20M-2-2 


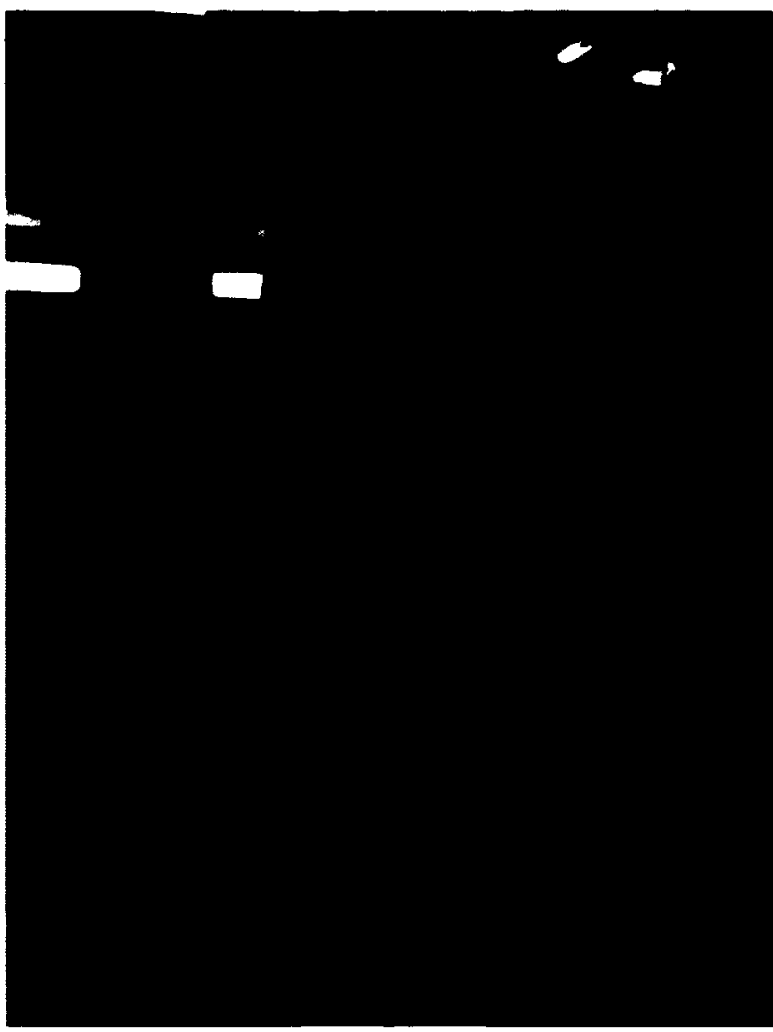

Figure 4-97: Crack Pattern After Test DB-20M-2-2

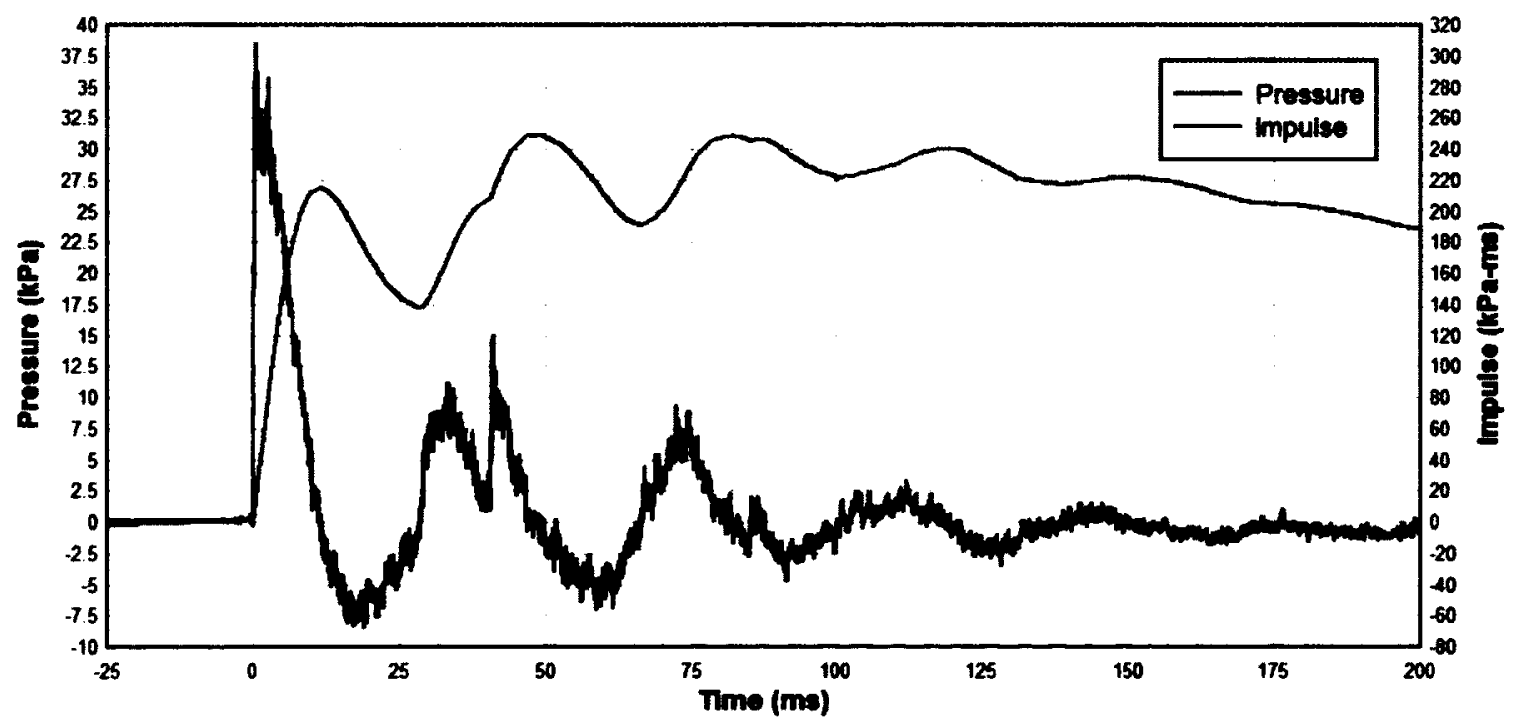

Figure 4-98: Pressure and Impulse Time History for Test DB-20M-3-1 


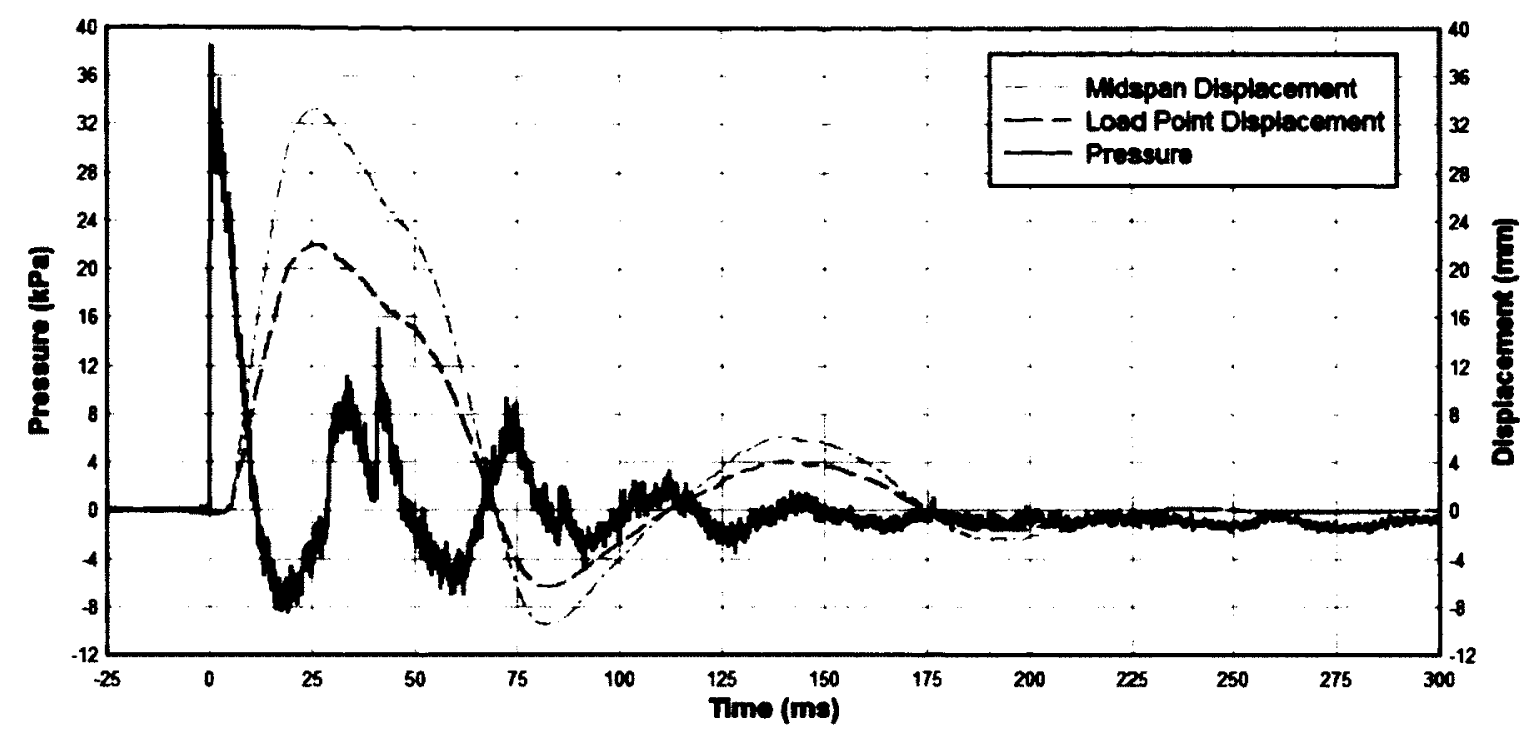

Figure 4-99: Pressure and Displacement Time History for Test DB-20M-3-1

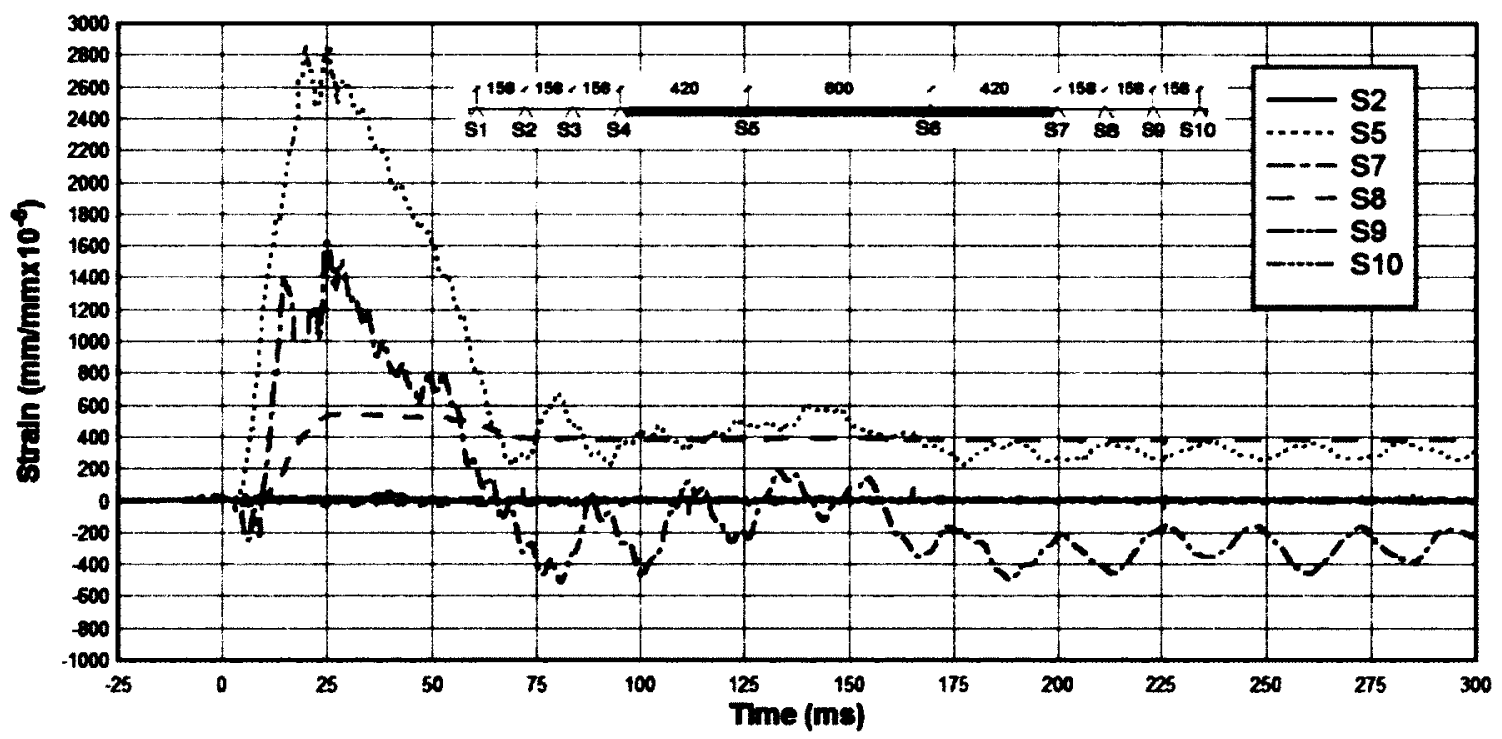

Figure 4-100: Strains in Steel for Test DB-20M-3-1 


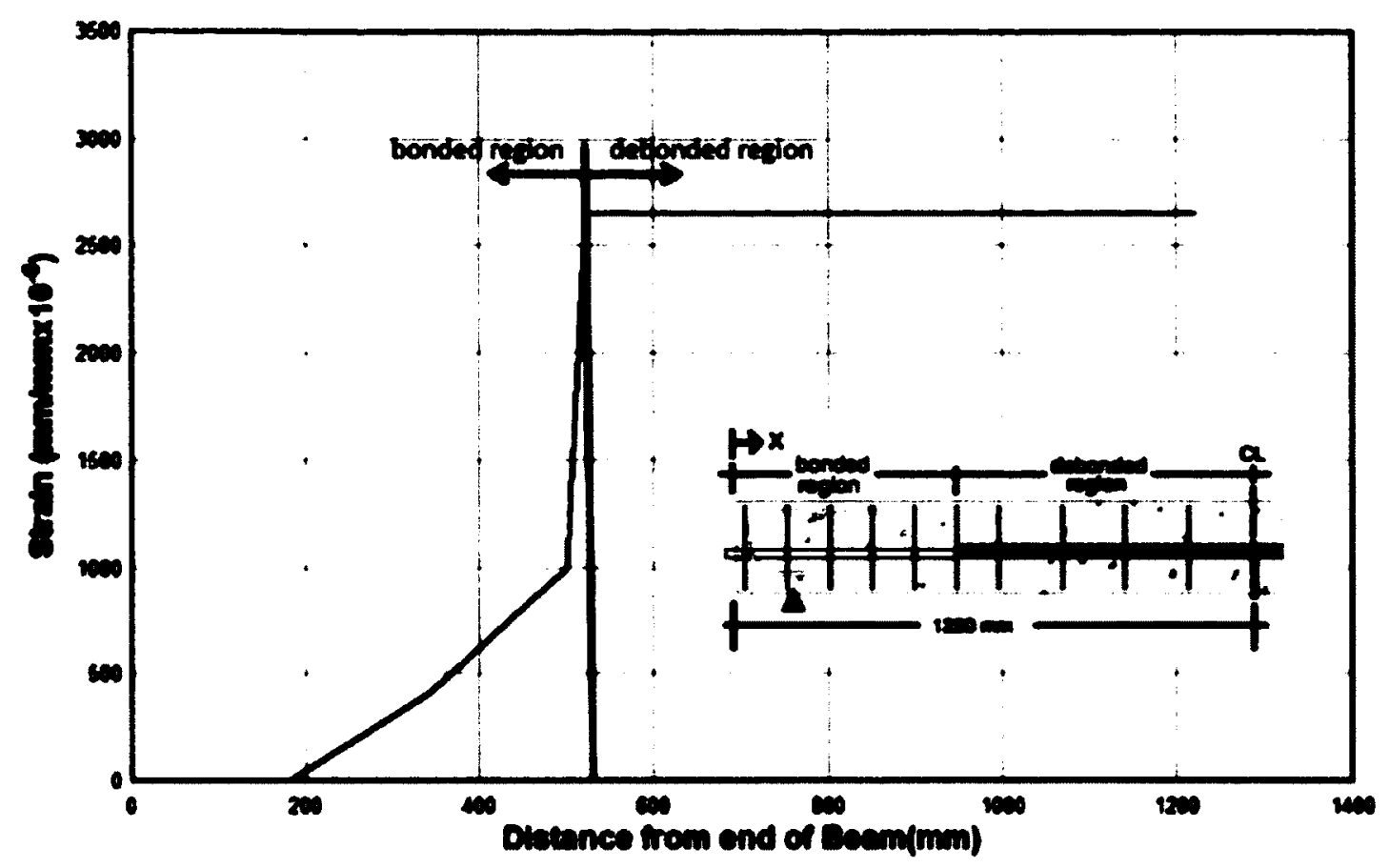

Figure 4-101: Strain Profile at Yield for Test DB-20M-3-1

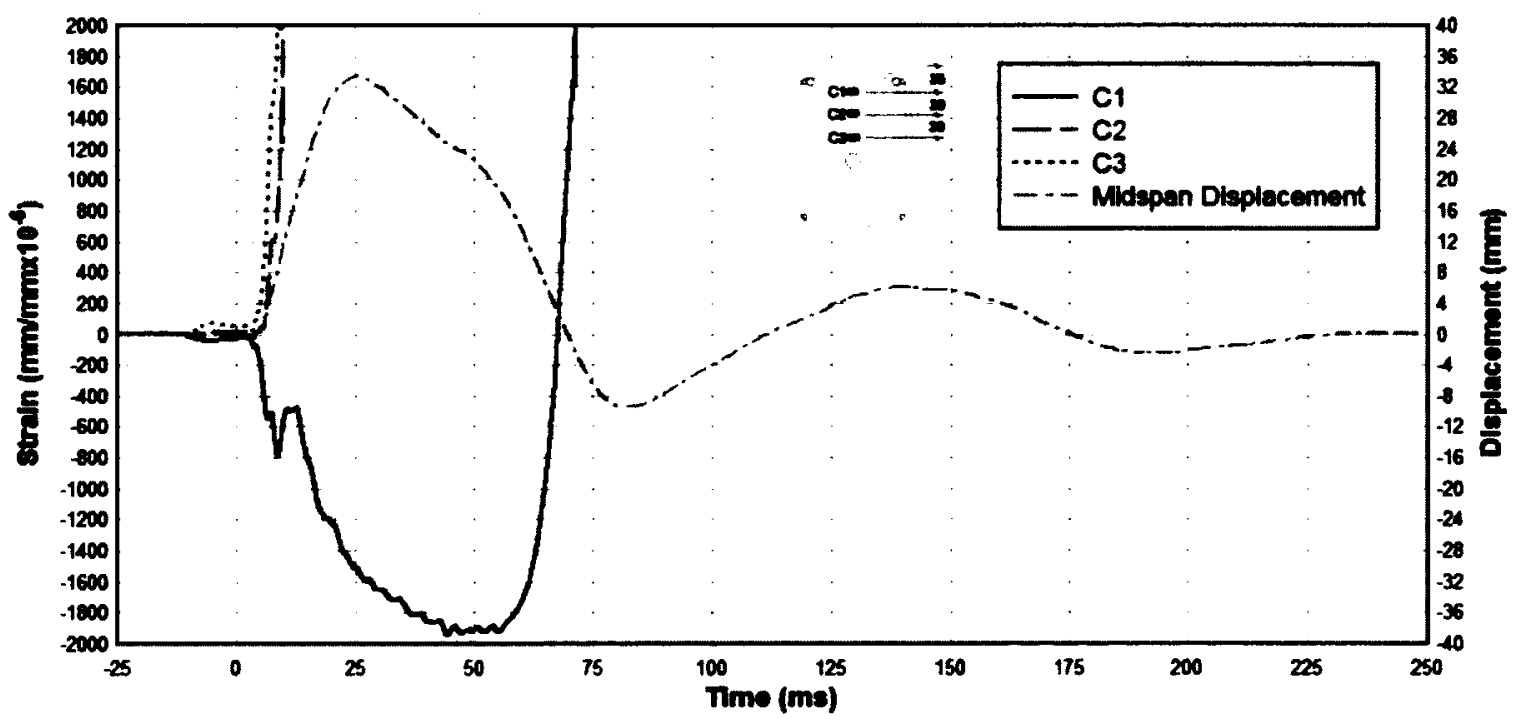

Figure 4-102: Strains in Concrete for Test DB-20M-3-1 


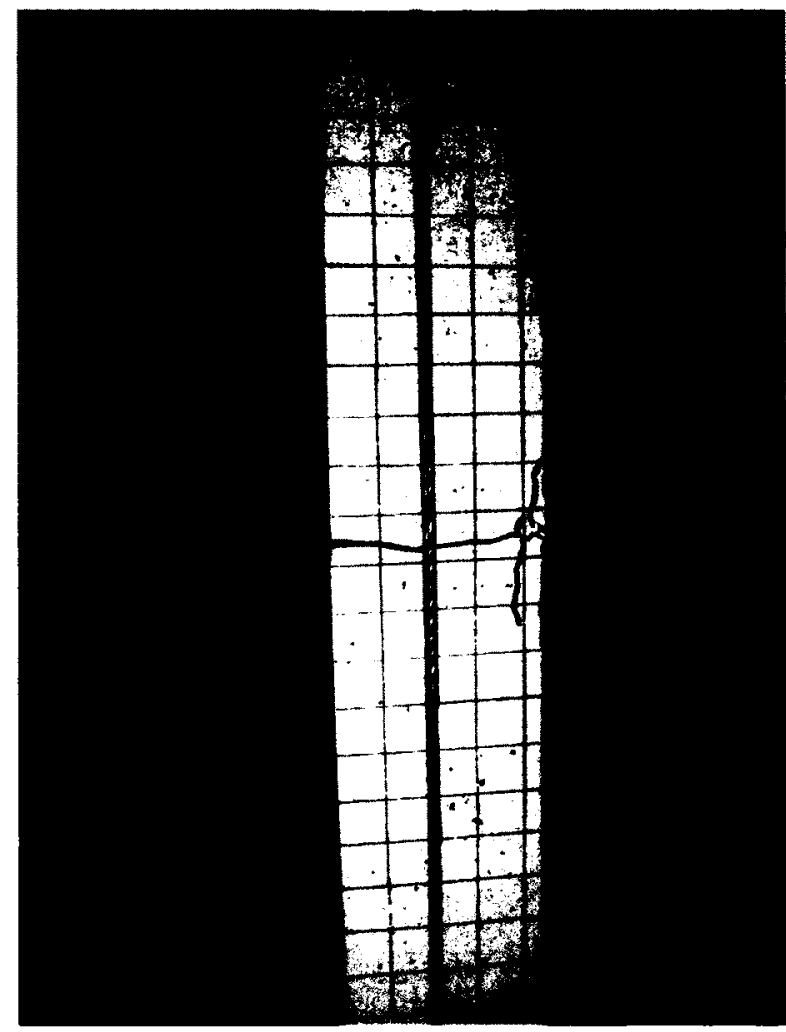

Figure 4-103: Crack Pattern After Test DB-20M-3-1

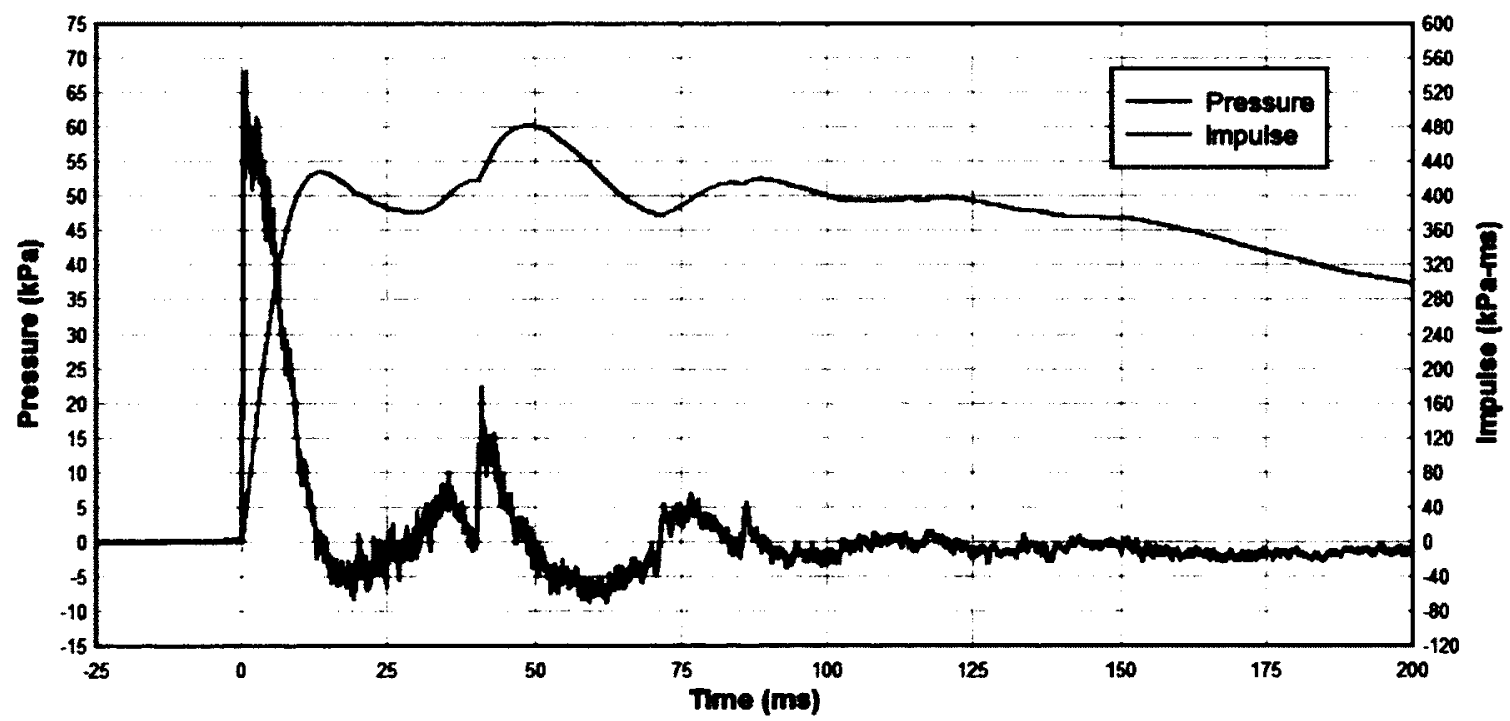

Figure 4-104: Pressure and Impulse Time History for Test DB-20M-3-2 


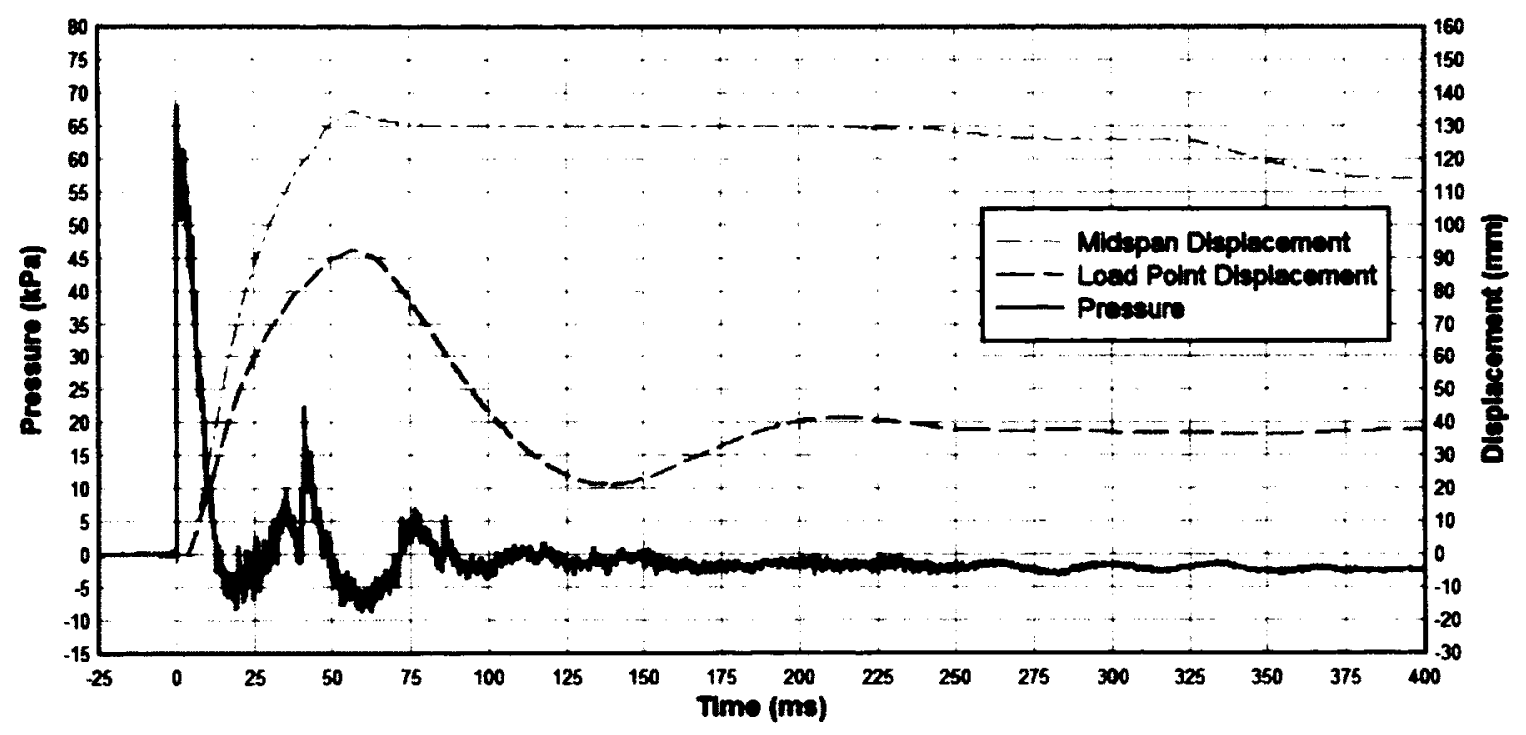

Figure 4-105: Pressure and Displacement Time History for Test DB-20M-3-2

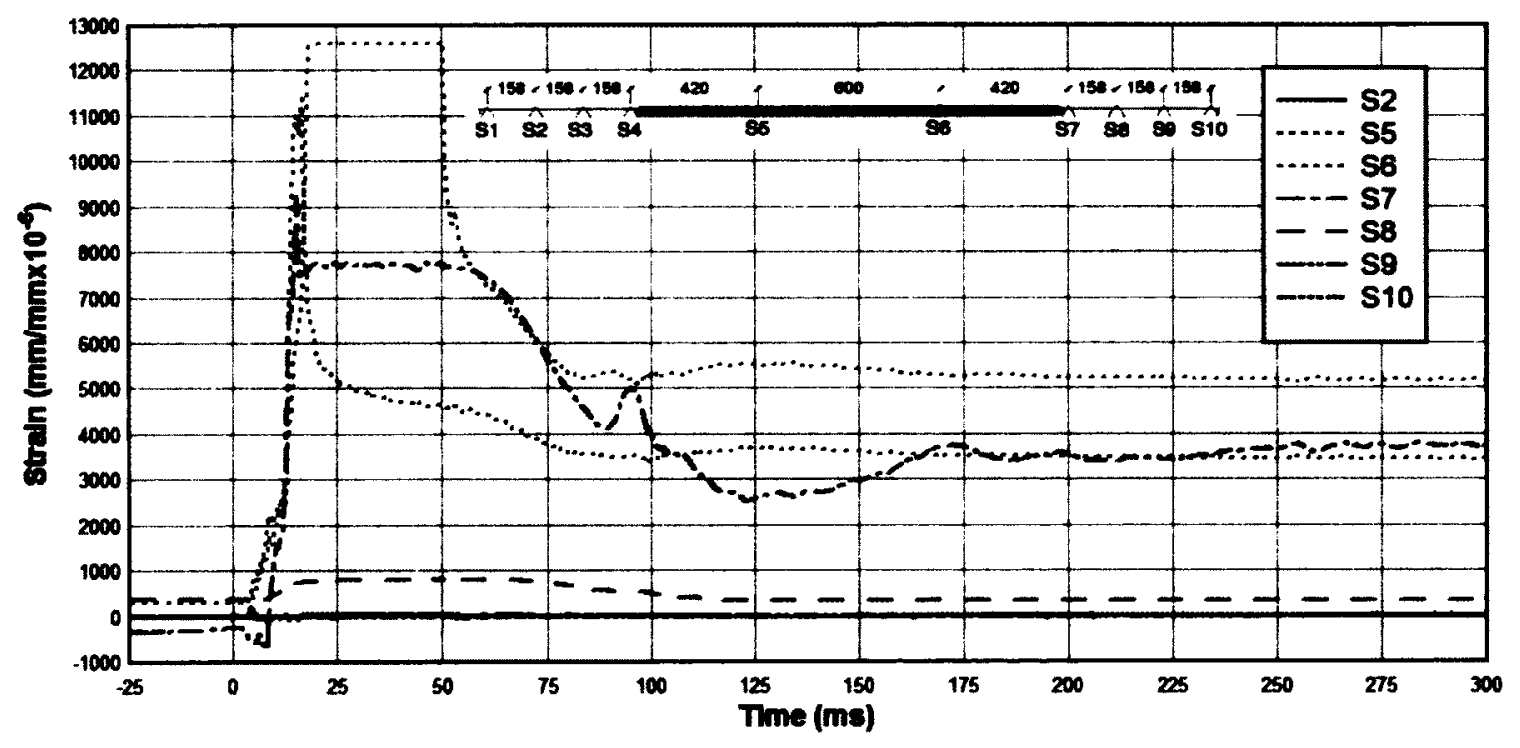

Figure 4-106: Strains in Steel for Test DB-20M-3-2 


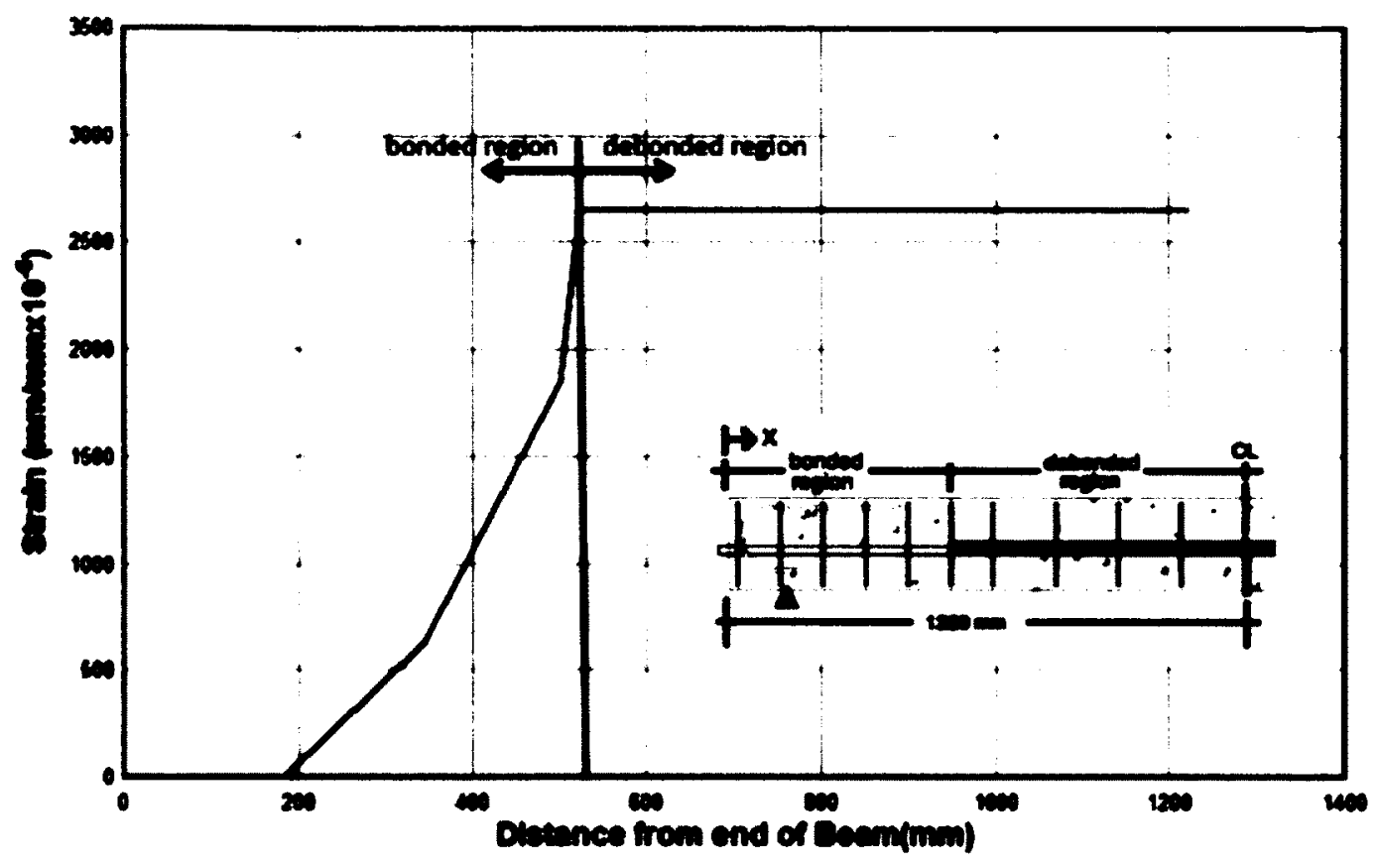

Figure 4-107: Strain Profile at Yield for Test DB-20M-3-2

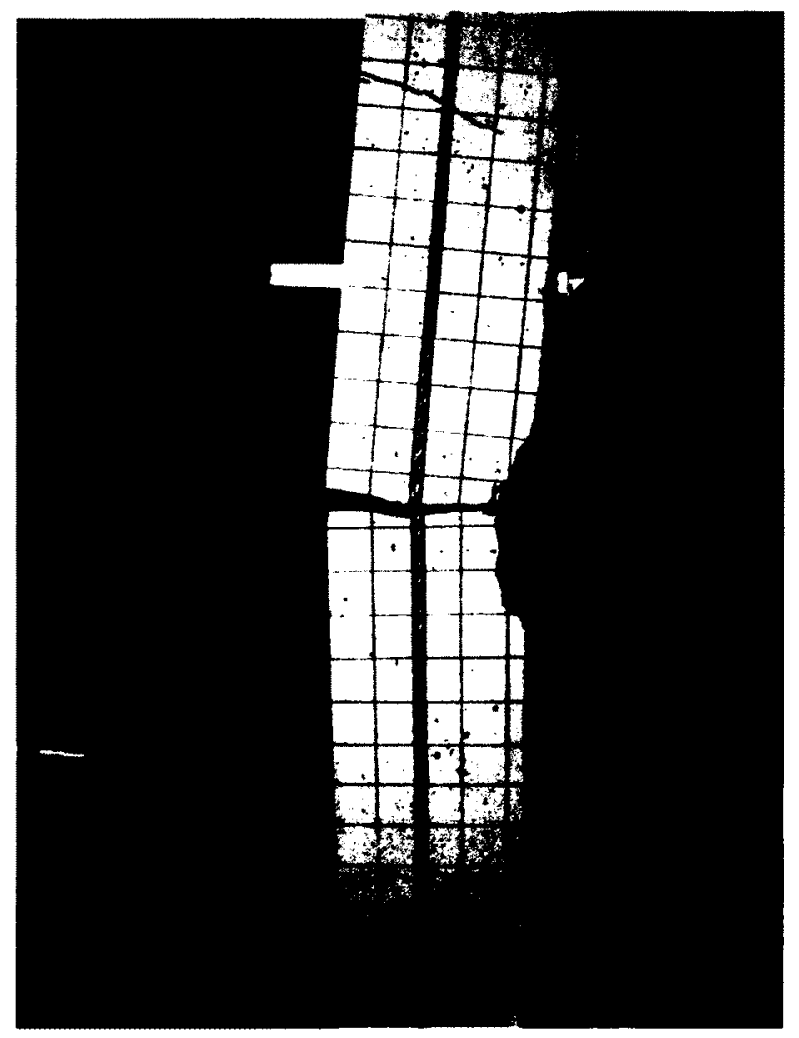

Figure 4-108: Crack Pattern After Test DB-20M-3-2 


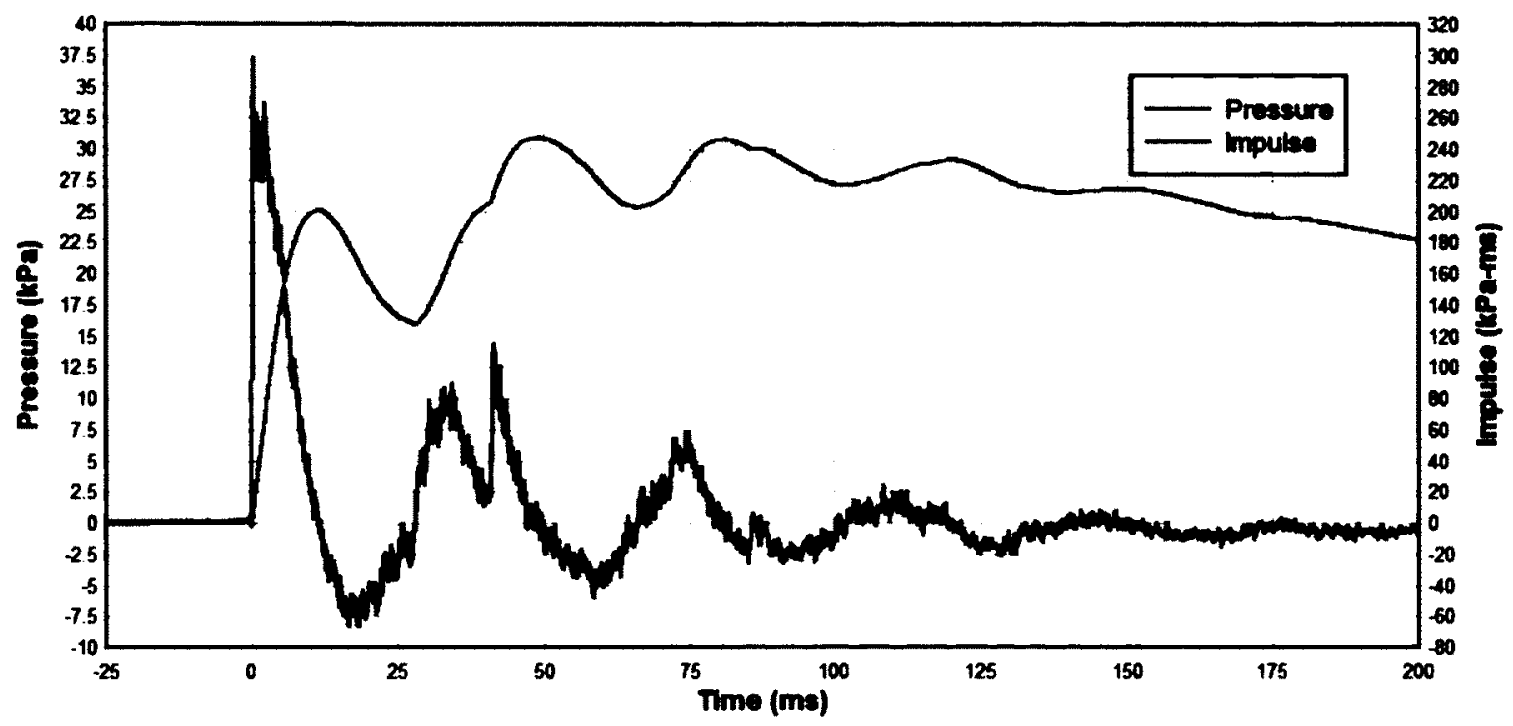

Figure 4-109: Pressure and Impulse Time History for Test DB-25M-1-1

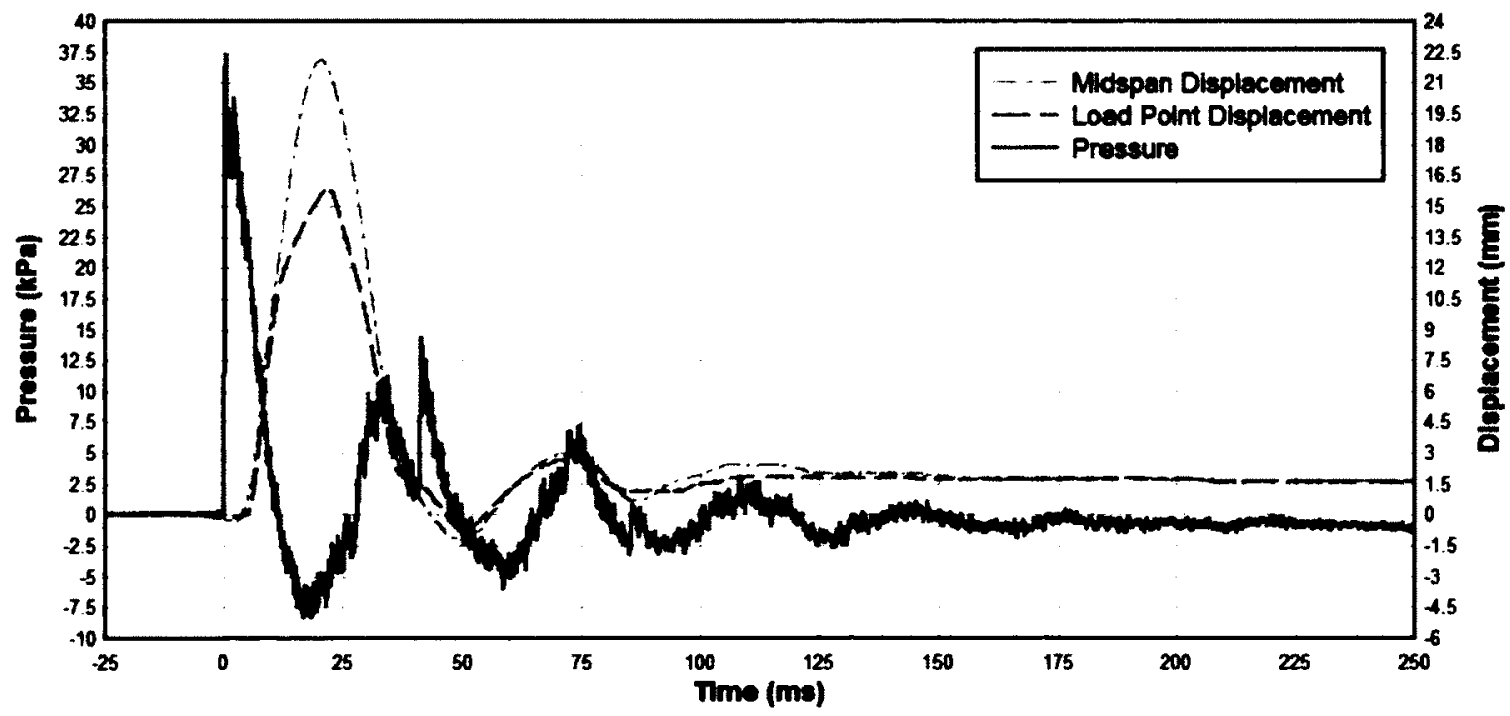

Figure 4-110: Pressure and Displacement Time History for Test DB-25M-1-1 


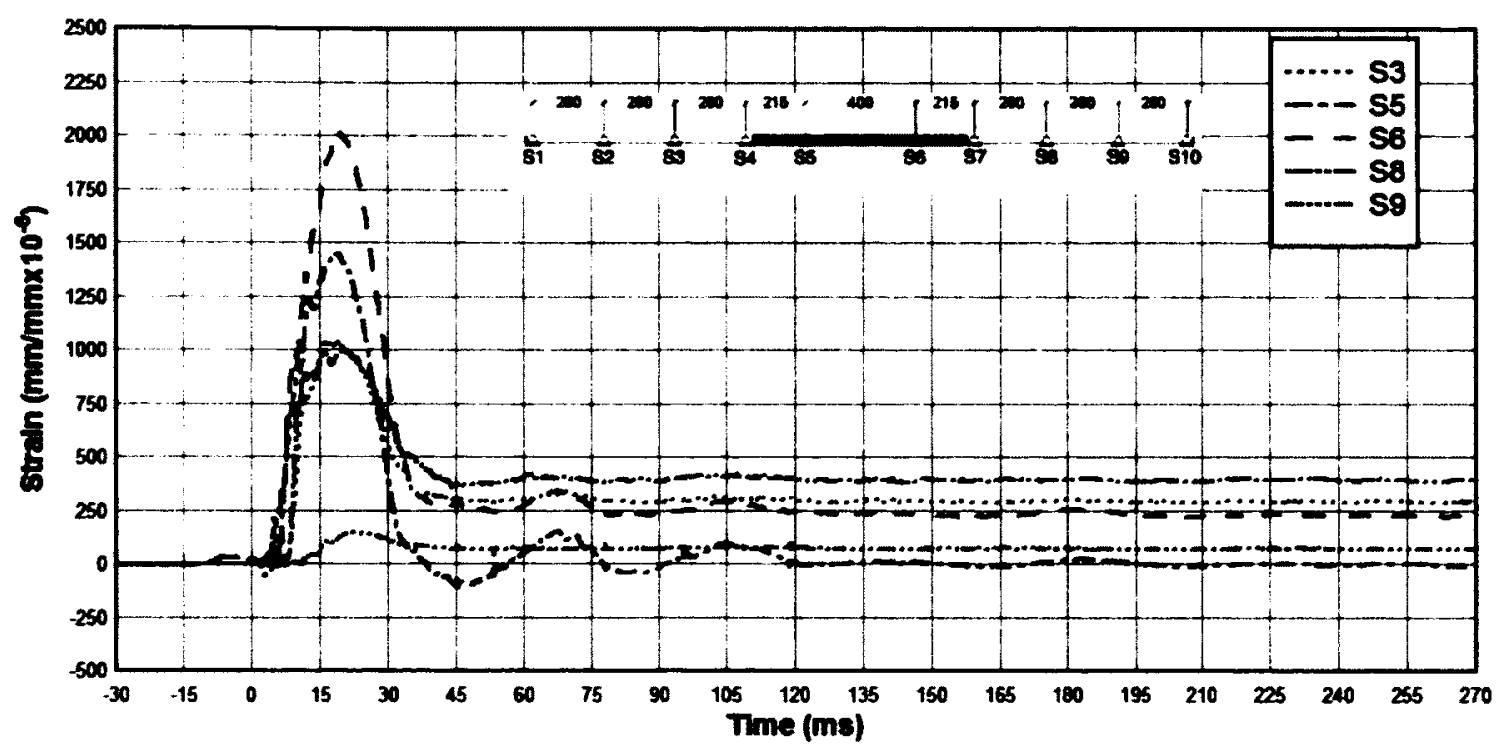

Figure 4-111: Strain in Steel for Test DB-25M-1-1

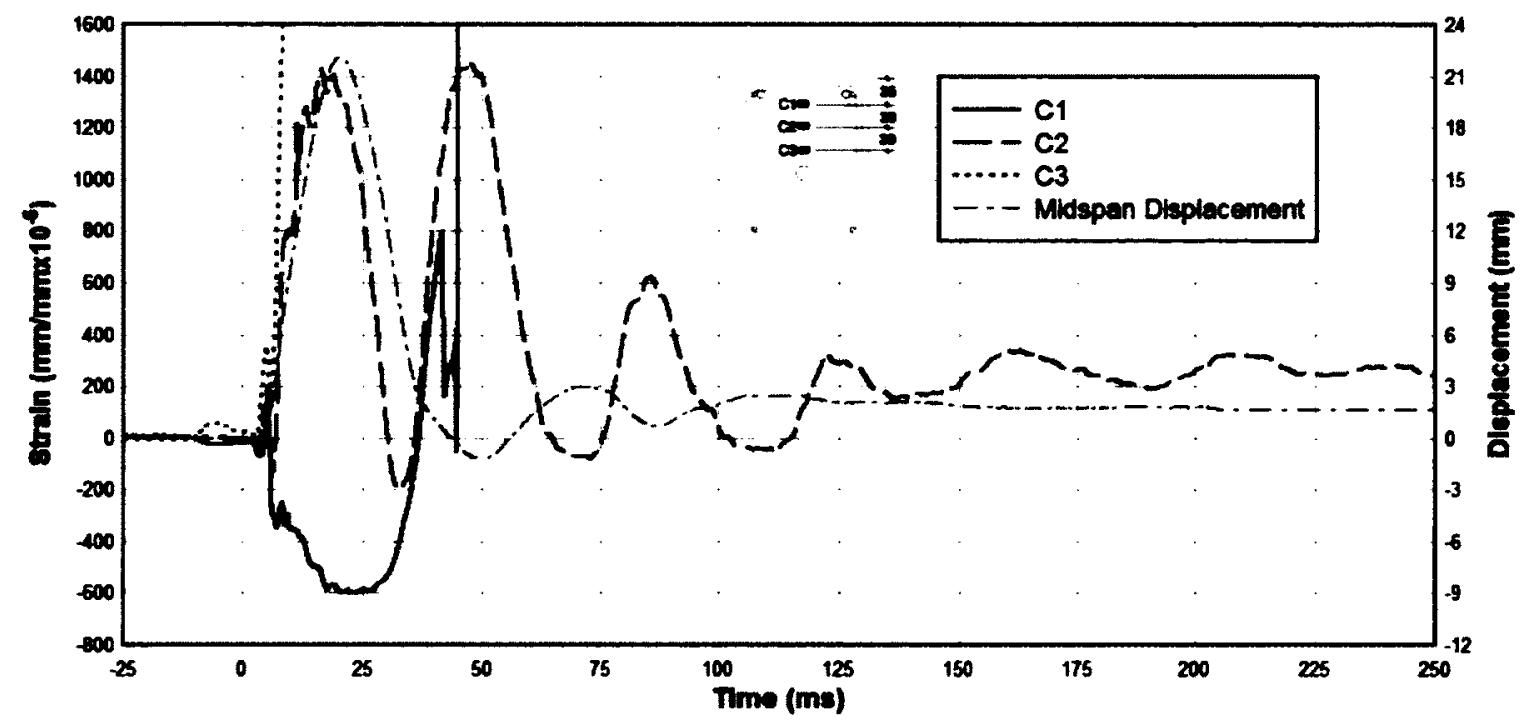

Figure 4-112: Strains in Concrete for Test DB-25M-1-1 


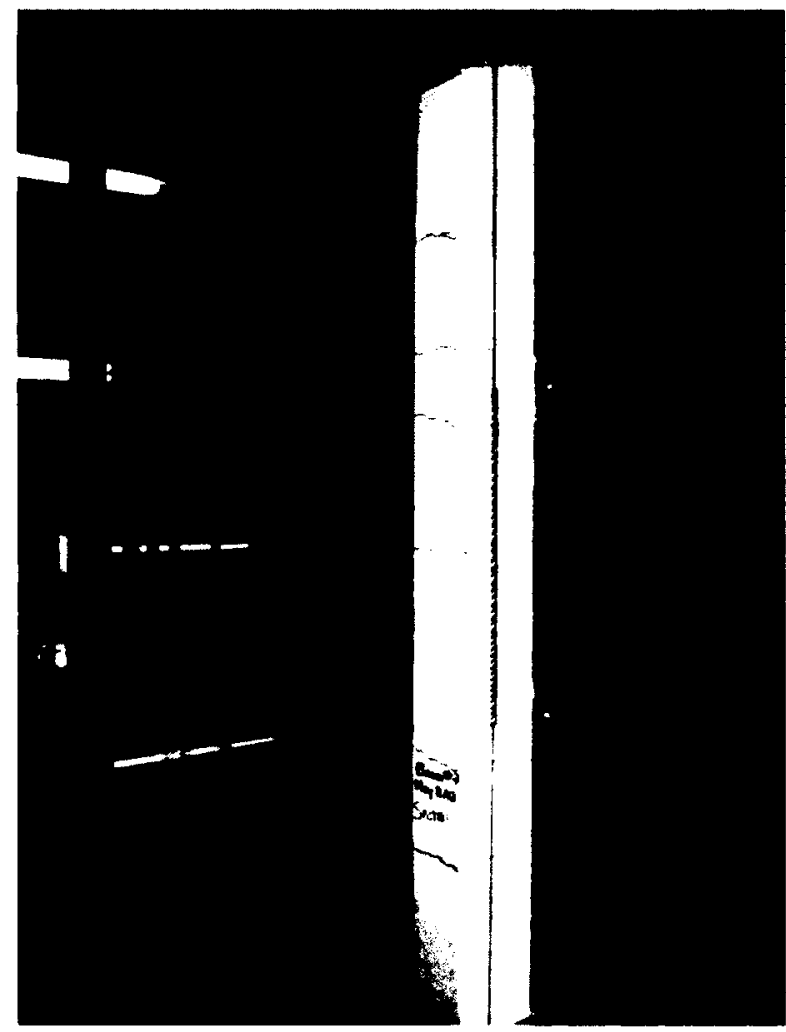

Figure 4-113: Crack Pattern After Test DB-25M-1-1

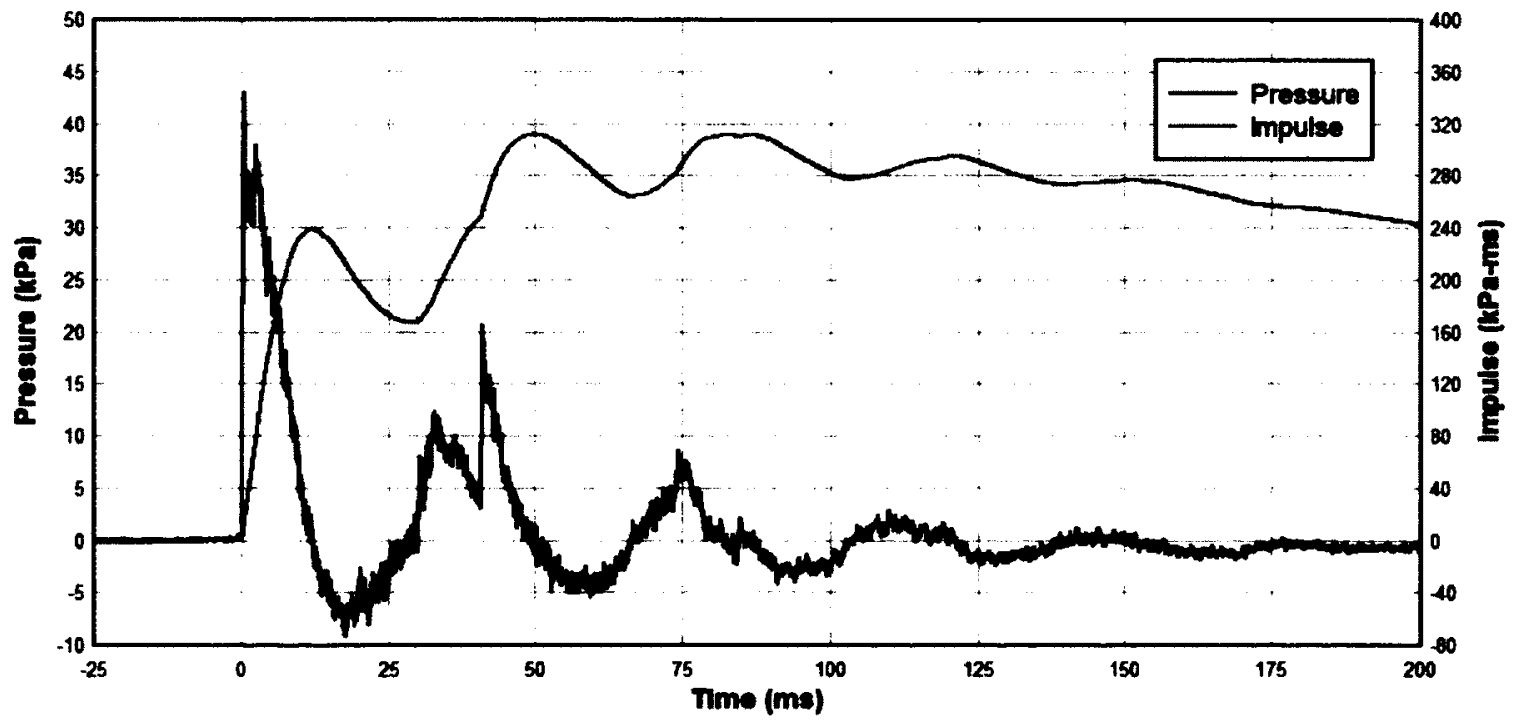

Figure 4-114: Pressure and Impulse Time History for Test DB-25M-1-2 


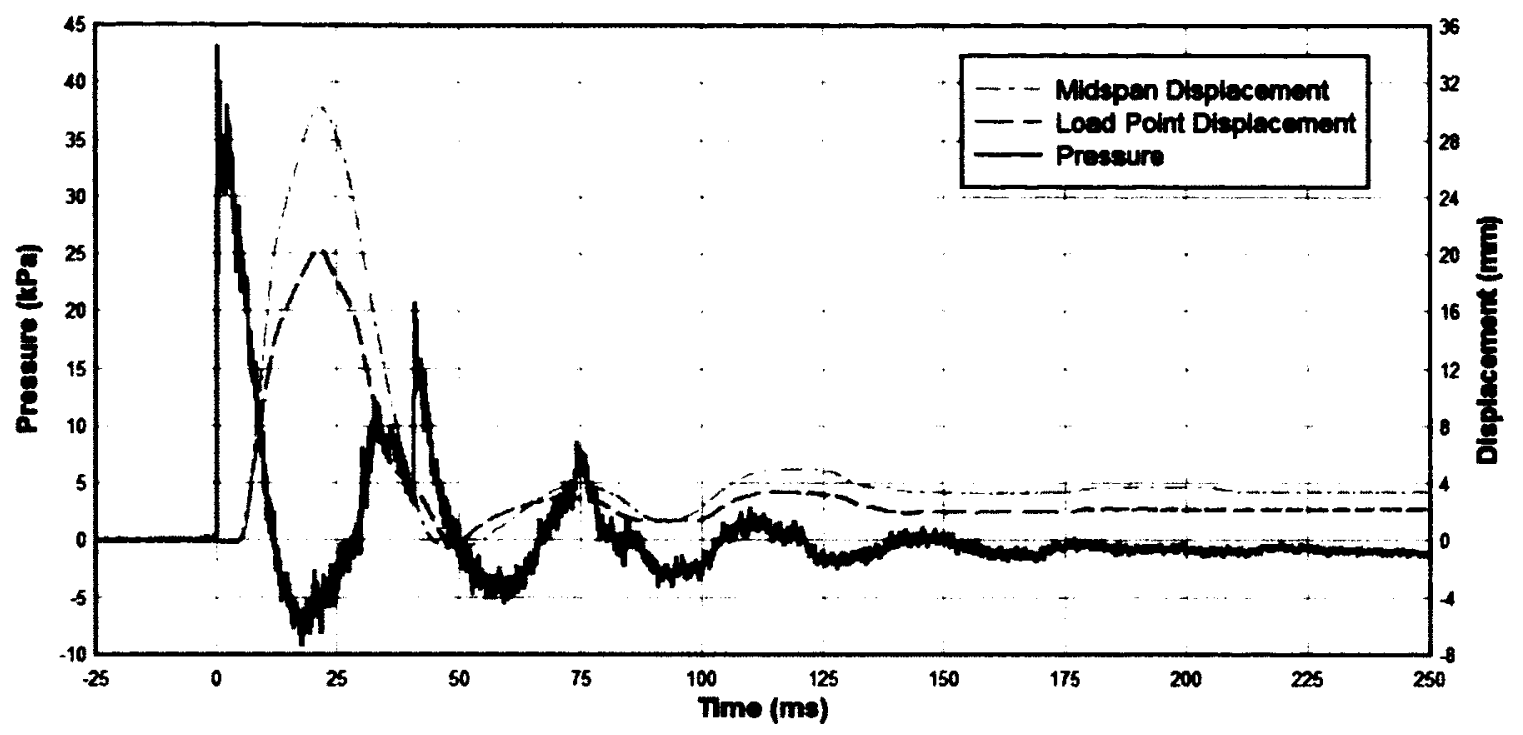

Figure 4-115: Pressure and Displacement Time History for Test DB-25M-1-2

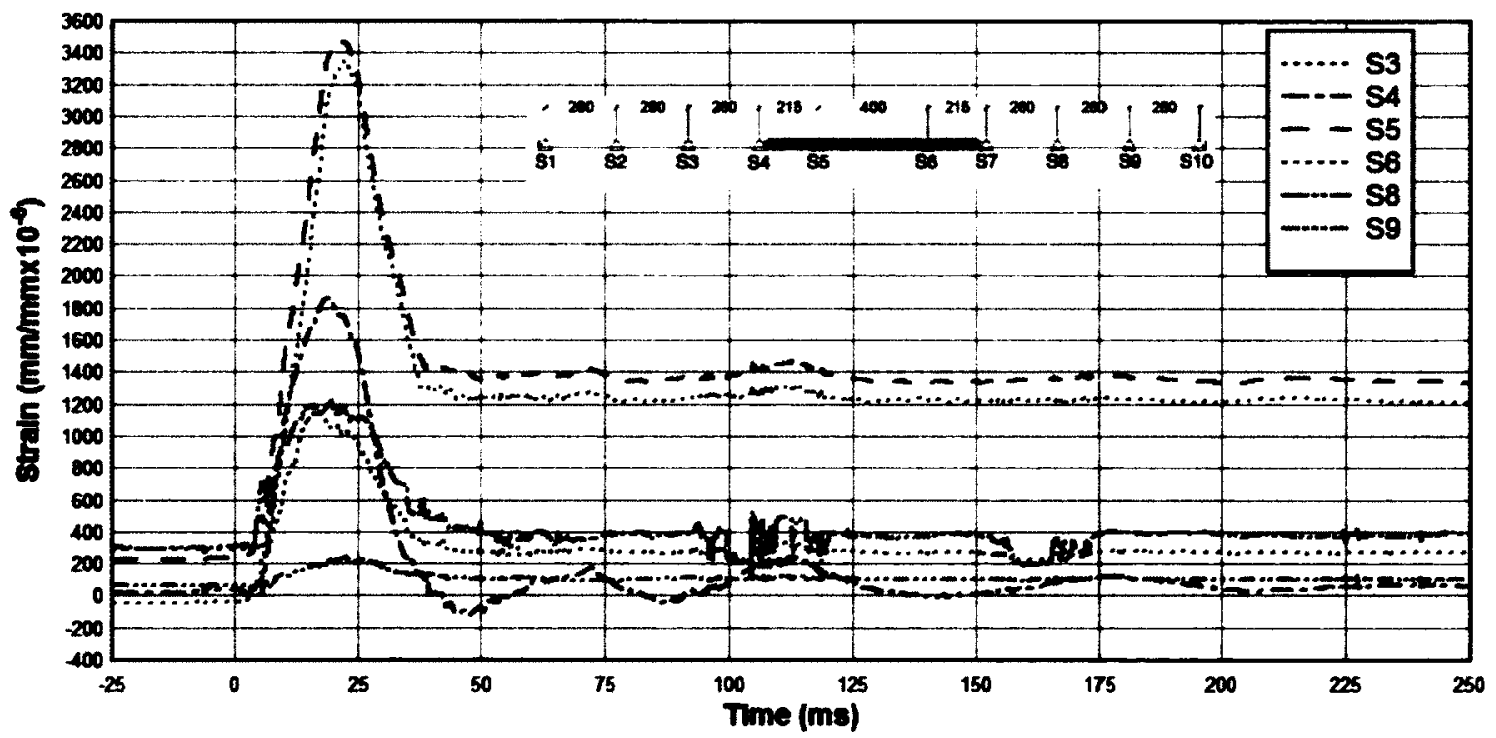

Figure 4-116: Strains in Steel for Test DB-25M-1-2 


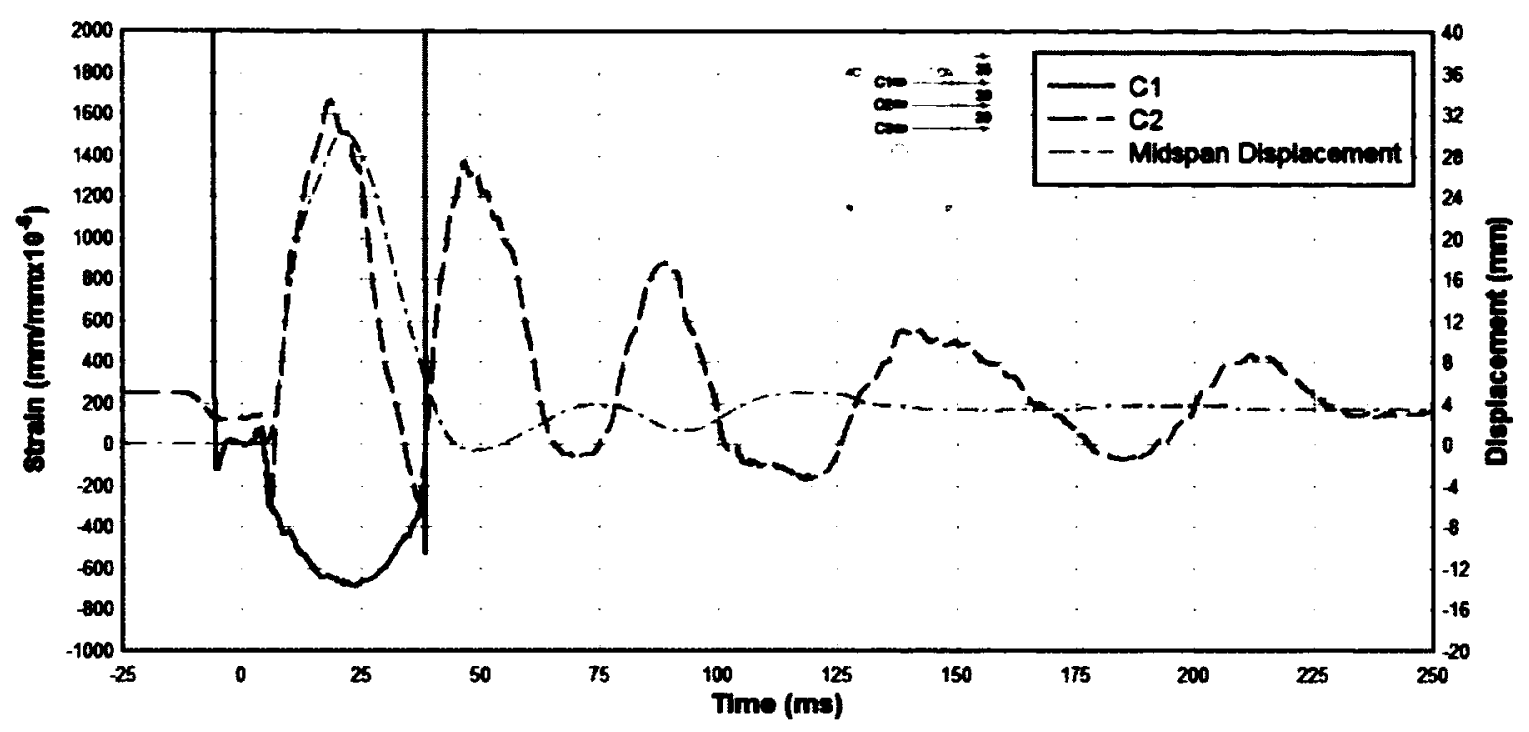

Figure 4-117: Strains in Concrete for Test DB-25M-1-2

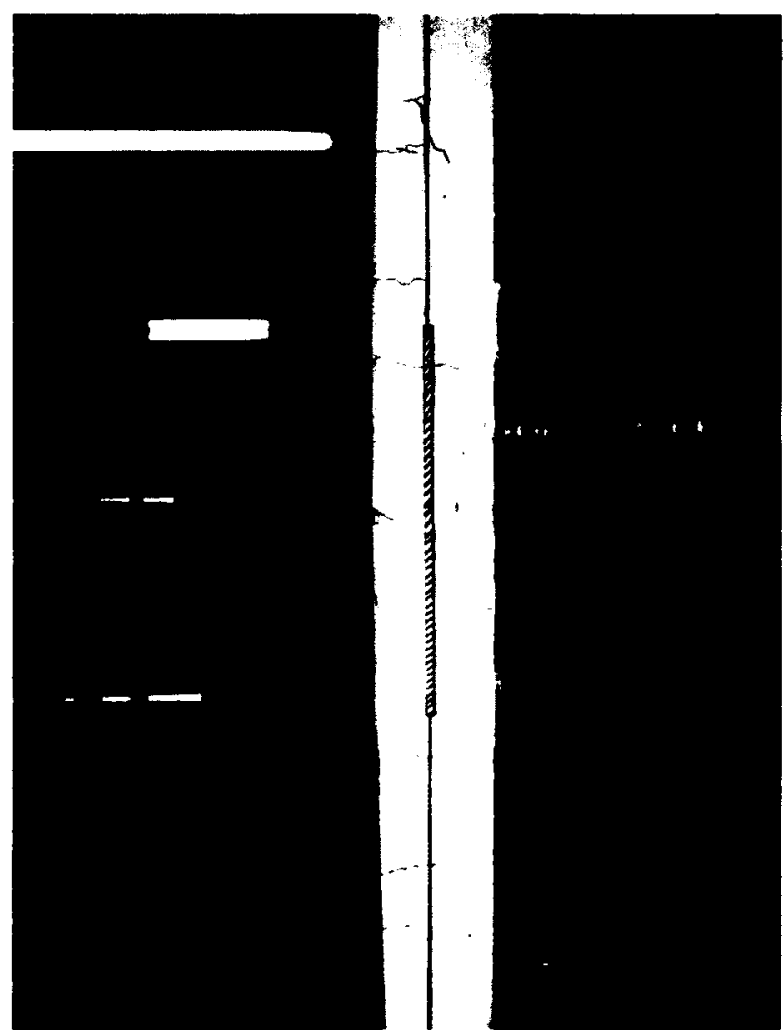

Figure 4-118: Crack Pattern After Test DB-25M-1-2 


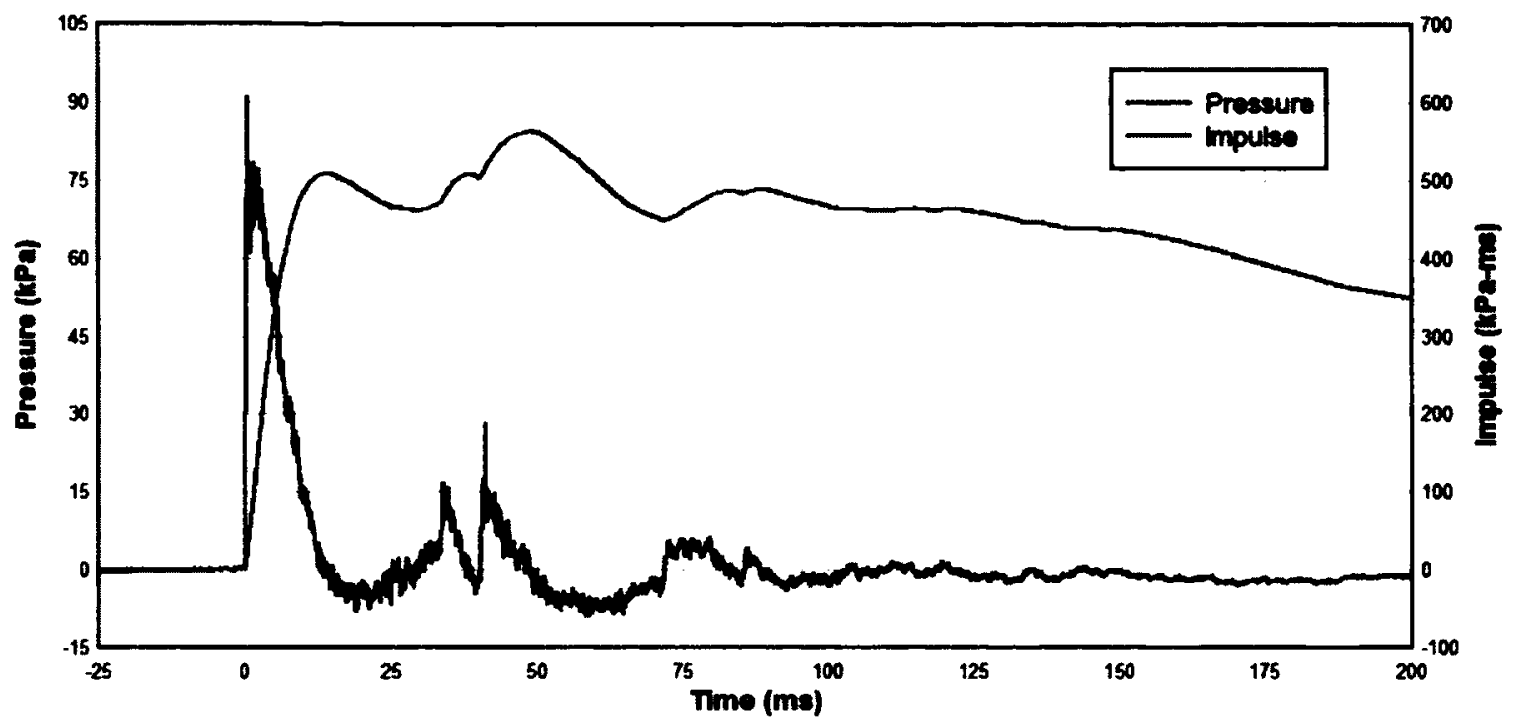

Figure 4-119: Pressure and Impulse Time History for Test DB-25M-1-3

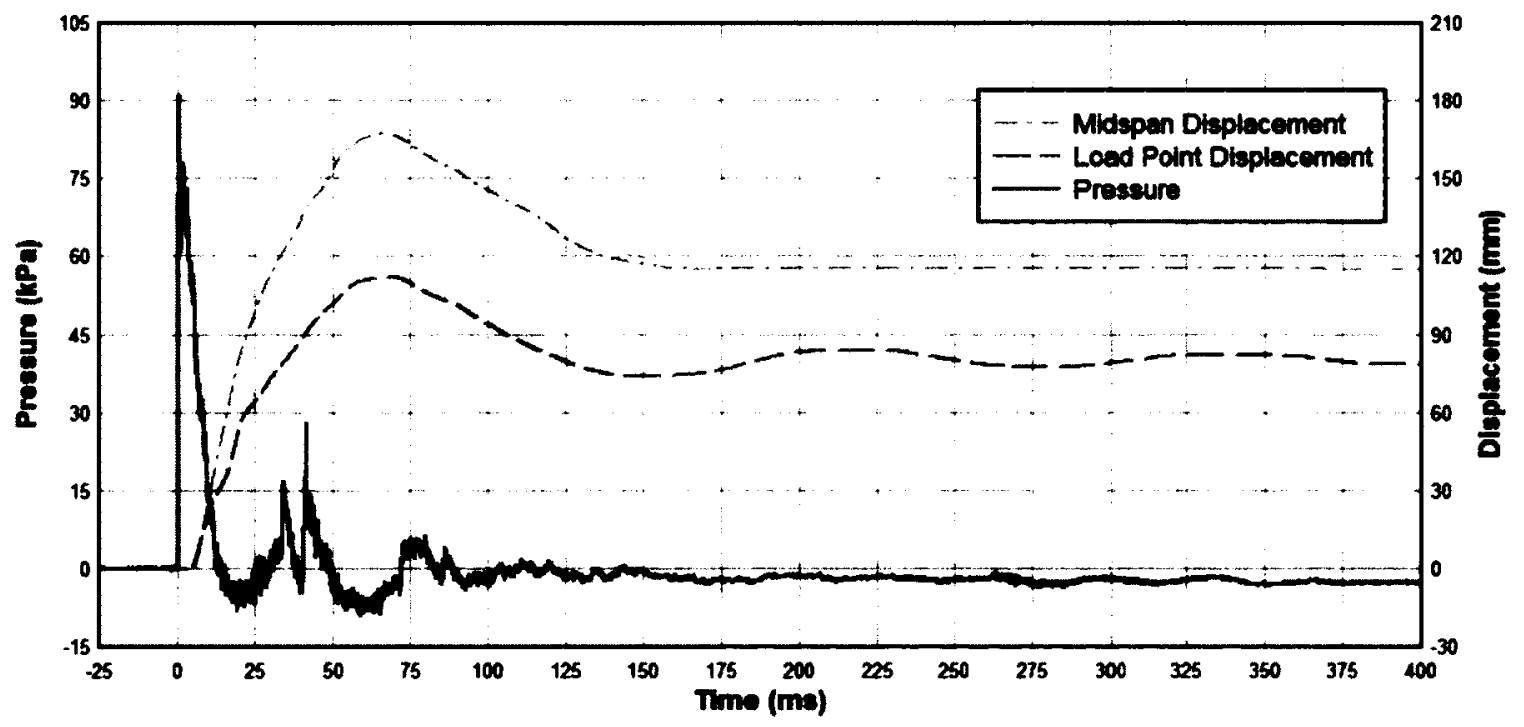

Figure 4-120: Pressure and Displacement Time History for Test DB-25M-1-3 


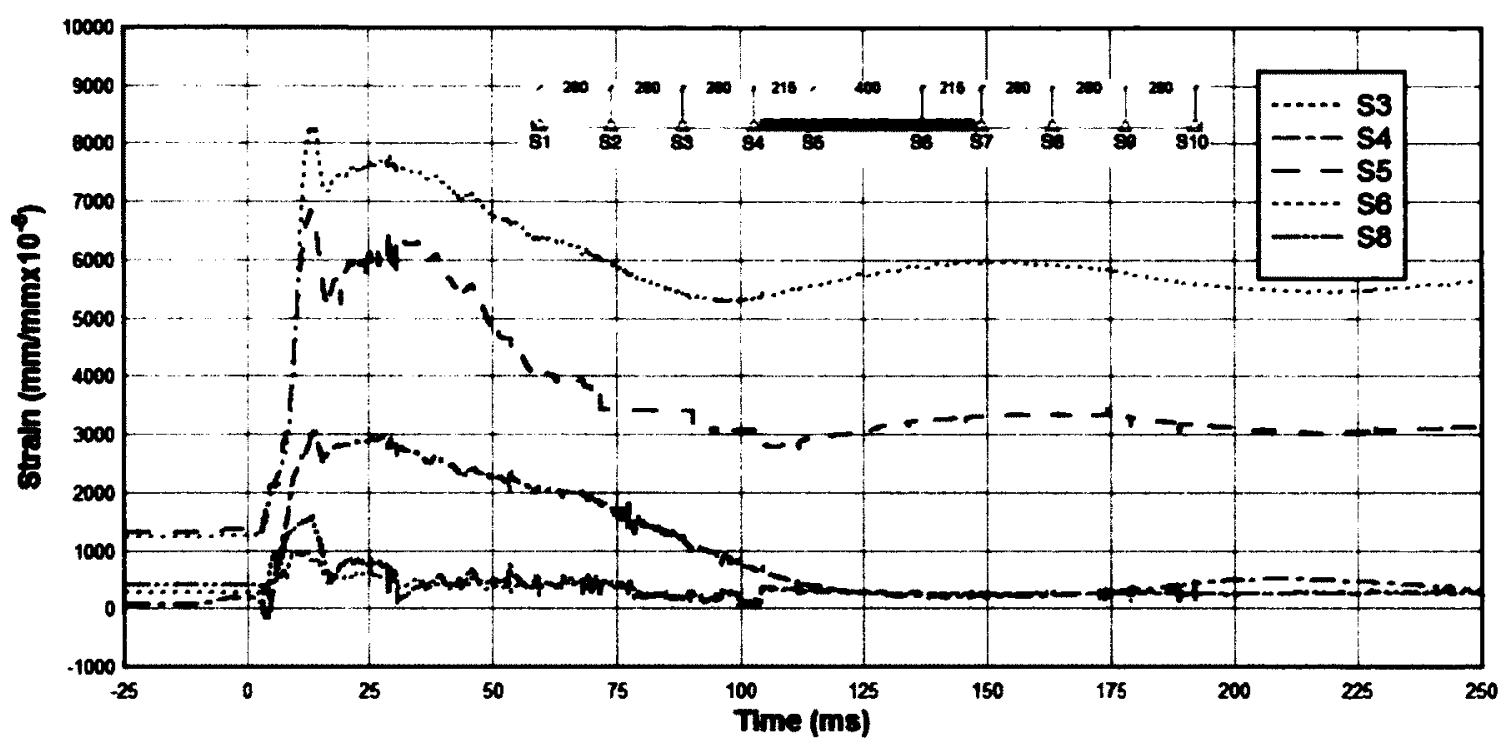

Figure 4-121: Strains in Steel for Test DB-25M-1-3

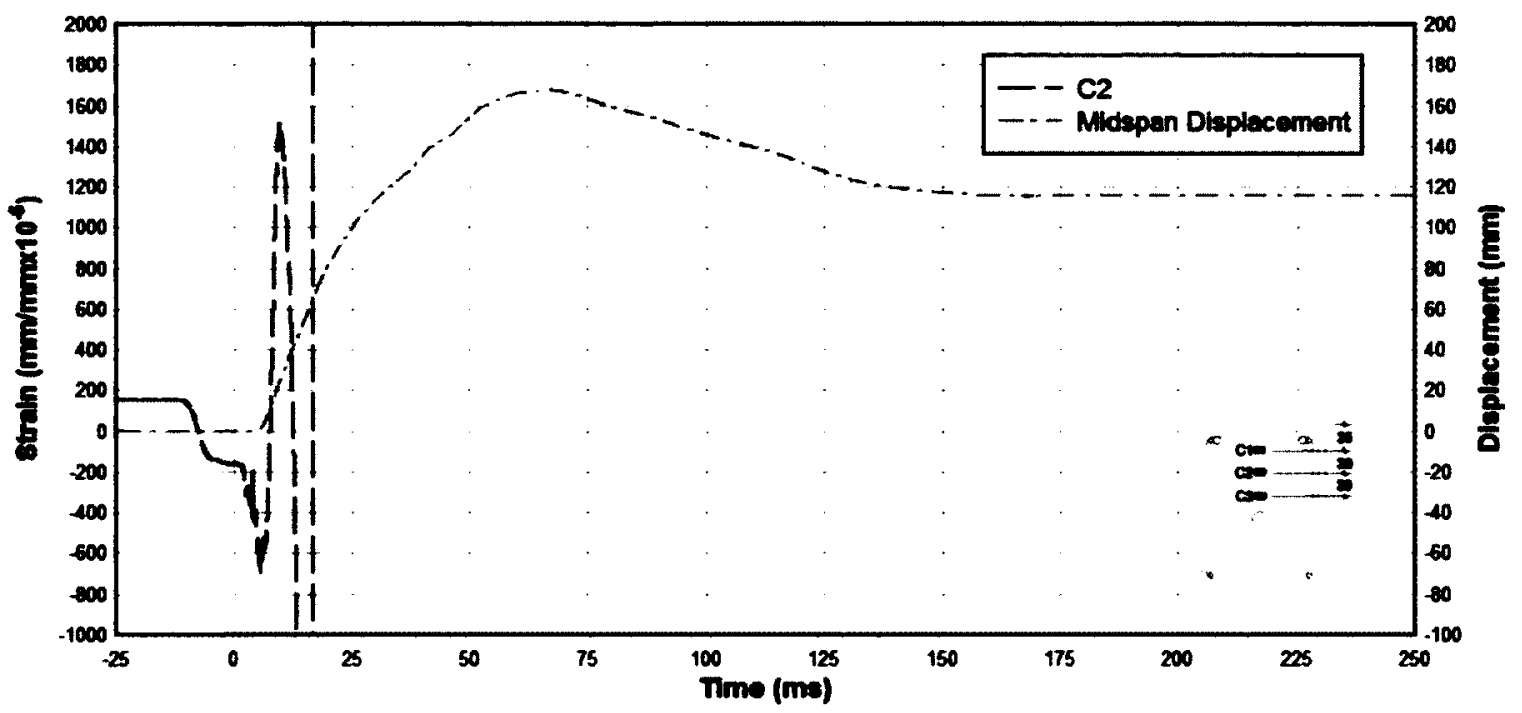

Figure 4-122: Strains in Concrete for Test DB-25M-1-3 


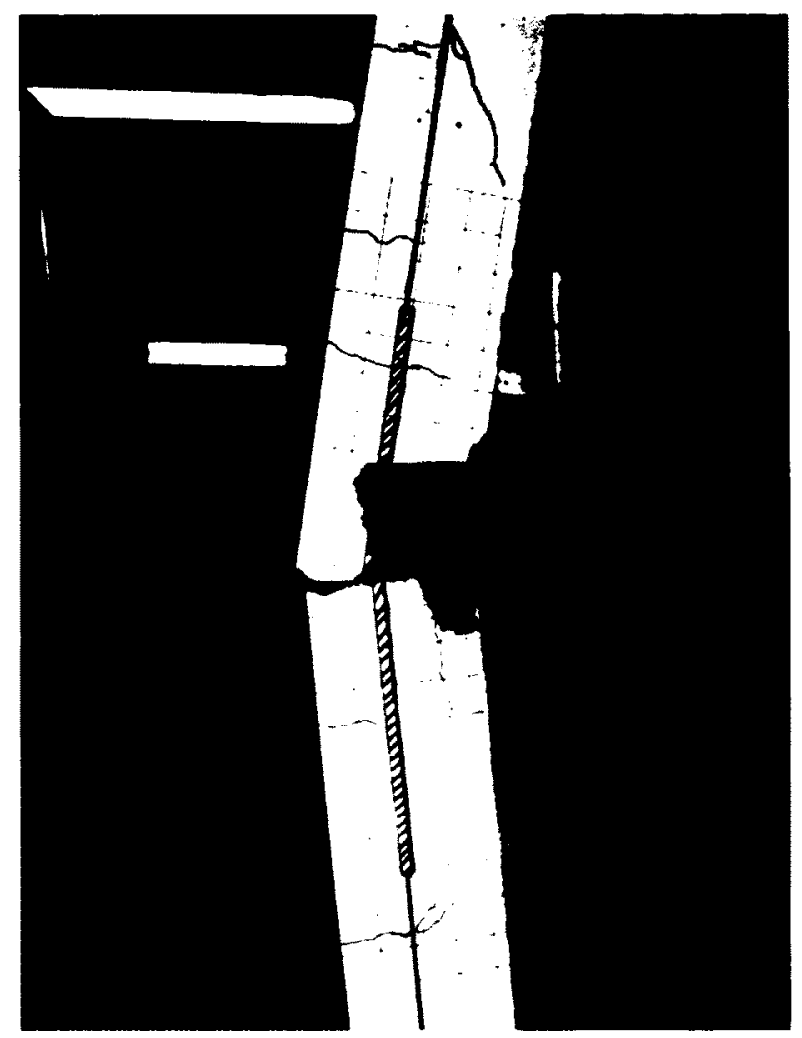

Figure 4-123: Crack Pattern After Test DB-25M-1-3

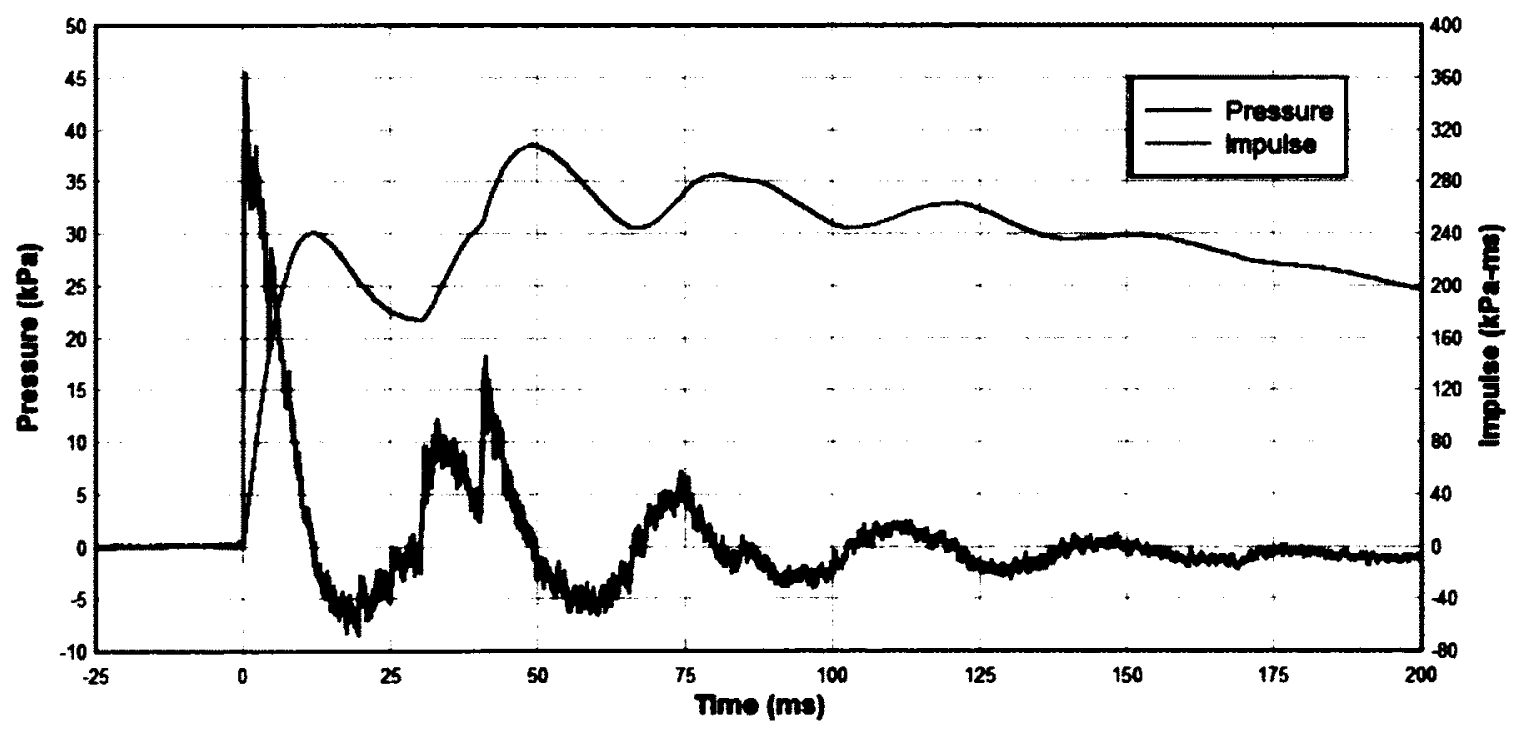

Figure 4-124: Pressure and Impulse Time History for Test DB-25M-2-1 


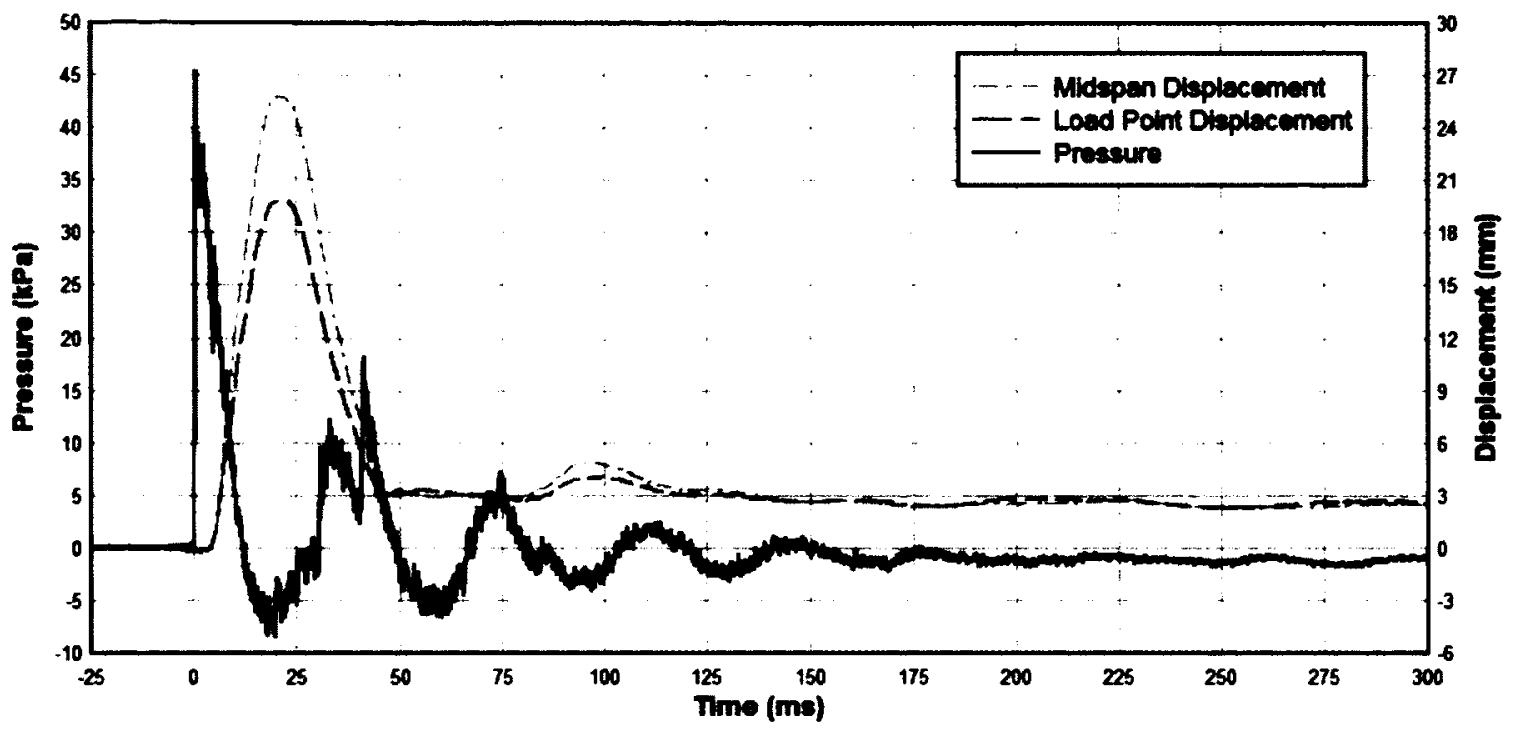

Figure 4-125: Pressure and Displacement Time History for Test DB-25M-2-1

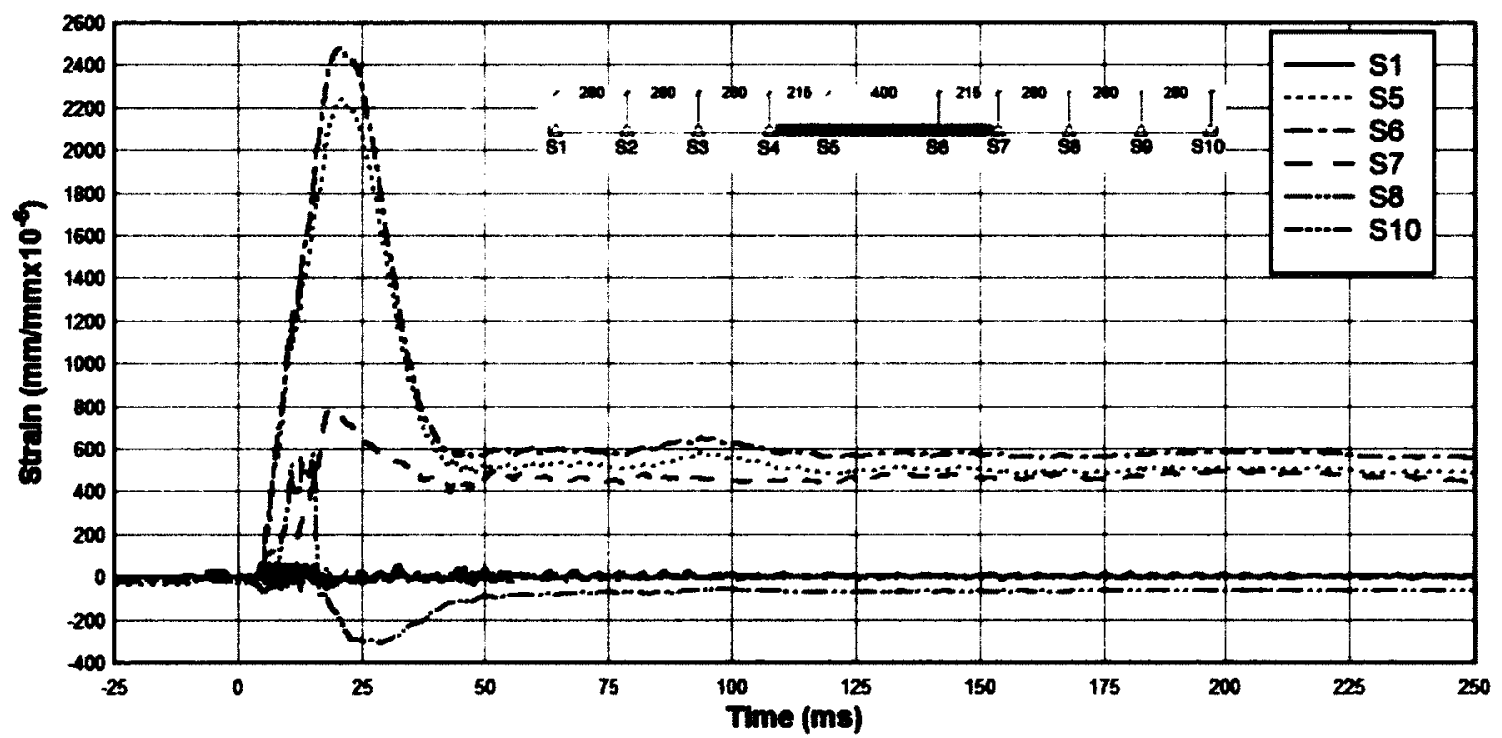

Figure 4-126: Strains in Steel for Test DB-25M-2-1 


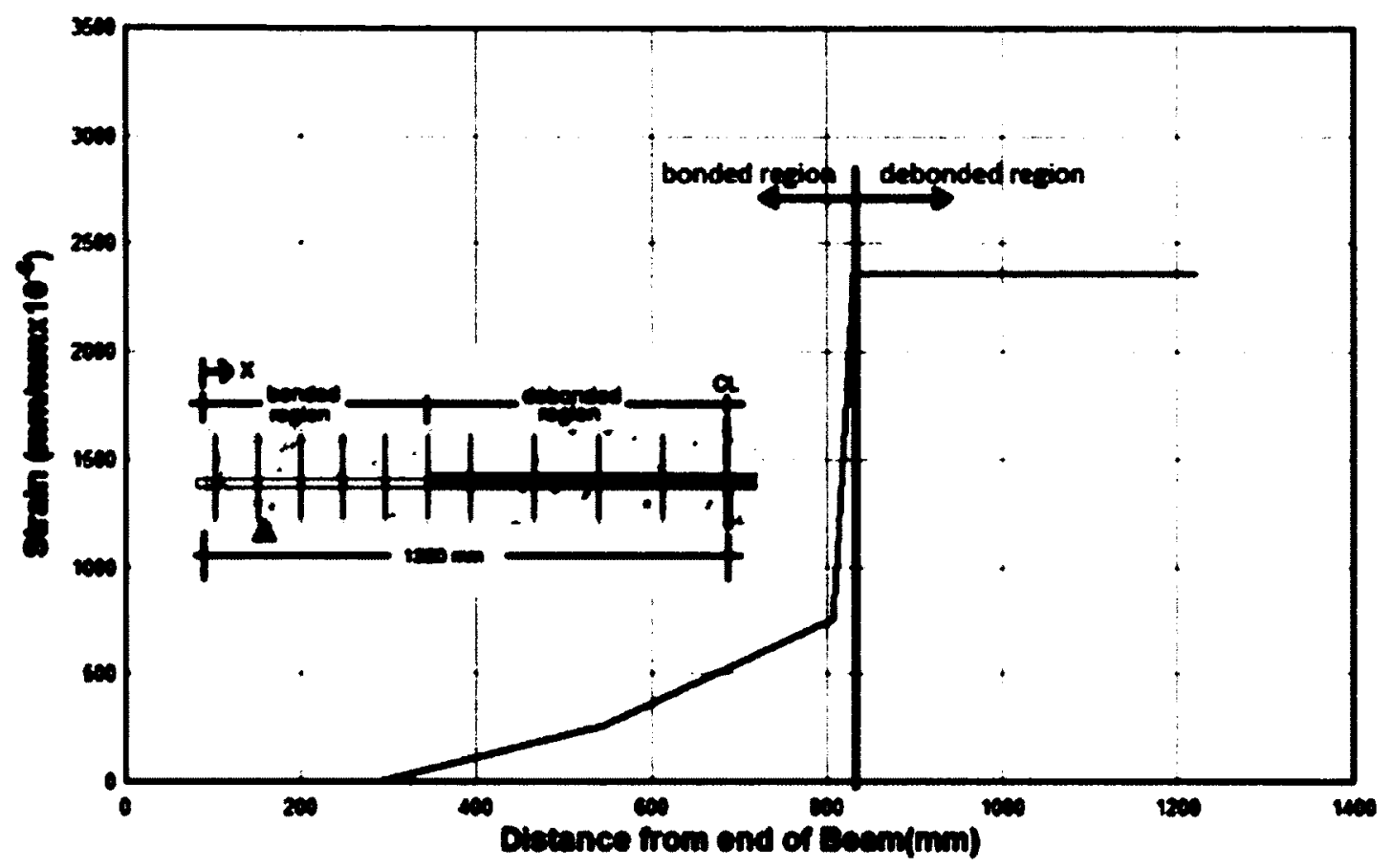

Figure 4-127: Strain Profile at Maximum Strain for Test DB-25M-2-1

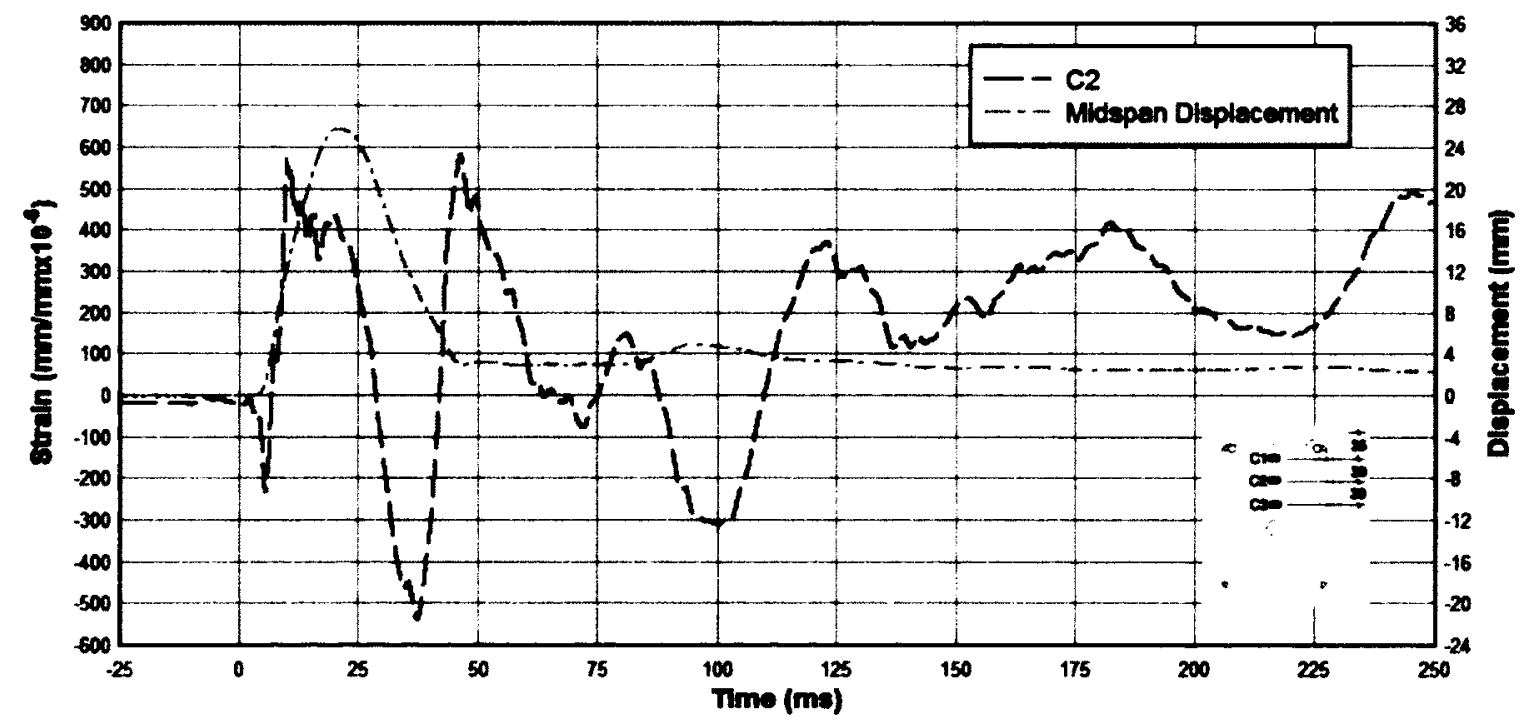

Figure 4-128: Strains in Concrete for Test DB-25M-2-1 


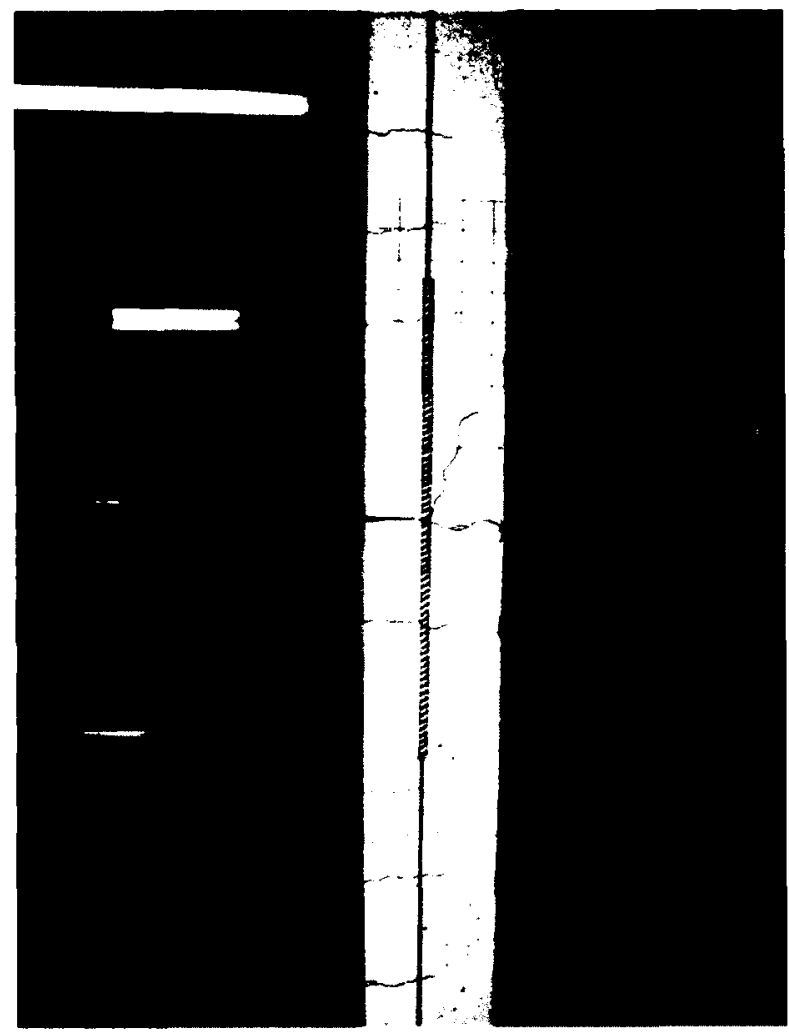

Figure 4-129: Crack Pattern After Test DB-25M-2-1

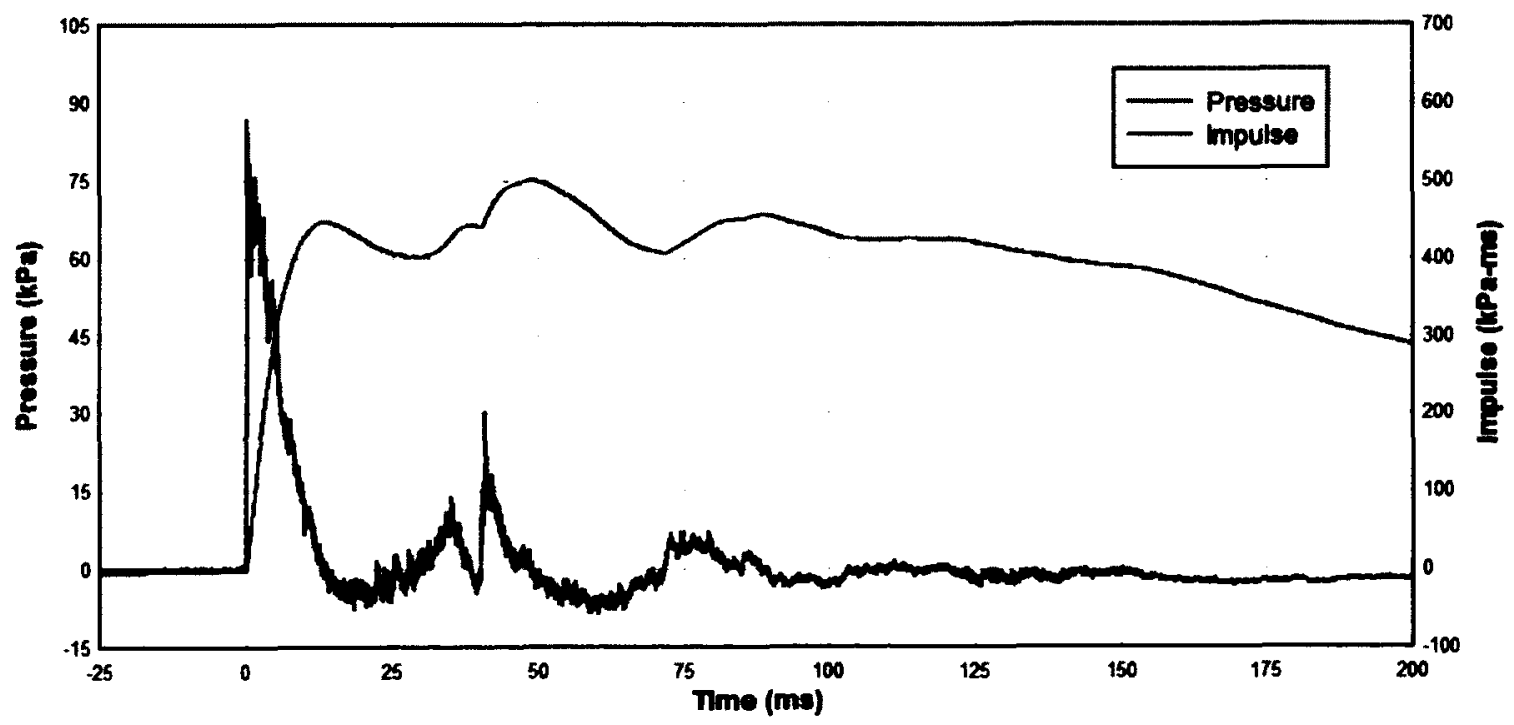

Figure 4-130: Pressure and Impulse Time History for Test DB-25M-2-2 


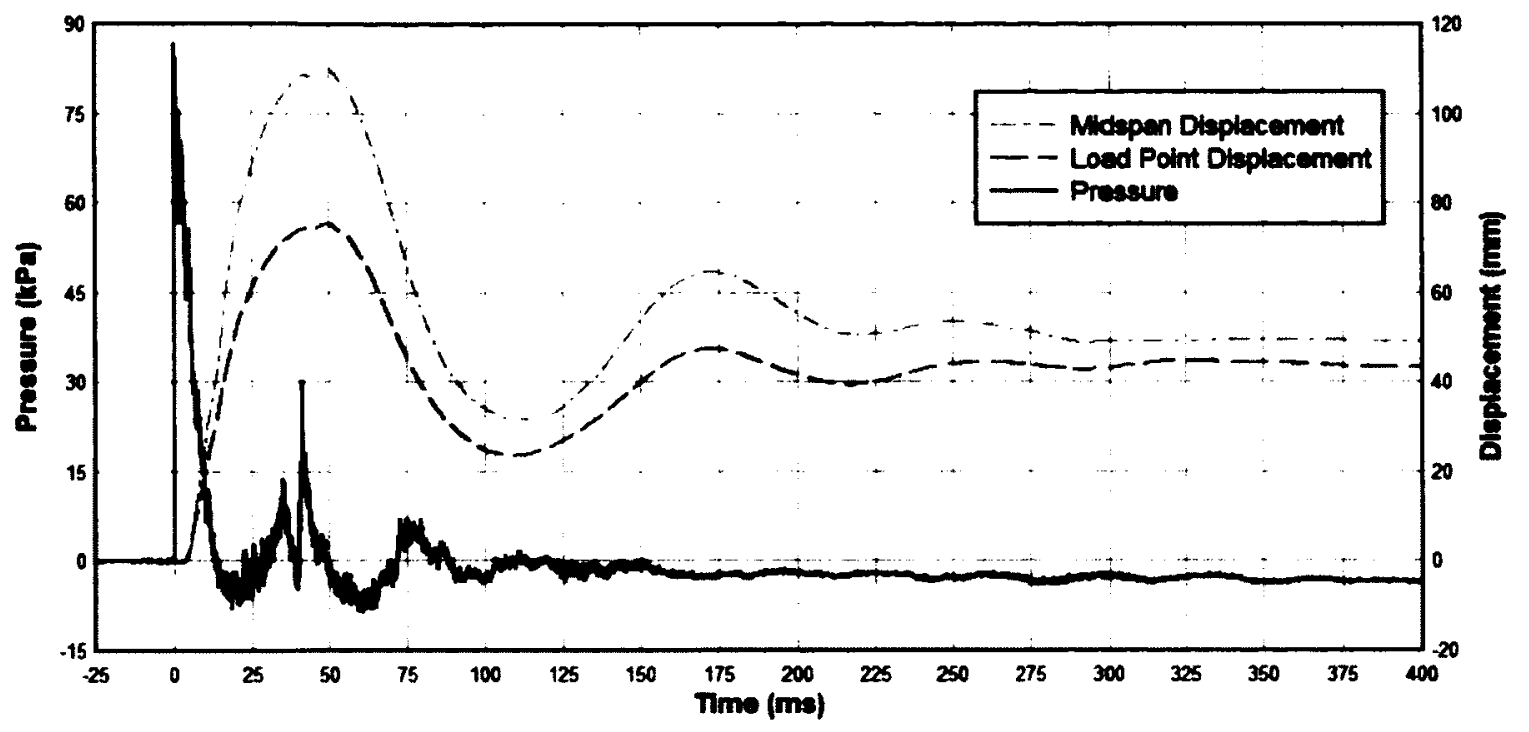

Figure 4-131: Pressure and Displacement Time History for Test DB-25M-2-2

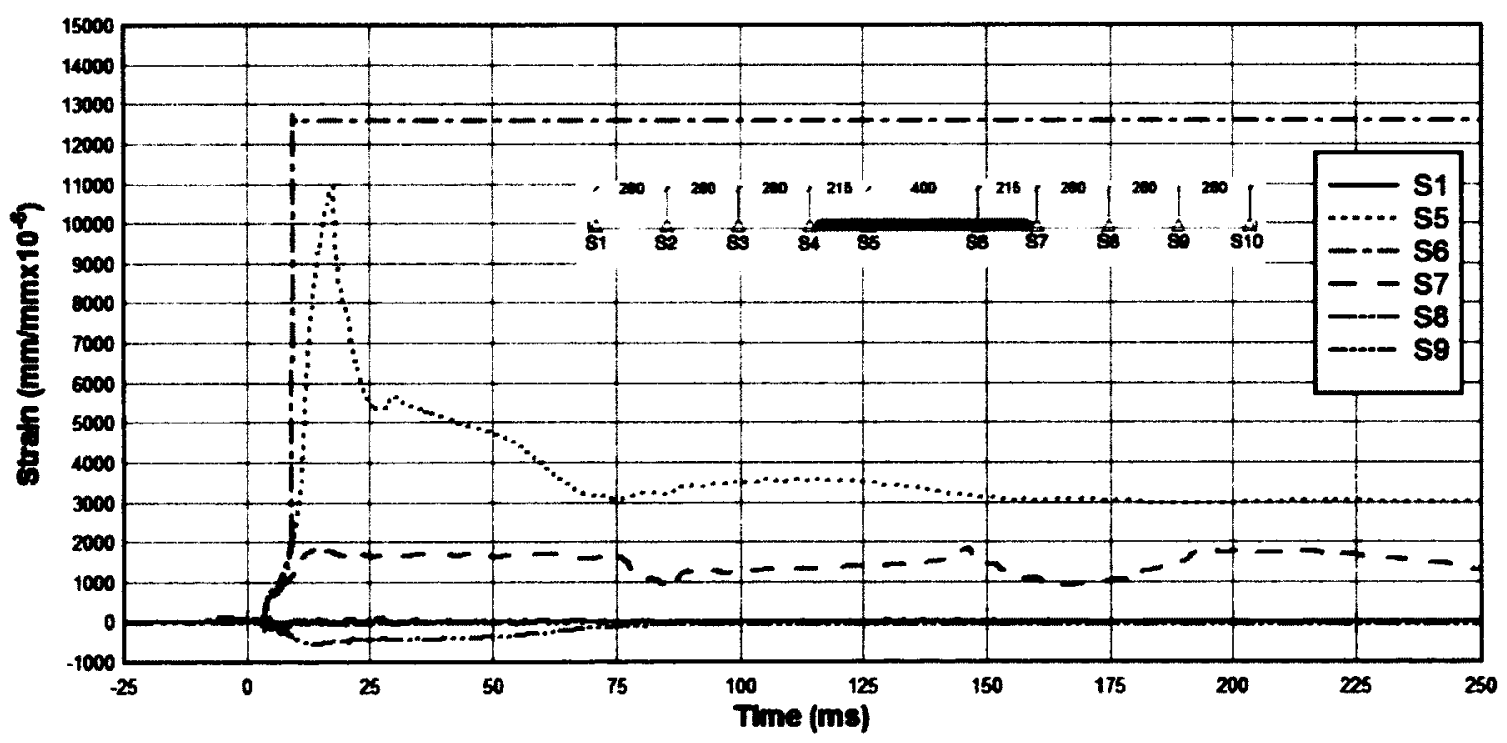

Figure 4-132: Strains in Steel for Test DB-25M-2-2 


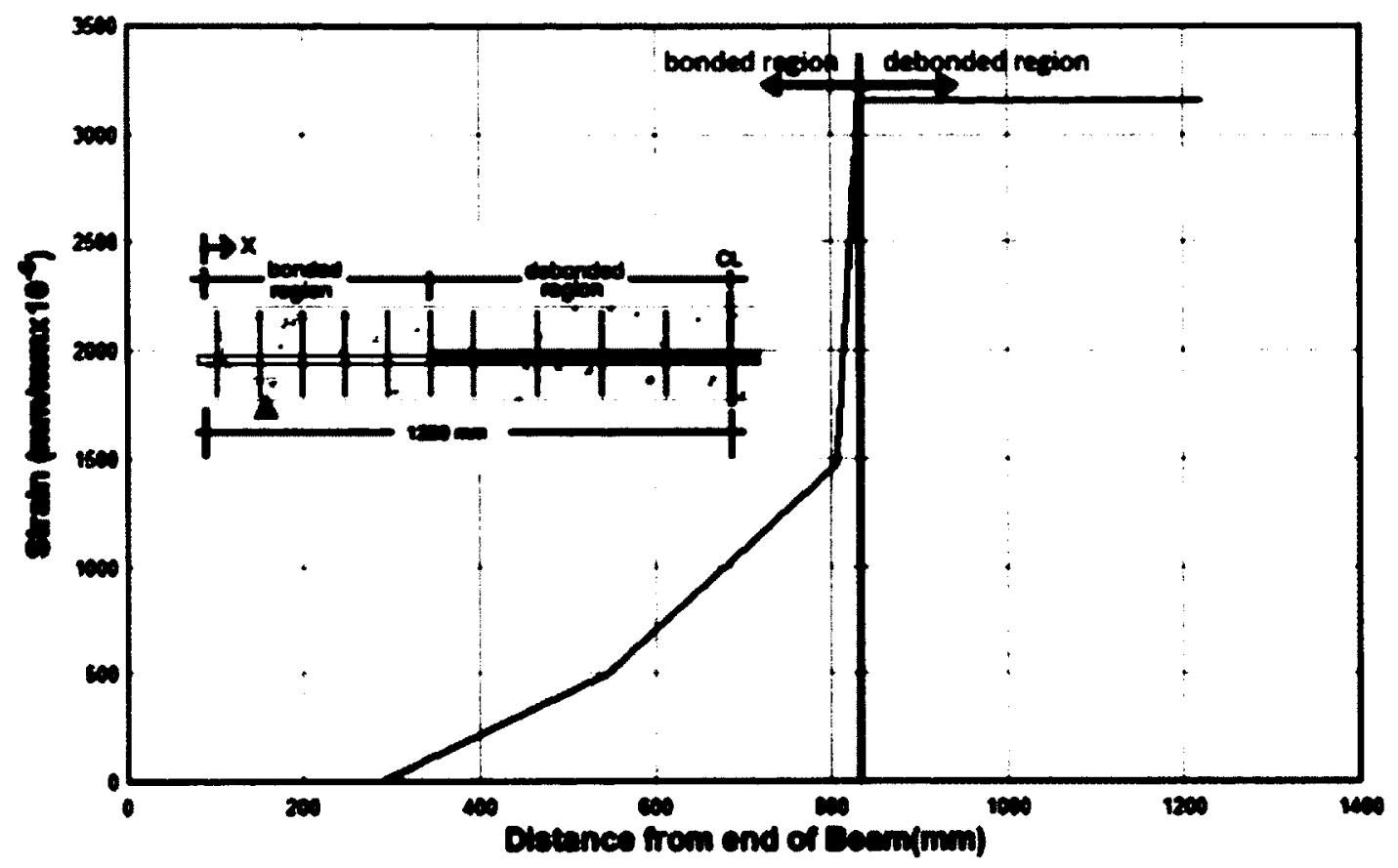

Figure 4-133: Strain Profile at Yield for Test DB-25M-2-2

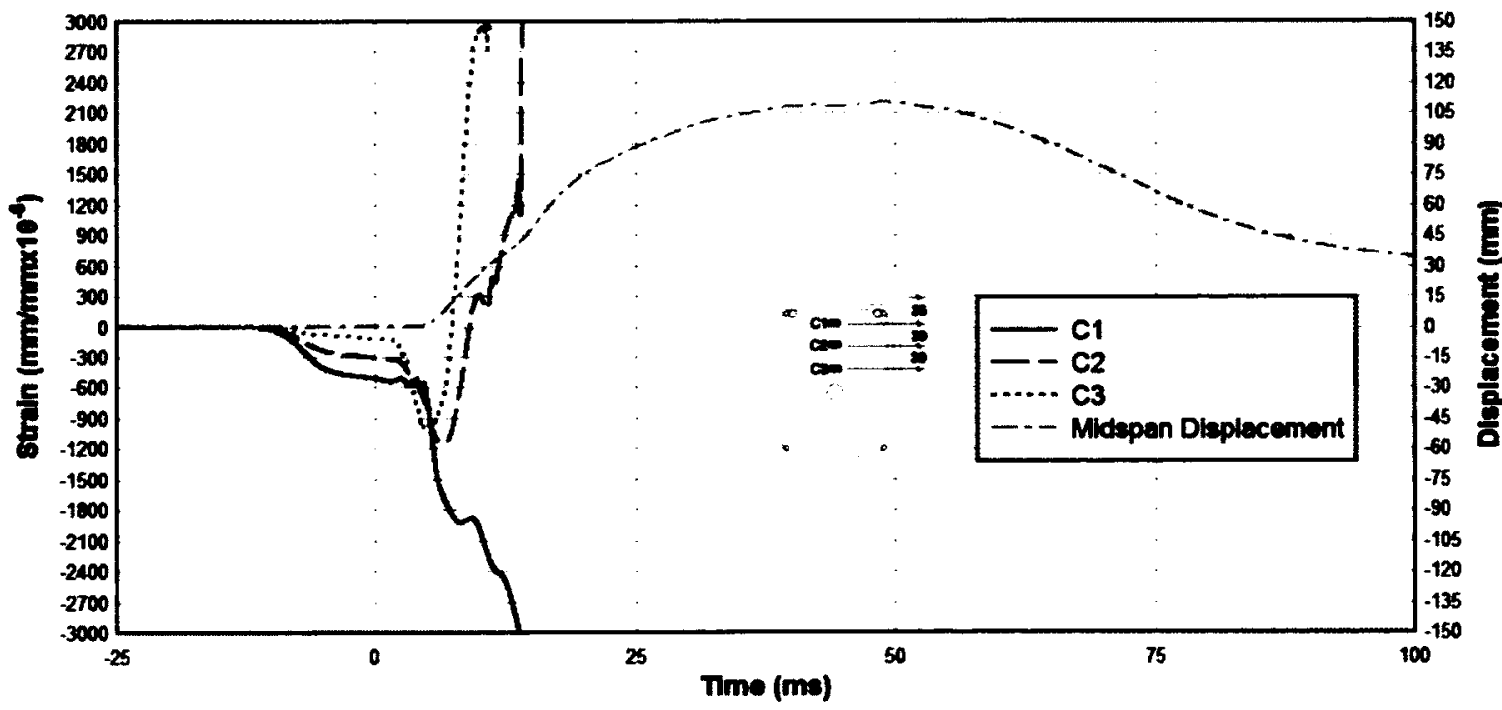

Figure 4-134: Strains in Concrete for Test DB-25M-2-2 


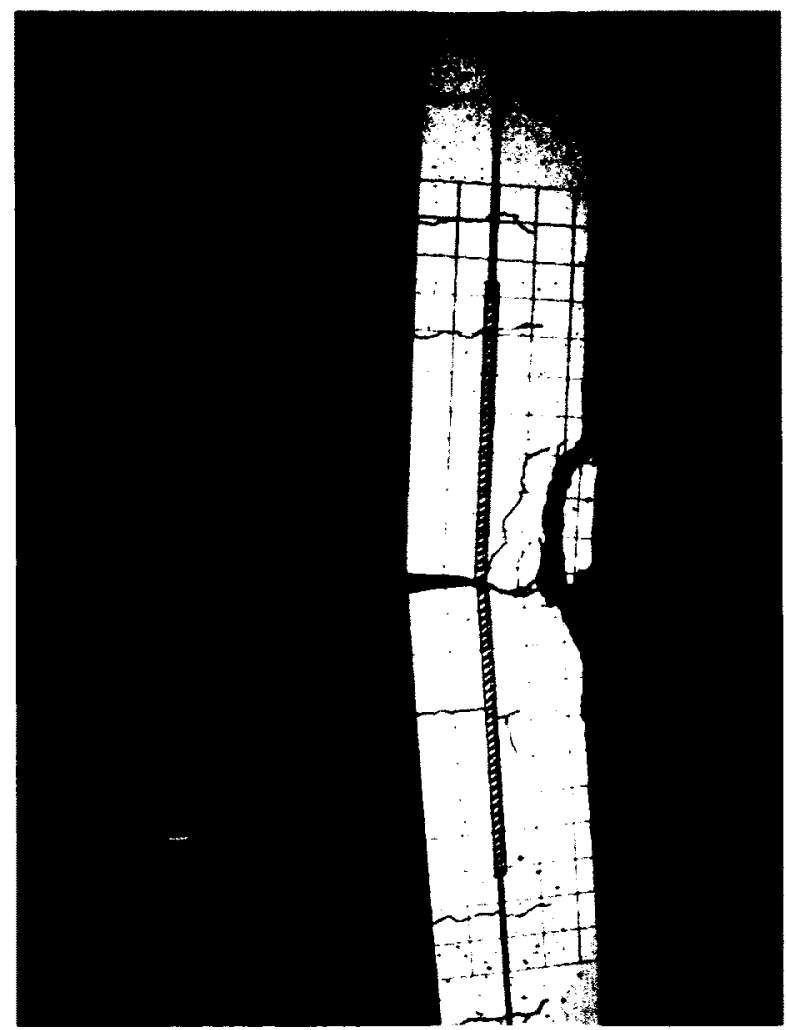

Figure 4-135: Crack Pattern After Test DB-25M-2-1

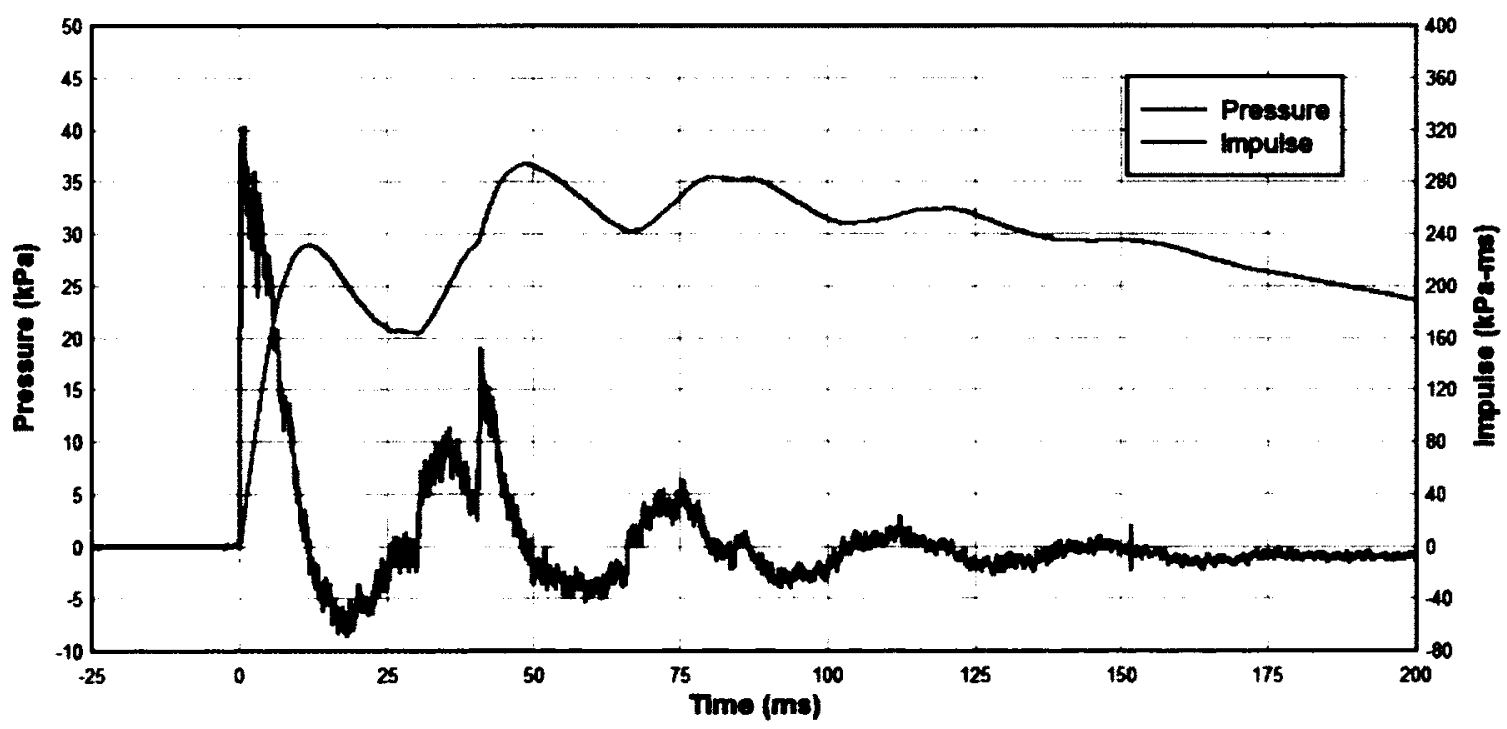

Figure 4-136: Pressure and Impulse Time History for Test DB-25M-3-1 


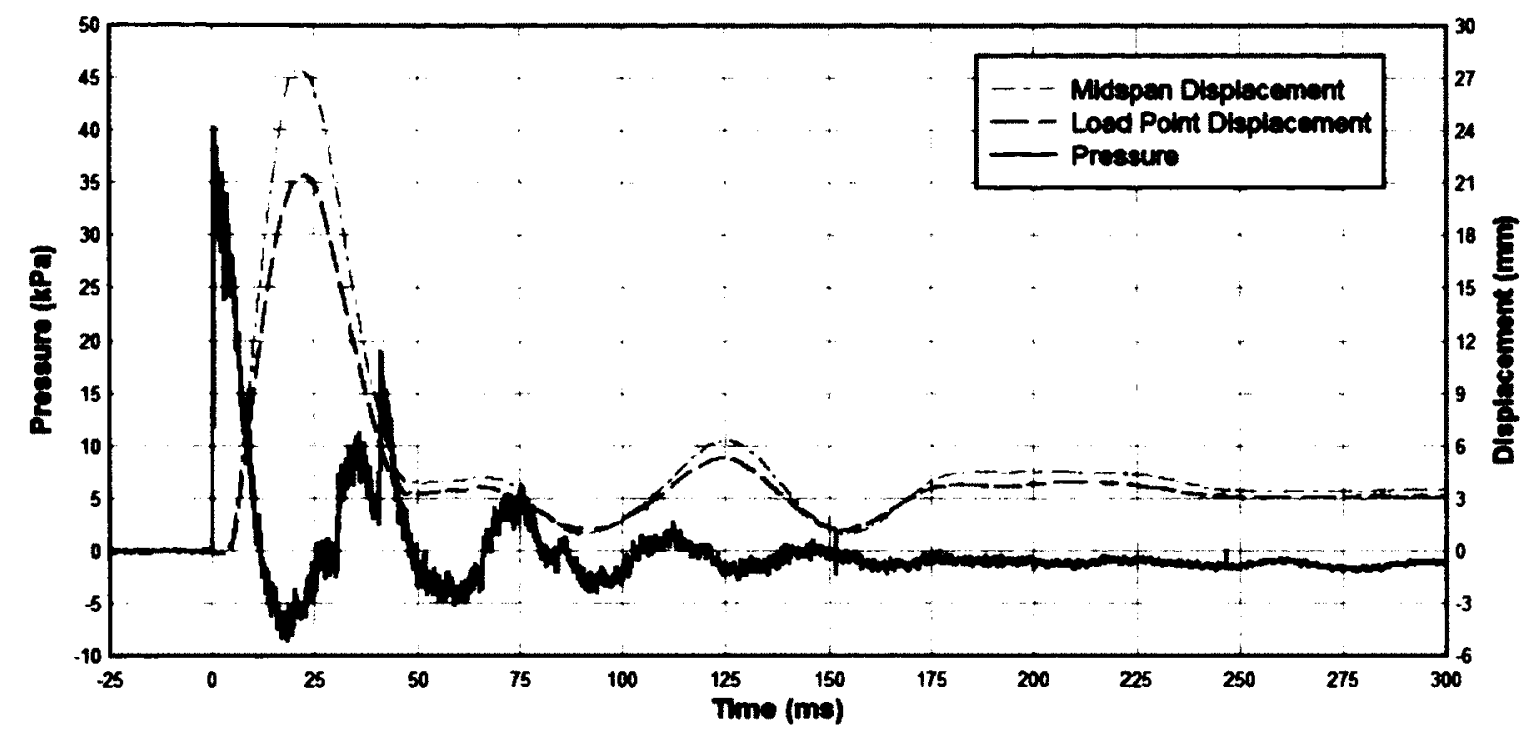

Figure 4-137: Pressure and Displacement Time History for Test DB-25M-3-1

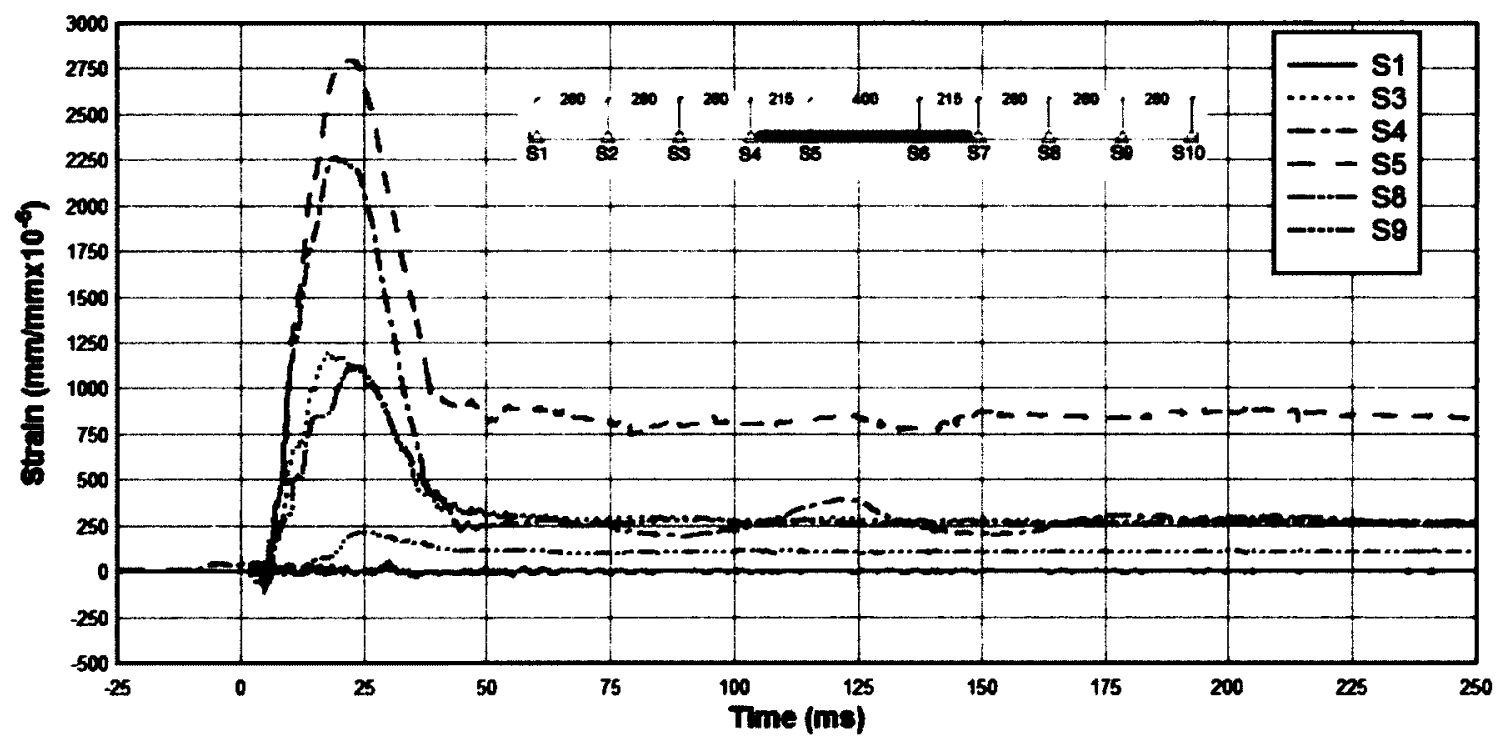

Figure 4-138: Strains in Steel for Test DB-25M-3-1 


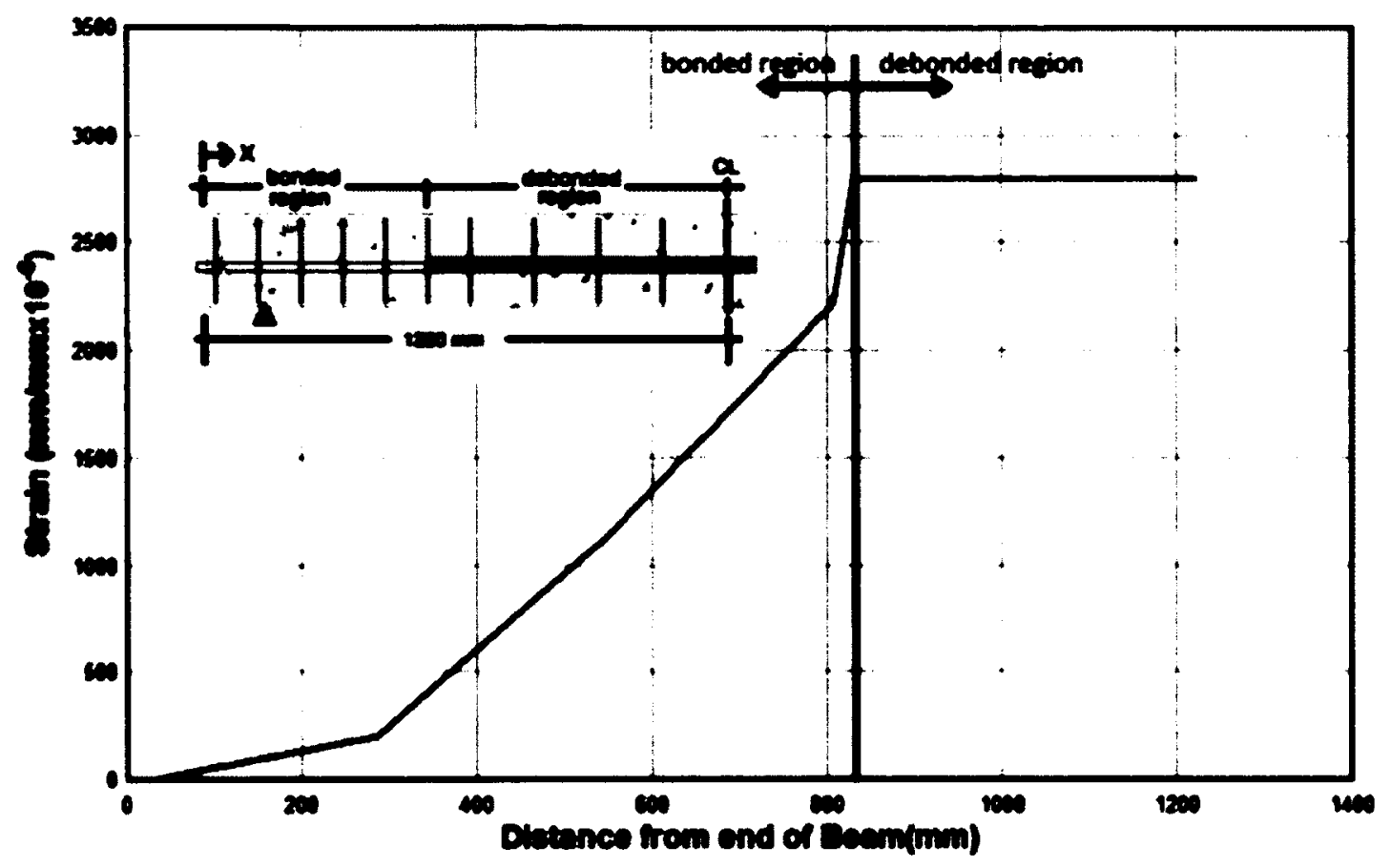

Figure 4-139: Strain Profile at Maximum Strain for Test DB-25M-3-1

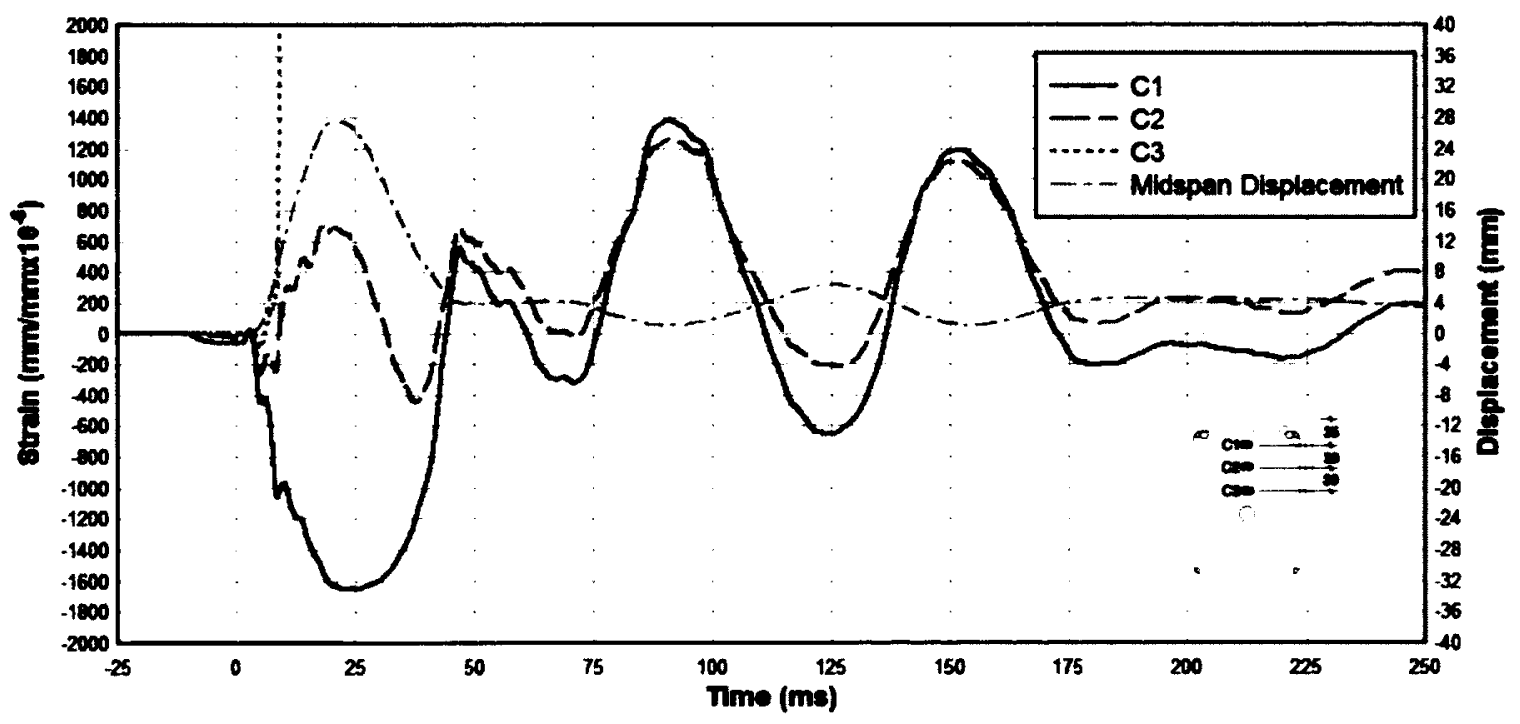

Figure 4-140: Strains in Concrete for Test DB-25M-3-1 


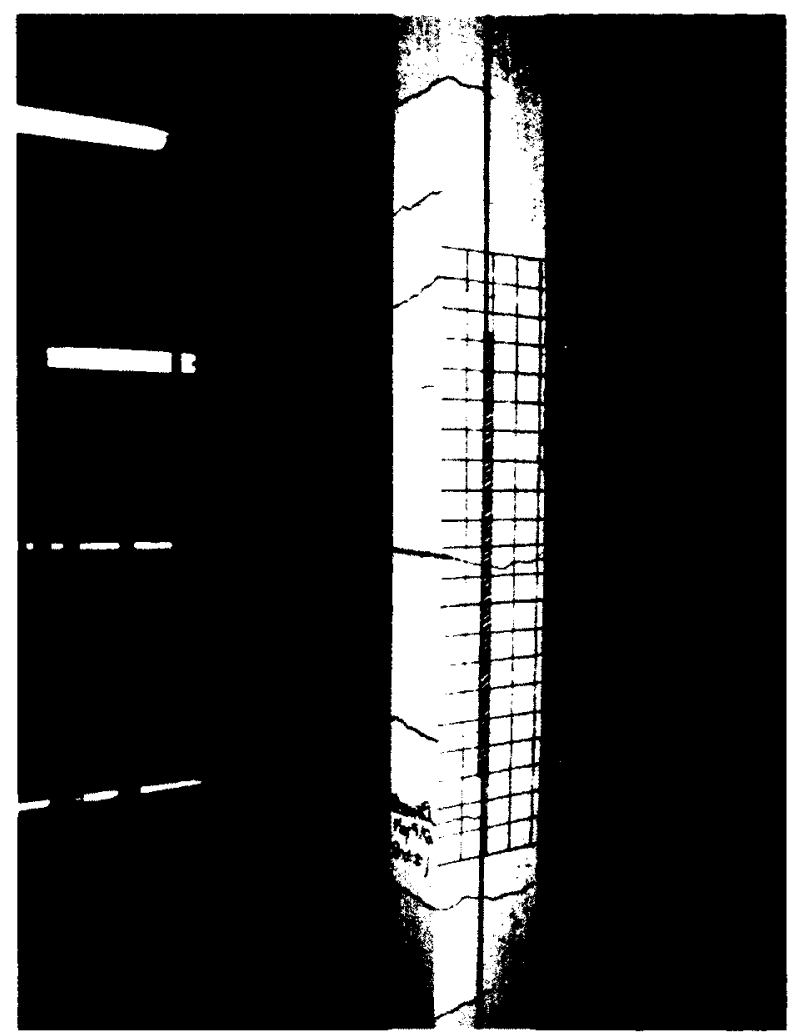

Figure 4-141: Crack Pattern After Test DB-25M-3-1

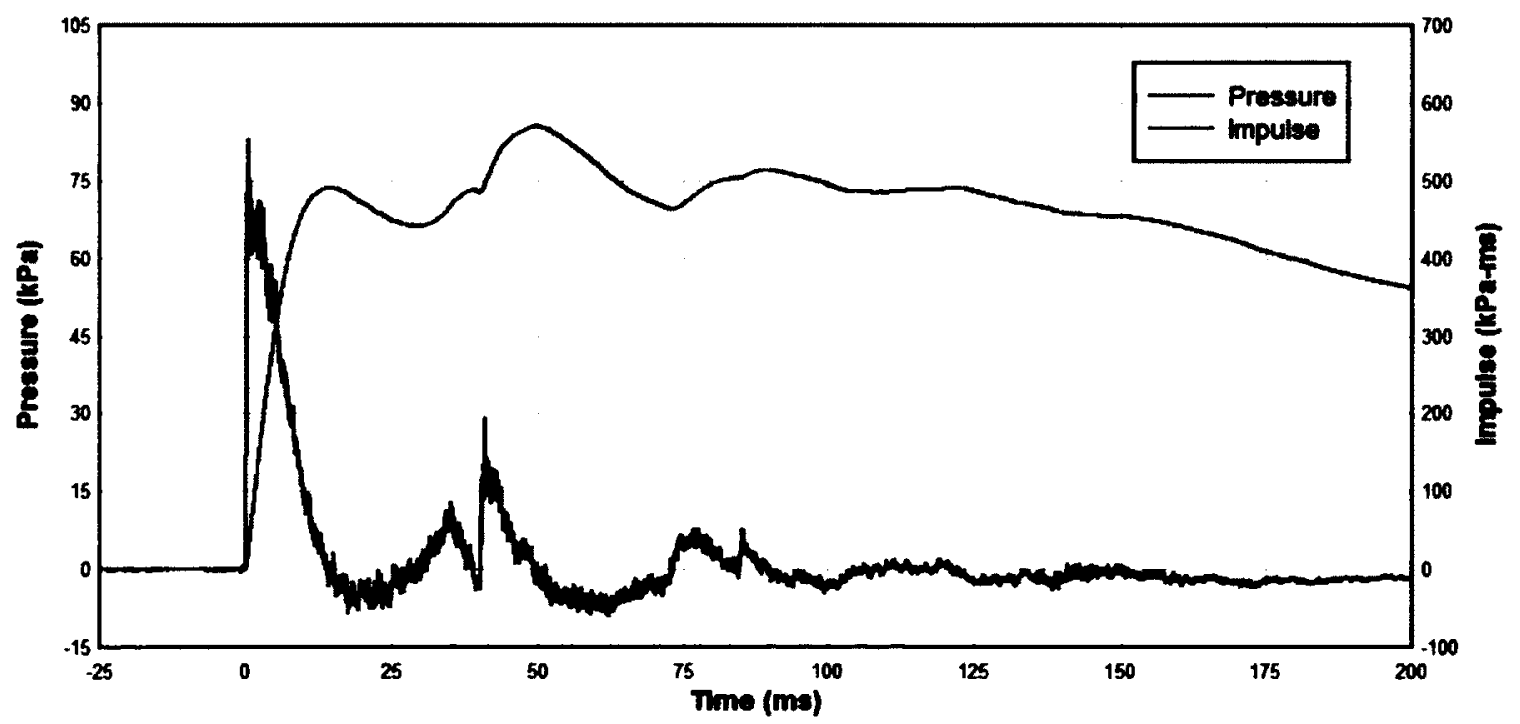

Figure 4-142: Pressure and Impulse Time History for Test DB-25M-3-2 


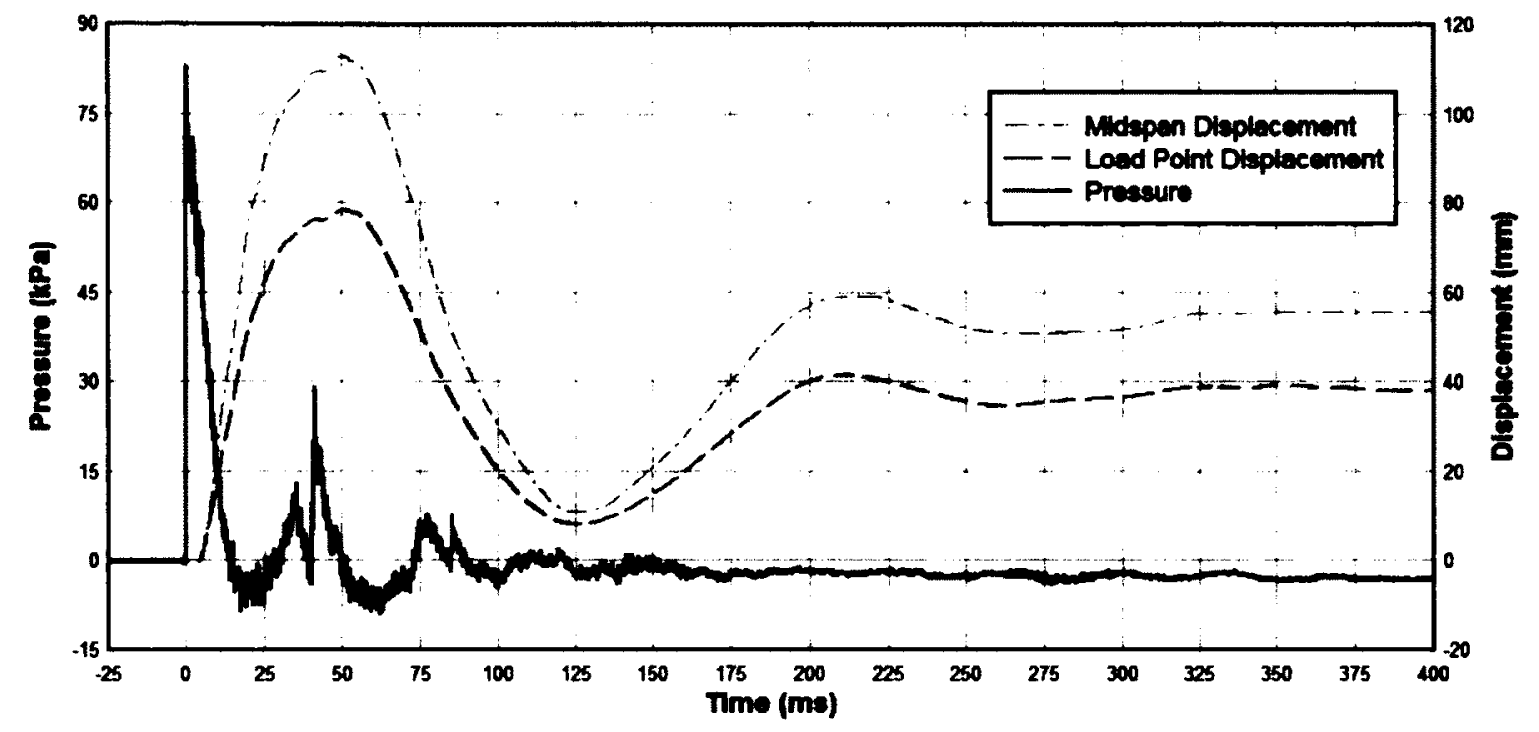

Figure 4-143: Pressure and Displacement Time History for Test DB-25M-3-2

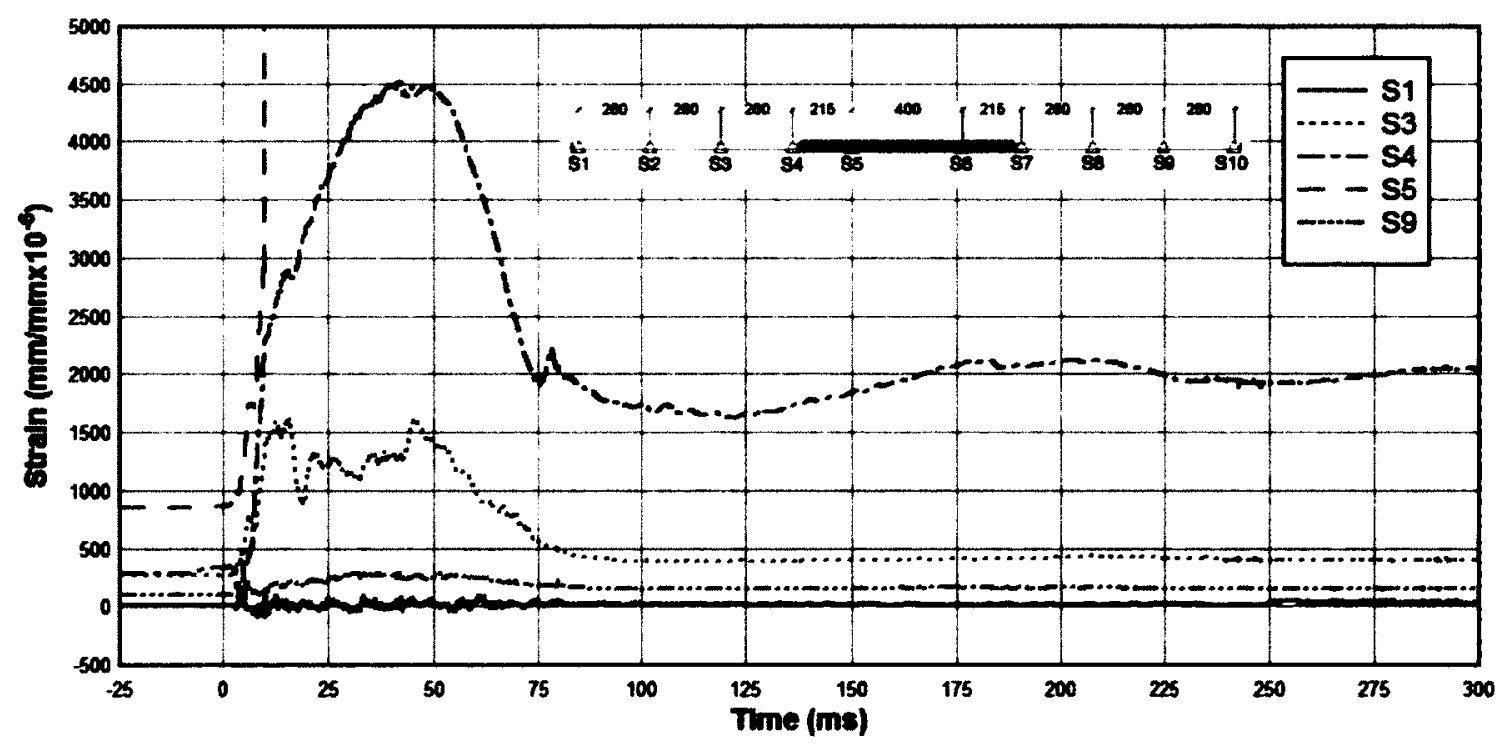

Figure 4-144: Strains in Steel for Test DB-25M-3-2 


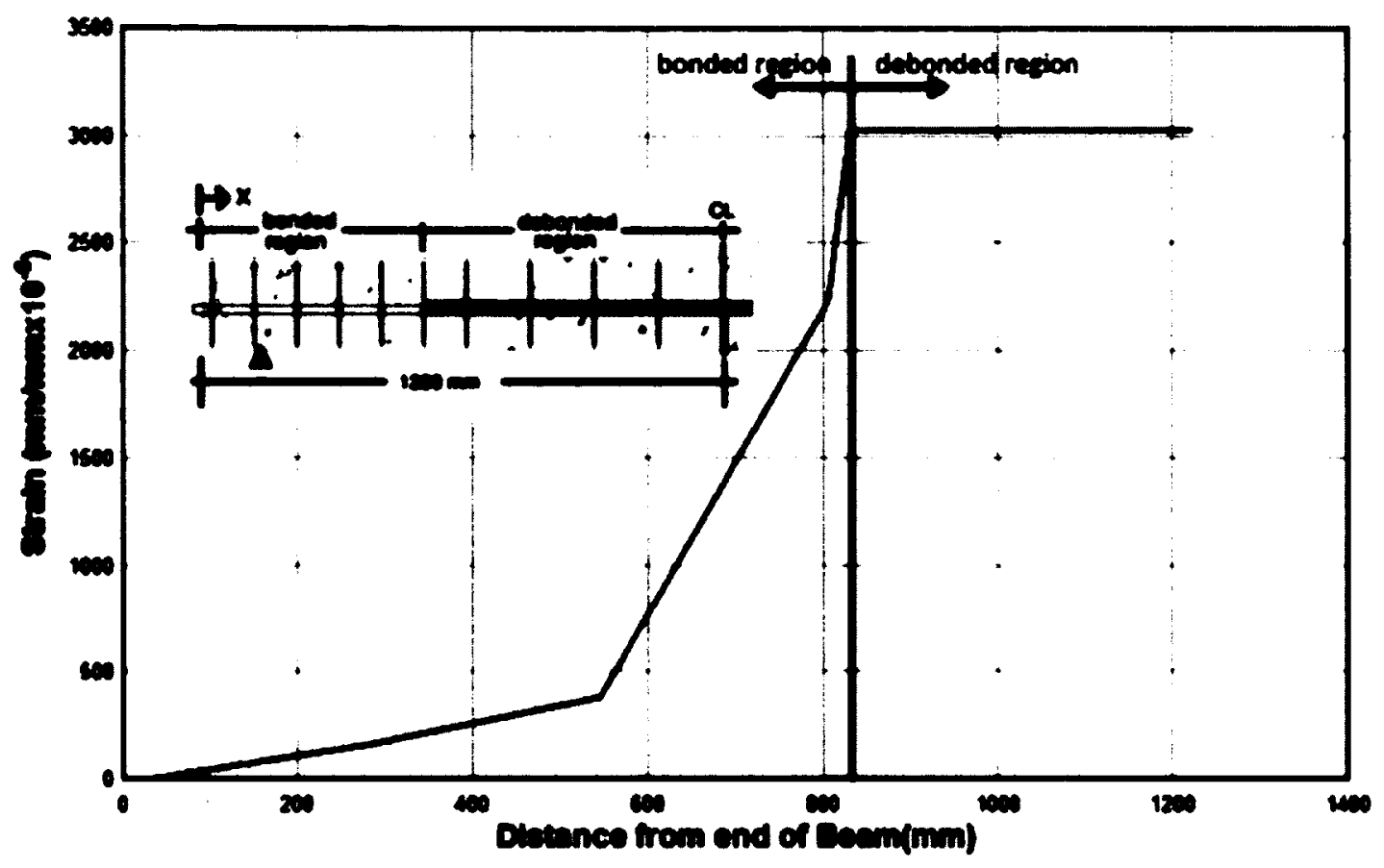

Figure 4-145: Strain Profile at Yield for Test DB-25M-3-2

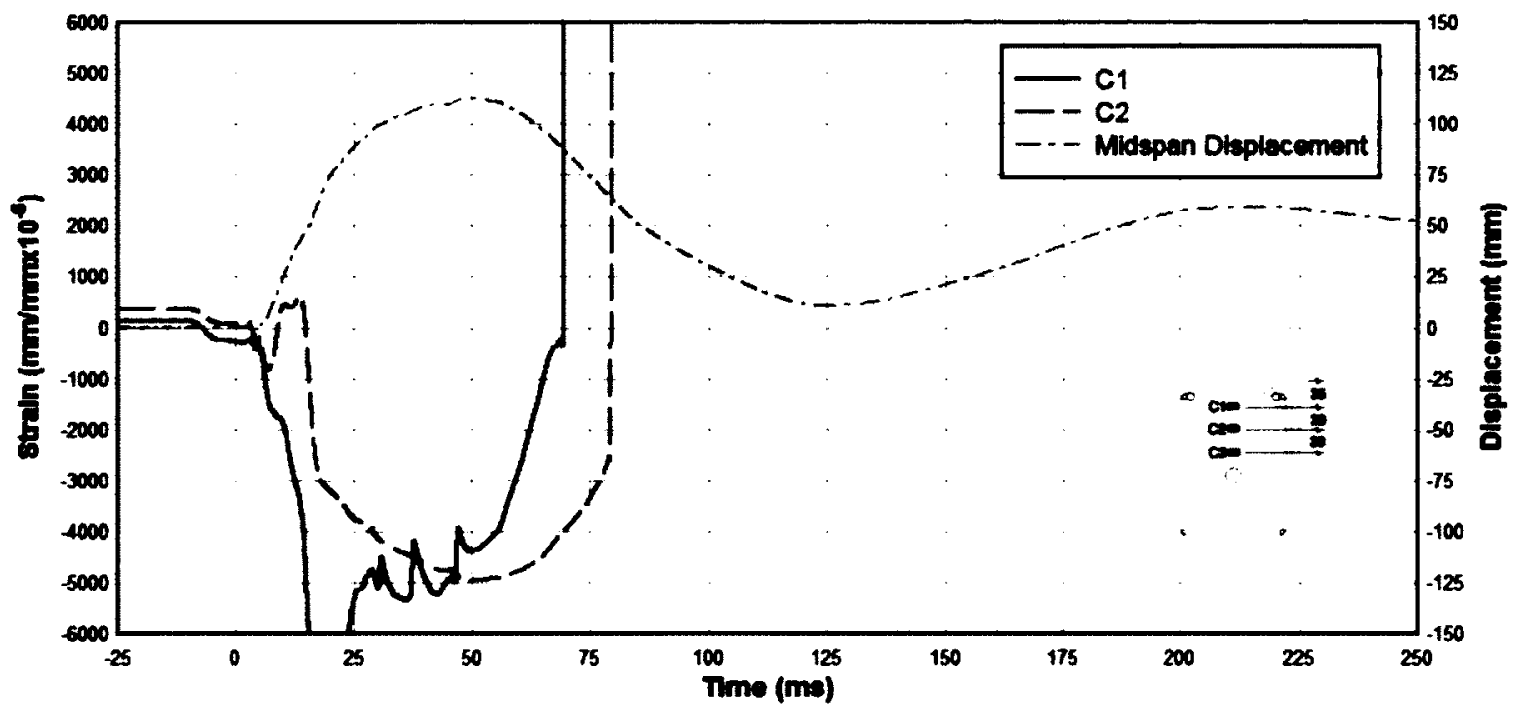

Figure 4-146: Strains in Concrete for Test DB-25M-3-2 


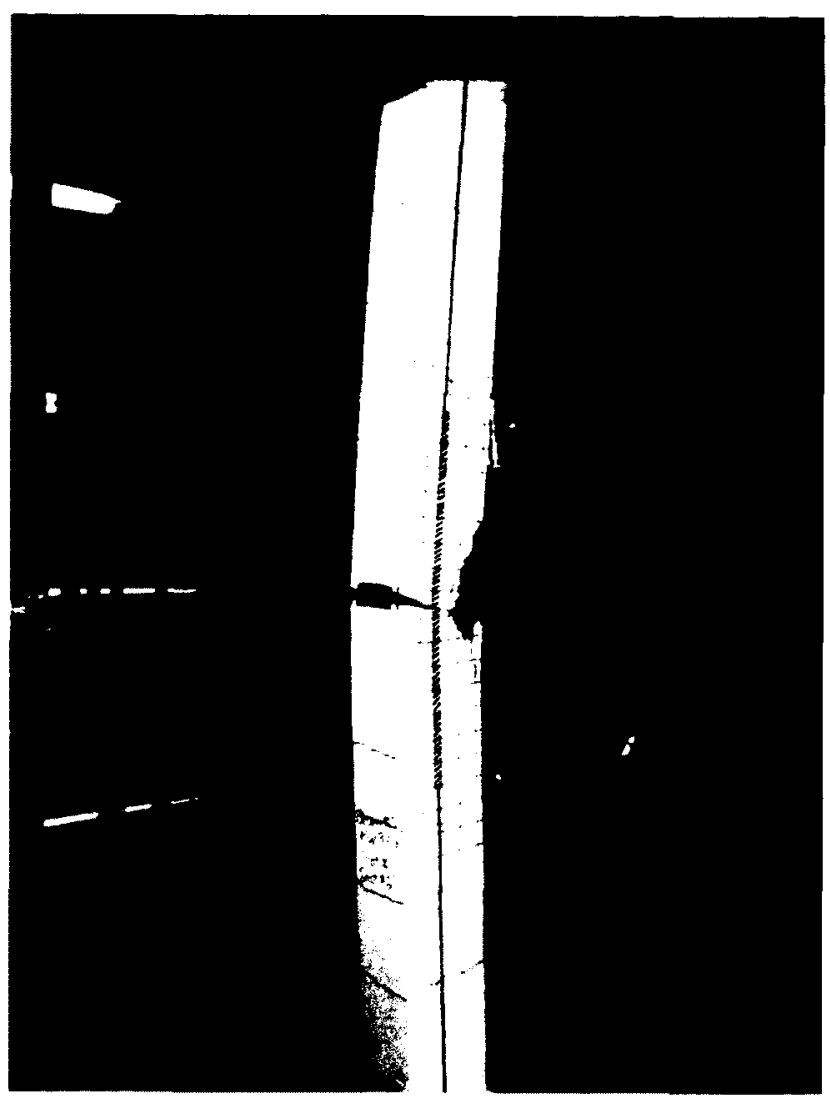

Figure 4-147: Crack Pattern After Test DB-25M-3-2 


\subsection{Comparison of Static and Dynamic Results}

The strain profile in the bonded region was produced at different times during each test so as to compare the strain profiles for static and dynamic tests. The first time at which the strain profile was plotted was when the steel in the debonded region reached a strain of $1500 \times 10^{-6}$. This value was arbitrarily chosen to be representative of reinforcement behaviour in the elastic region.

The second strain profile was plotted was when the strain in the debonded region reached either its static or dynamic yield strain, depending on whether the beam was tested statically or with the shock tube. The yield strains used were those determined in the ancillary testing for both static and dynamic cases. The yield strain was chosen since the main purpose of the experimental program is to determine whether current standards for calculating the development length are sufficient for blast design. Since the development length is a function of the yield strain and yield stress, the strain profile at the time when steel reached its yield strength is of utmost importance.

The strain profile plotted was when the strain in the debonded region surpassed its yield strain. Again, arbitrary strain values were chosen for consistency. For beams containing $15 \mathrm{M}$ and $20 \mathrm{M}$ reinforcement, the strain used was approximately $3000 \times 10^{-6}$. For beams containing $25 \mathrm{M}$ reinforcement, the strain used was $3500 \times 10^{-6}$. A greater strain value was used for $25 \mathrm{M}$ reinforcement because the dynamic yield strain of $25 \mathrm{M}$ rebar was above $3000 \times 10^{-6}$. 


\subsubsection{Comparison of SB-15M and DB-15M Beams}

The strains in the bonded region for elastic, yield, and post-yield strains were determined in all beams containing $15 \mathrm{M}$ reinforcement. The average strains in the bonded region from Tests SB-15M-1 and SB-15M-2 were used to produce the static strain profile (Table 4-15). The average strains in the bonded region from beams DB$15 \mathrm{M}-2-1$ and DB-15M-3-1 were used to produce the strain profile for shot 1 , and the average strains in the bonded region from beams DB-15M-2-2 and DB-15M-3-2 were used to produce the strain profile for shot 2 (Table 4-16).

\subsubsection{Elastic Region}

At the time when the strain in the debonded region for all $15 \mathrm{M}$ reinforcement reaches $1500 \times 10^{-6}$, the strain profile was plotted and shown in Figure 4-148. The strain profile for the static loading rate produced higher strain values than those for both dynamic tests. This is evidence that the strain from the steel is transferred to the concrete over a shorter length for high loading rates. Although the strains in shot 2, which produced the greatest strain rates, are slightly higher than those in shot 1 , the strain rates are of the same order of magnitude, thus having little effect on the difference in strains produced. One reason for higher strain values in shot 2 is that the longitudinal reinforcement had residual strains from shot 1 . 


\subsubsection{Yield Strain}

While the dynamic yield strain $\left(2740 \times 10^{-6}\right)$ is higher than the static yield strain $\left(2584 \times 10^{-6}\right)$, the length over which the strain changes from the yield strain to zero, otherwise known as the development length, appears to be much shorter for the dynamic case (Figure 4-149). That is, the bond strength was greater in tests with higher strain rates. The strain profile in the static test has higher strain values than the dynamic tests, however there is little difference between the strain profiles for shot 1 and shot 2 .

\subsubsection{Post-Yield Region}

The strain profile post-yield exhibits very similar behaviour to the strain profile at yield. The length over which the strain changes from approx. $3000 \times 10^{-6}$ to zero is shorter for the dynamic case than then static case (Figure 4-150). This proves that the bond strength is greater for higher strain rates. Again, the static strains were higher than those in the dynamic tests and the strain profiles for shot 1 and shot 2 were similar.

\subsubsection{Comparison of SB-20M and DB-20M Beams}

The strains in the bonded region for elastic, yield, and post-yield strains were determined in all beams containing $20 \mathrm{M}$ reinforcement. The average strains in the bonded region from Tests SB-20M-1 and SB-20M-2 were used to produce the static strain profile (Table 4-17). The average strains in the bonded region from beams DB20M-2-1 and DB-20M-3-1 were used to produce the strain profile for shot 1 , and the average strains in the bonded region from beams DB-20M-2-2 and DB-20M-3-2 were used to produce the strain profile for shot 2 (Table 4-18). 


\subsubsection{Elastic Region}

At the time when the strain in the debonded region for all $20 \mathrm{M}$ reinforcement reaches $1500 \times 10^{-6}$, the strain profile was plotted and shown Figure 4-151. The strain profile for the static loading rate produced higher strain values than those for shot 1 . Shot 2 had some strain values higher than the static strains. Although this is not the trend with most other tests, it is likely that high strains were produced in shot number 2 due to the damage made to the beam and residual strains after shot 1 . Observing the difference between the results from the static test and shot 1 more accurately reflect the difference in behaviour for static and dynamic cases since both test were conducted on beams that had no previous damage. Therefore, by observing the difference in these two tests, it can be concluded that the bond strength was higher in the dynamic test which produced a greater strain rate in the steel.

\subsubsection{Yield Strain}

For the tests on $20 \mathrm{M}$ reinforcement, the static yield strain was $2408 \times 10^{-6}$ while the dynamic yield strain was $2650 \times 10^{-6}$. The strain in the strain profile has lower values for dynamic tests than for the static tests (Figure 4-152). Similar to the strains in the elastic region for $20 \mathrm{M}$ reinforcement, the strain profile with the smallest strains, and therefore the greatest bond strength is that from shot 1. Again, it is likely that higher strains were apparent in shot 2 because there was already damage and residual strains in the beam before shot 2 was performed. 


\subsubsection{Post-Yield Region}

The strain profile post-yield shows very similar trends to that for $15 \mathrm{M}$ reinforcement. The strains in the strain profile for shot 1 and shot 2 are very similar. The curves for these dynamic strains lie under the static strain as shown in Figure 4-153. Lower values of strain for the dynamic case is evidence that the bond strength is greater for higher strain rates.

\subsubsection{Comparison of SB-25M and DB-25M Beams}

The strains in the bonded region for elastic, yield, and post-yield strains were determined in all beams containing $25 \mathrm{M}$ reinforcement. The average strains in the bonded region from Tests SB-25M-1 and SB-25M-2 were determined to produce the static strain profile (Table 4-19). The average strains in the bonded region from beams DB-25M-2-1 and DB-25M-3-1 were determined to produce the strain profile for shot 1, and the average strains in the bonded region from beams DB-25M-2-2 and DB-25M-3-2 were determined to produce the strain profile for shot 2 (Table 4-20).

\subsubsection{Elastic Region}

At the time when the strain in the debonded region for all $25 \mathrm{M}$ reinforcement reaches $1500 \times 10^{-6}$, the strain profile was plotted and shown in Figure 4-154. The strain profile for the static strain rate has the highest values of strain, and the strain profile for shot 1 has the lowest values of strain. Similar to the test on previous beams, the strain values in shot 2 may not be completely representative of the behaviour of the reinforcement at a strain rate of 0.2720 strain/s since the beam is already damaged and 
strained by shot 1 . It is however quite evident that the bond stress produced is greater in the dynamic tests than static tests.

\subsubsection{Yield Strain}

While the dynamic yield strain $\left(3163 \times 10^{-6}\right)$ is quite a bit higher than the static yield strain $\left(2448 \times 10^{-6}\right)$, the development length appears to be much shorter for the dynamic case (Figure 4-155). The bond strength in both shot 1 and shot 2 are greater than the static bond strength. In shot 1 the yield strain was not reached. Therefore the strain profile shown in Figure 4-155 is the strain profile when the strain in the debonded region reaches its maximum value. Although the strain profile of shot 1 has lower values than shot 2 at some points, the strain for shot 2 shows greater decreases in strain than in shot 1 . The behaviour of these test therefore show that a greater strain rate leads to a greater bond strength.

\subsubsection{Post-Yield Region}

The strain profile in the post yield region is shown in Figure 4-156. Only two curves are shown in this case since the strain from shot 1 did not reach the yield strain. The strain curves for shot 2 do however show significantly smaller strain values than that in the static tests. In a similar manner to all other beams, this shows that the decrease in strain over the same length is much greater for the dynamic tests. That is, higher strain rates produce greater bond strengths. 
Table 4-15: Average Strain Gauge Values for SB-15M Beams

\begin{tabular}{|c|c|c|c|c|c|c|c|}
\cline { 3 - 7 } \multicolumn{2}{c}{} & \multicolumn{2}{c|}{ Pre-Yield $\left(\mathrm{mm} / \mathrm{mm} \times 10^{-6}\right)$} & \multicolumn{2}{c|}{ Yield $\left(\mathrm{mm} / \mathrm{mm} \times 10^{-6}\right)$} & \multicolumn{2}{c|}{ Post-Yield $\left(\mathrm{mm} / \mathrm{mm} \times 10^{-6}\right)$} \\
\hline Gauges & $\begin{array}{c}\text { Distance } \\
(\mathrm{mm})\end{array}$ & SB-15M-1 & SB-15M-2 & SB-15M-1 & SB-15M-2 & SB-15M-1 & SB-15M-2 \\
\hline S1 and S10 & 25 & 0 & 0 & 0 & 0 & 0 & 0 \\
\hline S2 and S9 & 145 & 12 & 13 & 29 & 42 & 34 & 50 \\
\hline S3 and S8 & 265 & 177 & 328 & 441 & 811 & 510 & 902 \\
\hline S4 and S7 & 385 & 1524 & 1180 & 2228 & 1981 & 2341 & 2092 \\
\hline S5 and S6 & 423 & 1498 & 1503 & 2585 & 2591 & 3002 & 3023 \\
\hline
\end{tabular}

Table 4-16: Average Strain Gauge Values for DB-15M Beams

\begin{tabular}{|c|c|c|c|c|c|c|c|c|c|c|c|c|c|}
\hline \multirow[b]{2}{*}{ Gauges } & \multirow[b]{2}{*}{$\begin{array}{c}\text { Distance } \\
(\mathrm{mm})\end{array}$} & \multicolumn{4}{|c|}{ Pre-Yield $\left(\mathrm{mm} / \mathrm{mm} \times 10^{-6}\right)$} & \multicolumn{4}{|c|}{ Yield $\left(\mathrm{mm} / \mathrm{mm} \times 10^{-6}\right)$} & \multicolumn{4}{|c|}{ Post-Yield $\left(\mathrm{mm} / \mathrm{mm} \times 10^{-6}\right)$} \\
\hline & & 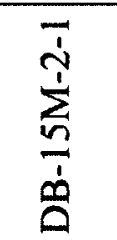 & $\begin{array}{l}\stackrel{N}{\sim} \\
\sum_{n}^{\prime} \\
\frac{1}{0} \\
\dot{0}\end{array}$ & $\begin{array}{l}\overrightarrow{1} \\
\stackrel{n}{n} \\
\frac{n}{n} \\
\frac{n}{0}\end{array}$ & $\frac{\substack{n\\
}}{\frac{n}{1}}$ & 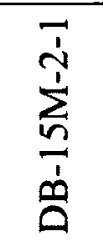 & 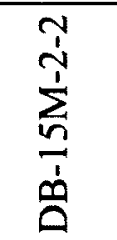 & 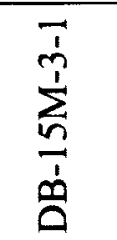 & 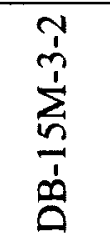 & $\frac{\vec{i}}{\sum_{n}^{\prime}}$ & $\begin{array}{l}\stackrel{y}{y} \\
\dot{y} \\
\dot{n} \\
\dot{n}\end{array}$ & 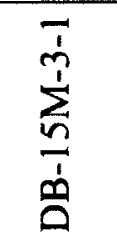 & $\frac{n}{\sum_{n}^{1}}$ \\
\hline $\mathrm{S} 1$ and $\mathrm{S} 10$ & 25 & 0 & 0 & 0 & 0 & 0 & 0 & 0 & 0 & 0 & 0 & 0 & 0 \\
\hline S2 and S9 & 145 & 76 & 22 & 22 & 28 & 21 & 9 & 7 & 3 & 76 & 22 & 22 & 28 \\
\hline S3 and S8 & 265 & 179 & 169 & 433 & 450 & 19 & 31 & 120 & 205 & 179 & 169 & 433 & 450 \\
\hline $\mathrm{S} 4$ and $\mathrm{S} 7$ & 385 & 2313 & 2639 & 2114 & 2198 & 1151 & 1343 & 1195 & 877 & 2313 & 2639 & 2114 & 2198 \\
\hline S5 and S6 & 423 & 2989 & 3006 & 2839 & 2999 & 1510 & 1499 & 1501 & 1499 & 2989 & 3006 & 2839 & 2999 \\
\hline
\end{tabular}


Table 4-17: Average Strain Gauge Values for SB-20M Beams

\begin{tabular}{|c|c|c|c|c|c|c|c|}
\cline { 3 - 8 } \multicolumn{2}{c}{} & \multicolumn{2}{c|}{ Pre-Yield $\left(\mathrm{mm} / \mathrm{mm} \times 10^{-6}\right)$} & \multicolumn{2}{c|}{ Yield $\left(\mathrm{mm} / \mathrm{mm} \times 10^{-6}\right)$} & \multicolumn{2}{c|}{ Post-Yield $\left(\mathrm{mm} / \mathrm{mm} \times 10^{-6}\right)$} \\
\hline Gauges & $\begin{array}{c}\text { Distance } \\
(\mathrm{mm})\end{array}$ & SB-20M-1 & SB-20M-2 & SB-20M-1 & SB-20M-2 & SB-20M-1 & SB-20M-2 \\
\hline S1 and S10 & 26 & 0 & 0 & 0 & 0 & 0 & 0 \\
\hline S2 and S9 & 184 & 9 & 8 & 20 & 19 & 26 & 24 \\
\hline S3 and S8 & 342 & 164 & 161 & 484 & 566 & 641 & 728 \\
\hline S4 and S7 & 500 & 1229 & 1225 & 2014 & 2008 & 2327 & 2323 \\
\hline S5 and S6 & 523 & 1500 & 1033 & 2408 & 1718 & 3001 & 1974 \\
\hline
\end{tabular}

Table 4-18: Average Strain Gauge Values for DB-20M Beams

\begin{tabular}{|c|c|c|c|c|c|c|c|c|c|c|c|c|c|}
\hline \multirow[b]{2}{*}{ Gauges } & \multirow[b]{2}{*}{$\begin{array}{l}\text { Distance } \\
(\mathrm{mm})\end{array}$} & \multicolumn{4}{|c|}{ Pre-Yield $\left(\mathrm{mm} / \mathrm{mm} \times 10^{-6}\right)$} & \multicolumn{4}{|c|}{ Yield $\left(\mathrm{mm} / \mathrm{mm} \times 10^{-6}\right)$} & \multicolumn{4}{|c|}{ Post-Yield $\left(\mathrm{mm} / \mathrm{mm} \times 10^{-6}\right)$} \\
\hline & & 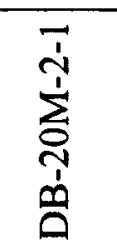 & 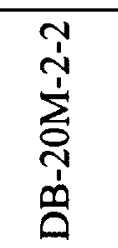 & 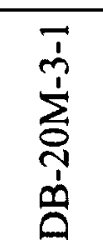 & 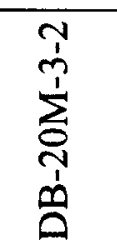 & 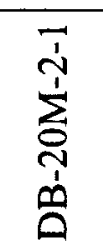 & 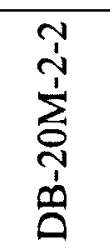 & 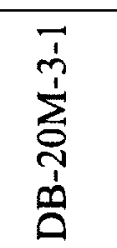 & 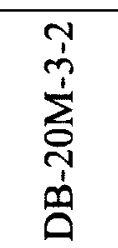 & 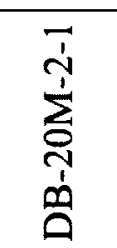 & 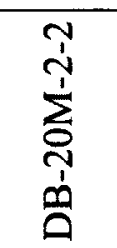 & 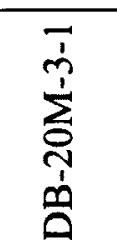 & 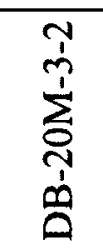 \\
\hline $\mathrm{S} 1$ and $\mathrm{S} 10$ & 26 & 0 & 0 & 0 & 0 & 0 & 0 & 0 & 0 & 0 & 0 & 0 & 0 \\
\hline $\mathrm{S} 2$ and $\mathrm{S} 9$ & 184 & 8 & 3 & 4 & 8 & 4 & 7 & 4 & 8 & 13 & 2 & 4 & 8 \\
\hline $\mathrm{S} 3$ and S8 & 342 & 377 & 234 & 409 & 626 & 103 & 71 & 61 & 410 & 461 & 289 & 540 & 719 \\
\hline S4 and S7 & 500 & 1543 & 1439 & 995 & 1853 & 792 & 769 & 420 & 1015 & 1735 & 1645 & 1608 & 1963 \\
\hline S5 and S6 & 523 & 2650 & 2653 & 2651 & 2650 & 1501 & 1500 & 1500 & 1497 & 2923 & 2999 & 2867 & 3007 \\
\hline
\end{tabular}


Table 4-19: Average Strain Gauge Values for SB-25M Beams

\begin{tabular}{|c|c|c|c|c|c|c|c|}
\cline { 3 - 7 } \multicolumn{2}{c}{} & \multicolumn{2}{c|}{ Pre-Yield $\left(\mathrm{mm} / \mathrm{mm} \times 10^{-6}\right)$} & \multicolumn{2}{c|}{ Yield $\left(\mathrm{mm} / \mathrm{mm} \times 10^{-6}\right)$} & \multicolumn{2}{c|}{ Post-Yield $\left(\mathrm{mm} / \mathrm{mm} \times 10^{-6}\right)$} \\
\hline Gauges & $\begin{array}{c}\text { Distance } \\
(\mathrm{mm})\end{array}$ & SB-25M-1 & SB-25M-2 & SB-25M-1 & SB-25M-2 & SB-25M-1 & SB-25M-2 \\
\hline S1 and S10 & 25 & 0 & 0 & 0 & 0 & 0 & 0 \\
\hline S2 and S9 & 285 & 208 & 213 & 727 & 360 & 680 & 788 \\
\hline S3 and S8 & 545 & 994 & 1019 & 1397 & 1305 & 1240 & 1506 \\
\hline S4 and S7 & 805 & 1494 & 1479 & 2418 & 2251 & 3067 & 2818 \\
\hline S5 and S6 & 830 & 1503 & 1505 & 2444 & 2447 & 3509 & 3008 \\
\hline
\end{tabular}

Table 4-20: Average Strain Gauge Values for DB-25M Beams

\begin{tabular}{|c|c|c|c|c|c|c|c|c|c|c|c|c|c|}
\hline \multirow[b]{2}{*}{ Gauges } & \multirow[b]{2}{*}{$\begin{array}{c}\text { Distance } \\
(\mathrm{mm})\end{array}$} & \multicolumn{4}{|c|}{ Pre-Yield $\left(\mathrm{mm} / \mathrm{mm} \times 10^{-6}\right)$} & \multicolumn{4}{|c|}{ Yield $\left(\mathrm{mm} / \mathrm{mm} \times 10^{-6}\right)$} & \multicolumn{4}{|c|}{ Post-Yield ( $\left.\mathrm{mm} / \mathrm{mm} \times 10^{-6}\right)$} \\
\hline & & $\begin{array}{l}\bar{\sim} \\
\stackrel{1}{\dot{s}} \\
\stackrel{2}{\sim} \\
\stackrel{n}{0}\end{array}$ & 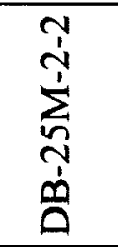 & $\begin{array}{l}\overrightarrow{1} \\
\stackrel{n}{\dot{n}} \\
\stackrel{n}{\sim} \\
\stackrel{0}{0}\end{array}$ & 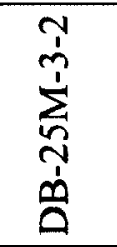 & 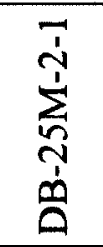 & 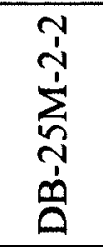 & $\begin{array}{l}\overrightarrow{1} \\
\dot{n} \\
\dot{n} \\
\tilde{n} \\
\dot{n} \\
\dot{0}\end{array}$ & $\begin{array}{l}\tilde{y} \\
\dot{1} \\
\dot{n} \\
\tilde{n} \\
\dot{n} \\
\dot{0}\end{array}$ & 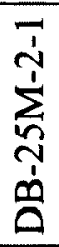 & 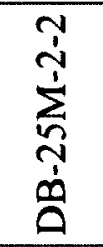 & $\begin{array}{l}\overrightarrow{1} \\
\dot{n} \\
\dot{n} \\
\tilde{n} \\
\dot{0} \\
\dot{0}\end{array}$ & $\begin{array}{l}\underset{1}{1} \\
\sum_{n}^{1} \\
\tilde{1} \\
\stackrel{0}{0}\end{array}$ \\
\hline $\mathrm{S} 1$ and $\mathrm{S} 10$ & 25 & 0 & 0 & 0 & 0 & 0 & 0 & 0 & 0 & 0 & 0 & 0 & 0 \\
\hline S2 and S9 & 285 & 3 & 1 & 155 & 201 & 3 & 1 & 203 & 164 & 0 & 0 & 0 & 164 \\
\hline S3 and S8 & 545 & 107 & 380 & 591 & 684 & 260 & 500 & 1121 & 382 & 0 & 514 & 0 & 1409 \\
\hline $\mathrm{S} 4$ and $\mathrm{S} 7$ & 805 & 309 & 1120 & 1327 & 1234 & 760 & 1473 & 2217 & 2240 & 0 & 1518 & 0 & 2260 \\
\hline S5 and S6 & 830 & 1500 & 1497 & 1501 & 1502 & 2363 & 3158 & 2798 & 3030 & 0 & 3500 & 0 & 3440 \\
\hline
\end{tabular}




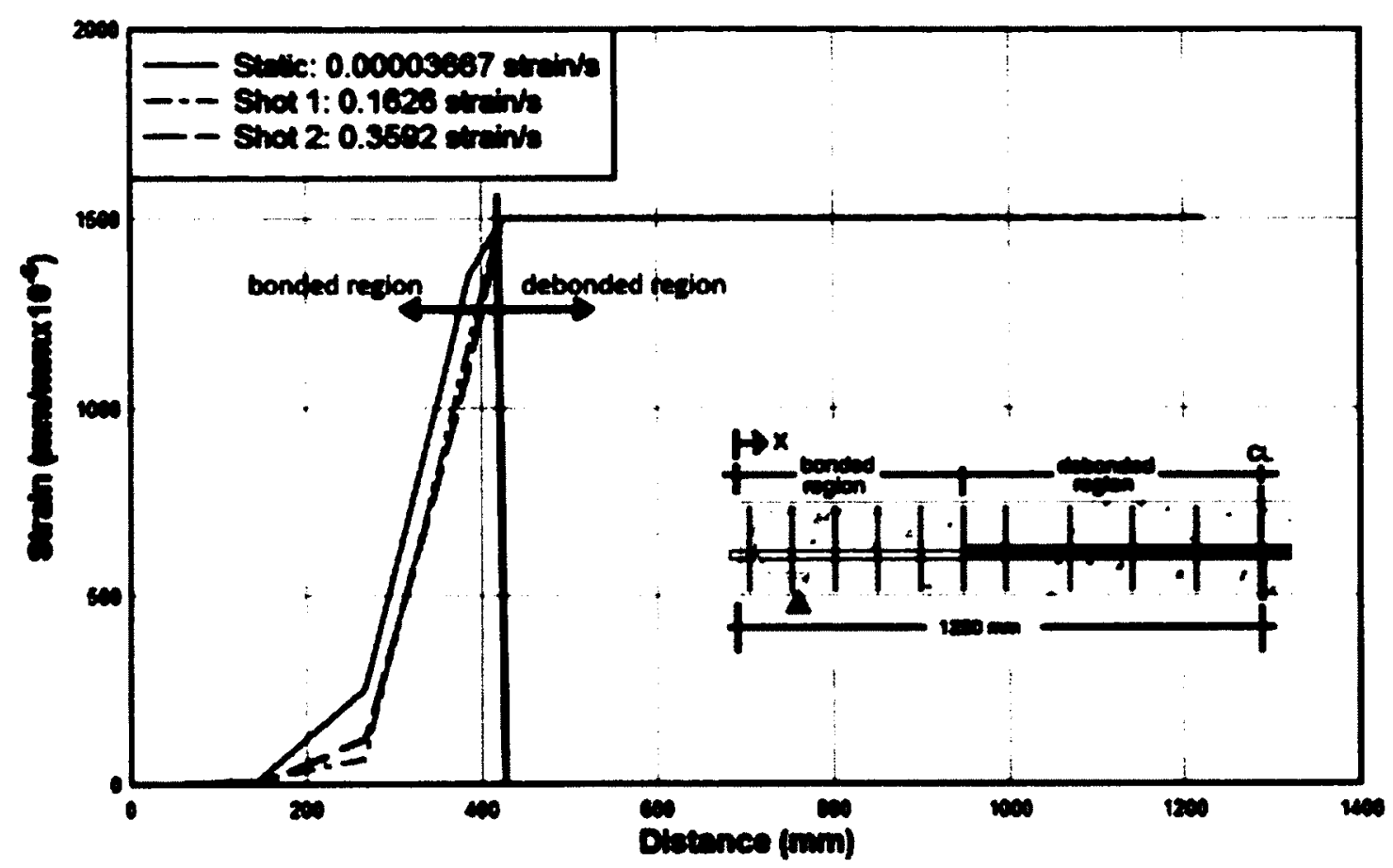

Figure 4-148: Strain Profile at 1500 microstrain in Debonded Region for 15M Reinforcement

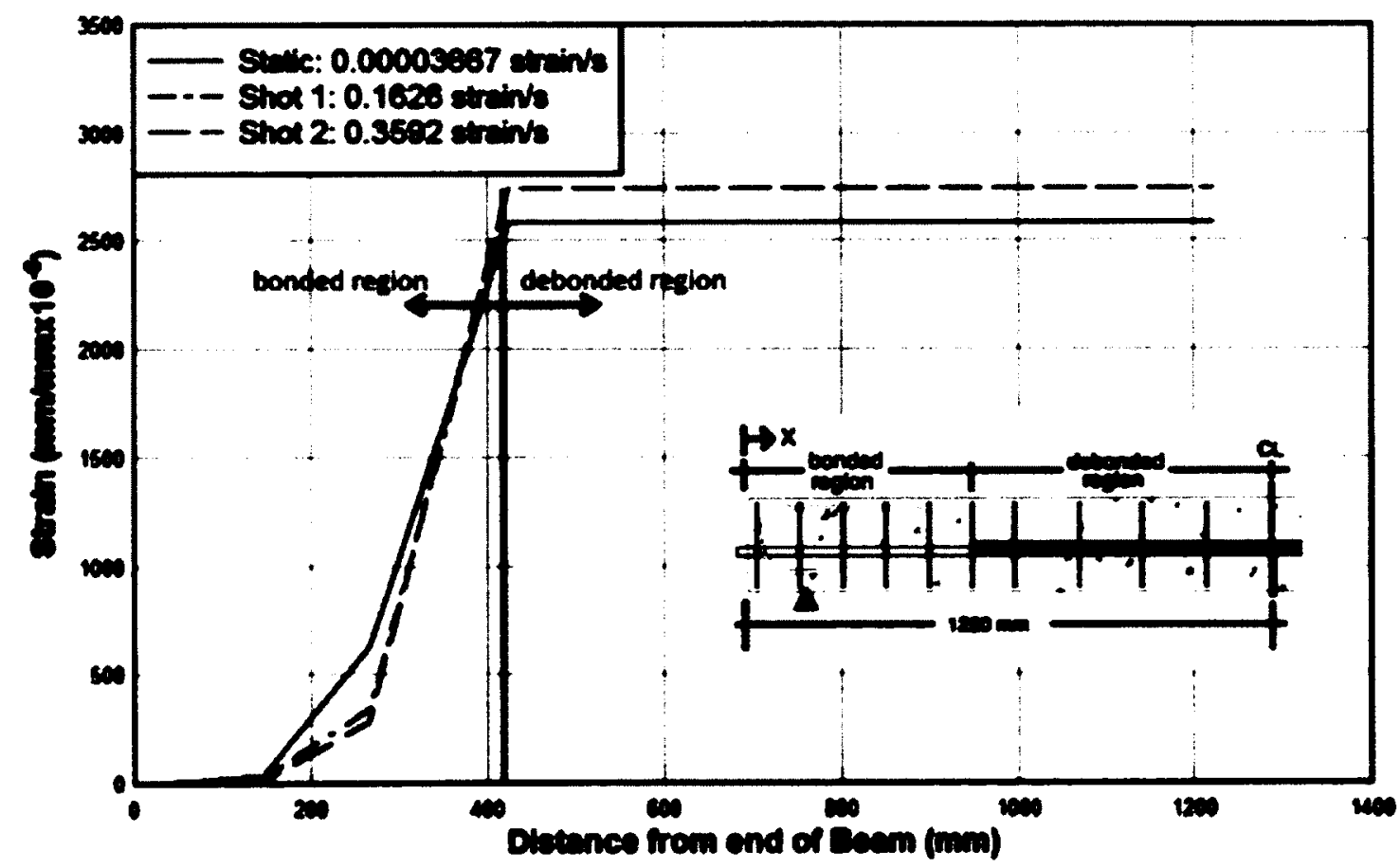

Figure 4-149: Strain Profile at Yield Strain in Debonded Region for 15M Reinforcement 


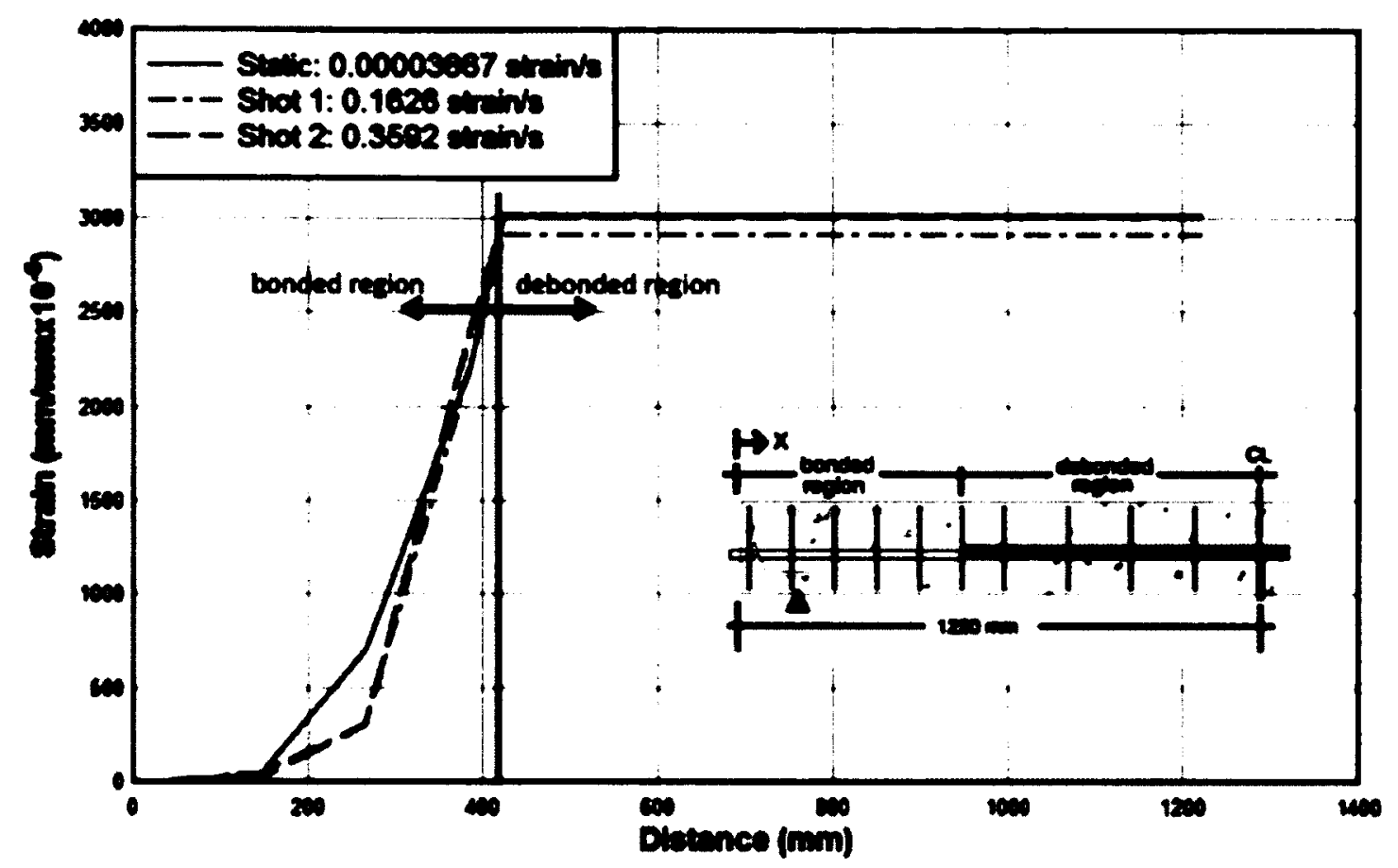

Figure 4-150: Strain Profile Post-Yield Strain in Debonded Region for 15M Reinforcement

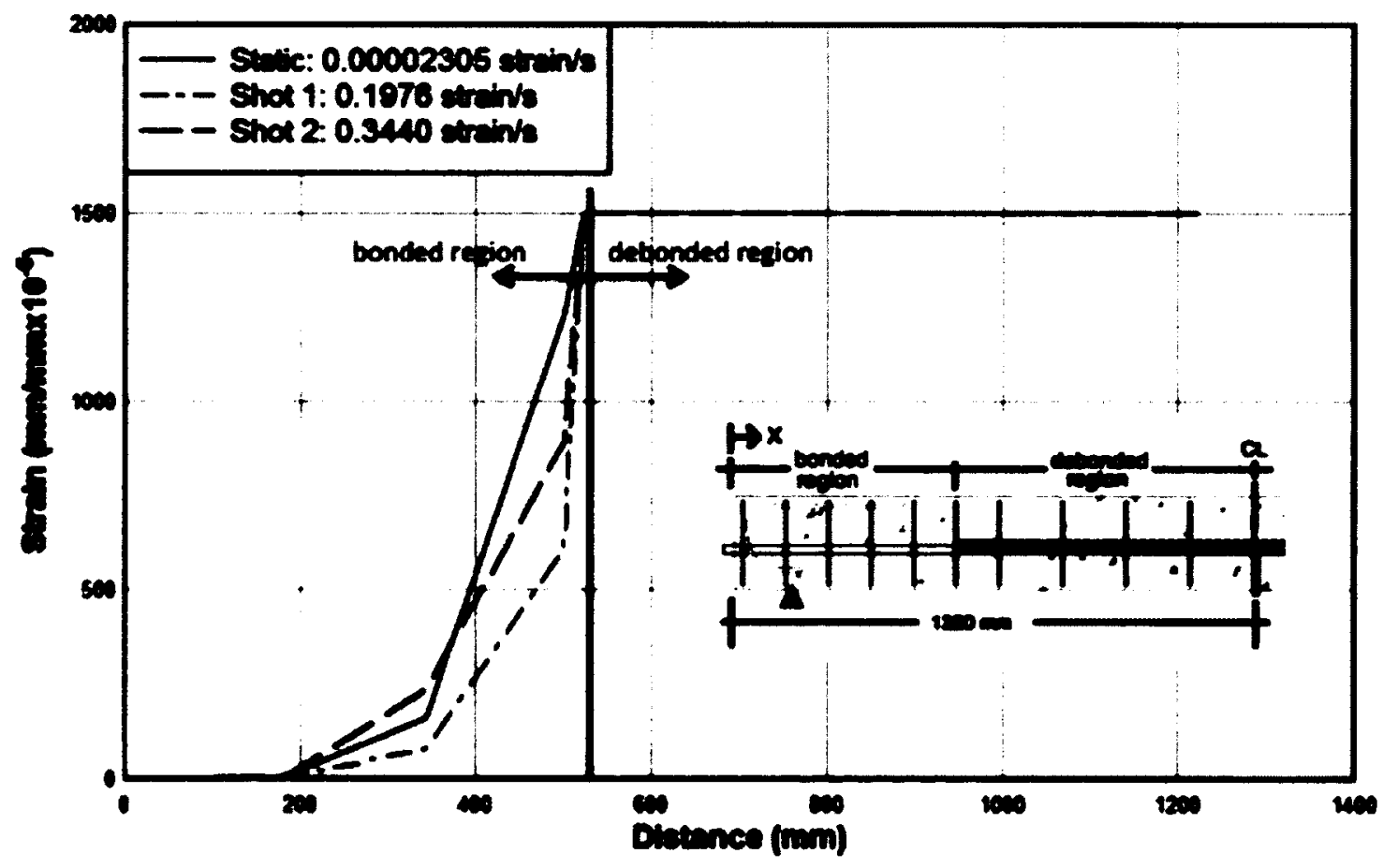

Figure 4-151: Strain Profile at 1500 microstrain in Debonded Region for 20M Reinforcement 


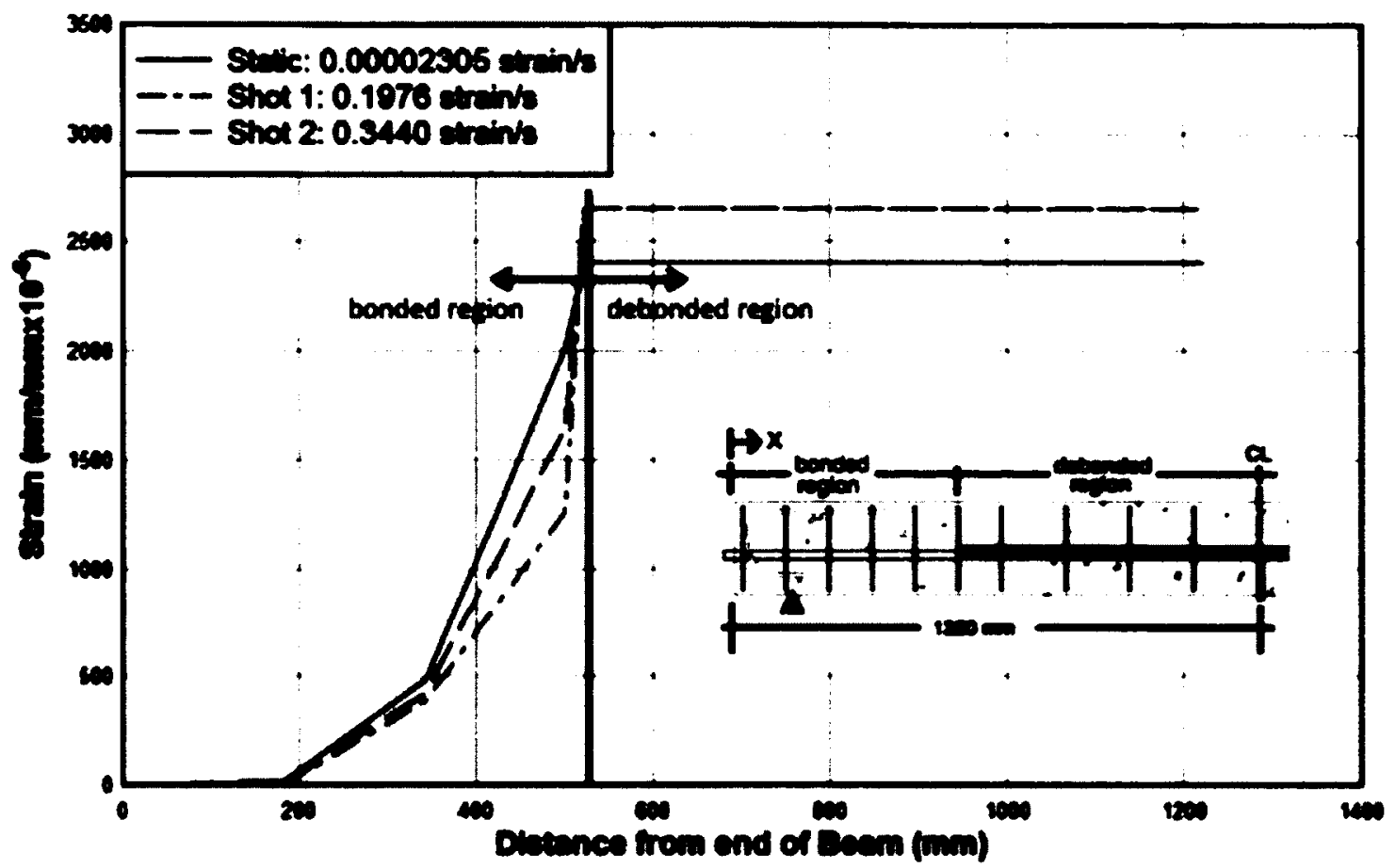

Figure 4-152: Strain Profile at Yield Strain in Debonded Region for 20M Reinforcement

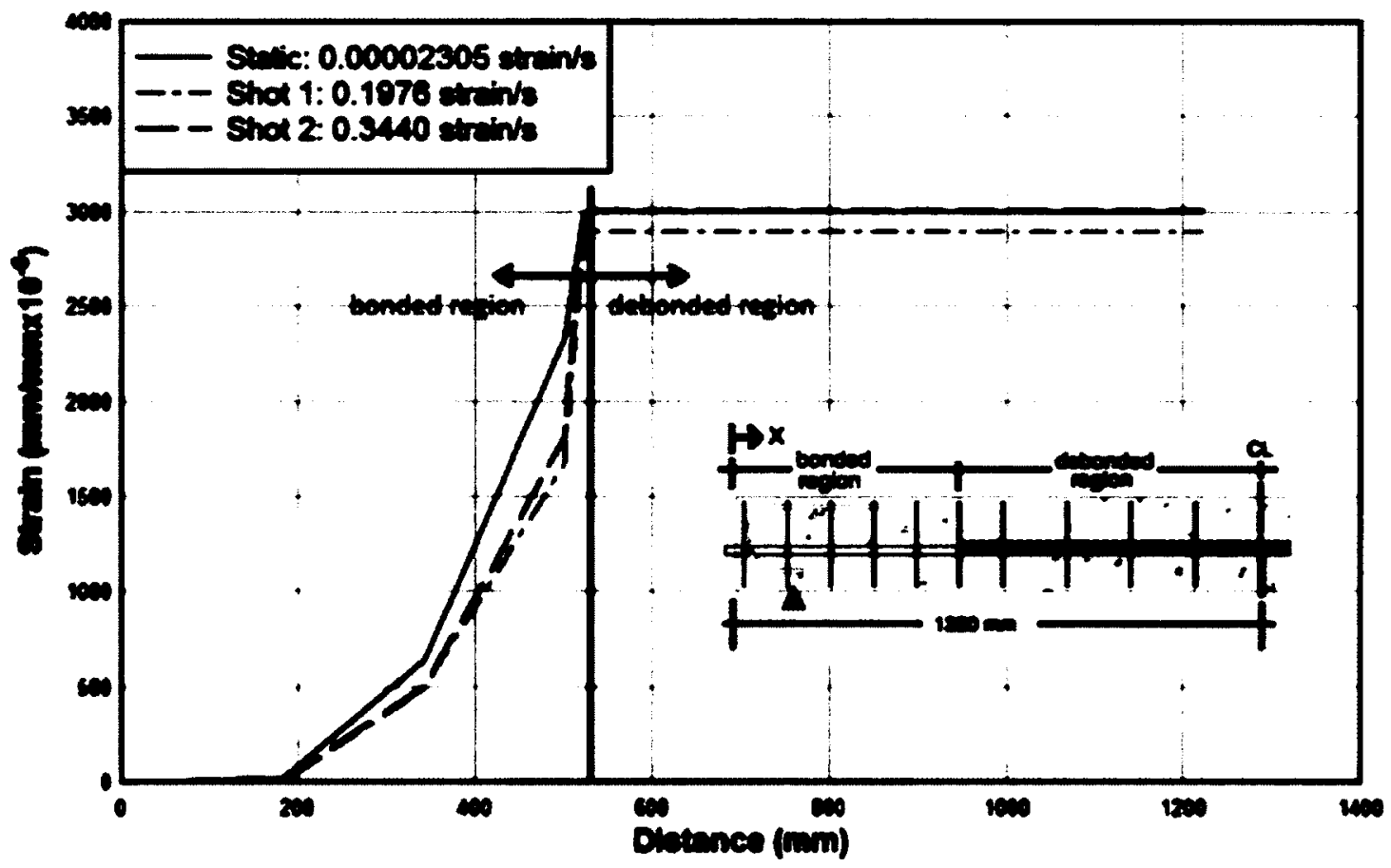

Figure 4-153: Strain Profile at Post-Yield Strain in Debonded Region for 20M Reinforcement 


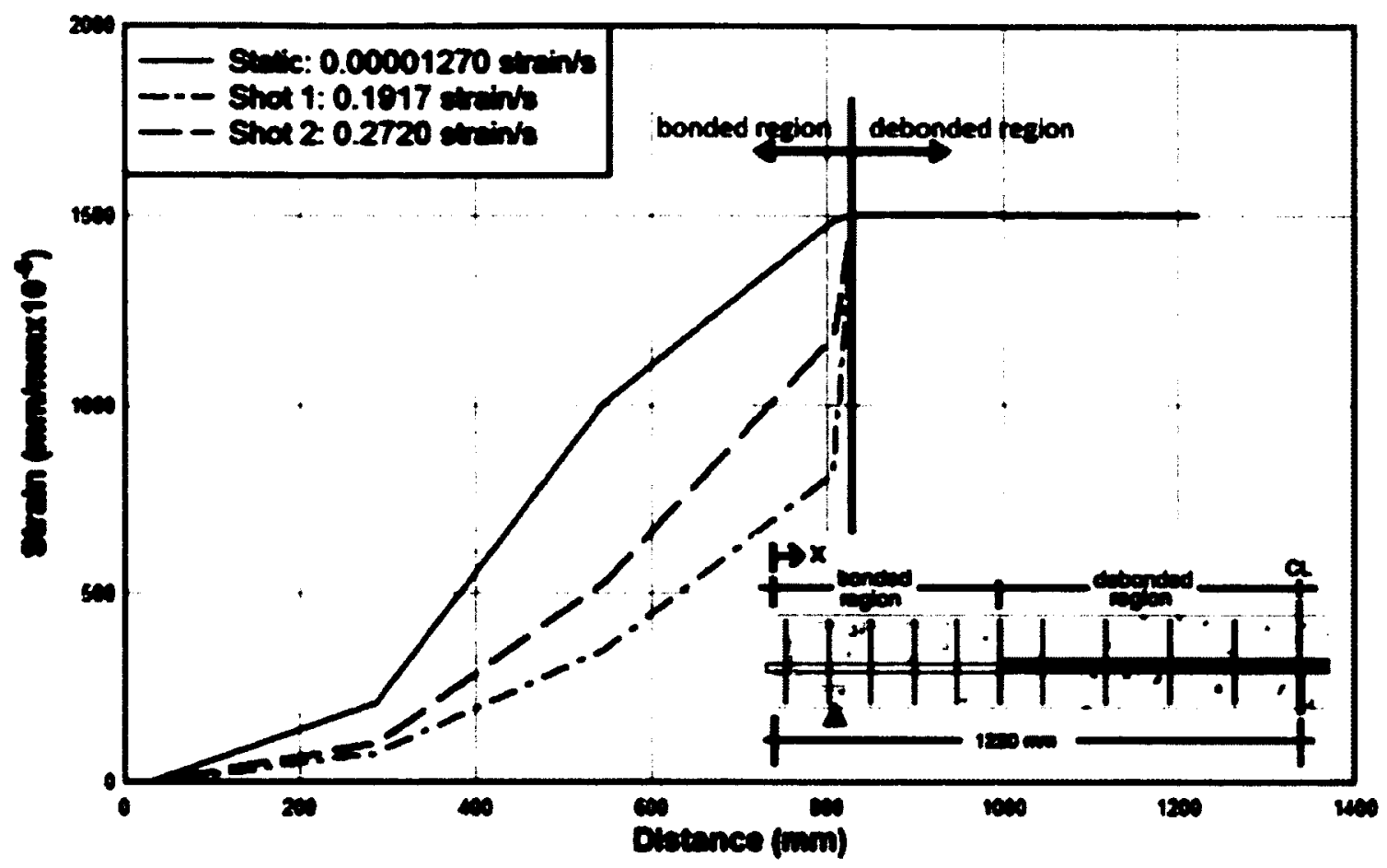

Figure 4-154: Strain Profile at 1500 microstrain in Debonded Region for 25M Reinforcement

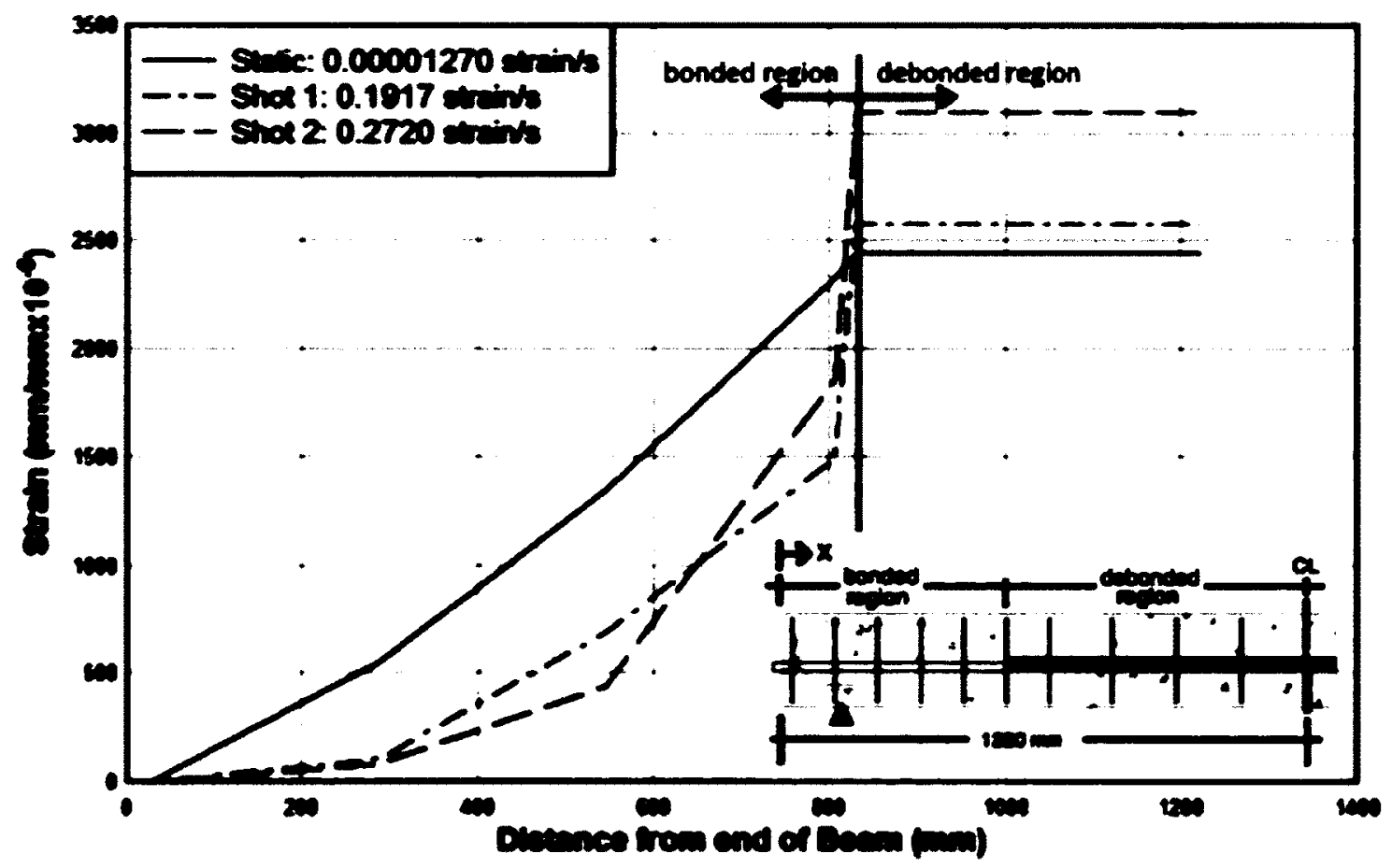

Figure 4-155: Strain Profile at Yield Strain in Debonded Region for 25M Reinforcement 


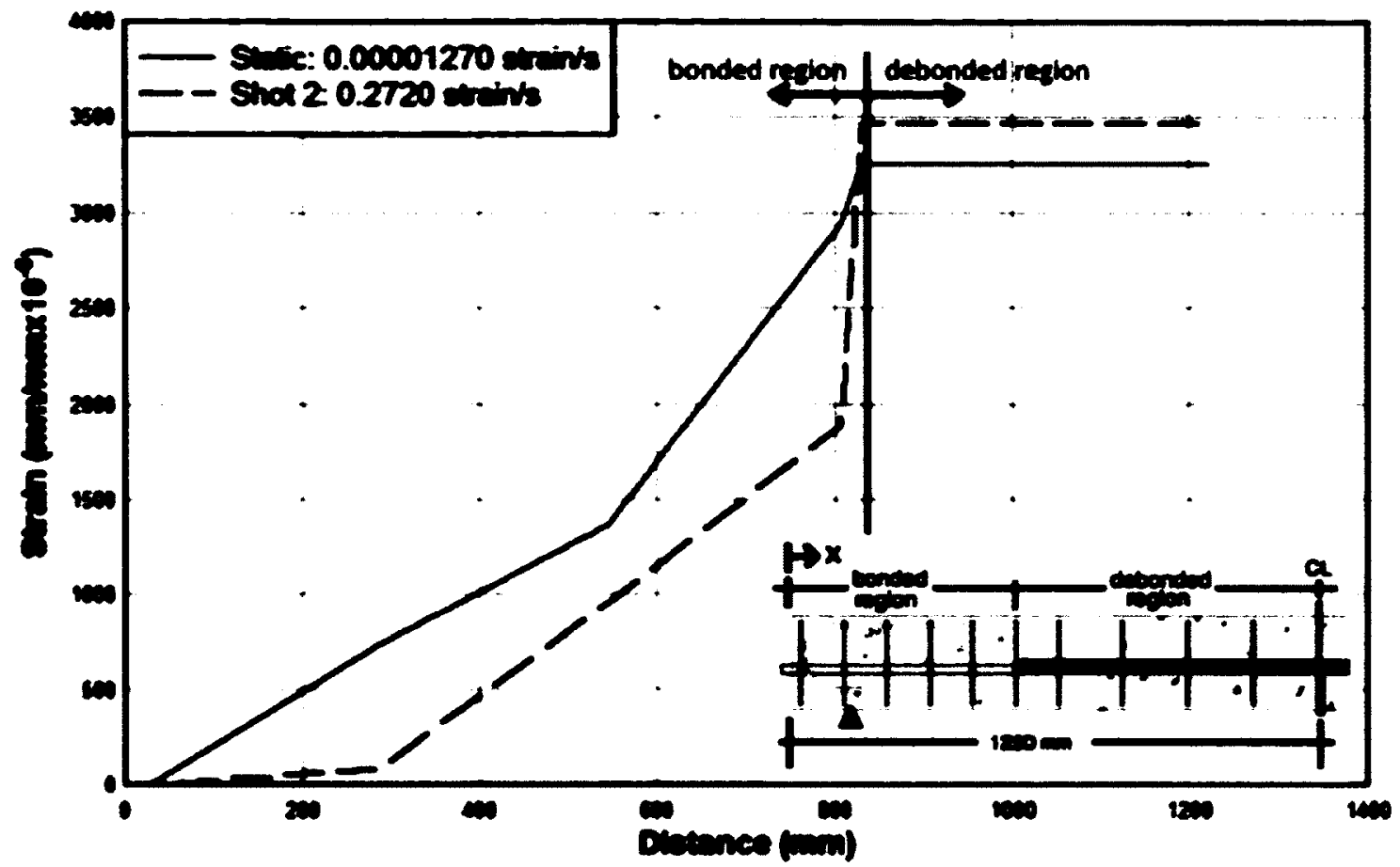

Figure 4-156: Strain Profile Post-Yield Strain in Debonded Region for 25M Reinforcement 


\subsection{Summary of Results}

The data acquired from the static and dynamic tests on the reinforced concrete beams shoed many results that were consistent between beams. The following points summarize the most important information gathered from the results of experimental program:

1. The development length provided was adequate for transfer of the dynamic yield stress of the reinforcing steel in all beams.

2. No reinforcement slip occurred during any test.

3. Dynamic testing of the reinforcing steel used strain rates of $0.1 \mathrm{strain} / \mathrm{s}$ and $0.2 \mathrm{strain} / \mathrm{s}$ to estimate the dynamic yield strain of the reinforcing bars in Shock Tube Testing.

4. In Shock Tube testing, a pressure and impulse combination was chosen so that reinforcing steel in the concrete beam would just exceed its dynamic yield stress. The average strain rate produced in the reinforcing steel during these tests was $0.18 \mathrm{strain} / \mathrm{s}$. The average maximum support rotation from these tests was $1.6^{\circ}$.

5. In Shock Tube testing where the maximum pressure and impulse combination were used, the average strain rate produced in the steel was $0.325 \mathrm{strain} / \mathrm{s}$. The average maximum support rotation from these tests was $6.5^{\circ}$.

6. Strain profiles were produced to compare the static strain profile to the dynamic strain profile for each size of reinforcement. From the strain profiles, it was noticed that the smallest strains occurred in the reinforcing steel in the beams undergoing Shock Tube testing, and where no test had previously been performed on the beam. 


\subsection{Sources of Error}

While the design, construction, and installation of test equipment were very carefully implemented, there exist sources of error within the experimental program. The construction of tests specimens involved many steps with detailed designs. Each step was executed carefully and involved precise installation and measurements. However, some errors installation, measurement, and handling during construction resulted in small differences between the constructed specimens. The static test beams were tested in the horizontal position while the shock tube test beams were tested in a vertical position in the open face of the shock tube. This meant that the direction of gravity loading and its effect on beam behaviour was different between two test setups. Again, measurements were made for proper installation, but there do exist sources of error in this step. Once the beams were installed, additional measuring devices were installed in a consistent manner before the tests were conducted. The tests were then performed and data was acquired. Installation of this equipment and operation of the shock tube and static test apparatus was another step within the experimental program where errors may have been introduced. The following section describes the sources of error from the installation of strain gauges, construction of specimens, installation of beams on test apparatus, installation of deflection measuring devices, and the installation and operation of the data acquisition systems.

\subsubsection{Construction of Specimens}

The construction of test specimens, as described in Chapter 3, was a very long and detailed process. Through the construction of the test specimens, the goal was to achieve 5 
identical beams containing each of the selected rebar; $15 \mathrm{M}, 20 \mathrm{M}$, and $25 \mathrm{M}$. Although it is not possible to construct the beams to be identical, measures were taken to ensure the details in each beam were as similar as possible. While sources of error may have resulted from each step in the construction of test specimens, only those having the greatest effect on the results are mentioned. These errors are as follows:

- Steel gauges may have been installed so that their orientation did not exactly coincide with the direction of longitudinal reinforcement. Misalignment of the gauge could introduce error in the strain value in the longitudinal direction.

- Longitudinal steel may have been moved during construction, offsetting the debonded region from its exact midspan location, and affecting the symmetry of the strain gauges

- Lead wires from the strain gauges may have been damaged during the installation of the vinyl pipe to create the debonded region.

- Steel gauges directly outside of the debonded region may have been moved very close to the debonded region during construction. If any voids were present in the concrete after casting, then gauge S4 or S7, may have behaved as though they were within the debonded region.

- Large voids existed in the concrete in some of the beams due to improper vibration of the concrete mix. If these voids were located at the depth of the longitudinal reinforcement, than the bond of the steel to the concrete would be effected. 


\subsubsection{Installation of Specimen on Shock tube or Static Loading Apparatus}

Once all beams were constructed, they were installed on either the static test apparatus or the shock tube. While the installation of the beams on the static setup was quite simple, some errors were made. Beam SB-20M-2 was placed, and aligned on the supports using the crane in the laboratory. During installation of the beam the crane was accidentally moved while still attached to the beam causing the beam to fall off its supports. Although the height of the fall was not very large, the impact of the concrete beam on the floor led to opening of the preformed cracked and rupture of all the concrete gauges.

Installation of the beam on the front of the shock tube was slightly more difficult due to low head room in the laboratory. The use of cranes, forklifts and jacks did however make it possible to get the beam in place at the center of the load transfer device. Once in place, the supports were installed and bolted tightly so the beam would not move vertically. During installation of Beam DB-15M-1-1, the top surface of the beam appeared to deflect at midspan. This was caused by the fact that the supports were placed closer to the shock tube than the load points. The location of the supports was then repaired in an attempt to ensure no stresses were applied to the beam before testing.

\subsubsection{Data Acquisition Installation and Operation}

Before testing, wire gauges or LVDTs were installed to measure displacements. All wires and cables from gauges and LVDTs were attached to the data acquisition system in order to record strains and displacements. Errors in installation of wire gauges and LVDTs as 
well as errors in the values recorded in the data acquisition may have occurred. These errors include the following:

- If the displacement gauges (including both LVDTs and wire gauges) were not installed perfectly perpendicular to the beam, then some error in the value of the displacement obtained during testing was introduced.

- While the beam is assumed to act as two rigid bodies, cracks were often observed at the location of the load points. This is because there exists some resistance to rotation.

- When the strain reached a value close to $12500 \times 10-6$ the strain leveled off and higher strains would not be recorded. While the strain limit of the gauge is $30000 \times 10-6$, it is possible that the data acquisition will not record higher values due to its limitations.

- Some strains in steel were negative. This was often recorded in gauges S3 or S8 during rebound of the beam. The reason for this is that when the steel in the midspan goes into the plastic region, it has irrecoverable strains. Upon rebound the steel is now longer, so at locations along the steel, adjacent to the plastically strained material, areas of compressive strain are formed.

- Concrete gauges broke quickly due to the high tensile strains produced at the midspan of the beam during shock tube testing. For static tests, the application of concrete gauges was more useful since the gauges last much longer. The goal of using the gauges was to determine the strain profile in the beam at different time steps. Unfortunately this could not be determined since only one of three gauges remained operable up to maximum deflection. 
- There is a small deviation in pressure values from both pressure gauges at the Shock Tube opening. For the pressure gauge located on the side of the shock tube, one source of error may be that as the load transfer device deflects, pressure escapes from the sides of the shock tube. For the pressure gauge located at the bottom of the shock tube, one source of error could be that there is a buildup of loose foils covering the pressure gauge within the shock tube caused by the rupturing of the diaphragm in each test.

- For shock tube testing, it is not possible to determine if the load at each load point is equal. Some error may be introduced by the assumption that the load is evenly distributed to both load points.

While sources of error do exist in the experimental program, many measures were taken to reduce sources of error. These include precise measurements during the construction of the specimens, careful installation and placement of the beams on the test apparatus, and the use of multiple specimens to determine average values. The results of the experimental program did show some consistency and some very obvious trends in the data so that conclusions cold be drawn. 


\section{Chapter: Analytical Work}

\subsection{Determination of Bond Strength from Strain Gauge Readings}

As described in Chapter 2, the bond stress may be calculated by the following equation:

$\mu=\frac{\Delta \mathrm{f}_{\mathrm{s}} \mathrm{d}_{\mathrm{b}}}{4 \Delta \mathrm{l}}$

Where $\Delta f_{s}$ is the change in tensile stress in the reinforcing steel, $d_{b}$ is the diameter of the reinforcing steel, and $\Delta l$ is the distance between points on the steel over which the change in bar stress occurs.

This equation can therefore be applied to the data obtained from static and dynamic testing, and the bond stress between the locations of two strain gauges on the steel reinforcement can be determined.

The bond stress was calculated at the time when the steel in the debonded region reached the yield strain for both static and dynamic tests. The stress at each point was determined by the following equation:

$f_{s}=\varepsilon_{s} E_{s}$

Where $\varepsilon_{s}$ is the strain in the steel and $E_{s}$ is the modulus of elasticity of steel (200 GPa).

The bond stress was then calculated and the stress over the reinforcing steel was determined. Due to the fact that the bond stress reached a strain very close to zero in the strain gauge second furthest away from the end, it was assumed the force in the steel was completely transferred to the concrete by the time it reached this gauge. The results obtained from calculating the bond stress between the gauges are shown in Table 5-1, Table 5-2, and Table 5-3. 


\begin{tabular}{|c|c|c|c|c|}
\hline $\begin{array}{l}n \\
u \\
\infty \\
z \\
u \\
n\end{array}$ & 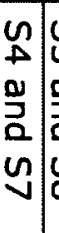 & 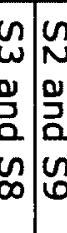 & 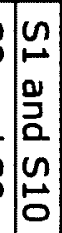 & 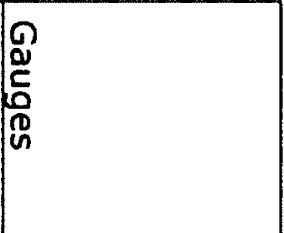 \\
\hline $\mid \begin{array}{l}\infty \\
w \\
0\end{array}$ & $\begin{array}{l}\infty \\
0 \\
\vdots\end{array}$ & & $\tilde{v}$ & Distance $(\mathrm{mm})$ \\
\hline $\mid \begin{array}{c}N \\
\Delta \\
\\
D \\
D\end{array}$ & $\left|\begin{array}{c}N \\
\mathbb{E} \\
\mathbb{\infty} \\
\infty\end{array}\right|$ & \begin{tabular}{|l}
$\omega$ \\
$\omega$ \\
$v$
\end{tabular} & 0 & $\begin{array}{c}\text { SB-25M-1 } \\
\left(\mathrm{mm} / \mathrm{mm} \times 10^{-6}\right)\end{array}$ \\
\hline $\mid \begin{array}{c}N \\
\dot{N} \\
\dot{D} \\
v\end{array}$ & $\mid \begin{array}{l}N \\
N \\
\sim \\
N\end{array}$ & & 0 & $\begin{array}{l}\text { SB-25M-2 } \\
\left(\mathrm{mm} / \mathrm{mm} \times 10^{-6}\right)\end{array}$ \\
\hline $\begin{array}{c}N \\
\dot{A} \\
\dot{a} \\
\sigma\end{array}$ & w & & 0 & $\begin{array}{c}\text { Average Static } \\
\text { Strain } \\
\left(\mathrm{mm} / \mathrm{mm} \times 10^{-6}\right)\end{array}$ \\
\hline $\begin{array}{c}n \\
\vdots \\
\end{array}$ & aे & $\begin{array}{l}\omega \\
b \\
b \\
\omega \\
\omega \\
\omega\end{array}$ & & $\begin{array}{c}\text { Average Static } \\
\text { Bond Stress } \\
\text { (Mpa) }\end{array}$ \\
\hline w & 2 & D. & 0 & $\begin{array}{l}\text { DB-25M-2-1 } \\
\left(\mathrm{mm} / \mathrm{mm} \times 10^{-6}\right)\end{array}$ \\
\hline $\mid \begin{array}{l}N \\
y \\
\infty \\
\infty\end{array}$ & $\left(\begin{array}{l}N \\
N\end{array}\right.$ & & 0 & $\begin{array}{l}\text { DB-25M-3-1 } \\
\left(\mathrm{mm} / \mathrm{mm} \times 10^{-6}\right)\end{array}$ \\
\hline 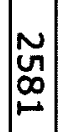 & $\left(\begin{array}{c}N \\
\sim \\
\sim\end{array}\right.$ & $\begin{array}{r}\tilde{N} \\
\sim\end{array}$ & 0 & $\begin{array}{c}\text { Average } \\
\text { Dynamic Strain } \\
\left(\mathrm{mm} / \mathrm{mm} \times 10^{-6}\right)\end{array}$ \\
\hline$\left|\begin{array}{|l}\infty \\
\omega \\
\omega \\
\end{array}\right|$ & $\mid \begin{array}{l}u \\
\omega \\
\omega\end{array}:$ & $\begin{array}{l}\overrightarrow{0} \\
\dot{v} \\
\dot{v}\end{array}$ & & $\begin{array}{c}\text { Average } \\
\text { Dynamic Bond } \\
\text { Stress (Mpa) }\end{array}$ \\
\hline & & & & DIF \\
\hline
\end{tabular}

\begin{tabular}{|c|c|c|c|c|c|}
\hline & 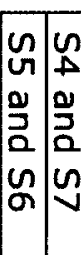 & 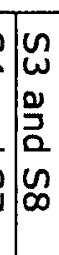 & 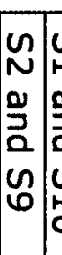 & 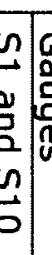 & \\
\hline & $\underset{\omega}{\sim})$ & $\left.\right|_{\mathbb{N}} ^{\omega}$ & \begin{tabular}{|l|}
$\vec{\infty}$ \\
$\vec{p}$ \\
$\vec{c}$
\end{tabular} & $\tilde{\sigma}$ & Distance $(\mathrm{mm})$ \\
\hline & 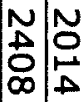 & $\vec{\infty}$ & No. & 0 & $\begin{array}{l}\text { SB-20M-1 } \\
\left(\mathrm{mm} / \mathrm{mm} \times 10^{-6}\right)\end{array}$ \\
\hline & 答 & |ू & $\mid$ & 0 & $\begin{array}{l}\text { SB-20M-2 } \\
\left(\mathrm{mm} / \mathrm{mm} \times 10^{-6}\right)\end{array}$ \\
\hline & 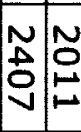 & Un & $\mid \omega$ & 0 & $\begin{array}{c}\text { Average Static } \\
\text { Strain } \\
\left(\mathrm{mm} / \mathrm{mm} \times 10^{-6}\right)\end{array}$ \\
\hline $\mid$ & $\mid \begin{array}{ll}a & 0 \\
\infty & 0 \\
\infty & v\end{array}$ & $\underset{N}{\omega}$ & i & & $\begin{array}{c}\text { Average Static } \\
\text { Bond Stress } \\
\text { (Mpa) }\end{array}$ \\
\hline & N & v & $\infty$ & 0 & $\begin{array}{l}\text { DB-20M-2-1 } \\
\left(\mathrm{mm} / \mathrm{mm} \times 10^{-6}\right)\end{array}$ \\
\hline & 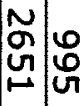 & 占 & 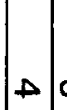 & 0 & $\begin{array}{l}\text { DB-20M-3-1 } \\
\left(\mathrm{mm} / \mathrm{mm} \times 10^{-6}\right)\end{array}$ \\
\hline & 芯| & $\mid \begin{array}{l}\omega \\
\omega \\
\omega\end{array}$ & & 0 & $\begin{array}{c}\text { Average } \\
\text { Dynamic Strain } \\
\left(\mathrm{mm} / \mathrm{mm} \times 10^{-6}\right)\end{array}$ \\
\hline 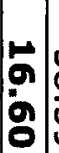 & $\begin{array}{ll}n & \\
\infty & u \\
\text { in } & 0 \\
0 & 0\end{array}$ & $\underset{\omega}{\omega}$ & $\left|\begin{array}{l}0 \\
0 \\
0 \\
1\end{array}\right|$ & & $\begin{array}{c}\text { Average } \\
\text { Dynamic Bond } \\
\text { Stress (Mpa) }\end{array}$ \\
\hline & & & & & DIF \\
\hline
\end{tabular}

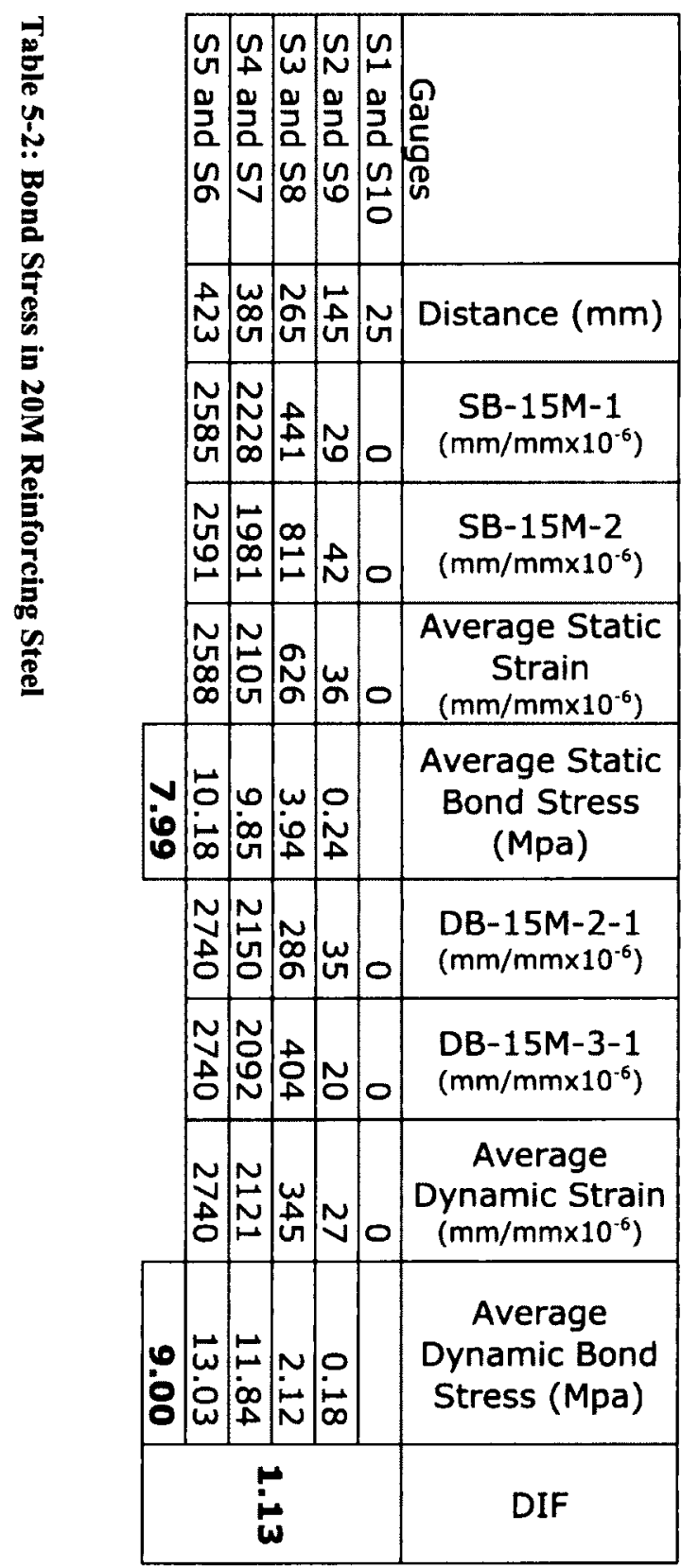

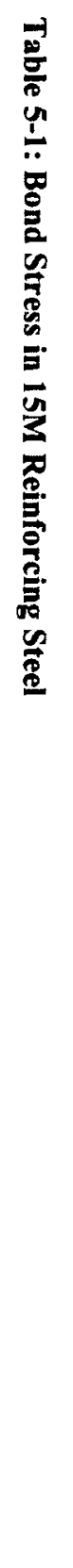


By calculating the bond stress for static tests and shock tube tests, it can be concluded that the dynamic bond stress is greater than the static bond stress.

\subsection{Empirical Formulas for Bond Strength}

Many equations have been developed to estimate the bond strength of steel to concrete for deformed bars confined by transverse reinforcement. These equations are described in the following section. It is important to note that these equations were derived for the use with imperial units.

Orangun, Jirsa, and Breen (1977) analyzed splice length tests and development length tests from a variety of sources and developed the following equation for determining the bond stress between concrete and reinforcement:

$\frac{\mu}{\sqrt{f_{c}^{\prime}}}=1.2+3 \frac{c_{\min }}{d_{b}}+50 \frac{d_{b}}{l_{d}}+\frac{A_{t r} f_{y t}}{500 s d_{b}}$

Where, $\mu$ is the bond strength, $f_{c}^{\prime}$ is the compressive strength of concrete, $d_{b}$ is the diameter of the reinforcing bar, $l_{d}$ is the development length, $A_{t r}$ is the area of transverse reinforcement, $f_{y t}$ is the yield strength of the transverse reinforcement, and $s$ is the center-tocenter spacing of the transverse reinforcement. $c_{\min }$ may be taken as the smaller of the clear bottom cover to the longitudinal reinforcement or the side cover to the longitudinal reinforcement (Orangun, Jirsa and Breen 1977)

Darwin et al. (1996) also analyzed a variety of bond tests and developed the following equation for bond strength: 


$$
\begin{gathered}
\frac{T}{\sqrt[4]{f_{c}^{\prime}}}=\left[63 l_{d}\left(c_{\min }+0.5 d_{b}\right)+2130 A_{b}\right]\left(0.1 \frac{c_{\max }}{c_{\min }}+0.9\right) \\
+2226 t_{r} t_{d} \frac{N A_{t r}}{n}+66
\end{gathered}
$$

$t_{r}=9.6 R_{r}+0.28$

$t_{d}=0.72 d_{b}+.028$

Where, $T$ is the bond force, $c_{\max }$ may be taken as the greater of the clear bottom cover to the longitudinal reinforcement or the side cover to the longitudinal reinforcement, $N$ is the number of stirrups within the development length, and $n$ is the number of bars being developed. The terms $t_{r}$ and $t_{d}$ were also introduced. The term $t_{r}$ is used to represent the effect of the relative rib area on the steel contribution to the bond force and $t_{d}$ is used to represent the effect of the bar size on the steel contribution to the bond force. $R_{r}$ is the relative rib area of the reinforcement and has an approximate value of 0.07 for regular reinforcement (ACI Committee 408 2003).

While many new variables are introduce in this equation, it is important to note that $\left(f_{c}^{\prime}\right)^{1 / 4}$ is used in this equation rather than $\left(f_{c}^{\prime}\right)^{1 / 2}$ as used by Orangun, Jirsa and Breen. This is due to the fact that it was more representative of the effect of the concrete compressive strength on the bond force.

Zuo and Darwin (1998) further modified the Darwin et al. (1996) equation and proposed the following:

$$
\begin{aligned}
& \frac{T}{\sqrt[4]{f_{c}^{\prime}}}=\left[59.8 l_{d}\left(c_{\min }+0.5 d_{b}\right)+2350 A_{b}\right]\left(0.1 \frac{c_{\max }}{c_{\min }}+0.9\right) \\
& +\left(31.14 t_{r} t_{d} \frac{N A_{t r}}{n}+4\right) \sqrt{f_{c}^{\prime}} \\
& t_{r}=9.6 R_{r}+0.28 \\
& t_{d}=0.78 d_{b}+.022
\end{aligned}
$$


All variables used in this equation are defined above.

ACI Committee 408 (2003) also made further changes to the bond force equation to yield the following:

$$
\begin{gathered}
\frac{T}{\sqrt[4]{f_{c}^{\prime}}}=\left[59.9 l_{d}\left(c_{\min }+0.5 d_{b}\right)+2400 A_{b}\right]\left(0.1 \frac{c_{\max }}{c_{\min }}+0.9\right) \\
+\left(30.88 t_{r} t_{d} \frac{N A_{t r}}{n}+3\right) \sqrt{f_{c}^{\prime}}
\end{gathered}
$$

$t_{r}=9.6 R_{r}+0.28$

$t_{d}=0.78 d_{b}+.022$

Table 5-4 shows the value of the variables that were used in the previously defined equations in the research program presented in this thesis. The numbers used for all variables were converted from SI units to imperial units before the application of the equations.

The development length used in this case is the minimum length over which the bar stress changed from its yield stress to zero in the tests. The value of $N$ was obtained by counting the number of stirrups within the development length observed in the construction of the beams. For the value of $s$, the spacing of stirrups changed from $100 \mathrm{~mm}$ to $150 \mathrm{~mm}$ within the development length for $25 \mathrm{M}$ bars. Therefore a weighted average of the stirrup spacings over the development length was calculated to achieve a suitable spacing.

Empirical equations were also used for dynamic cases. In order to employ these equations for dynamic testing, a dynamic increase factor of 1.19 (UFC 2008) was applied to the concrete strength to obtain the dynamic strength. Furthermore, the development length was the minimum length over which the bar stress changed from its yield stress to zero in shock tube testing. Again, the value of $N$ was obtained by counting the number of stirrups within the development length observed through testing. For $25 \mathrm{M}$ reinforcement the value of $s$ was again obtained by 
calculating the weighted average of the stirrup spacings over the development length from the shock tube tests.

Table 5-4: Variables used to calculate bond strength

\begin{tabular}{|c|c|c|c|}
\hline Variable & $15 \mathrm{M}$ & $20 M$ & 25M \\
\hline$f_{c}^{\prime}(\mathrm{MPa})$ - Static & 37.31 & 37.31 & 37.31 \\
\hline$f_{d c}{ }^{\prime}(\mathrm{MPa})$ - Dynamic & 44.40 & 44.40 & 44.40 \\
\hline$d_{b}(\mathrm{~mm})$ & 16.00 & 19.50 & 25.20 \\
\hline$A_{t r}\left(\mathrm{~mm}^{2}\right)$ & 62.34 & 62.34 & 62.34 \\
\hline$f_{y t}(\mathrm{MPa})$ & 580.00 & 580.00 & 580.00 \\
\hline$s(\mathrm{~mm})$ - Static & 100.00 & 100.00 & 108.33 \\
\hline$s(\mathrm{~mm})$ - Dynamic & 100.00 & 100.00 & 112.5 \\
\hline$c_{\min }(\mathbf{m m})$ & 77.00 & 75.25 & 72.40 \\
\hline$c_{\max }(\mathrm{mm})$ & 87.00 & 85.25 & 82.40 \\
\hline$N$ - Static & 3 & 4 & 7 \\
\hline$N$ - Dynamic & 3 & 4 & 5 \\
\hline$n$ & 1 & 1 & 1 \\
\hline $\boldsymbol{R}_{r}$ & 0.07 & 0.07 & 0.07 \\
\hline$t_{r}$ & 0.952 & 0.952 & 0.952 \\
\hline$t_{d}$ (Darwin et al. 1996) & 0.734 & 0.833 & 0.994 \\
\hline $\begin{array}{l}t_{d} \text { (Zuo and Darwin } \\
1998 \text {, ACI Committee } \\
408 \text { 2003) }\end{array}$ & 0.711 & 0.819 & 0.994 \\
\hline$l_{d}(\mathrm{~mm})$ - Static & 278.00 & 339.00 & 805.00 \\
\hline$l_{d}(\mathrm{~mm})$ - Dynamic & 278.00 & 339.00 & 545.00 \\
\hline
\end{tabular}

After applying the equations, the bond strength was converted back into SI units and the final results were reported. For equations based on the bond force the following equation was applied to achieve the value of bond strength:

$\mu=\frac{T}{l_{d} \pi d_{b}}$

The bond force obtained from applying these equations to the results of the development length observed in the experimental program are reported in the following tables. It is important 
to note that the development length used in these calculations was obtained by taking the distance from the beginning of the debonded region to the first strain gauge at which zero strain was observed, although it is likely that zero strain occurred over a shorter length. Therefore, the development length is quite conservative and likely greater than required. This also leads to under estimated bond strengths. The bond strengths calculated using the equations are shown in the following table:

Table 5-5: Bond strengths calculated from various empirical formulas

\begin{tabular}{|l|c|c|c|c|}
\cline { 2 - 5 } \multicolumn{1}{c|}{} & \multicolumn{4}{c|}{ Bond Strength (MPa) } \\
\cline { 2 - 5 } & $\begin{array}{c}\text { Orangun, } \\
\text { Jirsa, } \\
\text { Breen } \\
(1977)\end{array}$ & $\begin{array}{c}\text { Darwin et } \\
\text { al. (1996) }\end{array}$ & $\begin{array}{c}\text { Zuo and } \\
\text { Darwin } \\
(2000)\end{array}$ & $\begin{array}{c}\text { ACI } \\
\text { Committee } \\
\mathbf{4 0 8}(2003)\end{array}$ \\
\hline $15 \mathrm{M}$ Static & 12.72 & 9.65 & 10.14 & 9.35 \\
\hline 15M Dynamic & 13.87 & 10.08 & 10.78 & 9.89 \\
\hline $\begin{array}{l}\text { Ratio of Dynamic To } \\
\text { Static Bond Strength }\end{array}$ & 1.09 & 1.04 & 1.06 & 1.06 \\
\hline 20M Static & 10.67 & 8.49 & 8.85 & 8.11 \\
\hline 20M Dynamic & 11.64 & 8.87 & 9.42 & 8.57 \\
\hline $\begin{array}{l}\text { Ratio of Dynamic To } \\
\text { Static Bond Strength }\end{array}$ & 1.09 & 1.04 & 1.06 & 1.06 \\
\hline 25M Static & 7.72 & 5.97 & 6.03 & 5.56 \\
\hline 25M Dynamic & 8.76 & 6.81 & 7.11 & 6.53 \\
\hline $\begin{array}{l}\text { Ratio of Dynamic To } \\
\text { Static Bond Strength }\end{array}$ & 1.13 & 1.14 & 1.18 & 1.17 \\
\hline
\end{tabular}

By observing the results in the previous table, it is quite evident that the greatest increase in bond strength occurred for $25 \mathrm{M}$ bars. However, the spacing of the strain gauges on the bonded 
area of the $25 \mathrm{M}$ reinforcement was greater than that on both $15 \mathrm{M}$ and $20 \mathrm{M}$ reinforcement, thus increasing the uncertainty of the development length used to calculate the bond strength. Also, previous tests reported that the greatest increase in bond strength occurred for smaller size reinforcing bars (Shah 1963). It is therefore difficult to conclude whether the bar size had any significant influence on the increase in bond strength.

It is also possible that the strength of the reinforcement has an effect on the increase in bond stress. From the tensile steel tests, $15 \mathrm{M}$ reinforcing bars had the greatest static yield strength, followed by $25 \mathrm{M}$ bars, and $20 \mathrm{M}$ bars had the lowest strength. Therefore, no obvious trend relating the increase in bond strength to the yield strength of steel was observed here. However, during tensile steel tests, the reinforcing steel shows increase in strength under rapid loading rates. Therefore, it can be concluded that the DIF observed in steel is proportional to the increase in bond stress under high loading rates.

Greater accuracy in the results could be achieved by increasing the number of strain gauges within the bonded region and decreasing the spacing. While it is difficult to determine whether the size of reinforcement or strength of reinforcement had any effect on the bond stress, it is clear that the bond stress increases with the loading rate. After comparing both static strain profiles to dynamic strain profiles and bond stresses in both cases, it can be concluded that the development length of reinforcing steel required for static loading is also sufficient for dynamic loading. 


\section{Chapter: Conclusions}

\subsection{Summary}

The effect of strain rate on the development length of steel in reinforced concrete beams was investigated. Current research shows that the effect strain rate on the strength properties of both reinforced concrete and steel have been thoroughly investigated, while information on the interaction between the two materials is limited. Some researchers have looked at the influence of loading rate on bond strength through pullout tests. In these investigations, it was found that the bond strength increases with loading rate. However, standard pullout tests introduce extra confining forces, which may have an effect on the increase in bond strength. More accuracy could therefore be achieved through beam tests.

An experimental program was designed to investigate whether the development length required by the CSA A23.3-04 (2004) was sufficient for blast design. A total of 15 concrete beams were tested; 6 under static loading and 9 under dynamic loading using the shock tube. Loads great enough to achieve failure of the reinforced beams were employed in both test methods. The strains in the steel at different times were studied. The time when the steel reached its yield strength was thoroughly investigated to determine the approximate development length for all tests.

The strain profile in the bonded region of the steel was developed for all tests. Static strain profiles were compared to dynamic strain profiles for beams containing the same size of reinforcement. Equations were applied to the determine the average bond stress in beams undergoing static loading as well as the average bond stress in beams undergoing dynamic 
loading. Finally, the bond stresses achieved in dynamic tests were compared to those achieved in static tests.

\subsection{Conclusions}

The following conclusions can be drawn from the experimental program:

- The required development length for dynamic tests is always less than or equal to the required development length for static tests.

- No reinforcement slip was observed in any test at the unloaded end.

- The bond stress between concrete and steel increases with increased strain rate.

- The equation used to determine the development length required for static loads is sufficient for high loading rates.

- The $D I F$ obtained from steel tests is proportional to the increase in bond strength.

\subsection{Recommendations}

Recommendations for future research are as follows:

- Provide a greater number of strain gauges at closer spacings along the bonded region of reinforcing steel to obtain a more detailed and accurate strain profile. 
- Construct beams with a shorter debonded region. This will allow greater strains to be achieved in the steel reinforcement and the strain profile at high levels of strain to be analyzed.

- Investigate the effect of steel strength on the increase in bond stress. This can be achieved by testing beams of the same size reinforcement, but providing different strengths

- Investigate the effect of size of reinforcement on the increase in bond stress. By providing a greater variety of sizes of reinforcing bars, trends in the effect of size of reinforcement on bond stress increase under dynamic loading can be more thoroughly investigated. 


\section{Bibliography}

ACI Committee 318. (2008). "Building Code Requirements for Structural Concrete (ACI 31808) and Commentary." American Concrete Institute, Farmington Hills, MI, 204.

ACI Committee 408. (2003). "Bond and Development of Straight Reinforcing Bars in Tension." ACI Technical Document, 1-48.

ACI Committee 439. (1969). "Effect of Steel Strength and of Reinforcement Ratio on the Mode of Failure and Strain Energy Capacity of Reinforced Concrete Beams." ACI Journal Proceedings, 66(3), 165-173.

ASTM A370-11a (2011). "Standard Test Methods and Definitions for Mechanical Testing of Steel Products." ASTM International, West Conshohocken, PA.

ASTM C873 (2010). "Standard Test Method for Compressive Strength of Concrete Cylinders Cast in Place in Cylindrical Molds." ASTM International, West Conshohocken, PA.

Allen, R. L. (2006). The Port Chicago Mutiny: The Story of the Largest Mass Mutiny Trial in U.S. Naval History, Heyday, Berkeley, CA, 62-67.

Alsiwat, J. M., and Saatcioglu, M. (1992). "Reinforcement Anchorage Slip Under Monotonic Loading." Journal of Structural Engineering, 118(9), 2421-2438.

ASCE. (1997). Design of Blast Resistant Buildings in Petrochemical Facilities. Task Committee on Blast Resistant Design. American Society of Civil Engineers., Reston, VA.

Asprone, D., Cadoni, E., and Prota, A. (2009). "Tensile High Strain-Rate Behavior of Reinforcing Steel From an Existing Bridge.” ACI Structural Journal, 106(4), 523-529. 
Baker, W. E. et al. (1983). Explosion Hazards and Evaluation. Elsevier Scientific Publishing Company, New York.

Bangash, T. (2006). Explosion-Resistant Buildings: Design, Analysis, and Case Studies. Springer, London, UK.

CSA A23.3-04 (2004). "Design of Concrete Structures." Canadian Standards Association, Mississauga, Ontario.

CSA S850-12 (2012). "Design and Assessment of Buildings Subjected to Blast Loads." Canadian Standards Association, Mississauga, Ontario.

Comité Euro-International Du Béton (CEB). (1988). "Concrete Structures Under Impact and Impulsive Loading: Synthesis Report.” CEB Bulletin No. 187, Lausanne, Switzerland.

Darwin, D. (2005). "Tension Development Length and Lap Splice Design for Reinforced Concrete Members." Progress in Structural Engineering and Materials, 7(4), 210-225.

Esfahani, M. R., and Kianoush, M. R. (2005). "Development/splice length of reinforcing bars." ACI Structural Journal, 102(1), 22-30.

Flathau, W. J. (1971). "Dynamic Tests of Large Reinforcing Bar Splices." Rep. No. N-71-2, U.S. Army Engineer Waterways Experiment Station, Vicksburg, Mississippi.

Fu, H. C., Erki, M. A., and Seckin, M. (1991). "Review of Effects of Loading Rate on Reinforced Concrete.” Journal of Structural Engineering New York, N.Y., 117(12), 3660-3679.

Hansen, R. J., and Liepins, A. A. (1962). "Behavior of Bond Under Dynamic Loading." Journal of the American Concrete Institute, 59(4), 563-583. 
Health and Safety Executive (HSE 2012). "Flixborough (Nypro UK) Explosion 1st June 1974." http://www.hse.gov.uk/comah/sragtech/caseflixboroug74.htm (September 11, 2012).

Hyde, D. W. (1992). “Conventional Weapons Effects Program (CONWEP).” Technical Report, US Army Engineers Waterways Experimental Station, Vicksburg, MS.

Keenan, W. A., and Feldman, A. (1960). "Behavior and Design of Deep Structural Members Part 6: The Yield Strength of Intermediate Grade Reinforcing Bars Under Rapid Loading." University of Illinois, Urbana, IL.

Kingery, C. N., and Bulmash, G. (1984). "Airblast Parameters from TNT Spherical Air Burst and Hemispherical Surface Burst." ARBRL-TR-02555, Ballistic Research Laboratory, Aberdeen Proving Ground, MD.

Kluge, R. W., and Tuma, E. C. (1945). "Lapped Bar Splices in Concrete Beams." Journal of the American Concrete Institute, 17(1), 13-33.

Krauthammer, T., Marchand, K. A., Stevens, D. J., Bounds, W. L., and Nene, M. (1994). "Effects of Short Duration Dynamic Loads on RC Structures." Concrete International, 16(10), $57-63$.

Le Nard, H., and Bailly, P. (2000). "Dynamic Behaviour of Concrete: the Structural Effects on Compressive Strength Increase." Mechanics of Cohesive-Frictional Materials, 5(6), 491-510.

Li, Q. M., and Meng, H. (2003). “About the Dynamic Strength Enhancement of Concrete-Like Materials in a Split Hopkinson Pressure Bar Test." International Journal of Solids and Structures, 40(2), 343-360. 
Lloyd, A. (2010). "Performance of Reinforced Concrete Columns under Shock Tube Induced Shock Wave Loading." PhD thesis, University of Ottawa, Ottawa.

Lloyd, A., Jacques, E., Saatcioglu, M., Palermo, D., Nistor, I., and Tikka, T. (2011). "Capabilities and Effectiveness of using a Shock Tube to Simulate Blast Loading on Structures and Structural Components." ACI Special Publication, Behaviour of Concrete Structures Subjected to Blast and Impact Loadings.

Lu, Y., and Xu, K. (2004). "Modelling of Dynamic Behaviour of Concrete Materials Under Blast Loading." International Journal of Solids and Structures, 41(1), 131-143.

Mac Donald, L. M. (2005). Curse of the Narrows: The Halifax Explosion of 1917. HarperCollins, Toronto.

MacGregor, J. G. (1997). Reinforced Concrete: Mechanics and Design. Prentice Hall, Upper Saddle River, N.J.

Malvar, L. J. (1998). "Review of static and dynamic properties of steel reinforcing bars." $A C I$ Materials Journal; , 95(5), 609-616.

Malvar, L. J., and Crawford, J. E. (1998). "Dynamic Increase Factors for Steel Reinforcing Bars." Twenty-Eighth DDESB Seminar, Karagozian \& Case, Orlando, Florida, 1-16.

Malvar, L. J., and Ross, C. A. (1998). "Review of Strain Rate Effects for Concrete in Tension." ACI Materials Journal, 95(6), 735-739.

Mirza, S. A., and MacGregor, J. G. (1979). "Variability of Mechanical Properties of Reinforcing Bars." ASCE Journal Structural Division, 105(5), 921-937. 
Moehle, J. P., Wallace, J. W., and Hwang, S.. (1991). “Anchorage Lengths for Straight Bars in Tension." ACI Structural Journal, 88(5), 531-537.

Ngo, T., Mendis, P., Gupta, A., and Ramsay, J. (2007). "Blast Loading and Blast Effects on Structures - An Overview." Electronic Journal of Structural Engineering, 7 76-91.

Orangun, C. O., Jirsa, J. O., and Breen, J. E. (1977). "Reevaluation of Test Data on Development Length and Splices." ACI Journal Proceedings, 74(3), 114-122.

Park, R., and Paulay, T. (1975). "Bond and Anchorage." Reinforced Concrete Structures, John Wiley and Sons Inc., University of Canterbury, Christchurch, New Zealand, 392-495.

Park, R., and Ruitong, D. (1988). "Ductility of Doubly Reinforced Concrete Beam Sections." ACI Structural Journal, 85(2), 217-225.

Psyllides, G. (2011). "Evangelos Florakis blast kills 12." http://www.cyprusmail.com/cyprus/evangelos-florakis-blast-kills-12/20110711 (September 11, 2012).

Reinhardt, H. W. (1982). "Concrete Under Impact Loading - Tensile Strength and Bond." Heron, 27(3).

Shah, I. K. (1963). "Behavior of bond under dynamic loading." Massachusetts Institute of Technology, Cambridge, Massachusetts.

Solomos, G., and Berra, M. (2010). "Rebar Pullout Testing Under Dynamic Hopkinson Bar Induced Impulsive Loading." Materials and Structures, 43(1-2), 247-260.

Soroushian, P., and Choi, K. (1987). "Steel Mechanical Properties at Different Strain Rates." Journal of Structural Engineering New York, N.Y., 113(4), 663-672. 
Stephens, H. W. (1997). The Texas City Disaster, 1947. University of Texas Press, Austin, TX.

Unified Facilities Criteria (UFC) 3-340-02. (2008). Structures to Resist the Effects of Accidental Explosions. United States of America Department of Defense, Washington, D.C.

Vos, E., and Reinhardt, H. W. (1982). "Influence of Loading Rate on Bond In Reinforced Concrete." RILEM/CEB/IABSE/IASS Interassociation Symposium, Concrete Structures under Impact and Impulsive Loading, Berlin, Germany, 170-181.

Vos, E. (1983). "Influence of loading rate and radial pressure on bond in reinforced concrete : a numerical and experimental approach." Delft University Press.

Weathersby, J. H. (2003). "Investigation of Bond Slip Between Concrete and Steel Reinforcement Under Dynamic Loading Conditions." PhD thesis, Louisiana State University, Baton Rouge, Louisiana.

Yan, C., and Mindess, S. (1991). "Bond Between Concrete and Steel Reinforcing Bars Under Impact Loading." International Symposium on Brittle Matrix Composites (3rd), Elsevier Applied Science, London, 184-192.

Yan, D., and Lin, G. (2006). "Dynamic Properties of Concrete in Direct Tension." Cement and Concrete Research, 36(7), 1371-1378.

Yang, G., and Lok, T. (2007). "Analysis of RC Structures Subjected to Air-Blast Loading Accounting for Strain Rate Effect of Steel Reinforcement." International Journal of Impact Engineering, 34(12), 1924-1935. 
Zech, B., and Wittmann, F. H. (1979). "Variability and Mean Value of Strength of Concrete as a Function of Load." ACI Journal, 77(39), 358-362. 